\title{
MECHANISMS OF NUCLEOPHILIC SUBSTITUTION
}

by

\section{STUART WILLIAM PAINE}

A thesis submitted to the University of London in partial fulfilment of the requirements for the degree of Doctor of Philosophy in the Faculty of Science.

1993

The Christopher Ingold Laboratories,

Department of Chemistry,

University College London,

20, Gordon Street,

London WC1 HOAJ. 
ProQuest Number: 10044486

All rights reserved

INFORMATION TO ALL USERS

The quality of this reproduction is dependent upon the quality of the copy submitted.

In the unlikely event that the author did not send a complete manuscript and there are missing pages, these will be noted. Also, if material had to be removed, a note will indicate the deletion.

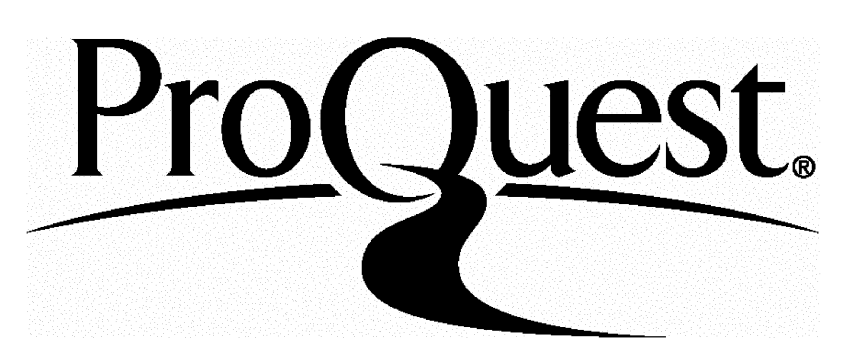

ProQuest 10044486

Published by ProQuest LLC(2016). Copyright of the Dissertation is held by the Author.

All rights reserved.

This work is protected against unauthorized copying under Title 17, United States Code. Microform Edition (c) ProQuest LLC.

\author{
ProQuest LLC \\ 789 East Eisenhower Parkway \\ P.O. Box 1346 \\ Ann Arbor, MI 48106-1346
}


Mechanisms of Nucleophilic Substitution 


\section{ABSTRACT}

The $15 \mathrm{~N}$ n.m.r. studies of various reactions that are believed to proceed via nucleophilic radical chain mechanisms did not show a C.I.D.N.P. effect.

The reaction of sodium nitrite with $p$-nitrocumyl bromide in dimethyl sulphoxide is a new and interesting system. No C.I.D.N.P. effect was observed for this reaction when followed by ${ }^{15} \mathrm{~N}$ n.m.r. spectroscopy. The reaction of sodium nitrite with $p$-nitrocumyl bromide in dimethyl sulphoxide proceeds via a heterolytic mechanism to give the products $\alpha, p$-dinitrocumene, $p$-nitrocumyl alcohol and $p$-nitro- $\alpha$-methylstyrene respectively. The overall disappearance of $p$-nitrocumyl bromide can be expressed as follows:

$$
-\left(d[\mathrm{RBr}]_{\mathrm{t}} / d t\right)=k_{\mathrm{s}}[\mathrm{RBr}]_{\mathrm{t}}+k_{3}^{\prime}[\mathrm{RBr}]_{\mathrm{t}}\left[\mathrm{NO}_{2}^{-}\right]_{\mathrm{t}}^{2}
$$

The unimolecular component of the overall rate of reaction can be attributed to the elimination of $p$-nitrocumyl bromide in dimethyl sulphoxide. The termolecular component is probably due to a variation in the rate constant for a bimolecular process caused by the addition of sodium perchlorate. There is strong evidence to support this premise as a very large termolecular rate constant was obtained when sodium perchlorate was excluded.

The reaction of lithium azide with $p$-nitrocumyl bromide in dimethyl sulphoxide proceeds via a heterolytic mechanism to give the products $p$-nitrocumyl azide, $p$ nitrocumyl alcohol and $p$-nitro- $\alpha$-methylstyrene respectively. The overall disappearance of $p$-nitrocumyl bromide can be expressed as follows:

$$
-\left(d[\mathrm{RBr}]_{\mathrm{t}} / d t\right)=k_{\mathrm{S}}[\mathrm{RBr}]_{\mathrm{t}}+k_{2}^{\prime}[\mathrm{RBr}]_{\mathrm{t}}\left[\mathrm{N}_{3}{ }^{-}\right]_{\mathrm{t}}
$$

Moreover, the reaction of tetrabutylammonium azide with $p$-nitrocumyl bromide in dimethyl sulphoxide also obeys, within experimental error, concurrent first and second order kinetics. 
The unimolecular component of the overall rate of reaction can be attributed to the elimination of $p$-nitrocumyl bromide in dimethyl sulphoxide. The bimolecular kinetic component is best explained by a "loose" $\mathrm{S}_{\mathrm{N}} 2 / \mathrm{E} 2 \mathrm{C}$ mechanism. The lack of an isotope effect for the bimolecular component indicates that there is very little carbocation character in the rate determining step. The large $k^{\mathrm{Br} / k^{\mathrm{Cl}}}$ ratio obtained for this reaction is indicative of $\mathrm{S}_{\mathrm{N}} 2$ reactions in a dipolar aprotic solvents. 
'My senses may deceive me. Perhaps my life is only a dream; even my knowledge of mathematics may be perverted by a malignant demon. But there is one thing I cannot doubt: "I think, therefore I am"; If I think at all, there must be something that is thinking.'

René Descartes

'The important thing is to not stop questioning.'

Albert Einstein

'Baloney is flattery so thick that it cannot be true and blarney is flattery so thin that we like it.' 
Mechanisms of Nucleophilic Substitution 


\section{ACKNOWLEDGEMENTS}

The author would like to thank the following:

Professor J.H. Ridd for his guidance, encouragement and patience throughout the course of the work.

Dr J.P.B. Sandall, Dr R.G. Coombes, Dr B.P. Roberts and Dr K.J. Hale for their useful discussions.

The Ridd, Garratt, Hale, Best and Thiru groups, especially Rob Claridge, Rupert Austin, Joe Christofi, Simon Thorn, Akbar Salam and Philip Tregenna-Piggot, for the great times we had together.

Sukh Bhangoo for his loyal and true fraternity.

All the friends and acquaintances who have come and gone during my stay at University College London.

The technical staff of the Chemistry Department, especially Dave Bowman and Dick Waymark of the Electronics section.

And my family for their endless love, support and encouragement. 
Mechanisms of Nucleophilic Substitution 


\section{TABLE OF CONTENTS}

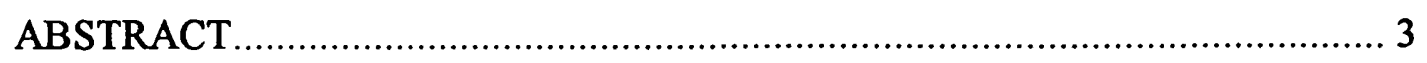

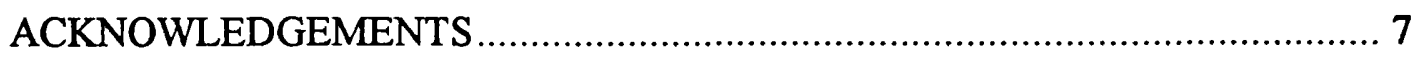

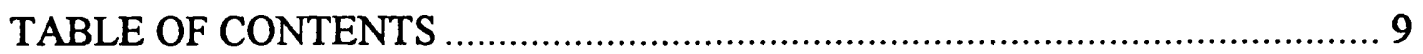

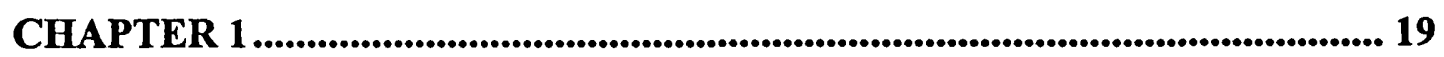

(Introduction)

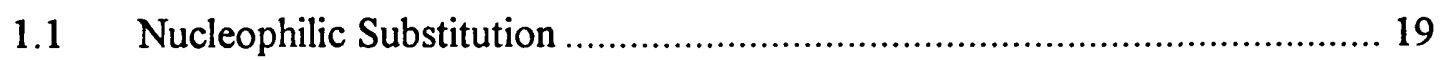

1.2 Nucleophilic Substitution at a Saturated Carbon................................... 19

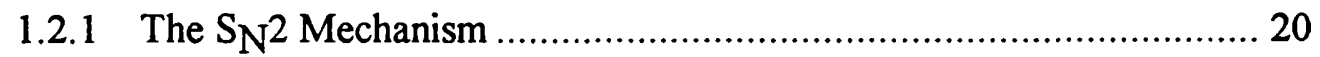

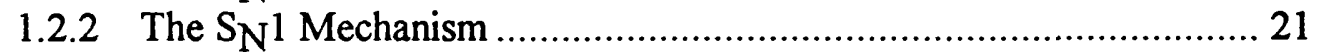

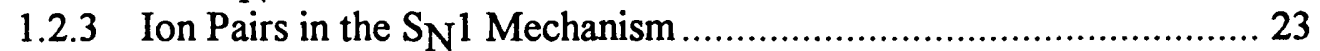

1.2.4 Ion Pairing and the Reactivity of Nucleophilic Anions.................. 24

1.2.5 The Effect of the Reaction Medium ........................................... 26

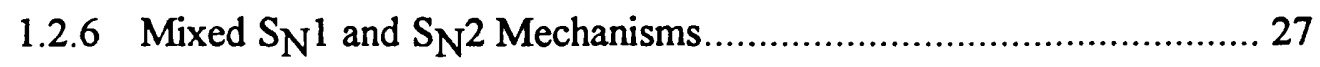

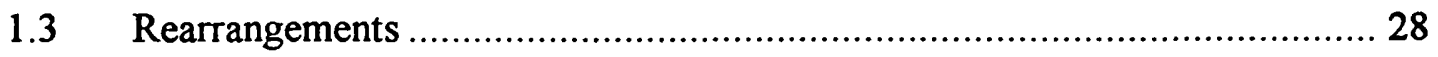

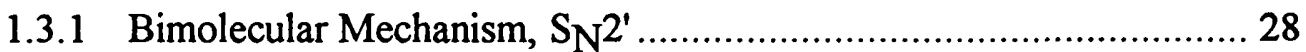

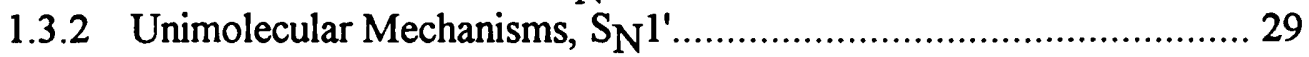

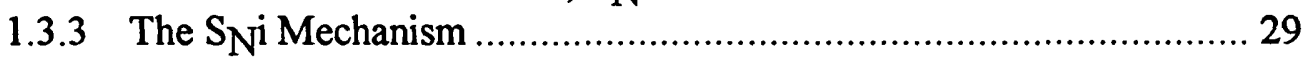

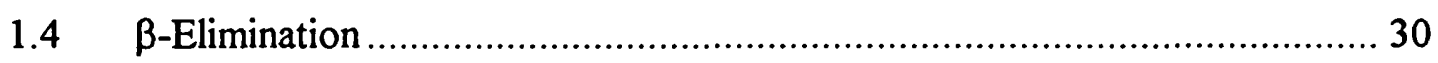

1.4.1 Unimolecular Mechanism, E1 f.............................................. 30

1.4.2 Bimolecular Mechanism, E2 .............................................. 31

1.5 Nucleophilic Substitution at a Vinylic Carbon......................................... 32

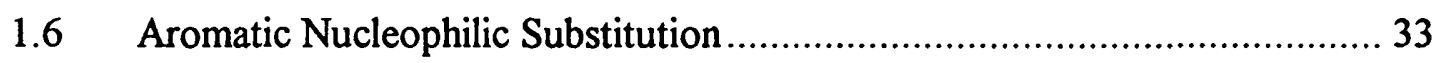

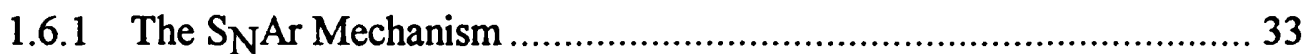

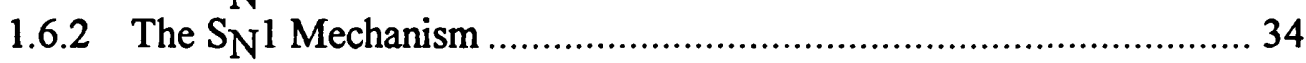

1.6.3 The Benzyne Mechanism ...................................................... 35

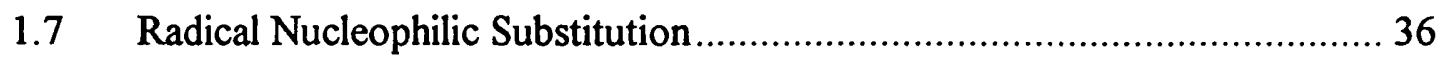

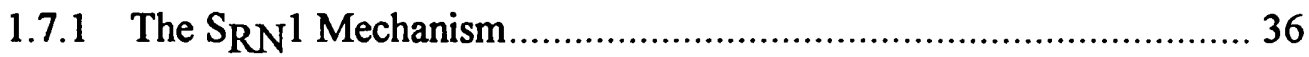

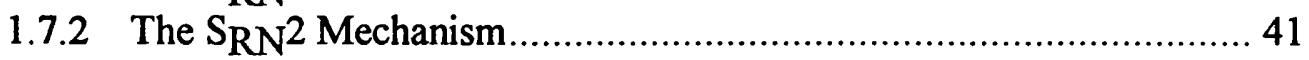

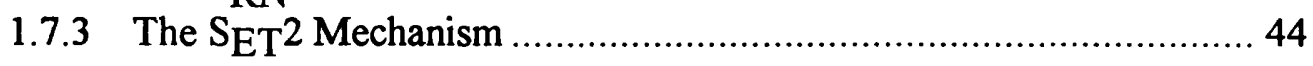


CHAPTER 2 47

(The Investigation of Various Radical Nucleophilic Substitution Reactions using

15 N N.M.R. Spectroscopy)

2.1 Introduction

$2.2 \quad 15 \mathrm{~N}$ N.M.R. Spectroscopy 47

2.3 Chemically Induced Dynamic Nuclear Polarisation 48

2.3.1 Interaction of a Nucleus with One Electron................................ 49

2.3.2 Systems of Two Electrons .................................................... 50

2.3.3 Kaptein's Rule ............................................................... 52

2.4 Nucleophilic Radical Chain Mechanisms ........................................... 52

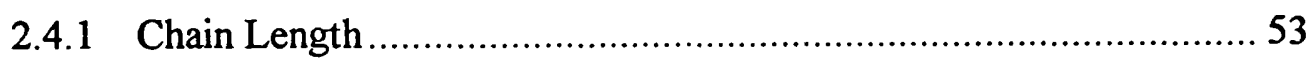

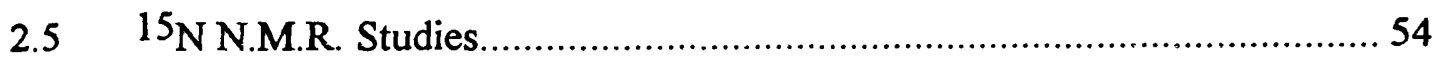

$2.640 \mathrm{MHz}^{15}$ N N.M.R. Study of the Reaction of the ${ }^{15} \mathrm{~N}$-Labelled Lithium Salt of 2-Nitropropane with $p$-Dinitrobenzene in Dimethyl Sulphoxide ....... 55

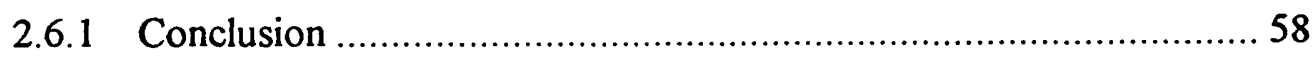

2.7 $40 \mathrm{MHz}^{15}$ N N.M.R. Study of the Reaction of Sodium Thiophenoxide with $15 \mathrm{~N}$-Labelled $p$-Nitrocumyl Chloride in a Dimethyl Sulphoxide:Methanol Solvent System ........................................................................ 62

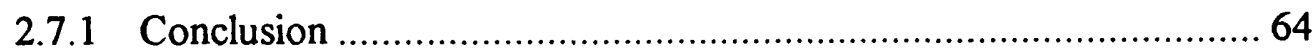

2.8 $40 \mathrm{MHz}^{15}$ N N.M.R. Study of the Reaction of Sodium Thiophenoxide with $15 \mathrm{~N}$-Labelled $p$-Nitrocumyl Chloride (Inhibited by a Radical Scavenger) in Dimethyl Sulphoxide .................................................................. 67

2.8.1 Conclusion ..................................................................... 70

$2.940 \mathrm{MHz}{ }^{15}$ N N.M.R. Study of the Reaction of ${ }^{15}$ N-Labelled Sodium Nitrite with $p$-Nitrocumyl Bromide in Dimethyl Sulphoxide............................. 70

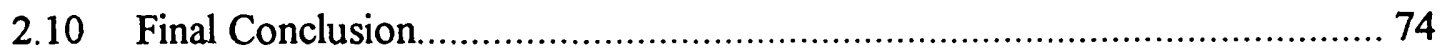


CHAPTER 3 75

(A Kinetic Study of the Reaction of Sodium Nitrite with $p$-Nitrocumyl Bromide in Dimethyl Sulphoxide, Part 1)

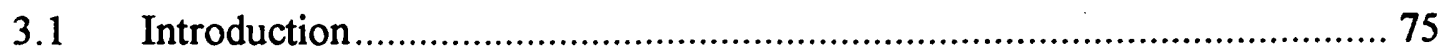

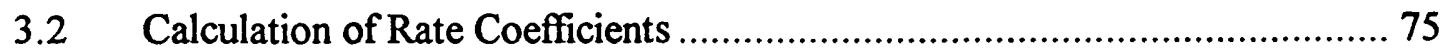

3.3 $400 \mathrm{MHz}{ }^{1}$ H N.M.R. Study of the Reaction of Sodium Nitrite with $p$-Nitrocumyl Bromide in Dimethyl Sulphoxide ................................... 76

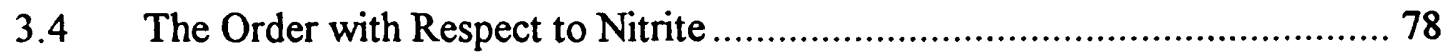

3.5 The Order with Respect to $p$-Nitrocumyl Bromide ................................... 98

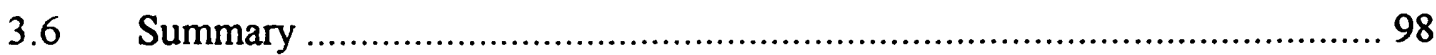

3.7 The Elimination of $p$-Nitrocumyl Bromide in Dimethyl Sulphoxide............ 103

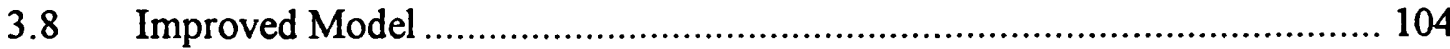

CHAPTER 4. 109

(A Kinetic Study of the Reaction of Sodium Nitrite with $p$-Nitrocumyl Bromide in Dimethyl Sulphoxide, Part 2)

4.1 Introduction 109

4.2 Initial Slopes for Concurrent First and Third Order Reactions 110

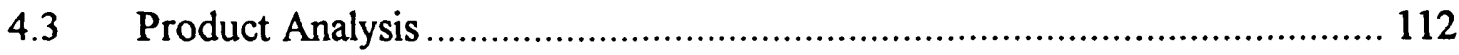

$4.4 \quad$ Initial Slopes of Product Formation ................................................. 120

4.5 Final Kinetic Model ....................................................................... 126

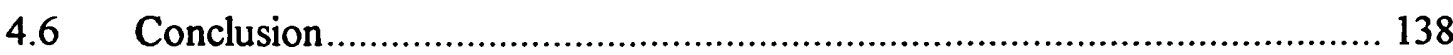

CHAPTER 5.............................................................................................. 139

(A Kinetic Study of the Reaction of Sodium Nitrite with $p$-Nitrocumyl Bromide in Dimethyl Sulphoxide, Part 3)

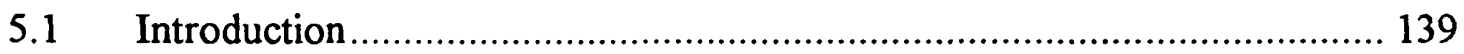

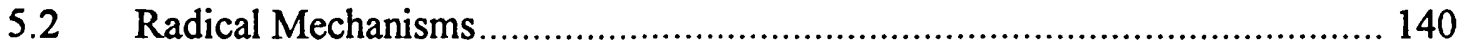


5.2.1 The Effect of $p$-Dinitrobenzene on the Rate of Reaction for the Reaction of Sodium Nitrite with $p$-Nitrocumyl Bromide in Dimethyl

Sulphoxide

5.2.2 The Effect of 4-Hydroxy Tempo on the Rate of Reaction for the Reaction of Sodium Nitrite with $p$-Nitrocumyl Bromide in Dimethyl Sulphoxide

5.2.3 The Effect of Ultraviolet Light on the Rate of Reaction for the Reaction of Sodium Nitrite with $p$-Nitrocumyl Bromide in Dimethyl Sulphoxide

5.2.4 Conclusion

5.3.1 The Effect of Sodium Bromide on the Rate of Reaction for the Reaction of Sodium Nitrite with $p$-Nitrocumyl Bromide in Dimethyl Sulphoxide

5.3.2 The Rate of Reaction for the Reaction of Sodium Nitrite with p-Nitrocumyl Bromide in a $95 \%$ C2D6SO : $5 \%$ H2O Solvent Mixture

5.3.3 The Effect of a Decrease in Ionic Strength on the Rate of Reaction. for the Reaction of Sodium Nitrite with $p$-Nitrocumyl Bromide in Dimethyl Sulphoxide.

5.4 Relative Reactivity of Free Nitrite and Ion Paired Nitrite with $p$-Nitrocumyl Bromide

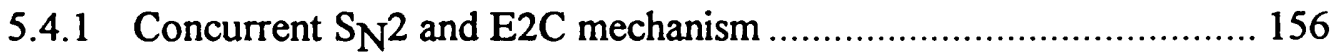

5.4.2 $\mathrm{S}_{\mathrm{N}} 2-\mathrm{Type}$ Ion Pair Mechanism .............................................. 157

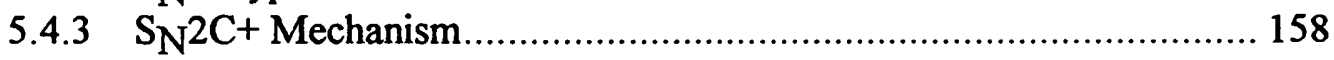

5.4.5 Elimination-Addition Mechanism ............................................. 160

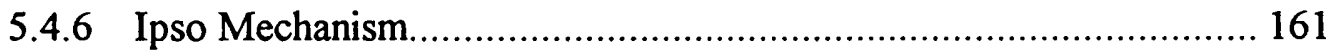

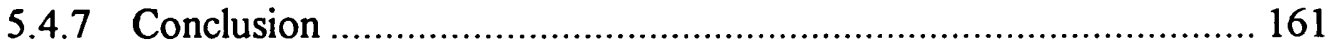

5.5 Heterolytic Termolecular Processes.................................................... 163

5.5.1 Termolecular Nucleophilic Substitution..................................... 163

5.5.2 A Possible Termolecular Nucleophilic Substitution Mechanism for the Reaction of Sodium Nitrite with $p$-Nitrocumyl Bromide in Dimethyl Sulphoxide.

5.6 Final Conclusion 168

CHAPTER 6

(A Kinetic Study of the Reaction of Lithium Azide with $p$-Nitrocumyl Bromide in Dimethyl Sulphoxide, Part 1)

6.1 Introduction 
6.2 Calculation of Rate Coefficients 172

6.3 $400 \mathrm{MHz}{ }^{1}$ H N.M.R. Study of the Reaction of Lithium Azide with p-Nitrocumyl Bromide in Dimethyl Sulphoxide

6.4 The Order with Respect to Azide ...................................................... 176

6.5 The Order with Respect to $p$-Nitrocumyl Bromide .............................. 188

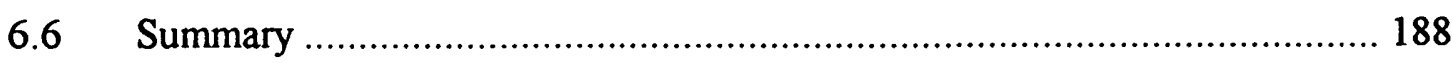

6.7 The Elimination of $p$-Nitrocumyl Bromide in Dimethyl Sulphoxide............ 192

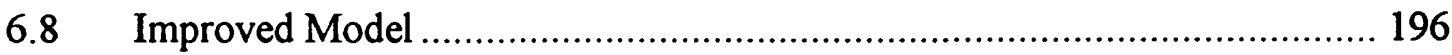

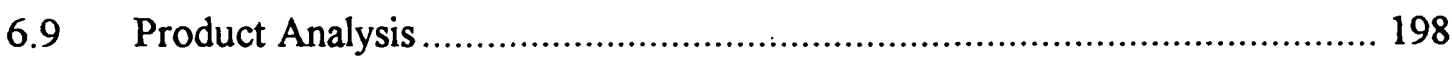

6.10 Initial Slopes of Product Formation .................................................. 206

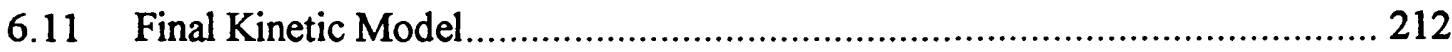

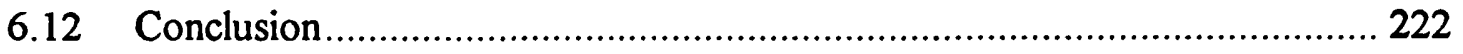

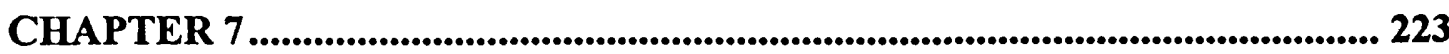

(A Kinetic Study of the Reaction of Lithium Azide with $p$-Nitrocumyl Bromide in Dimethyl Sulphoxide, Part 2)

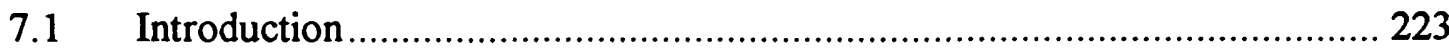

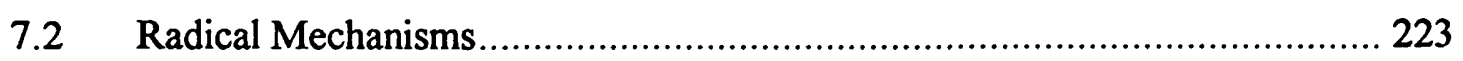

7.2.1 The Effect of $p$-Dinitrobenzene on the Rate of Reaction for the Reaction of Lithium Azide with $p$-Nitrocumyl Bromide in Dimethyl Sulphoxide ........................................................................... 224

7.2.2 The Effect of 4-Hydroxy Tempo on the Rate of Reaction for the Reaction of Lithium Azide with $p$-Nitrocumyl Bromide in Dimethyl Sulphoxide ....................................................................... 225

7.2.3 The Effect of Ultraviolet Light on the Rate of Reaction for the Reaction of Lithium Azide with $p$-Nitrocumyl Bromide in Dimethyl Sulphoxide ....................................................................... 226

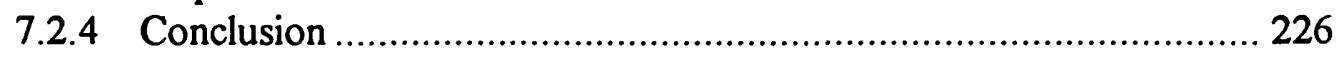

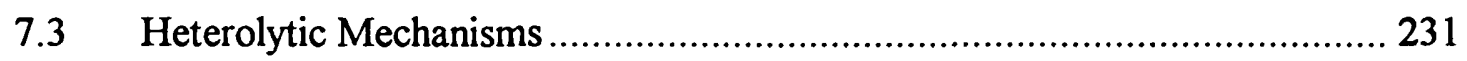

7.3.1 The Effect of Lithium Bromide on the Rate of Reaction for the Reaction of Lithium Azide with $p$-Nitrocumyl Bromide in Dimethyl Sulphoxide 
7.3.2 The Rate of Reaction for the Reaction of Lithium Azide with p-Nitrocumyl Bromide in a $95 \%$ C2D6SO : $5 \% \mathrm{H} 2 \mathrm{O}$

Solvent Mixture.

7.4 Mechanisms Leading to Second Order Kinetics 236

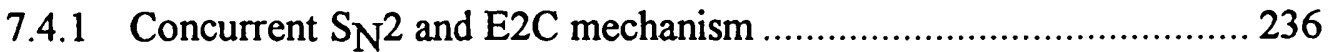

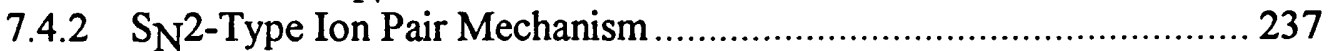

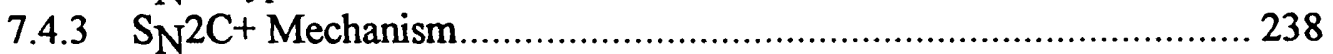

7.4.4 Carbanion Mechanism................................................................ 238

7.4.5 Elimination-Addition Mechanism ............................................. 239

7.4.6 Association between the Lithium Cation and $p$-Nitrocumyl

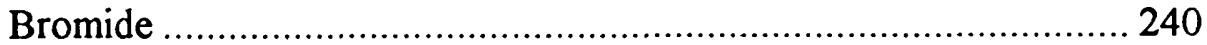

7.4.7 Ipso Mechanisms ............................................................... 240

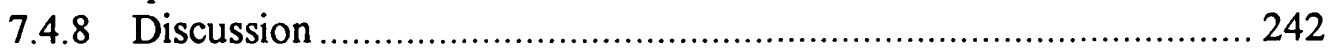

7.5 A Kinetic Study of the Reaction of Tetrabutylammonium Azide with p-Nitrocumyl Bromide in Dimethyl Sulphoxide.

7.5.1 $400 \mathrm{MHz}{ }^{1} \mathrm{H}$ Study of the Reaction of Tetrabutylammonium Azide with $p$-Nitrocumyl Bromide in Dimethyl Sulphoxide .................... 243

7.5.2 The Elimination of $p$-Nitrocumyl Bromide in Dimethyl Sulphoxide . 244

7.5.3 The Order with Respect to Azide............................................ 247

7.5.4 Conclusion .................................................................. 260

CHAPTER 8

(A Kinetic Study of the Reaction of Lithium Azide with $p$-Nitrocumyl Bromide in Dimethyl Sulphoxide, Part 3)

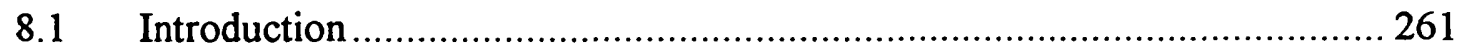

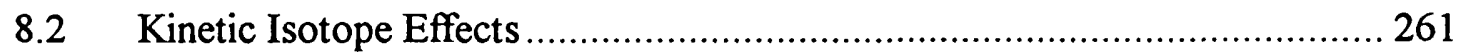

8.2.1 Primary Kinetic Isotope Effects ............................................... 261

8.2.2 $\alpha$-Secondary Kinetic Isotope Effects....................................... 262

8.2.3 $\beta$-Secondary Kinetic Isotope Effects ........................................ 262

8.2.4 Solvent Isotope Effects........................................................ 263

8.3 $\beta$-Secondary Deuterium Isotope Effects as Evidence for Carbonium Ion Character.

8.4 A Kinetic Study of the Reaction of Lithium Azide with ${ }^{2} \mathrm{D}_{6}$-labelled $p$-Nitrocumyl Bromide in Dimethyl Sulphoxide.

8.4.1 $60 \mathrm{MHz}^{2}$ H N.M.R. Study of the Reaction of Lithium Azide with ${ }^{2} \mathrm{D}_{6}$-Labelled $p$-Nitrocumyl Bromide in Dimethyl Sulphoxide .272

8.4.2 The Elimination of ${ }^{2} \mathrm{D}_{6}$-labelled $p$-Nitrocumyl Bromide in Dimethyl Sulphoxide 
8.4.3 The Order with Respect to Azide.. 277

8.4.4 $400 \mathrm{MHz}{ }^{1}$ H N.M.R. Study of the Reaction of Lithium Azide with ${ }^{2} \mathrm{D}_{6}$-Labelled $p$-Nitrocumyl Bromide in Dimethyl Sulphoxide . 280

8.4.5 The Elimination of ${ }^{2} \mathrm{D}_{6}$-labelled $p$-Nitrocumyl Bromide in Dimethyl Sulphoxide 281

8.4.6 The Order with Respect to Azide............................................. 281

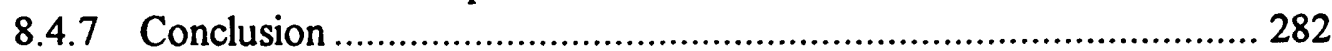

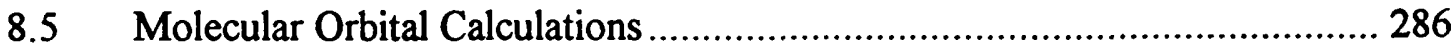

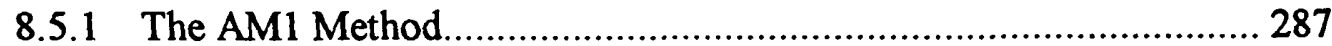

8.5.2 The PM3 Method ............................................................ 288

8.6. $200 \mathrm{MHz}{ }^{1}$ H N.M.R. Study of the Reaction of Lithium Azide with $p$-Nitrocumyl Chloride in Dimethyl Sulphoxide

8.6.1 The Order with Respect to Azide.............................................. 294

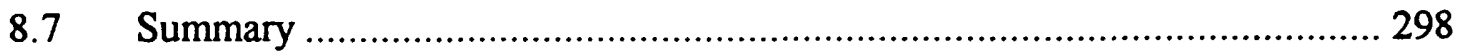

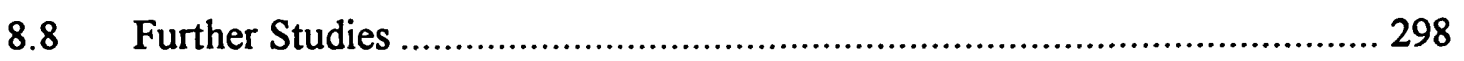

8.8.1 The Reaction of Lithium Azide with 2-Bromo-2( $p$-Nitrophenyl)Butane in Dimethyl Sulphoxide.

8.8.2 The Reaction of $p$-Nitrocumyl Bromide with Other Nucleophiles in Dimethyl Sulphoxide........................................................... 301

8.8.3 The Reaction of Sodium Thiophenoxide with $p$-Nitrocumyl Bromide in Dimethyl Sulphoxide............................................................ 301

8.8.4 The Reaction of the Lithium Salt of 2-Nitropropane with p-Nitrocumyl Bromide in Dimethyl Sulphoxide. 302

8.8.5 Conclusion 303

CHAPTER 9 305

(Experimental)

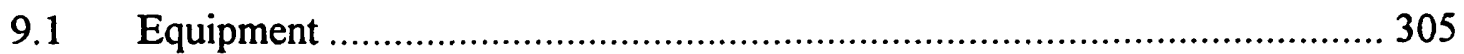

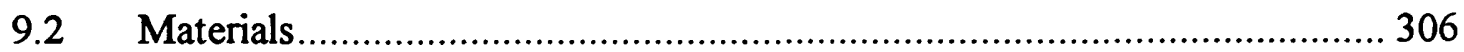

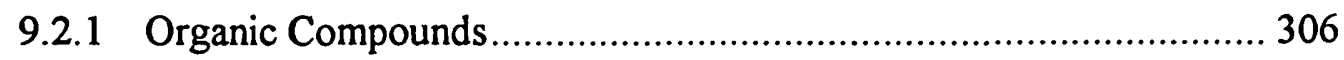

9.2.2 Inorganic Compounds ......................................................... 306

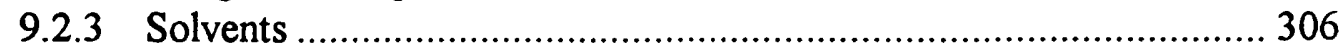

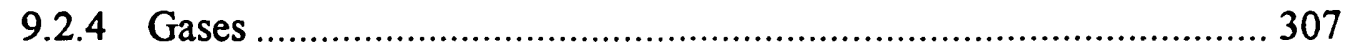

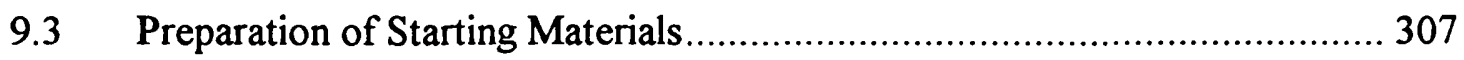

9.3.1 Preparation of the Lithium Salt of 2-Nitropropane ..................... 307 
9.3.2 Preparation of $15 \mathrm{~N}$-Labelled 2-Nitropropane ................................ 308

9.3.3 Preparation of the ${ }^{15} \mathrm{~N}$-Labelled Lithium Salt of 2-Nitropropane .... 308

9.3.4 Preparation of $p$-Nitrocumyl Alcohol ........................................... 309

9.3.5 Preparation of $p$-Nitrocumyl Chloride ........................................ 310

9.3.6 Preparation of $15 \mathrm{~N}$-Labelled $p$-Nitrocumyl Alcohol .................... 311

9.3.7 Preparation of $15 \mathrm{~N}$-Labelled $p$-Nitrocumyl Chloride ....................... 312

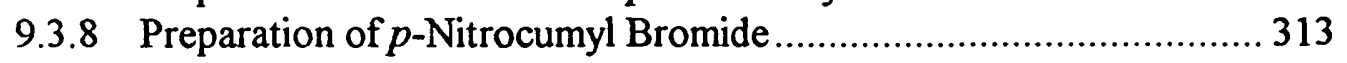

9.3.9 Preparation of Tetrabutylammonium Azide ............................... 314

9.3.10 Preparation of Tetrabutylammonium Perchlorate.......................... 315

9.3.11 Preparation of ${ }^{2} \mathrm{D}_{6}$-Labelled $p$-Nitrocumyl Alcohol .................... 316

9.3.12 Preparation of ${ }^{2} \mathrm{D}_{6}$-Labelled $p$-Nitrocumyl Bromide .................... 318

9.3.13 Preparation of 4-sec-Butylnitrobenzene....................................... 319

9.3.14 Preparation of 2-Bromo-2-( $p$-Nitrophenyl)Butane ...................... 320

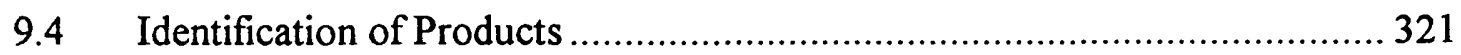

9.4.1 The Reaction of the Lithium Salt of 2-Nitropropane with p-Dinitrobenzene ................................................................... 321

9.4.2 The Reaction of the ${ }^{15} \mathrm{~N}$-Labelled Lithium Salt of 2-Nitropropane with $p$-Dinitrobenzene ......................................................... 322

9.4.3 The Reaction of Sodium Thiophenoxide with $p$-Nitrocumyl

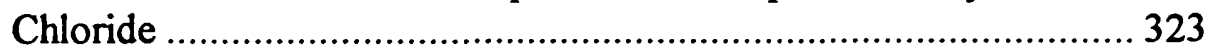

9.4.4 The Reaction of Sodium Thiophenoxide with ${ }^{15} \mathrm{~N}$-Labelled p-Nitrocumyl Chloride ............................................................. 324

9.4.5 The Reaction of Sodium Nitrite with $p$-Nitrocumyl Bromide .......... 325

9.4.6 The Reaction of ${ }^{15} \mathrm{~N}$-Labelled Sodium Nitrite with $p$-Nitrocumyl Bromide ............................................................................ 326

9.4.7 The Elimination of $p$-Nitrocumyl Bromide .............................. 326

9.4.8 The Reaction of Lithium Azide with $p$-Nitrocumyl Bromide........... 327

9.4.9 The Reaction of Tetrabutylammonium Azide with $p$-Nitrocumyl Bromide ........................................................................... 328

9.4.10 The Reaction of Lithium Azide with ${ }^{2} \mathrm{D}_{6}$-Labelled $p$-Nitrocumyl Bromide ............................................................................. 329

9.4.11 The Reaction of Lithium Azide with 2-Bromo-2-( $p$-Nitrophenyl)

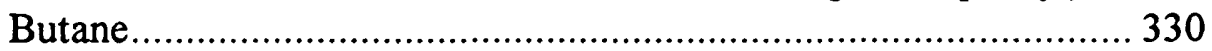

9.4.12 The Reaction of Sodium Thiophenoxide with $p$-Nitrocumyl Bromide ............................................................................... 331

9.4.13 The Reaction of the Lithium Salt of 2-Nitropropane with $p$-Nitrocumyl Bromide.......................................................... 332

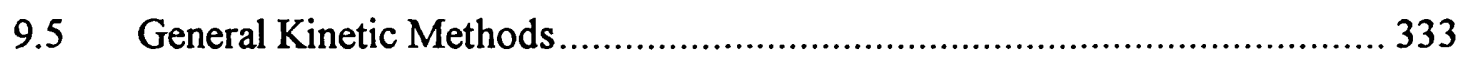

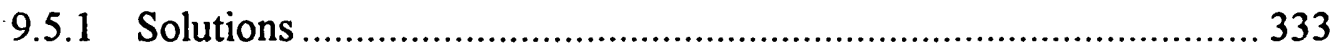

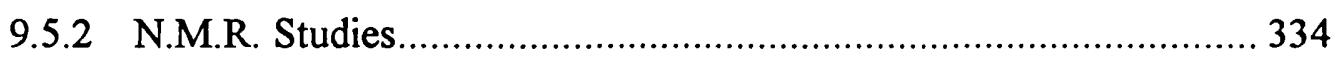


Mechanisms of Nucleophilic Substitution

To Mum, Dad and my brother Steve 
Mechanisms of Nucleophilic Substitution 


\section{CHAPTER 1}

\section{INTRODUCTION}

\subsection{Nucleophilic Substitution}

Nucleophilic substitutions are usually heterolytic reactions in which a group $X$ is displaced by a reagent $\mathrm{Y}$ with transfer of a pair of electrons from $\mathrm{Y}$ to the reaction centre, and from the reaction centre to $\mathrm{X}^{1}$ (Equation 1.1):

$$
\mathrm{R} \stackrel{\mathrm{r}}{\mathrm{X}}+\overline{\mathrm{Y}} \longrightarrow \mathrm{R}-\mathrm{Y}+\overline{\mathrm{X}}
$$

This equation says nothing about charges. Y may be neutral or negatively charged; RX may be neutral or positively charged. In these reactions the reagent $\mathrm{Y}$ and the displaced ion or molecule are nucleophiles, or Lewis bases. The terms solvolytic and non-solvolytic reaction are used to differentiate between the situations in which $\mathrm{Y}$ is, or is not, a solvent molecule.

This large class of substitution reactions, designated $\mathrm{S}_{\mathrm{N}}$, includes many reactions of preparative organic chemistry. The substitution may involve no net chemical change, for example, we can observe the isotopic exchange (Equation 1.2) and its stereochemical consequences at an optically active centre.

$$
\mathrm{R}-\mathrm{I}+{ }^{131} \mathrm{I}^{-} \longrightarrow \mathrm{R} \stackrel{131}{\longrightarrow} \mathrm{I}^{-} \mathrm{I}^{-}
$$

\subsection{Nucleophilic Substitution at a Saturated Carbon}

Nucleophilic substitution at a saturated carbon can occur via several mechanisms. The type of mechanism that occurs is dependent upon the substrate, nucleophile, leaving 
group, and the reaction conditions. By far the most common are the $S_{N} 1$ and $S_{N} 2$ mechanisms.

\subsubsection{The $\underline{\text { N }} \underline{2 \text { Mechanism }}$}

$\mathrm{S}_{\mathrm{N}} 2$ stands for substitution nucleophilic bimolecular. If the transition state (1) contains both $\mathrm{Y}$ and $\mathrm{RX}$ and no third species, the reaction has a bimolecular mechanism. In this mechanism there is attack from the rear to give inversion of configuration at the reaction centre (Scheme 1.1):

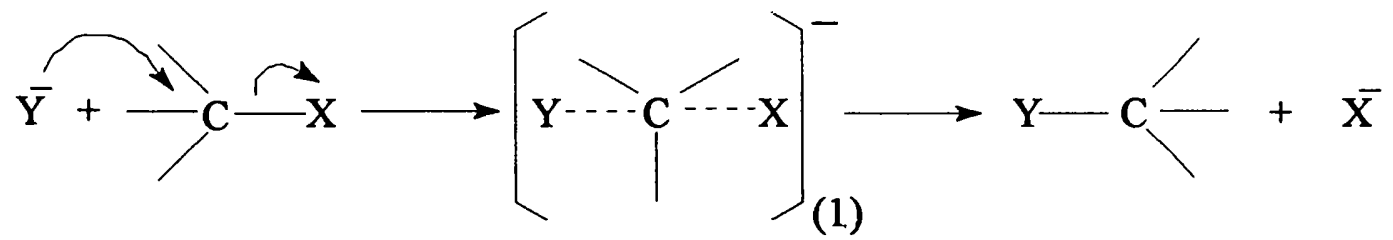

Scheme 1.1

The reaction is a one-step process with no intermediate (see, however, 1.2.6). The C-Y bond is formed as the C-X bond is broken and the energy necessary to break the C-X bond is supplied by simultaneous formation of the C-Y bond.

There is a large amount of evidence for the $S_{N} 2$ mechanism. First we consider the kinetic evidence. Since both the nucleophile and substrate are involved in the ratedetermining step, the reaction should be first order in each component, second order overall, and satisfy the rate expression (Equation 1.3):

$$
\text { Rate }=k[\mathrm{RX}][\mathrm{Y}]
$$

Generally this rate law has been found to apply, however, bimolecular is not always the same as second order. If a large excess of nucleophile is present the mechanism may still be bimolecular, though the experimentally determined kinetics will be first order (Equation 1.4): 


$$
\text { Rate }=k[\mathrm{RX}]
$$

This is often referred to as a pseudo-first-order reaction.

The kinetic evidence is a necessary but not a sufficient condition for the $\mathrm{S}_{\mathrm{N}} 2$ mechanism, since other mechanisms can be conceived that would also be consistent with these data. Much more convincing evidence is obtained from the fact that the mechanism predicts inversion of configuration when substitution occurs at a chiral carbon and this has been observed many times. This inversion of configuration is called the Walden inversion and was observed long before the $\mathrm{S}_{\mathrm{N}} 2$ mechanism was formulated by Hughes and Ingold ${ }^{2}$

\subsubsection{The $S_{N} 1$ Mechanism}

$\mathrm{S}_{\mathrm{N}} 1$ stands for substitution nucleophilic unimolecular. A dissociative mechanism can be formulated in which the transition state for the reaction does not contain $\mathrm{Y}$, but involves breaking of the $\mathrm{R}-\mathrm{X}$ bond. The first step is a slow ionisation of the substrate and is the rate determining step (Scheme 1.2):

$$
\begin{aligned}
& \mathrm{R}-\mathrm{X} \stackrel{\text { slow }}{\rightleftharpoons} \mathrm{R}^{+}+\overline{\mathrm{X}} \quad \text { Step } 1 \\
& \mathrm{R}^{+}+\overline{\mathrm{Y}} \stackrel{\text { fast }}{\longrightarrow} \mathrm{R}-\mathrm{Y} \quad \text { Step 2 }
\end{aligned}
$$

Scheme 1.2

The second is a rapid reaction between the intermediate carbocation and the nucleophile. The ionisation is always assisted by the solvent, since the energy necessary to break the bond is largely recovered by solvation of $\mathrm{R}^{+}$and of $\mathrm{X}^{-}$.

In looking for evidence for the $\mathrm{S}_{\mathrm{N}} 1$ mechanism the first notion is that it should be a first-order reaction following the rate law in Equation 1.4. Although the solvent is necessary to aid in the process of ionisation, it does not take part in the rate expression, 
since it is present in large excess. Many cases are known where pure first-order kinetics are followed, but in many other cases more complicated kinetics are found. We can explain this by taking into account the reversibility of the first step. The $\mathrm{X}^{-}$formed in this step competes with $\mathrm{Y}^{-}$for the cation and the rate law must be modified as follows (Scheme 1.3):

$$
\begin{aligned}
& \mathrm{R}-\mathrm{X} \quad \underset{k_{-1}}{\stackrel{k_{1}}{=}} \mathrm{R}^{+}+\overline{\mathrm{X}} \quad \text { Step } 1 \\
& \mathrm{R}^{+}+\mathrm{Y}^{-} \stackrel{k_{2}}{\longrightarrow} \mathrm{R}-\mathrm{Y} \quad \text { Step 2 }
\end{aligned}
$$

Scheme 1.3

$$
\text { Rate }=\frac{k_{1} k_{2}[\mathrm{RX}]\left[\mathrm{Y}^{-}\right]}{k_{-1}[\mathrm{X}]+k_{2}\left[\mathrm{Y}^{-}\right]}
$$

Thus the reaction will follow a first-order rate law during reaction only when $k_{2}\left[\mathrm{Y}^{-}\right]>>$ $k_{-1}\left[\mathrm{X}^{-}\right]$; that is, when all the carbocations are captured by $\mathrm{Y}^{-}$and converted into product, and the rate of reaction is that of the formation of the carbocations.

In many preparative reactions of organic chemistry, carbocations may be present in equilibrium with reactants, and react slowly with nucleophiles. The reaction may then follow an overall second-order rate law with respect to $\mathrm{RX}$ and $\mathrm{Y}^{-}$, since, if $k_{-1}\left[\mathrm{X}^{-}\right]>>$ $k_{2}\left[\mathrm{Y}^{-}\right]$, Equation 1.5 becomes:

$$
\text { Rate }=\frac{k_{1} k_{2}[\mathrm{RX}]\left[\mathrm{Y}^{-}\right]}{k_{-1}\left[\mathrm{X}^{-}\right]}
$$

The rate-limiting step of the reaction is now a bimolecular attack of the nucleophile upon a preformed carbocation, and the mechanism is designated $\mathrm{S}_{\mathrm{N}} 2 \mathrm{C}+$. It should then be 
possible to add $\mathrm{X}^{-}$extraneously and decrease the rate. This retardation of rate by the addition of $\mathrm{X}^{-}$is called the common-ion effect.

\subsubsection{Ion Pairs in the $S_{\underline{N}} \underline{1}$ Mechanism}

The stereochemical evidence for the $\mathrm{S}_{\mathrm{N}} 1$ mechanism is less clear-cut than it is for the $\mathrm{S}_{\mathrm{N}} 2$ mechanism. A free carbocation is planar and the nucleophile should attack with equal ease from either side of the plane, resulting in complete racemisation. Although many first-order substitutions do give complete racemisation, there are many others that do not. These results have led to the conclusion that in many $S_{N} 1$ reactions at least some of the products are not formed from free carbocations but rather from ion pairs. According to this concept, ${ }^{3} \mathrm{~S}_{\mathrm{N}} 1$ reactions proceed in the following manner (Scheme 1.4):

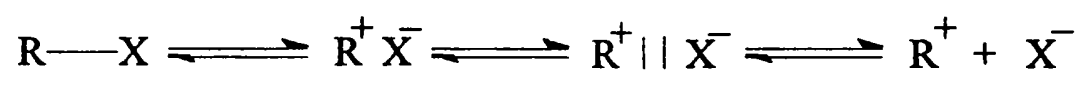

Scheme 1.4

In Scheme 1.4 (1) is an intimate or tight ion pair, (2) a loose or solvent separated ion pair, and (3) the dissociated ions each surrounded by molecules of solvent. The reaction in which the intimate ion pair recombines to give the original substrate is referred to as internal return. The reaction products can result from attack by the nucleophile at any stage. In the intimate ion pair (1), $\mathrm{X}^{-}$solvates the cation on the side from which it departed, while solvent molecules near (1) can only solvate it from the opposite side. Nucleophilic attack by a solvent molecule on (1) thus leads to inversion.

A comprehensive illustration of the possibilities for aliphatic nucleophilic substitution reactions involving a nucleophile $\mathrm{Y}^{-}$, ignoring the possibilities of elimination or rearrangement, is the following ${ }^{4}$ (Scheme 1.5): 


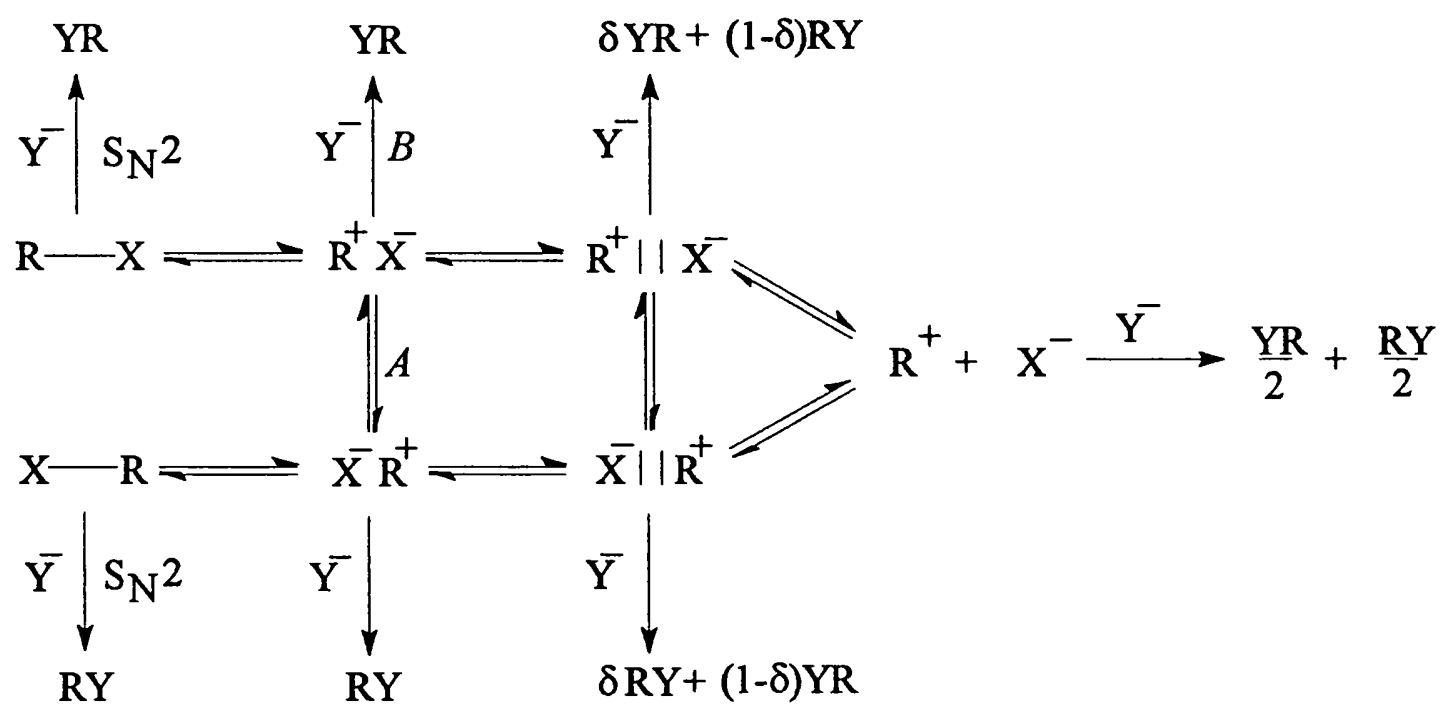

Scheme 1.5

RY and YR represent enantiomers and $\delta$ represents some fraction (Scheme 1.5). One possibility is direct attack by $\mathrm{Y}^{-}$on $\mathrm{RX}$ to give $\mathrm{YR}$ in a straight $\mathrm{S}_{\mathrm{N}} 2$ process (complete inversion). If the intimate ion pair $\mathrm{R}^{+} \mathrm{X}^{-}$is formed, then the solvent can attack at this stage to give total inversion, or a combination of inversion and racemisation if there is competition between reactions $A$ and $B$. Another possibility is the attack of $\mathrm{Y}^{-}$on the loose ion pair. If this is the case then more or perhaps total racemisation is expected. Finally, if $\mathrm{R}^{+}$is formed, it is planar, and attack by $\mathrm{Y}^{-}$gives complete racemisation. The ion pair concept thus predicts that $\mathrm{S}_{\mathrm{N}} 1$ reactions can display complete racemisation or partial inversion. The fact that this behaviour is generally found is evidence that ion pairs are involved in many $\mathrm{S}_{\mathrm{N}} 1$ reactions.

\subsubsection{Ion Pairing and the Reactivity of Nucleophilic Anions}

Salts are not fully dissociated in solvents of low dielectric constant, but exist as ion pairs or as higher ionic aggregates. Ion pairing occurs to a lesser extent in aprotic solvents such as dimethyl sulphoxide, but it is still important.

The free anion will be very much more reactive than the associated ion pair $\left(k_{\mathrm{F}}>\right.$ $k_{\mathrm{p}}$ ) and a rate expression for the parallel paths may be set up (Scheme 1.6): 


$$
\begin{gathered}
\overline{\mathrm{Y}}+\mathrm{RX} \stackrel{k_{\mathrm{F}}}{\longrightarrow} \mathrm{RY}+\overline{\mathrm{X}} \\
\mathrm{M}^{+} \overline{\mathrm{Y}}+\mathrm{RX} \stackrel{k_{\mathrm{P}}}{\longrightarrow} \mathrm{RY}+\mathrm{M}^{+} \mathrm{X}^{-} \\
k=\alpha k_{\mathrm{F}}+(1-\alpha) k_{\mathrm{P}}
\end{gathered}
$$

Scheme 1.6

$k, k_{\mathrm{F}}$, and $k_{\mathrm{P}}$ are the observed second order rate constant and the rate constants for reaction of the free ions and ion pairs, respectively; $\alpha$ is the degree of dissociation of $\mathrm{M}^{+} \mathrm{Y}^{-}$.

The available evidence suggests that most of the variation of the second order rate constant with salt concentration is explicable in terms of ionic association of the nucleophile. An example comes from measurements from the rates of reaction between halide ions and butyl toluene-p-sulphonate in acetone. The second order rate constants calculated from the known concentrations of free halide ions are reasonably independent of the nature of the cation. 5

\section{Table 1.1}

Reaction between halide ions and butyl toluene-p-sulphonate in acetone at $25^{\circ} \mathrm{C}$.

\begin{tabular}{|c|c|c|c|}
\hline Halide Salt & $\begin{array}{c}10^{4} \mathrm{~K} / \\
\mathrm{mol}^{-1} \mathrm{dm}^{3} \mathrm{~s}^{-1}\end{array}$ & $\begin{array}{c}10^{4} \mathrm{k} / \\
\mathrm{mol}^{-1} \mathrm{dm}^{3} \mathrm{~s}^{-1}\end{array}$ & $\begin{array}{c}10^{4} k_{\mathrm{F}} / \\
\mathrm{mol}^{-1} \mathrm{dm}^{3} \mathrm{~s}^{-1}\end{array}$ \\
\hline$(n-\mathrm{Bu})_{4} \mathrm{NCl}$ & 22.8 & 33.5 & 58 \\
\hline $\mathrm{LiCl}$ & 0.027 & 0.493 & 51 \\
\hline$(n-\mathrm{Bu})_{4} \mathrm{NBr}$ & 32.9 & 9.09 & 13 \\
\hline $\mathrm{LiBr}$ & 5.22 & 2.81 & 12 \\
\hline$(n-\mathrm{Bu})_{4} \mathrm{NI}$ & 64.8 & 1.68 & 2.0 \\
\hline $\mathrm{LiI}$ & 69.0 & 2.97 & 3.6 \\
\hline
\end{tabular}


Table 1.1 lists $K$, the equilibrium constant for dissociation of the salts, together with the observed and corrected second order rate constants $k$ and $k_{\mathrm{F}}$ respectively.

The extent of ion pairing decreases with increasing ionic size, and is comparatively unimportant for the tetraalkylammonium halides. The sequence of halide ion reactivities in acetone, corrected for ionic association, is chloride $>$ bromide $>$ iodide.

\subsubsection{The Effect of the Reaction Medium}

The effect of solvent on the rate of $\mathrm{S}_{\mathrm{N}} 1$ reactions depends on whether the substrate is neutral or positively charged. For neutral substrates, which make up the majority of cases, the more polar the solvent, the faster the reaction. This is due to a greater solvation energy for the transition state than in the starting compound and the energy of an ionic transition state is reduced by polar solvents (Table 1.2):

\section{Table 1.2}

\begin{tabular}{|c|c|c|c|c|}
\hline \multirow{2}{*}{$\begin{array}{c}\text { Initial state } \\
\mathrm{S}_{\mathrm{N}} 1\end{array}$} & \multirow[t]{2}{*}{ Transition state } & \multirow[t]{2}{*}{$\begin{array}{l}\text { Relative charge } \\
\text { in transition state }\end{array}$} & $\begin{array}{l}\text { How an increase } \\
\text { polarity affects }\end{array}$ & $\begin{array}{l}\text { nolvent } \\
\text { he rate }\end{array}$ \\
\hline & & & & \\
\hline$R-X$ & ${ }^{\delta+} \mathrm{R} \ldots \ldots \mathrm{X}^{\delta-}$ & Increased & \multicolumn{2}{|l|}{ Large increase } \\
\hline $\mathrm{R}-\mathrm{X}^{+}$ & ${ }^{\delta+} \mathrm{R} \ldots \ldots . . \mathrm{X}^{\delta+}$ & Dispersed & \multicolumn{2}{|l|}{ Small decrease } \\
\hline \multicolumn{5}{|l|}{$\mathrm{S}_{\mathrm{N}} 2$} \\
\hline $\mathrm{Y}^{-}+\mathrm{R}-\mathrm{X}$ & ${ }^{\delta-Y} \ldots . . . . . X^{\delta-}$ & Dispersed & Small decrease & (1) \\
\hline $\mathrm{Y}+\mathrm{R}-\mathrm{X}$ & ${ }^{\delta+} \mathrm{Y} \ldots . . \mathrm{R} \ldots \mathrm{X}^{\delta-}$ & Increased & Large increase & (2) \\
\hline $\mathrm{Y}^{-}+\mathrm{R}-\mathrm{X}^{+}$ & $\delta-Y \ldots . . . . X^{\delta+}$ & Decreased & Large decrease & (3) \\
\hline $\mathrm{Y}+\mathrm{R}-\mathrm{X}^{+}$ & $\delta+Y \ldots R \ldots X^{\delta+}$ & Dispersed & Small decrease & (4) \\
\hline
\end{tabular}




\section{CHAPTER 1}

For an $\mathrm{S}_{\mathrm{N}} 1$ reaction with a positively charged substrate the charge is more spread out in the transition state than in the starting ion, and a greater solvent polarity slows the reaction. Even for solvents with about equal polarity there is a difference between protic and aprotic solvents. $S_{N} 1$ reactions of uncharged substrates are more rapid in protic solvents, which can hydrogen bond with the leaving group.

For $\mathrm{S}_{\mathrm{N}} 2$ reactions, the effect of the solvent depends on which of the four charge types the reaction conforms to. In types (1) and (4), an initial charge is dispersed in the transition state, so that the reaction is impeded by polar solvents. In type (3) initial charges are decreased in the transition state, so that the reaction is even more impeded by polar solvents. However, reactions of type (2) are aided by polar solvents as the reactants are uncharged and the transition state has built up charge. The difference between protic and aprotic solvents must be examined for $\mathrm{S}_{\mathrm{N}} 2$ reactions. The transition state is more solvated in polar aprotic solvents than in protic ones for reactions of types (1) and (3). Moreover, the original charged nucleophile is less solvated in aprotic solvents so the rate of attack by small anions is most greatly increased by the change from a protic to an aprotic solvent. Reaction types (2) and (4) are much less sensitive to the difference between protic and aprotic solvents.

The addition of an external salt generally affects the rates of $S_{N} 1$ and $S_{N} 2$ reactions in the same way as an increase in solvent polarity. This is not quantitative as different salts have different effects. The rates of $S_{\mathrm{N}} 1$ reactions are usually increased by the addition of salts (salt effect). However, as mentioned previously, the addition of the leaving group ion can sometimes decreases the rate (common ion effect). 6

\subsubsection{Mixed $\mathrm{S}_{\mathbf{N}} \underline{1 \text { and }} \mathrm{S}_{\mathbf{N}} \underline{2 \text { Mechanisms }}$}

Some reactions of a given substrate under a given set of conditions display all the characteristics of $\mathrm{S}_{\mathrm{N}} 2$ mechanisms. There are other reactions that proceed by $\mathrm{S}_{\mathrm{N}} 1$ mechanisms, but cases are found that cannot be characterised so easily. Two main theories have been devised to explain these uncharacterised cases. One theory holds that intermediate behaviour is caused by a mechanism that is neither "pure" $\mathrm{S}_{\mathrm{N}} 1$ nor "pure" 
$\mathrm{S}_{\mathrm{N}} 2$, but some in between type. According to the second theory, there is no intermediate mechanism, and borderline behaviour is caused by simultaneous operation of both the $\mathrm{S}_{\mathrm{N}} 1$ and $\mathrm{S}_{\mathrm{N}} 2$ mechanism.

Sneen 7,8 has formulated an intermediate-mechanism theory that applies not only to borderline behaviour but to all nucleophilic substitutions at a saturated carbon. According to Sneen, all $\mathrm{S}_{\mathrm{N}} 1$ and $\mathrm{S}_{\mathrm{N}} 2$ reactions can be accommodated by one fundamental mechanism (the ion pair mechanism). The substrate first ionises to an intermediate ion pair which is then converted to products (Scheme 1.7):

$$
\mathrm{R} \longrightarrow \mathrm{X} \stackrel{k_{1}}{\rightleftharpoons} \mathrm{R}^{+} \overrightarrow{\mathrm{X}} \stackrel{k_{2}}{\rightleftharpoons} \text { Products }
$$

Scheme 1.7

The difference between the $S_{N} 1$ and $S_{N} 2$ mechanisms is that in the former case the creation of the ion pair $\left(k_{1}\right)$ is rate-determining, while in the $\mathrm{S}_{\mathrm{N}} 2$ mechanism its destruction $\left(k_{2}\right)$ is rate determining. Borderline behaviour is found where the rates of creation and destruction of the ion pair are of the same size.

An alternative view that also favours an intermediate mechanism is that of Schleyer and co-workers. ${ }^{9}$ They believe that the key to the problem is vary degrees of nucleophilic solvent assistance to ion pair formation and have proposed an $\mathrm{S}_{\mathrm{N}} 2$ (intermediate) mechanism.

\subsection{Rearrangements}

\subsubsection{Bimolecular Mechanism, $\underline{S}_{\mathbf{N}} \underline{\underline{\prime}}$}

In this mechanism, nucleophilic attack upon the $\gamma$-carbon atom of an allylic compound displaces a pair of electrons and through conjugative electron transfer breaks the $\mathrm{C}-\mathrm{X}$ bond (Scheme 1.8): 


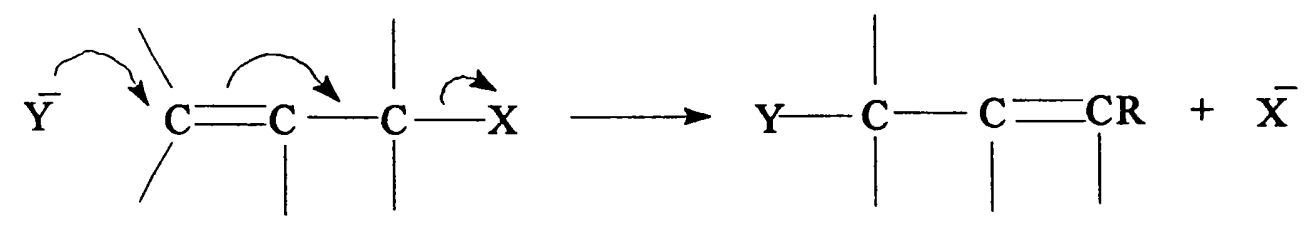

Scheme 1.8

\subsubsection{Unimolecular Mechanisms, $\underline{\text { Un }} \underline{\underline{1}}$}

The first step in this mechanism is the creation of a carbocation whose rearrangement is synchronous with, or subsequent to the breaking of the C-X bond. Wagner-Meerwein rearrangements of saturated systems are of this category (Scheme 1.9):<smiles>[R]C([R2])(C)C([X])(C)C</smiles><smiles>[Y][C+](C)C([R2])(C)CC</smiles>

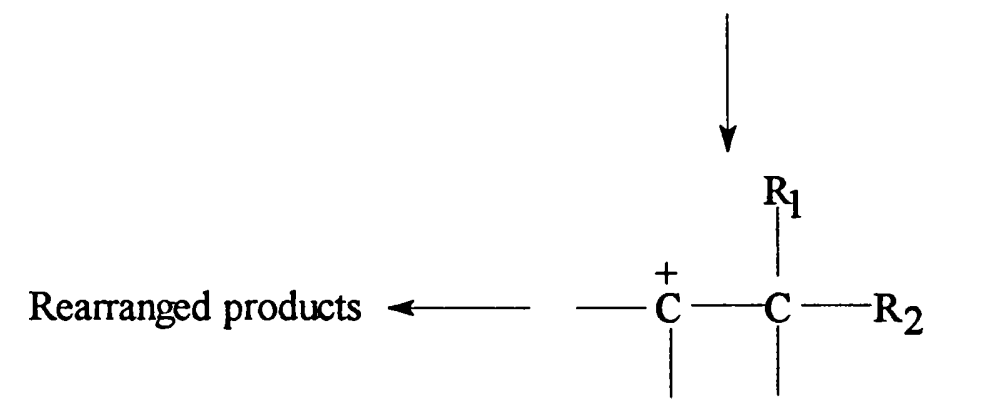

Scheme 1.9

\subsubsection{The $S_{\underline{N}} \underline{\text { Mechanism }}$}

In the $\mathrm{S}_{\mathrm{N}^{\mathrm{i}}}$ mechanism ${ }^{10}$ (substitution nucleophilic internal) part of the leaving group must be able to attack the substrate, detaching itself from the rest of the leaving group in the process. The first step is dissociation into an intimate ion pair (Scheme 1.10): 


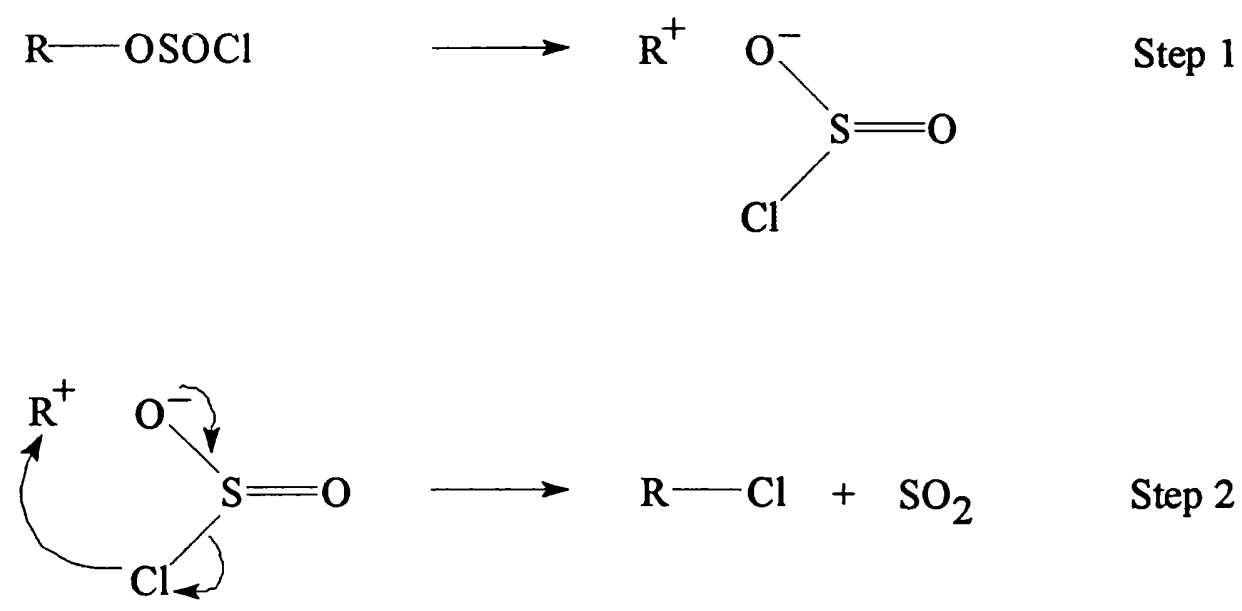

Scheme 1.10

But in the second step part of the leaving group attacks $\mathrm{R}^{+}$from the front side since it is unable to get to the rear. This results in retention of configuration.

The example shown is probably the most important case of this mechanism yet discovered, since the reaction of alcohols with thionyl chloride to give alkyl halides usually proceeds in this way, the first step being the formation of the alkyl chlorosulphite.

\section{$1.4 \quad$ B-Elimination}

The substitution process is often accompanied by $\beta$-elimination of $\mathrm{HX}$, and again both uni- and bi-molecular mechanisms are recognised.

\subsubsection{Unimolecular Mechanism, E1}

The first step in the E1 (unimolecular) mechanism is the formation of a carbocation which instead of being captured by a nucleophile may lose a proton (Scheme 1.11): 


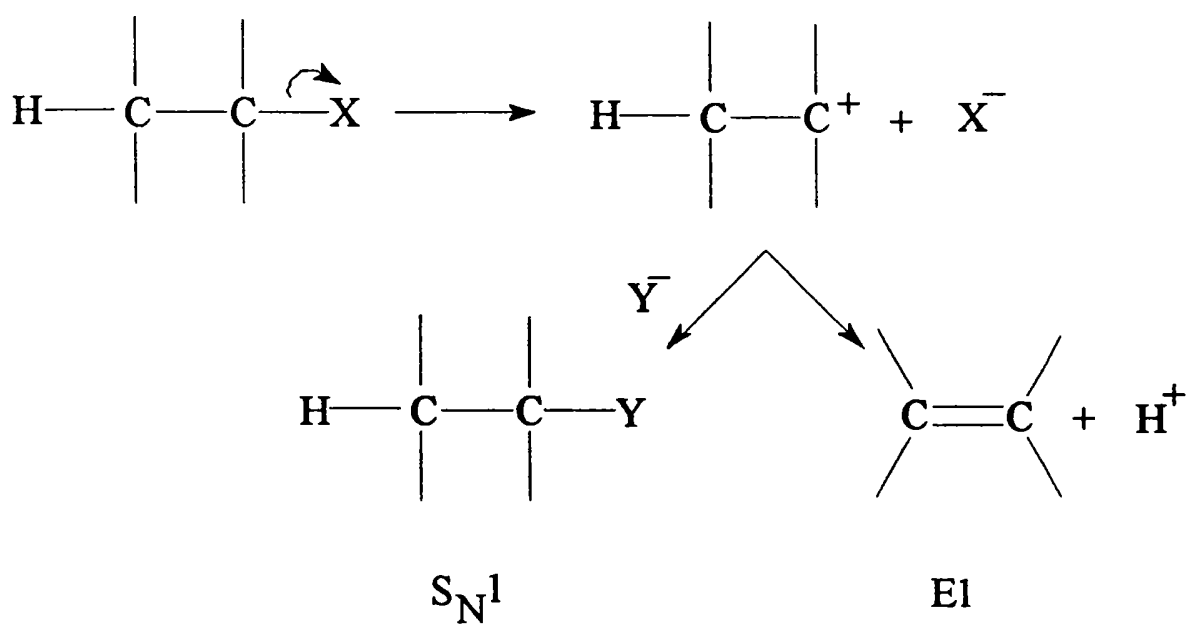

Scheme 1.11

\subsubsection{Bimolecular Mechanism, E2}

In the E2 (bimolecular) mechanism, a base $\left(\mathrm{B}^{-}\right)$removes a proton, which is usually in a trans-anti configuration to the group X (Scheme 1.12):

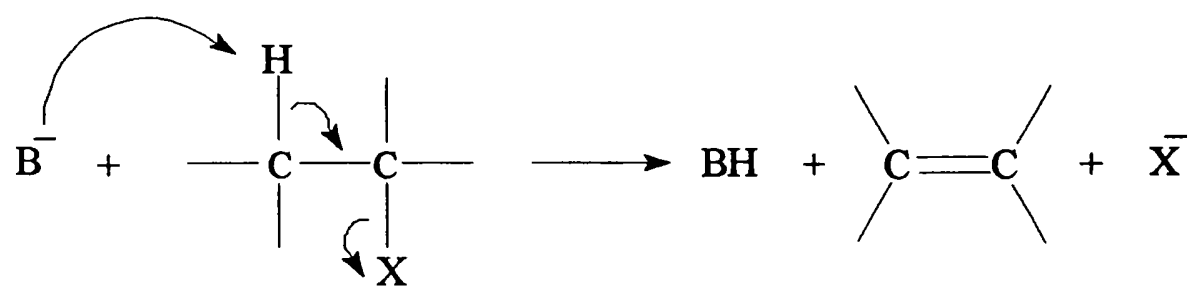

Scheme 1.12

If bimolecular substitution is accompanied by bimolecular elimination the rate of disappearance of the organic compound should be the sum of two distinct chemical reactions, whose contributions can be separated by the analysis of products and rates. In contrast the $\mathrm{S}_{\mathrm{N}} 1$ and $\mathrm{E} 1$ mechanisms have a common rate limiting step, and the products are determined in the fast decomposition of the carbocation. 


\subsection{Nucleophilic Substitution at a Vinylic Carbon}

Nucleophilic substitution at a vinylic carbon is laborious, but many examples are known. The most common mechanisms are the tetrahedral mechanism and the intimately related addition-elimination mechanism. It should be noted that both of these mechanisms are unfeasible at a saturated substrate.

In the tetrahedral mechanism, an addition-elimination (adN-E) type mechanism, $\mathrm{Y}^{-}$attacks to give an intermediate containing both $\mathrm{X}$ and $\mathrm{Y}$, and then $\mathrm{X}$ leaves (Scheme 1.13):

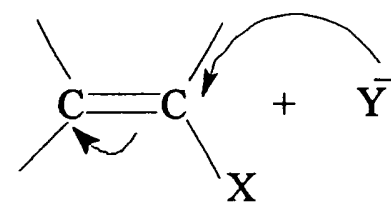<smiles>[Y]CC(C)(C)C(C)=CC</smiles><smiles>[Y]C(C)=C(C)C</smiles>

Scheme 1.13

Such an intermediate can stabilise itself by combining with a positive species. When it does, the reaction is nucleophilic addition to a $\mathrm{C}=\mathrm{C}$ double bond (Scheme 1.14):
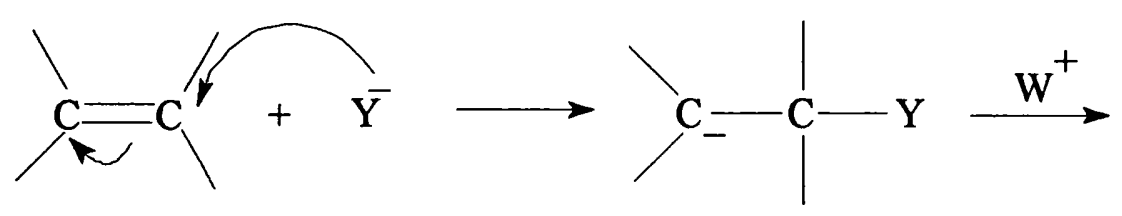<smiles>[Y1]C(C)(C)C([Y])(C)C</smiles>

\section{Scheme 1.14}

For the tetrahedral mechanism the kinetics are first order each in the substrate and in the nucleophile. In most cases where the stereochemistry has been investigated, retention of configuration is observed. The closely related addition-elimination mechanism usually involves a nucleophilic addition to a double bond followed by an E2 elimination reaction. 
Vinyl substrates are disinclined to undergo $S_{N} 1$ reactions, but they can be made to do so by the use of an $\alpha$-group that stabilises the vinyl cation and by the use of a very good leaving group. Another mechanism, involving an elimination-addition sequence, has been observed in vinyl systems and usually involves an E2 elimination followed by a nucleophilic addition.

\subsection{Aromatic Nucleophilic Substitution}

\subsubsection{The $\mathbf{S}_{\mathbf{N}}$ Ar Mechanism}

The $\mathrm{S}_{\mathrm{N}} \mathrm{Ar}$ Mechanism is probably the most important mechanism for nucleophilic aromatic substitution and consists of two steps (Scheme 1.15):

Step 1

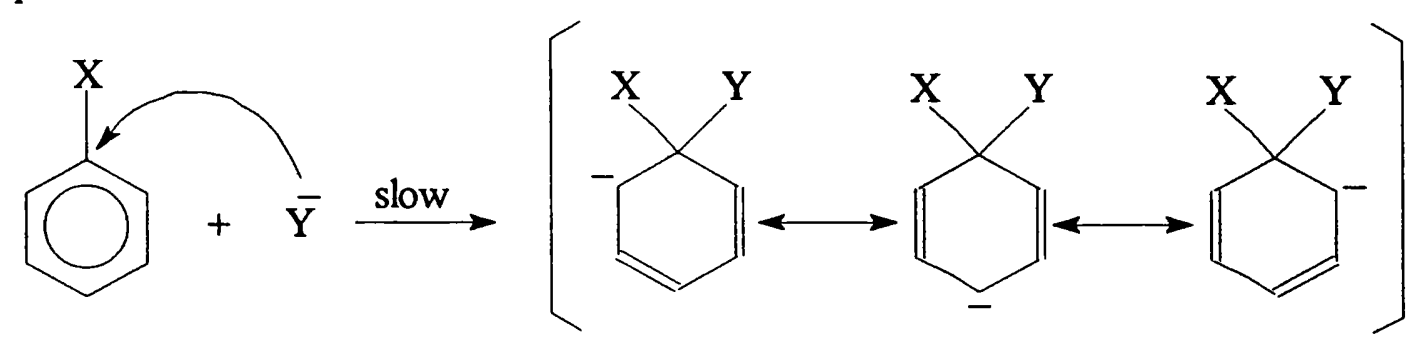

Step 2

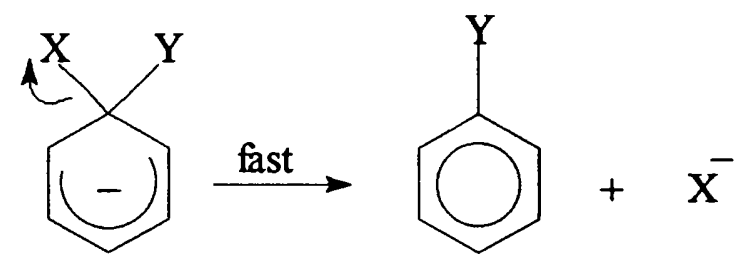

Scheme 1.15

The first step is usually, but not always, rate determining. The attacking nucleophile forms a bond with the substrate, giving a Meisenheimer intermediate, and then the leaving group 
departs. It can be seen that this mechanism greatly resembles the tetrahedral mechanism discussed in Scheme 1.13.

There is a great abundance of evidence for the $\mathrm{S}_{\mathrm{N}} \mathrm{Ar}$ mechanism. Probably the most convincing evidence was the isolation, as long ago as 1902, of the intermediate (1) in the reaction between ethyl picrate and methoxide ion (Scheme 1.16):

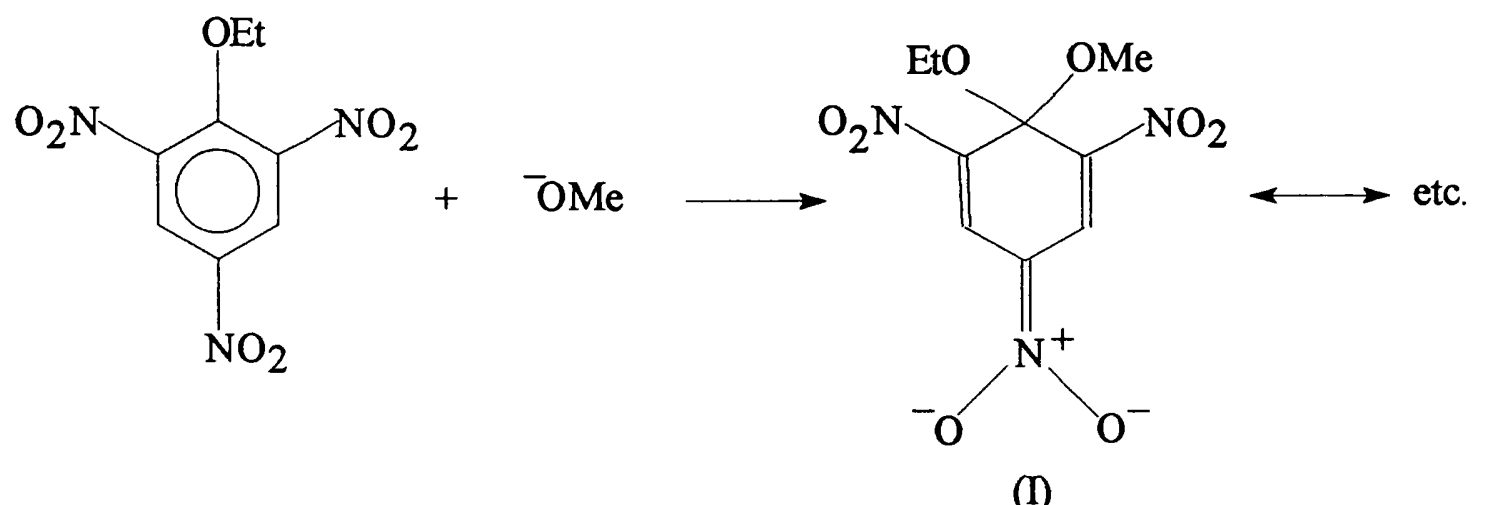

Scheme 1.16

Intermediates of this type are stable salts, called Meisenheimer salts, and many more have been isolated since 1902. If the mechanism were similar to either the $\mathrm{S}_{\mathrm{N}} 1$ or $\mathrm{S}_{\mathrm{N}} 2$ mechanisms, the $\mathrm{Ar}-\mathrm{X}$ bond would be broken in the rate-determining step. In the $\mathrm{S}_{\mathrm{N}} \mathrm{Ar}$ mechanism this bond is not broken until after the rate-determining step, that is, if step 1 is rate-determining. We would predict from this that, if the $\mathrm{S}_{N} \mathrm{Ar}$ mechanism is operating, a change in leaving group should not have much effect on the rate of reaction. This prediction can be used to gain evidence for the $\mathrm{S}_{\mathrm{N}} \mathrm{Ar}$ mechanism.

\subsubsection{The $S_{N} 1$ Mechanism}

An $\mathrm{S}_{\mathrm{N}} 1$ mechanism has never been observed with certainty for aryl halides and sulphonates. It is in reactions with diazonium salts that this mechanism is important (Scheme 1.17): 
Step 1

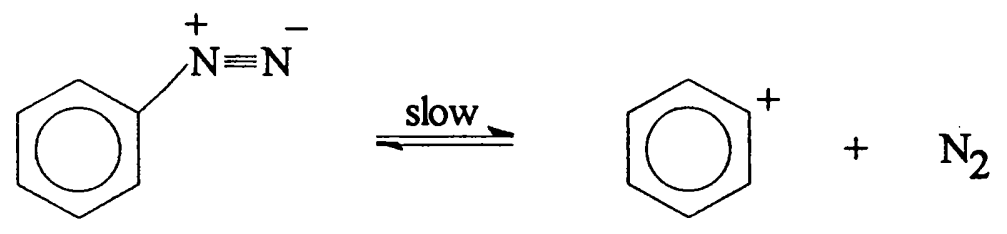

Step 2

Scheme 1.17

There is a great abundance of evidence for the $S_{\mathrm{N}} 1$ mechanism with aryl cations as intermediates. The reaction rate is first order in diazonium salt and independent of the concentration of $\mathrm{Y}^{-}$. Also, the effects of ring substituents on the rate are consistent with a unimolecular rate-determining cleavage.

\subsubsection{The Benzyne Mechanism}

There are some aromatic nucleophilic substitutions that occur on aryl halides that have no activating groups and that require stronger bases than those normally used. Also, the incoming group does not always take the position vacated by the leaving group (cine substitution). A mechanism that can explain all these facts involves elimination followed by addition (Scheme 1.18):

Step 1

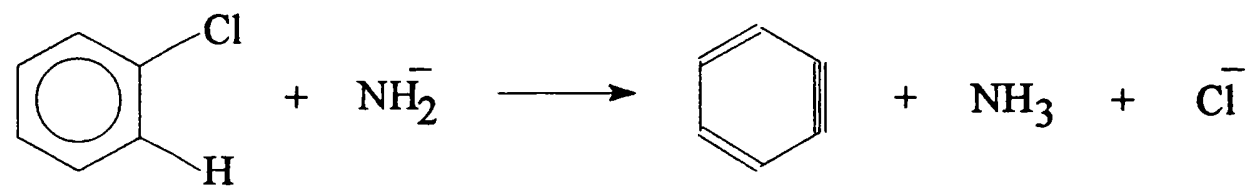

(1) 
Step 2

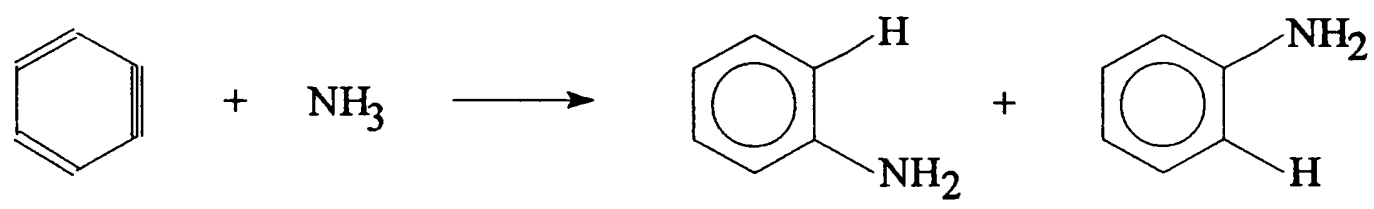

(1)

Scheme 1.18

The species (1) is called a benzyne and the mechanism is known as the benzyne mechanism. If the aryl halide contains two ortho substituents, the reaction should not be able to occur. This is indeed the case. ${ }^{11}$ There are some aromatic nucleophilic substitution reactions that operate by still other mechanisms, among them an addition elimination mechanism.

\subsection{Radical Nucleophilic Substitution}

There has been recent increasing interest in electron-transfer processes in organic chemistry. One class of reactions that has attracted considerable attention are nucleophilic substitution reactions previously considered to be polar in nature but for which alternative electron-transfer (ET) pathways have been proposed. The rapidly lengthening list of such reactions has spawned a subsequent debate focusing on the so called Polar-ET dichotomy that has been intense and at times controversial.

\subsubsection{The $\mathbf{S}_{\mathrm{RN}}$ Mechanism}

A well established electron-transfer mechanism is the $\mathrm{S}_{\mathrm{RN}} 1$ mechanism. In this mechanism a product of net substitution is obtained via a radical-chain mechanism involving as the key step, transfer or photoinjection of an electron into a $\pi$-acceptor substituent or orbital of the substrate (Scheme 1.19): 


$$
\begin{gathered}
\mathrm{RX}+\overline{\mathrm{Y}} \frac{h v}{\text { s.e.t }}[\mathrm{RX}]^{-}+\dot{\mathrm{Y}} \\
{[\mathrm{RX}]^{-} \longrightarrow \mathrm{R}^{\cdot}+\overline{\mathrm{X}}} \\
\mathrm{R}^{\cdot}+\overline{\mathrm{Y}} \longrightarrow[\mathrm{RY}]^{-} \\
{\left[\mathrm{RY}^{-}+\mathrm{RX}\right.}
\end{gathered}
$$

Scheme 1.19

The term $\mathrm{S}_{\mathrm{RN}}$ l (substitution, radical nucleophilic, unimolecular) was suggested by Bunnett 12 in his studies of substitution reactions of halogenoarenes. Bunnett derived the term $S_{R N} 1$ from the obvious similarity of steps (2) and (3) with the $S_{N} 1$ mechanism. Initiation of the chain reaction requires electron capture by the substrate to form its radical anion. The propagation steps of the chain reaction are shown in steps (2) to (4).

A considerable array of evidence has been presented to support $\mathrm{S}_{\mathrm{R}} 1$ mechanisms for reactions involving various different types of substrate. Bunnett et al. ${ }^{12}$ treated three 5-halo- and three 6-halo-1,2,4-trimethylbenzenes, the halogens being chlorine, bromine and iodine, with $\mathrm{KNH}_{2}$ in $\mathrm{NH}_{3}$, anticipating reaction by the benzyne mechanism. Inasmuch as all six substrates should give the same benzyne, regardless of the position or identity of the halogen, all were expected to give the same product ratio of 6-amino isomer (2) to 5-amino isomer (3) (Scheme 1.20). That expectation was fulfilled for the bromo and chloro substrates; all four gave a (2)/(3) product ratio of 1.46 . However, the 5- and 6-iodo substrates gave product ratios of 0.63 and 5.9, respectively, both representing enrichment in unrearranged product, as compared to the benzyne product ratio of 1.46. Bunnett et al. concluded that a nonrearranging substitution mechanism was in competition with the benyne mechanism. 
<smiles>[X]c1cc(C)c(C)cc1C</smiles>

(1)<smiles>Cc1cc(C)c(C)c(N)c1</smiles>

(2)<smiles>Cc1cc(C)c(N)cc1C</smiles>

(3)

Scheme 1.20

Bunnett et al. found that a radical scavenger (tetraphenylhydrazine) largely suppressed the nonrearranging component of the reactions of 5- and 6-iodo substrates. Furthermore, the addition of potassium metal steered substitution entirely to unrearranged products. It was proposed that besides the benzyne mechanism, the $\mathrm{S}_{\mathrm{RN}} 1$ mechanism was also operating here.

Much of the original evidence for the $S_{R N} 1$ mechanism comes from work by Kornblum et al. ${ }^{13-15}$ They have shown that $p$-nitrocumyl chloride and $\alpha, p$-dinitrocumene undergo a facile type of substitution at the tertiary carbon atom ${ }^{16}$. In these reactions a wide variety of anions smoothly displace the chlorine of (1a), or the aliphatic nitro group of (1b) (Scheme 1.21):<smiles>[X]C(C)(C)c1ccc([N+](=O)[O-])cc1</smiles>

Scheme 1.21 
These transformations occur at room temperature and proceed to completion in minutes or hours. For example, 17 when $p$-nitrocumyl chloride was treated with sodium azide in hexamethylphosphoramide (HMPA) the reaction was 65\% complete in 75 seconds, but in the presence of $10 \mathrm{~mol} \%$ of $p$-dinitrobenzene (strong electron acceptor) no reaction occurred. Strong electron acceptors can prevent single electron transfer reactions by destroying the radical anion intermediates.

When $\alpha, p$-dinitrocumene was treated with the lithium salt of 2-nitropropane in (HMPA), the reaction gave a 56\% yield of 2,3,-di-methyl-2-nitro-3-(p-nitrophenyl)butane in 40 minutes (Equation 1.7):

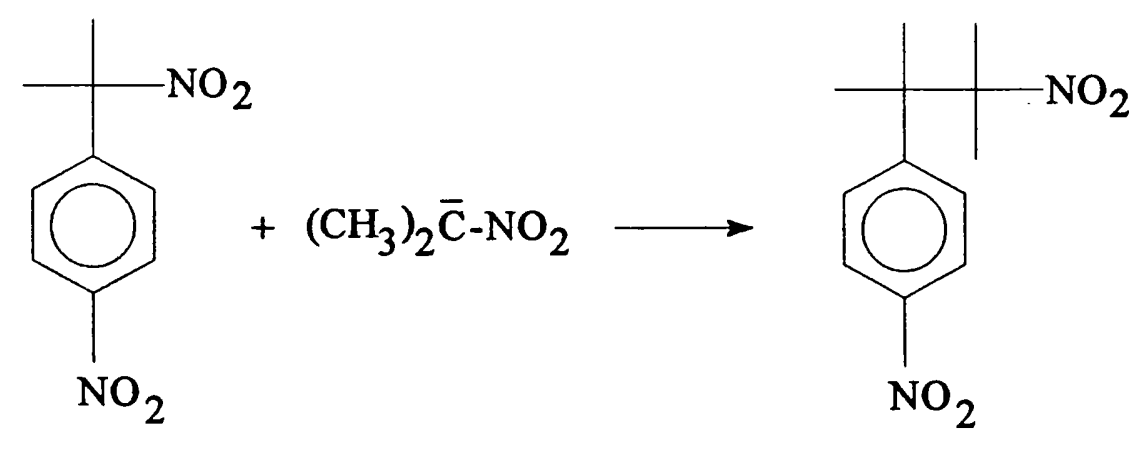

When $5 \mathrm{~mol} \%$ of di-tert-butyl nitroxide was present, none of the product was obtained and $97 \%$ of the starting $\alpha, p$-dinitrocumene was recovered.

When $p$-nitrocumyl chloride was treated with sodium nitrite in dimethyl sulphoxide and the reaction carried out under two 20 Watt white fluorescent lights, the reaction gave a half-life of 12 hours. A duplicate experiment in the dark typically had a half-life of 300 hours. The product, $\alpha, p$-dinitrocumene, was obtained with a yield of $91 \%$.

These transformations are generally much faster in (HMPA) compared to dimethyl sulphoxide and dimethyl formamide. However, when $p$-nitrocumyl chloride was treated with sodium thiophenoxide at $0^{\circ} \mathrm{C}$ in dimethyl formamide, the displacement of chloride 
occurred rapidly with a half-life of 2 minutes. A $95 \%$ yield of pure tertiary sulphide was isolated (Equation 1.8):
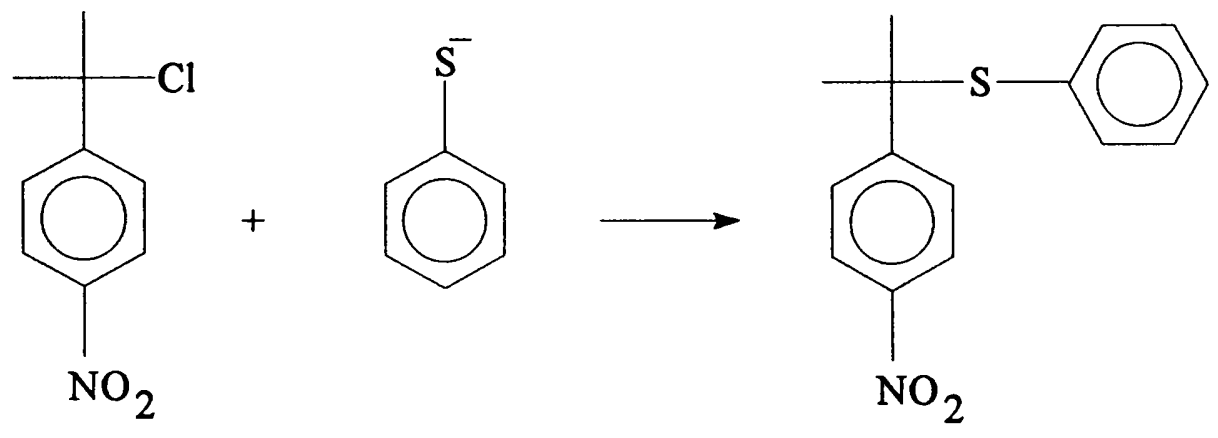

When $100 \mathrm{~mol} \%$ of $m$-dinitrubenzere was present, only $29 \%$ reaction occurred in 10 minutes and the time needed for the reaction to go to completion was about 45 minutes.

Electron spin resonance spectroscopy has been used to probe two of the steps postulated for the $\mathrm{S}_{\mathrm{RN}} 1$ mechanism for $p$-nitrobenzyl and $p$-nitrocumyl systems. ${ }^{18}$ These two steps are electron capture by $p$-nitrobenzyl and $p$-nitrocumyl derivatives to form radical anions and their dissociation to yield radicals and anions [steps (1) and (2) in Scheme 1.9]. A range of radical-anions $\left(p-\mathrm{NO}_{2} \mathrm{C}_{6} \mathrm{H}_{4} \mathrm{CH}_{2} \mathrm{X}\right)^{--}$, with $\mathrm{X}=\mathrm{I}, \mathrm{Br}, \mathrm{Cl}$, and $\mathrm{SCN}$ and $\left(\mathrm{p}-\mathrm{NO}_{2} \mathrm{C}_{6} \mathrm{H}_{4} \mathrm{CMe}_{2} \mathrm{X}\right)^{--}$, with $\mathrm{X}=\mathrm{Br}$ andNO${ }_{2}$ have been unambiguously identified by e.s.r. spectroscopy and shown to be long lived at low temperature. The results indicate that the $p$-nitrobenzyl radical-anions do not dissociate to give $p$-nitro benzyl radicals at the temperatures used ( $77 \mathrm{~K}$ to $160 \mathrm{k})$. However, dissociation of the $p$ nitrocumyl radical-anions $\left(p-\mathrm{NO}_{2} \mathrm{C}_{6} \mathrm{H}_{4} \mathrm{CMe}_{2} \mathrm{X}\right)^{-}$, with $\mathrm{X}=\mathrm{Br}$ and $\mathrm{NO}_{2}$, to $p$ nitrocumyl radicals $\left(p-\mathrm{NO}_{2} \mathrm{C}_{6} \mathrm{H}_{4} \mathrm{C}^{\prime} \mathrm{Me}_{2}\right)$ and bromide and nitrite anions respectively was clearly observed. 


\subsubsection{The $\underline{S}_{\mathrm{RN}} \underline{2 \text { Mechanism }}$}

There is evidence ${ }^{19}$ to support an alternative mechanism to the $\mathrm{S}_{\mathrm{RN}} 1$ process. This alternative mechanism proposes that the nucleophile reacts directly with the radical anion, $\mathrm{RX}^{-}$, derived from the starting material. The product radical anion, $\mathrm{RY}^{-}$, transfers an electron to starting material to continue the chain (Scheme 1.22):

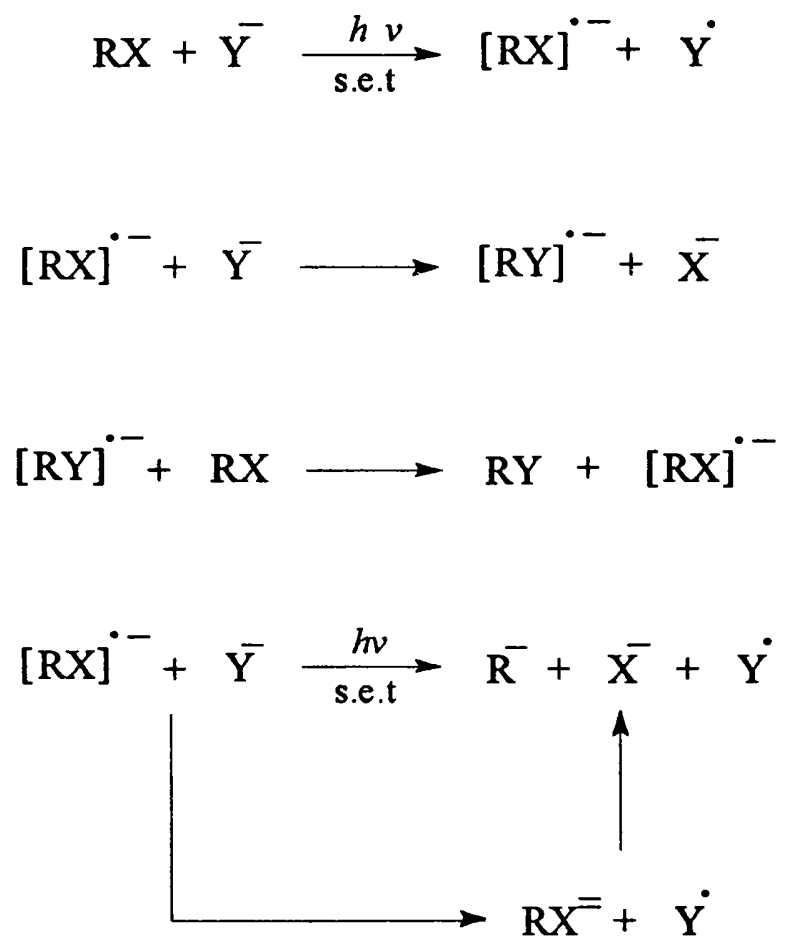

\section{Scheme 1.22}

There is very positive evidence for the reaction of various nucleophiles with aromatic radical anions that do not dissociate. Chambers and Adams ${ }^{20}$ showed that the $p$ dinitrobenzene radical anion generated electrochemically reacted with the water in dimethyl formamide to give $p$-nitrophenol. Shein has suggested that substitution reactions of $p$-dinitrobenzene ${ }^{21}, p$-nitrochlorobenzene 22 and 2,4-dinitrochlorobenzene 23 involve reaction of nucleophiles with various radical anions. Albe and Ikegamo 24,25 have demonstrated that displacement of nitrite ion by hydroxide ion from $o$ - or $p$ - 
dinitrobenzene is kinetically controlled by the attack of hydroxide ion on the dinitrobenzene radical anion.

P.G. Sammes et al. ${ }^{26}$ has shown that $p$-dinitrobenzene undergoes nucleophilic substitution with sodium phenoxide and several hindered 2,6-substituted phenoxides to afford diphenyl ethers. A series of inhibition studies provided information on the mechanism of the reaction of $p$-nitrobenzene with the phenoxide (1) (Scheme 1.23):<smiles>Cc1cc(Br)c(O[NH3+])c(Br)c1</smiles>

(1)<smiles>O=[N+]([O-])c1ccc([N+](=O)[O-])cc1</smiles>

(2)<smiles>Cc1cc(Br)c(Oc2ccc([N+](=O)[O-])cc2)c(Br)c1</smiles>

(3)

Scheme 1.23

The reaction of $p$-dinitrobenzene with the phenoxide (1) in dry dimethyl sulphoxide at $90{ }^{\circ} \mathrm{C}$ for 16 hours gave the diphenyl ether (3) in $65 \%$ yield. The inhibition by radical scavengers has been suggested as one of the criteria for the assignment of a radical chain process. ${ }^{27}$ In the presence of one equivalent of 1,1-diphenyl-2-picrylhydrazyl, a free radical, only $p$-dinitrobenzene was isolated from the reaction mixture. The same results were observed with elemental sulphur as the free radical scavenger. Sammes et al. were cautious in assigning the $\mathrm{S}_{\mathrm{RN}} 1$ mechanism to these reactions and concluded that these reactions were radical in nature.

In a recent report ${ }^{28}$ it was shown that the reactions of $p$-nitrobenzonitrile and 4nitrophthalonitrile with the lithium salts of 2-R-5-nitro-1,3-dioxanes led to the expulsion of the nitrite ion and formation of a carbon-carbon bond. It was also shown that the radical anions of 4-nitrophthalonitrile and p-nitrobenzonitrile were formed during the reactions. These radical anions are stable towards dissociation of nitrite ion. It was found 
that oxygen lowered the rates of reactions. These observations are precisely those that have been found for substitutions on aromatic radical anions. Since the radical anions did not dissociate and since the reactions are inhibited with oxygen there is no viable alternative to the direct reaction between the radical anion and the nucleophile.

Russell et al. 29 have shown that the reaction of mono-enolate anions ( $\mathrm{RCOC}^{-} \mathrm{HR}^{\prime}$ ) with $\mathrm{O}_{2} \mathrm{NCMe}_{2} \mathrm{X}$ where $\mathrm{X}=\mathrm{Cl}, \mathrm{NO}_{2}, p-\mathrm{MePhSO}_{2}$ yield coupling $\left(\mathrm{RCOCH}\left(\mathrm{R}^{\prime}\right)\left(\mathrm{CMe}_{2} \mathrm{NO}_{2}\right)\right.$ and enolate dimerisation products $\left(\mathrm{RCOCH}\left(\mathrm{R}^{\prime}\right) \mathrm{CH}\left(\mathrm{R}^{\prime}\right) \mathrm{COR}\right)$ by free radical chain mechanisms involving bimolecular substitution or electron transfer reactions between the enolate anion and the intermediate nitro alkane radical anion $\left(\mathrm{XCMe}_{2} \mathrm{NO}_{2}^{-\cdot}\right)$.

The radical anion $\mathrm{RX}^{-\cdot}$ can accept another electron, step (4), to give the dianion $\mathrm{RX}^{=}$. This dianion then dissociates to $\mathrm{R}^{-}$and $\mathrm{X}^{-}$. There is strong evidence that this is the correct mechanism for the electrochemical reduction of halonitrobenzenes in liquid ammonia. Teherani and $\mathrm{Bard}^{30}$ have prepared the radical anions from $o, m, p$ chloronitrobenzenes, $m$-bromonitrobenzene and $o, m, p$-iodonitrobenzenes in liquid ammonia. The radical anions did not dissociate under these conditions but rather accepted another electron to give the dianions which did dissociate. The dianion from $\mathrm{m}-$ chloronitrobenzene did not dissociate. Saveant and Thiebault 31 have studied the electrochemical reduction of halobenzophenones in liquid ammonia. They found that the dianion of $m$-fluorobenzophenone did not dissociate. The dianions of $p$-chloro, $m$-bromo and $p$-bromo-benzophenones did. The reduction of $\mathrm{m}$-chlorobenzophenone gave different products depending on the conditions. There was no dissociation of the radical anion. The results certainly show that aromatic radical anions can accept a second electron to give a dianion which can then dissociate to the aryl anion and the leaving group.

It thus appears that in both aromatic and aliphatic chemistry, the bimolecular interaction between a nucleophile and a radical anion can occur. In view of this conclusion it seems appropriate to be cautious in assigning the $\mathrm{S}_{\mathrm{RN}} 1$ mechanism to all nucleophilic substitution processes proceeding via a radical chain sequence. 


\subsubsection{The SET $\underline{2 \text { Mechanism }}$}

Thermal radical nucleophilic substitution reactions have been discovered that are believed to occur by an $\mathrm{S}_{\mathrm{N}}$ 2-type single electron transfer $\left(\mathrm{S}_{\mathrm{ET}} 2\right)$ mechanism 32,33 or a non-chain radical mechanism. The first step in the $\mathrm{S}_{\mathrm{ET}} 2$ mechanism is the formation of an electron donor-acceptor complex followed by a single electron transfer reaction to form a radical anion and radical cation pair. The reactions directed to the final products will then be completed within a solvent cage (Scheme 1.24):

$$
\mathrm{RX}+\mathrm{Y}^{-} \longrightarrow \mathrm{RX}^{-}+\mathrm{Y}^{\cdot} \longrightarrow \mathrm{R}^{-} \mathrm{X}^{-} \mathrm{Y}^{-} \longrightarrow \mathrm{RY}
$$

Scheme 1.24

These reactions do not require the initiation by photoradiation, solvated electrons, or an electrode, and obey second-order kinetics.

Zhang et al. ${ }^{34}$ have studied the reactions of various $p$-nitrohalobenzenes with the sodium salt of ethyl $\alpha$-cyanoacetate carbanion $\left[\mathrm{Na}^{+-} \mathrm{CH}(\mathrm{CN}) \mathrm{CO}_{2} \mathrm{Et}\right]$ in dimethyl sulphoxide. They have detected the E.S.R. spectra of the various p-nitrohalobenzene radical anions and the ultra-violet spectra of the corresponding electron donor-acceptor complexes. Moreover, these reactions were inhibited, or completely prevented, by addition of a small amount of $p$-dinitrobenzene (strong electron acceptor). The addition of galvinoxyl and nitroxyl radicals (radical scavengers) to these reactions gave little or no retardation. The results are consistent with the conclusion that these reactions proceed via a non-chain radical mechanism.

\subsection{4 $\pi$-Complex/Charge Transfer Complex}

Aromatic nucleophilic substitutions and additions are strongly assisted by electron withdrawing groups such as $\mathrm{NO}_{2}$. There is strong evidence in apolar solvents for radical 
mechanisms involved in aromatic substitution. However, the $\mathrm{S}_{\mathrm{N}} \mathrm{Ar}$ mechanism (see 1.6.1) has been assumed to be correct for reactions in polar hydroxylic solvents.

Bunton et al. ${ }^{35}$ have reinvestigated nucleophilic substitutions involving nitroarenes, azines, and their halo and arenesulphonate derivatives and believe that they have shown the $\mathrm{S}_{\mathrm{N}} \mathrm{Ar}$ mechanism to be inadequate in solvents of high water content. Two intermediates were seen spectrophotometrically en route to the Meisenheimer complex. The postulated intermediates are a $\pi$-complex (2) and a charge-transfer complex of a radical anion and $\mathrm{OH}(3)$ (Scheme 1.25):

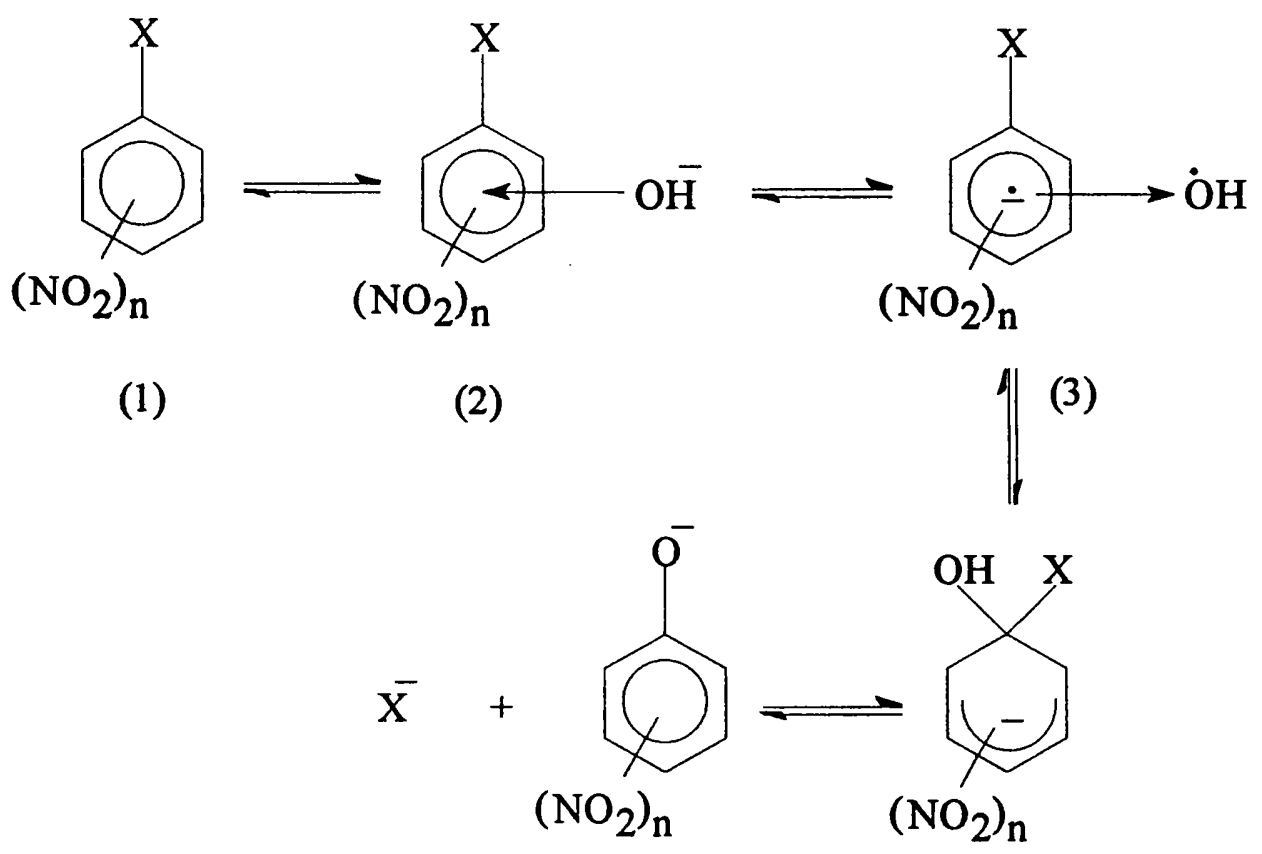

(5)

(4)

Scheme 1.25

The charge-transfer complex of the arene radical anion and $\mathrm{OH}$ then forms a Meisenheimer complex (4). Bunton et al. found that aromatic nucleophilic addition and substitution by $\mathrm{OH}^{-}\left(\mathrm{OD}^{-}\right)$in ${ }^{2} \mathrm{D}_{6}$-labelled-dimethyl sulphoxide- ${ }^{2} \mathrm{D}_{2} \mathrm{O}$ or ${ }^{2} \mathrm{D}_{2} \mathrm{O}$ were for many nitrobenzenes, naphthalenes, and activated azines accompanied by extensive hydrogen exchange. However, substrates that readily formed Meisenheimer complexes or 
overall substitution products were the least readily exchanged. With some overall substitutions exchange was greater in products than in unreacted substrate, which showed that exchange involved an intermediate on the reaction path between substrate and product. This intermediate is believed to be a charge-transfer complex of a radical anion and $\mathrm{OH}(3)$, and it exchanged aromatic hydrogen with ${ }^{2} \mathrm{D}_{2} \mathrm{O}$. Line broadening of the n.m.r. proton signals of the unreacted substrate was also observed and is probably due to interaction between this complex and substrate (Scheme 1.26):

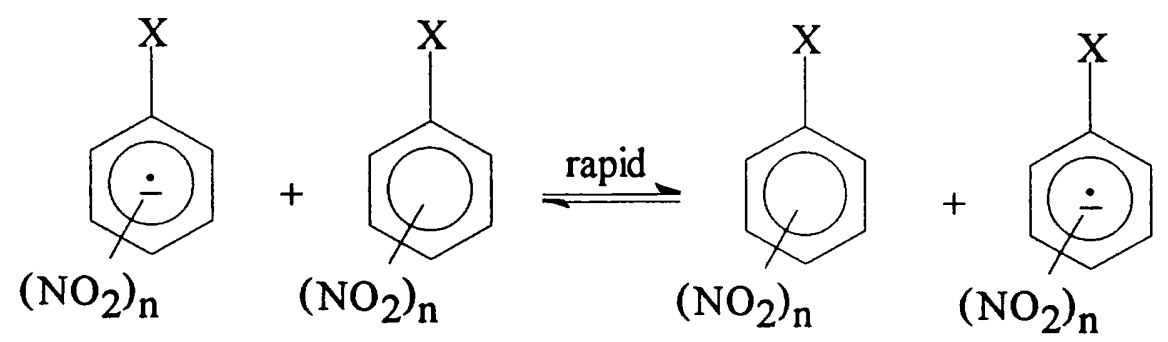

Scheme 1.26

This complex slowly dissociated and gave very extensive line broadening, especially in less aqueous media, but in aqueous media it went forward to products.

This was an unexpected set of results in that in more than one hundred previous investigations $^{36,37}$ of related systems in several laboratories using both stopped-flow and relaxation methods such intermediates had not been detected. Crampton et al. 38 examined Bunton's claim and looked at the initial stages of these reactions. They did not detect the proposed intermediates, their results showing direct conversion of the parent nitrocompounds into Meisenheimer complexes. At present, this is probably the most controversial area of nucleophilic aromatic substitution. 


\section{CHAPTER 2}

\section{The Investigation of Various Radical Nucleophilic Substitution Reactions using}

\section{$15 \underline{\text { N N.M.R. Spectroscopy }}$}

\subsection{Introduction}

Over the past three decades, great progress has been made in the field of radical nucleophilic substitution reactions. Many reactions long thought to be polar nucleophilic substitution reactions were reinvestigated and found, at least to a certain extent, to proceed via single-electron transfer mechanisms. The rapidly lengthening list of such reactions has spawned an ensuing debate centring on the so called Polar-Electron Transfer dichotomy.

Various examples of radical nucleophilic substitution reactions were discussed in the previous chapter. We saw that there were four basic types of mechanisms; $S_{R N} 1$, $\mathrm{S}_{\mathrm{RN}} 2, \mathrm{~S}_{\mathrm{ET}} 2$ and $\pi$-complex/charge transfer complex. The transfer of a single electron is common to all four mechanisms.

As we have seen, evidence for these various radical nucleophilic substitution mechanisms comes mainly from inhibition and initiation studies. Recently, the spectroscopic technique of Electron Spin Resonance has been used to probe two of the steps postulated for the $S_{R N} 1$ mechanism. ${ }^{18}$ A method that has not been used to probe radical nucleophilic substitution reactions is the technique of Chemically Induced Dynamic Nuclear Polarisation (C.I.D.N.P.).

\section{$2.2 \quad 15$ N N.M.R. Spectroscopy}

Many of the radical nucleophilic substitution reactions that have been discussed in the previous chapter contain nitrogen either in the substrate or the nucleophile. The ${ }^{15} \mathrm{~N}$ nucleus was chosen for the technique of Chemically Induced Dynamic Nuclear Polarisation (C.I.D.N.P.). Before considering C.I.D.N.P. effects, it is useful to look more 
generally at ${ }^{15} \mathrm{~N}$ n.m.r. spectroscopy. Various data ${ }^{39}$ for the ${ }^{1} \mathrm{H},{ }^{14} \mathrm{~N}$, and ${ }^{15} \mathrm{~N}$ nuclei are shown in Table 2.1:

Table 2.1

\begin{tabular}{|c|c|c|c|}
\hline Nucleus & $1 \mathrm{H}$ & $14_{\mathrm{N}}$ & $15 \mathrm{~N}$ \\
\hline $\begin{array}{c}\text { Nuclear Spin } \\
\text { Quantum No, I }\end{array}$ & $1 / 2$ & 1 & $1 / 2$ \\
\hline $\begin{array}{c}\text { Magnetogyric ratio, } \\
\gamma\end{array}$ & $26.75 \times 10^{7}$ & $3.87 \times 10^{7}$ & $-2.71 \times 10^{7}$ \\
\hline $\begin{array}{c}\text { Nuclear Quadruple, } \\
\text { Q/10-28 } \mathrm{m}^{2}\end{array}$ & --- & +0.07 & $-\cdots$ \\
\hline $\begin{array}{c}\text { Natural Abundance/ } \\
\%\end{array}$ & 99.985 & 99.63 & 0.37 \\
\hline
\end{tabular}

The ${ }^{14} \mathrm{~N}$ nucleus is quadrupolar and the use of ${ }^{14} \mathrm{~N}$ n.m.r. spectroscopy is restricted by the broad lines thus obtained. The ${ }^{15} \mathrm{~N}$ nucleus, like the ${ }^{1} \mathrm{H}$ nucleus, is not quadrupolar and, hence, no restriction applies. Like the proton, the ${ }^{15} \mathrm{~N}$ nucleus has a spin quantum number of $1 / 2$ : the nucleus has therefore two energy levels available to it in a magnetic field. However, unlike the proton, the natural abundance of the ${ }^{15} \mathrm{~N}$ nucleus is low and it is also much less sensitive to radiofrequency radiation than the proton (a factor of 0.0019 relative to ${ }^{1} \mathrm{H}$ for equal numbers of nuclei). It is therefore desirable to use enriched materials.

The negative magnetogyric ratio, $\gamma$, for the ${ }^{15} \mathrm{~N}$ nucleus means that its lower energy state has a magnetic quantum number, $m_{\mathrm{I}}$, of $-1 / 2$, whereas for the ${ }^{1} \mathrm{H}$ nucleus the lower energy state corresponds to $\mathrm{m}_{\mathrm{I}}$ being equal to $+1 / 2$. For the $15 \mathrm{~N}$ nucleus, an n.m.r. spectrometer that uses a frequency of $400 \mathrm{MHz}$ for protons will use $40.52 \mathrm{MHz}$ for ${ }^{15} \mathrm{~N}$. The range of chemical shifts for ${ }^{15} \mathrm{~N}$ spectroscopy covers approximately $500 \mathrm{ppm}$.

\subsection{Chemically Induced Dynamic Nuclear Polarisation}

If n.m.r. spectra are obtained of a solution in which a radical reaction is taking place, then the n.m.r. signals due to the starting materials and the products may show 
anomalous intensities (either enhanced absorption or emission). These anomalies arise from the phenomenon of Chemically Induced Dynamic Nuclear Polarisation or C.I.D.N.P.

The phenomenon of C.I.D.N.P. was first observed independently by Bargon, Fischer, and Johnsen 40 , and Ward and Lawler. ${ }^{41,42}$ Initial attempts to explain the phenomenon in terms of the Overhauser effect or dynamic nuclear polarisation led it to be called C.I.D.N.P., but did not explain all the experimental results.

The radical pair, or C.K.O., theory was proposed independently by Closs ${ }^{43}$, and Kaptein and Oosterhoff. ${ }^{44}$ This new theory explained all of the experimental results and from now on all discussion of C.I.D.N.P. will be made in terms of this theory.

\subsubsection{Interaction of a Nucleus with One Electron}

An electron has spin quantum number, $S$, of $1 / 2$, and magnetic quantum numbers, $m_{s}$, of $+1 / 2$ and $-1 / 2$. The energy of an electron in an applied magnetic field is given by Equation 2.1:

$$
\mathrm{E}=\mathrm{m}_{\mathrm{s}} \mathrm{g} \beta \mathrm{B}
$$

where $g$ is the Landé $g$ factor (2.002319 for a free electron), $\beta$ is the Bohr magneton, and $B$ is the magnetic field strength. As with the $15^{N}$ nucleus the energy of the lowest state corresponds to $m_{s}$ equal to $-1 / 2$.

If the electron's spin is coupled to a nuclear spin then the expression becomes Equation 2.2:

$$
E=m_{s} g \beta B+a m_{s} m_{I}
$$

where ' $a$ ' is the hyperfine coupling constant. In other words, coupling to a nuclear spin leads to splitting of the electronic energy states and, hence, of the electron spin resonance lines. 
A more important consequence in terms of C.I.D.N.P. is the effect of the coupling on the rate of precession of the electron. According to quantum mechanics, the electron spin is not directly aligned with the field but at an angle to it and precesses around this direction. The angular velocity of the precession, $\omega$, is related to the energy of the electron and in the absence of nuclear coupling is given by Equation 2.3:

$$
\omega=(2 \pi / h) g \beta B
$$

If the electron is coupled to a nuclear spin then the expression becomes Equation 2.4:

$$
\omega=(2 \pi / h)\left(g \beta B+a m_{I}\right)
$$

\subsubsection{Systems of Two Electrons}

For a system of two coupled electrons (the situation in a radical pair) the total spin quantum, $S$, equals 0 or 1 . If $S$ equals 0 then the system is in a singlet state; if $S$ equals 1 then the system is in the triplet state. In the singlet state the spins are opposed, in the triplet state they can have three relative configurations (Figure 2.1):

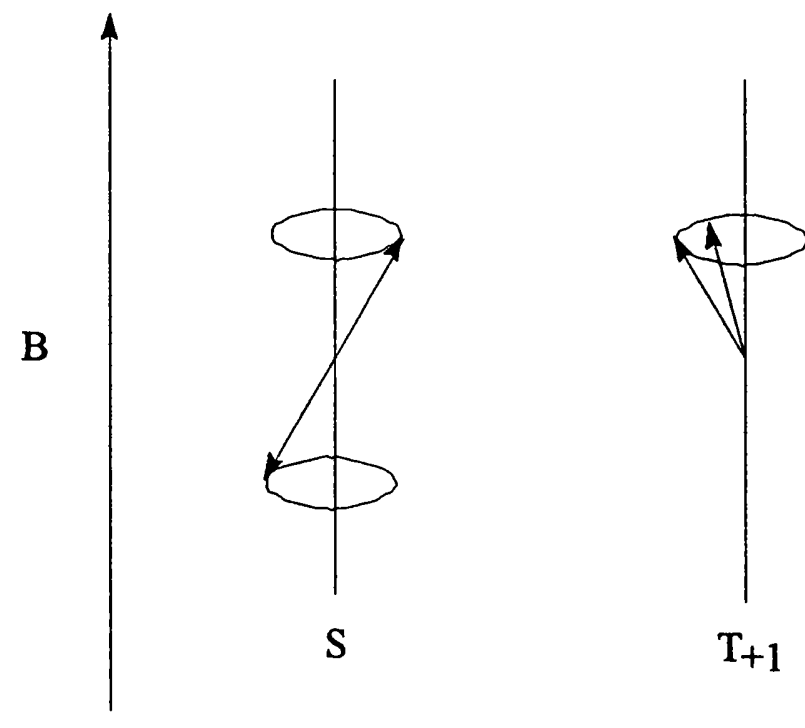

Singlet state $(\mathrm{S}=0)$

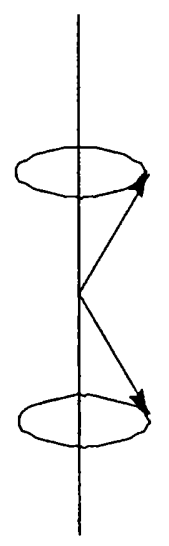

$\mathrm{T}_{0}$

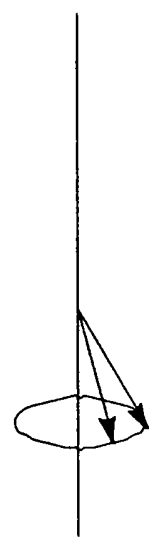

T. 1

Figure 2.1 
If the electrons are not precessing at the same frequency then the $S=0$ and $T_{0}$ states can interconvert. The rate of interconversion, or intersystem crossing, is dependent on the rate of precession of the two electrons. Hence, in the absence of nuclear coupling, the rate of interconversion is given by Equation 2.5:

$$
\omega_{1}-\omega_{2}=(2 \pi / \mathrm{h}) \beta B \Delta \mathrm{g}
$$

where $\Delta \mathrm{g}$ is the difference in $\mathrm{g}$ value $\left(\mathrm{g}_{1}-\mathrm{g}_{2}\right)$.

If one of the electrons, say electron 1 , is coupled with a nucleus with a hyperfine coupling constant ' $a$ ' then the expression becomes Equation 2.6:

$$
\omega_{1}-\omega_{2}=(2 \pi / h)\left(\beta B \Delta g+a m_{I}\right)
$$

Hence, depending on the sign of 'a', one of the two values of $m_{I}$ will increase $\left(\omega_{1}-\omega_{2}\right)$ and one will decrease it. Thus the rate of interconversion of the singlet and triplet states depends on the direction of nuclear spins.

For example, consider a radical pair consisting of a p-nitrobenzyl fluoride radical anion and a ${ }^{15} \mathrm{~N}$-labelled nitrogen dioxide radical. The $\mathrm{g}$ value for the $p$-nitrobenzyl fluoride radical anion is equal to $2.002^{45}$, and for the nitrogen dioxide radical the $\mathrm{g}$ value is equal to 2.0000 .46 Hence, $\Delta g$ will be negative. The hyperfine coupling constant, ' $a$ ', for the $15 \mathrm{~N}$ nucleus will be negative because of the negative magnetogyric ratio of this nucleus.

If the radical pair is initially in a triplet state then it will have to undergo interconversion to the singlet state before the radicals can couple. The value of $\left|\omega_{1}-\omega_{2}\right|$ must, therefore, be as large as possible. We therefore need $a_{\mathrm{I}}$ to be negative, hence, $\mathrm{m}_{\mathrm{I}}$ should be positive. So the products will be formed with an excess of $15 \mathrm{~N}$ nuclei in their upper spin state, and the ${ }^{15} \mathrm{~N}$ n.m.r. signals due to the products will appear in emission.

If the radical pair is initially in a singlet state, then interconversion to the triplet state will facilitate the separation of the radicals. The products will, therefore, tend to 
have a larger excess of ${ }^{15} \mathrm{~N}$ nuclei in their lower spin state than at thermal equilibrium. Hence, the ${ }^{15} \mathrm{~N}$ signals due to the products will appear in enhanced absorption.

\subsubsection{Kaptein's Rule}

The phase of the net polarisation, $\Gamma$, can be predicted from Kaptein's rule. ${ }^{47}$ For use with $15 \mathrm{~N}$ n.m.r. spectroscopy, Kaptein's rule has to be modified 48 to allow for the negative magnetogyric ratio of the ${ }^{15} \mathrm{~N}$ nucleus (Equation 2.7 ):

$$
\Gamma=-\mu \varepsilon \mathrm{a} \Delta \mathrm{g}
$$

If $\Gamma$ is + , net absorption, $A$

If $\Gamma$ is -, net Emission, $E$

where $\mu=+$ for a radical pair formed from a triplet precursor.

- for a radical pair formed from a singlet precursor.

$\varepsilon=+$ for products arising from singlet radical pairs.

- for products arising from triplet radical pairs.

$a=$ the sign of the hyperfine coupling constant for the ${ }^{15} \mathrm{~N}$ nucleus.

$\Delta \mathrm{g}=$ the sign of the difference in $\mathrm{g}$ value $\left(\mathrm{g}_{1}-\mathrm{g}_{2}\right)$, where $\mathrm{g}_{1}$ is the $\mathrm{g}$ value of the radical containing the $15 \mathrm{~N}$ nucleus.

\subsection{Nucleophilic Radical Chain Mechanisms}

A well established nucleophilic radical substitution mechanism is the $\mathrm{S}_{\mathrm{RN}} 1$ mechanism. As we have seen, there is evidence for an alternative mechanism; the $\mathrm{S}_{\mathrm{RN}}{ }^{2}$ 
mechanism. The $S_{R N} 1$ and $S_{R N} 2$ mechanisms are both nucleophilic radical chain mechanisms and have a lot in common (Scheme 2.1):

(1) Initiation $\left(\mathrm{RX}+\mathrm{Y}^{-}=\mathrm{RX}^{\cdot-}+\mathrm{Y}^{-}\right)$

(2) Propagation

(3) Termination

\section{Scheme 2.1}

Chemically induced dynamic nuclear polarisation effects have never previously been observed for nucleophilic radical substitution reactions. C.I.D.N.P. effects will only be observed in the steps involving radical pairs. Hence, a C.I.D.N.P. effect may result from the initiation or termination steps in a radical chain process.

\subsubsection{Chain Length}

Chain length may be defined in several ways. It may be defined theoretically as the number of successful chain-propagation steps resulting from a single original chain carrier. Or it may be considered the number of cycles before the chain is interrupted.

Experimental definitions of chain length are often used. For a photochemical reaction the chain length is the quantum yield. For a thermal reaction there may be used the ratio of the overall rate of reaction to the rate of the first step, the first step being set equal to the rate of the completely inhibited reaction, that is, with chains cut short by the rapid removal of chain carriers by inhibitors.

If a reaction has a large chain length then the rate of propagation will be far greater than the rate of initiation or termination. Hence, C.I.D.N.P. effects will be impaired by reactions with long chain lengths. 


\section{$2.5 \quad \underline{15} \underline{\text { N N.M.R. Studies }}$}

This particular chapter concerns itself with the investigation of various nucleophilic substitution reactions, which are believed to proceed via radical chain mechanisms, using ${ }^{15} \mathrm{~N}$ n.m.r. spectroscopy. The ${ }^{15} \mathrm{~N}$ nucleus has a long relaxation halflife ( $\sim 3 \mathrm{~min})$, hence, it is a good nucleus to use for C.I.D.N.P. studies. The optimum conditions for observing a C.I.D.N.P. effect require that the reaction under consideration has a half life of 10 minutes or less, ${ }^{49}$ and $15_{\mathrm{N}}$ n.m.r. spectroscopy requires high concentrations of substrate $\left(\geq 0.1 \mathrm{~mol} \mathrm{dm}^{-3}\right)$. Moreover, the ${ }^{15} \mathrm{~N}$ n.m.r. spectra must be obtained proton coupled in order to remove the possibility of a nuclear Overhauser effect. These conditions must be taken into account when selecting reactions for investigation.

All of the reactions in this chapter were initially followed using ${ }^{1}$ H n.m.r. so that an approximate idea of the rate could be obtained. These preliminary spectra were obtained using a $100 \mathrm{MHz}$ continuous wave n.m.r. spectrometer.

The ${ }^{15} \mathrm{~N}$ n.m.r. spectra were recorded using a $400 \mathrm{MHz}$ pulsed Fourier transform n.m.r. spectrometer. The use of a Fourier transform n.m.r. spectrometer for ${ }^{15} \mathrm{~N}$ n.m.r. spectroscopy requires the use, as far as possible, of deuterated materials, with the obvious exception of the compound being studied; thus deuterated solvents were used. Reaction solutions were made up as described in Section 9.5.1. The spectra were recorded at specific time intervals automatically. The temperature of the n.m.r. probe was maintained at a constant value during all of the $15 \mathrm{~N}$ n.m.r. studies using the spectrometer's variable temperature controller. The temperature of the n.m.r. probe was found to be $(30 \pm 1){ }^{\circ} \mathrm{C}$ for all studies.

In all of the ${ }^{15} \mathrm{~N}$ n.m.r. studies, spectra where accumulated consisting of $128 \mu \mathrm{s}$ pulses each followed by a 1.066 second acquisition time and a 10 second delay. The total time for each spectrum was thus 2 minutes 12 seconds. The time ascribed to each spectrum was the mid-point of the accumulation. At the end of each study a further spectrum of about 3000 pulses was accumulated, using the same pulse width, acquisition time and delay, to provide final (infinity) values of the products and reference signals. 
The variation of the intensity of the ${ }^{15} \mathrm{~N}$ n.m.r. signal due to a product will be expressed in terms of the quantity $I_{t} / I_{\infty} ; I_{t}$ is the ratio of the intensity of the product's n.m.r. signal to that due to the reference in a spectrum taken at time $t$, and $I_{\infty}$ is the same ratio for the infinity spectrum.

\section{6 $40 \mathrm{MHz} 15$ NN.M.R. Study of the Reaction of the 15 N-Labelled Lithium Salt of 2-Nitropropane with p-Dinitrobenzene in Dimethyl Sulphoxide}

Shein has suggested that substitution reactions of $p$-dinitrobenzene, ${ }^{21} p$ nitrochlorobenzene 22 and 2,4-dinitrochlorobenzene 23 involve reaction of nucleophiles with various radical anions. There is other evidence to suggest that substitution reactions of $p$-dinitrobenzene proceed via an $\mathrm{S}_{\mathrm{RN}} 2$ radical chain mechanism. 24,25

Kornblum et al. 50 have shown that when $p$-dinitrobenzene was treated with the lithium salt of 2-nitropropane in various dipolar aprotic solvents, the product obtained was $\alpha, p$-dinitrocumene. We reinvestigated this reaction and found that when $p$ dinitrobenzene was treated with the lithium salt of 2-nitropropane (equimolar) in dimethyl sulphoxide and under an argon atmosphere (see 9.4.1), the reaction was $90 \%$ complete within 3 minutes at $30^{\circ} \mathrm{C}$ (Equation 2.8):

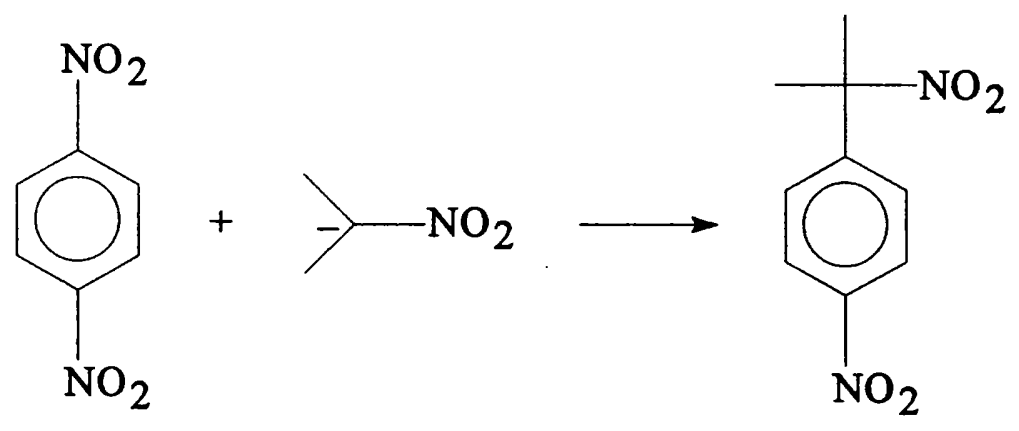

Clearly, the rate of reaction for Equation 2.8 is of ideal speed for observing a C.I.D.N.P. effect. 

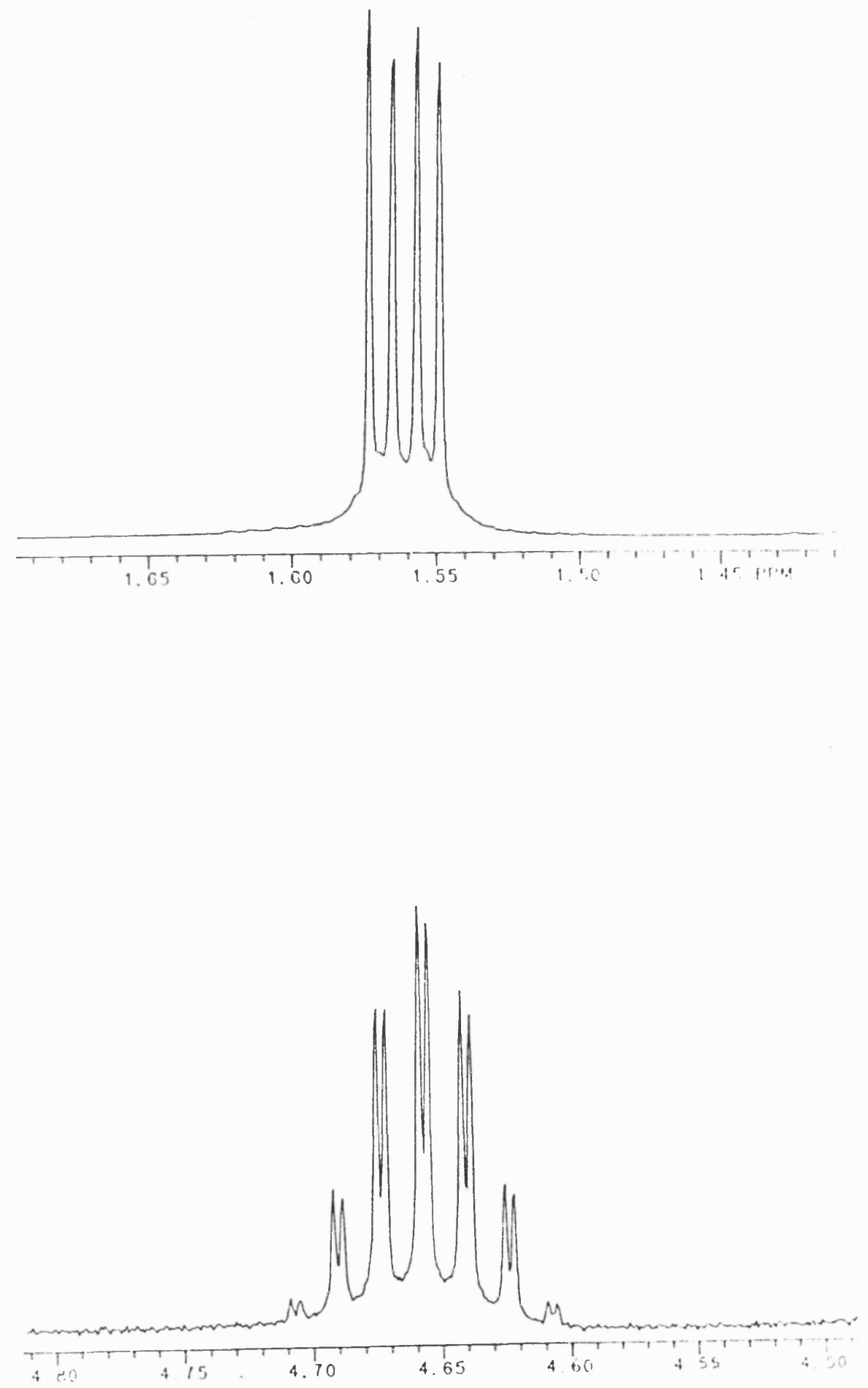

Figure 2.2: The $400 \mathrm{MHz}{ }^{1} \mathrm{H}$ n.m.r. spectrum (expanded) of ${ }^{15} \mathrm{~N}$-labelled 2-nitropropane $\left(\mathrm{CDCl}_{3}\right)$ 


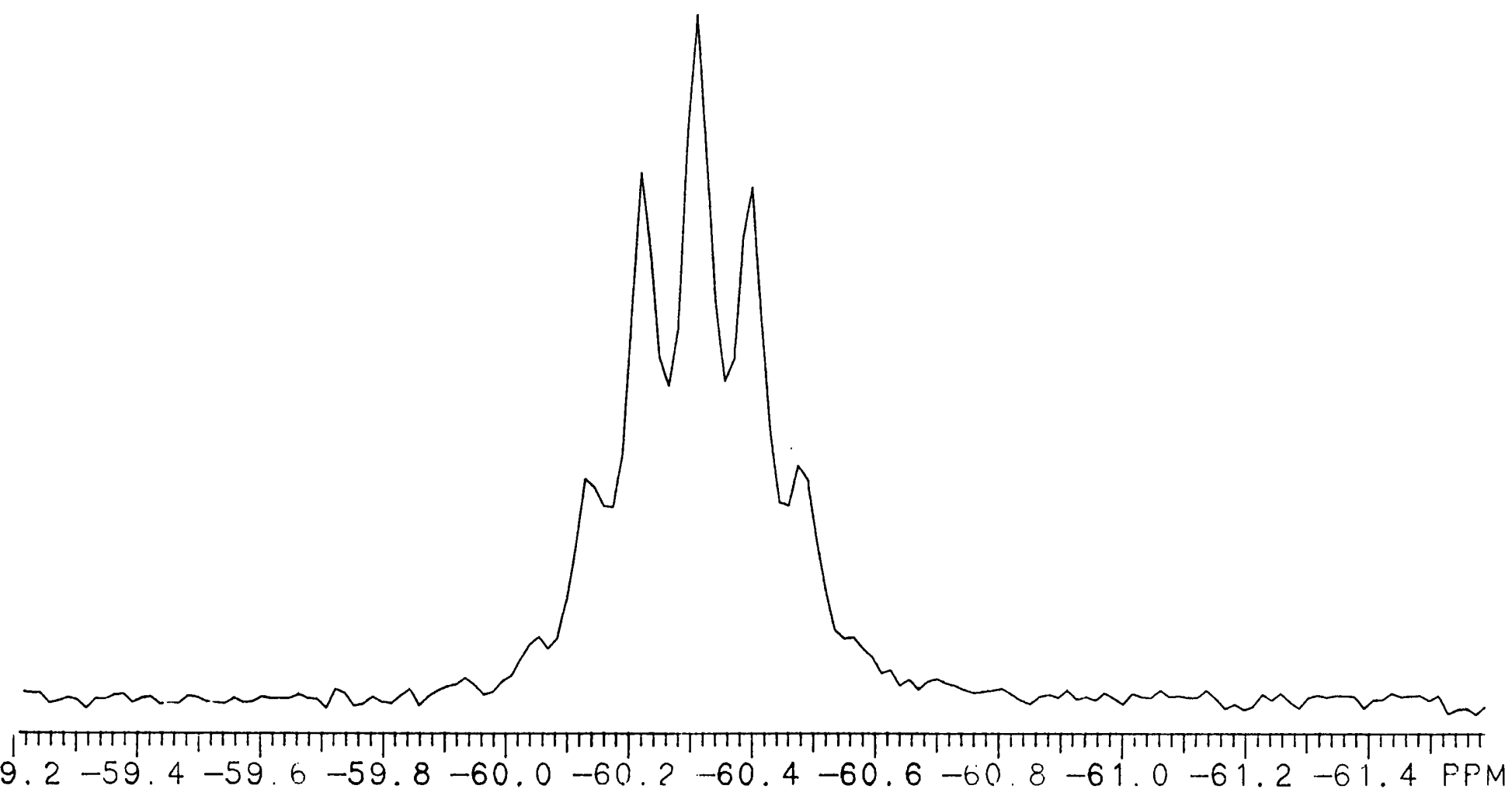

Figure 2.3: The $40 \mathrm{MHz}{ }^{15} \mathrm{~N}$ n.m.r. Spectrum of the ${ }^{15_{N}}$-labelled lithium salt of 2-nitropropane $\left(\mathrm{C}_{2} \mathrm{D}_{6} \mathrm{SO}\right)$ 
The ${ }^{15} \mathrm{~N}$-labelled lithium salt of 2-nitropropane was prepared from ${ }^{15} \mathrm{~N}$-labelled 2 nitropropane (see 9.3.3). The $400 \mathrm{MHz}{ }^{1} \mathrm{H}$ n.m.r. spectrum (expanded) of ${ }^{15} \mathrm{~N}$-labelled 2-nitropropane $\left(\mathrm{CDCl}_{3}\right)$ shows superb ${ }^{15} \mathrm{~N}$ coupling to the ${ }^{1} \mathrm{H}$ nuclei (Figure 2.2). The $40 \mathrm{MHz}{ }^{15} \mathrm{~N}$ n.m.r. spectrum of the ${ }^{15} \mathrm{~N}$-labelled lithium salt of 2 -nitropropane shows ${ }^{1} \mathrm{H}$ coupling to the ${ }^{15} \mathrm{~N}$ nucleus (Figure 2.3 ).

The reaction in Equation 2.8 was initially followed using $100 \mathrm{MHz}{ }^{1} \mathrm{H}$ n.m.r. spectroscopy. For initial concentrations of $p$-dinitrobenzene and the ${ }^{15} \mathrm{~N}$-labelled lithium salt of 2-nitropropane equal to $0.15 \mathrm{~mol} \mathrm{dm}^{-3}$ and $0.10 \mathrm{~mol} \mathrm{dm}^{-3}$ respectively, the reaction was complete within 2 minutes at $30^{\circ} \mathrm{C}$.

Two duplicate ${ }^{15} \mathrm{~N}$ n.m.r. studies were performed; the initial concentrations of $p$ dinitrobenzene and the ${ }^{15} \mathrm{~N}$-labelled lithium salt of 2-nitropropane were set equal to 0.15 mol dm-3 and $0.10 \mathrm{~mol} \mathrm{dm}^{-3}$ respectively. ${ }^{15} \mathrm{~N}$-Labelled nitrobenzene was used as an external reference. The values of $I_{t} / I_{\infty}$ at given times, derived from these ${ }^{15}$ N n.m.r. studies, are presented in Tables 2.2 and 2.3; the spectra in Figure 2.4 correspond to the data in Table 2.2 .

When taking experimental error into account, there are no anomalous values for $\mathrm{I}_{\mathrm{t}} / \mathrm{I}_{\infty}$ on examining both Tables 2.2 and 2.3. Moreover, there are no real signs of enhanced absorption or emission for the product signal in Figure 2.4 . The ${ }^{15} \mathrm{~N}$ n.m.r. signal due to the product, ${ }^{15} \mathrm{~N}$-labelled $\alpha, p$-dinitrocumene, is very small (Figure 2.4), however, it must be remembered that the signal is in fact a septet due to ${ }^{1} \mathrm{H}$ coupling.

\subsubsection{Conclusion}

The reaction of the ${ }^{15} \mathrm{~N}$-labelled lithium salt of 2 -nitropropane with $p$ dinitrobenzene in dimethyl sulphoxide does not give a significant C.I.D.N.P. effect, when followed by $15_{\mathrm{N}}$ n.m.r. This reaction is believed to proceed via a radical chain mechanism. C.I.D.N.P. effects will only result from the initiation and termination steps. The probable reason for not observing a C.I.D.N.P. effect is that the chain length for this reaction is very long, that is, the rate of propagation is far greater than the rate of either initiation or termination. 
Table 2.2

Temperature

Solvent

Reference

[p-dinitrobenzene $]_{0}$

$0.15 \mathrm{~mol} \mathrm{dm}^{-3}$

$\left[{ }^{15} \mathrm{~N} \text {-labelled salt }\right]_{0}$

$0.10 \mathrm{~mol} \mathrm{dm}^{-3}$

\begin{tabular}{|c|c|c|}
\hline Time Range / s & Mid-point Time / s & $\mathbf{I}_{\mathbf{t}} \mathbf{I}_{\infty}$ \\
\hline 0 & 0 & 0 \\
\hline $60-192$ & 126 & 0.496 \\
\hline $195-327$ & 261 & 0.581 \\
\hline $330-462$ & 396 & 0.945 \\
\hline $765-897$ & 831 & 0.631 \\
\hline $900-1032$ & 966 & 0.861 \\
\hline
\end{tabular}


Table 2.3

Temperature

Solvent

Reference

[p-dinitrobenzene $]_{0}$

$\left[{ }^{15} \mathrm{~N} \text {-labelled salt }\right]_{0}$
$40 \mathrm{MHz} 15$ N.M.R. Study of the Reaction of the 15 N-

Labelled Lithium Salt of 2-Nitropropane with p-

Dinitrobenzene (Part 2)

$30^{\circ} \mathrm{C}$

$99.9 \% \mathrm{C}_{2} \mathrm{D}_{6} \mathrm{SO}$

$15 \mathrm{~N}$-labelled nitrobenzene $(0.00 \mathrm{ppm})$

$0.15 \mathrm{~mol} \mathrm{dm}^{-3}$

$0.10 \mathrm{~mol} \mathrm{dm}^{-3}$

\begin{tabular}{|c|c|c|}
\hline Time Range / s & Mid-point Time / s & $\mathrm{I}_{\mathbf{t}} / \mathrm{I}_{\infty}$ \\
\hline 0 & 0 & 0 \\
\hline $60-192$ & 126 & 0.474 \\
\hline $195-327$ & 261 & 0.392 \\
\hline $330-462$ & 396 & 0.665 \\
\hline $765-897$ & 831 & 0.621 \\
\hline $900-1032$ & 966 & 0.539 \\
\hline
\end{tabular}



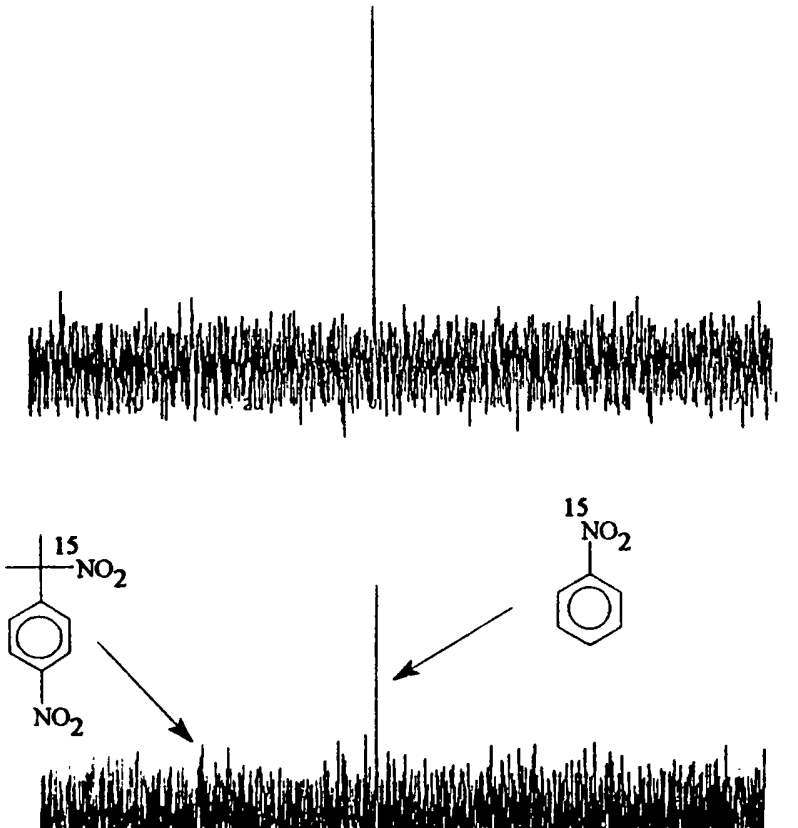

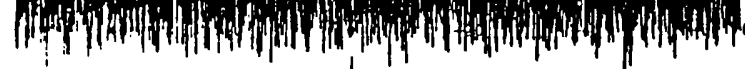<smiles>O=[N+]([O-])c1ccccc1</smiles>
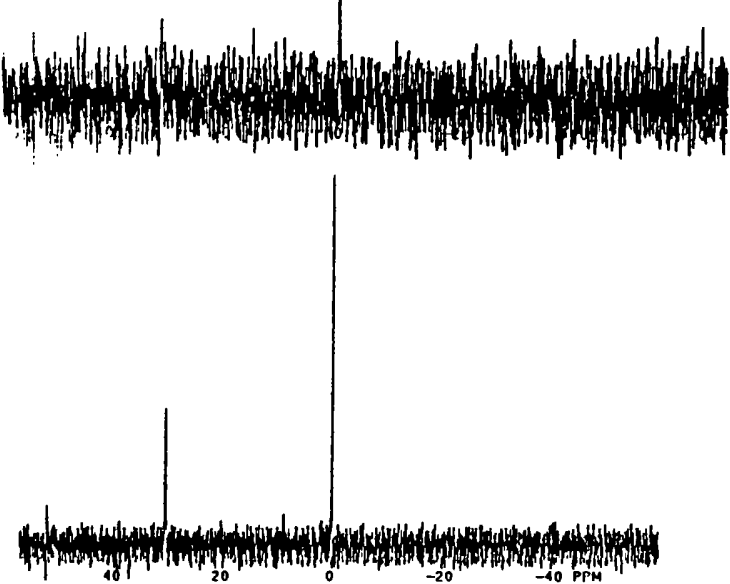

Time $=261 \mathrm{~s}$

Time $=831 \mathrm{~s}$

$$
\text { Time }=\infty
$$

\section{Figure 2.4}

$15 \mathrm{~N} \mathrm{n.m.r.} \mathrm{study} \mathrm{of} \mathrm{the} \mathrm{reaction} \mathrm{of} \mathrm{the} 15 \mathrm{~N}$-labelled lithium salt of 2-nitropropane with $p$ dinitrobenzene in ${ }^{2} \mathrm{D}_{6}$-labelled dimethyl sulphoxide (Table 2.2). 


\subsection{MHz 15 N N.M.R. Study of the Reaction of Sodium Thiophenoxide with}

\section{N-Labelled p-Nitrocumyl Chloride in a Dimethyl Sulphoxide:Methanol}

\section{Solvent System}

Kornblum et al. ${ }^{17}$ found that when $p$-nitrocumyl chloride was treated with sodium thiophenoxide at $0{ }^{\circ} \mathrm{C}$ in dimethyl formamide, the displacement of chloride occurred rapidly with a half-life of 2 minutes. A $95 \%$ yield of pure tertiary sulphide was isolated (Equation 2.9):
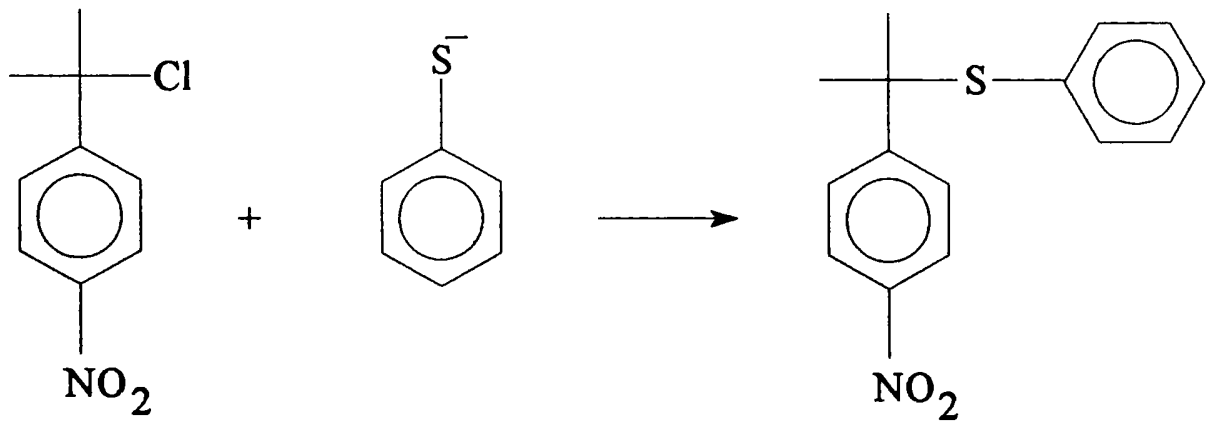

When $100 \mathrm{~mol} \%$ of $m$-dinitrobenzene was present, only $29 \%$ reaction occurred in 10 minutes and the time needed for the reaction to go to completion was about 45 minutes.

We reinvestigated this reaction and found that when sodium thiophenoxide was treated with p-nitrocumyl chloride (two fold excess) in dimethyl sulphoxide and under an argon atmosphere (see 9.4.3), the reaction was complete instantaneously at $30^{\circ} \mathrm{C}$. This reaction was found to be slower in dimethyl sulphoxide/methanol solvent systems. Clearly, the rate of reaction for Equation 2.9 is of ideal speed for observing a C.I.D.N.P. effect.

The ${ }^{15} \mathrm{~N}$-labelled $p$-nitrocumyl chloride was prepared as described in section 9.3.7. The $400 \mathrm{MHz}{ }^{1} \mathrm{H}$ n.m.r. spectrum of ${ }^{15} \mathrm{~N}$-labelled $p$-nitrocumyl chloride $\left(\mathrm{CDCl}_{3}\right)$ shows ${ }^{15} \mathrm{~N}$ coupling to the meta protons in the aromatic ring (Figure 2.5): 


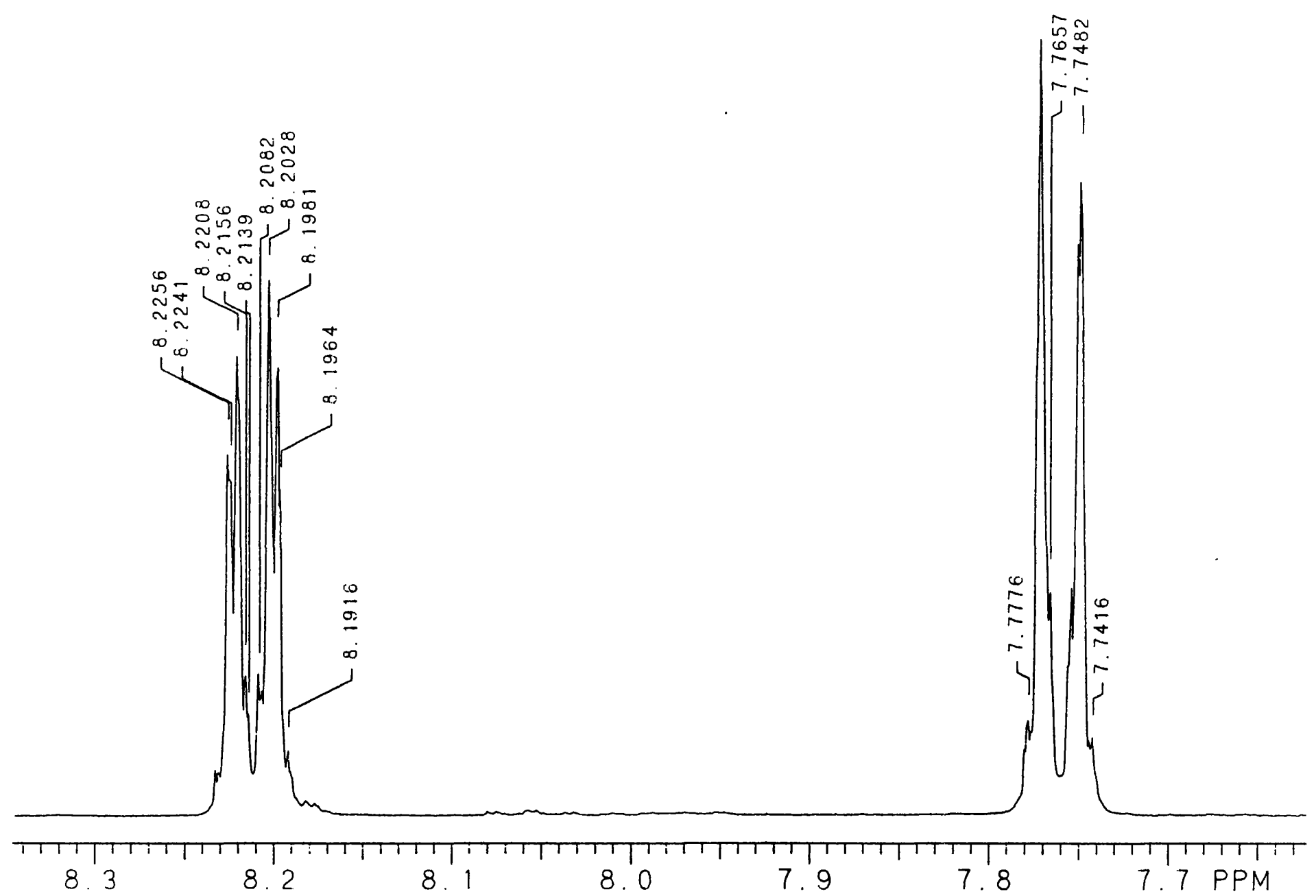

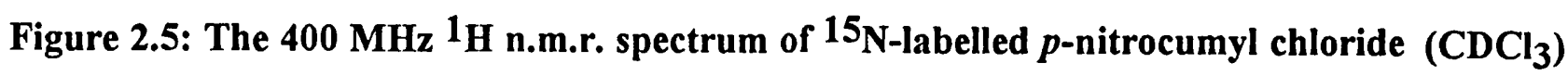


The reaction in Equation 2.9 was initially followed using $100 \mathrm{MHz}{ }^{1} \mathrm{H}$ n.m.r. spectroscopy. A solvent system of $65 \%{ }^{2} D_{6}$-labelled dimethyl sulphoxide : $35 \%{ }^{2} D_{4}$ labelled methanol was used. For initial concentrations of both sodium thiophenoxide and ${ }^{15} \mathrm{~N}$-labelled $p$-nitrocumyl chloride equal to $0.20 \mathrm{~mol} \mathrm{dm}^{-3}$, the reaction had a half-life of 3 minutes at $30^{\circ} \mathrm{C}$.

One ${ }^{15} \mathrm{~N}$ study was performed; the initial concentrations of sodium thiophenoxide and ${ }^{15} \mathrm{~N}$-labelled $p$-nitrocumyl chloride were both set equal to $0.20 \mathrm{~mol} \mathrm{dm}^{-3} \cdot{ }^{15} \mathrm{~N}-$ labelled nitromesitylene was used as an external reference. A solvent system of $65 \%$ ${ }^{2} \mathrm{D}_{6}$-labelled dimethyl sulphoxide : $35 \%{ }^{2} \mathrm{D}_{4}$-labelled methanol was used. The values of $I_{t} / I_{\infty}$ at given times, derived from this ${ }^{15} \mathrm{~N}$ study, are presented in Table 2.4; the spectra in Figure 2.6 correspond to the data in Table 2.4. There are no anomalous values for $I_{t} / I_{\infty}$ on examining Table 2.4. Moreover, there are no signs of enhanced absorption or emission for the product signal in Figure 2.6.

\subsubsection{Conclusion}

The reaction of ${ }^{15} \mathrm{~N}$-labelled $p$-nitrocumyl chloride with sodium thiophenoxide in a dimethyl sulphoxide:methanol solvent system did not give a C.I.D.N.P. effect when followed by ${ }^{15} \mathrm{~N}$ n.m.r. This is another reaction that is believed to proceed via a radical chain mechanism. C.I.D.N.P. effects will only result from the initiation and termination steps. Again, the probable reason for not observing a C.I.D.N.P. effect is that the chain length for this reaction is very long, that is, the rate of propagation is far greater than the rate of either initiation or termination. 
Table 2.4

\section{$40 \mathrm{MHz} 15$ N N.M.R. Study of the Reaction of Sodium}

\section{Thiophenoxide with 15 N-Labelled p-Nitrocumyl chloride}

Temperature

Solvent

Reference

[sodium salt $]_{0}$

[substrate $]_{0}$ $30^{\circ} \mathrm{C}$

$65 \% \mathrm{C}_{2} \mathrm{D}_{6} \mathrm{SO}: 35 \% \mathrm{CD}_{3} \mathrm{OD}$

$15 \mathrm{~N}$-labelled nitromesitylene $(0.00 \mathrm{ppm})$

$0.20 \mathrm{~mol} \mathrm{dm}^{-3}$

$0.20 \mathrm{~mol} \mathrm{dm}^{-3}$

\begin{tabular}{|c|c|c|}
\hline Time Range / & Mid-point Time/s & $\mathrm{I}_{\mathbf{t}} / \mathrm{I}_{\infty}$ \\
\hline 0 & 0 & 0 \\
\hline $60-192$ & 126 & 0.229 \\
\hline $195-327$ & 261 & 0.759 \\
\hline $330-462$ & 396 & 0.735 \\
\hline $465-597$ & 531 & 0.741 \\
\hline $600-732$ & 666 & 0.911 \\
\hline $1035-1167$ & 1101 & 0.836 \\
\hline $1470-1602$ & 1536 & 0.539 \\
\hline
\end{tabular}




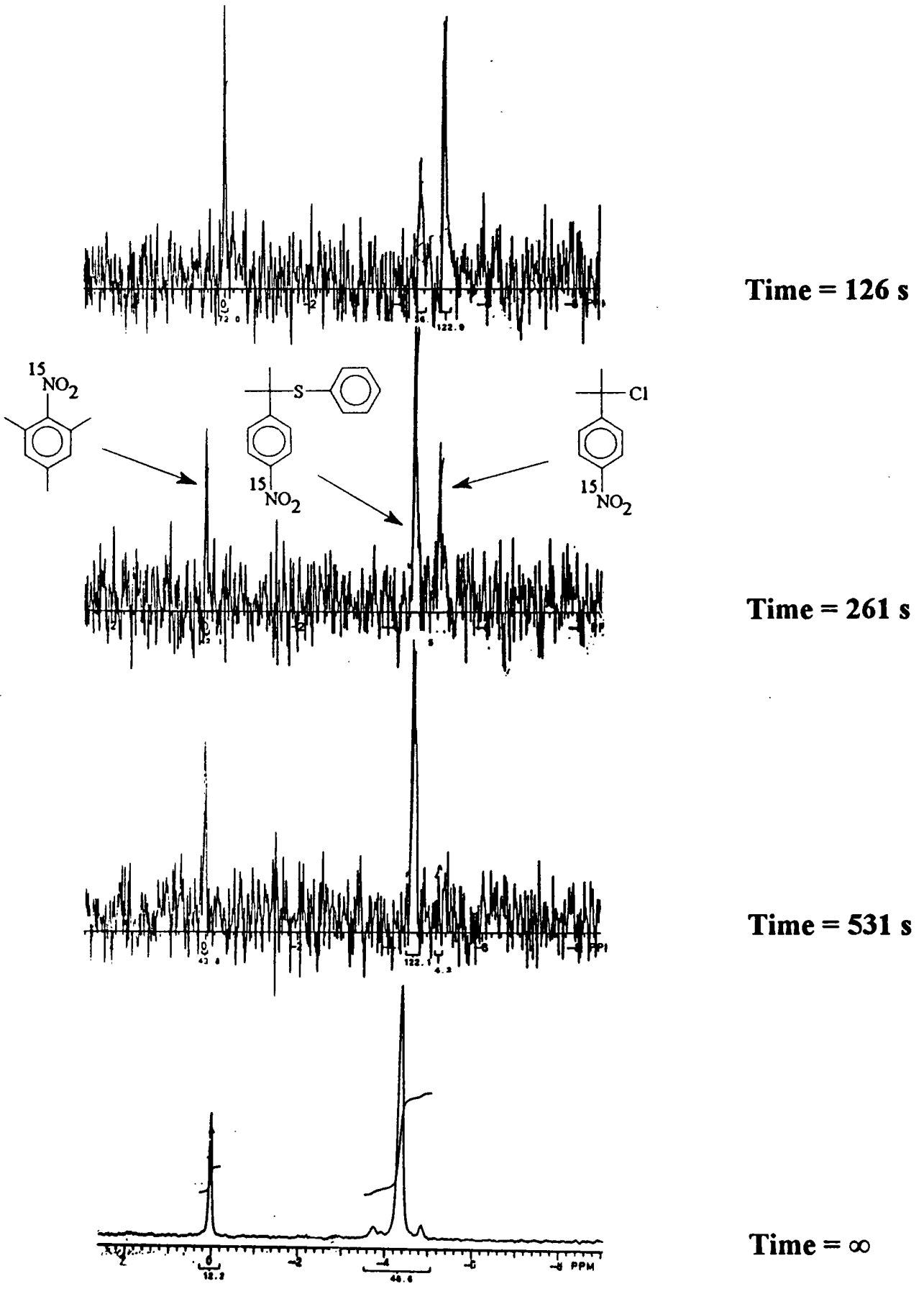

\section{Figure 2.6}

$15 \mathrm{~N}$ n.m.r. study of the reaction of $15 \mathrm{~N}$-labelled $p$-nitrocumyl chloride with sodium thiophenoxide in a $65 \%{ }^{2} \mathrm{D}_{6}$-labelled dimethyl sulphoxide : $35 \%{ }^{2} \mathrm{D}_{4}$-labelled methanol solvent system (Table 2.4). 


\section{8 $40 \mathrm{MHz} 15$ N N.M.R. Study of the Reaction of Sodium Thiophenoxide with 15 N-Labelled p-Nitrocumyl Chloride (Inhibited by a Radical Scavenger) in Dimethyl Sulphoxide}

Radical Scavengers can depress the rate of a radical chain reaction. The scavenger can trap the free-radical intermediates (the chain carriers) and therefore shorten the chain length. A very good radical scavenger is 4-hydroxy-2,2,6,6,-tetramethyl-1-piperidinyloxy or 4-hydroxy tempo for short.

The effect of 4-hydroxy tempo on the rate of reaction for Equation 2.9 was quite dramatic. For initial concentrations of both sodium thiophenoxide and ${ }^{15} \mathrm{~N}-1$ abelled $p$ nitrocumyl chloride equal to $0.20 \mathrm{~mol} \mathrm{dm}^{-3}$ and in the presence of $0.02 \mathrm{~mol} \mathrm{dm}^{-3} 4$ hydroxy tempo, there was no sign of reaction for 2 hours in a dimethyl sulphoxide solvent system at $30^{\circ} \mathrm{C}$.

However, for initial concentrations of both sodium thiophenoxide and $15 \mathrm{~N}-$ 1 abelled $p$-nitrocumyl chloride equal to $0.10 \mathrm{~mol} \mathrm{dm}^{-3}$ and in the presence of $\sim 3 \times 10^{-4}$ mol dm${ }^{-3}$ of 4-hydroxy tempo, the reaction had a half life of $\sim 2$ minutes in a dimethyl sulphoxide solvent system at $30{ }^{\circ} \mathrm{C}$. The reaction in this case went to about $80 \%$ completion. This very small concentration of 4-hydroxy tempo represents one granule of the radical scavenger in $4 \mathrm{~cm}^{-3}$ of dimethyl sulphoxide.

One ${ }^{15} \mathrm{~N}$ study was performed; the initial concentrations of sodium thiophenoxide and $15 \mathrm{~N}$-labelled $p$-nitrocumyl chloride were both set equal to $0.10 \mathrm{~mol} \mathrm{dm}^{-3} \cdot{ }^{15} \mathrm{~N}$ labelled nitromesitylene was used as an external reference. 4-hydroxy tempo was present in the reaction mixture at a concentration of approximately $3 \times 10^{-4} \mathrm{~mol} \mathrm{dm}^{-3}$. The values of $I_{t} / I_{\infty}$ at given times, derived from this $15_{N}$ study, are presented in Table 2.5; the spectra in Figure 2.7 correspond to the data in Table 2.5. There are no anomalous values for $I_{t} / I_{\infty}$ on examining Table 2.4 . Moreover, there are no signs of enhanced absorption or emission for the product signal in Figure 2.7. It is clear, from Figure 2.7, that this reaction went to about $75 \%$ completion. 
Table 2.5

Temperature

Solvent

Reference

[sodium salt]0

$0.10 \mathrm{~mol} \mathrm{dm}^{-3}$

[substrate] 0

[4-hydroxy tempo]0

$30^{\circ} \mathrm{C}$

$99.9 \% \mathrm{C}_{2} \mathrm{D}_{6} \mathrm{SO}$
$40 \mathrm{MHz} 15$ N N.M.R. Study of the Reaction of Sodium

Thiophenoxide with 15 N-Labelled $p$-Nitrocumyl Chloride

${ }^{15} \mathrm{~N}$-labelled nitromesitylene $(0.00 \mathrm{ppm})$

\begin{tabular}{|c|c|c|}
\hline Time Range / s & Mid-point Time / s & $\mathrm{I}_{\mathbf{t}} / \mathrm{I}_{\infty}$ \\
\hline 0 & 0 & 0 \\
\hline $60-192$ & 126 & 0.554 \\
\hline $195-327$ & 261 & 0.928 \\
\hline $330-462$ & 396 & 0.932 \\
\hline $465-597$ & 531 & 1.017 \\
\hline $600-732$ & 666 & 0.921 \\
\hline $1035-1167$ & 1101 & 1.037 \\
\hline $1470-1602$ & 1536 & 0.899 \\
\hline
\end{tabular}




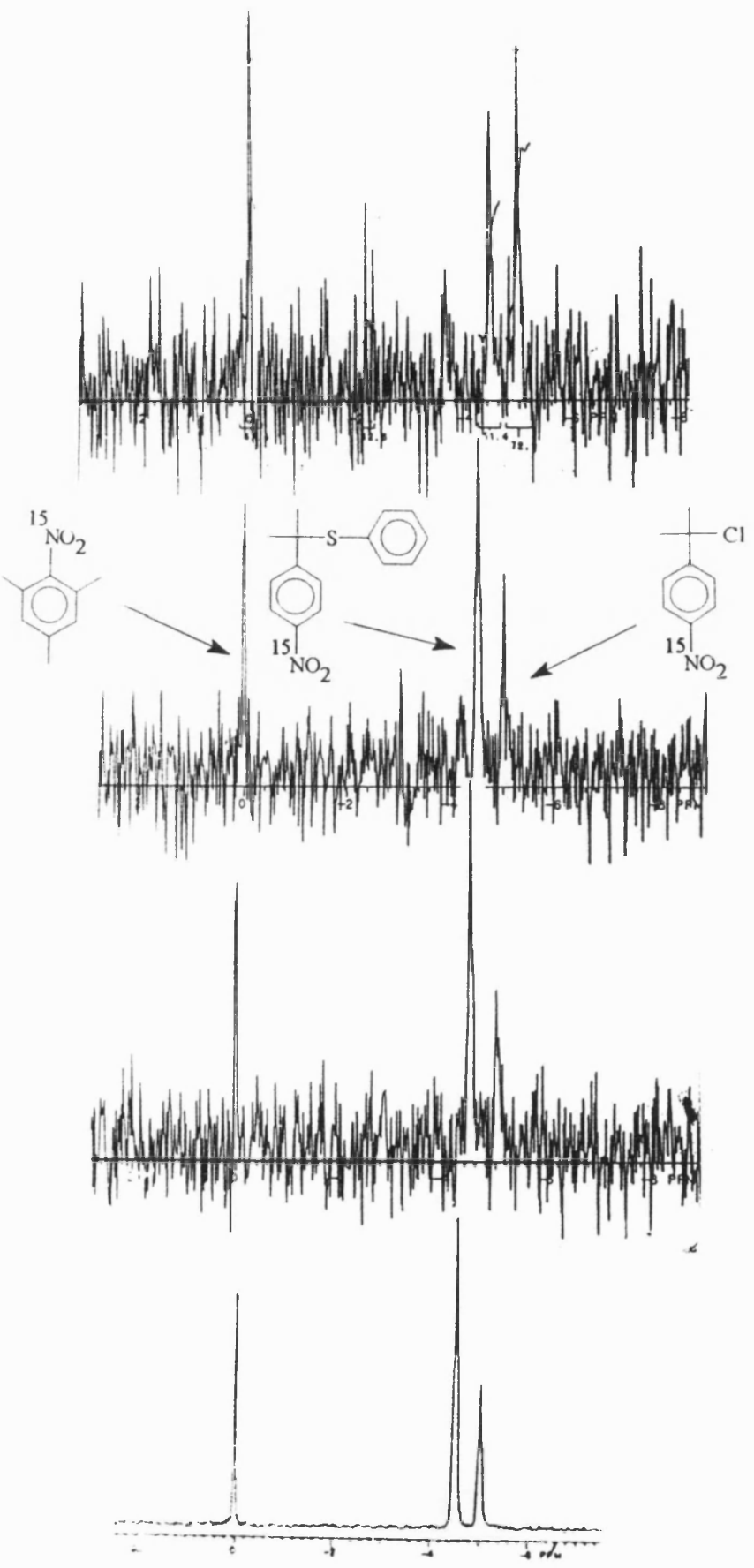

Time $=126 \mathrm{~s}$

Time $=261 \mathrm{~s}$

Time $=531 \mathrm{~s}$

Time $=\infty$

\section{Figure 2.7}

$15 \mathrm{~N}$ n.m.r. study of the reaction of $15 \mathrm{~N}$-labelled $p$-nitrocumyl chloride with sodium thiophenoxide (inhibited by a radical scavenger) in a ${ }^{2} \mathrm{D}_{6}$-labelled dimethyl sulphoxide solvent system (Table 2.4). 


\subsubsection{Conclusion}

The reaction of ${ }^{15} \mathrm{~N}$-labelled $p$-nitrocumyl chloride with sodium thiophenoxide, inhibited by a radical scavenger, in a dimethyl sulphoxide solvent system does not give a C.I.D.N.P. effect when followed by ${ }^{15} \mathrm{~N}$ n.m.r. C.I.D.N.P. effects will only result from the initiation and termination steps. It seems that the chain length for this reaction is just too long, even when it has been shortened by the addition of a scavenger, in order to observe a C.I.D.N.P. effect.

\section{$2.940 \mathrm{MHz} 15$ N.M.R. Study of the Reaction of 15 N-Labelled Sodium Nitrite with p-Nitrocumyl Bromide in Dimethyl Sulphoxide}

Komblum et al. 17 found that when $p$-nitrocumyl chloride was treated with sodium nitrite in dimethyl sulphoxide and the reaction carried out under two 20 Watt white fluorescent lights, the reaction gave a half-life of 12 hours. A duplicate experiment in the dark typically had a half-life of 300 hours. The product, $\alpha, p$-dinitrocumene, was obtained with a yield of $91 \%$. The exclusive formation of a tertiary nitro product from the reaction of nitrite with a tertiary alkyl halide is very rare indeed. ${ }^{51}$ It is therefore not surprising that this reaction is believed to proceed via a nucleophilic radical chain mechanism.

$15 \mathrm{~N}$-Labelled sodium nitrite can be obtained quite easily; however, its reaction with $p$-nitrocumyl chloride in dimethyl sulphoxide would be far too slow in order to give a C.I.D.N.P. effect. One would expect the reaction of sodium nitrite to be faster with $p$ nitrocumyl bromide than the chloro analogue in dimethyl sulphoxide. There is no known literature on the reaction of sodium nitrite with $p$-nitrocumyl bromide in dimethyl sulphoxide and this makes it an interesting system to study.

When p-nitrocumyl bromide was treated with sodium nitrite (five fold excess) in dimethyl sulphoxide and under an argon atmosphere (see 9.4.5), the reaction had a halflife of 35 minutes at $30^{\circ} \mathrm{C}$ (Equation 2.10): 


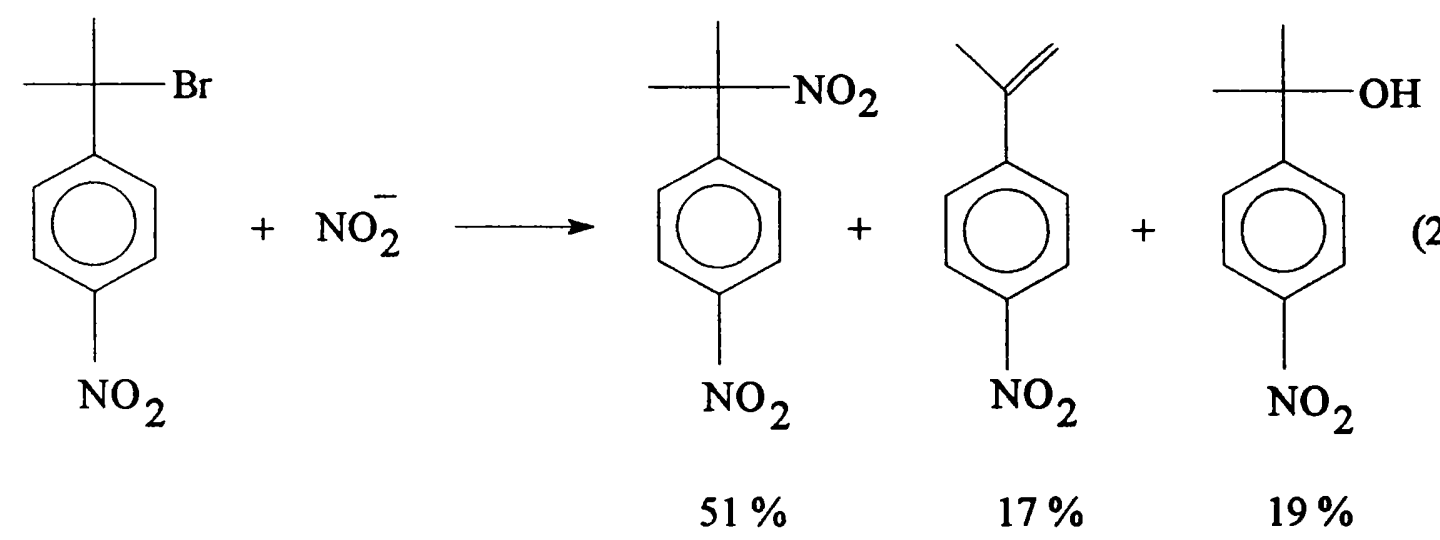

Unlike the $p$-nitrocumyl chloride reaction, the product here is not exclusively $\alpha, p$ dinitrocumene. Significant amounts of $p$-nitrocumyl alcohol and $\alpha$-methyl-p-nitromethyl styrene were also formed. The ratio of products formed in Equation 2.10 is fairly common for the reaction of nitrite with a primary alkyl halide, 52 however, it is not common for the reaction of nitrite with a tertiary alkyl halide. ${ }^{53}$ As the nitrite anion is ambident, it is not surprising to obtain both $\alpha, p$-dinitrocumene and $p$-nitrocumyl alcohol.

The reaction in Equation 2.10 was initially followed using $100 \mathrm{MHz}{ }^{1} \mathrm{H}$ n.m.r. spectroscopy For initial concentrations of $p$-nitrocumyl bromide and ${ }^{15} \mathrm{~N}$-labelled sodium nitrite equal to $0.20 \mathrm{~mol} \mathrm{dm}^{-3}$ and $1.00 \mathrm{~mol} \mathrm{dm}^{-3}$ respectively, the reaction had a half-life of 30 minutes at $30^{\circ} \mathrm{C}$. The rate of reaction in this case is not of optimum speed for observing a C.I.D.N.P. effect. Nevertheless, the rate should be fast enough to observe a possible C.I.D.N.P. effect. The rate may be increased by raising the temperature; however, as the temperature of the reaction is increased so the percentage of alcohol and alkene go up, that is, the products not containing the ${ }^{15} \mathrm{~N}$ nucleus.

One ${ }^{15} \mathrm{~N}$ study was performed; the initial concentrations of $p$-nitrocumyl bromide and $15 \mathrm{~N}$-labelled sodium nitrite were set equal to $0.20 \mathrm{~mol} \mathrm{dm}^{-3}$ and $1.00 \mathrm{~mol} \mathrm{dm}^{-3}$ respectively. ${ }^{15} \mathrm{~N}$-Labelled nitromesitylene was used as an external reference. The values of $I_{t} I_{\infty}$ at given times, derived from this ${ }^{15} \mathrm{~N}$ study, are presented in Table 2.6; the spectra in Figure 2.8 correspond to the data in Table 2.6. There are no anomalous values for $I_{t} / I_{\infty}$ on examining Table 2.6. Moreover, there are no signs of enhanced absorption or emission for the product signal in Figure 2.8 . 
Table 2.6

Temperature

Solvent

Reference
$40 \mathrm{MHz} 15$ N N.M.R. Study of the Reaction of $p$ -

\section{Nitrocumyl Bromide with $\underline{15}$ N-Labelled Sodium Nitrite}

$30^{\circ} \mathrm{C}$

$99.9 \% \mathrm{C}_{2} \mathrm{D}_{6} \mathrm{SO}$

${ }^{15} \mathrm{~N}$-labelled nitromesitylene $(0.00 \mathrm{ppm})$

$\left[{ }^{15} \mathrm{~N} \text {-sodium nitrite }\right]_{0} \quad 1.00 \mathrm{~mol} \mathrm{dm}^{-3}$

[p-nitrocumyl bromide $]_{0} \quad 0.20 \mathrm{~mol} \mathrm{dm}^{-3}$

\begin{tabular}{|c|c|c|}
\hline Time Range / s & Mid-point Time / & $\mathrm{I}_{\mathrm{t}} / \mathrm{I}_{\infty}$ \\
\hline 0 & 0 & 0 \\
\hline $450-582$ & 516 & 0 \\
\hline $705-837$ & 771 & 0.302 \\
\hline $1140-1272$ & 1206 & 0.283 \\
\hline $1575-1707$ & 1641 & 0.423 \\
\hline $2745-2877$ & 2811 & 0.448 \\
\hline $3480-3612$ & 3546 & 0.629 \\
\hline $4215-4347$ & 4281 & 0.680 \\
\hline $4950-5082$ & 5016 & 0.727 \\
\hline
\end{tabular}




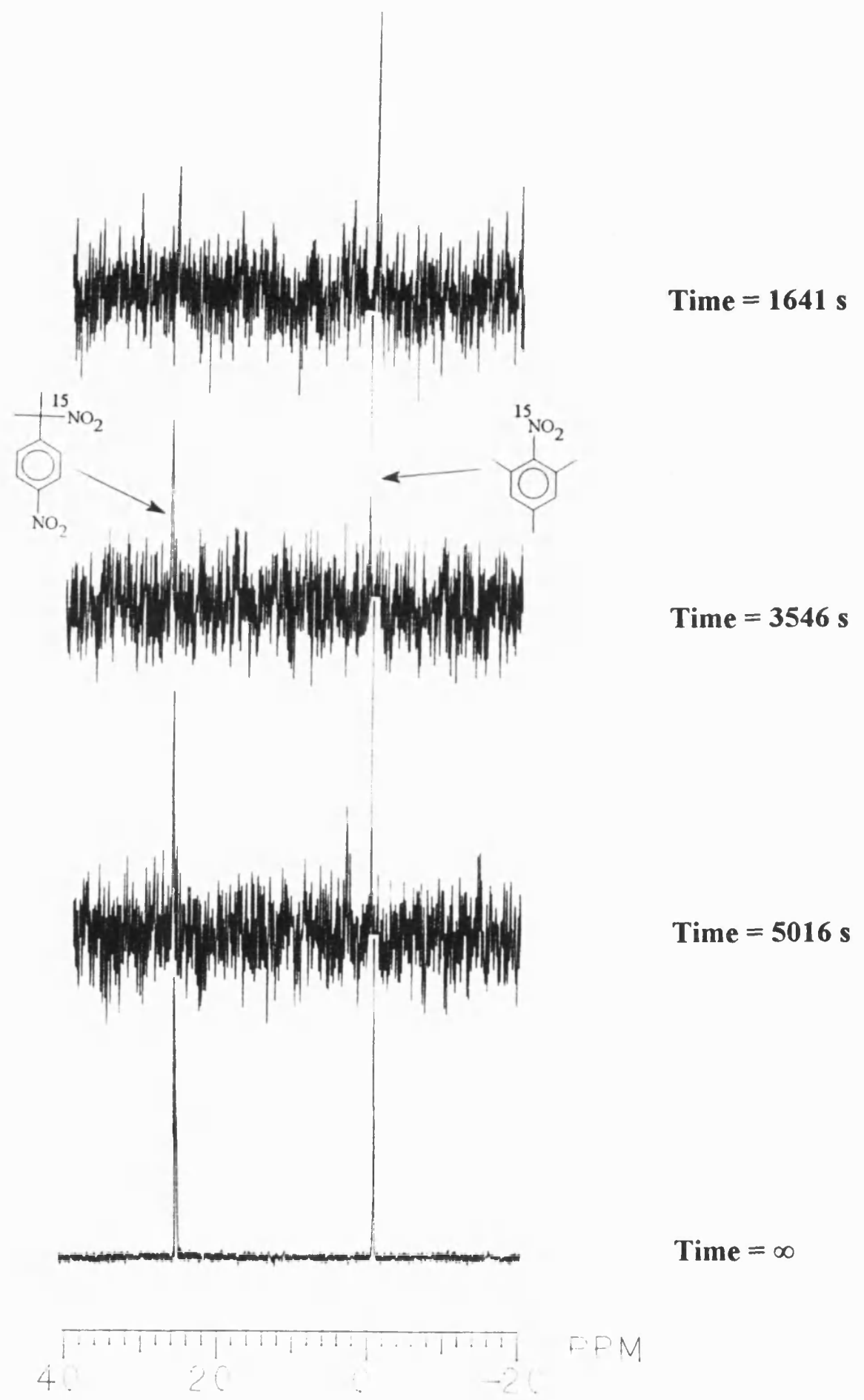

Figure 2.8

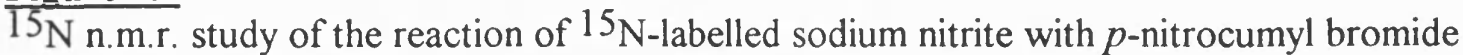
in ${ }^{2} \mathrm{D}_{6}$-labelled dimethyl sulphoxide (Table 2.6). 


\subsection{Final Conclusion}

The ${ }^{15} \mathrm{~N}$ n.m.r. studies of various reactions that are believed to proceed via nucleophilic radical chain mechanisms did not show a C.I.D.N.P. effect. This is probably due to the reactions in question having a very large chain length. For a long chain length, the steps involving the radical pairs (initiation and termination steps) will be insignificant compared to the propagation step.

The reaction of ${ }^{15} \mathrm{~N}$-labelled sodium nitrite with $p$-nitrocumyl bromide in dimethyl sulphoxide is a new and interesting system. No C.I.D.N.P. effect was observed for this reaction. The reason for no effect is unclear and obviously more work on this system must be carried out. A C.I.D.N.P. effect for a radical nucleophilic substitution reaction may one day be observed if a reaction can be found that has a very short chain length. 


\section{CHAPTER 3}

\section{A Kinetic Study of the Reaction of Sodium Nitrite with p-Nitrocumyl Bromide in}

\section{Dimethyl Sulphoxide}

\section{PART 1}

\subsection{Introduction}

It was mentioned in the previous chapter that there was no known literature on the reaction of $p$-nitrocumyl bromide with the nitrite anion and we observed no C.I.D.N.P. effect in the reaction of ${ }^{15} \mathrm{~N}$-labelled sodium nitrite with $p$-nitrocumyl bromide. A decision was made to investigate the reaction of $p$-nitrocumyl bromide with the nitrite anion. In chapters 3,4 , and 5 a detailed kinetic investigation of this reaction will be carried out. This particular chapter concerns itself with the raw kinetic data of the reaction in question, and looks at the possibility of fitting a simple kinetic model.

In chapter 2 we saw that when $p$-nitrocumyl bromide was treated with sodium nitrite (five fold excess) in dimethyl sulphoxide and under an argon atmosphere (see 9.4.5), the reaction had a half-life of 30 minutes at $30^{\circ} \mathrm{C}$ (Equation 3.1 ):

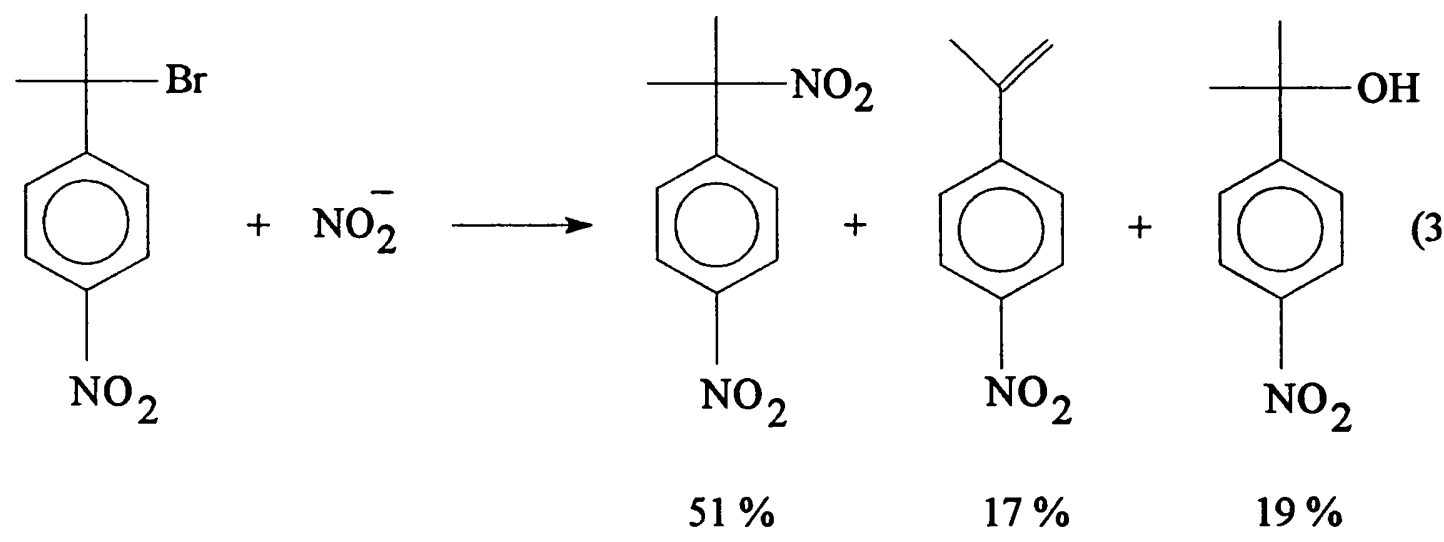

As the nitrite anion is ambident, it is not surprising to obtain both $\alpha, p$-dinitrocumene and p-nitrocumyl alcohol as isolated products. It will be shown that the alcohol formed comes mainly from the breakdown of $p$-nitrocumyl nitrite, however, both a small fraction of 
alcohol and the alkene are produced from the elimination of $p$-nitrocumyl bromide in dimethyl sulphoxide.

\subsection{Calculation of Rate Coefficients}

From spectra taken during the kinetic studies, it was possible to calculate the concentrations of p-nitrocumyl bromide and products at given times. The start of each kinetic study was taken as being when the p-nitrocumyl bromide solution was added to the salt solution (see 9.5.1). It was, therefore, possible to calculate rate coefficients for the disappearance of $p$-nitrocumyl bromide using the method of least squares or, if necessary, the computer programmes GEAR and GIT. The programme GEAR does a simple numerical integration whose output is the concentration of the species versus time. GIT compares the GEAR output with experimental data and allows optimisation by variation of rate constants. Most of the rate coefficients are reported along with their corresponding correlation coefficients, $r$, and standard errors, $\sigma$ (expressed as a percentage of the rate coefficient). A residual plot is often helpful in identifying unusual or highly influential observations and in revealing patterns in the data that may suggest how an improved fit can be achieved. A desirable plot is one that exhibits no particular pattern (such as curvature or much greater spread in one part of the plot than in another part) and has no point that is far removed from others. Looking at a residual plot after fitting a line amounts to examining (y) after removing any linear dependence on (x). This can sometimes more clearly bring out the existence of a non-linear relationship. It will be seen that the first point in a kinetic run is usually slightly removed from others. This is probably an error resulting from the mixing of the two solutions before a kinetic run.

\section{3 $400 \mathrm{MHz}$ - N.M.R. Study of the Reaction of Sodium Nitrite with $p$ -}

\section{Nitrocumyl Bromide in Dimethyl Sulphoxide}

All of the kinetic studies in chapters 3,4 and 5 were followed using a $400 \mathrm{MHz}$ pulsed Fourier transform n.m.r. spectrometer. The use of a Fourier transform n.m.r. 
spectrometer for ${ }^{1} \mathrm{H}$ n.m.r. spectroscopy requires the use, as far as possible, of deuterated materials, with the obvious exception of the compound being studied; thus deuterated solvents were used. Reaction solutions were made up as described in Section 9.5.1. The spectra were recorded at specific time intervals automatically. The temperature of the n.m.r. probe was maintained at a constant value during all of the ${ }^{1} \mathbf{H}$ n.m.r. studies using the spectrometer's variable temperature controller. The temperature of the n.m.r. probe was found to be $(30 \pm 1)^{\circ} \mathrm{C}$ for all studies.

The courses of the reactions were followed by observing the growth and disappearance of the ${ }^{1} \mathrm{H}$ n.m.r. signals in the aliphatic region (Figure 3.1). As well as the isolated products, the formation of an intermediate can be seen in Figure 3.1. This intermediate is more than likely to be $p$-nitrocumyl nitrite. The concentrations of each species, at given times, were calculated from their integrals (I) as follows (Equations 3.2, $3.3,3.4,3.5$ and 3.6$)$ :

$\left(\mathrm{C}_{9} \mathrm{H}_{10} \mathrm{NO}_{2}\right)=\mathrm{R}$

$[\mathrm{RBr}]_{\mathrm{t}}$

$$
=\frac{\mathrm{I}(\mathrm{RBr}) \times[\mathrm{RBr}]_{0}}{\mathrm{I}(\mathrm{RBr})+\mathrm{I}\left(\mathrm{RNO}_{2}\right)+\mathrm{I}(\mathrm{ROH})+\mathrm{I}(\text { Intermediate })+2 \mathrm{I} \text { (Alkene) }}
$$

$\left[\mathrm{RNO}_{2}\right]_{\mathrm{t}}=\frac{\mathrm{I}\left(\mathrm{RNO}_{2}\right) \times[\mathrm{RBr}]_{0}}{\mathrm{I}(\mathrm{RBr})+\mathrm{I}\left(\mathrm{RNO}_{2}\right)+\mathrm{I}(\mathrm{ROH})+\mathrm{I}(\text { Intermediate })+2 \mathrm{I} \text { (Alkene) }}$

$[\mathrm{ROH}]_{\mathrm{t}}=\frac{\mathrm{I}(\mathrm{ROH}) \times[\mathrm{RBr}]_{0}}{\mathrm{I}(\mathrm{RBr})+\mathrm{I}\left(\mathrm{RNO}_{2}\right)+\mathrm{I}(\mathrm{ROH})+\mathrm{I}(\text { Intermediate })+2 \mathrm{I} \text { (Alkene) }}$ 


$$
\begin{aligned}
& {\left[\text { Intermediate }_{t}=\frac{\mathrm{I}(\text { Intermediate }) \times[\mathrm{RBr}]_{0}}{\mathrm{I}(\mathrm{RBr})+\mathrm{I}\left(\mathrm{RNO}_{2}\right)+\mathrm{I}(\mathrm{ROH})+\mathrm{I}(\text { Intermediate })+2 \mathrm{I} \text { (Alkene) }}\right.} \\
& {\left[\text { Alkene }_{\mathrm{t}}=\frac{2 \mathrm{I} \text { (Alkene) } \mathrm{x}[\mathrm{RBr}]_{0}}{\left.\mathrm{I}(\mathrm{RBr})+\mathrm{I}\left(\mathrm{RNO}_{2}\right)+\mathrm{I}(\mathrm{ROH})+\mathrm{I} \text { (Intermediate }\right)+2 \mathrm{I} \text { (Alkene) }}\right.}
\end{aligned}
$$

In each kinetic study 10 spectra were accumulated, each consisting of $820 \mu \mathrm{s}$ pulses each followed by a two second acquisition time (see 9.5.2). For the purpose of calculating rate coefficients, the time ascribed to each spectrum was the mid-point of the accumulation.

\subsection{The Order with Respect to Nitrite}

Five series of kinetic studies were performed, each at a different initial concentration of sodium nitrite, but with the initial concentration of $p$-nitrocumyl bromide held constant. The ionic strength of the reaction solution was held essentially constant by the addition of sodium perchlorate. The concentration of $p$-nitrocumyl bromide at given times, derived from these kinetic studies, are presented in Tables 3.1, 3.2, 3.3, 3.4 and 3.5; the spectra in Figure 3.1 correspond to the data in Table 3.2. The spectrum for time equal to zero was obtained by taking an ${ }^{1} \mathrm{H}$ n.m.r. spectrum of just the $p$-nitrocumyl bromide solution on its own. For time equal to zero, the concentration of $p$-nitrocumyl bromide in the reaction mixture was set equal to one half the concentration of just the $p$ nitrocumyl bromide solution on its own. Figure 3.2 shows the disappearance of $p$ nitrocumyl bromide in its reaction with sodium nitrite for various different initial molarities of sodium nitrite (Tables 3.1, 3.2, 3.3, 3.4 and 3.5). Clearly, the rate of reaction is dependent on the initial concentration of sodium nitrite.

First order rate coefficients were calculated assuming that the reaction was first order with respect to $p$-nitrocumyl bromide (Figures 3.3, 3.5, 3.7, 3.9 and 3.11). 
Time $=0 \mathrm{~s}$

Time $=1200 \mathrm{~s}$

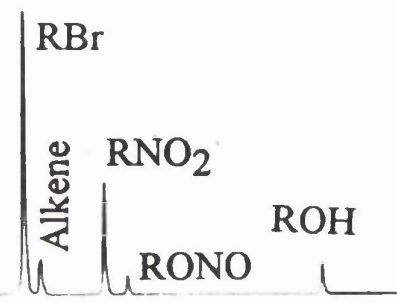

Time $=2400 \mathrm{~s}$

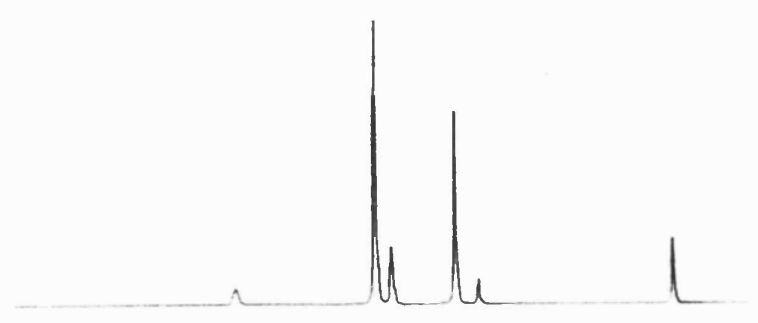

Time $=3600 \mathrm{~s}$

Figure 3.1

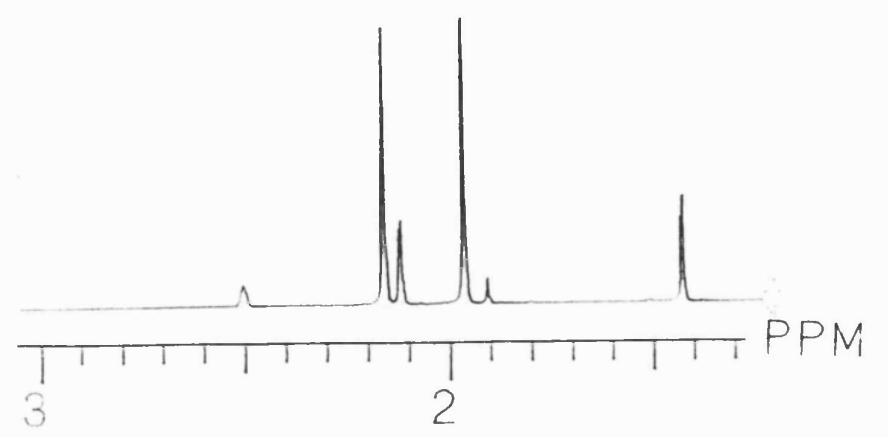

Time $=4800 \mathrm{~s}$

The growth and disappearance of the ${ }^{1} \mathrm{H}$ n.m.r. signals in the aliphatic region for the reaction of sodium nitrite with $p$-nitrocumyl bromide in ${ }^{2} \mathrm{D}_{6}$-labelled dimethyl sulphoxide (Table 3.2). 


\section{Table 3.1}

Temperature

Solvent

$[\mathrm{RBr}]_{0}$

$\left[\mathrm{NaNO}_{2}\right]_{0}$

$\left[\mathrm{NaClO}_{4}\right]_{0}$

\section{The Order with Respect to Nitrite Part 1}

$30^{\circ} \mathrm{C}$

$99.9 \% \mathrm{C}_{2} \mathrm{D}_{6} \mathrm{SO}$

$0.20 \mathrm{~mol} \mathrm{dm}^{-3}$

$\left(\mathrm{R}=\mathrm{C}_{9} \mathrm{H}_{10} \mathrm{NO}_{2}\right)$

$1.00 \mathrm{~mol} \mathrm{dm}-3$

$0.00 \mathrm{~mol} \mathrm{dm}^{-3}$

\begin{tabular}{|c|c|c|}
\hline Time Range $/ \mathrm{s}$ & Mid-point Time / & {$[\mathrm{RBr}]_{\mathrm{t}} / \mathrm{mol} \mathrm{dm}^{-3}$} \\
\hline 0 & 0 & 0.200 \\
\hline $442-458$ & 450 & 0.161 \\
\hline $892-908$ & 900 & 0.140 \\
\hline $1342-1358$ & 1350 & 0.122 \\
\hline $1792-1808$ & 1800 & 0.106 \\
\hline $2242-2258$ & 2250 & 0.092 \\
\hline $2692-2708$ & 2700 & 0.081 \\
\hline $3142-3158$ & 3150 & 0.070 \\
\hline $3592-3608$ & 3600 & 0.061 \\
\hline $4042-4508$ & 4050 & 0.054 \\
\hline
\end{tabular}


Table 3.2

Temperature

Solvent

[RBr] 0

$\left[\mathrm{NaNO}_{2}\right]_{0}$

$\left[\mathrm{NaClO}_{4}\right]_{0}$

\section{The Order with Respect to Nitrite Part 2}

$30^{\circ} \mathrm{C}$

$99.9 \% \mathrm{C}_{2} \mathrm{D}_{6} \mathrm{SO}$

$0.20 \mathrm{~mol} \mathrm{dm}^{-3}$

$\left(\mathrm{R}=\mathrm{C}_{9} \mathrm{H}_{10} \mathrm{NO}_{2}\right)$

$0.80 \mathrm{~mol} \mathrm{dm}-3$

$0.20 \mathrm{~mol} \mathrm{dm}^{-3}$

\begin{tabular}{|c|c|c|}
\hline Time Range $/ \mathrm{s}$ & Mid-point Time $/ \mathrm{s}$ & {$[\mathrm{RBr}]_{\mathrm{t}} / \mathrm{mol} \mathrm{dm}^{-3}$} \\
\hline 0 & 0 & 0.200 \\
\hline $592-608$ & 600 & 0.170 \\
\hline $1192-1208$ & 1200 & 0.145 \\
\hline $1792-1808$ & 1800 & 0.122 \\
\hline $2392-2408$ & 2400 & 0.109 \\
\hline $2992-3008$ & 3000 & 0.095 \\
\hline $3592-3608$ & 3600 & 0.084 \\
\hline $4192-4208$ & 4200 & 0.073 \\
\hline $4792-4808$ & 4800 & 0.064 \\
\hline $5392-5408$ & 5400 & 0.056 \\
\hline
\end{tabular}


Table 3.3

Temperature

Solvent

[RBr]0

$\left[\mathrm{NaNO}_{2}\right]_{0}$

$\left[\mathrm{NaClO}_{4}\right]_{0}$
The Order with Respect to Nitrite Part 3

$30^{\circ} \mathrm{C}$

$99.9 \% \mathrm{C}_{2} \mathrm{D}_{6} \mathrm{SO}$

$0.20 \mathrm{~mol} \mathrm{dm}^{-3}$

$\left(\mathrm{R}=\mathrm{C}_{9} \mathrm{H}_{10} \mathrm{NO}_{2}\right)$

$0.60 \mathrm{~mol} \mathrm{dm}-3$

$0.40 \mathrm{~mol} \mathrm{dm}^{-3}$

\begin{tabular}{|c|c|c|}
\hline Time Range / s & Mid-point Time / s & {$[\mathrm{RBr}]_{\mathrm{t}} / \mathrm{mol} \mathrm{dm}^{-3}$} \\
\hline 0 & 0 & 0.200 \\
\hline $892-908$ & 900 & 0.167 \\
\hline $1792-1808$ & 1800 & 0.147 \\
\hline $2692-2708$ & 2700 & 0.128 \\
\hline $3592-3608$ & 3600 & 0.112 \\
\hline $4492-4508$ & 4500 & 0.098 \\
\hline $5392-5408$ & 5400 & 0.086 \\
\hline $6292-6308$ & 6300 & 0.075 \\
\hline $7192-7208$ & 7200 & 0.065 \\
\hline $8092-8108$ & 8100 & 0.057 \\
\hline
\end{tabular}


Table 3.4

Temperature

Solvent

[RBr]o

$\left[\mathrm{NaNO}_{2}\right]_{0}$

$\left[\mathrm{NaClO}_{4}\right]_{0}$

\section{The Order with Respect to Nitrite Part 4}

$30^{\circ} \mathrm{C}$

$99.9 \% \mathrm{C}_{2} \mathrm{D}_{6} \mathrm{SO}$

$0.20 \mathrm{~mol} \mathrm{dm}^{-3}$

$\left(\mathrm{R}=\mathrm{C}_{9} \mathrm{H}_{10} \mathrm{NO}_{2}\right)$

$0.40 \mathrm{~mol} \mathrm{dm}-3$

$0.60 \mathrm{~mol} \mathrm{dm}^{-3}$

\begin{tabular}{|c|c|c|}
\hline Time Range / s & Mid-point Time/s & {$[\mathrm{RBr}]_{\mathrm{t}} / \mathrm{mol} \mathrm{dm}^{-3}$} \\
\hline 0 & 0 & 0.200 \\
\hline $1192-1208$ & 1200 & 0.174 \\
\hline $2392-2408$ & 2400 & 0.159 \\
\hline $3592-3608$ & 3600 & 0.145 \\
\hline $4792-4808$ & 4800 & 0.131 \\
\hline $5992-6008$ & 6000 & 0.119 \\
\hline $7192-7208$ & 7200 & 0.110 \\
\hline $8392-8408$ & 8400 & 0.100 \\
\hline $9592-9608$ & 9600 & 0.092 \\
\hline $10792-10808$ & 10800 & 0.084 \\
\hline
\end{tabular}


Table 3.5

Temperature

Solvent

[RBr]0

$\left[\mathrm{NaNO}_{2}\right]_{0}$

$\left[\mathrm{NaClO}_{4}\right]_{0}$
The Order with Respect to Nitrite Part 5

$30^{\circ} \mathrm{C}$

$99.9 \% \mathrm{C}_{2} \mathrm{D}_{6} \mathrm{SO}$

$0.20 \mathrm{~mol} \mathrm{dm}^{-3}$

$\left(\mathrm{R}=\mathrm{C}_{9} \mathrm{H}_{10} \mathrm{NO}_{2}\right)$

$0.20 \mathrm{~mol} \mathrm{dm}-3$

$0.80 \mathrm{~mol} \mathrm{dm}^{-3}$

\begin{tabular}{|c|c|c|}
\hline Time Range / & Mid-point Time $/ \mathrm{s}$ & {$[\mathrm{RBr}]_{\mathrm{t}} / \mathrm{mol} \mathrm{dm}^{-3}$} \\
\hline 0 & 0 & 0.200 \\
\hline $2992-3008$ & 3000 & 0.154 \\
\hline $5992-6008$ & 6000 & 0.133 \\
\hline $8992-9008$ & 9000 & 0.113 \\
\hline $11992-12008$ & 12000 & 0.095 \\
\hline $14992-15008$ & 15000 & 0.080 \\
\hline $17992-18008$ & 18000 & 0.067 \\
\hline $20992-21008$ & 21000 & 0.056 \\
\hline $23992-24008$ & 24000 & 0.046 \\
\hline $26992-27008$ & 27000 & 0.039 \\
\hline
\end{tabular}




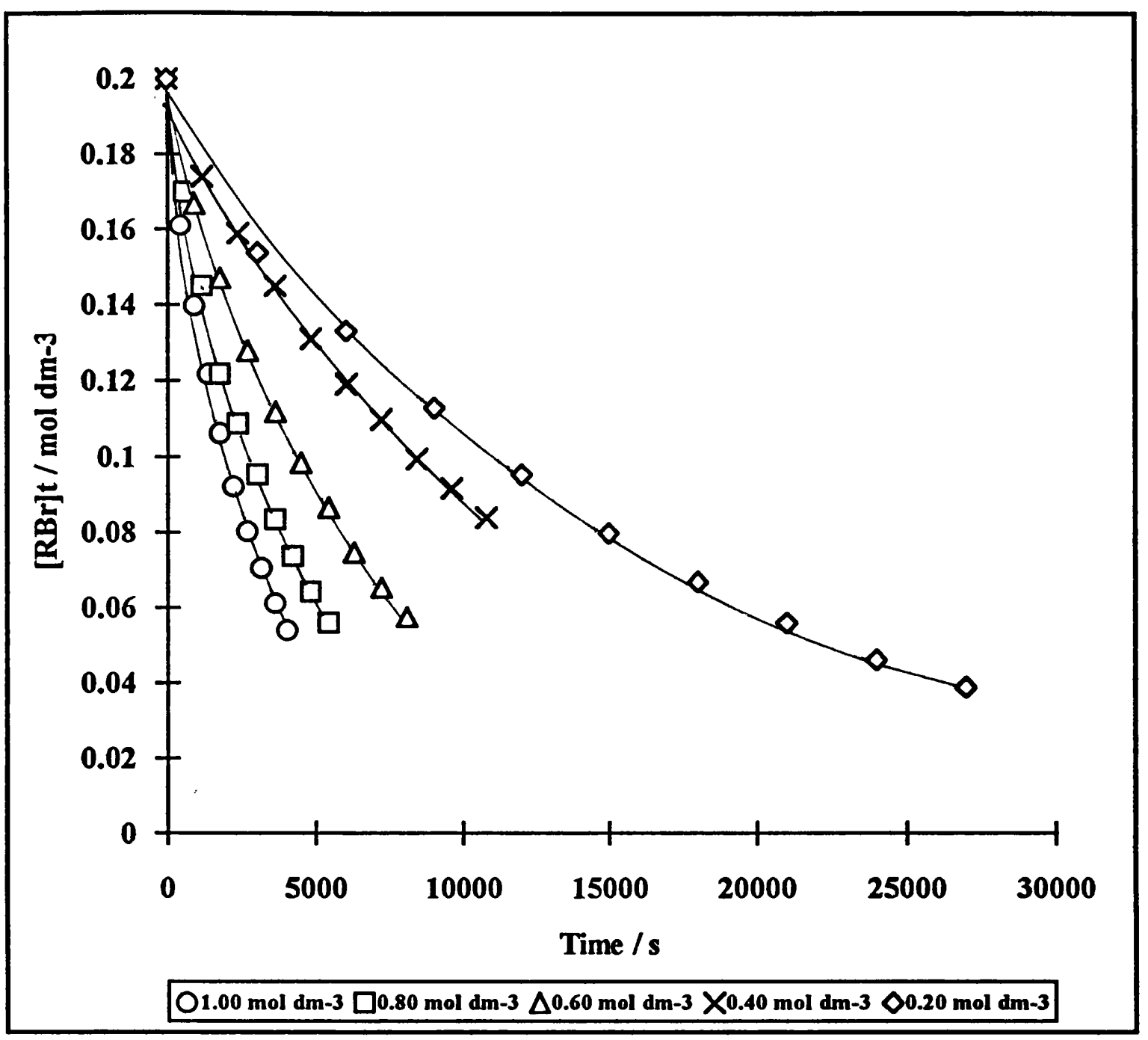

\section{Figure 3.2}

A comparison of the disappearance of $p$-nitrocumyl bromide in its reaction with sodium nitrite for various different initial molarities of sodium nitrite (Tables 3.1, 3.2, 3.3, 3.4 and 3.5). 
Second order rate coefficients were calculated assuming that the reaction was first order with respect to both $p$-nitrocumyl bromide and sodium nitrite (Figures 3.4, 3.6, 3.8, 3.10 and 3.12). It will be seen that the data fits neither first order nor second order kinetics.

For the initial concentration of sodium nitrite equal to $1.00 \mathrm{~mol} \mathrm{dm}^{-3}$, the plot for an overall first order reaction is a good fit (Figure 3.3). However, when the residuals are examined it can be seen that they go from negative to positive with the very first point slightly removed from others. The plot for an overall second order reaction is a slightly better fit and this is shown by the correlation coefficient obtained (Figure 3.4). The residual plot goes from positive to negative and the very first point is slightly removed from others.

For the initial concentration of sodium nitrite equal to $0.80 \mathrm{~mol} \mathrm{dm}^{-3}$, the plot for an overall first order reaction is again a reasonable fit (Figure 3.5). However, when the residuals are examined it can be seen that the pattern is a curved one with the fourth point slightly removed from others. The plot for an overall second order reaction is again a very good fit and this is exemplified by the correlation coefficient obtained (Figure 3.6). The residual plot is fairly random with the fourth point slightly removed from others.

For the initial concentration of sodium nitrite equal to $0.60 \mathrm{~mol} \mathrm{dm}^{-3}$, the plot for an overall first order reaction is a very good fit indeed (Figure 3.7). When the residuals are examined it can be seen that the pattern is a curved one with the first point slightly removed from others. The plot for an overall second order reaction is again a very good fit (Figure 3.8). The residual plot has no real significant pattern and has the second point slightly removed from others.

For the initial concentration of sodium nitrite equal to $0.40 \mathrm{~mol} \mathrm{dm}^{-3}$, the plot for an overall first order reaction is again a good fit (Figure 3.9). When the residuals are examined it can be seen that the pattern is a fairly random one with the first point slightly removed from others. The plot for an overall second order reaction is again a very good fit (Figure 3.10). The residual plot has no real significant pattern and has the second point slightly removed from others. 
For the initial concentration of sodium nitrite equal to $0.20 \mathrm{~mol} \mathrm{dm}$, the plot for an overall first order reaction is a very good fit indeed (Figure 3.11). When the residuals are examined it can be seen that the pattern is a random one with the first and second points slightly removed from others. The plot for an overall second order reaction is a very poor fit indeed and this is exemplified by the poor correlation coefficient obtained (Figure 3.12). In fact, the second order rate constant $\left(k_{2}\right)$ obtained in this case has no real meaning. The residual plot has a strong curved pattern with the first point slightly removed from others.

The data from Tables 3.1, 3.2, 3.3, 3.4 and 3.5 do not really fit either overall first order kinetics or overall second order kinetics. The first order rate constants $\left(k_{1}\right)$ vary significantly for the different kinetic runs. This indicates that an overall first order model is a poor fit to the data obtained from Tables 3.1, 3.2, 3.3, 3.4 and 3.5. The second order rate constants $\left(k_{2}\right)$ do not vary as much compared to the first order rate constants, however, there is a distinct pattern in their variation. As the concentration of nitrite decreases so the second order rate constant decreases for the kinetic runs, indicating a poor fit to an overall second order model. 


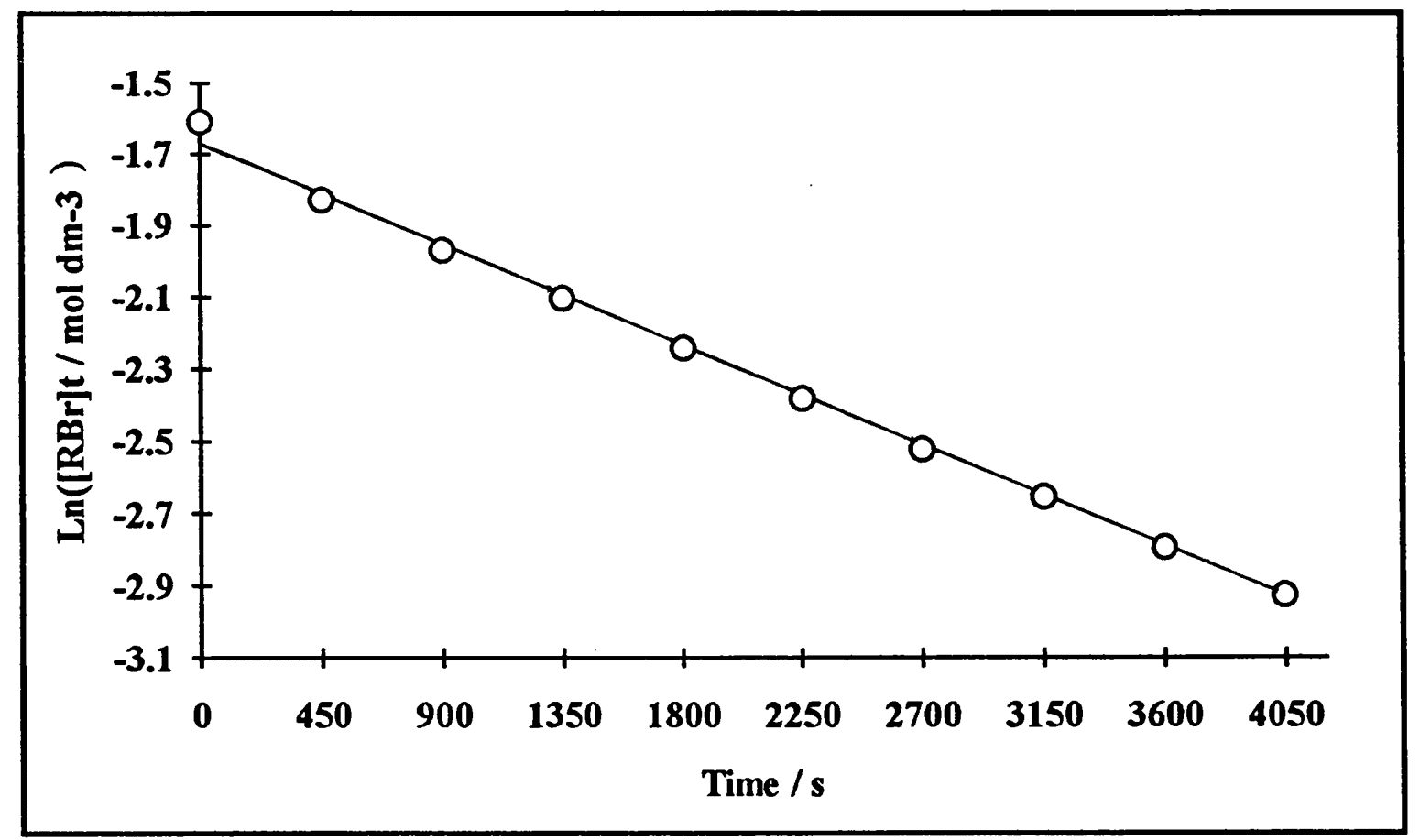

(a)

$$
\begin{aligned}
& \mathrm{k}_{1}=3.15 \times 10^{-4} \mathrm{~s}^{-1} \\
& \mathrm{r}=0.9986 \\
& \sigma=1.86 \%
\end{aligned}
$$

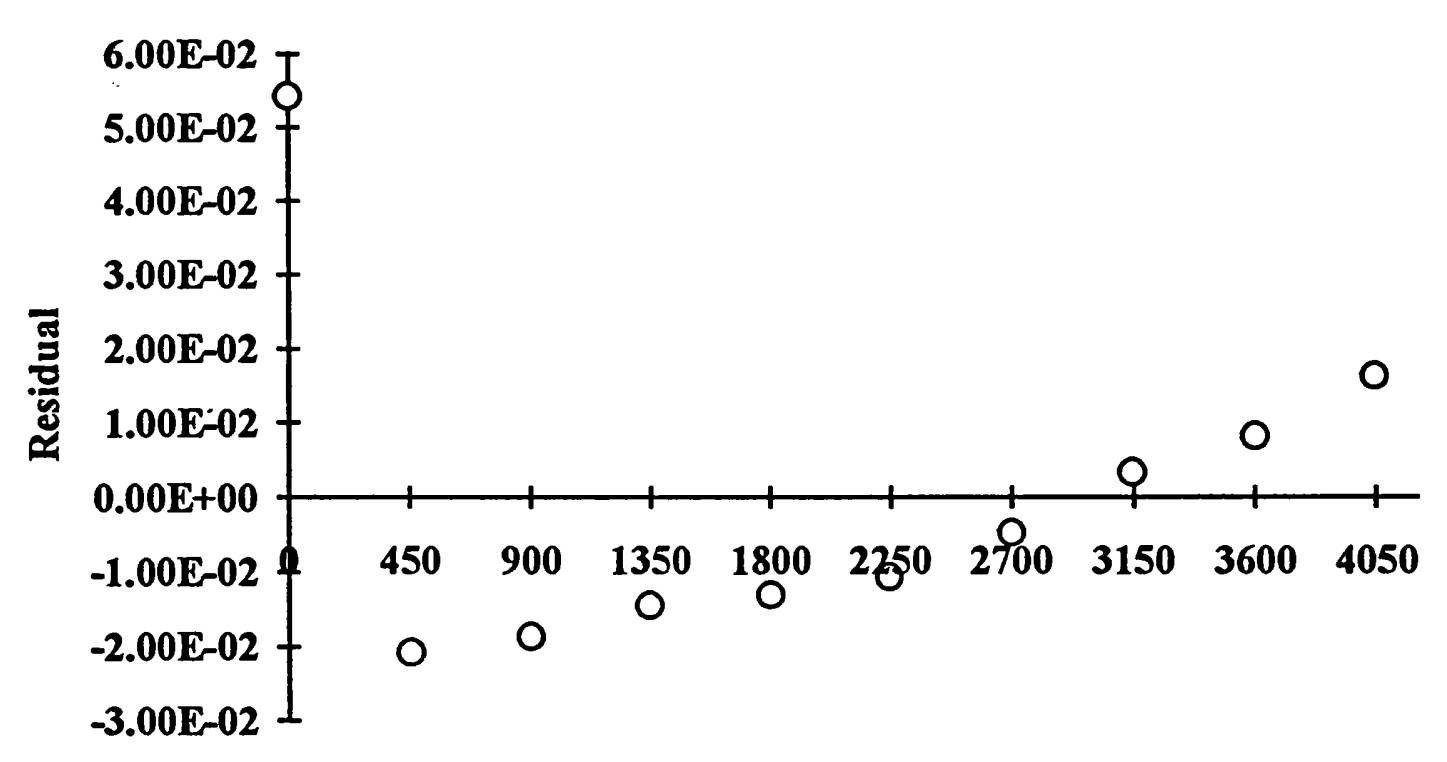

Time / s

(b)

Figure 3.3

Plots of (a) $\operatorname{Ln}\left([\mathrm{RBr}]_{t}\right)$ and (b) Residuals against time / $s$ for the reaction of $p$-nitrocumyl bromide with sodium nitrite (Table 3.1). 


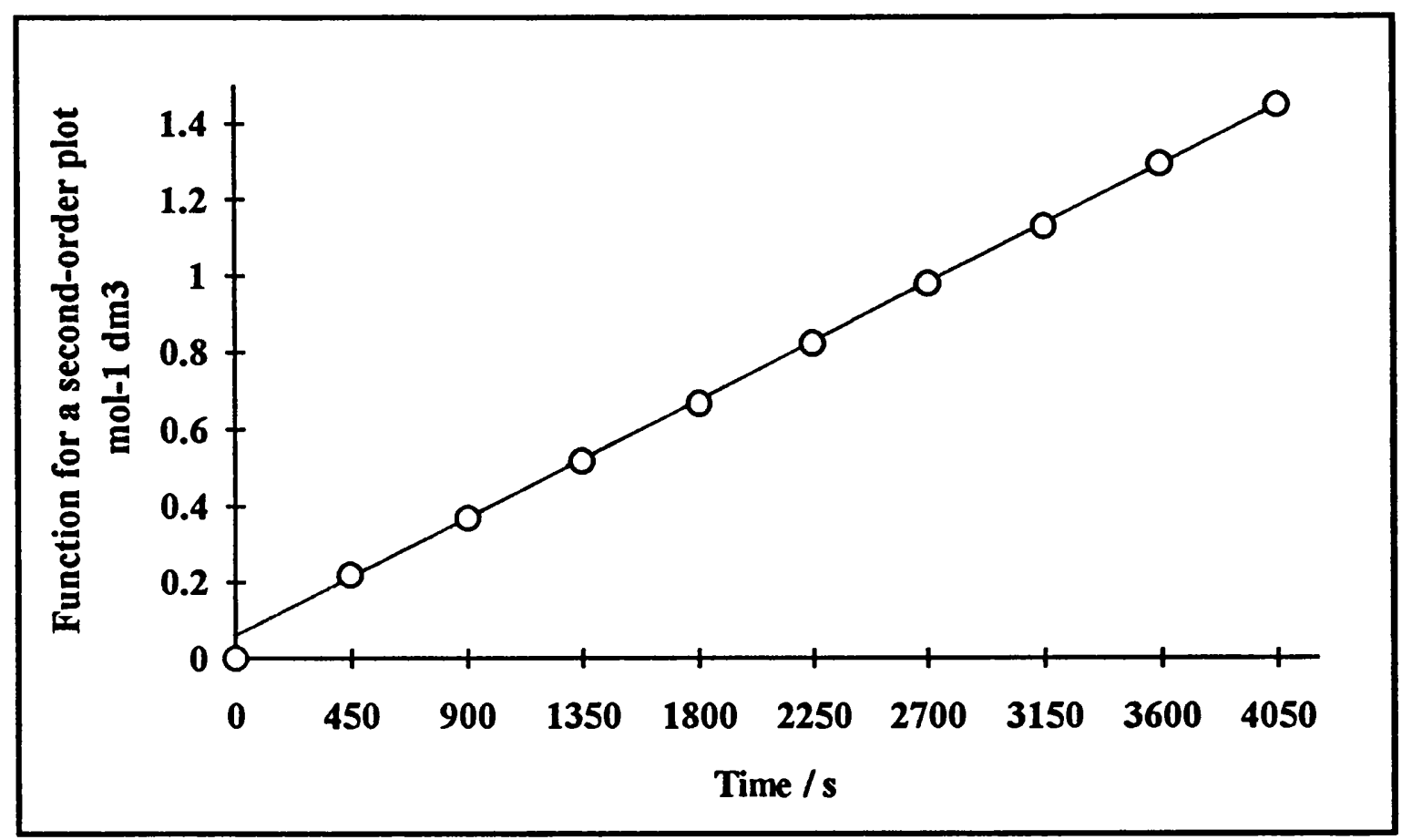

(a)

$$
\begin{aligned}
\mathrm{k}_{2}(\mathrm{a} \neq \mathrm{b}) & =3.48 \times 10^{-4} \mathrm{~mol}^{-1} \mathrm{dm}^{3} \mathrm{~s}^{-1} \\
\mathrm{r} & =0.9994 \\
\sigma & =1.26 \%
\end{aligned}
$$

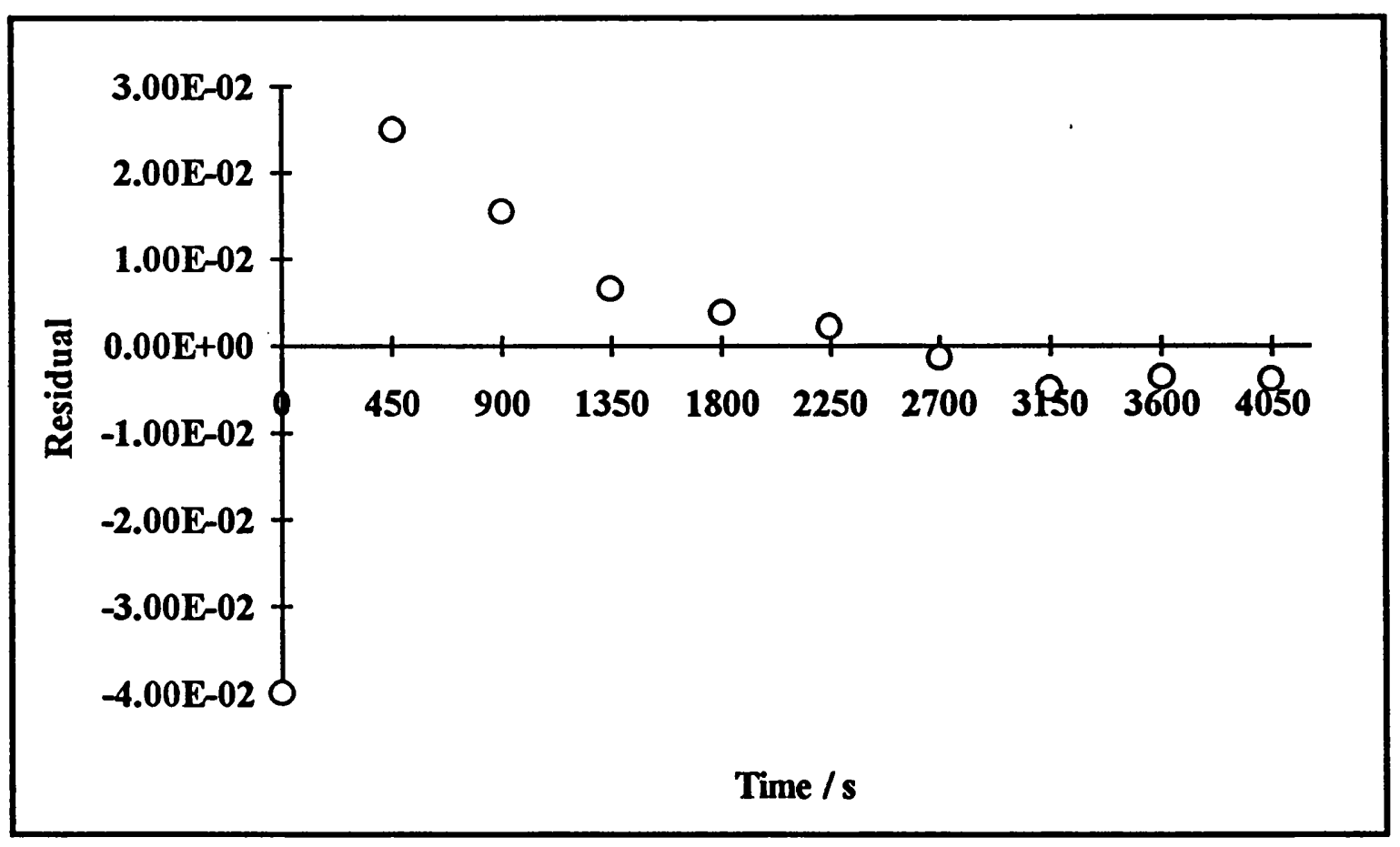

(b)

\section{Figure 3.4}

Plots of (a) Function for second-order plot $/ \mathrm{mol}^{-1} \mathrm{dm}^{3}$ and (b) Residuals against time / s for the reaction of $p$-nitrocumyl bromide with sodium nitrite (Table 3.1). 


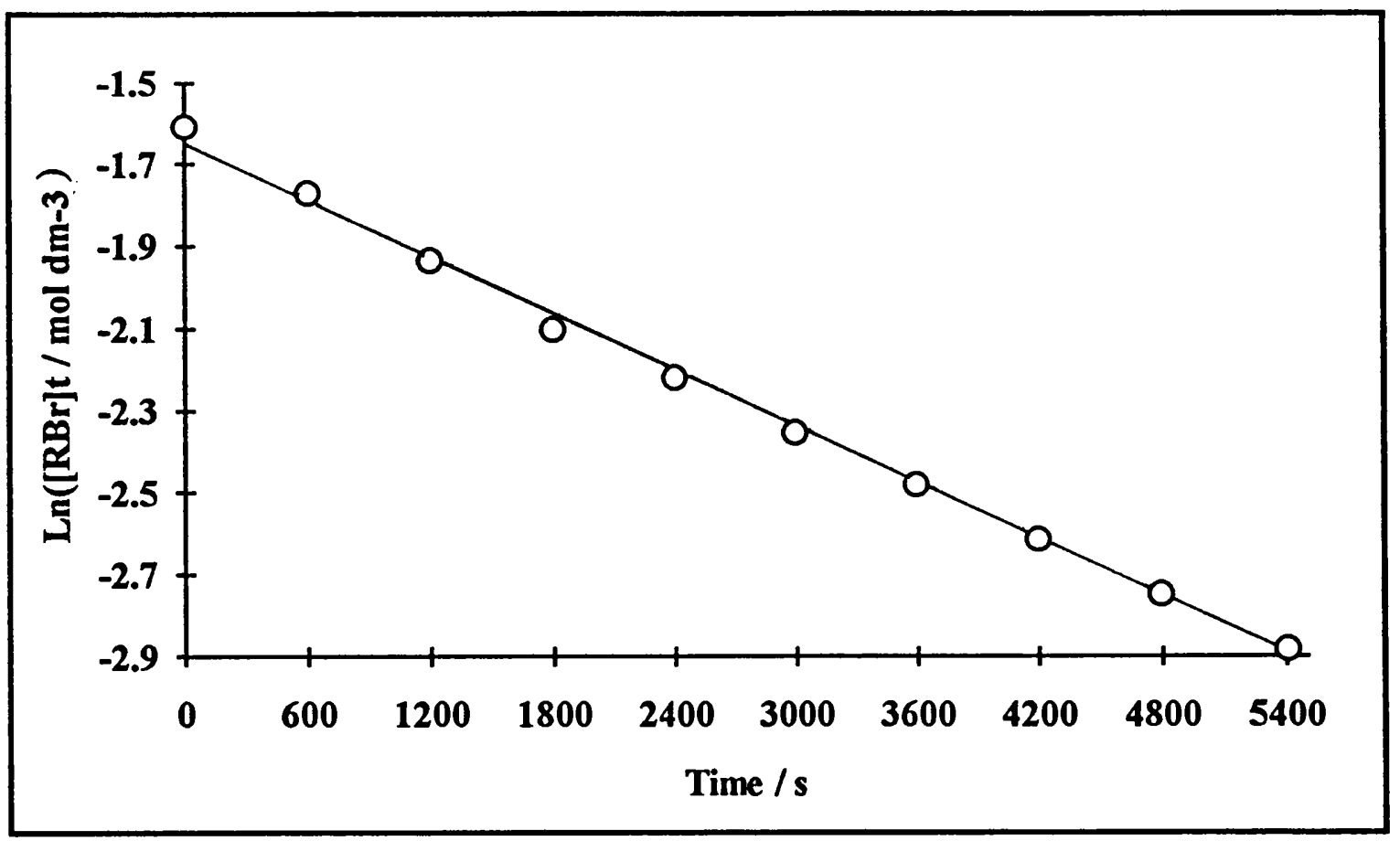

(a)

$$
\begin{aligned}
& \mathrm{k}_{1}=2.32 \times 10^{-4} \mathrm{~s}^{-1} \\
& \mathrm{r}=0.9987 \\
& \sigma=1.79 \%
\end{aligned}
$$

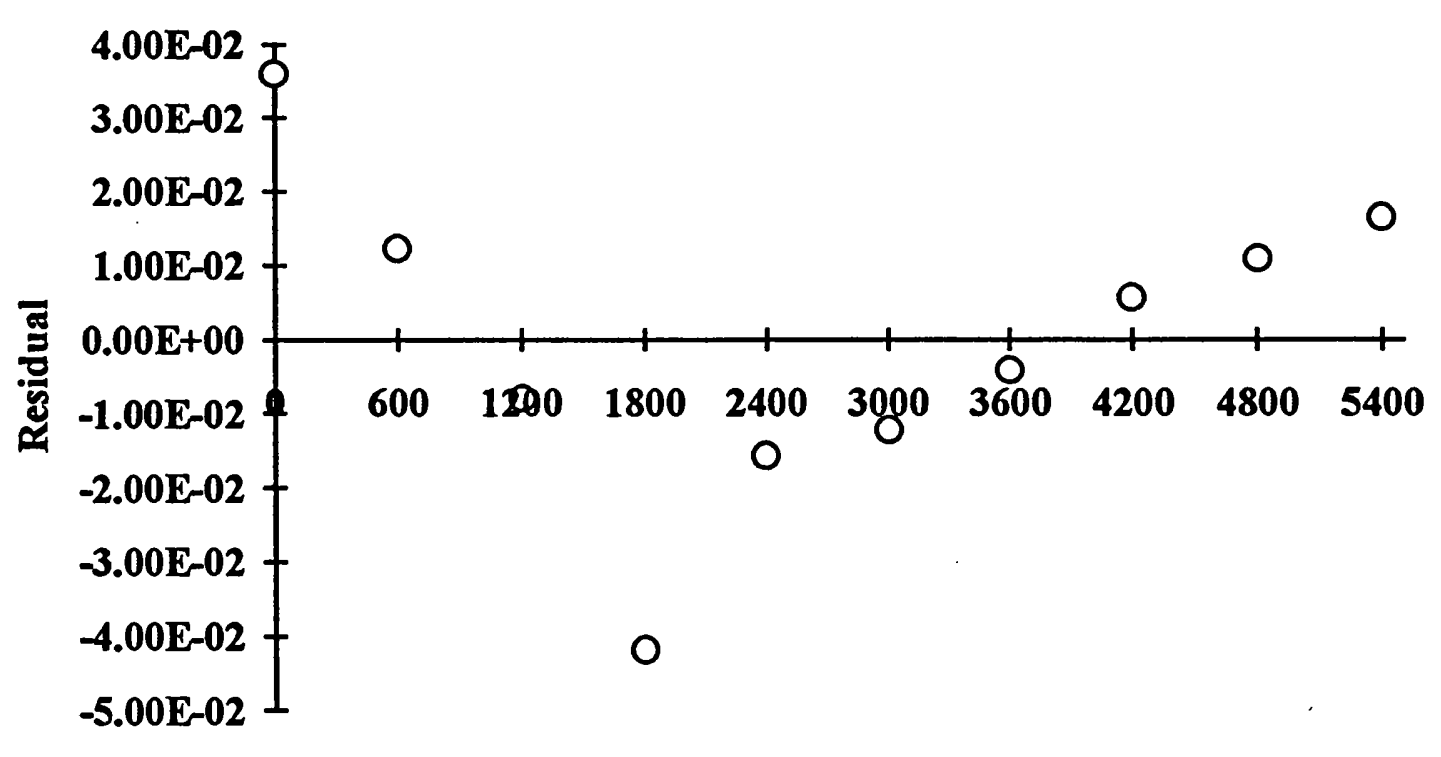

Time / s

(b)

Figure 3.5

Plots of (a) $\mathrm{Ln}\left([\mathrm{RBr}]_{\mathrm{t}} / \mathrm{mol} \mathrm{dm}^{-3}\right.$ ) and (b) Residuals against time / $\mathrm{s}$ for the reaction of $p$-nitrocumyl bromide with sodium nitrite (Table 3.2). 


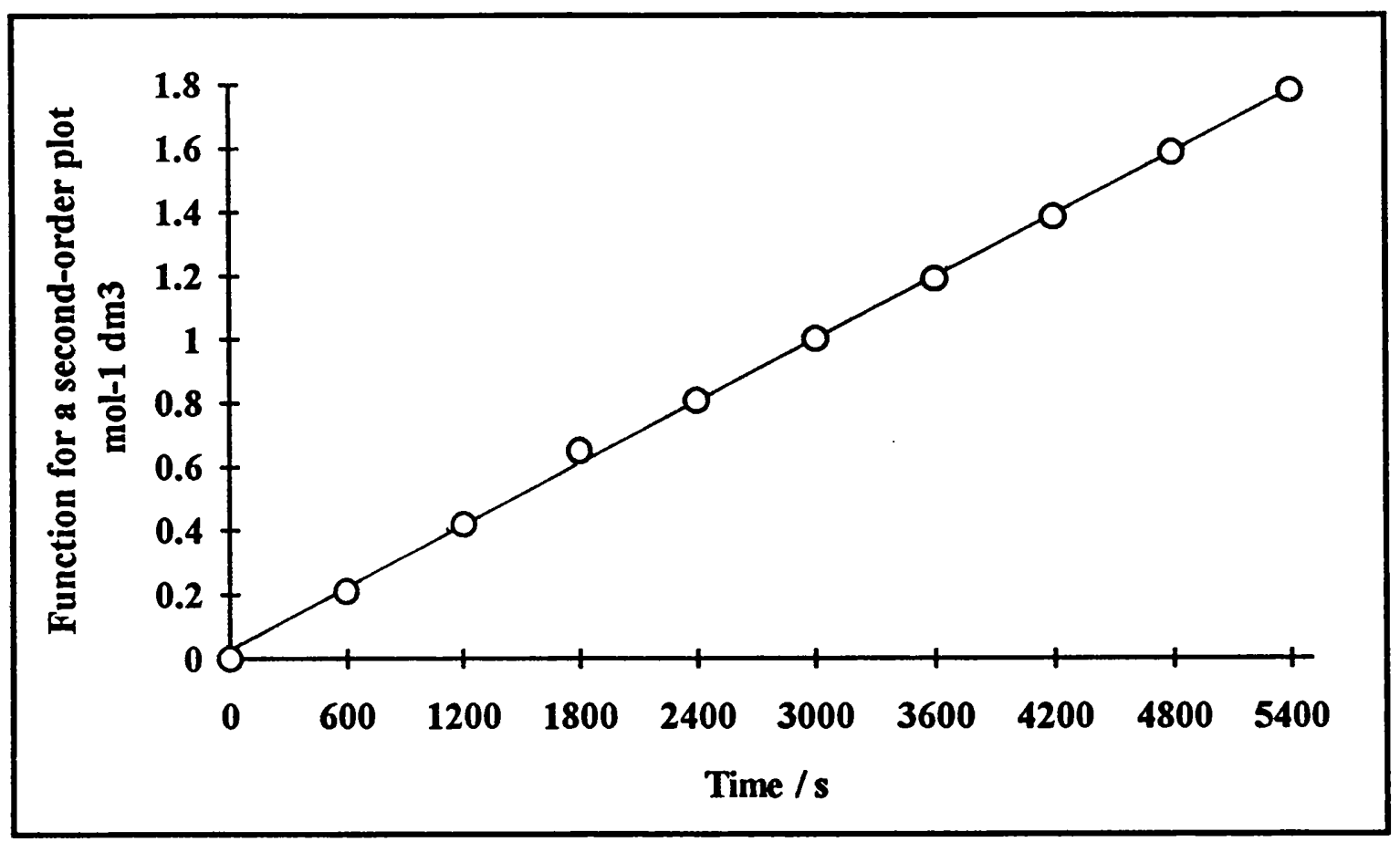

(a)

$$
\begin{aligned}
\mathrm{k}_{2}(\mathrm{a} \neq \mathrm{b}) & =3.27 \times 10^{-4} \mathrm{~mol}^{-1} \mathrm{dm}^{3} \mathrm{~s}^{-1} \\
\mathrm{r} & =0.9996 \\
\sigma & =1.02 \%
\end{aligned}
$$

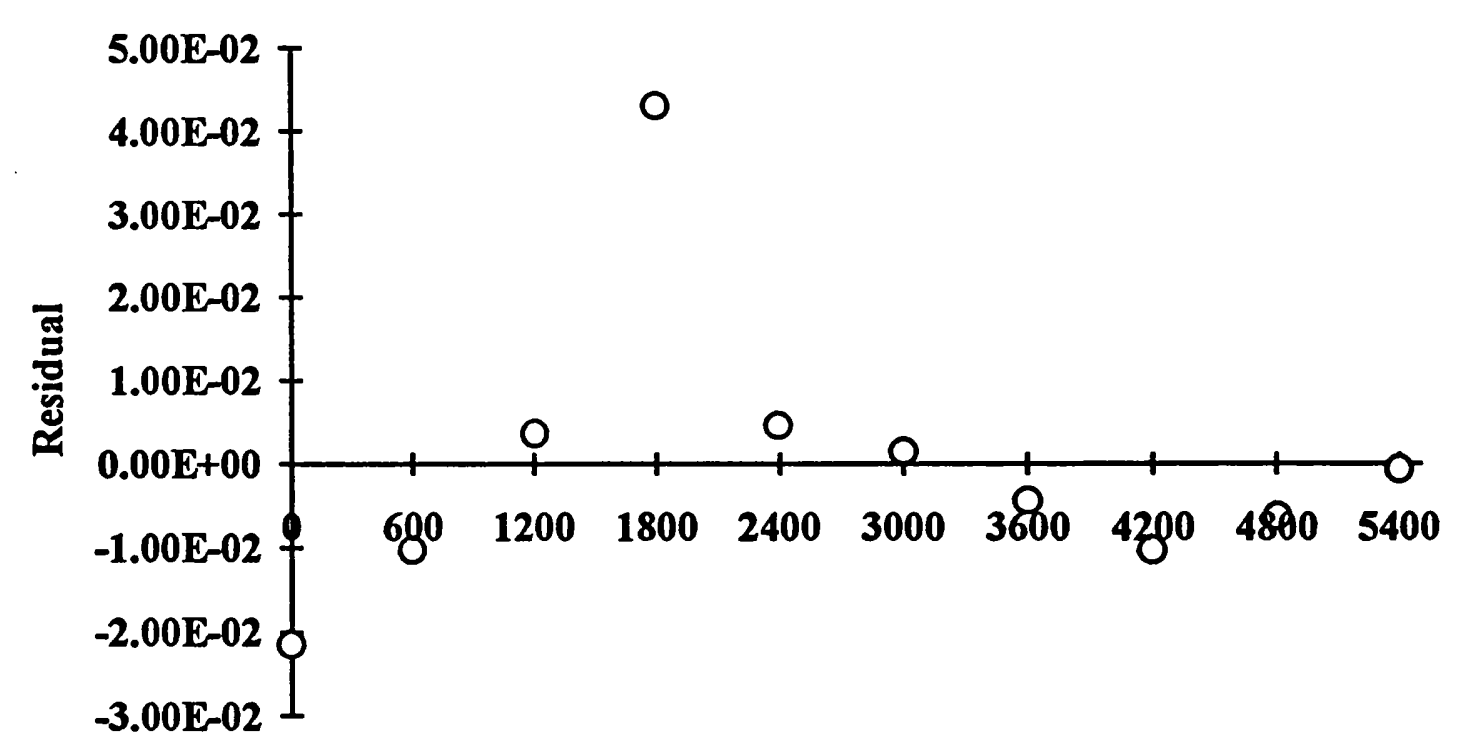

Time /s

(b)

Figure 3.6

Plots of (a) Function for second-order plot / $\mathrm{mol}^{-1} \mathrm{dm}^{-3}$ and (b) Residuals against time / $\mathrm{s}$ for the reaction of $p$-nitrocumyl bromide with sodium nitrite (Table 3.2). 


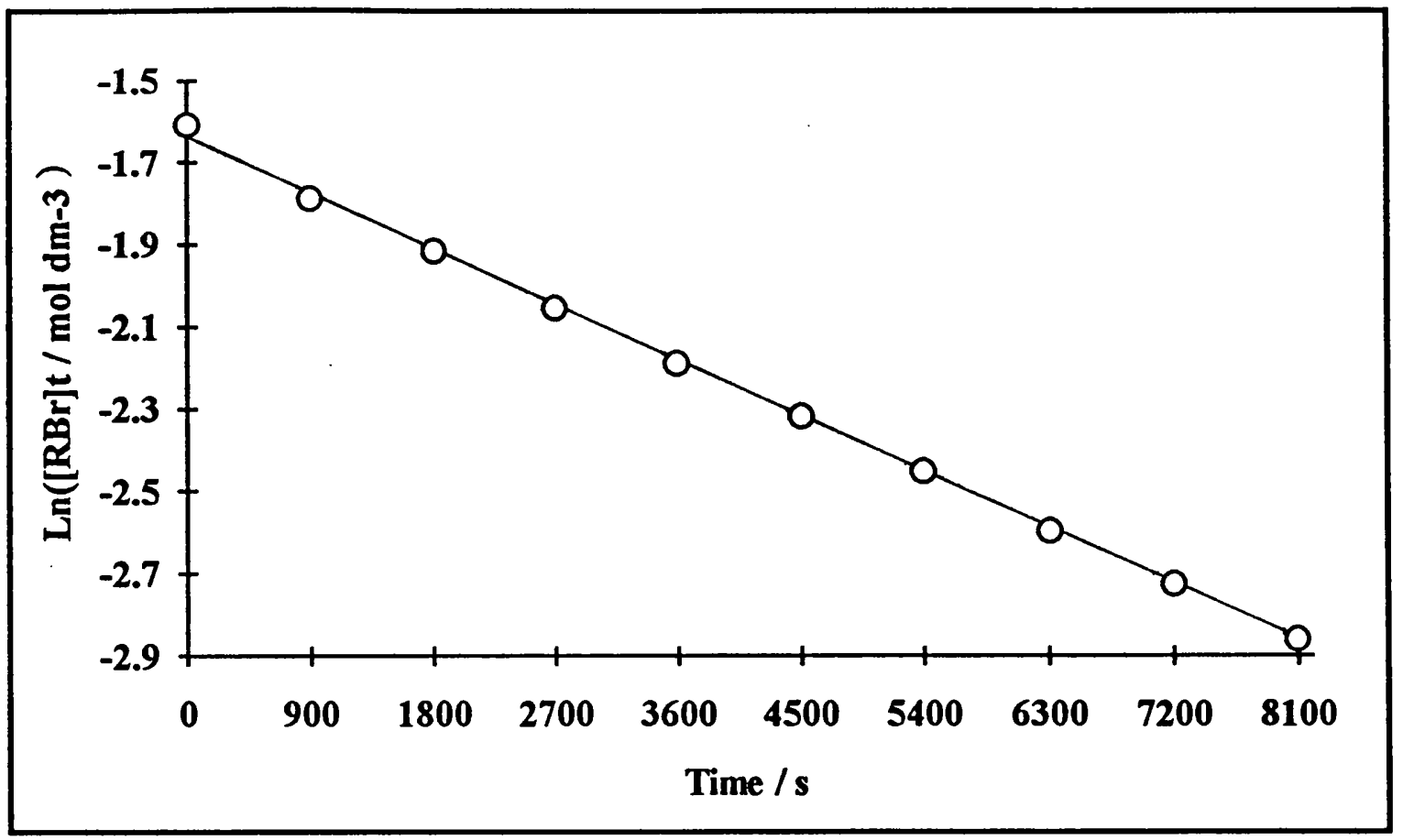

(a)

$$
\begin{aligned}
& \mathrm{k}_{1}=1.52 \times 10^{-4} \mathrm{~s}^{-1} \\
& \mathrm{r}=0.9996 \\
& \sigma=1.04 \%
\end{aligned}
$$

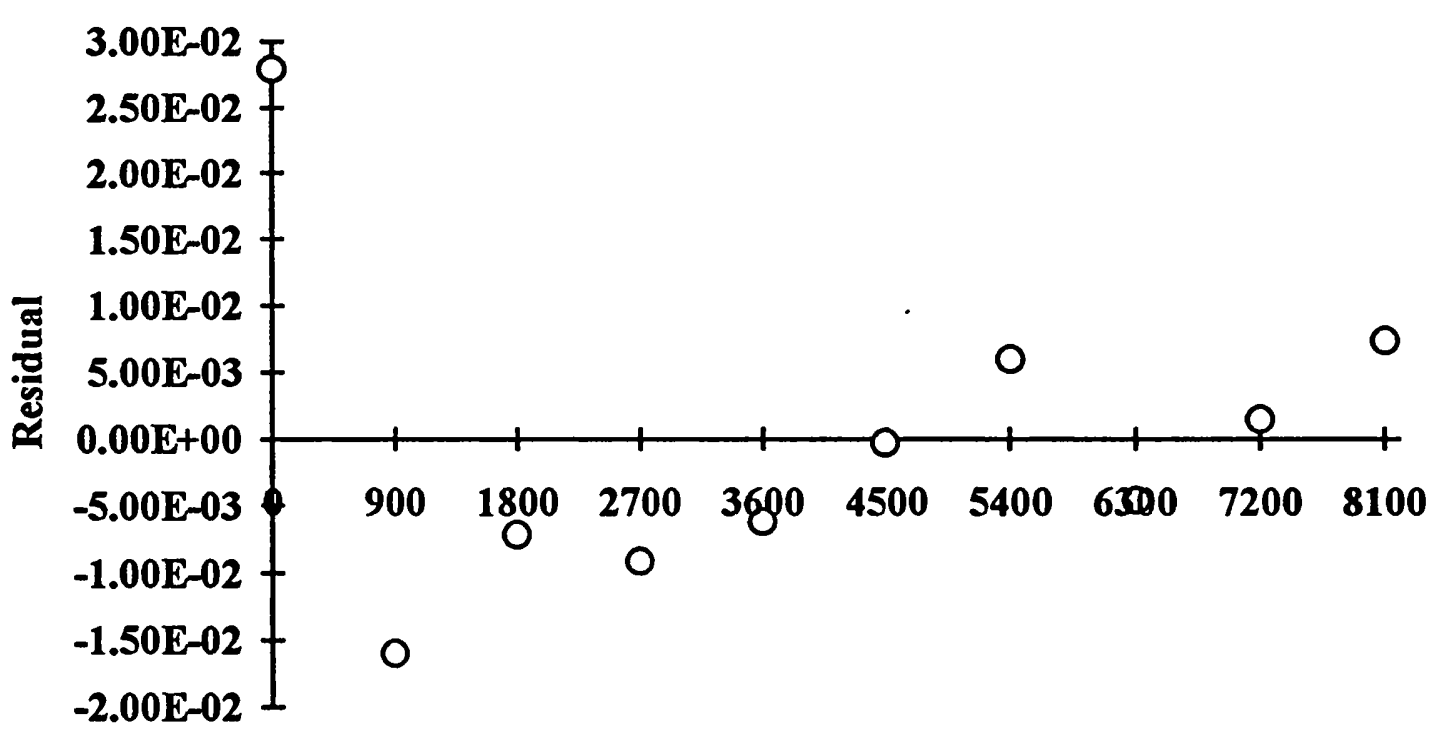

Time / s

(b)

\section{Figure 3.7}

Plots of (a) $\mathrm{Ln}\left([\mathrm{RBr}]_{\mathrm{t}} / \mathrm{mol} \mathrm{dm}^{-3}\right)$ and (b) Residuals against time / $\mathrm{s}$ for the reaction of p-nitrocumyl bromide with sodium nitrite (Table 3.3). 


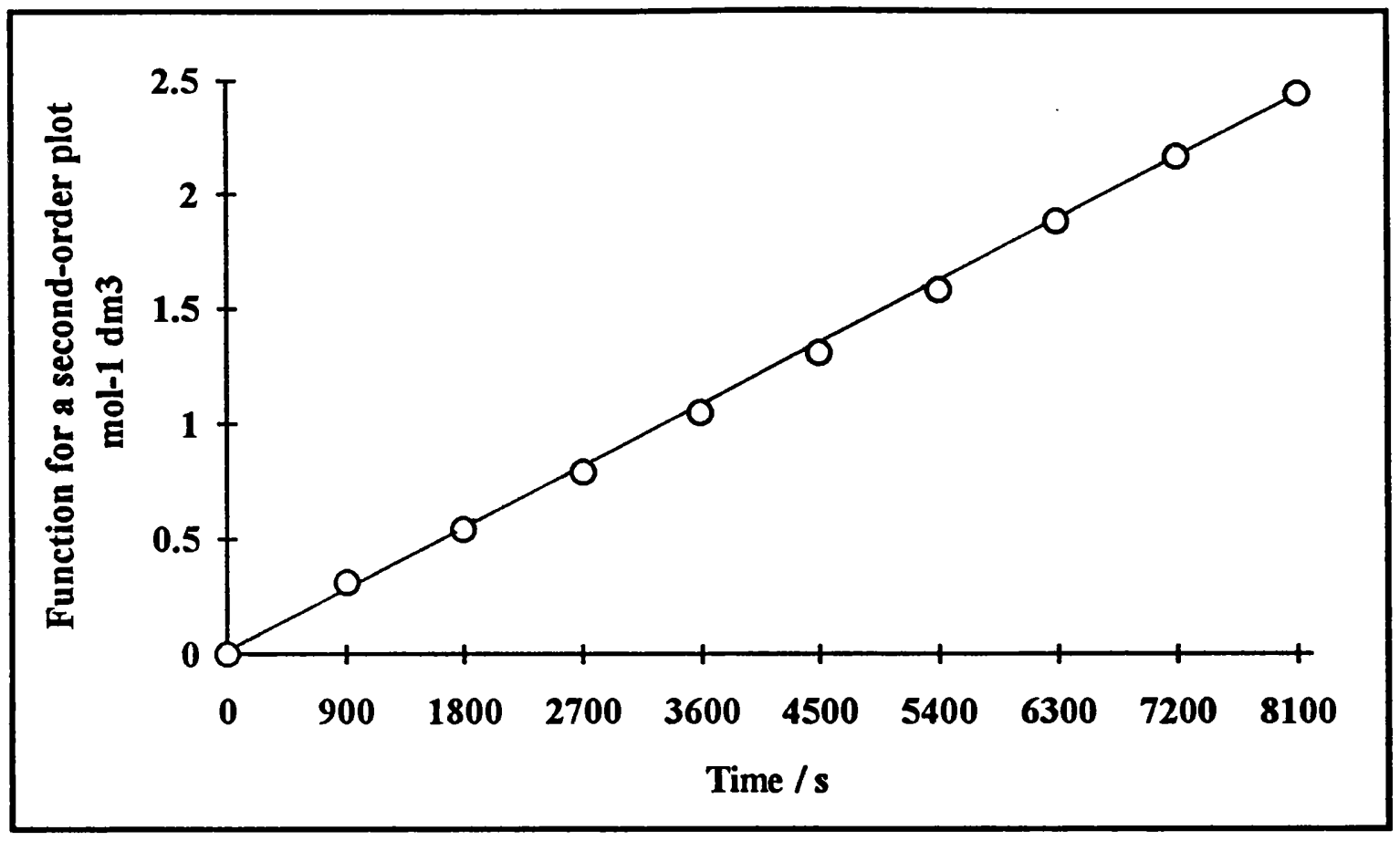

(a)

$$
\begin{aligned}
\mathrm{k}_{2}(\mathrm{a} \neq \mathrm{b}) & =2.98 \times 10^{-4} \mathrm{~mol}^{-1} \mathrm{dm}^{3} \mathrm{~s}^{-1} \\
\mathrm{r} & =0.9996 \\
\sigma & =1.04 \%
\end{aligned}
$$

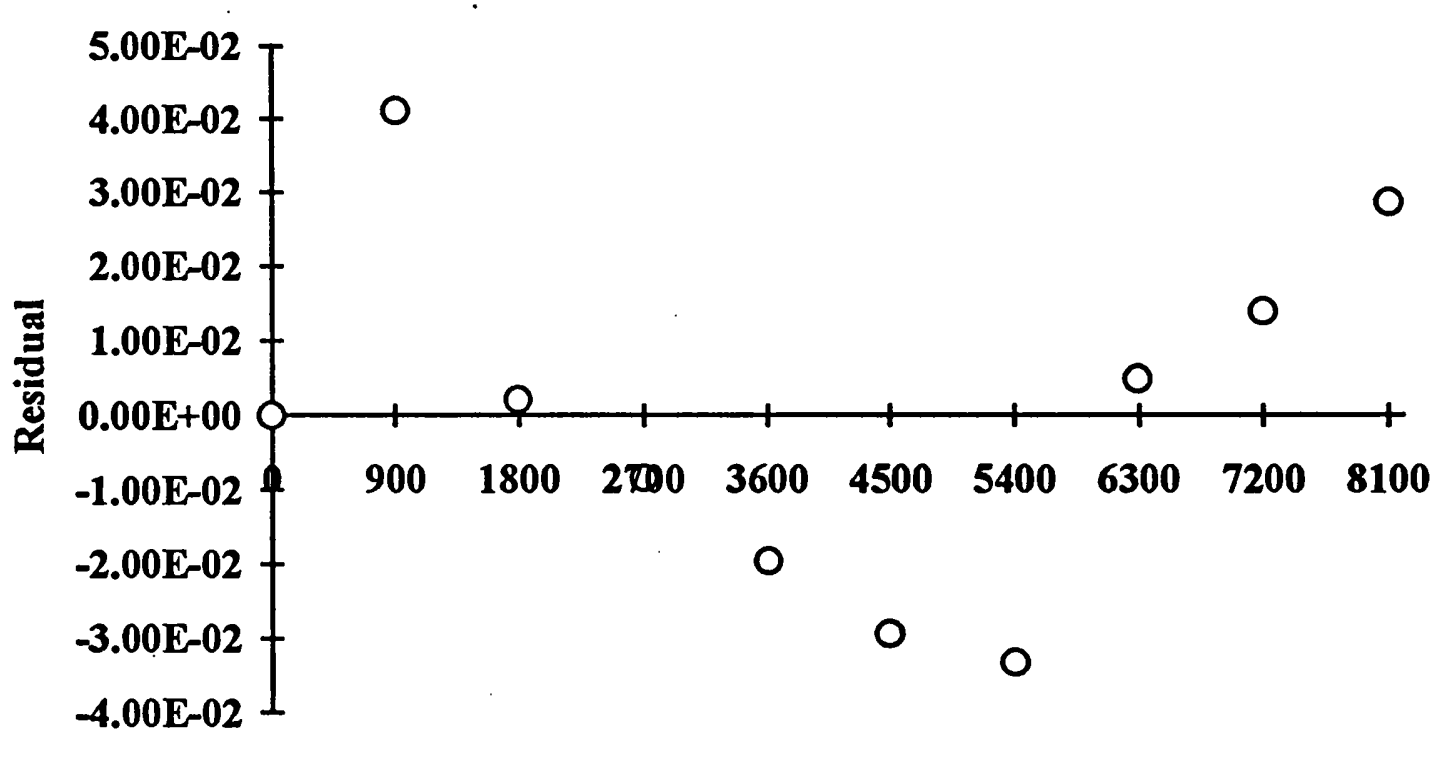

Time /s

(b)

\section{Figure 3.8}

Plots of (a) Function for second-order plot / $\mathrm{mol}^{-1} \mathrm{dm}^{3}$ and (b) Residuals against time / s for the reaction of $p$-nitrocumyl bromide with sodium nitrite (Table 3.3). 


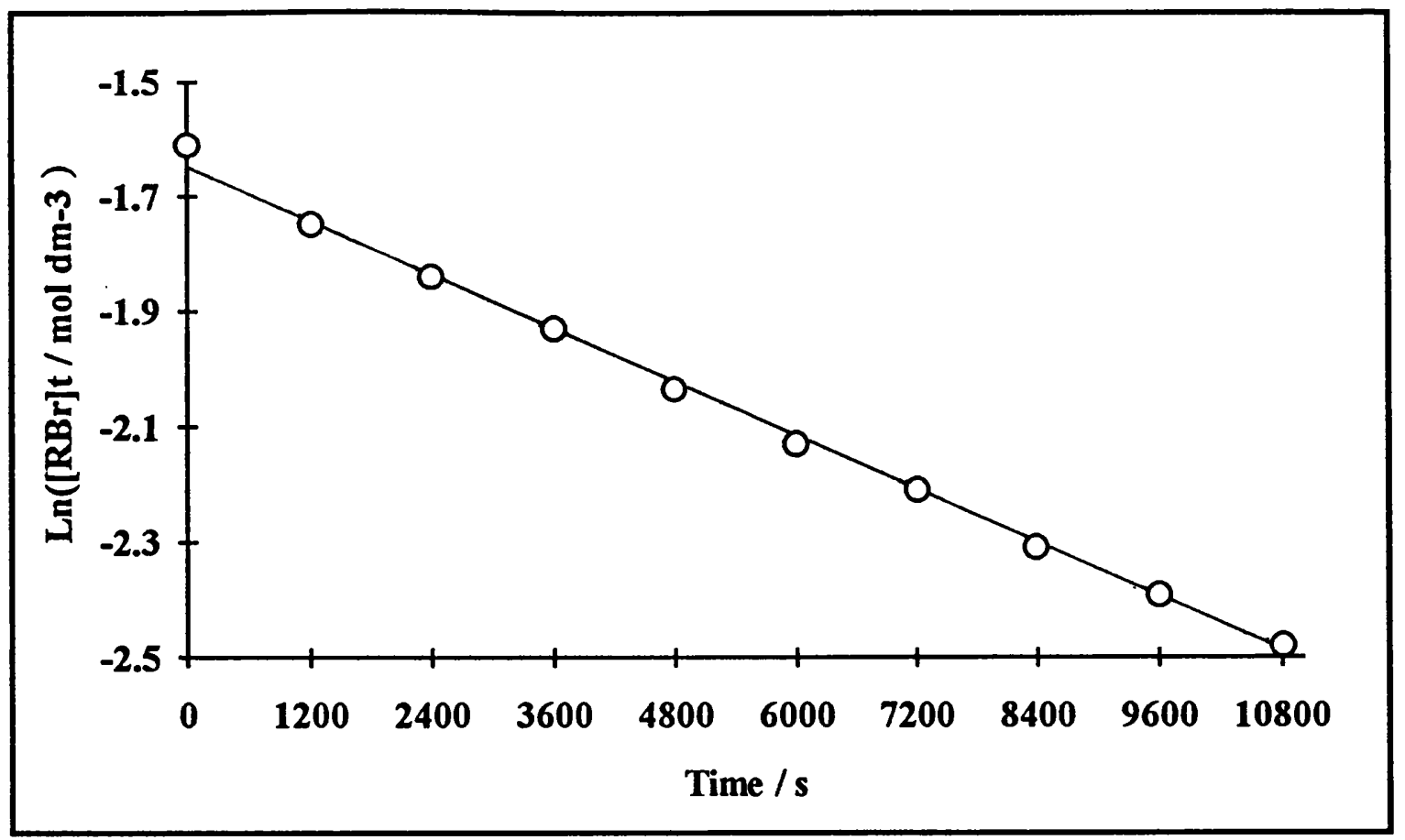

(a)

$$
\begin{aligned}
& \mathrm{k}_{1}=7.88 \times 10^{-4} \mathrm{~s}^{-1} \\
& \mathrm{r}=0.9987 \\
& \sigma=1.79 \%
\end{aligned}
$$

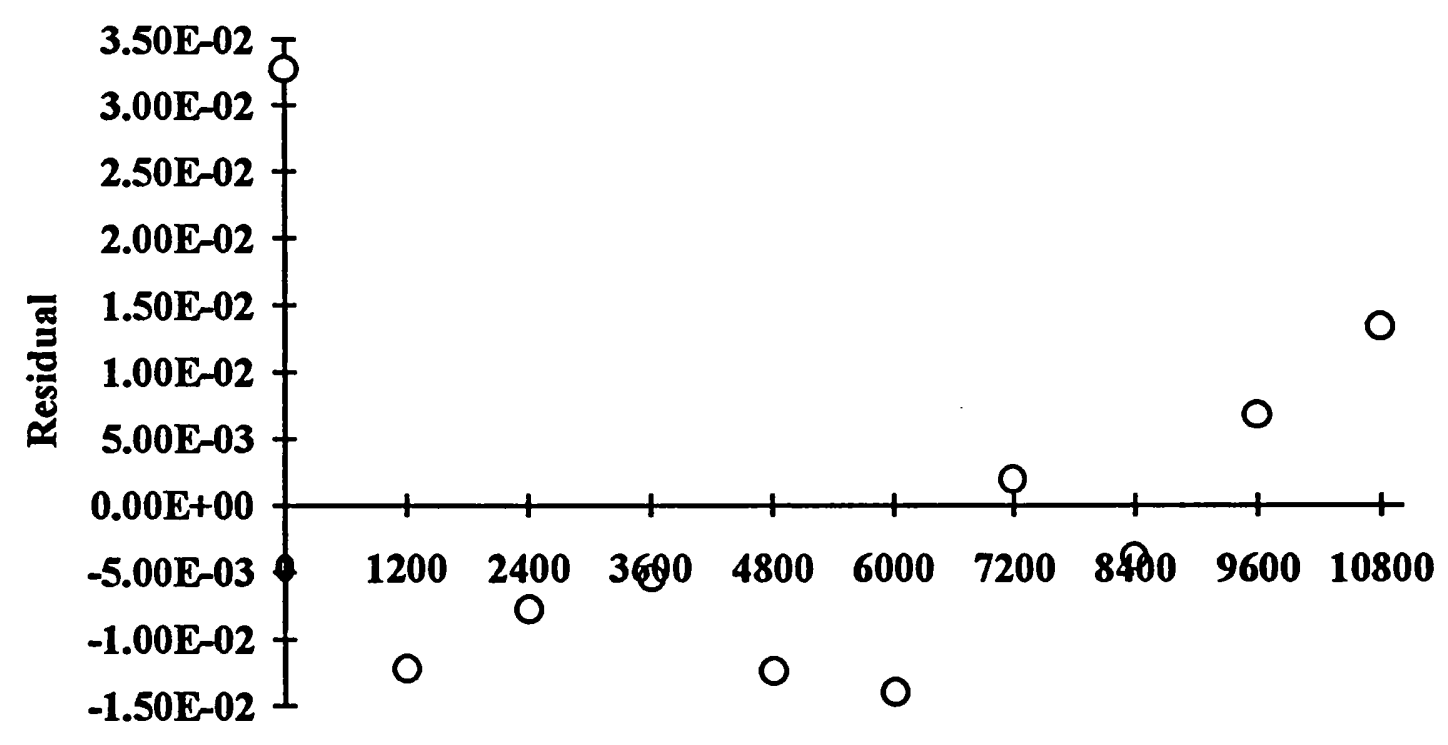

Time / s

(b)

\section{Figure 3.9}

Plots of (a) $\operatorname{Ln}\left([\mathrm{RBr}]_{\mathrm{t}} / \mathrm{mol} \mathrm{dm}^{-3}\right)$ and (b) Residuals against time / $\mathrm{s}$ for the reaction of p-nitrocumyl bromide with sodium nitrite (Table 3.4). 


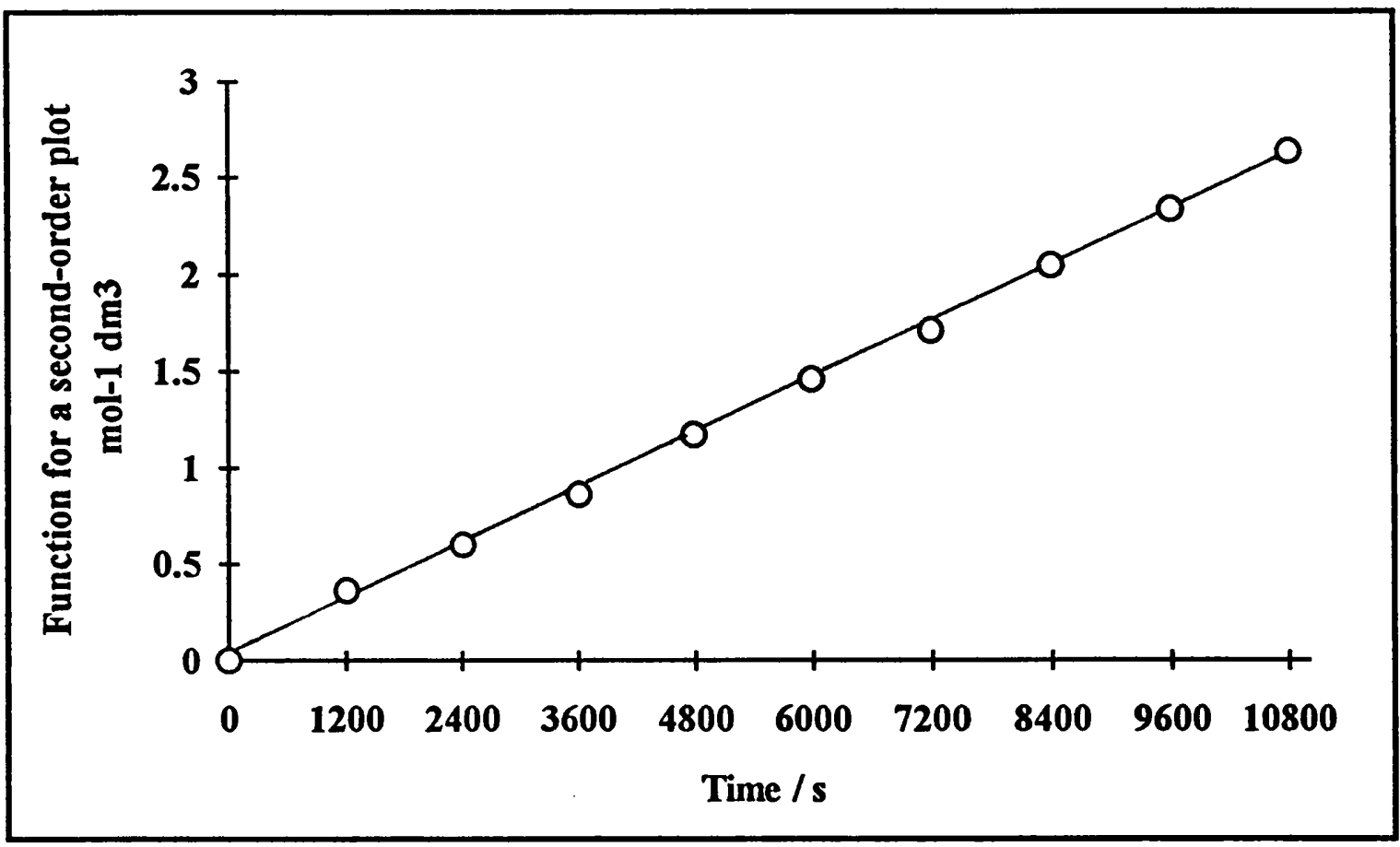

(a)

$$
\begin{aligned}
k_{2}(a \neq b) & =2.40 \times 10^{-4} \mathrm{~mol}^{-1} \mathrm{dm}^{3} \mathrm{~s}^{-1} \\
r & =0.9996 \\
\sigma & =0.96 \%
\end{aligned}
$$

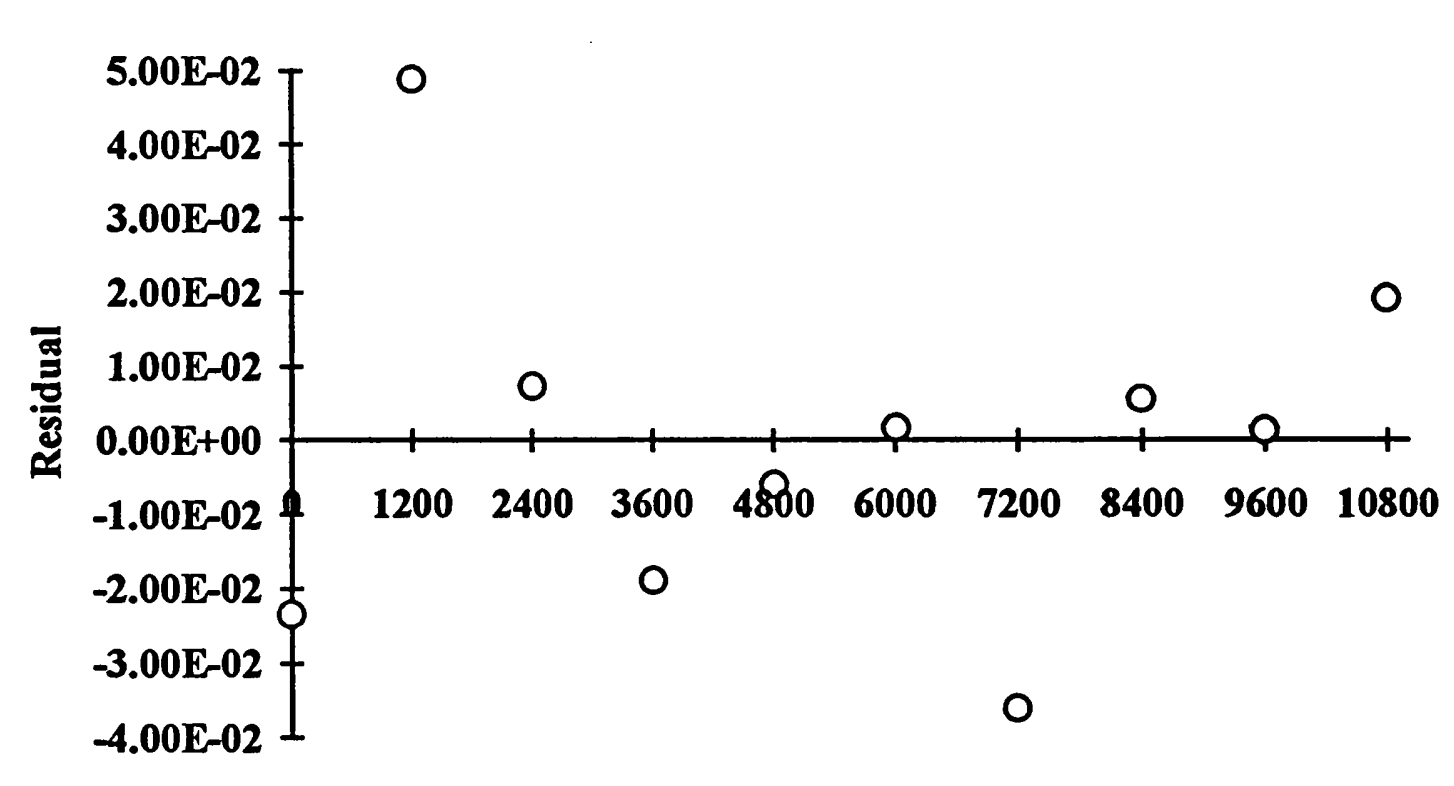

Time / s

(b)

Figure 3.10

Plots of (a) Function for second-order plot $/ \mathrm{mol}^{-1} \mathrm{dm}^{3}$ and (b) Residuals against time / $\mathrm{s}$ for the reaction of $p$-nitrocumyl bromide with sodium nitrite (Table 3.4). 


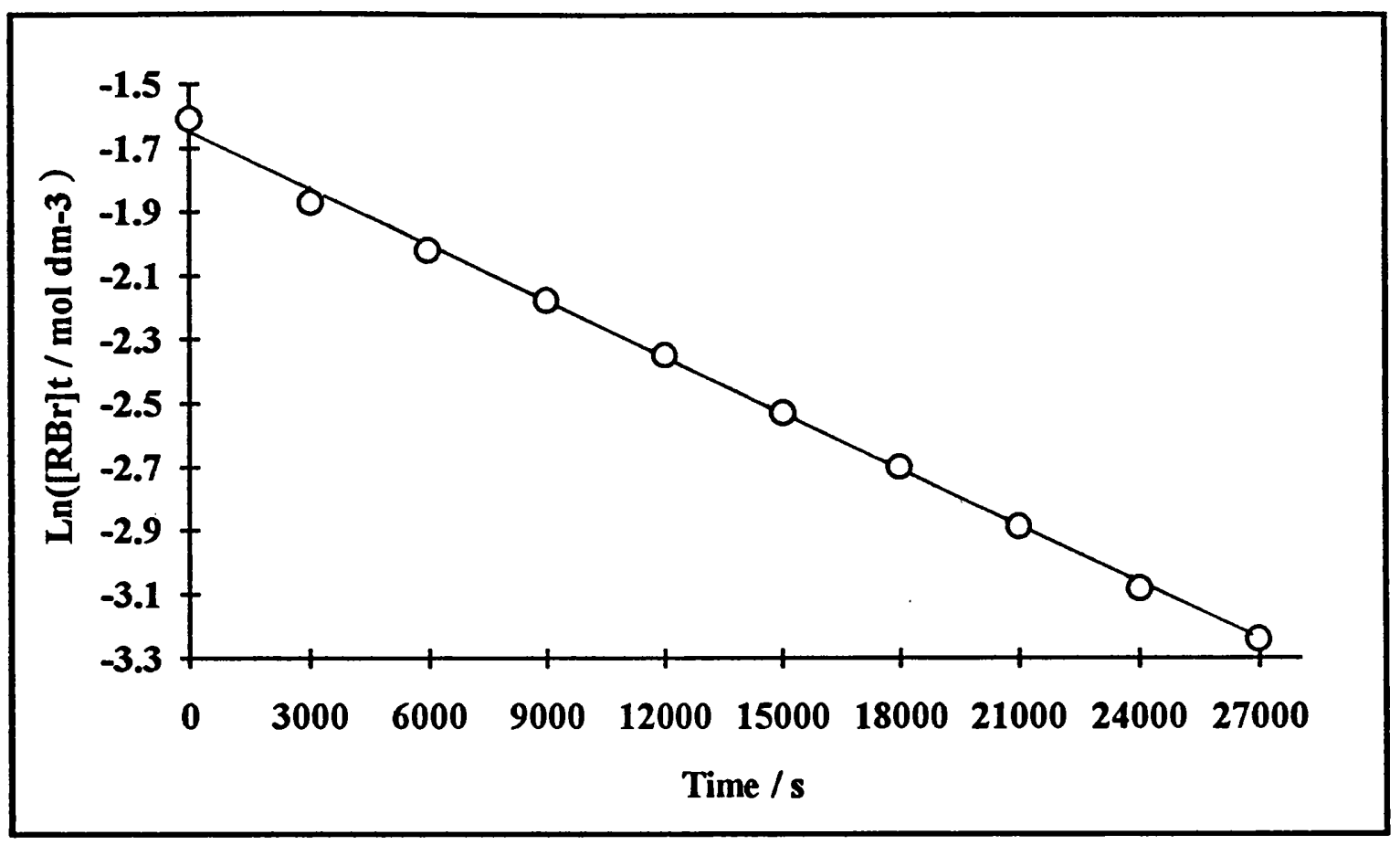

(a)

$$
\begin{aligned}
& \mathrm{k}_{1}=5.91 \times 10^{-5} \mathrm{~s}^{-1} \\
& \mathbf{r}=0.9992 \\
& \sigma=1.40 \%
\end{aligned}
$$

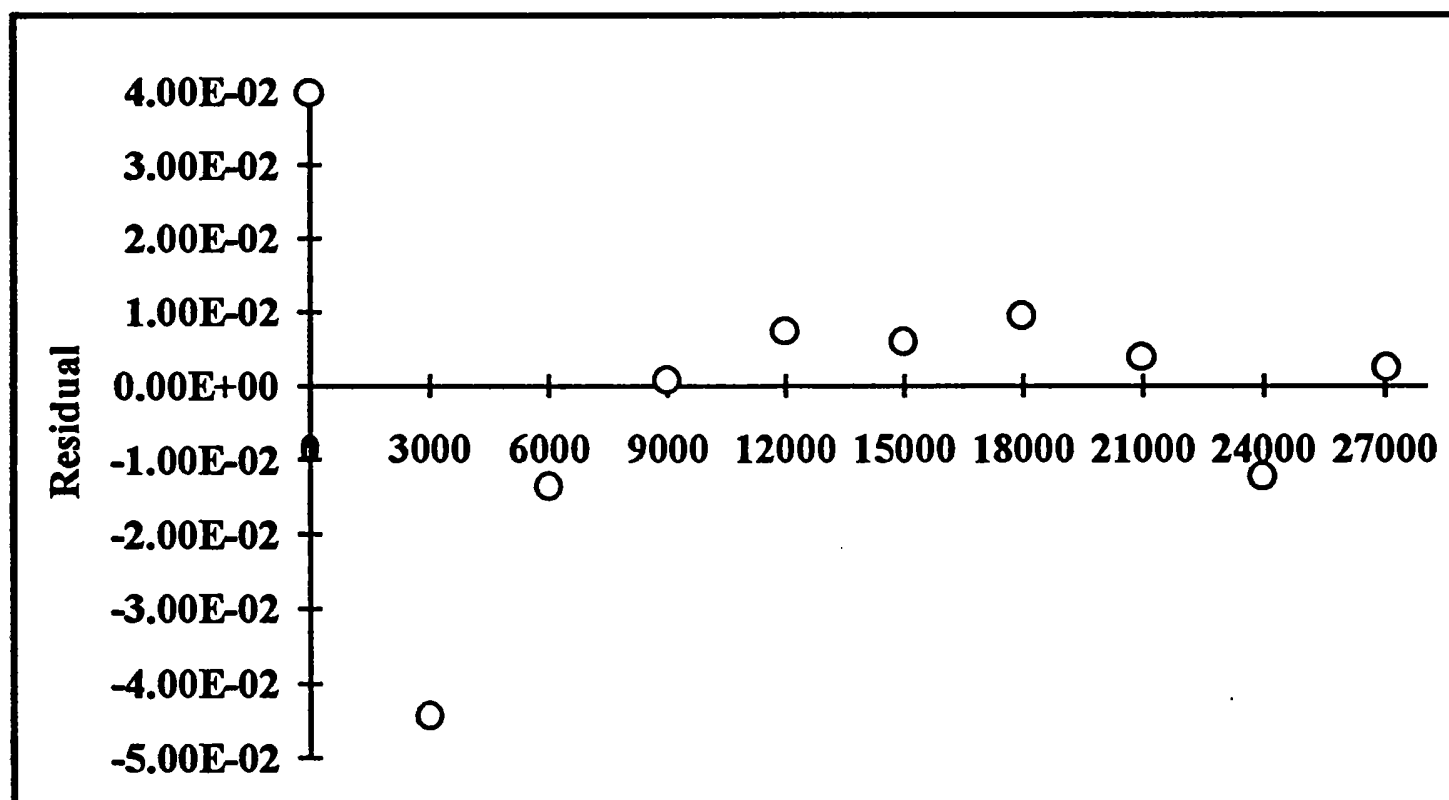

Time /s

(b)

Figure 3.11

Plots of (a) $\mathrm{Ln}\left([\mathrm{RBr}]_{\mathrm{t}} / \mathrm{mol} \mathrm{dm}^{-3}\right)$ and (b) Residuals against time / $\mathrm{s}$ for the reaction of p-nitrocumyl bromide with sodium nitrite (Table 3.5). 


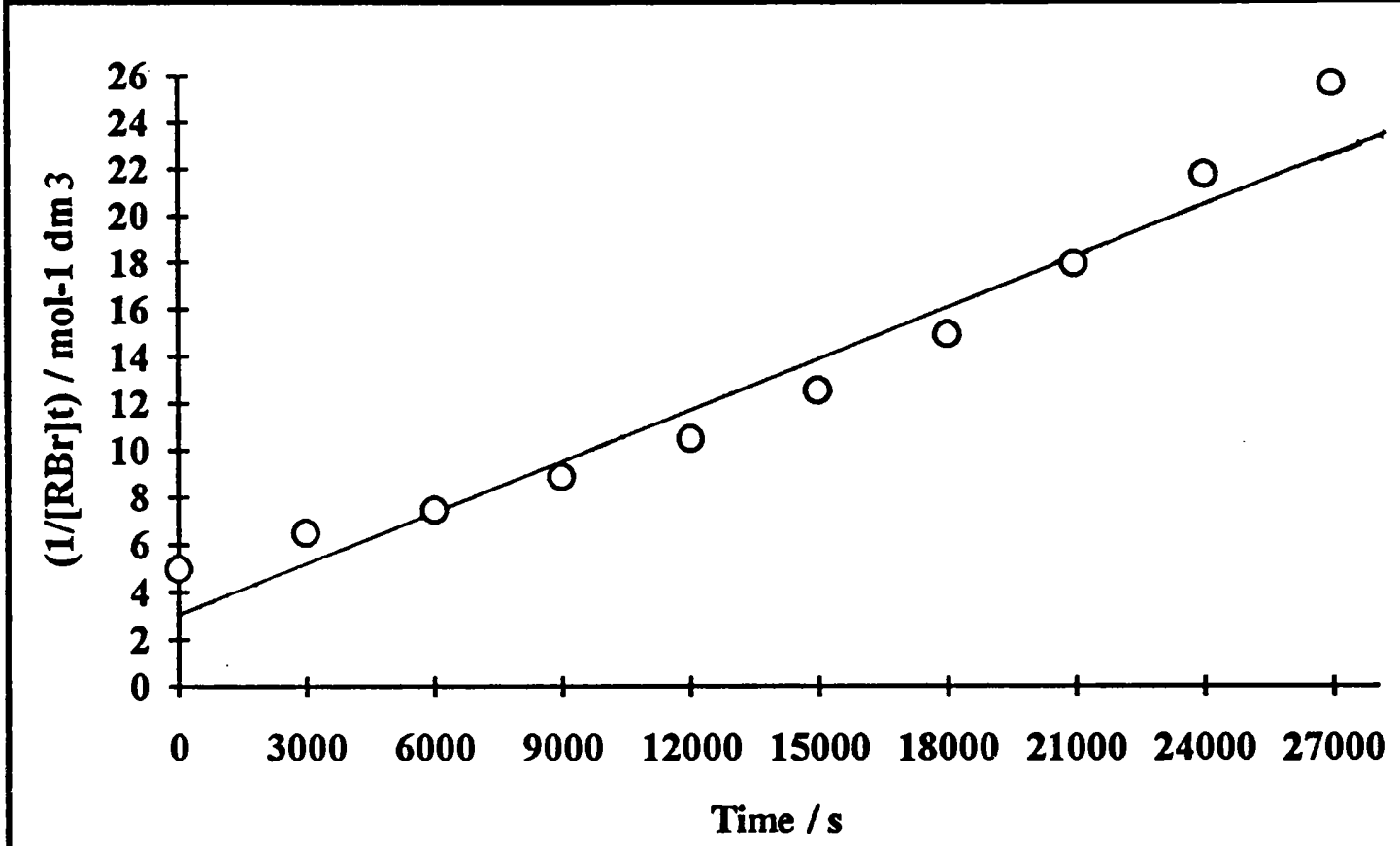

(a)

$$
\begin{aligned}
\mathrm{k}_{2}(\mathrm{a}=\mathrm{b}) & =7.36 \times 10^{-4} \mathrm{~mol}^{-1} \mathrm{dm}^{3} \mathrm{~s}^{-1} \\
\mathrm{r} & =0.9754 \\
\sigma & =7.98 \%
\end{aligned}
$$

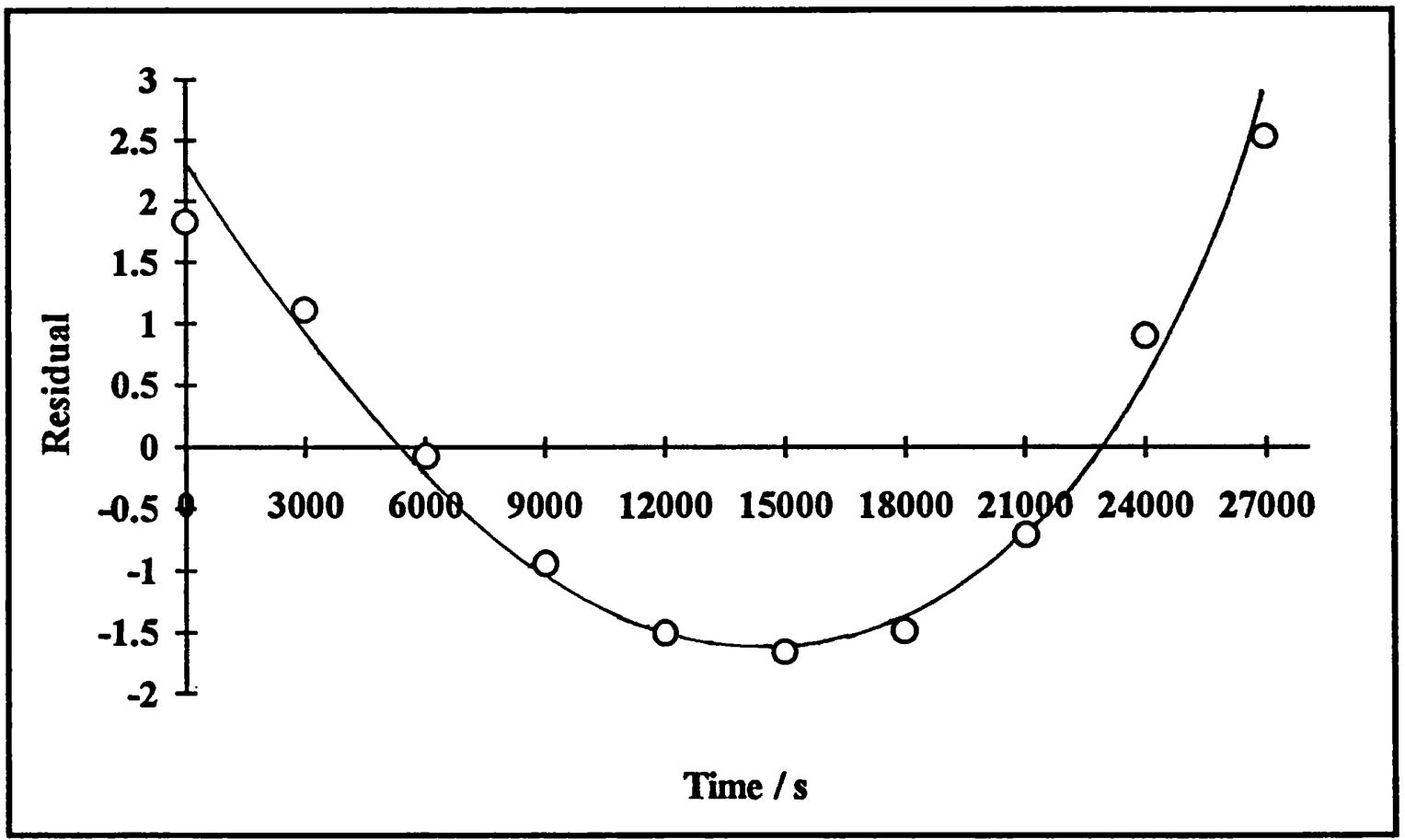

(b)

\section{Figure 3.12}

Plots of (a) Function for second-order plot $/ \mathrm{mol}^{-1} \mathrm{dm}^{-3}$ and (b) Residuals against time / $\mathrm{s}$ for the reaction of $p$-nitrocumyl bromide with sodium nitrite (Table 3.5). 


\subsection{The Order with Respect to $p$-Nitrocumyl Bromide}

One kinetic study was performed; with an initial concentration of $p$-nitrocumyl bromide half the initial concentration used in section 3.4. The ionic strength of the reaction solution was again held essentially constant by the addition of sodium perchlorate. The concentrations of $p$-nitrocumyl bromide at given times, derived from this kinetic study, are presented in Table 3.6. Again, the spectrum for time equal to zero was obtained by taking an ${ }^{1} \mathrm{H}$ n.m.r. spectrum of just the $p$-nitrocumyl bromide solution on its own. For time equal to zero, the concentration of $p$-nitrocumyl bromide in the reaction mixture was set equal to one half the concentration of just the p-nitrocumyl bromide solution on its own.

Rate coefficients were calculated assuming that the reaction was overall first order with respect to $p$-nitrocumyl bromide (Figure 3.13 ) and first order with respect to both $p$ nitrocumyl bromide and lithium azide, that is, second order overall (Figure 3.14).

For the initial concentrations of $p$-nitrocumyl bromide equal to $0.10 \mathrm{~mol} \mathrm{dm}^{-3}$ and sodium nitrite equal to $0.20 \mathrm{~mol} \mathrm{dm}^{-3}$ (Figures 3.13 and 3.14) the plot for an overall first order reaction is a reasonable fit. However, when the residuals are examined it can be seen that the pattern is a curved one with the very first point slightly removed from others. The plot for an overall second order reaction is a good fit, but the residual plot has a minor pattern with its fourth point slightly removed from others.

\subsection{Summary}

A summary of first $\left(k_{1}\right)$ and second order rate constants $\left(k_{2}\right)$ are shown in Table 3.7. The first and second order rate constants obtained from varying the initial concentration of sodium nitrite have no real correlation with the first and second order rate constants obtained from the variation of the initial concentration of p-nitrocumyl bromide. The rate of reaction for the reaction between sodium nitrite and $p$-nitrocumyl bromide is dependent on both the sodium nitrite and p-nitrocumyl bromide concentrations, however, it does not obey an overall second order model. 
Table 3.6

Temperature

Solvent

[RBr]0

$\left[\mathrm{NaNO}_{2}\right]_{0}$

$\left[\mathrm{NaClO}_{4}\right]_{0}$

\section{The Order with Respect to p-Nitrocumyl Bromide}

$30^{\circ} \mathrm{C}$

$99.9 \% \mathrm{C}_{2} \mathrm{D}_{6} \mathrm{SO}$

$0.10 \mathrm{~mol} \mathrm{dm}^{-3}$

$\left(\mathrm{R}=\mathrm{C}_{9} \mathrm{H}_{10} \mathrm{NO}_{2}\right)$

$0.20 \mathrm{~mol} \mathrm{dm}-3$

$0.80 \mathrm{~mol} \mathrm{dm}^{-3}$

\begin{tabular}{|c|c|c|}
\hline Time Range / & Mid-point Time $/ \mathrm{s}$ & {$[\mathrm{RBr}]_{\mathrm{t}} / \mathrm{mol} \mathrm{dm}^{-3}$} \\
\hline 0 & 0 & 0.100 \\
\hline $1792-1808$ & 1800 & 0.085 \\
\hline $3592-3608$ & 3600 & 0.073 \\
\hline $5392-5408$ & 5400 & 0.063 \\
\hline $7192-7208$ & 7200 & 0.057 \\
\hline $8992-9008$ & 9000 & 0.051 \\
\hline $10792-10808$ & 10800 & 0.046 \\
\hline $12592-12608$ & 12600 & 0.041 \\
\hline $14392-14408$ & 14400 & 0.037 \\
\hline $16192-16208$ & 16200 & 0.033 \\
\hline
\end{tabular}




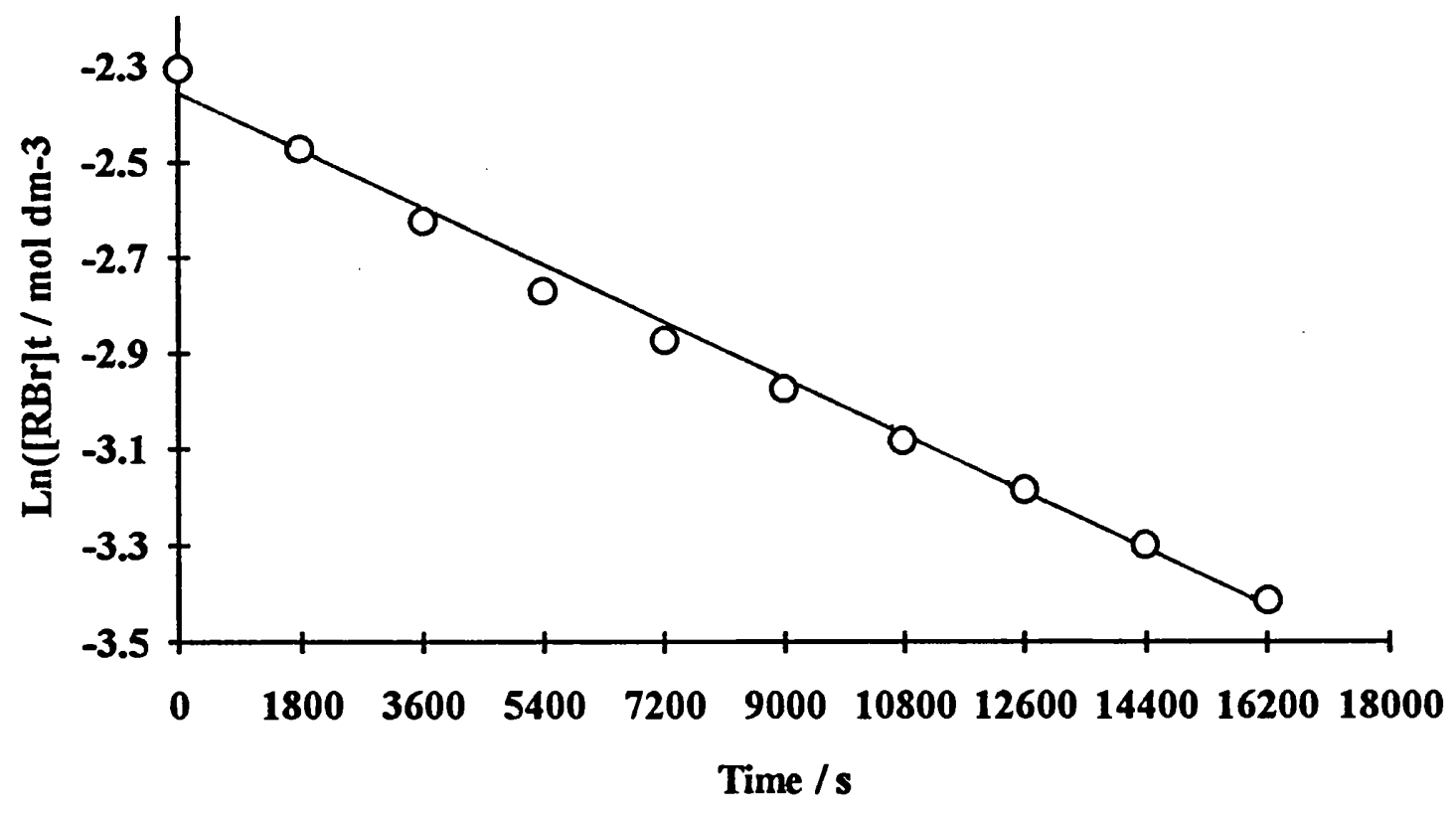

(a)

$$
\begin{aligned}
& \mathrm{k}_{1}=6.61 \times 10^{-5} \mathrm{~s}^{-1} \\
& \mathrm{r}=0.9961 \\
& \sigma=3.14 \%
\end{aligned}
$$

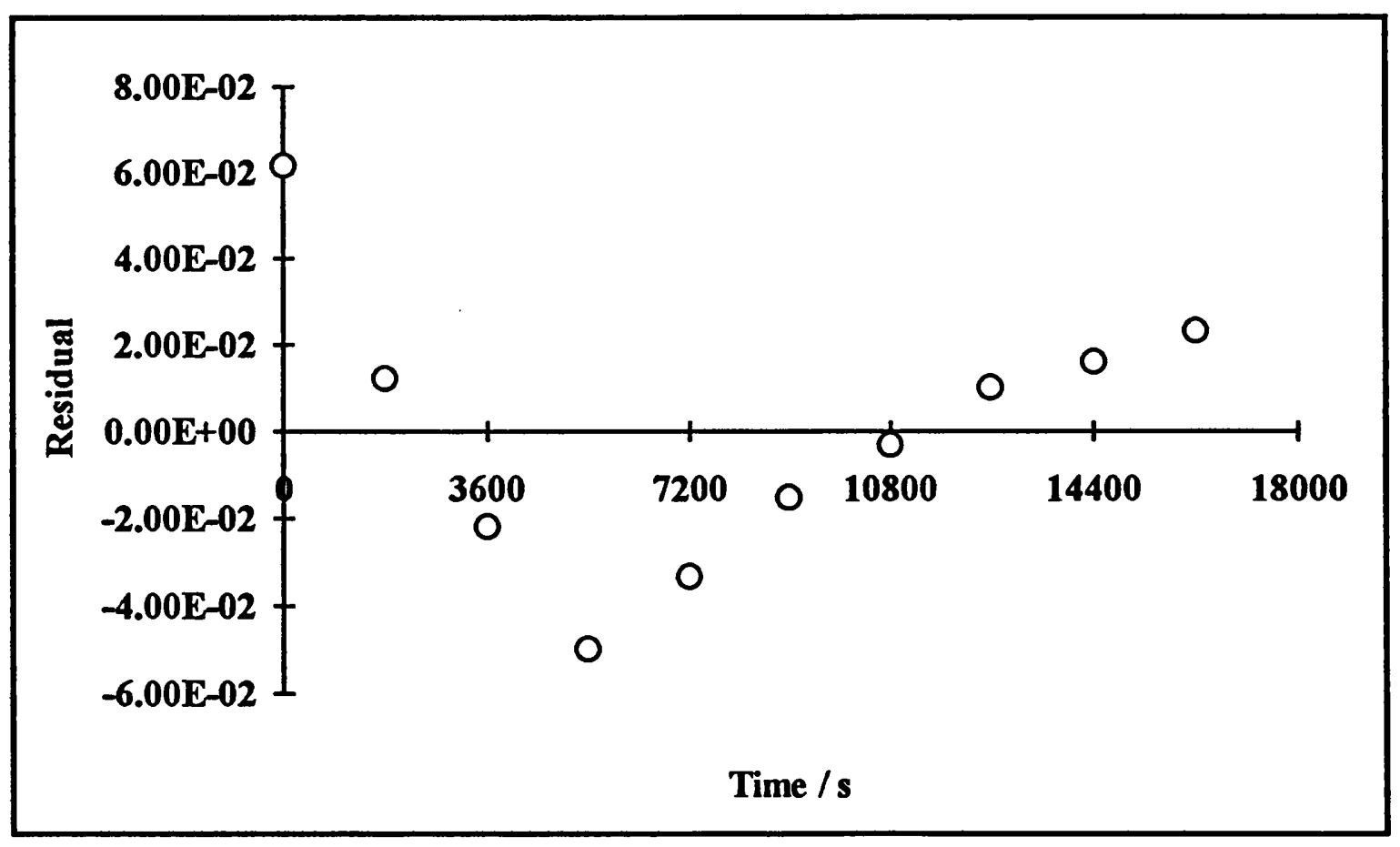

(b)

\section{Figure 3.13}

Plots of (a) $\mathrm{Ln}\left([\mathrm{RBr}]_{\mathrm{t}} / \mathrm{mol} \mathrm{dm}^{-3}\right)$ and (b) Residuals against time / $\mathrm{s}$ for the reaction of $p$-nitrocumyl bromide with sodium nitrite (Table 3.6). 

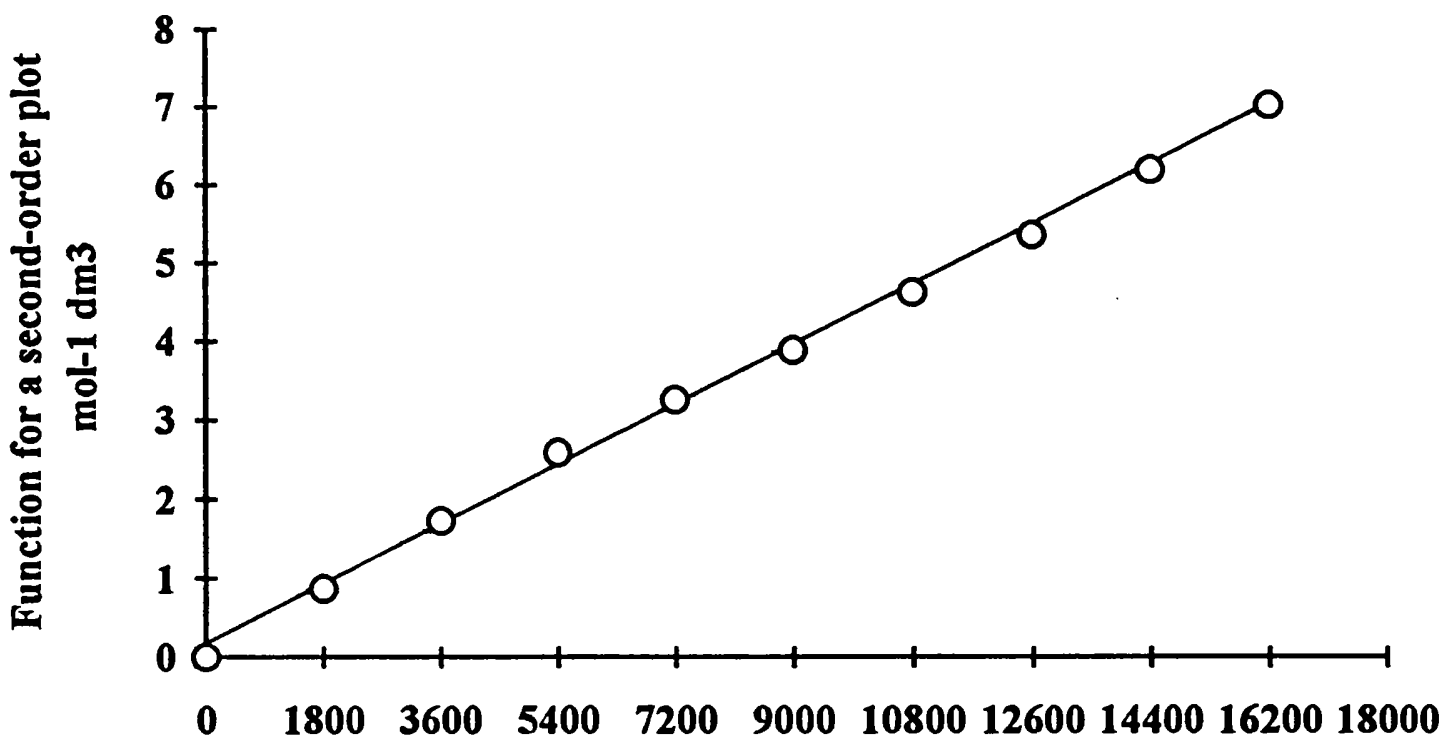

Time / s

(a)

$$
\begin{aligned}
\mathrm{k}_{2}(\mathrm{a} \neq \mathrm{b}) & =4.21 \times 10^{-4} \mathrm{~mol}^{-1} \mathrm{dm}^{3} \mathrm{~s}^{-1} \\
\mathrm{r} & =0.9991 \\
\sigma & =1.50 \%
\end{aligned}
$$

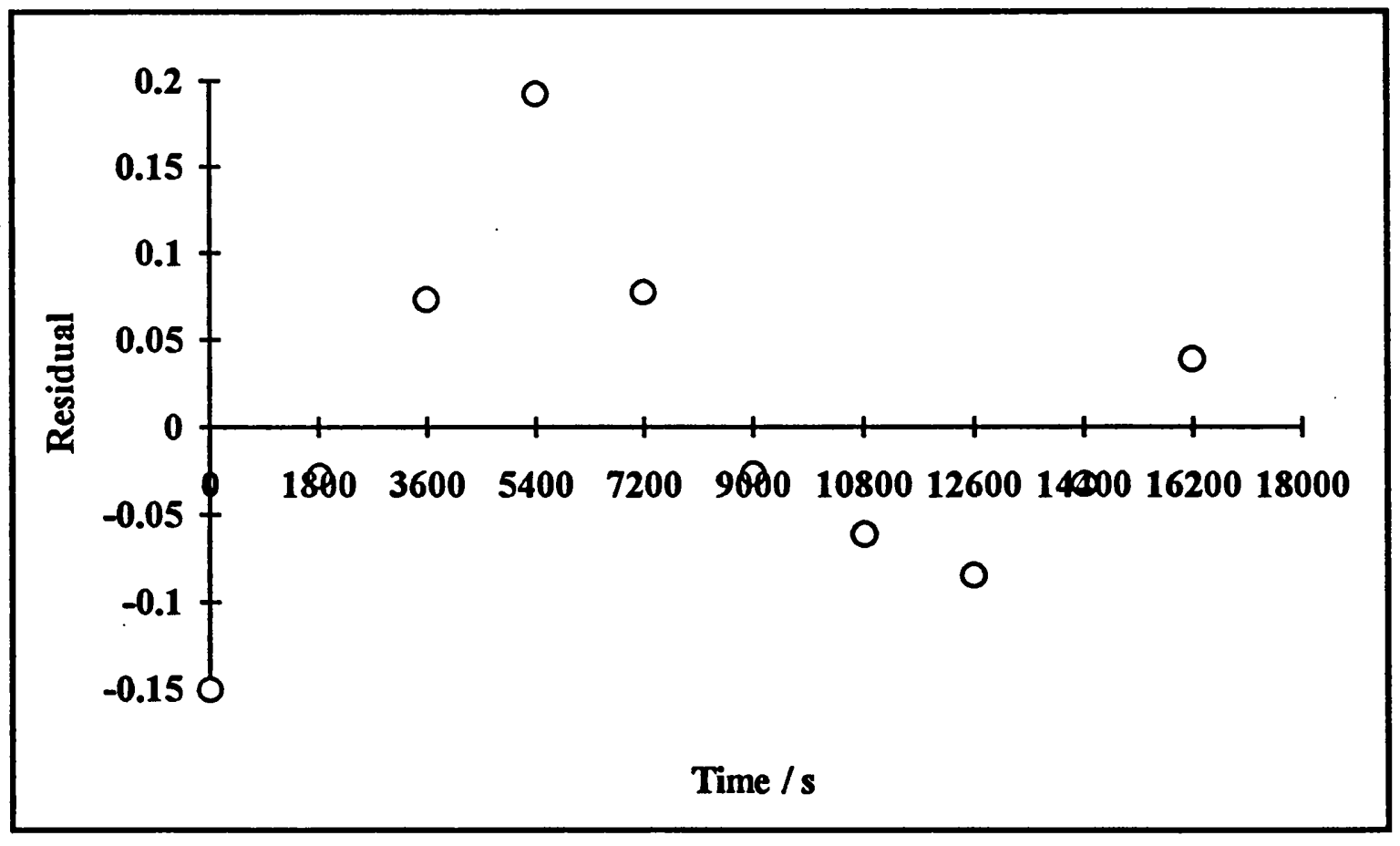

(b)

\section{Figure 3.14}

Plots of (a) Function for second-order plot $/ \mathrm{mol}^{-1} \mathrm{dm}^{-3}$ and (b) Residuals against time / $s$ for the reaction of $p$-nitrocumyl bromide with sodium nitrite (Table 3.6). 
Table 3.7

A summary of first and second order rate constants with their corresponding correlation coefficients, $r$, and standard errors, $\sigma$, for the reaction of $p$-nitrocumyl bromide with sodium nitrite (Tables 3.1, 3.2, 3.3, 3.4, 3.5 and 3.6).

\begin{tabular}{|c|c|c|c|c|c|c|}
\hline $\begin{array}{l}{\left[\mathrm{NaNO}_{2}\right]_{0}} \\
/ \mathrm{mol} \mathrm{dm}^{-3}\end{array}$ & $\begin{array}{l}{[R B r]_{0} /} \\
\mathrm{mol} \mathrm{dm}^{-3}\end{array}$ & $\begin{array}{r}{\left[\mathrm{NaClO}_{4}\right]_{6}} \\
/ \mathrm{mol} \mathrm{dm}^{-3}\end{array}$ & $\begin{array}{c}10^{4} k_{1} / \\
s^{-1}\end{array}$ & $\begin{array}{c}\mathbf{r} \\
\sigma / \%\end{array}$ & $\begin{array}{c}10^{4} k_{2} / \\
\mathrm{dm}^{3} \mathrm{mor}^{-1} \mathrm{~s}^{-1}\end{array}$ & $\begin{array}{c}\mathbf{r} \\
\sigma / \%\end{array}$ \\
\hline 1.00 & 0.20 & 0.00 & 3.15 & $\begin{array}{c}0.9986 \\
1.86\end{array}$ & 3.48 & $\begin{array}{c}0.9994 \\
1.26\end{array}$ \\
\hline 0.80 & 0.20 & 0.20 & 2.32 & $\begin{array}{c}0.9987 \\
1.79\end{array}$ & 3.27 & $\begin{array}{c}0.9996 \\
1.02\end{array}$ \\
\hline 0.60 & 0.20 & 0.40 & 1.52 & $\begin{array}{c}0.9996 \\
1.04\end{array}$ & 2.98 & $\begin{array}{c}0.9996 \\
1.04\end{array}$ \\
\hline 0.40 & 0.20 & 0.60 & 0.788 & $\begin{array}{c}0.9987 \\
1.79\end{array}$ & 2.40 & $\begin{array}{c}0.9996 \\
0.96\end{array}$ \\
\hline 0.20 & 0.20 & 0.80 & 0.591 & $\begin{array}{c}0.9992 \\
1.40\end{array}$ & 7.36 & $\begin{array}{c}0.9754 \\
7.98\end{array}$ \\
\hline 0.20 & 0.10 & 0.80 & 0.661 & $\begin{array}{c}0.9961 \\
3.14\end{array}$ & 4.21 & $\begin{array}{c}0.9991 \\
1.50\end{array}$ \\
\hline
\end{tabular}

\section{Table 3.8}

A summary of first and second order rate constants (Isolated points deleted) ${ }^{*}$ with their corresponding correlation coefficients, $r$, and standard errors, $\sigma$, for the reaction of $p$ nitrocumyl bromide with sodium nitrite (Tables 3.1, 3.2, 3.3, 3.4, 3.5 and 3.6).

\begin{tabular}{|c|c|c|c|c|c|c|}
\hline $\begin{array}{l}{\left[\mathrm{NaNO}_{2}\right]_{0}} \\
/ \mathrm{mol} \mathrm{dm}^{-3}\end{array}$ & $\begin{array}{l}{[R B r]_{0} /} \\
\mathrm{mol} \mathrm{dm}^{-3}\end{array}$ & $\begin{array}{r}{\left[\mathrm{NaClO}_{4}\right]_{0}} \\
/ \mathrm{mol} \mathrm{dm}^{-3}\end{array}$ & $\begin{array}{c}10^{4} k_{1}^{*} / \\
s^{-1}\end{array}$ & $\begin{array}{c}\mathbf{r}^{*} \\
\sigma^{*} / \%\end{array}$ & $\begin{array}{c}10^{4} k_{2}^{*} / \\
\mathrm{dm}^{3} \mathrm{~mol}^{-1} \mathrm{~g}^{-1}\end{array}$ & $\begin{array}{c}r^{*} \\
\sigma^{*} / \%\end{array}$ \\
\hline 1.00 & 0.20 & 0.00 & 3.05 & $\begin{array}{c}1.0000 \\
0.29\end{array}$ & 3.41 & $\begin{array}{c}1.0000 \\
0.37\end{array}$ \\
\hline 0.80 & 0.20 & 0.20 & 2.33 & $\begin{array}{c}0.9993 \\
1.38\end{array}$ & 3.28 & $\begin{array}{c}0.9999 \\
0.48\end{array}$ \\
\hline 0.60 & 0.20 & 0.40 & 1.49 & $\begin{array}{c}0.9999 \\
0.40\end{array}$ & 2.98 & $\begin{array}{c}0.9994 \\
1.31\end{array}$ \\
\hline 0.40 & 0.20 & 0.60 & 0.765 & $\begin{array}{c}0.9997 \\
0.86\end{array}$ & 2.38 & $\begin{array}{c}0.9996 \\
1.11\end{array}$ \\
\hline 0.20 & 0.20 & 0.80 & 0.580 & $\begin{array}{c}0.9995 \\
1.14\end{array}$ & 7.36 & $\begin{array}{c}0.9754 \\
7.98\end{array}$ \\
\hline 0.20 & 0.10 & 0.80 & 0.639 & $\begin{array}{c}0.9986 \\
2.17\end{array}$ & 4.18 & $\begin{array}{c}0.9996 \\
1.13\end{array}$ \\
\hline
\end{tabular}


Any points that were slightly removed from the others were deleted from the data and new rate constants calculated (Table 3.8). The new rate constants are very similar to the old ones, however, their correlation coefficients and corresponding errors are much improved on the old rate constants.

\subsection{The Elimination of $p$-Nitrocumyl Bromide in Dimethyl Sulphoxide}

When $p$-nitrocumyl bromide was treated with a large excess of dimethyl sulphoxide (solvent) at room temperature and over a period of 9 hours the products isolated were the alkene, alcohol and starting material (see section 9.4.7) (Equation 3.7):

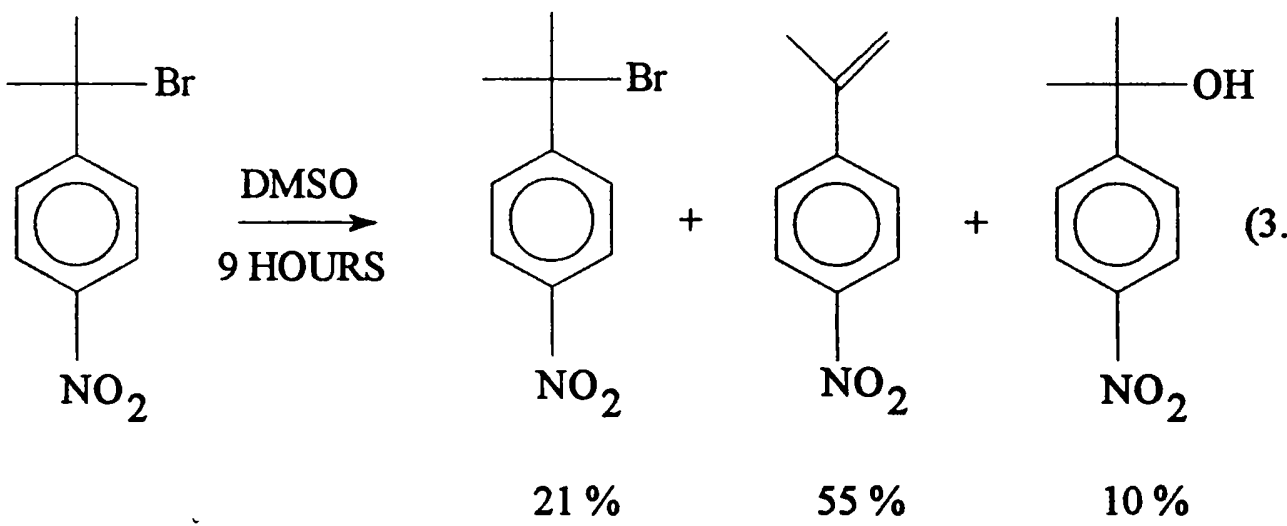

The alkene is formed via an elimination reaction. Dimethyl sulphoxide has two nucleophilic centres ${ }^{54}$ so the elimination could either be an E1 or E2 mechanism. Primary alkyl bromides can be oxidised to aldehydes easily and in good yields with dimethyl sulphoxide. 55,56 The dimethyl sulphoxide may in this case oxidise $p$-nitrocumyl bromide to $p$-nitrocumyl alcohol. As the dimethyl sulphoxide is in large excess the reaction will either be first order or pseudo first order. If this elimination occurs with $p$-nitrocumyl bromide in the absence of sodium nitrite then there is no reason why p-nitrocumyl bromide should not eliminate in the presence of sodium nitrite. So it is important to take into account the elimination of $p$-nitrocumyl bromide.

One kinetic study was performed; the initial concentration of $p$-nitrocumyl bromide was equal to the initial concentration used in section 3.4. No sodium nitrite was 
added but the ionic strength of the reaction solution was again held essentially constant by the addition of sodium perchlorate. The concentrations of $p$-nitrocumyl bromide at given times, derived from this kinetic study, are presented in Table 3.9. As the solvent was in excess, a rate coefficient was calculated assuming that the reaction was first order with respect to $p$-nitrocumyl bromide (Figure 3.15).

For the elimination of $p$-nitrocumyl bromide in dimethyl sulphoxide, the plot for an overall first order reaction is a very good fit. When the residuals are examined it can be seen that the pattern is fairly random with the very first point slightly removed from others. The first order rate constant obtained for this elimination $\left(k_{\mathrm{s}}\right)$ indicates that this process is moderately slow compared to the reaction between sodium nitrite and $p$ nitrocumyl bromide.

\subsection{Improved Model}

The rate of reaction for the reaction between sodium nitrite and $p$-nitrocumyl bromide is dependent on both the sodium nitrite and p-nitrocumyl bromide concentrations, however, it does not obey an overall second order model. A model incorporating the elimination of $p$-nitrocumyl bromide in dimethyl sulphoxide can easily be formulated. If a reaction mechanism involves a reactant which can undergo two or more reactions independently and concurrently, the reactions are called parallel or side reactions.

In complicated reactions, it is often desirable to adopt other methods for at least a preliminary survey of kinetics. The initial reaction rate often provides helpful information, for in a sufficiently slow reaction, the rate $-\left(d[\mathrm{RBr}]_{\mathrm{t}} / d t\right)$ can be found with some precision before there has been any extensive chemical change.

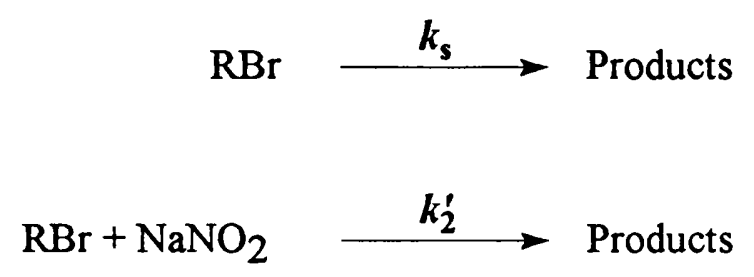


Table 3.9

Temperature

Solvent

$[\mathrm{RBr}]_{0}$

$\left[\mathrm{NaNO}_{2}\right]_{0}$

$\left[\mathrm{NaClO}_{4}\right]_{0}$
The Elimination of $p$-Nitrocumyl Bromide in Dimethyl

Sulphoxide

$30^{\circ} \mathrm{C}$

$99.9 \% \mathrm{C}_{2} \mathrm{D}_{6} \mathrm{SO}$

$0.20 \mathrm{~mol} \mathrm{dm}^{-3}$

$\left(\mathrm{R}=\mathrm{C}_{9} \mathrm{H}_{10} \mathrm{NO}_{2}\right)$

$0.00 \mathrm{~mol} \mathrm{dm}^{-3}$

$1.00 \mathrm{~mol} \mathrm{dm}^{-3}$

\begin{tabular}{|c|c|c|}
\hline Time Range $/ \mathrm{s}$ & Mid-point Time $/ \mathrm{s}$ & {$[\mathrm{RBr}]_{\mathrm{t}} / \mathrm{mol} \mathrm{dm}^{-3}$} \\
\hline 0 & 0 & 0.200 \\
\hline $3592-3608$ & 3600 & 0.184 \\
\hline $7192-7208$ & 7200 & 0.160 \\
\hline $10792-10808$ & 10800 & 0.137 \\
\hline $14392-14408$ & 14400 & 0.116 \\
\hline $17992-18008$ & 18000 & 0.099 \\
\hline $21592-21608$ & 21600 & 0.085 \\
\hline $25192-25208$ & 25200 & 0.072 \\
\hline $28792-28808$ & 28800 & 0.062 \\
\hline $32392-32408$ & 32400 & 0.053 \\
\hline
\end{tabular}




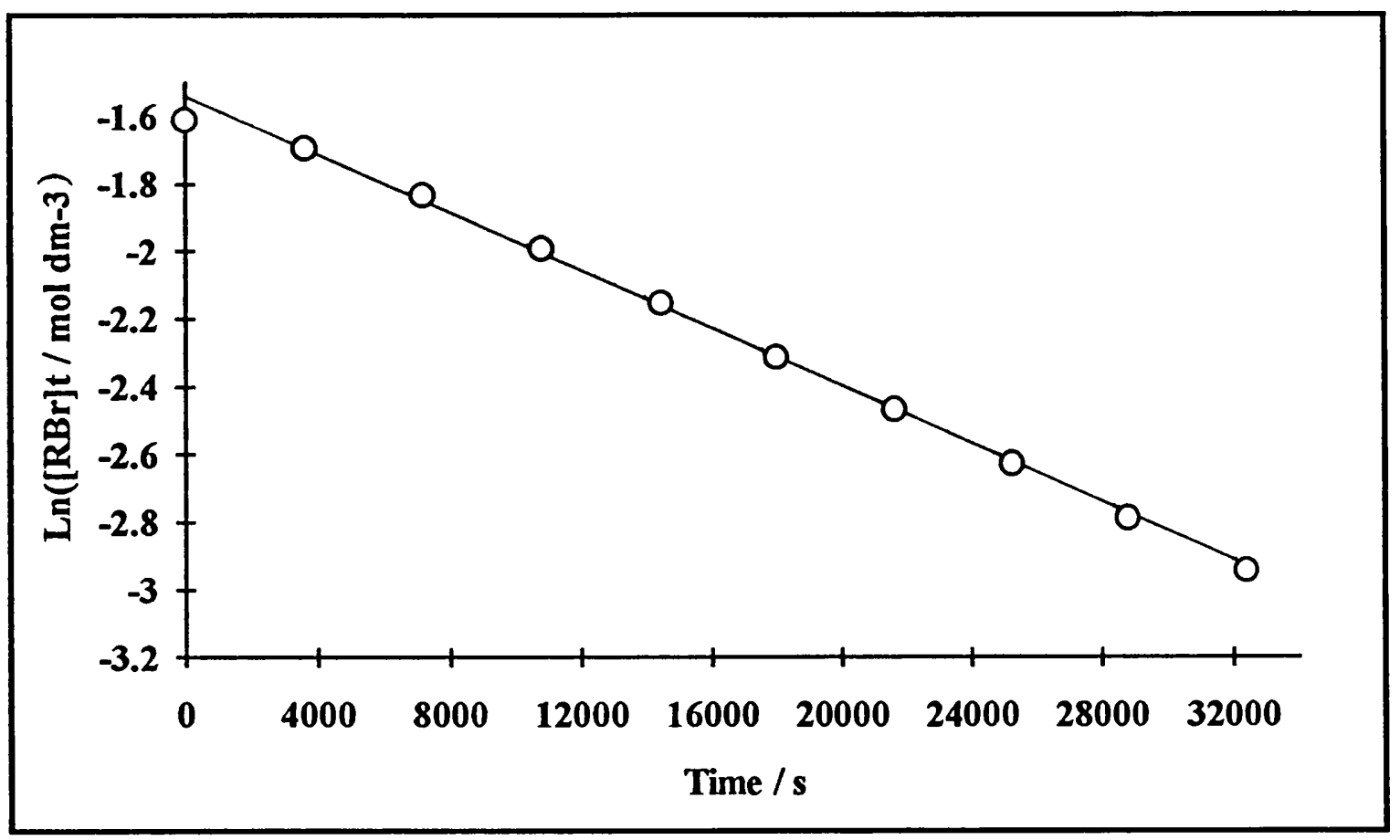

(a)

$$
\begin{aligned}
& \mathrm{k}_{1}=4.25 \times 10^{-5} \mathrm{~s}^{-1} \\
& \mathrm{r}=0.9987 \\
& \sigma=1.81 \%
\end{aligned}
$$

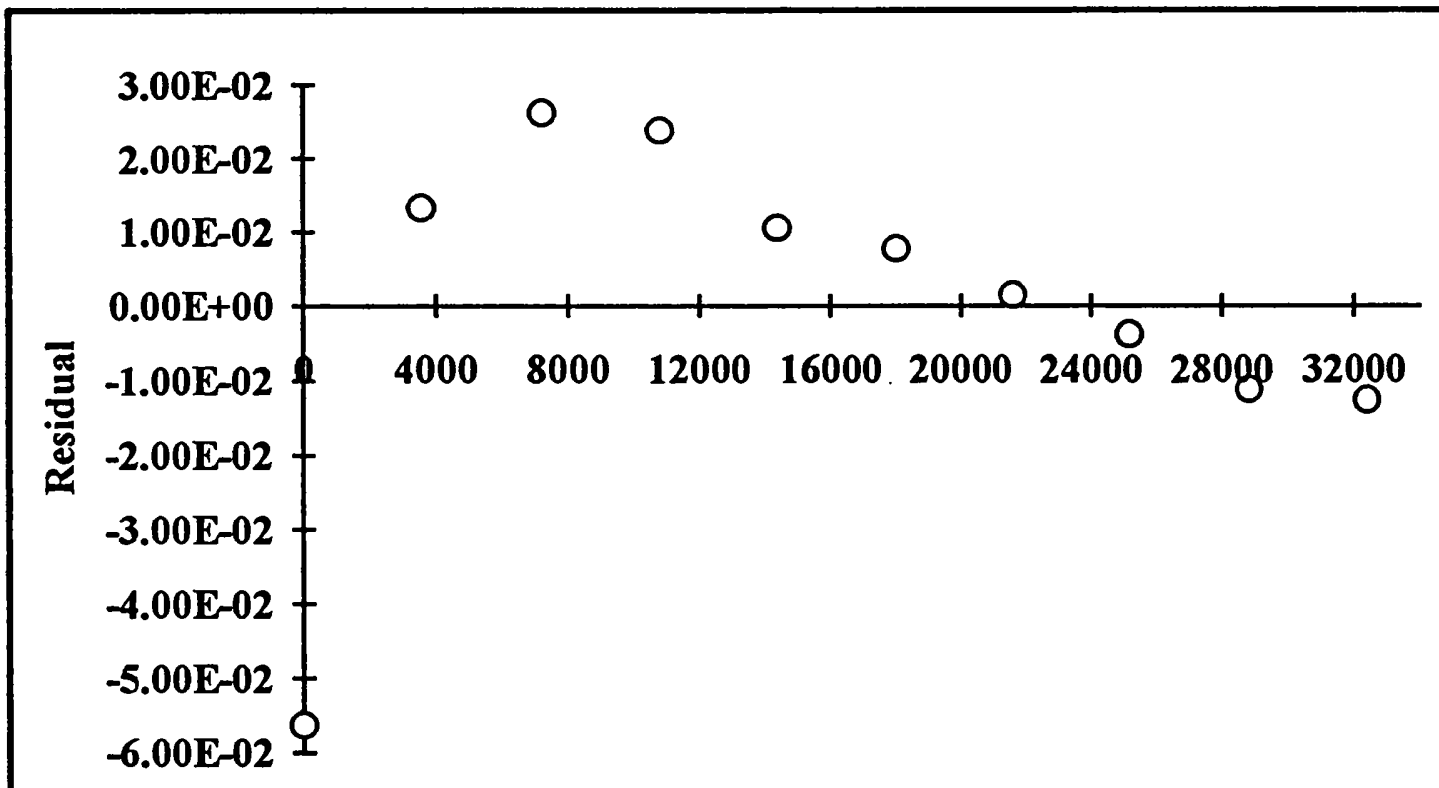

Time / s

(b)

\section{Figure 3.15}

Plots of (a) $\mathrm{Ln}\left([\mathrm{RBr}]_{\mathrm{t}} / \mathrm{mol} \mathrm{dm}^{-3}\right)$ and (b) Residuals against time / $\mathrm{s}$ for the elimination of $p$-nitrocumyl bromide in dimethyl sulphoxide. 
Combining Equations (3.8) and (3.9) the rate can be written quite generally as Equation (3.10):

$$
-\left(d[\mathrm{RBr}]_{\mathrm{t}} / d t\right)=k_{\mathrm{s}}[\mathrm{RBr}]_{\mathrm{t}}+k_{2}^{\prime}[\mathrm{RBr}]_{\mathrm{t}}\left[\mathrm{NO}_{2}^{-}\right]_{\mathrm{t}}
$$

At time equal to $0 \mathrm{~s}$ the initial rate will be Equation (3.11):

$$
-\left(d[\mathrm{RBr}]_{0} / d t\right)=k_{\mathrm{s}}[\mathrm{RBr}]_{0}+k_{2}^{\prime}[\mathrm{RBr}]_{0}\left[\mathrm{NO}_{2}^{-}\right]_{0}
$$

Equation 3.11 can be rearranged into Equation 3.12:

$$
-\left(d[\mathrm{RBr}]_{0} / d t\right) /[\mathrm{RBr}]_{0}=k_{\mathrm{s}}+k_{2}^{\prime}\left[\mathrm{NO}_{2}^{-}\right]_{0}
$$

Making the simplification that the initial concentration of free nitrite ion is equal to the initial concentration of sodium nitrite, then rate constants can be obtained by plotting $-\left(d[\mathrm{RBr}]_{0} / d t\right) /[\mathrm{RBr}]_{0}$ versus $\left[\mathrm{NO}_{2}^{-}\right]_{0}$ (Figure 3.3).

The initial slopes were calculated by first fitting third order polynomials to the disappearance of $p$-nitrocumyl bromide. If a kinetic run had its first point obviously removed from others then the point was deleted and a third order function fitted to the remaining points. The initial slopes were then evaluated by substituting time equal to zero into the differentiated polynomials. The point for the elimination of $p$-nitrocumyl bromide $\left(\left[\mathrm{NO}_{2}^{-}\right]_{0}=0.00 \mathrm{~mol} \mathrm{dm}-3\right)$ was included in Figure 3.16. It is fairly obvious that the plot in Figure 3.16 is a poor fit to Equation 3.12. If the plot were a good fit to Equation 3.12, we would expect to find a straight line relationship as opposed to a curved one. A concurrent first and second order model does not fit the experimental data so a new model has to be found. The next chapter will deal with finding a kinetic model that comfortably fits the data obtained from the various kinetic runs. 


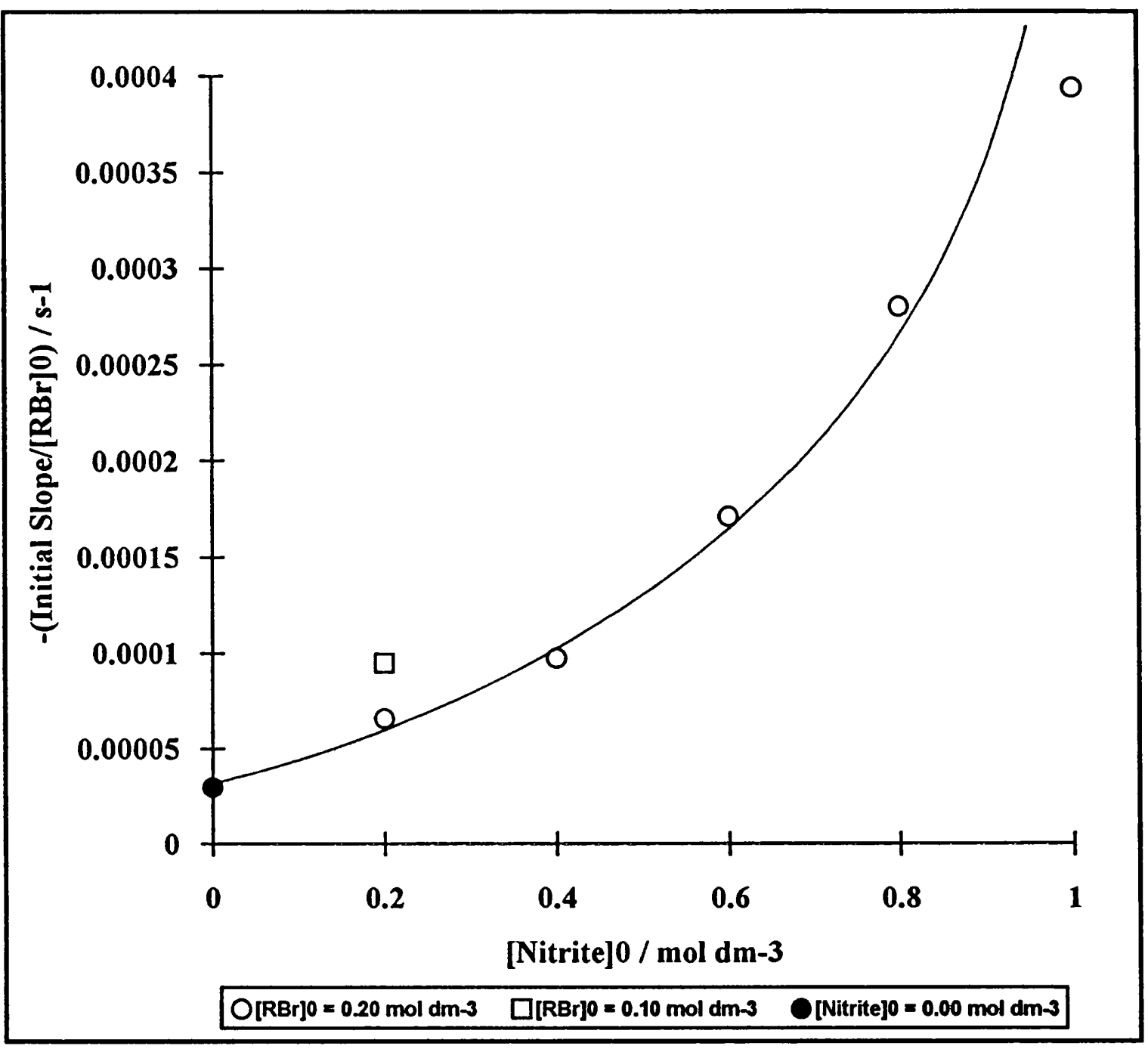

\section{Figure 3.16}

A plot of $-\left(d[\mathrm{RBr}]_{0} / d t\right) /[\mathrm{RBr}]_{0}$ versus $\left[\mathrm{NO}_{2}^{-}\right]_{0}$ for the data contained in Tables 3.1, $3.2,3.3,3.4,3.5,3.6$, and 3.9. 


\section{CHAPTER 4}

\section{A Kinetic Study of the Reaction of Sodium Nitrite with p-Nitrocumyl Bromide in \\ Dimethyl Sulphoxide}

PART 2

\subsection{Introduction}

A new model is necessary in order to explain the kinetic experimental data. In this chapter a new model will be postulated that not only fits to the disappearance of $p$ nitrocumyl bromide, it also fits to the creation of products. This chapter only deals with the kinetic model and the derivation of any rate equations. In chapter 5 , the possible mechanisms that may give rise to the observed kinetics will be discussed

The curved plot in Figure 3.16 suggests that the rate of reaction depends on an order of nitrite higher than one. There are cases in the literature of third order nucleophilic substitution reactions of the type (Scheme 4.1):

$$
\begin{gathered}
\mathrm{A}+\mathrm{B}=\text { Products } \\
-(\mathrm{d}[\mathrm{A}] / \mathrm{dt})=k_{3}[\mathrm{~A}]^{2}[\mathrm{~B}]
\end{gathered}
$$

Scheme 4.1

An example of Scheme 4.1 has been given by C. Gardener Swain. 57 Swain showed that triphenyl methyl (trityl) chloride reacted with methanol in dry benzene solution to give termolecular kinetics. This example will be discussed in more detail in chapter 5 . 


\subsection{Initial Slopes for Concurrent First and Third Order Reactions}

Assuming we have concurrent first and third order reactions (of the type in

Scheme 4.1) then:

$$
-\left(d[\mathrm{RBr}]_{\mathrm{t}} / d t\right)=k_{\mathrm{S}}[\mathrm{RBr}]_{\mathrm{t}}+k_{3}^{\prime}[\mathrm{RBr}]_{\mathrm{t}}\left[\mathrm{NO}_{2}^{-}\right]_{\mathfrak{t}}^{2}
$$

At time equal to $0 \mathrm{~s}$ the initial rate will be Equation (4.2):

$$
-\left(d[\mathrm{RBr}]_{0} / d t\right)=k_{\mathrm{s}}[\mathrm{RBr}]_{0}+k_{3}^{\prime}[\mathrm{RBr}]_{0}\left[\mathrm{NO}_{2}^{-}\right]_{0}^{2}
$$

Equation 4.2 can be rearranged into Equation 4.3:

$$
-\left(d[\mathrm{RBr}]_{0} / d t\right) /[\mathrm{RBr}]_{0}=k_{\mathrm{s}}+k_{3}^{\prime}\left[\mathrm{NO}_{2}^{-}\right]_{0}^{2}
$$

Making the simplification that the initial concentration of free nitrite ion is equal to the initial concentration of sodium nitrite, then rate constants can be obtained by plotting $-\left(d[\mathrm{RBr}]_{0} / d t\right) /[\mathrm{RBr}]_{0}$ versus $\left[\mathrm{NO}_{2}{ }^{-}\right]_{0}{ }^{2}$ (Figure 4.1). A straight line was fitted to the plot in Figure 4.1 using the method of least squares.

The points for the elimination of $p$-nitrocumyl bromide $\left(\left[\mathrm{NO}_{2}{ }^{-}\right]_{0}=0.00 \mathrm{~mol}\right.$ $\mathrm{dm}^{-3}$ ) and the $[\mathrm{RBr}]=0.10 \mathrm{~mol} \mathrm{dm}^{-3}$ kinetic run were included in Figure 4.1, but were not used to determine the least squares fit. The point for the elimination of $p$-nitrocumyl bromide fits nicely on the straight line obtained, however, the point for the $[\mathrm{RBr}]=0.10$ mol dm${ }^{-3}$ kinetic run lies off the line. For a $0.10 \mathrm{~mol} \mathrm{dm}^{-3}$ substrate solution, larger errors are found in the ${ }^{1} \mathrm{H}$ n.m.r. integrals compared to solutions of higher concentration, and this may account for the error entailed. 


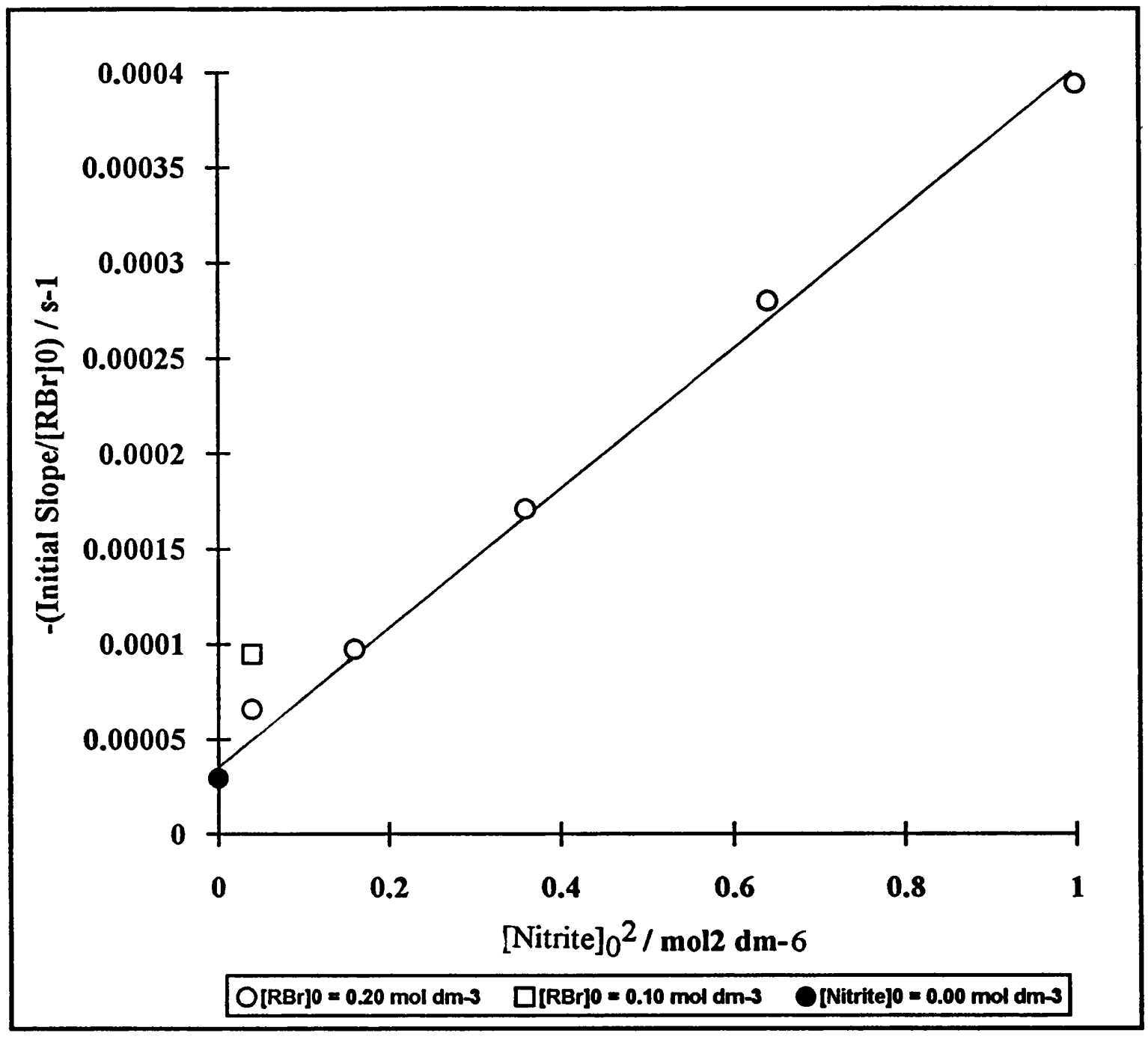

$$
\begin{aligned}
k_{\mathrm{s}} & =4.78 \times 10^{-5} \mathrm{~s}^{-1} \\
k_{3}^{\prime} & =3.50 \times 10^{-4} \mathrm{~mol}^{-2} \mathrm{dm}^{6} \mathrm{~s}^{-1} \\
\mathrm{r} & =0.9990
\end{aligned}
$$

\section{Figure 4.1}

A plot of $-\left(d[\mathrm{RBr}]_{0} / d t\right) /[\mathrm{RBr}]_{0}$ versus $\left[\mathrm{NO}_{2}^{-}\right]_{0}^{2}$ for the data contained in Tables 3.1, $3.2,3.3,3.4,3.5,3.6$, and 3.9 . 
The model for concurrent first and third order reactions seems to give a very good fit to the data in Tables 3.1, 3.2, 3.3, 3.4, and 3.5 and this is exemplified by the correlation coefficient obtained. As mentioned earlier the method of initial reaction rate is one technique used for a preliminary survey of the kinetics. The technique only gives approximate rate constants but provides a useful starting point for more advanced methods.

\subsection{Product Analysis}

Observing the formation of products within a reaction provides a fair alternative and complement to following the disappearance of the starting materials in determining the overall order of a reaction. Figures $4.2,4.3,4.4,4.5,4.6$ and 4.7 show the formation of products versus time for the various kinetic runs. On examining these Figures it is reasonable to say that the rate of formation of $\alpha, p$-dinitrocumene is dependent on the initial concentration of sodium nitrite. In each Figure an intermediate can be seen, however, this intermediate is not detected when an infinity ${ }^{1} \mathrm{H}$ n.m.r. spectrum is taken. The rate of formation of $p$-nitrocumyl alcohol does not level off like the other products over the time periods concerned. This is a strong indication that the alcohol derives itself from the intermediate. The intermediate in question is undoubtedly $p$-nitrocumyl nitrite which probably reacts with traces of either hydrogen bromide or water; tertiary nitrites are very unstable and usually breakdown to the alcohol. 52

Figure 4.8 compares the formation of $\alpha, p$-dinitrocumene for various different initial molarities of sodium nitrite. Again, it is clear that the rate of formation of $\alpha, p$ dinitrocumene is dependent on the initial concentration of sodium nitrite.

Figure 4.9 compares the combined formation of $p$-nitrocumyl nitrite and $p$ nitrocumyl alcohol for various different initial molarities of sodium nitrite. The problem with comparing just the formation of $p$-nitrocumyl nitrite, for various different initial molarities of sodium nitrite, is that the $p$-nitrocumyl nitrite also decomposes to the alcohol. 


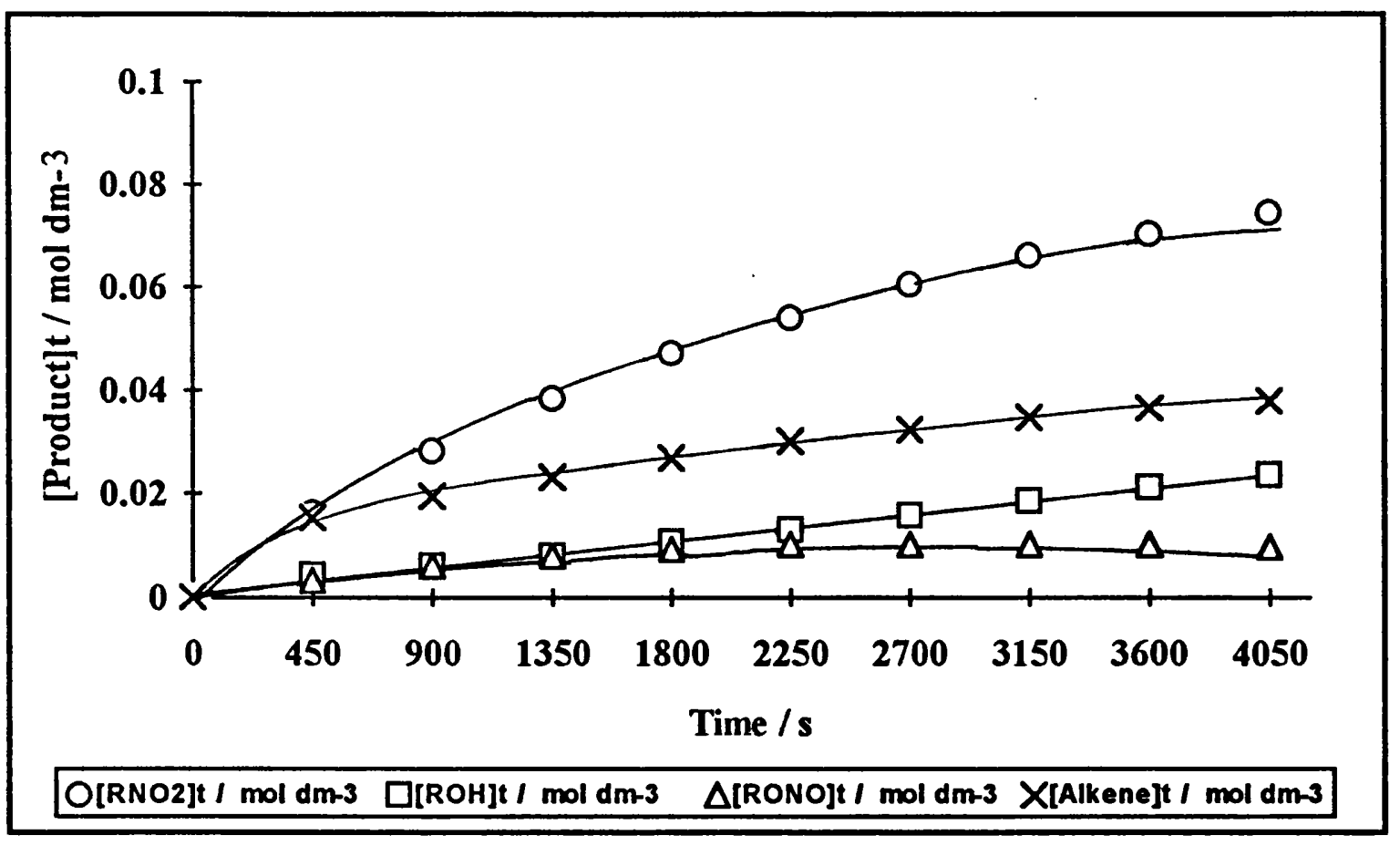

\section{Figure 4.2}

The formation of products for the reaction of sodium nitrite with $p$-nitrocumyl bromide in dimethyl sulphoxide. (Table 3.1; $\left[\mathrm{NaNO}_{2}\right]_{0}=1.00 \mathrm{~mol} \mathrm{dm}^{-3},[\mathrm{RBr}]_{0}=0.20 \mathrm{~mol} \mathrm{dm}^{-3}$, $\left[\mathrm{NaClO}_{4}\right]_{0}=0.00 \mathrm{~mol} \mathrm{dm}^{-3}$ ).

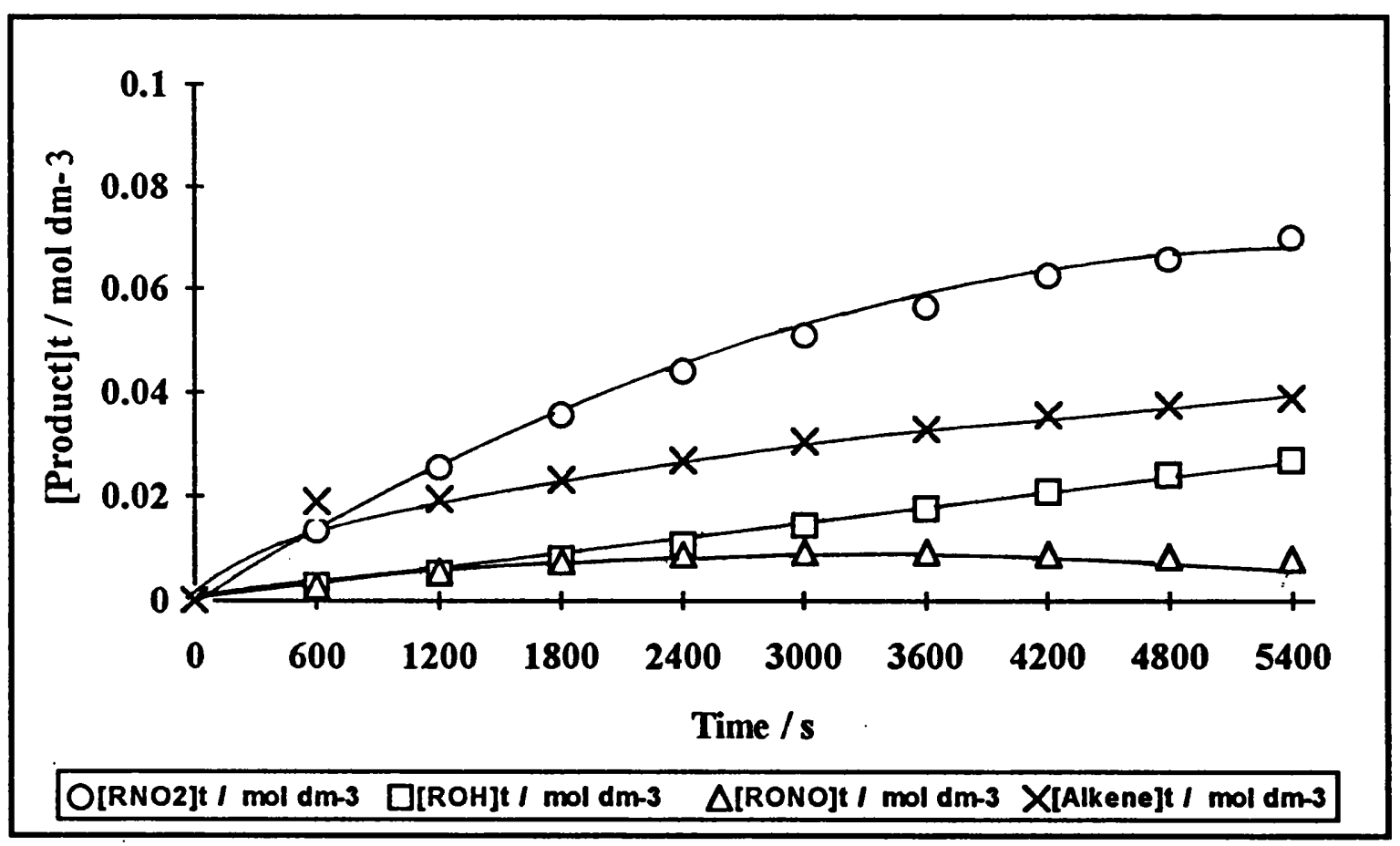

\section{Figure 4.3}

The formation of products for the reaction of sodium nitrite with $p$-nitrocumyl bromide in dimethyl sulphoxide. (Table 3.2; $\left[\mathrm{NaNO}_{2}\right]_{0}=0.80 \mathrm{~mol} \mathrm{dm}^{-3},[\mathrm{RBr}]_{0}=0.20 \mathrm{~mol} \mathrm{dm}^{-3}$, $\left[\mathrm{NaClO}_{4}\right]_{0}=0.20 \mathrm{~mol} \mathrm{dm}^{-3}$ ). 


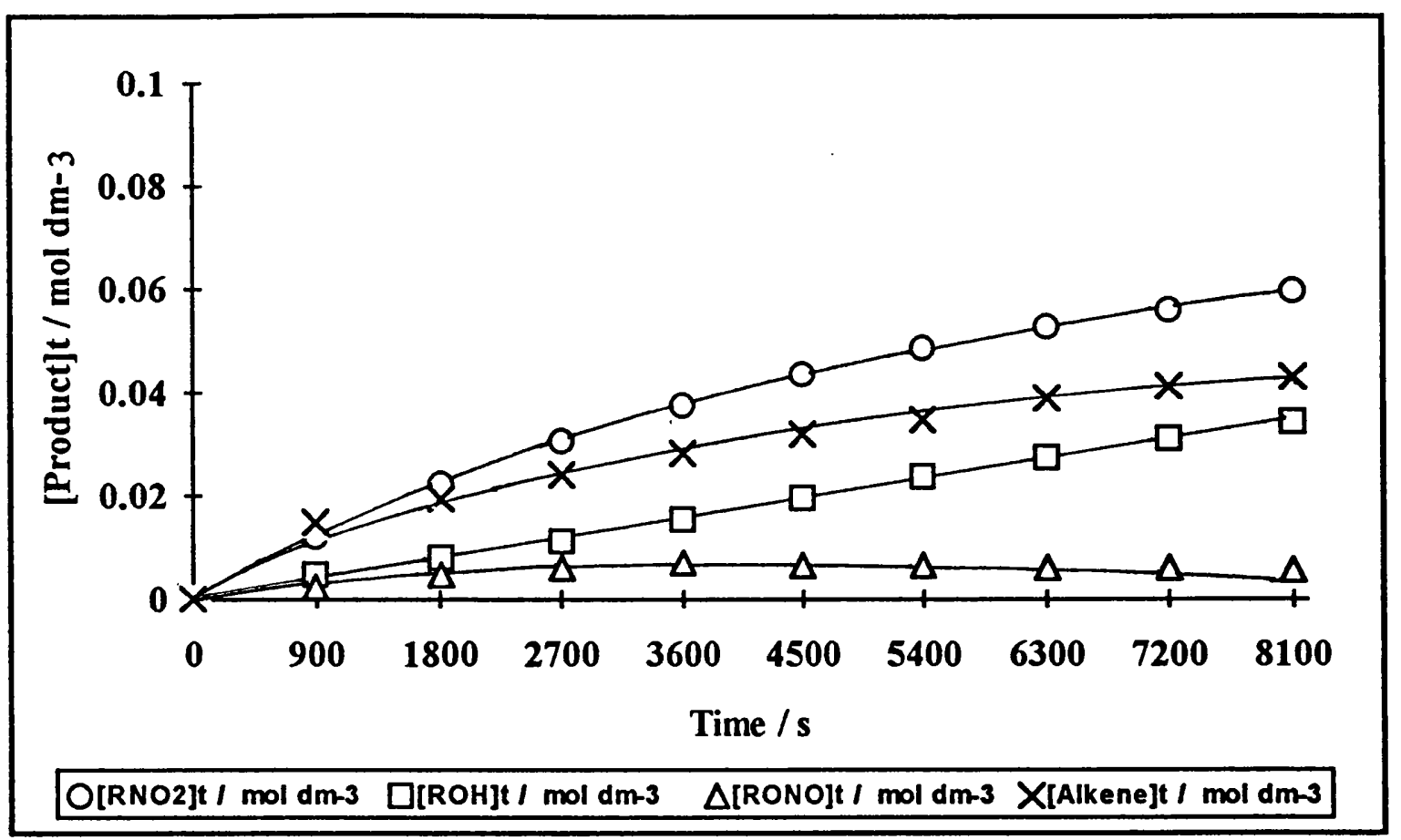

Figure 4.4

The formation of products for the reaction of sodium nitrite with $p$-nitrocumyl bromide in dimethyl sulphoxide. (Table 3.3; $\left[\mathrm{NaNO}_{2}\right]_{0}=0.60 \mathrm{~mol} \mathrm{dm}^{-3},[\mathrm{RBr}]_{0}=0.20 \mathrm{~mol} \mathrm{dm}^{-3}$, $\left[\mathrm{NaClO}_{4}\right]_{0}=0.40 \mathrm{~mol} \mathrm{dm}^{-3}$ ).

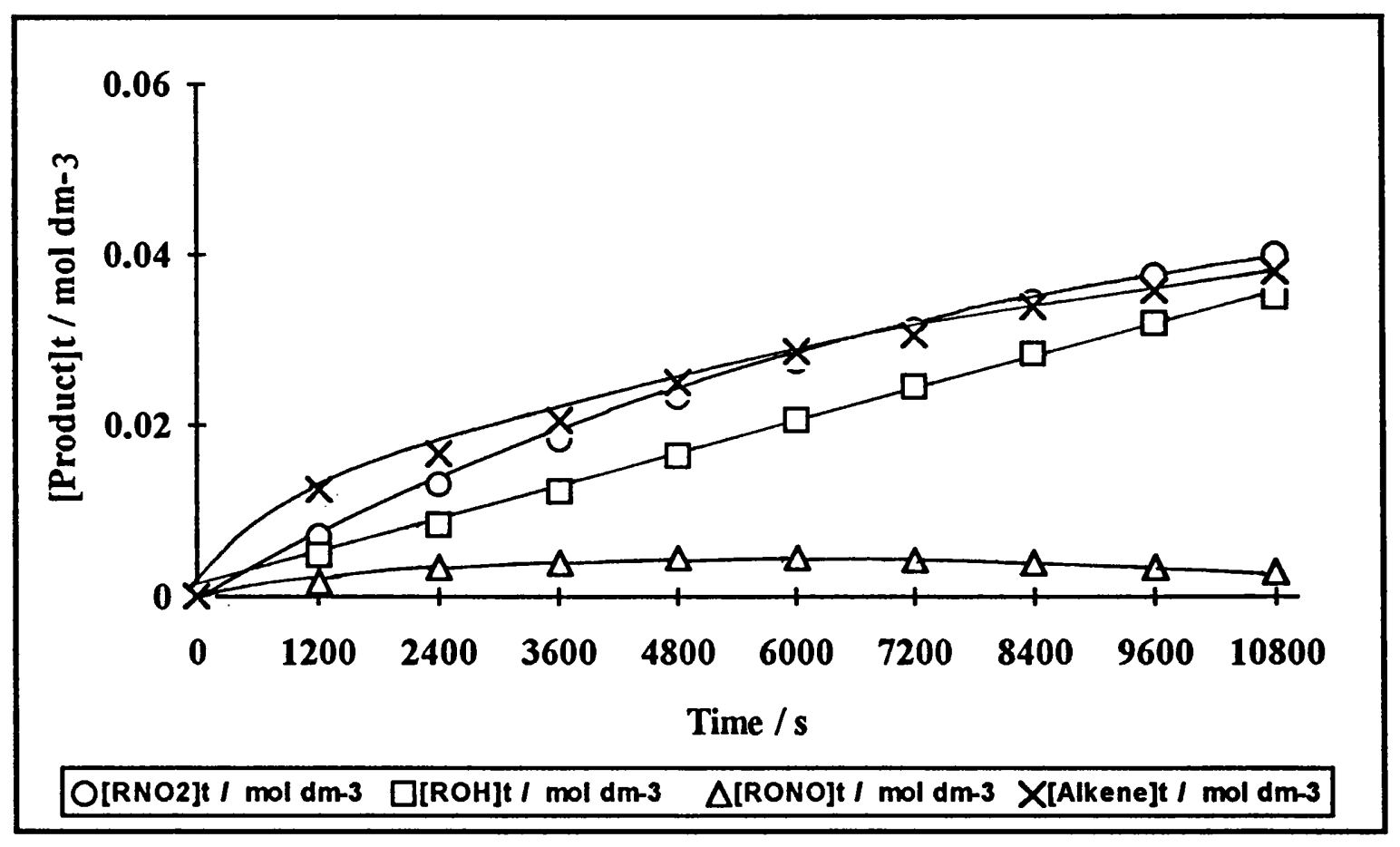

\section{Figure 4.5}

The formation of products for the reaction of sodium nitrite with $p$-nitrocumyl bromide in dimethyl sulphoxide. (Table 3.4; $\left[\mathrm{NaNO}_{2}\right]_{0}=0.40 \mathrm{~mol} \mathrm{dm}^{-3},[\mathrm{RBr}]_{0}=0.20 \mathrm{~mol} \mathrm{dm}^{-3}$, $\left.\left[\mathrm{NaClO}_{4}\right]_{0}=0.60 \mathrm{~mol} \mathrm{dm}^{-3}\right)$. 


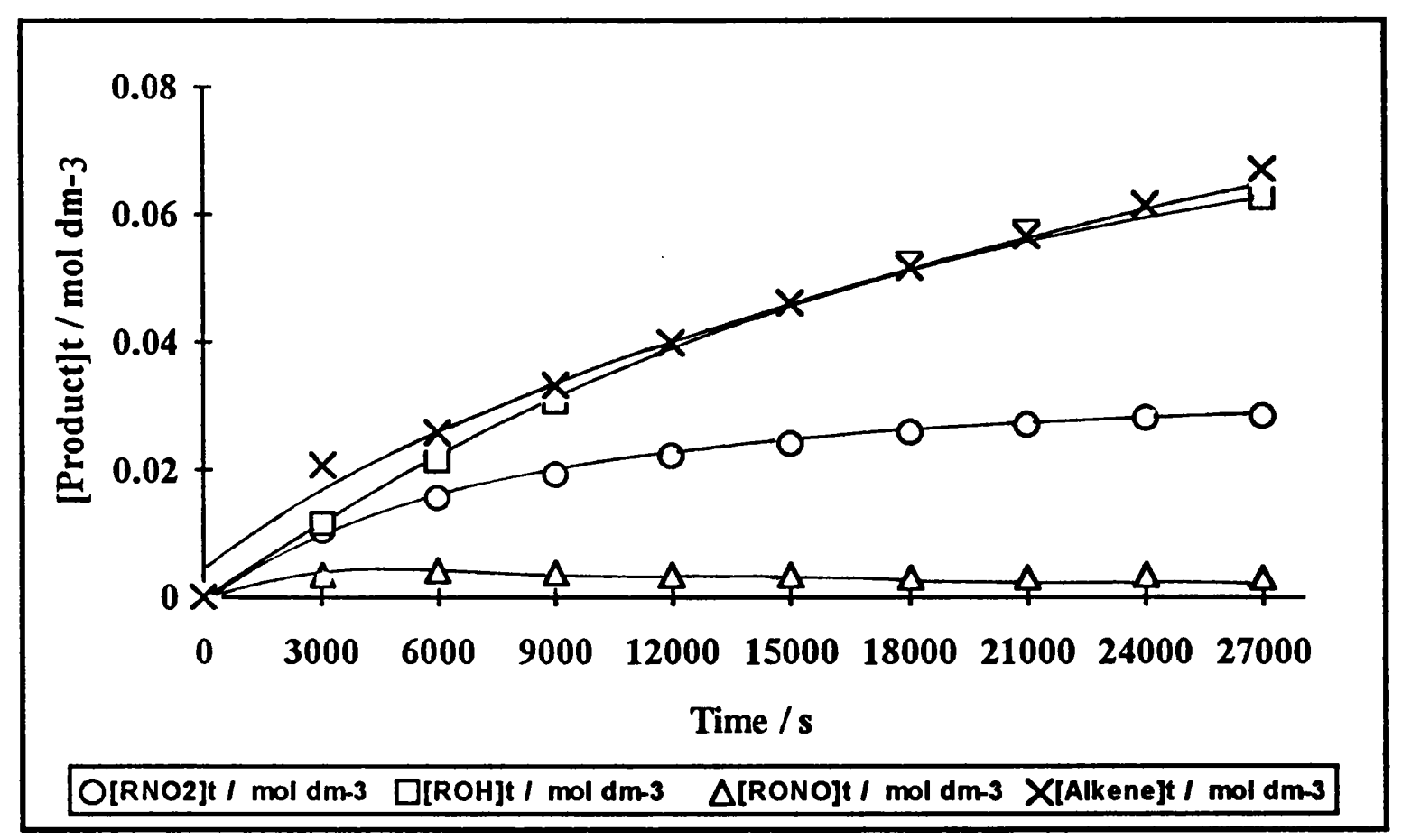

\section{Figure 4.6}

The formation of products for the reaction of sodium nitrite with $p$-nitrocumyl bromide in dimethyl sulphoxide. (Table 3.5; $\left[\mathrm{NaNO}_{2}\right]_{0}=0.20 \mathrm{~mol} \mathrm{dm}^{-3},[\mathrm{RBr}]_{0}=0.20 \mathrm{~mol} \mathrm{dm}^{-3}$, $\left[\mathrm{NaClO}_{4}\right]_{0}=0.80 \mathrm{~mol} \mathrm{dm}^{-3}$ ).

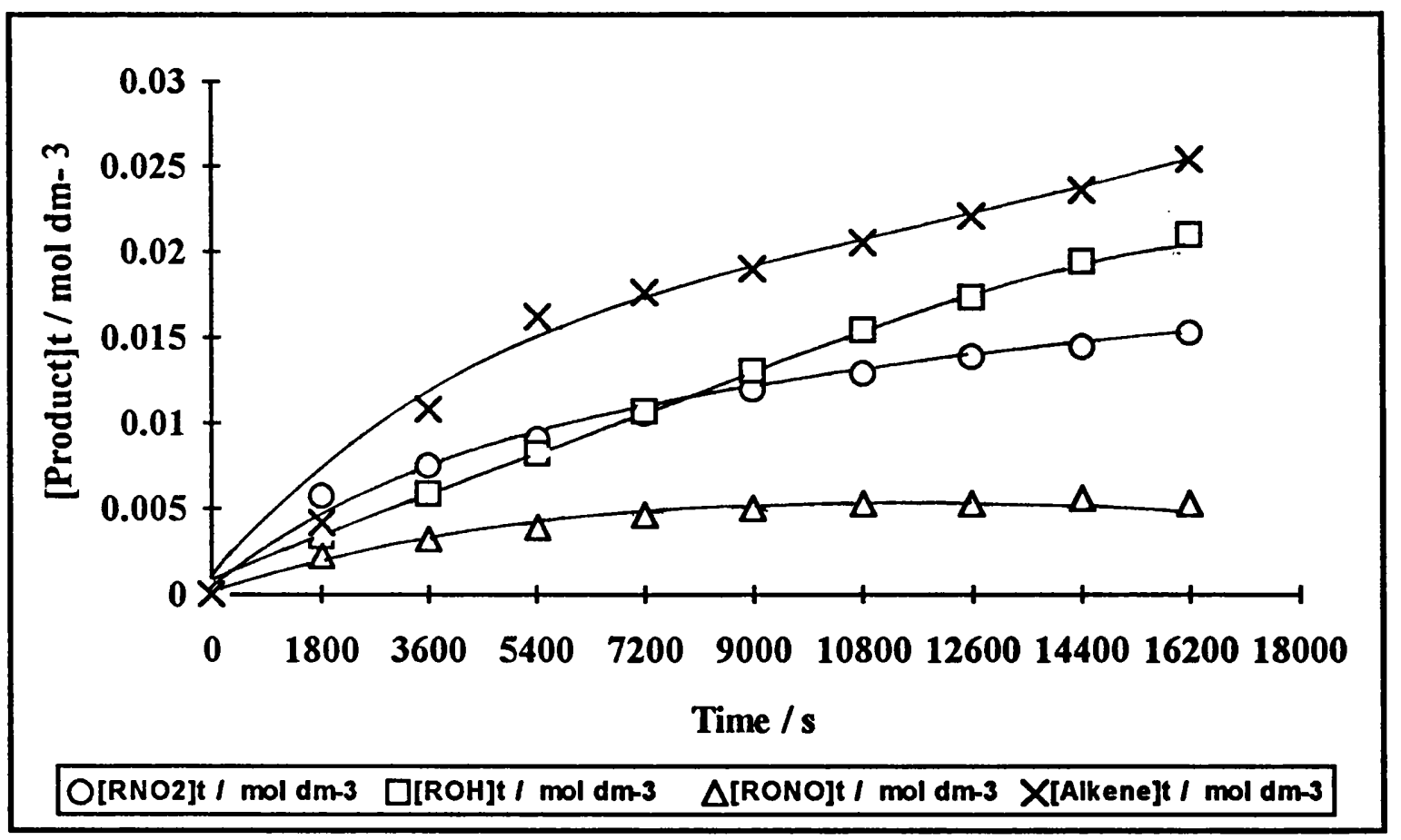

Figure 4.7

The formation of products for the reaction of sodium nitrite with $p$-nitrocumyl bromide in dimethyl sulphoxide. (Table 3.6; $\left[\mathrm{NaNO}_{2}\right]_{0}=0.20 \mathrm{~mol} \mathrm{dm}^{-3},[\mathrm{RBr}]_{0}=0.10 \mathrm{~mol} \mathrm{dm}^{-3}$, $\left.\left[\mathrm{NaClO}_{4}\right]_{0}=0.80 \mathrm{~mol} \mathrm{dm}^{-3}\right)$. 
On examining Figure 4.9, it is disputable that the rate of formation of oxygen alkylated products is dependent on the initial concentration of sodium nitrite. Included in Figure 4.9 , is the formation of alcohol derived from the elimination of $p$-nitrocumyl bromide in dimethyl sulphoxide. This formation is very slow up to a period of $5000 \mathrm{~s}$, but increases significantly after that time period.

Figure 4.10 compares the formation of $p$-nitro- $\alpha$-methylstyrene for various different initial molarities of sodium nitrite. It is disputable that the rate of formation of $p$ nitro- $\alpha$-methylstyrene is dependent on the initial concentration of sodium nitrite. It can be seen that the initial rate of formation of the alkene, based on the curve fitted, is very large. This is due to a modicum of the $p$-nitro- $\alpha$-methylstyrene being formed prior to mixing, via the elimination of $p$-nitrocumyl bromide in the substrate solution.

Table 4.1 displays the percentage yields of products for the various kinetic runs. There is a noticeable trend within the table; The percentage yield of $\alpha, p$-dinitrocumene decreases slowly at first, and then more significantly as the initial concentration of sodium nitrite decreases. Both the percentage yield of $p$-nitrocumyl alcohol and $p$-nitro- $\alpha$ methylstyrene increase with decreasing initial concentration of sodium nitrite. These two products increase slowly at first, and then more significantly as the initial concentration of sodium nitrite decreases. 


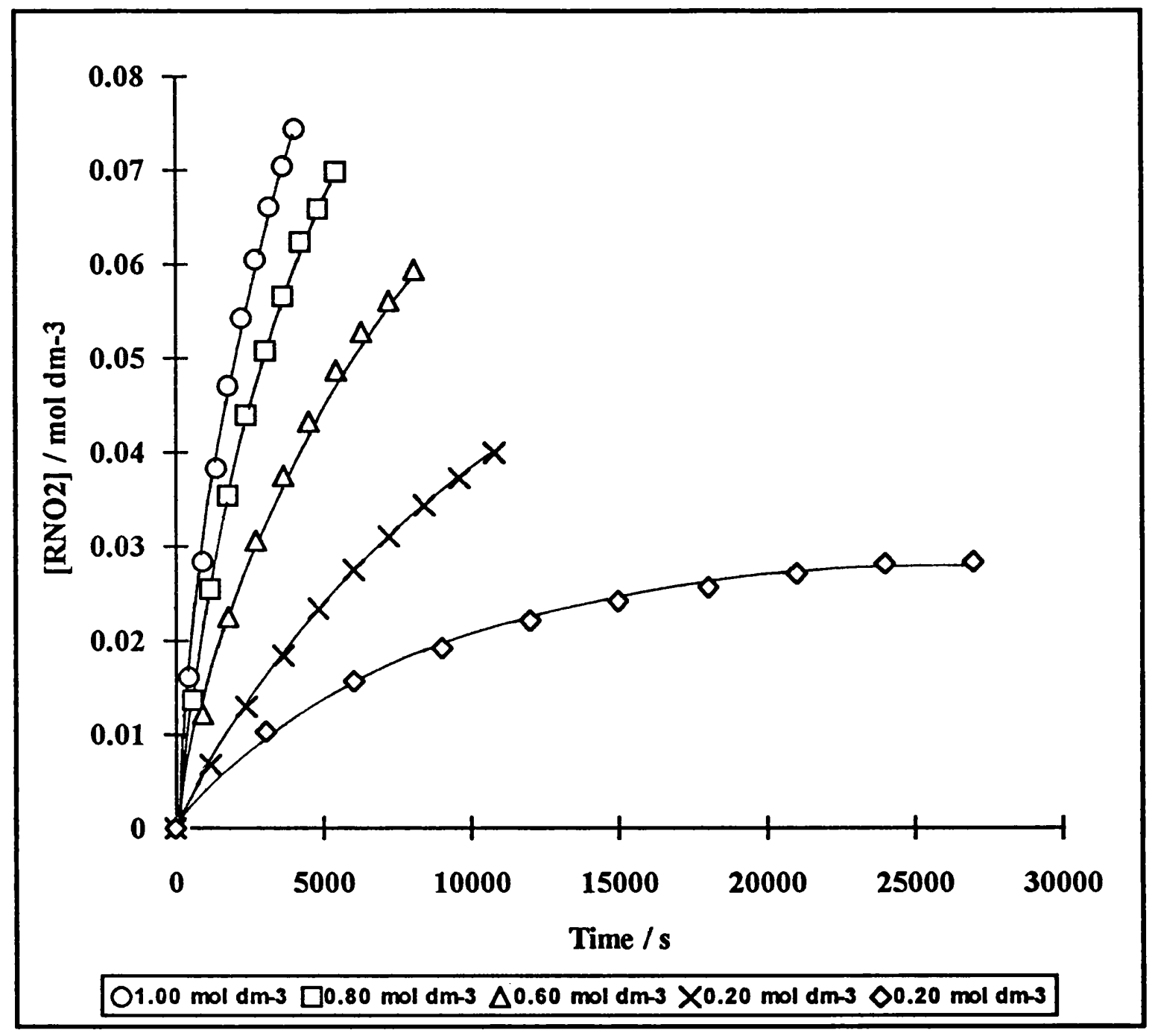

\section{Figure 4.8}

A comparison of the formation of $\alpha, p$-dinitrocumene for various different initial molarities of sodium nitrite (Tables 3.1, 3.2, 3.3, 3.4 and 3.5). 


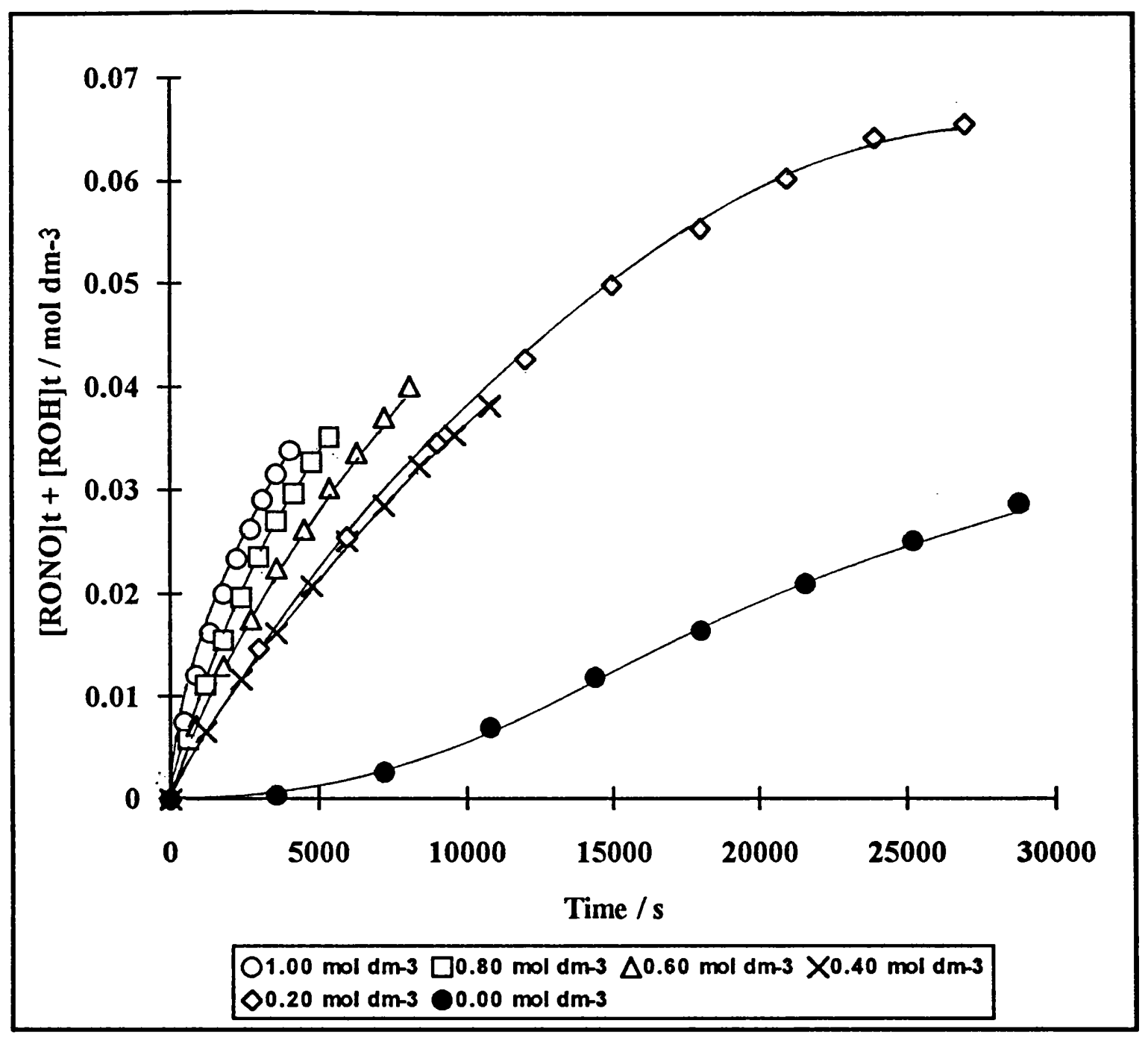

Figure 4.9

A comparison of the formation of ( $p$-nitrocumyl alcohol $+p$-nitrocumyl nitrite) for various different initial molarities of sodium nitrite (Tables 3.1, 3.2, 3.3, 3.4, 3.5 and 3.9). 


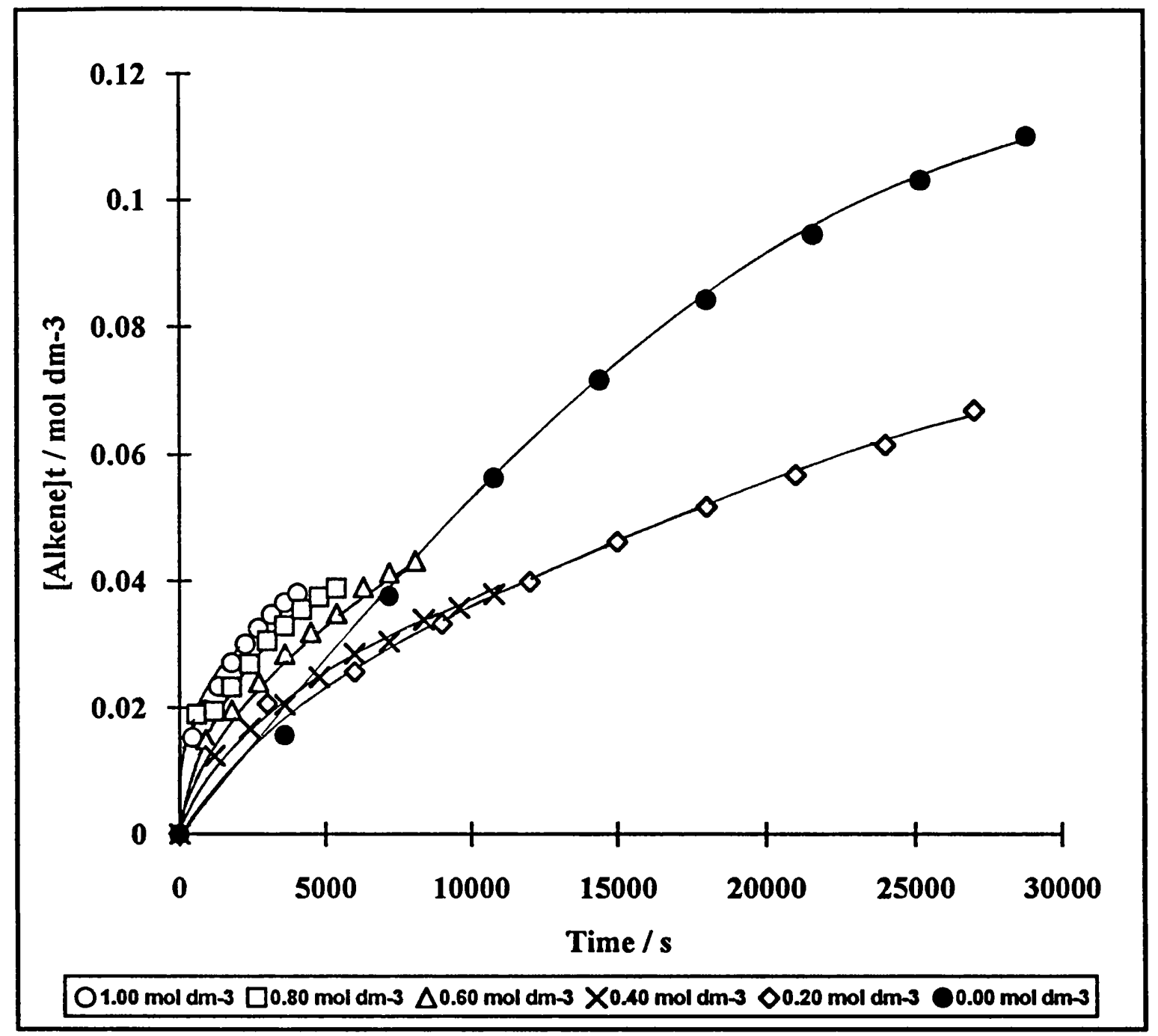

\section{Figure 4.10}

A comparison of the formation of $p$-nitro- $\alpha$-methylstyrene for various different initial molarities of sodium nitrite (Tables 3.1, 3.2, 3.3, 3.4, 3.5 and 3.9). 


\section{Table 4.1}

A comparison of product percentage yields ${ }^{*}$ for the reaction of $p$-nitrocumyl bromide with sodium nitrite in dimethyl sulphoxide.

("Product percentage yields obtained via ${ }^{1} \mathrm{H}$ n.m.r. spectroscopy of the various reaction solutions at infinity).

\begin{tabular}{|c|c|c|c|c|c|}
\hline $\begin{array}{c}{\left[\mathrm{NaNO}_{2}\right]_{0} /} \\
\mathrm{mol} \mathrm{dm}^{-3}\end{array}$ & $\begin{array}{c}{[\mathrm{RBr}]_{\mathbf{0}} /} \\
\mathrm{mol} \mathrm{dm}^{-3}\end{array}$ & $\begin{array}{c}{\left[\mathrm{NaClO}_{4}\right]_{\mathbf{0}}} \\
/ \mathrm{mol} \mathrm{dm}^{-3}\end{array}$ & $\begin{array}{c}\mathrm{RNO}_{2} / \\
\%\end{array}$ & $\begin{array}{c}\text { ROH } / \\
\%\end{array}$ & $\begin{array}{c}\text { Alkene } / \\
\%\end{array}$ \\
\hline 1.00 & 0.20 & 0.00 & 55 & 23 & 22 \\
\hline 0.80 & 0.20 & 0.20 & 54 & 26 & 20 \\
\hline 0.60 & 0.20 & 0.40 & 47 & 29 & 24 \\
\hline 0.40 & 0.20 & 0.60 & 38 & 35 & 27 \\
\hline 0.20 & 0.20 & 0.80 & 20 & 45 & 35 \\
\hline 0.20 & 0.10 & 0.80 & 29 & 43 & 29 \\
\hline
\end{tabular}

\subsection{Initial Slopes of Product Formation}

It was mentioned in the previous section that there was a some uncertainty concerning the dependency of the rate of formation of both the alkylated products and alkene on the initial concentration of sodium nitrite. The method of initial slopes is a quantitative technique which should settle any dispute. The initial slopes of product formation can also be used to complement the conclusions derived from the initial slopes of $p$-nitrocumyl bromide disappearance (Section 3.8). If the formation of a product derives itself from a termolecular reaction then:

$$
\left(d[\text { Product }]_{0} / d t\right) /[\mathrm{RBr}]_{0}=k(\mathrm{P})_{3}\left[\mathrm{NO}_{2}^{-}\right]_{0}^{2}
$$


A plot of $\left(d[\text { Product }]_{0} / d t\right) /[\mathrm{RBr}]_{0}$ versus $\left[\mathrm{NO}_{2}^{-}\right] 0^{2}$ should give a straight line through the origin with gradient $k(\mathrm{P}) 3$. However, if the formation of a product derives itself from a unimolecular reaction then:

$$
\left(d[\text { Product }]_{0} / d t\right) /[\mathrm{RBr}]_{0}=k(\mathrm{P}) 1
$$

A plot of $\left(d[\text { Product }]_{0} / d t\right) /[\mathrm{RBr}]_{0}$ versus $\left[\mathrm{NO}_{2}{ }^{-}\right]_{0}^{2}$ in the case of (4.5) should give a straight line with no slope. If the formation of a product derives itself from concurrent unimolecular and termolecular reactions then:

$$
\left(d[\text { Product }]_{0} / d t\right) /[\mathrm{RBr}]_{0}=k(\mathrm{P}) 1+k(\mathrm{P}) 3\left[\mathrm{NO}_{2}^{-}\right]_{0}^{2}
$$

A plot of $\left(d[\text { Product }]_{0} / d t\right) /[\mathrm{RBr}]_{0}$ versus $\left[\mathrm{NO}_{2}^{-}\right]_{0}^{2}$ should give a straight line with intercept $k(\mathrm{P}) 1$ and gradient $k(\mathrm{P}) 3$.

The initial slopes were calculated in the usual way and straight lines were fitted to the different plots by the method of least squares. A good straight line with a positive slope and a very small intercept is obtained for the plot derived from the formation of $\alpha, p-$ dinitrocumene (Figure 4.11). The point for the $[\mathrm{RBr}]_{0}=0.10 \mathrm{~mol} \mathrm{dm}^{-3}$ kinetic run was included in Figure 4.11, but was not used to determine the least squares fit. Figure 4.11 suggests that $\alpha, p$-dinitrocumene is formed almost exclusively from a termolecular reaction, as the intercept is so small.

A straight line is obtained for the plot derived from the formation of $p$-nitro- $\alpha$ methylstyrene (Figure 4.12), and the line has a moderately large intercept. The points for the elimination of $p$-nitrocumyl bromide $\left(\left[\mathrm{NO}_{2}^{-}\right]_{0}=0.00 \mathrm{~mol} \mathrm{dm}^{-3}\right)$ and the $[\mathrm{RBr}]=$ $0.10 \mathrm{~mol} \mathrm{dm}^{-3}$ kinetic run were included in Figure 4.12, but were not used to determine the least squares fit. The point for the elimination of $p$-nitrocumyl bromide is close to the straight line obtained. Figure 4.12 suggests that $p$-nitro- $\alpha$-methylstyrene is formed from concurrent unimolecular and termolecular reactions. The initial slopes for the formation of the alkene, based on the curve fitted, are larger than expected. This is due to a small 
amount of $p$-nitro- $\alpha$-methylstyrene being formed prior to mixing, via the elimination of $p$ nitrocumyl bromide in the substrate solution. This implies that the value obtained for $k$ (Alkene) 3 is higher that the true rate constant. The unimolecular component seems to have derived itself from the elimination of $p$-nitrocumyl bromide.

There are two straight lines obtained for the plot derived from the formation of oxygen alkylated products. (Figure 4.13). The formation of oxygen alkylated products amounts to the combined concentrations of $p$-nitrocumyl nitrite and $p$-nitrocumyl alcohol. For the first straight line, the points for the elimination of $p$-nitrocumyl bromide $\left(\left[\mathrm{NO}_{2}^{-}\right]_{0}\right.$ $=0.00 \mathrm{~mol} \mathrm{dm}^{-3}$ ) and the $[\mathrm{RBr}]=0.10 \mathrm{~mol} \mathrm{dm}^{-3}$ kinetic run were included, but were not used to determine the least squares fit. The first line is an indifferent fit to the points and the point for the elimination of $p$-nitrocumyl bromide is far removed from the straight line obtained. In the elimination of $p$-nitrocumyl bromide, the rate of formation of the alcohol is initially very slow, in fact, up to a period of 5000 seconds the formation is almost negligible. After 5000 seconds the rate of formation of the alcohol is more significant and this has an effect on the initial slopes for the slower kinetic runs. It must be remembered that the initial slopes are calculated from third order curves fitted to the combined concentrations of $p$-nitrocumyl nitrite and $p$-nitrocumyl alcohol.

For the second straight line, ${ }^{*}$ only the points for the elimination of $p$-nitrocumyl bromide and the kinetic runs for $\left[\mathrm{NO}_{2}^{-}\right]_{0}=1.00$ and $0.80 \mathrm{~mol} \mathrm{dm}^{-3}$ were included. Even though only three points were used, a very good fit is obtained. The $k$ (comb) 3 obtained from the second straight line ${ }^{*}$ is probably nearer to the true third order rate constant than the $k(\mathrm{comb}) 3$ obtained from the first straight line. Figure 4.13 suggests that $p$-nitrocumyl nitrite and p-nitrocumyl alcohol are formed from concurrent unimolecular and termolecular reactions. It must be stressed that the rate constants obtained from the initial slopes method are only approximate, however, these rate constants serve as a good starting point for more advanced models. 


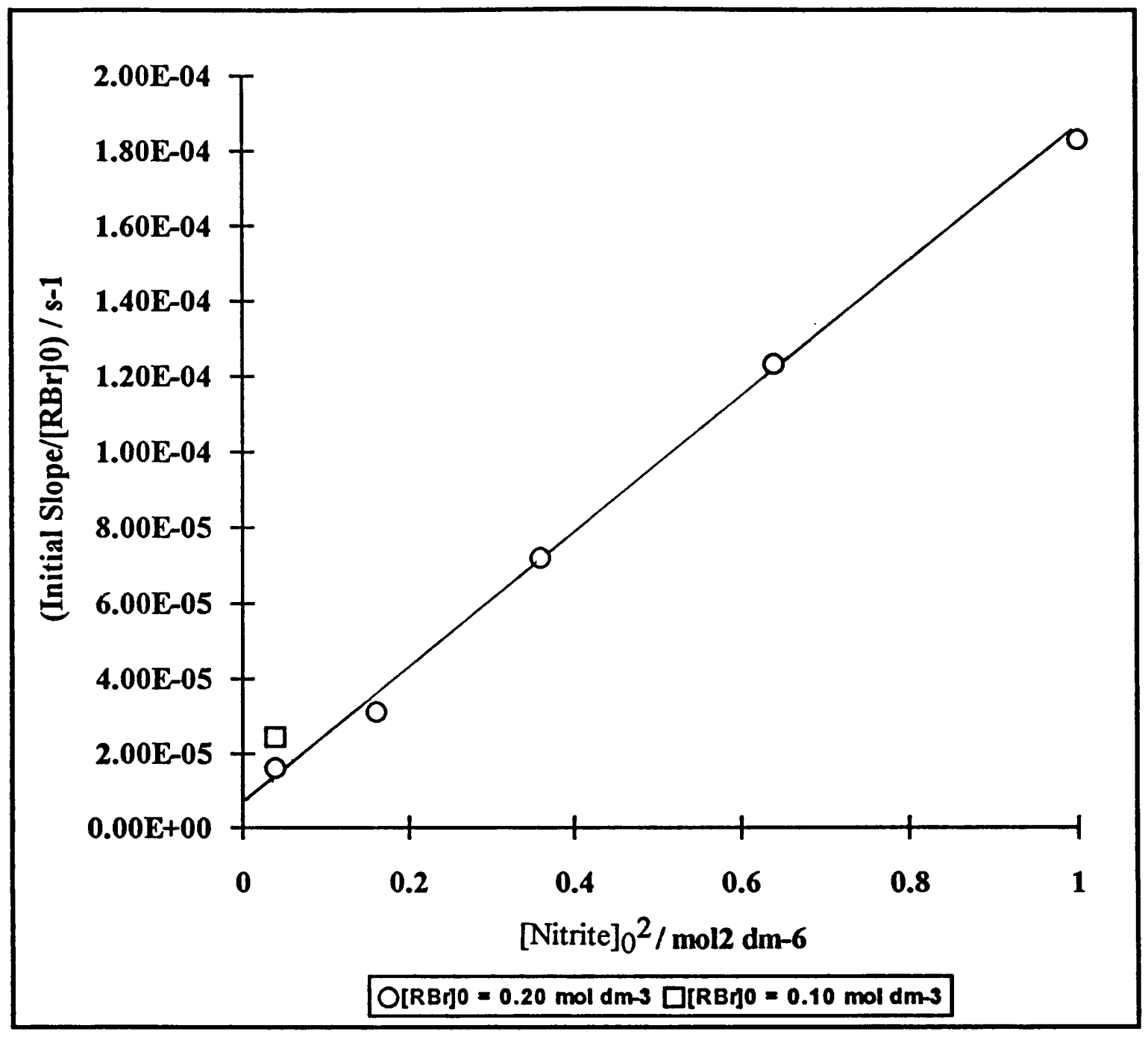

$$
\begin{aligned}
k\left(\mathrm{RNO}_{2}\right) 1 & =7.01 \times 10^{-6} \mathrm{~s}^{-1} \\
k\left(\mathrm{RNO}_{2}\right) 3 & =1.77 \times 10^{-4} \mathrm{~mol}^{-2} \mathrm{dm}^{6} \mathrm{~s}^{-1} \\
\mathrm{r} & =0.9991
\end{aligned}
$$

\section{Figure 4.11}

A plot of $\left(d\left[\mathrm{RNO}_{2}\right] 0^{\prime} d t\right) /[\mathrm{RBr}]_{0}$ versus $\left[\mathrm{NO}_{2}{ }^{-}\right]_{0}^{2}$ for the formation of $\alpha, p-$ dinitrocumene. 


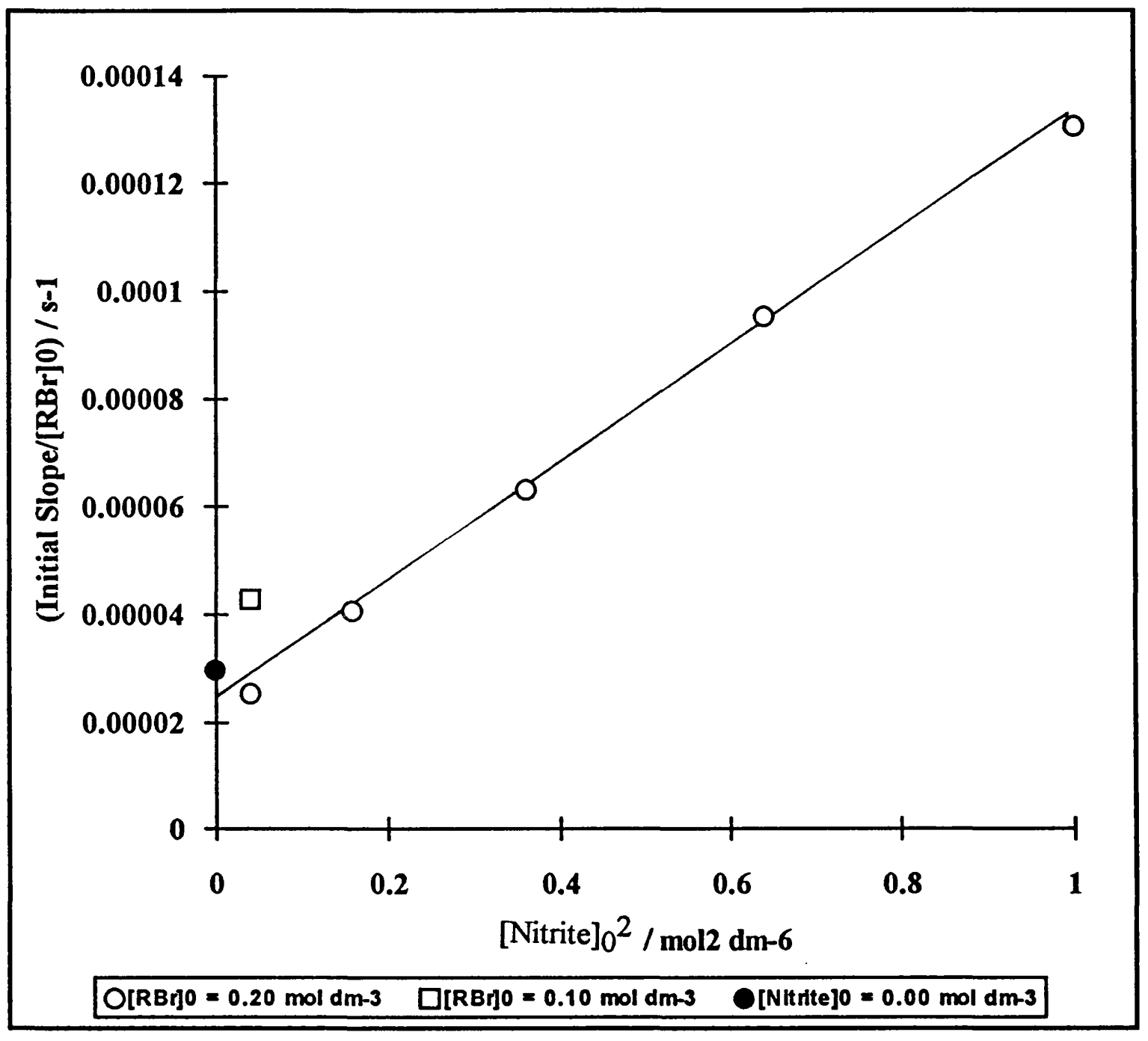

$$
\begin{aligned}
k \text { (Alkene) } 1 & =2.52 \times 10^{-5} \mathrm{~s}^{-1} \\
k \text { (Alkene) } 3 & =1.06 \times 10^{-4} \mathrm{~mol}^{-2} \mathrm{dm}^{6} \mathrm{~s}^{-1} \\
\mathrm{r} & =0.9974
\end{aligned}
$$

\section{Figure 4.12}

A plot of $\left(d[\text { Alkene }]_{0} / d t\right) /[\mathrm{RBr}]_{0}$ versus $\left[\mathrm{NO}_{2}-\right]_{0}^{2}$ for the formation of $p$-nitro- $\alpha$ methylstyrene. 


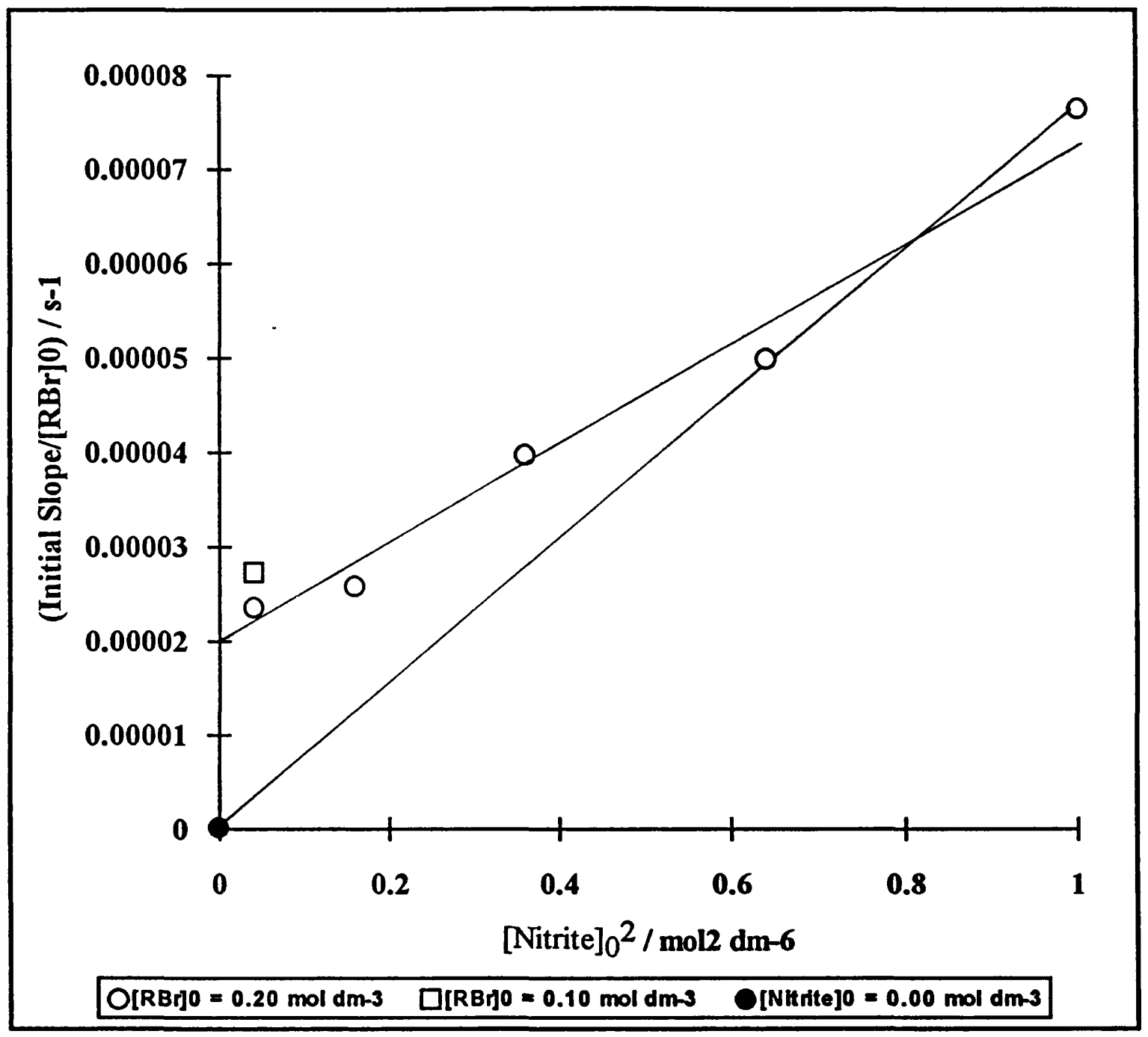

$$
\begin{aligned}
k \text { (comb) } 1 & =1.89 \times 10^{-5} \mathrm{~s}^{-1} \\
k \text { (comb) } 3 & =5.51 \times 10^{-5} \mathrm{~mol}^{-2} \mathrm{dm}^{6} \mathrm{~s}^{-1} \\
\mathrm{r} & =0.9908
\end{aligned}
$$

$$
\begin{aligned}
k(\text { comb })^{*} 1 & =4.55 \times 10^{-7} \mathrm{~s}^{-1} \\
k(\text { comb })^{*} 3 & =7.64 \times 10^{-5} \mathrm{~mol}^{-2} \mathrm{dm}^{6} \mathrm{~s}^{-1} \\
\mathrm{r} & =0.9999
\end{aligned}
$$

\section{Figure 4.13}

A plot of $\left(d[\mathrm{comb}]_{0} / d t\right) /[\mathrm{RBr}]_{0}$ versus $\left[\mathrm{NO}_{2}^{-}\right]_{0}^{2}$ for the combined formations of $p$ nitrocumyl nitrite and $p$-nitrocumyl alcohol. 


\subsection{Final Kinetic Model}

A detailed kinetic investigation has been carried out on the reaction of sodium nitrite with $p$-nitrocumyl bromide in dimethyl sulphoxide. After piecing together all the available data a final kinetic model can be postulated. This model can be divided into three reaction types:

\section{Termolecular Reactions}

$$
\begin{aligned}
& \mathrm{RBr}+2 \mathrm{NO}_{2}^{-} \stackrel{k\left(\mathrm{RNO}_{2}\right)_{3}}{\longrightarrow} \mathrm{RNO}_{2}+\mathrm{NO}_{2}^{-}+\mathrm{Br}^{-} \\
& \mathrm{RBr}+2 \mathrm{NO}_{2}^{-} \stackrel{k(\mathrm{RONO})}{\longrightarrow} \mathrm{RONO}+\mathrm{NO}_{2}^{-}+\mathrm{Br}^{-} \\
& \mathrm{RBr}+2 \mathrm{NO}_{2}{ }^{-} \stackrel{k \text { (Alkene) }}{\longrightarrow} \text { Alkene }+\mathrm{HNO}_{2}+\mathrm{NO}_{2}^{-}+\mathrm{Br}^{-}
\end{aligned}
$$

\section{Unimolecular Reactions}

$$
\begin{array}{lll} 
& \stackrel{k \text { (Allkene) } 1}{\longrightarrow} & \\
& & \text { Alkene }+\mathrm{HBr} \\
\mathrm{RBr} & \stackrel{k(\mathrm{ROH}) 1}{\longrightarrow} & \mathrm{ROH}+\mathrm{Br}^{-}
\end{array}
$$

\section{Auxiliary Reactions}

$$
\mathrm{RONO}+\mathrm{H}^{+} \stackrel{k_{(\mathrm{AUX})}}{\longrightarrow} \mathrm{ROH}+\mathrm{NO}^{+}
$$




$$
\mathrm{HBr}+\mathrm{NO}_{2}^{-} \stackrel{k_{(\mathrm{AUX})}^{\prime}}{\longrightarrow} \mathrm{HNO}_{2}+\mathrm{Br}^{-}
$$

The disappearance of $p$-nitrocumyl bromide can now be expressed as the following:

$$
\begin{gathered}
-\left(d[\mathrm{RBr}]_{\mathrm{t}} / d t\right)= \\
\left(k(\text { Alkene) } 1+k(\mathrm{ROH}) 1)[\mathrm{RBr}]_{\mathrm{t}}+\left(k\left(\mathrm{RNO}_{2}\right) 3+k(\mathrm{ONO}) 3+k(\text { Alkene) } 3)[\mathrm{RBr}]_{\mathrm{t}}\left[\mathrm{NO}_{2}{ }^{-}\right]_{\mathrm{t}}{ }^{2}\right.\right.
\end{gathered}
$$

Equation 4.14 can be simplified to Equation 4.15, which is in fact the same as Equation 4.1:

$$
-\left(d[\mathrm{RBr}]_{\mathrm{t}} / d t\right)=k_{\mathrm{S}}[\mathrm{RBr}]_{\mathrm{t}}+k_{3}^{\prime}[\mathrm{RBr}]_{\mathrm{t}}\left[\mathrm{NO}_{2}{ }^{-}\right]_{\mathrm{t}}^{2}
$$

Values for $k_{\mathrm{S}}$ and $k_{3}^{\prime}$ have already been estimated by the method of initial slopes, however, more advanced techniques are necessary in order to verify Equation 4.15. The computer programmes GEAR and GIT were used to evaluate $k_{\mathrm{S}}$ and $k_{3}^{\prime}$ using the estimations from the initial slopes method. To simplify matters, the first order component for the formation of $p$-nitrocumyl alcohol (Equation 4.11) was neglected from the model. The first order component for the formation of $p$-nitrocumyl alcohol is almost negligible up to a time period of $5000 \mathrm{~s}$, and minor compared with the first order component for the formation of $p$-nitro- $\alpha$-methylstyrene. This simplification implies that one mole of $\mathrm{HBr}$ is formed from one mole of $p$-nitrocumyl bromide.

Table 4.2 displays a variety of rate constants for the reaction of sodium nitrite with $p$-nitrocumyl bromide in dimethyl sulphoxide. We have already seen that the rate constants obtained for an overall first order model have a poor correlation. For an overall second order model the situation is no better. The concurrent third and first order rate constants, $k_{3}^{\prime}$ and $k_{\mathrm{S}}$ respectively, obtained from the computer programmes GEAR and GIT are shown in Table 4.2. The third order rate constants obtained for the various 
kinetic runs show excellent agreement. The concurrent first order rate constants show good agreement both for the various kinetic runs and with the first order rate constant obtained for the elimination of $p$-nitrocumyl bromide. The rate constants obtained from the computer programmes GEAR and GIT seem to verify that the overall reaction of sodium nitrite with $p$-nitrocumyl bromide in dimethyl sulphoxide proceeds by concurrent unimolecular and termolecular reactions as postulated in Equations 4.7 to 4.13 . It must be pointed out at this stage that since GEAR and GIT are based on a single run they may sometimes give anomalous values.

\section{Table 4.2}

A comparison of various rate constants for the kinetic runs in Tables 3.1, 3.2, 3.3, 3.4, 3.5, 3.6 and 3.9.

\begin{tabular}{|c|c|c|c|c|c|c|}
\hline $\begin{array}{c}{\left[\mathrm{NaNO}_{2}\right]_{\mathbf{0}}} \\
/ \mathrm{mol} \mathrm{dm}^{-3}\end{array}$ & $\begin{array}{c}{[\mathrm{RBr}]_{\mathbf{0}}} \\
/ \mathrm{mol} \mathrm{dm}^{-3}\end{array}$ & $\begin{array}{c}{\left[\mathrm{NaClO}_{4}\right]_{\mathbf{0}}} \\
/ \mathrm{mol} \mathrm{dm}^{-3}\end{array}$ & $\begin{array}{c}10^{4} \boldsymbol{k}_{\mathbf{1}} / \\
\mathbf{s}^{-1}\end{array}$ & $\begin{array}{c}10^{4} \boldsymbol{k}_{\mathbf{2}} / \\
\mathrm{dm}^{\mathbf{3}} \mathrm{mol}^{-1} \mathbf{s}^{-1}\end{array}$ & $\begin{array}{c}10^{4} \boldsymbol{k}_{\mathbf{3}} / \\
\mathrm{dm}^{6} \mathbf{m o l}^{-2} \mathbf{s}^{-1}\end{array}$ & $\begin{array}{c}10^{5} \boldsymbol{k}_{\mathbf{s}} / \\
\mathbf{g}^{-1}\end{array}$ \\
\hline 1.00 & 0.20 & 0.00 & 3.15 & 3.48 & 3.96 & 4.20 \\
\hline 0.80 & 0.20 & 0.20 & 2.32 & 3.27 & 3.93 & 4.28 \\
\hline 0.60 & 0.20 & 0.40 & 1.52 & 2.98 & 3.98 & 3.96 \\
\hline 0.40 & 0.20 & 0.60 & 0.788 & 2.40 & 3.96 & 4.20 \\
\hline 0.20 & 0.20 & 0.80 & 0.591 & 7.36 & 3.96 & 4.56 \\
\hline 0.00 & 0.10 & 0.80 & 0.661 & 4.21 & 3.60 & 5.31 \\
\hline
\end{tabular}

An alternative approach would be to obtain an integrated expression for concurrent unimolecular and termolecular reactions. This is not easy, but it can be done as long as you again neglect the first order component for the formation of $p$-nitrocumyl alcohol (Equation 4.11). Equation 4.15 can be expressed as Equation 4.16: 


$$
-(d \mathrm{~A} / d t)=k_{\mathrm{S}} \mathrm{A}+k_{3}^{\prime} \mathrm{AB}^{2}
$$

$\mathrm{A}$ and $\mathrm{B}$ are here used for the concentrations of the corresponding substances, $p$ nitrocumyl bromide and nitrite respectively. In the simplified model, one mole of $\mathrm{HBr}$ is formed from one mole of $p$-nitrocumyl bromide and it is fairly safe to assume that one mole of $\mathrm{HBr}$ will remove one mole of nitrite more rapidly than any other reaction.

In this case $\mathrm{A}_{0}-\mathrm{A}=\mathrm{B}_{0}-\mathrm{B}$ and

$$
-(d \mathrm{~A} / d t)=k_{\mathrm{s}} \mathrm{A}+k_{3}^{\prime} \mathrm{A}\left(\mathrm{B}_{0}-\mathrm{A}_{0}+\mathrm{A}\right)^{2}
$$

Where $A_{0}$ and $B_{0}$ are the initial concentrations. Equation 4.17 can be expressed as follows:

$$
\frac{-k_{3}^{\prime} d \mathrm{~A}}{k_{\mathrm{s}} \mathrm{A}+k_{3}^{\prime} \mathrm{A}\left(\mathrm{B}_{0}-\mathrm{A}_{0}+\mathrm{A}\right)^{2}}=k_{3}^{\prime} d t
$$

Equation 4.18 was integrated on both sides. The integration of the left hand side of this equation is far from trivial. The function was integrated using the mathematical computer programme DERIVE ${ }^{\mathrm{T}}$. The result of integration, after evaluating the constant of integration, is:

$$
\frac{k_{3}^{\prime}\left[2 \sqrt{k_{3}^{\prime}}\left(\mathrm{B}_{0}-\mathrm{A}_{0}\right)\left[T A N^{-1}\left[\mathrm{~B} \sqrt{k_{3}^{\prime} / k_{\mathrm{S}}}\right]-T A N^{-1}\left[\mathrm{~B}_{0} \sqrt{k_{3}^{\prime} / k_{\mathrm{S}}}\right]\right]+\sqrt{k_{\mathrm{S}}} L n\left[\frac{\mathrm{A}_{0}^{2}\left(k_{3}^{\prime} \mathrm{B}^{2}+k_{3}\right)}{\mathrm{A}^{2}\left(k_{3} \mathrm{~B}_{0}^{2}+k_{\mathrm{s}}\right)}\right]\right]}{2 \sqrt{k_{\mathrm{S}}}\left(k_{3}^{\prime}\left(\mathrm{B}_{0}-\mathrm{A}_{0}\right)^{2}+k_{\mathrm{S}}\right)}=k_{3}^{\prime} t
$$

Equation 4.19

The rate constants obtained from GEAR and GIT and the data obtained from Tables 3.1, $3.2,3.3,3.4,3.5$ and 3.6 were substituted into the function on the left hand side of 
Equation 4.19, and the resulting values plotted against time (Figures 4.14, 4.15, 4.16, 4.17, 4.18 and 4.19). The function on the left hand side of Equation 4.19 will now be referred to as the function for a concurrent first and third order reaction. These plots are not only a means of testing the fit of the model to the data, but also give new termolecular rate constants from the slopes of the graphs. If the model is a good one, then the new termolecular rate constants $\left(k_{3}^{\prime \prime}\right)$ should give a good agreement with the values derived from GEAR and GIT.

It can be seen from Figures 4.14, 4.15, 4.16, 4.17, 4.18 and 4.19 that a concurrent first and third order model is a very good fit to the data derived from the various kinetic runs. This is exemplified by the excellent correlation coefficients obtained from the plots. Some of the residual plots do show some form of pattern, however, these patterns are not as distinct as the ones obtained from the plots for overall first order and overall second order models.

Table 4.3 compares the termolecular rate constants $\left(k_{3}^{\prime}\right)$ obtained from the GEAR and GET programmes with the corresponding termolecular rate constants $\left(k_{3}{ }_{3}\right)$ obtained from Equation 4.19. There is very good agreement between the two sets of rate constants, however as one would expect, they are not identical. Even though $k_{3}^{\prime}$ is used to obtain $k_{3}^{\prime \prime}$, the results are not identical because the GEAR and GIT programmes minimise the deviation of data points to the model, where a plot of a concurrent first and third order function versus time calculates a slope of value $k_{3}^{\prime \prime}$. For the initial concentrations of both sodium nitrite and $p$-nitrocumyl bromide equal to $0.20 \mathrm{~mol} \mathrm{dm}^{-3}$, the value of $k_{3}^{\prime \prime}$ obtained is slightly out compared to all the other termolecular rate constants. As mentioned earlier in the chapter, the component of $p$-nitrocumyl alcohol formed becomes more significant for time periods greater than $5000 \mathrm{~s}$. This component is neglected in the working model, so for the slower kinetic runs, slight deviations will be observed. 


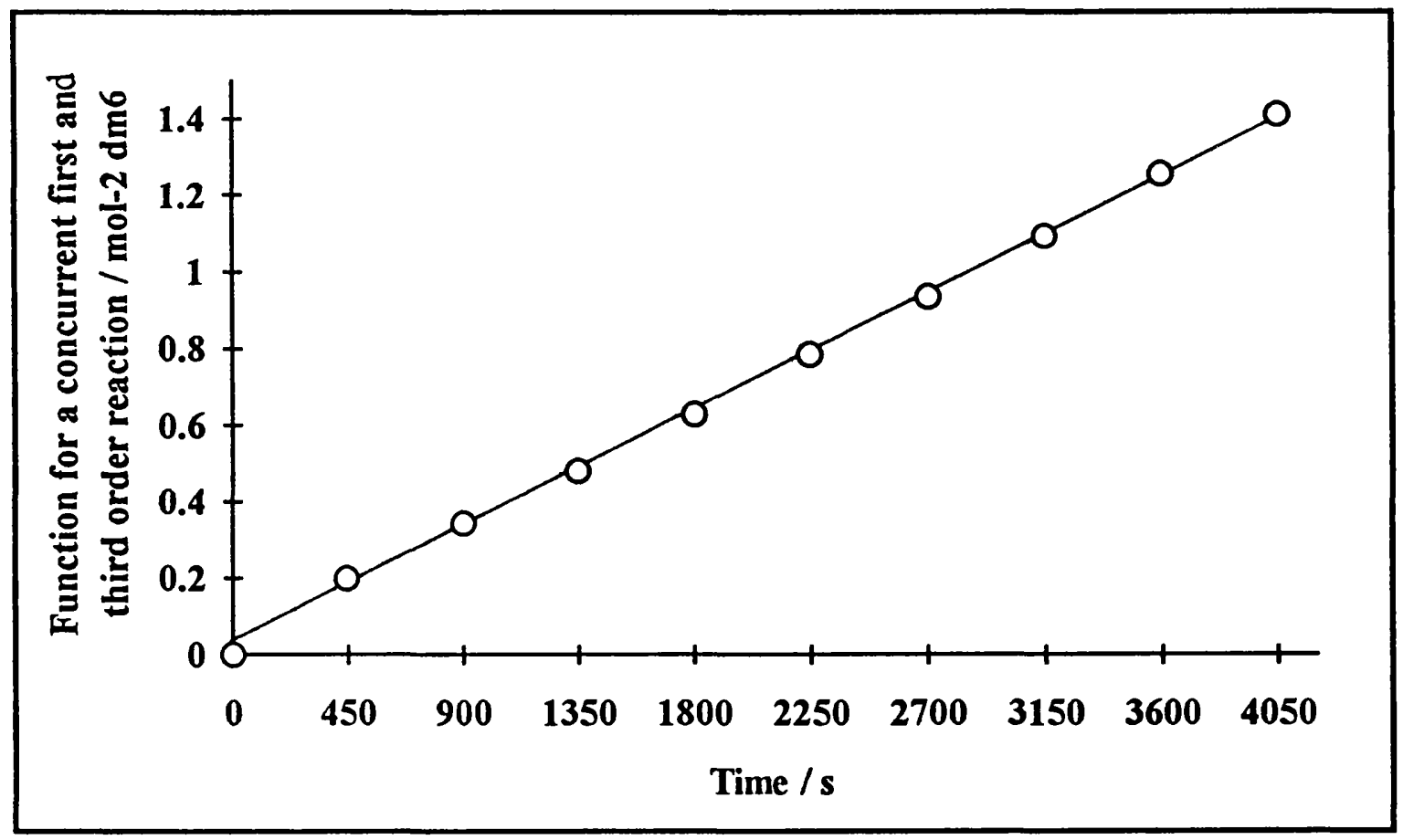

(a)

$$
\begin{aligned}
\mathrm{k}_{3}{ }_{3} & =3.41 \times 10^{-4} \mathrm{~mol}^{-2} \mathrm{dm}^{6} \mathrm{~s}^{-1} \\
\mathrm{r} & =0.9996 \\
\sigma & =1.00 \%
\end{aligned}
$$

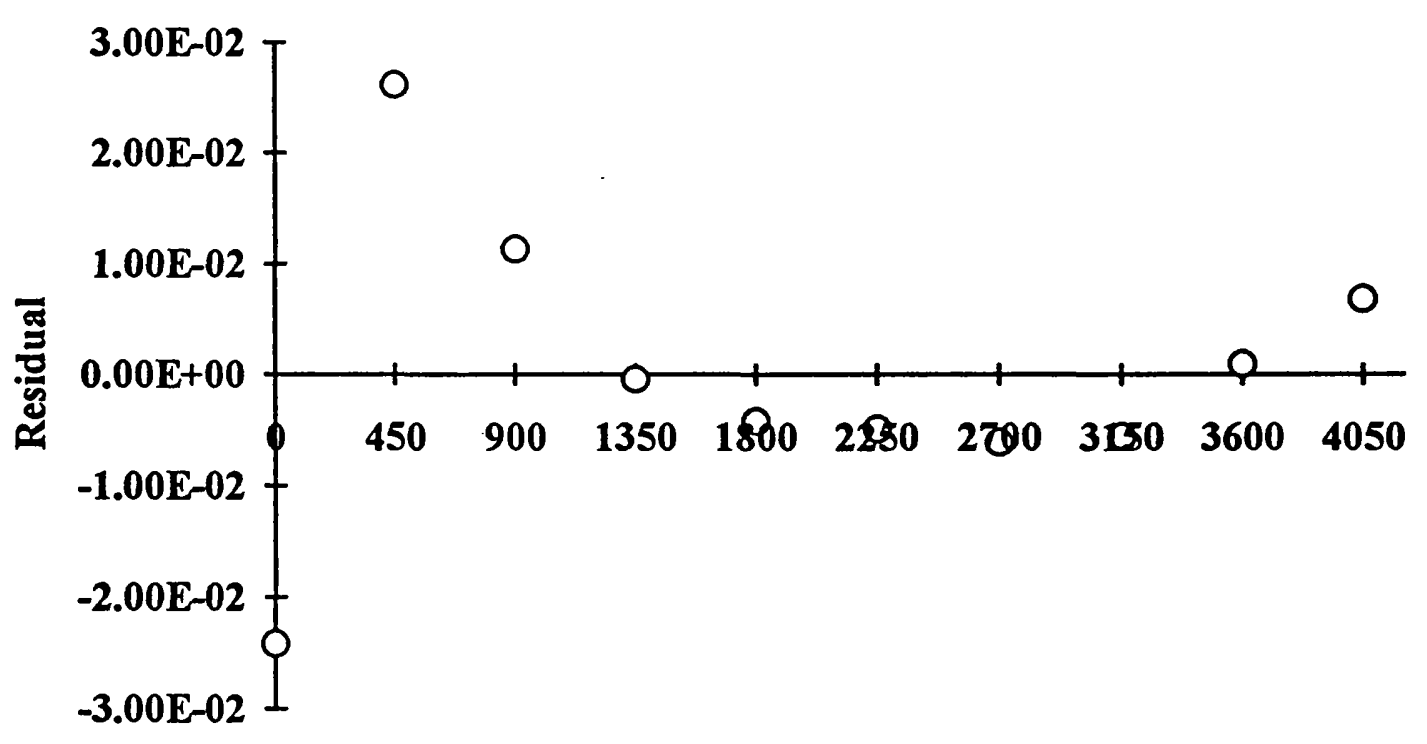

Time /s

(b)

Figure 4.14

Plots of (a) Function for a concurrent first and third order reaction $/ \mathrm{mol}^{-2} \mathrm{dm}^{6}$ and (b) Residuals against time / $\mathrm{s}$ for the reaction of $p$-nitrocumyl bromide with sodium nitrite (Table 3.1). 


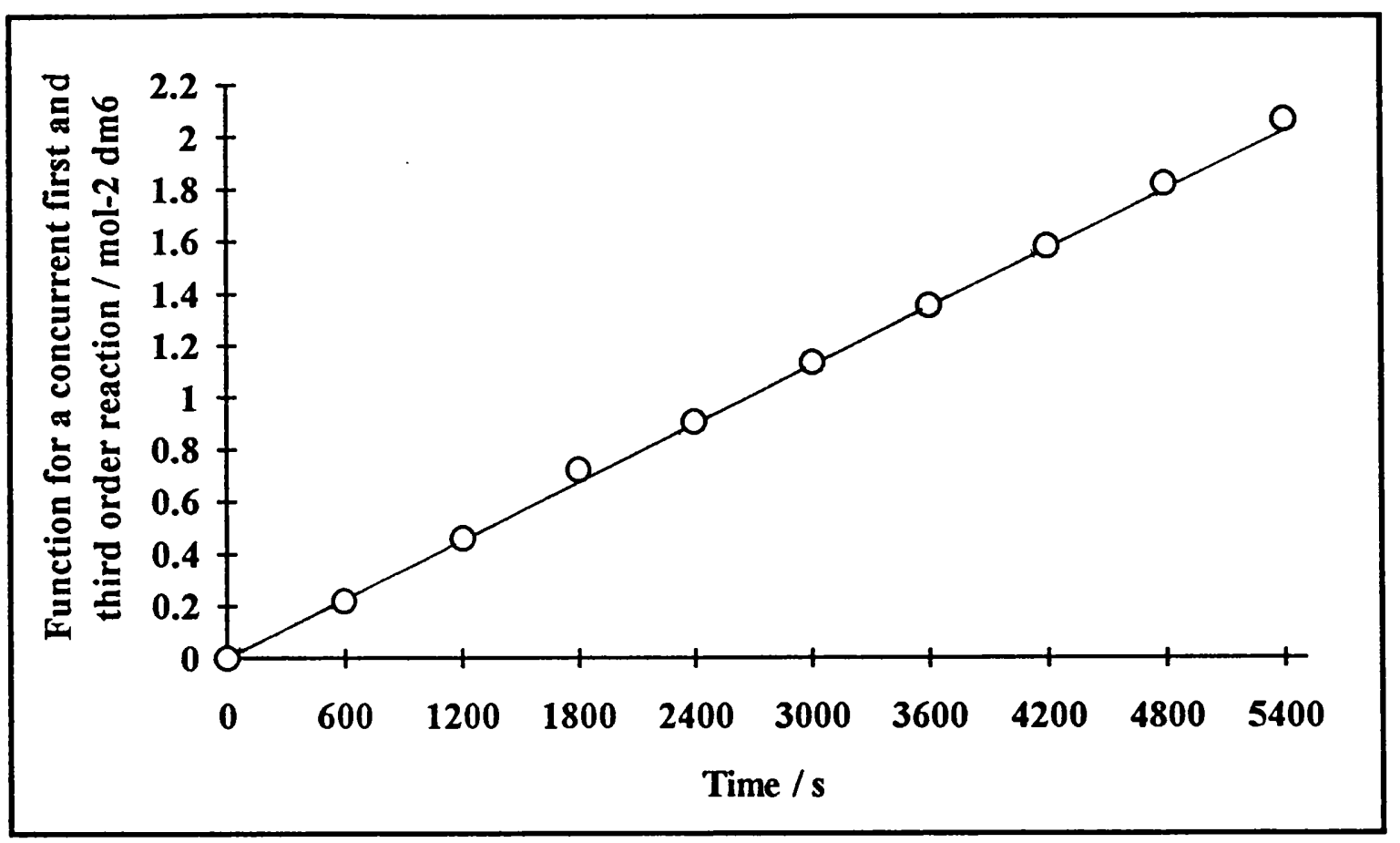

(a)

$$
\begin{aligned}
& \mathrm{k}_{3}=3.79 \times 10^{-4} \mathrm{~mol}^{-2} \mathrm{dm}^{6} \mathrm{~s}^{-1} \\
& \mathrm{r}=0.9997 \\
& \sigma=0.83 \%
\end{aligned}
$$

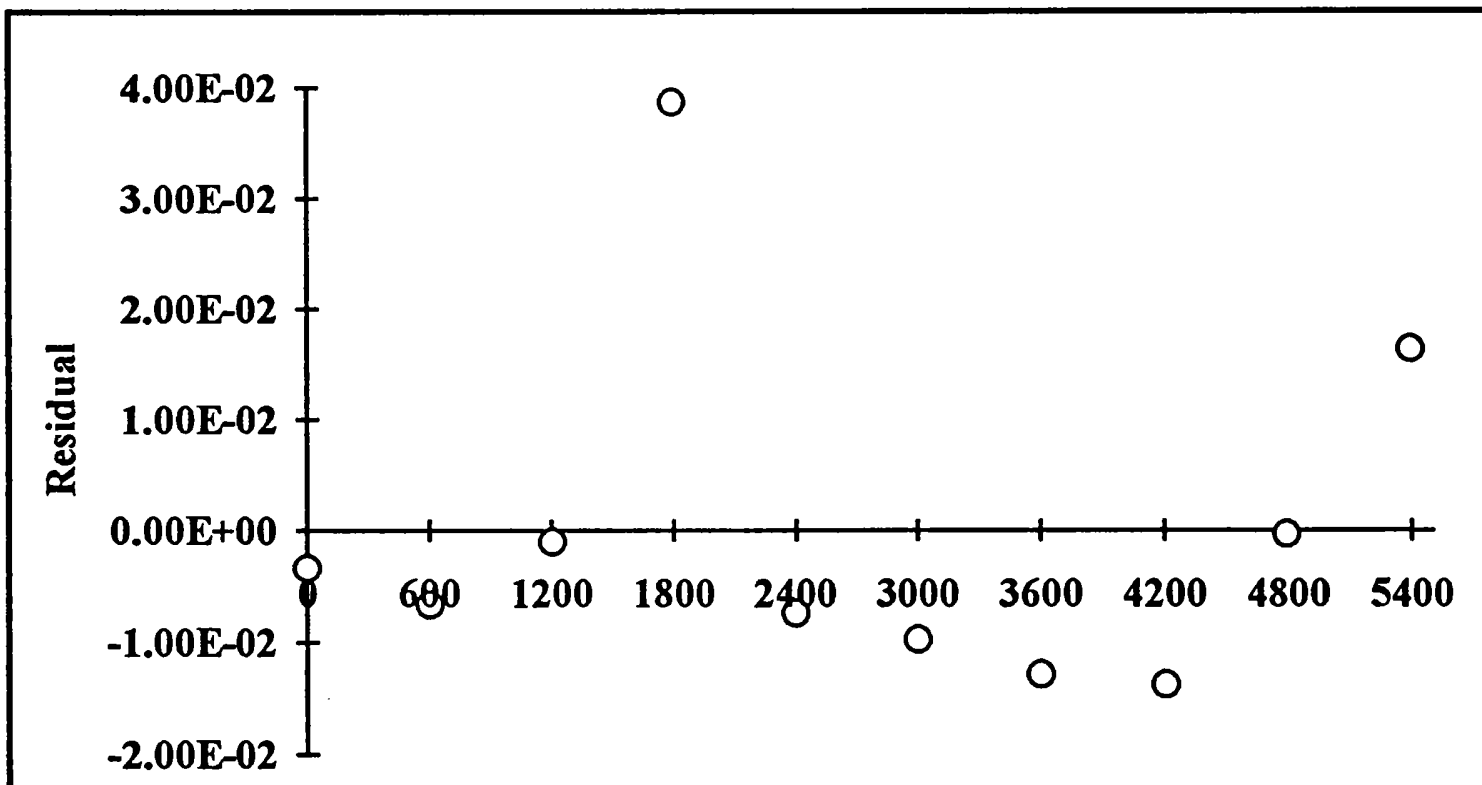

Time / s

(b)

\section{Figure 4.15}

Plots of (a) Function for a concurrent first and third order reaction $/ \mathrm{mol}^{-2} \mathrm{dm}^{6}$ and (b) Residuals against time / $\mathbf{s}$ for the reaction of $p$-nitrocumyl bromide with sodium nitrite (Table 3.2). 


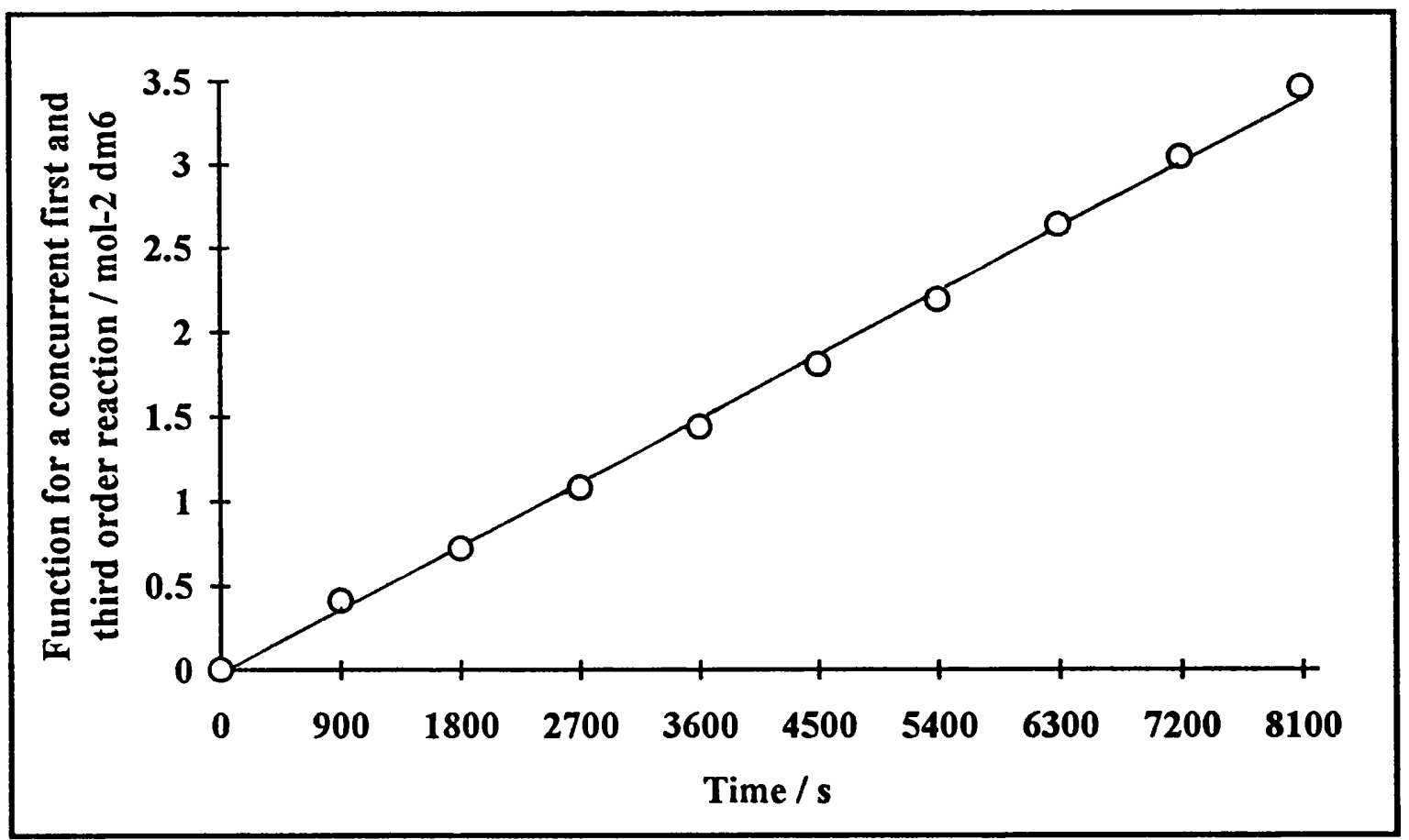

(a)

$$
\begin{aligned}
\mathrm{k}^{\prime \prime}{ }_{3} & =4.23 \times 10^{-4} \mathrm{~mol}^{-2} \mathrm{dm}^{6} \mathrm{~s}^{-1} \\
\mathrm{r} & =0.9991 \\
\sigma & =1.50 \%
\end{aligned}
$$

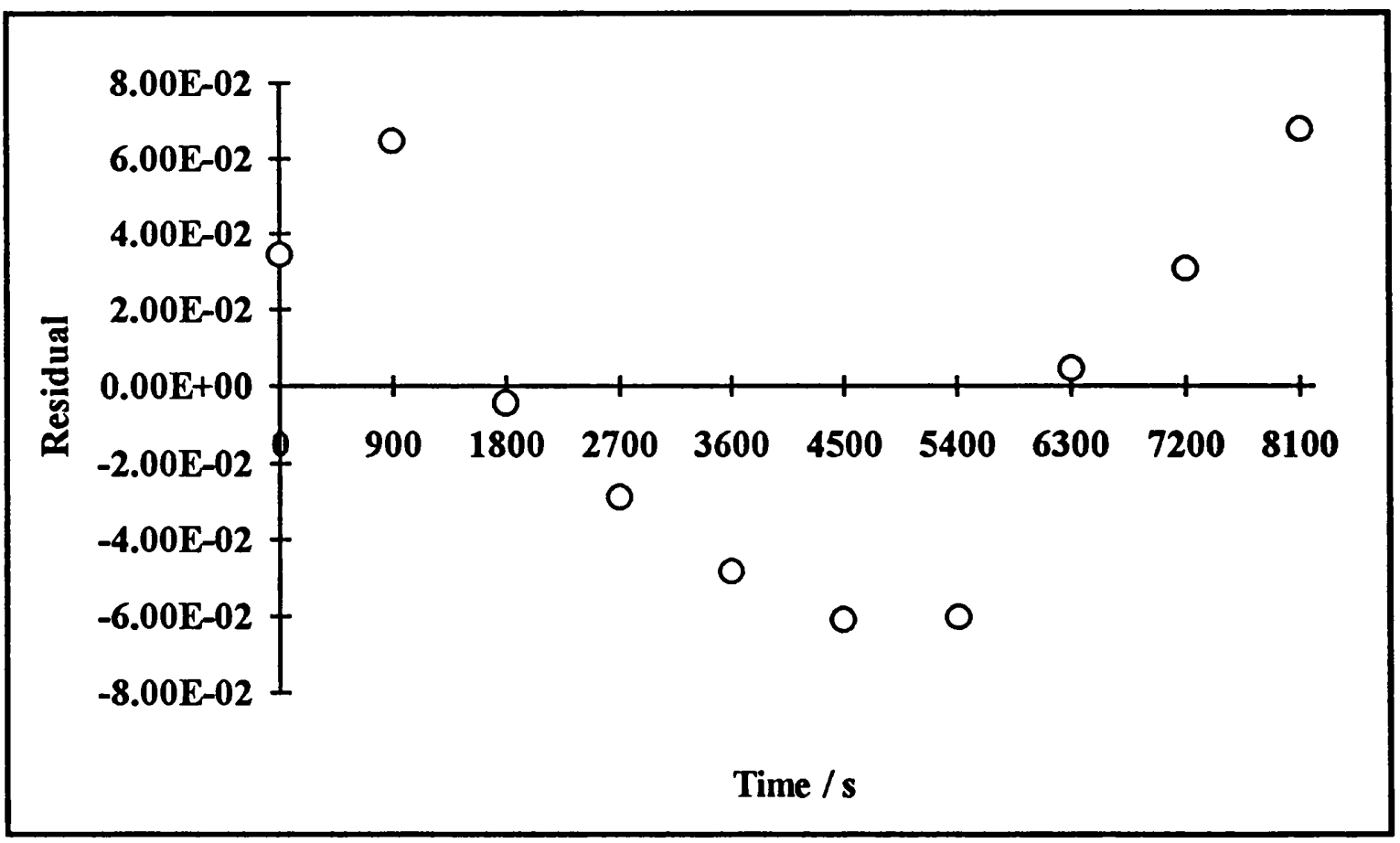

(b)

Figure 4.16

Plots of (a) Function for a concurrent first and third order reaction $/ \mathrm{mol}^{-2} \mathrm{dm}^{6}$ and (b) Residuals against time / $\mathrm{s}$ for the reaction of $p$-nitrocumyl bromide with sodium nitrite (Table 3.3). 


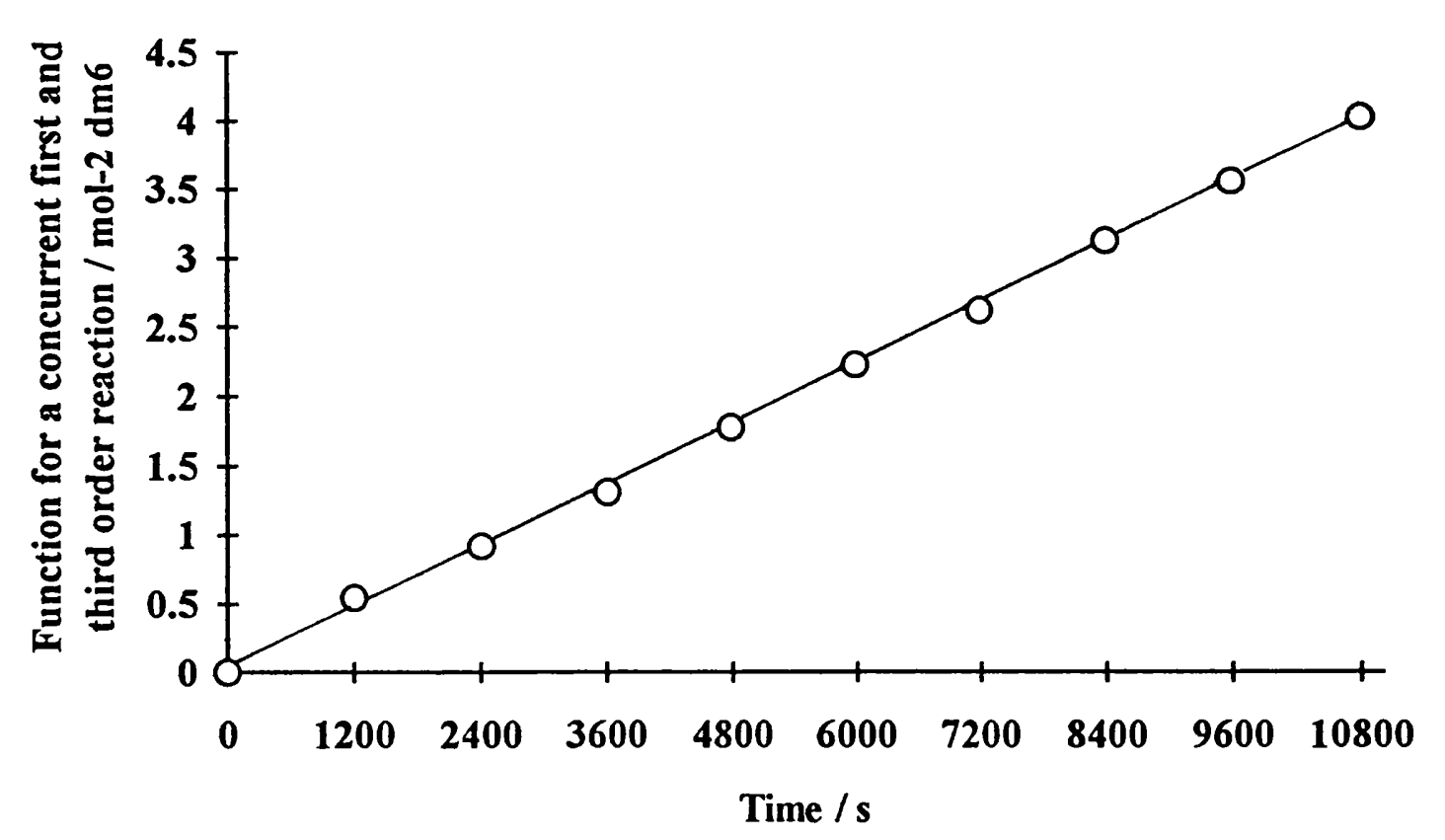

(a)

$$
\begin{aligned}
\mathrm{k}_{3}^{\prime \prime} & =3.67 \times 10^{-4} \mathrm{~mol}^{-2} \mathrm{dm}^{6} \mathrm{~s}^{-1} \\
\mathrm{r} & =0.9996 \\
\sigma & =0.94 \%
\end{aligned}
$$

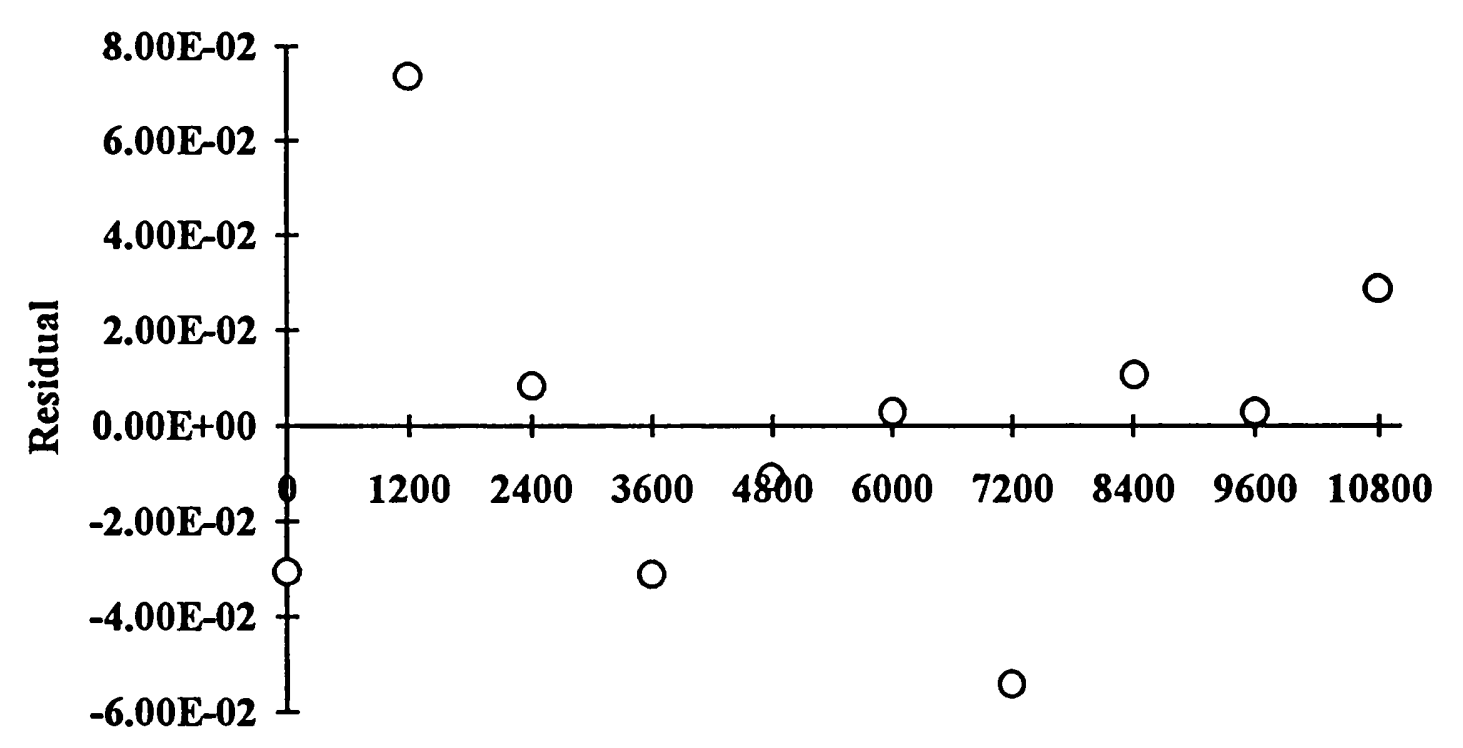

Time / s

(b)

Figure 4.17

Plots of (a) Function for a concurrent first and third order reaction $/ \mathrm{mol}^{-2} \mathrm{dm}^{6}$ and (b) Residuals against time / $\mathrm{s}$ for the reaction of $p$-nitrocumyl bromide with sodium nitrite (Table 3.4). 


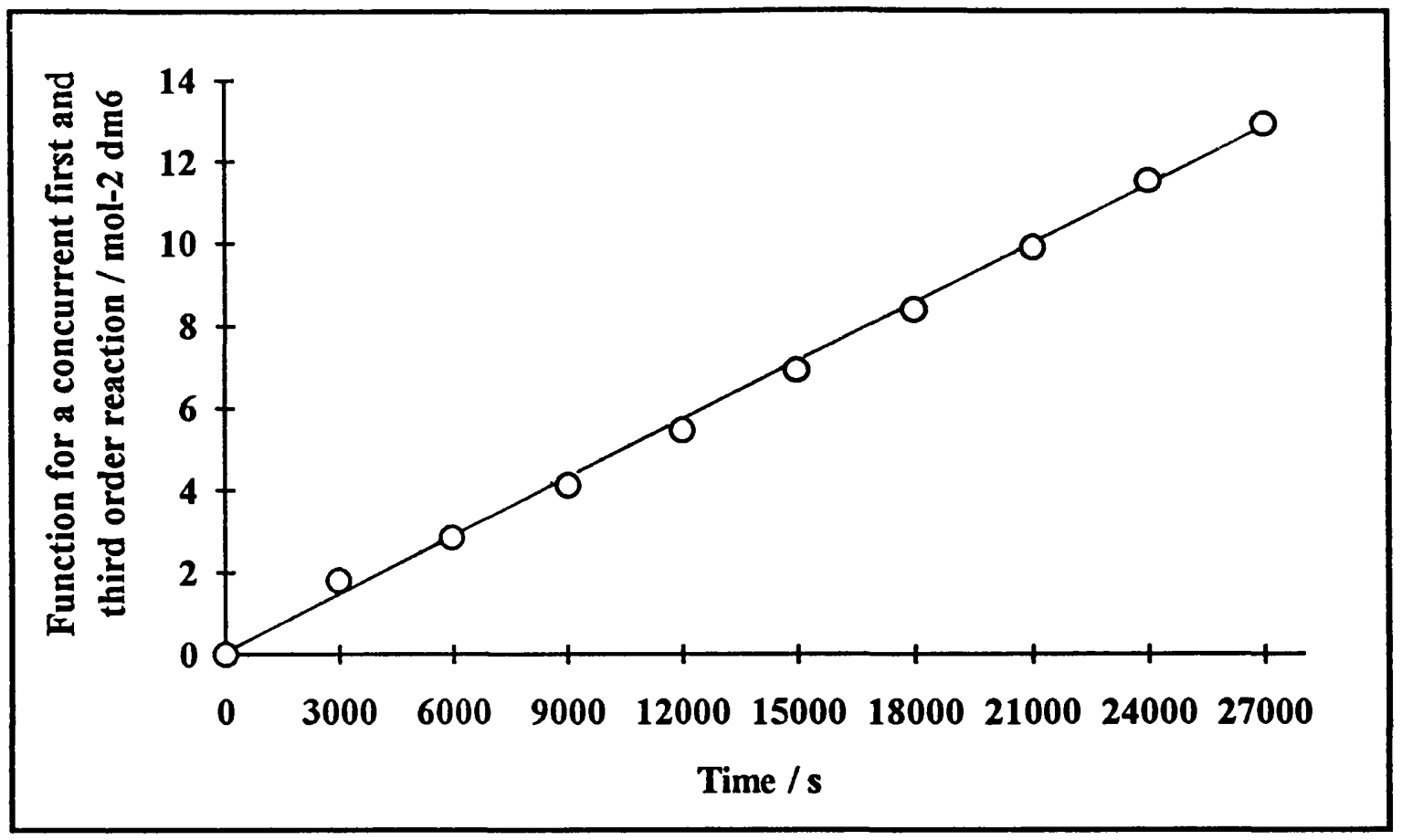

(a)

$$
\begin{aligned}
& \mathrm{k}_{3}=4.73 \times 10^{-4} \mathrm{~mol}^{-2} \mathrm{dm}^{6} \mathrm{~s}^{-1} \\
& \mathrm{r}=0.9991 \\
& \sigma=1.53 \%
\end{aligned}
$$

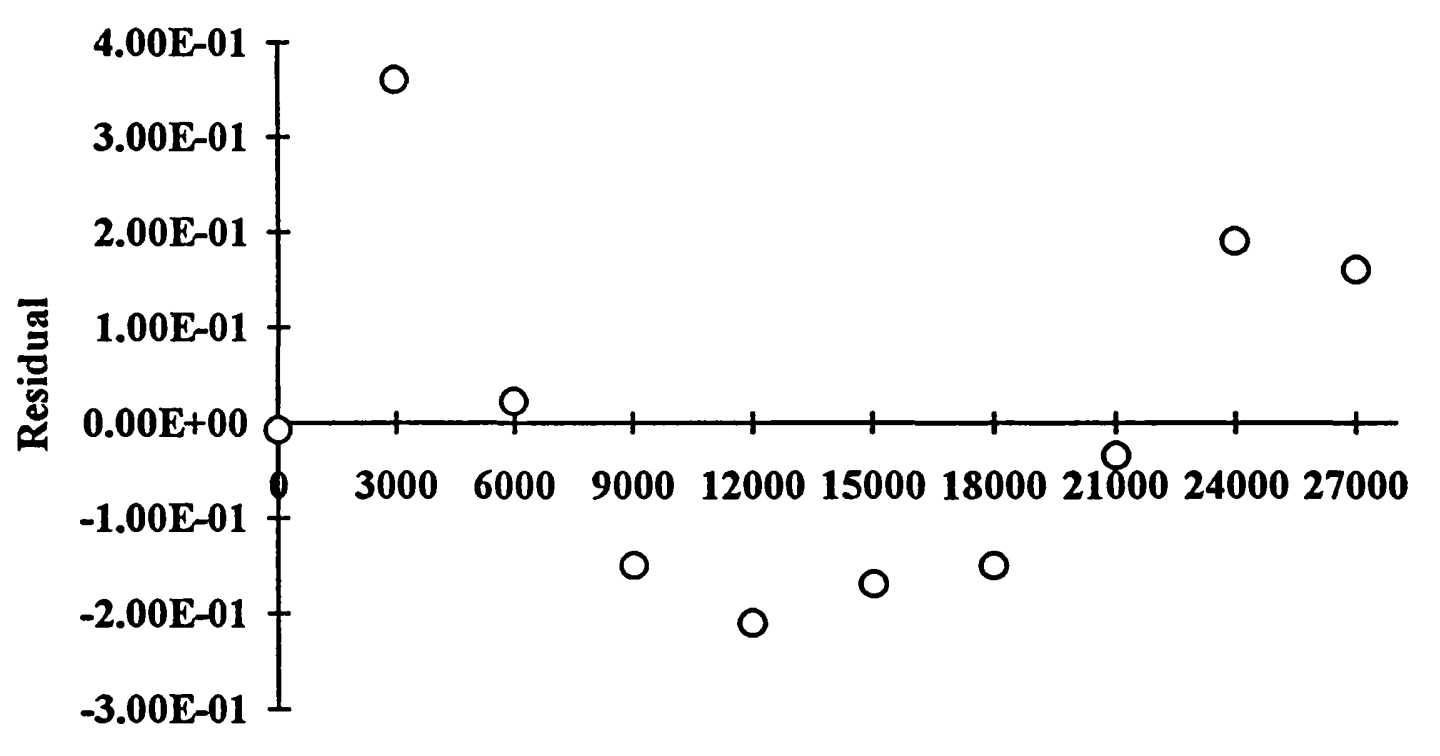

Time / s

(b)

Figure 4.18

Plots of (a) Function for a concurrent first and third order reaction $/ \mathrm{mol}^{-2} \mathrm{dm}^{6}$ and (b) Residuals against time / $\mathrm{s}$ for the reaction of $p$-nitrocumyl bromide with sodium nitrite (Table 3.5). 


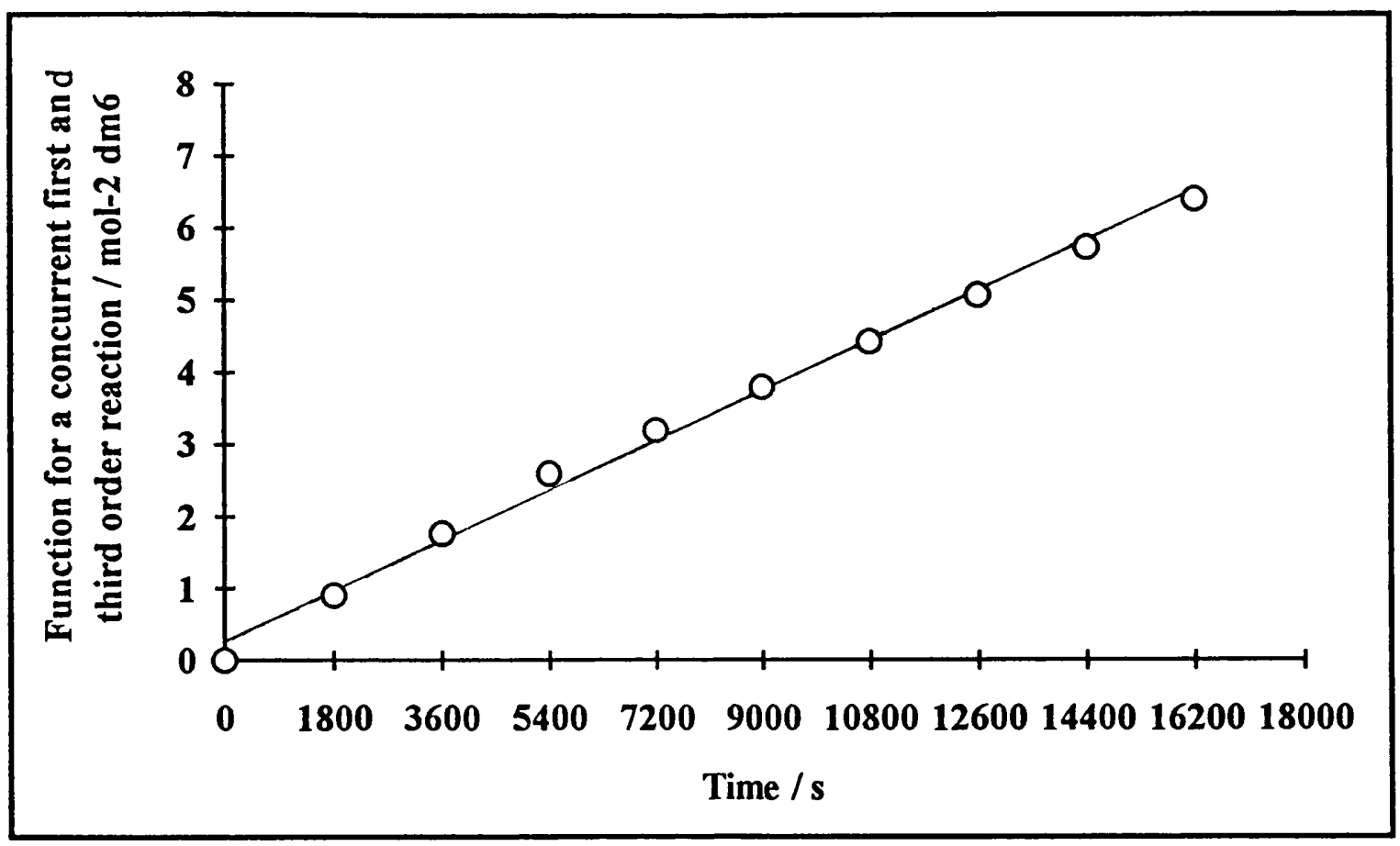

(a)

$$
\begin{aligned}
\mathrm{k}_{3}^{\prime \prime} & =3.83 \times 10^{-4} \mathrm{~mol}^{-2} \mathrm{dm}^{6} \mathrm{~s}^{-1} \\
r & =0.9974 \\
\sigma & =2.56 \%
\end{aligned}
$$

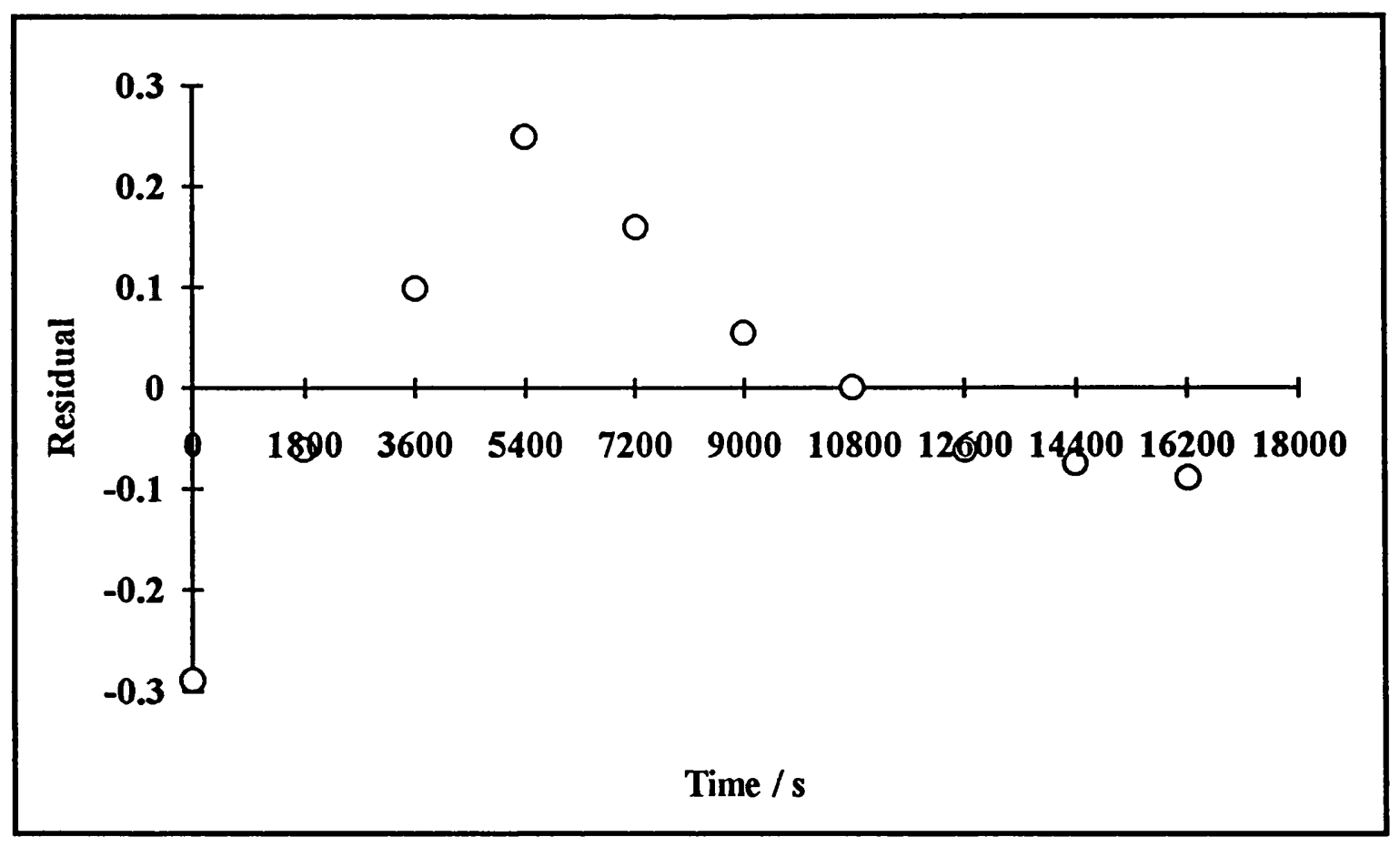

(b)

Figure 4.19

Plots of (a) Function for a concurrent first and third order reaction $/ \mathrm{mol}^{-2} \mathrm{dm}^{6}$ and (b) Residuals against time / $s$ for the reaction of $p$-nitrocumyl bromide with sodium nitrite (Table 3.6). 
Table 4.3

A comparison of termolecular rate constants derived from GEAR and GIT, $\left(k_{3}^{\prime}\right)$, with the termolecular rate constants derived from Equation $4.19,\left(k_{3}{ }_{3}\right)$.

\begin{tabular}{|c|c|c|c|c|c|c|}
\hline $\begin{array}{c}{\left[\mathrm{NaNO}_{2}\right]_{0}} \\
/ \mathrm{mol} \mathrm{dm}^{-3}\end{array}$ & $\begin{array}{c}{[R B r]_{0}} \\
/ \mathrm{mol} \mathrm{dm}^{-3}\end{array}$ & $\begin{array}{c}{\left[\mathrm{NaClO}_{4}\right]_{0}} \\
/ \mathrm{mol} \mathrm{dm}^{-3}\end{array}$ & $\begin{array}{c}10^{5} \boldsymbol{k}_{\mathrm{s}} / \\
\mathrm{s}^{-1}\end{array}$ & $\begin{array}{c}10^{4} \mathrm{k}_{3}^{\prime} / \\
\mathrm{dm}^{6} \mathrm{~mol}^{-2} \mathbf{s}^{-1}\end{array}$ & $\begin{array}{c}10^{4} \mathrm{k}_{3}^{\prime \prime} / \\
\mathrm{dm}^{6} \mathrm{~mol}^{-2} \mathbf{s}^{-1}\end{array}$ & $\begin{array}{c}\mathbf{r} \\
\sigma / \%\end{array}$ \\
\hline 1.00 & 0.20 & 0.00 & 4.20 & 3.96 & 3.41 & $\begin{array}{c}0.9996 \\
1.00\end{array}$ \\
\hline 0.80 & 0.20 & 0.20 & 4.28 & 3.93 & 3.79 & $\begin{array}{c}0.9997 \\
0.83\end{array}$ \\
\hline 0.60 & 0.20 & 0.40 & 3.96 & 3.98 & 4.23 & $\begin{array}{c}0.9991 \\
1.50\end{array}$ \\
\hline 0.40 & 0.20 & 0.60 & 4.20 & 3.96 & 3.67 & $\begin{array}{c}0.9996 \\
0.94\end{array}$ \\
\hline 0.20 & 0.20 & 0.80 & 4.56 & 3.96 & 4.73 & $\begin{array}{c}0.9991 \\
1.53\end{array}$ \\
\hline 0.20 & 0.10 & 0.80 & 5.31 & 3.60 & 3.83 & $\begin{array}{c}0.9974 \\
2.56\end{array}$ \\
\hline
\end{tabular}

\section{Table 4.4}

A comparison of termolecular rate constants derived from GEAR and GIT, $\left(k_{3}^{\prime}\right)$, with the termolecular rate constants (Isolated points deleted) ${ }^{*}$ derived from Equation $4.19,\left(k_{3}^{\prime \prime}{ }^{*}\right)$.

\begin{tabular}{|c|c|c|c|c|c|c|}
\hline $\begin{array}{c}{\left[\mathrm{NaNO}_{2}\right]_{0}} \\
/ \mathrm{mol} \mathrm{dm}^{-3}\end{array}$ & $\begin{array}{c}{[R B r]_{0}} \\
/ \mathrm{mol} \mathrm{dm}^{-3}\end{array}$ & $\begin{array}{c}{\left[\mathrm{NaClO}_{4}\right]_{0}} \\
/ \mathrm{mol} \mathrm{dm}^{-3}\end{array}$ & $\begin{array}{c}10^{5} \boldsymbol{k}_{\mathrm{s}} / \\
\mathbf{s}^{-1}\end{array}$ & $\begin{array}{c}10^{4} \mathrm{k}_{3}^{\prime} / \\
\mathrm{dm}^{6} \mathrm{mor}^{-2} \mathbf{s}^{-1}\end{array}$ & $\begin{array}{c}10^{4} \mathrm{k}_{3}^{*} / \\
\mathrm{dm}^{6} \mathrm{~mol}^{-2} \mathbf{s}^{-1}\end{array}$ & $\begin{array}{c}\mathbf{r}^{*} \\
\sigma^{*} / \%\end{array}$ \\
\hline 1.00 & 0.20 & 0.00 & 4.20 & 3.96 & 3.36 & $\begin{array}{c}0.9998 \\
0.71\end{array}$ \\
\hline 0.80 & 0.20 & 0.20 & 4.28 & 3.93 & 3.81 & $\begin{array}{c}0.9999 \\
0.45\end{array}$ \\
\hline 0.60 & 0.20 & 0.40 & 3.96 & 3.98 & 4.23 & $\begin{array}{c}0.9991 \\
1.49\end{array}$ \\
\hline 0.40 & 0.20 & 0.60 & 4.20 & 3.96 & 3.71 & $\begin{array}{c}0.9998 \\
0.60\end{array}$ \\
\hline 0.20 & 0.20 & 0.80 & 4.56 & 3.96 & 4.80 & $\begin{array}{c}0.9995 \\
1.08\end{array}$ \\
\hline 0.20 & 0.10 & 0.80 & 5.31 & 3.60 & 3.69 & $\begin{array}{c}0.9985 \\
1.77\end{array}$ \\
\hline
\end{tabular}


The residual plots in Figures 4.14, 4.15, 4.16, 4.17, 4.18 and 4.19 show that some points are slightly removed from the others. These points were deleted from the data and new rate constants calculated (Table 4.4). The new rate constants $\left(k_{3}{ }^{*}\right)$ are very similar to the old ones $\left(k_{3}\right)$ however, their correlation coefficients and corresponding errors are much improved on the old rate constants.

\subsection{Conclusion}

The evidence would suggest that the reaction of sodium nitrite with $p$-nitrocumyl bromide in dimethyl sulphoxide proceeds via a series of concurrent unimolecular and termolecular reactions as outlined in Equations 4.7 to 4.13. Undoubtedly, the unimolecular component comes from the elimination of $p$-nitrocumyl bromide in dimethyl sulphoxide. The termolecular component of the reaction is rare, but examples do exist in nucleophilic substitution 57 and electrophilic addition 58,59 . This termolecular component probably involves two nitrite molecules, as well as the substrate, within the rate determining step. Unlike most termolecular reactions, only one molecule of nitrite reacts with the substrate.

As time is fairly scarce on the Varian VXR-400 n.m.r. spectrometer, there was no time to duplicate the kinetic runs carried out in this chapter. However, we will see that several kinetic runs, carried out in the next chapter, act as a measure of reproducibility for certain runs in this chapter.

In the very first chapter, we saw that nucleophilic substitution mechanisms were split into two main groups, one being radical and the other heterolytic. The fact that we observed no C.I.D.N.P. effect in the reaction of $15^{N}$-labelled sodium nitrite with $p$ nitrocumyl bromide may indicate that this reaction proceeds via a non-radical process. In the next chapter, the possible mechanisms giving rise to the observed kinetics will be discussed by a process of elimination and deduction. 


\section{CHAPTER 5}

\section{A Kinetic Study of the Reaction of Sodium Nitrite with p-Nitrocumyl Bromide in \\ Dimethyl Sulphoxide}

\section{PART 3}

\subsection{Introduction}

This chapter is concerned with the termolecular kinetic component in the reaction of sodium nitrite with $p$-nitrocumyl bromide in dimethyl sulphoxide. The termolecular component of the kinetics observed in the previous chapter was the result of either a radical or heterolytic process. Firstly the type of process must be deduced, that is, whether the process is radical or not, and secondly, the best mechanism to match the observed kinetics must be found. Other kinetic runs must be carried out in order to distinguish between the many mechanisms possible. In this chapter a process of elimination and deduction will be effected so as to reach a conclusion concerning the mechanism of the reaction under question.

Kornblum et al. ${ }^{17}$ found that when p-nitrocumyl chloride was treated with sodium nitrite in dimethyl sulphoxide and the reaction carried out under two 20 Watt white fluorescent lights, the reaction gave a half-life of 12 hours. A duplicate experiment in the dark typically had a half-life of 300 hours. The product, $\alpha$,p-dinitrocumene, was obtained with a yield of $91 \%$. This reaction is generally accepted to occur via a radical chain mechanism, however, this reaction is far too slow in order to observe a C.I.D.N.P. effect and that is why the reaction of ${ }^{15} \mathrm{~N}$-labelled sodium nitrite with $p$-nitrocumyl bromide was investigated. No C.I.D.N.P. effect was observed for this reaction, but the lack of this effect does not necessarily imply that the reaction is completely heterolytic. A good place to start, in finding a mechanism to fit the kinetics, would be to try and rule out the possibility of a radical mechanism. 


\subsection{Radical Mechanisms}

In chapter one we saw that there were four basic types of radical nucleophilic substitution mechanisms; $\mathrm{S}_{\mathrm{RN}} 1, \mathrm{~S}_{\mathrm{RN}} 2, \mathrm{~S}_{\mathrm{ET}} 2$ and $\pi$-complex/charge transfer complex. The transfer of a single electron is common to all four mechanisms. Strong electron acceptors can prevent single electron transfer reactions by destroying the radical anion intermediates. $p$-Dinitrobenzene, $m$-dinitrobenzene, and $o$-dinitrobenzene are very strong electron acceptors and have been used widely as radical anion inhibitors to test for single electron transfer reactions. ${ }^{16}$ The inhibition of reaction rate resulting from addition of strong electron acceptors is consistent with either a chain $\left(\mathrm{S}_{\mathrm{RN}} 1\right.$ and $\left.\mathrm{S}_{\mathrm{RN}} 2\right)$ or non-chain radical mechanism ( $\mathrm{S}_{\mathrm{ET}} 2$ and $\pi$-complex/charge transfer complex), because radical anions are the reactive intermediates in both types of radical mechanisms.

The inhibition of radical scavengers has been suggested by Tobe and Chanon 16 as one of the criteria for the assignment of the $\mathrm{S}_{\mathrm{RN}} 1$ mechanism. Galvinoxyl and nitroxyl radicals are common radical scavengers used to test for the $S_{R N} 1$ reaction. For both the $\mathrm{S}_{\mathrm{RN}} 1$ and $\mathrm{S}_{\mathrm{RN}} 2$ mechanisms, radical scavengers can trap the free-radical intermediates (the chain carriers) and therefore depress the rate of reaction. Radical scavengers may not significantly affect the rates of the non-chain reactions $\left(\mathrm{S}_{\mathrm{ET}}{ }^{2}\right.$ and $\pi$-complex/charge transfer complex) when the reactive radical intermediates are held within the solvent cage which the radical scavengers cannot penetrate.

That light may speed up a radical anion substitution process was first recognised during a study of the reactions of $p$-nitrobenzyl chloride. 60 The photoinjection of an electron into a $\pi$-acceptor substituent or orbital of the substrate was bound to speed up the radical anion substitution process. Since then numerous examples of light effects have been found, some of them very large. 61,62 Kornblum et al. 63 found that monochromatic light with a wavelength of $470 \mathrm{~nm}$ (violet region) was exceedingly effective in initiating the reaction of $p$-nitrocumyl chloride with sodium azide.

We now have three kinetic experiments in which we can confirm or rule out a radical mechanism. Rate coefficients for these kinetic experiments were calculated assuming that the reactions were: (1) overall first order with respect to $p$-nitrocumyl 
bromide $\left(k_{1}\right)$, (2) first order with respect to both $p$-nitrocumyl bromide and sodium nitrite, that is, second order overall $\left(k_{2}\right)$, and (3) concurrent first and third order $\left(k_{\mathrm{S}}\right.$ and $k_{3}^{\prime}$ ). The concurrent first and third order rate constants were calculated using GEAR and GIT. Again, estimates for $k_{\mathrm{S}}$ and $k_{3}^{\prime}$ were obtained from the initial slopes method (See 4.2) and substituted into the computer programmes. The rate constants obtained from GEAR and GIT, with their corresponding data (Tables 5.1, 5.2 and 5.3), were then substituted into the function for a concurrent first and third order reaction. The resulting values were plotted against time and the new rate constants $\left(k_{3}{ }_{3}\right)$ were obtained from the slopes of the graphs. The new termolecular rate constants $\left(k_{3}{ }_{3}\right)$ should act as a verification for the termolecular rate constants obtained from the GEAR and GIT computer programmes.

\subsubsection{The Effect of $p$-Dinitrobenzene on the Rate of Reaction for the Reaction of Sodium Nitrite with p-Nitrocumyl Bromide in Dimethyl Sulphoxide}

One kinetic study was performed; the initial concentration of p-nitrocumyl bromide was set equal to $0.20 \mathrm{~mol} \mathrm{dm}^{-3}$ and the initial concentration of sodium nitrite was set equal to $1.00 \mathrm{~mol} \mathrm{dm}^{-3}$. $p$-Dinitrobenzene, a strong electron acceptor, was present in the reaction solution at an initial concentration of $0.10 \mathrm{~mol} \mathrm{dm}^{-3}$. The concentration of $p$-nitrocumyl bromide at given times, derived from this kinetic study, are presented in Table 5.1. The spectrum for time equal to zero was obtained by taking an ${ }^{1} \mathbf{H}$ n.m.r. spectrum of the $p$-nitrocumyl bromide/p-dinitrobenzene solution. For time equal to zero, the concentration of $p$-nitrocumyl bromide in the reaction mixture was set equal to one half the concentration of just the $p$-nitrocumyl bromide/p-dinitrobenzene solution on its own.

Tables 5.4 and 5.5 display all the above mentioned rate constants. It is clear to see, from these Tables, that the presence of the strong electron acceptor does not significantly affect the rate of reaction. 
Table 5.1

Temperature

Solvent

$[\mathrm{RBr}]_{0}$

$\left[\mathrm{NaNO}_{2}\right]_{0}$

$\left[\mathrm{NaClO}_{4}\right]_{0}$

$[p \text {-dinitrobenzene }]_{0}$
The Effect of $p$-Dinitrobenzene on the Reaction of Sodium

\section{Nitrite with p-Nitrocumyl Bromide in Dimethyl Sulphoxide}

$30^{\circ} \mathrm{C}$

$99.9 \% \mathrm{C}_{2} \mathrm{D}_{6} \mathrm{SO}$

$0.20 \mathrm{~mol} \mathrm{dm}^{-3}$

$\left(\mathrm{R}=\mathrm{C}_{9} \mathrm{H}_{10} \mathrm{NO}_{2}\right)$

$1.00 \mathrm{~mol} \mathrm{dm}^{-3}$

$0.00 \mathrm{~mol} \mathrm{dm}^{-3}$

$0.10 \mathrm{~mol} \mathrm{dm}^{-3}$

\begin{tabular}{|c|c|c|}
\hline Time Range / & Mid-point Time / & {$[\mathrm{RBr}]_{\mathrm{t}} / \mathrm{moldm}^{-3}$} \\
\hline 0 & 0 & 0.200 \\
\hline $442-458$ & 450 & 0.176 \\
\hline $892-908$ & 900 & 0.153 \\
\hline $1342-1358$ & 1350 & 0.125 \\
\hline $1792-1808$ & 1800 & 0.107 \\
\hline $2242-2258$ & 2250 & 0.094 \\
\hline $2692-2708$ & 2700 & 0.083 \\
\hline $3142-3158$ & 3150 & 0.073 \\
\hline $3592-3608$ & 3600 & 0.066 \\
\hline $4042-4508$ & 4050 & 0.058 \\
\hline
\end{tabular}


Table 5.2

Temperature

Solvent

$[\mathrm{RBr}]_{0}$

$\left[\mathrm{NaNO}_{2}\right]_{0}$

$\left[\mathrm{NaClO}_{4}\right]_{0}$

[4-hydroxy tempo]0
The Effect of 4-Hydroxy Tempo on the Reaction of Sodium

Nitrite with p-Nitrocumyl Bromide in Dimethyl Sulphoxide

$30^{\circ} \mathrm{C}$

$99.9 \% \mathrm{C}_{2} \mathrm{D}_{6} \mathrm{SO}$

$0.20 \mathrm{~mol} \mathrm{dm}^{-3}$

$\left(\mathrm{R}=\mathrm{C}_{9} \mathrm{H}_{10} \mathrm{NO}_{2}\right)$

$1.00 \mathrm{~mol} \mathrm{dm}^{-3}$

$0.00 \mathrm{~mol} \mathrm{dm}^{-3}$

$0.02 \mathrm{~mol} \mathrm{dm}^{-3}$

\begin{tabular}{|c|c|c|}
\hline Time Range / s & Mid-point Time/s & {$[\mathrm{RBr}]_{\mathrm{t}} / \mathrm{mol} \mathrm{dm}^{-3}$} \\
\hline 0 & 0 & 0.200 \\
\hline $442-458$ & 450 & 0.173 \\
\hline $892-908$ & 900 & 0.150 \\
\hline $1342-1358$ & 1350 & 0.119 \\
\hline $1792-1808$ & 1800 & 0.103 \\
\hline $2242-2258$ & 2250 & 0.090 \\
\hline $2692-2708$ & 2700 & 0.081 \\
\hline $3142-3158$ & 3150 & 0.070 \\
\hline $3592-3608$ & 3600 & 0.062 \\
\hline $4042-4508$ & 4050 & 0.054 \\
\hline
\end{tabular}


Table 5.3

Temperature

Solvent

U.V. irradiation

[RBr]0

$\left[\mathrm{NaNO}_{2}\right]_{0}$

$\left[\mathrm{NaClO}_{4}\right]_{0}$
The Effect of Ultraviolet Light on the Reaction of Sodium

Nitrite with p-Nitrocumyl Bromide in Dimethyl Sulphoxide

$30^{\circ} \mathrm{C}$

$99.9 \% \mathrm{C}_{2} \mathrm{D}_{6} \mathrm{SO}$

15 minutes

$0.20 \mathrm{~mol} \mathrm{dm}^{-3}$

$\left(\mathrm{R}=\mathrm{C}_{9} \mathrm{H}_{10} \mathrm{NO}_{2}\right)$

$0.20 \mathrm{~mol} \mathrm{dm}^{-3}$

$0.80 \mathrm{~mol} \mathrm{dm}^{-3}$

\begin{tabular}{|c|c|c|}
\hline Time Range / s & Mid-point Time $/ \mathrm{s}$ & {$[\mathrm{RBr}]_{\mathrm{t}} / \mathrm{mol} \mathrm{dm}^{-3}$} \\
\hline 0 & 0 & 0.200 \\
\hline $2992-3008$ & 3000 & 0.176 \\
\hline $5992-6008$ & 6000 & 0.150 \\
\hline $8992-9008$ & 9000 & 0.127 \\
\hline $11992-12008$ & 12000 & 0.109 \\
\hline $14992-15008$ & 15000 & 0.093 \\
\hline $17992-18008$ & 18000 & 0.079 \\
\hline $20992-21008$ & 21000 & 0.066 \\
\hline $23992-24008$ & 24000 & 0.056 \\
\hline $26992-27008$ & 27000 & 0.047 \\
\hline
\end{tabular}


There is a sufficient amount of $p$-dinitrobenzene present in the reaction mixture to effect a retardation, if the reaction proceeded via radical anion intermediates: The majority of the reaction must proceed via a mechanism that has no radical anion intermediates.

\subsubsection{The Effect of 4-Hydroxy Tempo on the Rate of Reaction for the Reaction of \\ Sodium Nitrite with p-Nitrocumyl Bromide in Dimethyl Sulphoxide}

One kinetic study was performed; the initial concentration of $p$-nitrocumyl bromide was set equal to $0.20 \mathrm{~mol} \mathrm{dm}^{-3}$ and the initial concentration of sodium nitrite was set equal to $1.00 \mathrm{~mol} \mathrm{dm}^{-3}$. 4-Hydroxy Tempo, a nitroxyl radical, was present in the reaction solution at an initial concentration of $0.02 \mathrm{~mol} \mathrm{dm}^{-3}$. The concentrations of $p$ nitrocumyl bromide at given times, derived from this kinetic study, are presented in Table 5.2. For time equal to zero, the concentration of $p$-nitrocumyl bromide in the reaction mixture was set equal to one half the concentration of just the p-nitrocumyl bromide/4hydroxy tempo solution on its own.

Tables 5.4 and 5.5 display all the above mentioned rate constants. It is clear from these Tables that the presence of the radical scavenger does not significantly affect the rate of reaction. There is a sufficient amount of 4-hydroxy tempo present in the reaction mixture to effect a retardation, if the reaction proceeded via free-radical intermediates: The majority of the reaction must proceed via a mechanism that has no free-radical intermediates.

\subsubsection{The Effect of Ultraviolet Light on the Rate of Reaction for the Reaction of \\ Sodium Nitrite with p-Nitrocumyl Bromide in Dimethyl Sulphoxide}

One kinetic study was performed; both the initial concentrations of $p$-nitrocumyl bromide and sodium nitrite were set equal to $0.20 \mathrm{~mol} \mathrm{dm}^{-3}$. The reaction mixture in the n.m.r. tube was initially irradiated with ultraviolet light for 15 minutes before being placed into the cavity of the n.m.r. machine. The concentrations of $p$-nitrocumyl bromide at given times, derived from this kinetic study, are presented in Table 5.3. For time equal to zero, the concentration of $p$-nitrocumyl bromide in the reaction mixture was set equal to one 
mixture was set equal to one half the concentration of just the $p$-nitrocumyl bromide solution on its own. Tables 5.4 and 5.5 display all the above mentioned rate constants. It is clear from these Tables that irradiation of the reaction mixture does not significantly affect the rate of reaction. Irradiation would not have a long term effect and so it is only the first point after $900 \mathrm{~s}$ that we should compare with the other runs.

\subsubsection{Conclusion}

The evidence would suggest that the reaction of sodium nitrite with $p$-nitrocumyl bromide in dimethyl sulphoxide proceeds via a non-radical process: $p$-dinitrobenzene, 4hydroxy tempo do not retard the reaction, ultraviolet light does not accelerate the reaction, and no C.I.D.N.P. effect was observed in the reaction of $15 \mathrm{~N}$-labelled sodium nitrite with $p$-nitrocumyl bromide. These three kinetic experiments also act as a measure of reproducibility for certain kinetic runs carried out in the previous chapter. Complex kinetics can quite conveniently be attributed to radical type reactions, however, the evidence suggests that we have in fact a heterolytic process. It is ironic that, in looking for a radical nucleophilic substitution reaction, we find a heterolytic process that obeys concurrent unimolcular and termolecular kinetics. The type of heterolytic mechanism responsible for the observed kinetics must now be narrowed down. 


\section{Table 5.4}

The effect of various radical/radical anion inhibitors and inducers on the reaction rate of the reaction of sodium nitrite with $p$-nitrocumyl bromide in dimethyl sulphoxide.

\begin{tabular}{|c|c|c|c|c|c|c|}
\hline $\begin{array}{c}{\left[\mathrm{NaNO}_{2}\right]_{0}} \\
/ \mathrm{mol} \mathrm{dm}^{-3}\end{array}$ & $\begin{array}{c}{[R B r]_{0}} \\
/ \mathrm{mol} \mathrm{dm}^{-3}\end{array}$ & $\begin{array}{c}{\left[\mathrm{NaClO}_{4}\right]_{0}} \\
/ \mathrm{mol} \mathrm{dm}^{-3}\end{array}$ & $\begin{array}{c}10^{4} k_{1} / \\
s^{-1} \\
\end{array}$ & $\begin{array}{c}10^{4} k_{2} / \\
\mathrm{dm}^{3} \mathrm{~mol}^{-1} \mathrm{~s}^{-1} \\
\end{array}$ & $\begin{array}{r}10^{4} k_{3}^{\prime} / \\
\mathrm{dm}^{6} \mathrm{~mol}^{-2} \mathrm{~s}^{-1} \\
\end{array}$ & $\begin{array}{c}10^{5} k_{s} / \\
s^{-1} \\
\end{array}$ \\
\hline 1.00 & 0.20 & 0.00 & 3.15 & 3.48 & 3.96 & 4.20 \\
\hline \multicolumn{3}{|c|}{$+p$-dinitrobenzene $\left(0.10 \mathrm{~mol} \mathrm{dm}^{-3}\right)$} & 3.10 & 3.41 & 3.23 & 4.39 \\
\hline \multicolumn{3}{|c|}{ + 4-hydroxy tempo $\left(0.02 \mathrm{~mol} \mathrm{dm}^{-3}\right)$} & 3.24 & 3.57 & 3.48 & 3.72 \\
\hline 0.20 & 0.20 & 0.80 & 0.591 & 7.36 & 3.96 & 4.56 \\
\hline \multicolumn{3}{|c|}{ + ultraviolet light (15 minutes) } & 0.539 & 5.84 & 3.19 & 4.46 \\
\hline
\end{tabular}

\section{Table 5.5}

A comparison of termolecular rate constants derived from GEAR and GIT, $\left(k_{3}^{\prime}\right)$, with the termolecular rate constants (Isolated points deleted) ${ }^{*}$ derived from Equation $4.19,\left(k_{3}^{\prime \prime}{ }^{*}\right)$.

\begin{tabular}{|c|c|c|c|c|c|c|}
\hline $\begin{array}{c}{\left[\mathrm{NaNO}_{2}\right]_{0}} \\
/ \mathrm{mol} \mathrm{dm}^{-3}\end{array}$ & $\begin{array}{c}{[R B r]_{0}} \\
/ \mathrm{mol} \mathrm{dm}^{-3}\end{array}$ & $\begin{array}{c}{\left[\mathrm{NaClO}_{4}\right]_{0}} \\
/ \mathrm{mol} \mathrm{dm}^{-3}\end{array}$ & $\begin{array}{c}10^{5} k_{s} / \\
s^{-1}\end{array}$ & $\begin{array}{c}10^{4} k_{3}^{\prime} / \\
\mathrm{dm}^{6} \mathrm{~mol}^{-2} \mathrm{~s}^{-1}\end{array}$ & $\begin{array}{l}10^{4} \mathrm{k}_{3}{ }^{*} / \\
\mathrm{dm}^{6} \mathrm{~mol}^{-2} \mathrm{~s}^{-1}\end{array}$ & $\begin{array}{c}\mathbf{r}^{*} \\
\sigma^{*} / \%\end{array}$ \\
\hline 1.00 & 0.20 & 0.00 & 4.20 & 3.96 & 3.36 & $\begin{array}{c}0.9998 \\
0.71 \\
\end{array}$ \\
\hline \multicolumn{3}{|c|}{$+p$-dinitrobenzene $\left(0.10 \mathrm{~mol} \mathrm{dm}^{-3}\right)$} & 4.39 & 3.23 & 3.18 & $\begin{array}{c}0.9989 \\
1.66 \\
\end{array}$ \\
\hline \multicolumn{3}{|c|}{ + 4-hydroxy tempo $\left(0.02 \mathrm{~mol} \mathrm{dm}^{-3}\right)$} & 3.72 & 3.48 & 3.45 & $\begin{array}{c}0.9988 \\
1.74 \\
\end{array}$ \\
\hline 0.20 & 0.20 & 0.80 & 4.56 & 3.96 & 4.80 & $\begin{array}{c}0.9995 \\
1.08 \\
\end{array}$ \\
\hline \multicolumn{3}{|c|}{ + ultraviolet light (15 minutes) } & 4.46 & 3.19 & 3.65 & $\begin{array}{c}0.9993 \\
1.25\end{array}$ \\
\hline
\end{tabular}




\subsection{Heterolytic Mechanisms}

We saw in the previous chapter that the termolecular kinetic component in the reaction of sodium nitrite with $p$-nitrocumyl bromide in dimethyl sulphoxide came from three reactions (Equations 4.7, 4.8 and 4.9):

\section{Termolecular Reactions}

$$
\begin{array}{lll}
\mathrm{RBr}+2 \mathrm{NO}_{2}^{-} & \stackrel{k\left(\mathrm{RNO}_{2}\right)}{\longrightarrow} & \mathrm{RNO}_{2}+\mathrm{NO}_{2}^{-}+\mathrm{Br}^{-} \\
\mathrm{RBr}+2 \mathrm{NO}_{2}^{-} & \stackrel{k \text { (RONO) }}{\longrightarrow} & \mathrm{RONO}+\mathrm{NO}_{2}^{-}+\mathrm{Br}^{-} \\
\mathrm{RBr}+2 \mathrm{NO}_{2}^{-} & \stackrel{k \text { (Allene) }}{\longrightarrow} & \text { Alkene }+\mathrm{HNO}_{2}+\mathrm{NO}_{2}^{-}+\mathrm{Br}^{-}
\end{array}
$$

The termolecular kinetic component could be explained in terms of either a concerted mechanism or an attack of nitrite on p-nitrocumyl bromide to give an intermediate, followed by attack of a second nitrite on the intermediate to give products. There are, however, other explanations for the termolecular kinetics obtained and these will be discussed in more detail later on.

Three more experiments were carried out in order to shed a little more light on the nature of the mechanism occurring in the reaction of sodium nitrite with $p$-nitrocumyl bromide in dimethyl sulphoxide. Rate coefficients for these kinetic experiments were calculated assuming that the reactions were: (1) overall first order with respect to $p$ nitrocumyl bromide $\left(k_{1}\right)$, (2) first order with respect to both $p$-nitrocumyl bromide and sodium nitrite, that is, second order overall $\left(k_{2}\right)$, and (3) concurrent first and third order $\left(k_{\mathrm{S}}\right.$ and $\left.k_{3}^{\prime}\right)$. The concurrent first and third order rate constants were calculated using GEAR and GIT. Again, estimates for $k_{\mathrm{S}}$ and $k_{3}^{\prime}$ were obtained from the initial slopes method (see 4.2) and substituted into the computer programmes. The rate constants 
obtained from GEAR and GIT, with their corresponding data (Tables 5.6, 5.7 and 5.8), were then substituted into the function for a concurrent first and third order reaction. The resulting values were plotted against time and the new rate constants $\left(k^{\prime \prime}{ }_{3}\right)$ were obtained from the slopes of the graphs. The new termolecular rate constants $\left(k_{3}^{\prime \prime}\right)$ should act as a verification for the termolecular rate constants obtained from the GEAR and GIT computer programmes.

\subsubsection{The Effect of Sodium Bromide on the Rate of Reaction for the Reaction of}

\section{Sodium Nitrite with $p$-Nitrocumyl Bromide in Dimethyl Sulphoxide}

One kinetic study was performed; the initial concentration of $p$-nitrocumyl bromide was set equal to $0.20 \mathrm{~mol} \mathrm{dm}^{-3}$ and the initial concentration of sodium nitrite was set equal to $0.80 \mathrm{~mol} \mathrm{dm}-3$. Sodium bromide was present in the reaction solution at an initial concentration of $0.20 \mathrm{~mol} \mathrm{dm}^{-3}$. The concentration of $p$-nitrocumyl bromide at given times, derived from this kinetic study, are presented in Table 5.6. For time equal to zero, the concentration of $p$-nitrocumyl bromide in the reaction mixture was set equal to one half the concentration of just the $p$-nitrocumyl bromide solution on its own.

Tables 5.9 and 5.10 display all the above mentioned rate constants. It is clear from these Tables that addition of sodium bromide to the mixture does not significantly affect the rate of reaction. This indicates that there is no common ion effect.

\subsubsection{The Rate of Reaction for the Reaction of Sodium Nitrite with p-Nitrocumyl Bromide in a $95 \% \mathrm{C}_{2} \underline{D}_{6} \underline{\mathrm{SO}: 5 \% \mathrm{H}_{2}}$ O Solvent Mixture}

One kinetic study was performed; the initial concentration of $p$-nitrocumyl bromide was set equal to $0.20 \mathrm{~mol} \mathrm{dm}^{-3}$ and the initial concentration of sodium nitrite was set equal to $1.00 \mathrm{~mol} \mathrm{dm}^{-3}$. The solvent used was a $95 \% \mathrm{C}_{2} \mathrm{D}_{6} \mathrm{SO}: 5 \% \mathrm{H}_{2} \mathrm{O}$ mixture. The concentration of $p$-nitrocumyl bromide at given times, derived from this kinetic study, are presented in Table 5.7. For time equal to zero, the concentration of $p$ nitrocumyl bromide in the reaction mixture was set equal to one half the concentration of just the $p$-nitrocumyl bromide solution on its own. 
Tables 5.9 and 5.10 display all the above mentioned rate constants. It is clear from these Tables that the presence of water moderately slows the reaction down. Hydrogen bonding between water and nitrite will lower the nucleophilicity of nitrite, also, an increase in the polarity of the solvent could destabilise an $\mathrm{S}_{\mathrm{N}} 2$ transition state.

\subsubsection{The Effect of a Decrease in Ionic Strength on the Rate of Reaction for the}

\section{Reaction of Sodium Nitrite with p-Nitrocumyl Bromide in Dimethyl}

\section{Sulphoxide}

One kinetic study was performed; the initial concentrations of both $p$-nitrocumyl bromide and sodium nitrite were set equal to $0.20 \mathrm{~mol} \mathrm{dm}^{-3}$. No sodium perchlorate was added to the reaction mixture. The concentration of $p$-nitrocumyl bromide at given times, derived from this kinetic study, are presented in Table 5.8. For time equal to zero, the concentration of $p$-nitrocumyl bromide in the reaction mixture was set equal to one half the concentration of just the $p$-nitrocumyl bromide solution on its own.

Tables 5.9 and 5.10 display all the above mentioned rate constants. It is clear from these Tables that a decrease in the ionic strength causes an increase in reaction rate. The termolecular rate constant, $k_{3}^{\prime}$, is about six times larger than any of the termolecular rate constants derived from kinetic runs that have a total ionic strength of $1.00 \mathrm{~mol} \mathrm{dm}^{-3}$. This may indicate a negative salt effect, but it could also indicate that sodium perchlorate increases the association between the sodium cation and the nitrite anion. 
Table 5.6

Temperature

Solvent

$[\mathrm{RBr}]_{0}$

$\left[\mathrm{NaNO}_{2}\right]_{0}$

$\left[\mathrm{NaClO}_{4}\right]_{0}$

$[\mathrm{NaBr}]_{0}$
The Effect of Sodium Bromide on the Reaction of Sodium

Nitrite with p-Nitrocumyl Bromide in Dimethyl Sulphoxide

$30^{\circ} \mathrm{C}$

$99.9 \% \mathrm{C}_{2} \mathrm{D}_{6} \mathrm{SO}$

$0.20 \mathrm{~mol} \mathrm{dm}^{-3}$

$\left(\mathrm{R}=\mathrm{C}_{9} \mathrm{H}_{10} \mathrm{NO}_{2}\right)$

$0.80 \mathrm{~mol} \mathrm{dm}-3$

$0.00 \mathrm{~mol} \mathrm{dm}^{-3}$

$0.20 \mathrm{~mol} \mathrm{dm}^{-3}$

\begin{tabular}{|c|c|c|}
\hline Time Range / s & Mid-point Time/s & {$[\mathrm{RBr}]_{\mathrm{t}} / \mathrm{mol} \mathrm{dm}^{-3}$} \\
\hline 0 & 0 & 0.200 \\
\hline $592-608$ & 600 & 0.153 \\
\hline $1192-1208$ & 1200 & 0.130 \\
\hline $1792-1808$ & 1800 & 0.114 \\
\hline $2392-2408$ & 2400 & 0.099 \\
\hline $2992-3008$ & 3000 & 0.086 \\
\hline $3592-3608$ & 3600 & 0.074 \\
\hline $4192-4208$ & 4200 & 0.065 \\
\hline $4792-4808$ & 4800 & 0.057 \\
\hline $5392-5408$ & 5400 & 0.049 \\
\hline
\end{tabular}


Table 5.7

Temperature

Solvent

$[\mathrm{RBr}]_{0}$

$\left[\mathrm{NaNO}_{2}\right]_{0}$

$\left[\mathrm{NaClO}_{4}\right]_{0}$
The Effect of $\mathrm{H}_{2} \underline{\mathrm{O} \text { on the Reaction of Sodium Nitrite }}$ with p-Nitrocumyl Bromide in Dimethyl Sulphoxide

$30^{\circ} \mathrm{C}$

$95 \% \mathrm{C}_{2} \mathrm{D}_{6} \mathrm{SO}: 5 \% \mathrm{H}_{2} \mathrm{O}$

$0.20 \mathrm{~mol} \mathrm{dm}^{-3}$

$\left(\mathrm{R}=\mathrm{C}_{9} \mathrm{H}_{10} \mathrm{NO}_{2}\right)$

$1.00 \mathrm{~mol} \mathrm{dm}-3$

$0.00 \mathrm{~mol} \mathrm{dm}-3$

\begin{tabular}{|c|c|c|}
\hline Time Range $/ \mathrm{s}$ & Mid-point Time $/ \mathrm{s}$ & {$[\mathrm{RBr}]_{\mathrm{t}} / \mathrm{mol} \mathrm{dm}^{-3}$} \\
\hline 0 & 0 & 0.200 \\
\hline $442-458$ & 450 & 0.182 \\
\hline $892-908$ & 900 & 0.155 \\
\hline $1342-1358$ & 1350 & 0.136 \\
\hline $1792-1808$ & 1800 & 0.119 \\
\hline $2242-2258$ & 2250 & 0.105 \\
\hline $2692-2708$ & 2700 & 0.095 \\
\hline $3142-3158$ & 3150 & 0.083 \\
\hline $3592-3608$ & 3600 & 0.074 \\
\hline $4042-4508$ & 4050 & 0.065 \\
\hline
\end{tabular}


Table 5.8

Temperature

Solvent

$[\mathrm{RBr}]_{0}$

$\left[\mathrm{NaNO}_{2}\right]_{0}$

$\left[\mathrm{NaClO}_{4}\right]_{0}$
The Effect of a Decrease in Ionic Strength on the Reaction of Sodium Nitrite with p-Nitrocumyl Bromide in Dimethyl Sulphoxide

$30^{\circ} \mathrm{C}$

$99.9 \% \mathrm{C}_{2} \mathrm{D}_{6} \mathrm{SO}$

$0.20 \mathrm{~mol} \mathrm{dm}^{-3}$

$\left(\mathrm{R}=\mathrm{C}_{9} \mathrm{H}_{10} \mathrm{NO}_{2}\right)$

$0.20 \mathrm{~mol} \mathrm{dm}-3$

$0.00 \mathrm{~mol} \mathrm{dm}^{-3}$

\begin{tabular}{|c|c|c|}
\hline Time Range / s & Mid-point Time $/ \mathrm{s}$ & {$[\mathrm{RBr}]_{\mathrm{t}} / \mathrm{mol} \mathrm{dm}^{-3}$} \\
\hline 0 & 0 & 0.200 \\
\hline $2992-3008$ & 3000 & 0.139 \\
\hline $5992-6008$ & 6000 & 0.105 \\
\hline $8992-9008$ & 9000 & 0.082 \\
\hline $11992-12008$ & 12000 & 0.066 \\
\hline $14992-15008$ & 15000 & 0.053 \\
\hline $17992-18008$ & 18000 & 0.043 \\
\hline $20992-21008$ & 21000 & 0.036 \\
\hline $23992-24008$ & 24000 & 0.029 \\
\hline $26992-27008$ & 27000 & 0.024 \\
\hline
\end{tabular}




\section{Table 5.9}

The effect of various experiments on the reaction rate of the reaction of sodium nitrite with $p$-nitrocumyl bromide in dimethyl sulphoxide.

\begin{tabular}{|c|c|c|c|c|c|c|}
\hline $\begin{array}{c}{\left[\mathrm{NaNO}_{2}\right]_{0}} \\
/ \mathrm{mol} \mathrm{dm}^{-3}\end{array}$ & $\begin{array}{c}{[R B r]_{0}} \\
/ \mathrm{mol} \mathrm{dm}^{-3}\end{array}$ & $\begin{array}{c}{\left[\mathrm{NaClO}_{4}\right]_{\mathbf{0}}} \\
/ \mathrm{mol} \mathrm{dm}^{-3}\end{array}$ & $\begin{array}{c}10^{4} \boldsymbol{k}_{1} / \\
\mathbf{s}^{-1}\end{array}$ & $\begin{array}{c}10^{4} \boldsymbol{k}_{\mathbf{2}} / \\
\mathrm{dm}^{\mathbf{3}} \mathbf{m o l}^{-1} \mathbf{s}^{-1}\end{array}$ & $\begin{array}{c}10^{4} \boldsymbol{k}_{\mathbf{3}}^{\prime} / \\
\mathrm{dm}^{6} \mathbf{m o l}^{-2} \mathbf{s}^{-1}\end{array}$ & $\begin{array}{c}10^{5} \boldsymbol{k}_{\mathbf{s}} / \\
\mathbf{s}^{-1}\end{array}$ \\
\hline 1.00 & 0.20 & 0.00 & 3.15 & 3.48 & 3.96 & 4.20 \\
\hline \multicolumn{2}{|c|}{$95 \% \mathrm{C}_{2} \mathrm{D}_{6} \mathrm{SO}: 5 \% \mathrm{H}_{2} \mathrm{O}$} & 2.79 & 3.04 & 2.71 & 4.30 \\
\hline 0.80 & 0.20 & 0.20 & 2.32 & 3.27 & 3.93 & 4.28 \\
\hline $\mathrm{NaBr}\left(0.20 \mathrm{~mol} \mathrm{dm}^{-3}\right)$ & 0.00 & 2.47 & 3.53 & 4.38 & 4.59 \\
\hline 0.20 & 0.20 & 0.80 & 0.591 & 7.36 & 3.96 & 4.56 \\
\hline 0.20 & 0.20 & 0.00 & 0.762 & 13.2 & 24.6 & 5.78 \\
\hline
\end{tabular}

\section{Table 5.10}

A comparison of termolecular rate constants derived from GEAR and GIT, $\left(k_{3}^{\prime}\right)$, with the termolecular rate constants (Isolated points deleted) ${ }^{*}$ derived from Equation $4.19,\left(k^{\prime \prime}{ }^{*}\right)$.

\begin{tabular}{|c|c|c|c|c|c|c|}
\hline $\begin{array}{c}{\left[\mathrm{NaNO}_{2}\right]_{0}} \\
/ \mathrm{mol} \mathrm{dm}^{-3}\end{array}$ & $\begin{array}{c}{[R B r]_{0}} \\
/ \mathrm{mol} \mathrm{dm}^{-3}\end{array}$ & $\begin{array}{c}{\left[\mathrm{NaClO}_{4}\right]_{0}} \\
/ \mathrm{mol} \mathrm{dm}^{-3}\end{array}$ & $\begin{array}{c}10^{5} \boldsymbol{k}_{\mathrm{s}} / \\
\mathbf{s}^{-1}\end{array}$ & $\begin{array}{c}10^{4} \boldsymbol{k}_{3}^{\prime} / \\
\mathrm{dm}^{6} \mathrm{~mol}^{-2} \mathbf{s}^{-1}\end{array}$ & $\begin{array}{c}10^{4} \boldsymbol{k}_{3}^{\prime \prime} / \\
\mathrm{dm}^{6} \mathrm{~mol}^{-2} \mathbf{s}^{-1}\end{array}$ & $\begin{array}{c}\mathbf{r}^{*} \\
\sigma^{*} / \%\end{array}$ \\
\hline 1.00 & 0.20 & 0.00 & 4.20 & 3.96 & 3.36 & $\begin{array}{c}0.9998 \\
0.71\end{array}$ \\
\hline \multicolumn{2}{|c|}{$95 \% \mathrm{C}_{2} \mathrm{D}_{6} \mathrm{SO}: 5 \% \mathrm{H}_{2} \mathrm{O}$} & 4.30 & 2.71 & 2.80 & $\begin{array}{c}0.9998 \\
0.59\end{array}$ \\
\hline 0.80 & 0.20 & 0.20 & 4.28 & 3.93 & 3.81 & $\begin{array}{c}0.9999 \\
0.45\end{array}$ \\
\hline $\mathrm{NaBr}\left(0.20 \mathrm{~mol} \mathrm{dm}^{-3}\right)$ & 0.00 & 4.59 & 4.38 & 4.05 & $\begin{array}{c}0.9996 \\
0.85\end{array}$ \\
\hline 0.20 & 0.20 & 0.80 & 4.56 & 3.96 & 4.80 & $\begin{array}{c}0.9995 \\
1.08\end{array}$ \\
\hline 0.20 & 0.20 & 0.00 & 5.78 & 24.6 & 26.1 & 0.9999 \\
\hline
\end{tabular}




\subsection{Relative Reactivity of Free Nitrite and Ion Paired Nitrite with p-Nitrocumyl Bromide}

Since heterolytic mechanisms that give termolecular kinetics are rare, 57 one must be on the alert for other pathways leading to the observed kinetics. In our analysis of the kinetic data, we made the simplification that one mole of sodium nitrite gave one mole of free nitrite. In reality, sodium nitrite will be incompletely dissociated. Salts are not fully dissociated in solvents of low dielectric constant, but exist as ion pairs or as higher ionic aggregates. Ion pairing occurs to a lesser extent in aprotic solvents such as dimethyl sulphoxide, but it is still important.

The free nitrite will be very much more reactive than the associated ion pair $\left(k_{\mathrm{F}}>\right.$ $k_{\mathrm{p}}$ ) and a rate expression for the parallel paths may be set up (Scheme 5.1):

$$
\begin{gathered}
\mathrm{NO}_{2}^{-}+\mathrm{RBr} \stackrel{k_{\mathrm{F}}}{\longrightarrow} \mathrm{RNO}_{2}+\mathrm{Br}^{-} \\
\mathrm{Na}^{+} \mathrm{NO}_{2}^{-}+\mathrm{RBr} \stackrel{k_{\mathrm{P}}}{\longrightarrow} \mathrm{RNO}_{2}+\mathrm{Na}^{+} \mathrm{Br}^{-} \\
k=\alpha k_{\mathrm{F}}+(1-\alpha) k_{\mathrm{P}}
\end{gathered}
$$

Scheme 5.1

$k, k_{\mathrm{F}}$, and $k_{\mathrm{P}}$ are the observed second order rate constant and the rate constants for reaction of the free ions and ion pairs, respectively; $\alpha$ is the degree of dissociation of $\mathrm{Na}^{+} \mathrm{NO}_{2}^{-}$.

Sodium perchlorate was added to the sodium nitrite solutions so that a constant ionic strength was maintained. Sodium perchlorate will also be associated in dimethyl sulphoxide and the following equilibria can be set up (Equations 5.1 and 5.2): 


$$
\begin{aligned}
& \mathrm{Na}^{+} \mathrm{NO}_{2}^{-} \stackrel{k_{\mathrm{a}}^{\mathrm{N}}}{\rightleftharpoons} \mathrm{Na}^{+}+\mathrm{NO}_{2}^{-} \\
& \mathrm{Na}^{+} \mathrm{ClO}_{4}^{-} \stackrel{k_{\mathrm{a}}^{\mathrm{P}}}{\rightleftharpoons} \mathrm{Na}^{+}+\mathrm{ClO}_{4}^{-}
\end{aligned}
$$

If $k_{\mathrm{a}}^{\mathrm{P}} \gg k^{\mathrm{N}}$, and the concentration of sodium perchlorate increases, then the equilibrium in Equation 5.1 may be shifted to the left. This would increase the extent of association between the nitrite anion and the sodium cation. In the kinetic runs carried out in chapter 3 , the concentration of sodium perchlorate was increased as the concentration of sodium nitrite decreased. If the addition of sodium perchlorate did increase the extent of association, then the observed kinetics may be explained in terms of a bimolecular mechanism. In effect, the second order rate constant, $k$, would decrease with sodium perchlorate concentration increase. If the observed termolecular kinetics were a result of a variation in the second order rate constant, $k$, then this would be purely coincidental. The following bimolecular mechanisms (5.4.1 to 5.4.6) are based on the premise that the observed termolecular kinetics are a result of a variation in the second order rate constants. The term nitrite refers to both free and associated nitrite.

\subsubsection{Concurrent $\mathrm{S} N 2$ and E2C mechanism}

If the second order rate constant, $k$, is varying, then several bimolecular mechanisms can be envisaged. One mechanism that could be envisaged would be a concurrent $\mathrm{S}_{\mathrm{N}} 2$ and $\mathrm{E} 2 \mathrm{C}$ mechanism (Transition State 5.1). The E2C mechanism, ${ }^{64}$ as opposed to the E2 Mechanism, is characterised by strong nucleophiles that are weak bases. The reactions are favoured by good leaving groups, the reactivity order is tertiary $>$ secondary $>$ primary, and they are favoured by dipolar aprotic solvents.

In Transition state 5.1, nitrite may interact in the transition state with the $\beta$ hydrogen as well as with the $\alpha$-carbon, however, the nitrite interacts mainly with the carbon. 


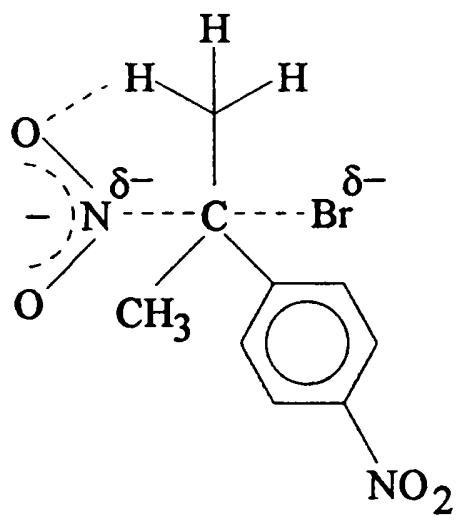

Transition State 5.1

The presence of the $p$-nitrophenyl group will help to stabilise the electron rich transition state and in dimethyl sulphoxide the transition state will be stabilised relative to the initial state. Alkylation should preferentially occur at the most polarisable centre of the ambident anion, the site with the lowest electronegativity, that is, nitrogen Attack by nitrogen would help to lessen any positive charge on the benzylic carbon in Transition State 5.1. The experimental evidence favours this transition state; the percentage yield of $\alpha, p$ dinitrocumene is greater than the percentage yield of $p$-nitrocumyl alcohol for high concentrations of sodium nitrite and low concentrations of sodium perchlorate (Table 4.1). Since $S_{N} 2$ mechanisms at tertiary carbon atoms are rare, $65-67$ one must be on the alert for other pathways leading to the observed kinetics.

\subsection{2 $\underline{\text { S}} \underline{\text { 2-Type Ion Pair Mechanism }}$}

An alternative to the classical $\mathrm{S}_{\mathrm{N}} 2$ mechanism would be an $\mathrm{S}_{\mathrm{N}}$-type ion pair mechanism (Scheme 5.2). The nitrite molecule (free or associated) assists in the formation of a tight ion pair (Scheme 5.2). Nitrite may interact with the $\beta$-hydrogen as well as with the $\alpha$-carbon, however, the nitrite interacts mainly with the carbon. 

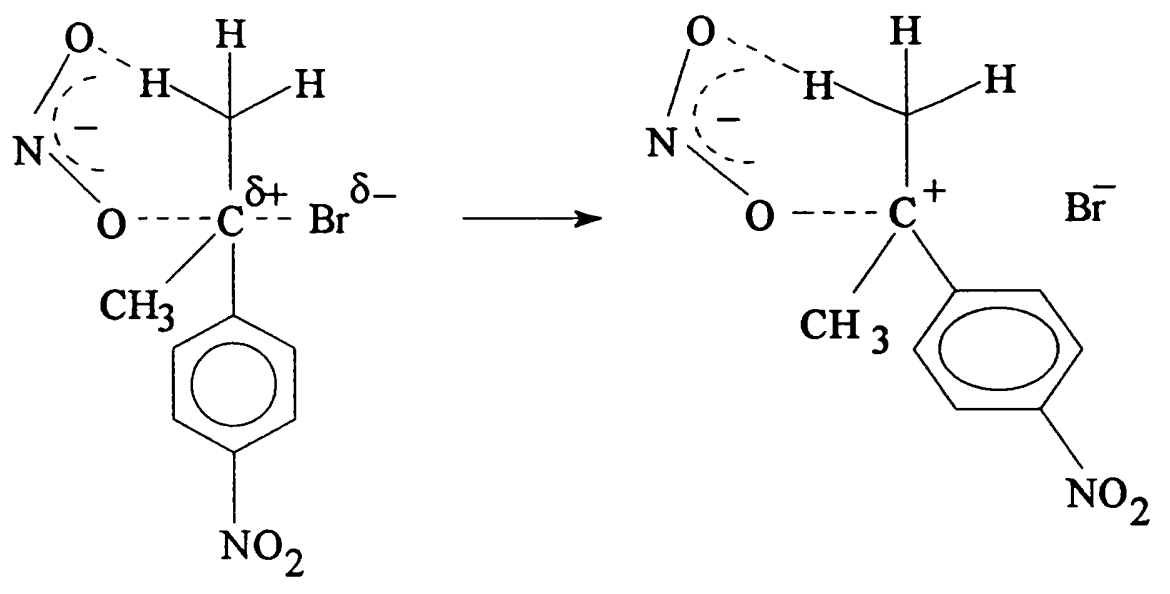

Scheme 5.2

Alkylation will preferentially occur at the most electronegative part of the ambident anion, that is, oxygen. Attack by oxygen would help to form a positive charge on the benzylic carbon in Scheme 5.2. The experimental evidence does not favour this transition state. The $\mathrm{S}_{\mathrm{N}}$ 2-type ion pair mechanism differs from the classical $\mathrm{S}_{\mathrm{N}} 2$ mechanism in that it postulates the formation of an intermediate. The two mechanisms differ with respect to the magnitude of the positive charge on the tertiary carbon in the transition state. It should be small in Transition State 5.1 and large in the one leading to the ion pair in Scheme 5.2.

The formation of the tight ion pair may not need the assistance of nitrite. In this case the $\mathrm{C}-\mathrm{Br}$ bond is broken heterolytically and reversibly in a preliminary step without participation of the nitrite anion, the principal driving force being solvation of the bromide atom. The reaction is then completed by slow attack of nitrite on this intimate ion pair. There is very little difference between these two ion pair mechanisms and in either event the nucleophile is involved in the rate limiting step.

\subsection{3 $\underline{\text { S }} \underline{2} \underline{C}+$ Mechanism}

One could imagine a mechanism, (Scheme 5.3), in which a carbocation is in fast equilibrium with the $p$-nitrocumyl substrate. Nitrite (free or associated) may attack the carbocation at a slow rate to form the substituted products and give second order kinetics. The alkene would be formed from the carbocation via an E1 elimination and its 
rate of formation would be independent of sodium nitrite. The addition of sodium bromide would shift the equilibrium to the left and the reaction would be inhibited (common ion effect), however, no common ion effect was observed (See 5.3.1). The experimental evidence suggests that the formation of the alkene is dependent upon the concentration of sodium nitrite, so Scheme 5.3 is unfavourable.

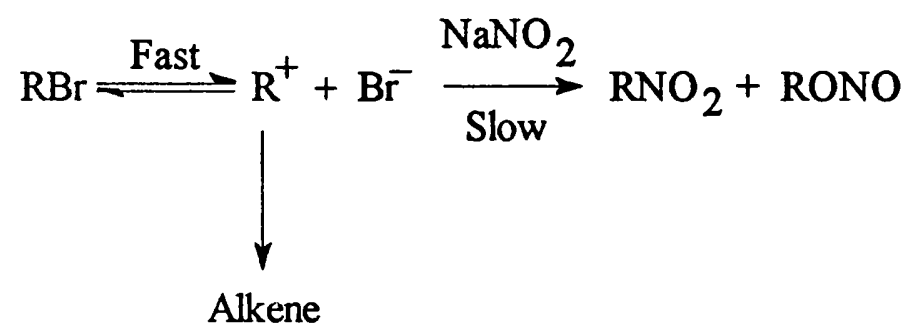

Scheme 5.3

\subsubsection{Carbanion Mechanism}

The electron withdrawing $p$-nitro substituent would help to stabilise a carbanion. The possibility that nitrite attacks bromine to give a carbanion and this carbanion then gives rise to the observed product by displacing bromide ion from the nitryl bromide was considered (Scheme 5.4):

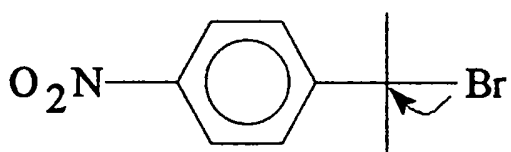

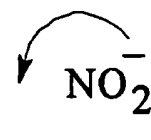<smiles>CC(=O)c1ccc([N+](=O)[O-])cc1</smiles>

$\mathrm{BrNO}_{2}$<smiles>CC(C)(C)[N+](=O)[O-]</smiles><smiles>CCO[N+](=O)c1ccc(C(C)(C)[N+](=O)[O-])cc1</smiles> 


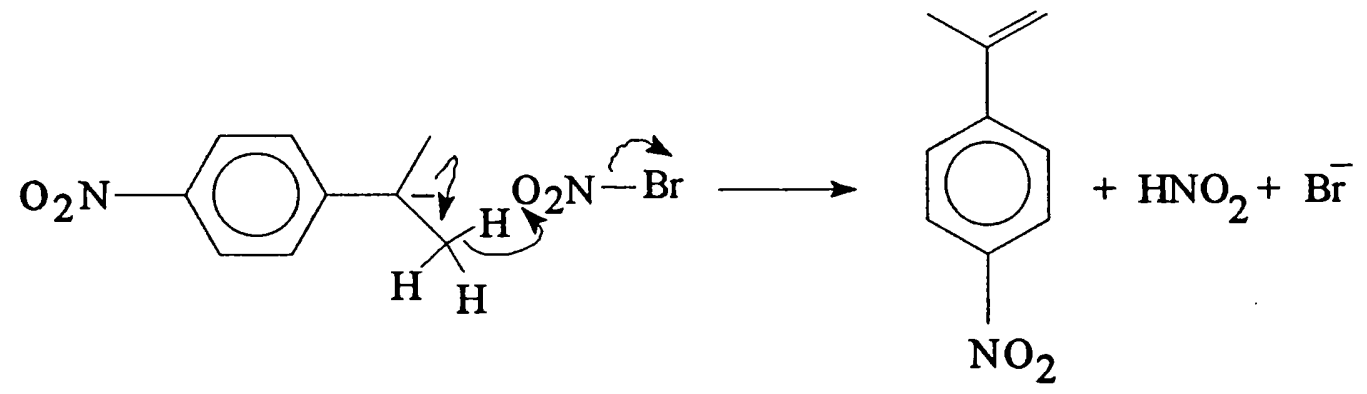

Scheme 5.4

If this were the case, one would expect either nitrous acid or traces of water to intercept the carbanion to give $p$-nitrocumene. No $p$-nitrocumene was detected experimentally. Moreover, nitryl bromide is unknown, but nitryl fluoride and nitryl chloride have been prepared. 68 This evidence suggests that a carbanion mechanism is unlikely.

\subsubsection{Elimination-Addition Mechanism}

Rather than having a substitution process, one can envisage an eliminationaddition mechanism. This would be an E2 elimination followed by electrophilic addition of nitrous acid (Scheme 5.5):

$$
\begin{aligned}
\mathrm{RBr}+\mathrm{NO}_{2}^{-} & \longrightarrow \text { Alkene }+\mathrm{HNO}_{2}+\mathrm{Br} \\
\text { Alkene }+\mathrm{HNO}_{2} & \longrightarrow \mathrm{RNO}_{2}+\mathrm{RONO}
\end{aligned}
$$

Scheme 5.5

The electrophilic addition would preferentially occur at the most electronegative part of the ambident anion, that is, oxygen. If this mechanism was in progress then we would expect the formation of alkene to level offquite rapidly, but experimentally we do not see this (see 4.3). It was found experimentally, that nitrous acid did not readily add to $p$-nitro- 
$\alpha$-methylstyrene in dimethyl sulphoxide under normal conditions. Again this is another mechanism that is

\subsubsection{Inso Mechanism}

With a little imagination a mechanism can be postulated that involves nitrite attack ipso to the isopropyl group. The intermediate could then undergo either neighbouring group participation or a 1,2 shift to give the desired products (Scheme 5.6). There is evidence $^{69}$ for the existence of this type of complex, especially in trinitro aromatics, as we shall see later on. This mechanism is as appealing as the concurrent $\mathrm{S}_{\mathrm{N}} 2$ and E2C mechanism. If it were at all possible, isolation of the Meisenheimer complex would be a sure way of proving the ipso mechanism. The presence of the $p$-nitro group will help to stabilise the electron rich complex.

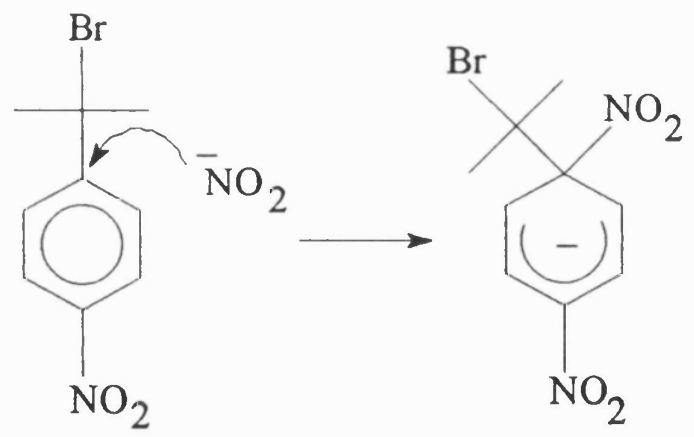

Scheme 5.6

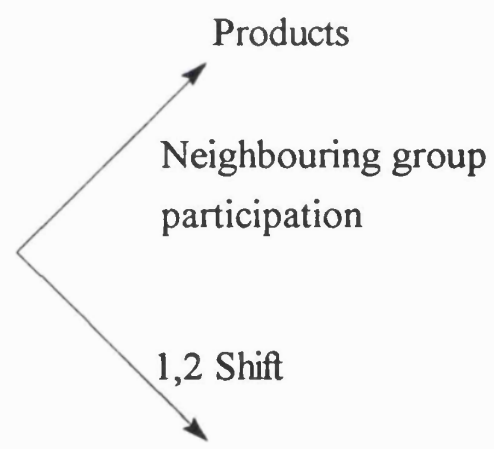

Products

\subsubsection{Conclusion}

These mechanisms are based on the premise that the observed termolecular kinetics are a result of a variation in the second order rate constants due to the addition of sodium perchlorate. The premise is not a strong one as there is no reason why sodium perchlorate should dissociate to an enormously greater extent than sodium nitrite in a 
solvent such as dimethyl sulphoxide. The extent of ion pairing decreases with increasing ionic size. Even though perchlorate is a larger anion than nitrite, both anions are large with respect to anions that are known to have low dissociation constants with the sodium cation. 5 The premise also relies on the fact that variation in the second order rate constants due to the addition of sodium perchlorate coincidentally gives termolecular kinetics. The probability of this occurring is very small, however, it is still finite.

The concurrent $\mathrm{S}_{\mathrm{N}} 2$ and $\mathrm{E} 2 \mathrm{C}$ mechanism and the ipso mechanism are the best processes to explain the kinetic and experimental results, assuming the second order rate constants are varying due to the addition of sodium perchlorate. The extravagant ipso mechanism is quite appealing, however, there are no examples which one could compare to our system.

As we have already mentioned, $\mathrm{S}_{\mathrm{N}} 2$ mechanisms at tertiary alkyl bromides are rare. ${ }^{65-67}$ Bordwell et al. 51 found that when $\mathrm{ArSO}_{2} \mathrm{CH}=\mathrm{CHC}\left(\mathrm{CH}_{3}\right)_{2} \mathrm{Br}$ was treated with sodium nitrite in dimethyl formamide at $25^{\circ} \mathrm{C}$ for 45 hours, the exclusive product was the corresponding tertiary nitro $\mathrm{S}_{\mathrm{N}}$ 2-type compound (Scheme 5.7):

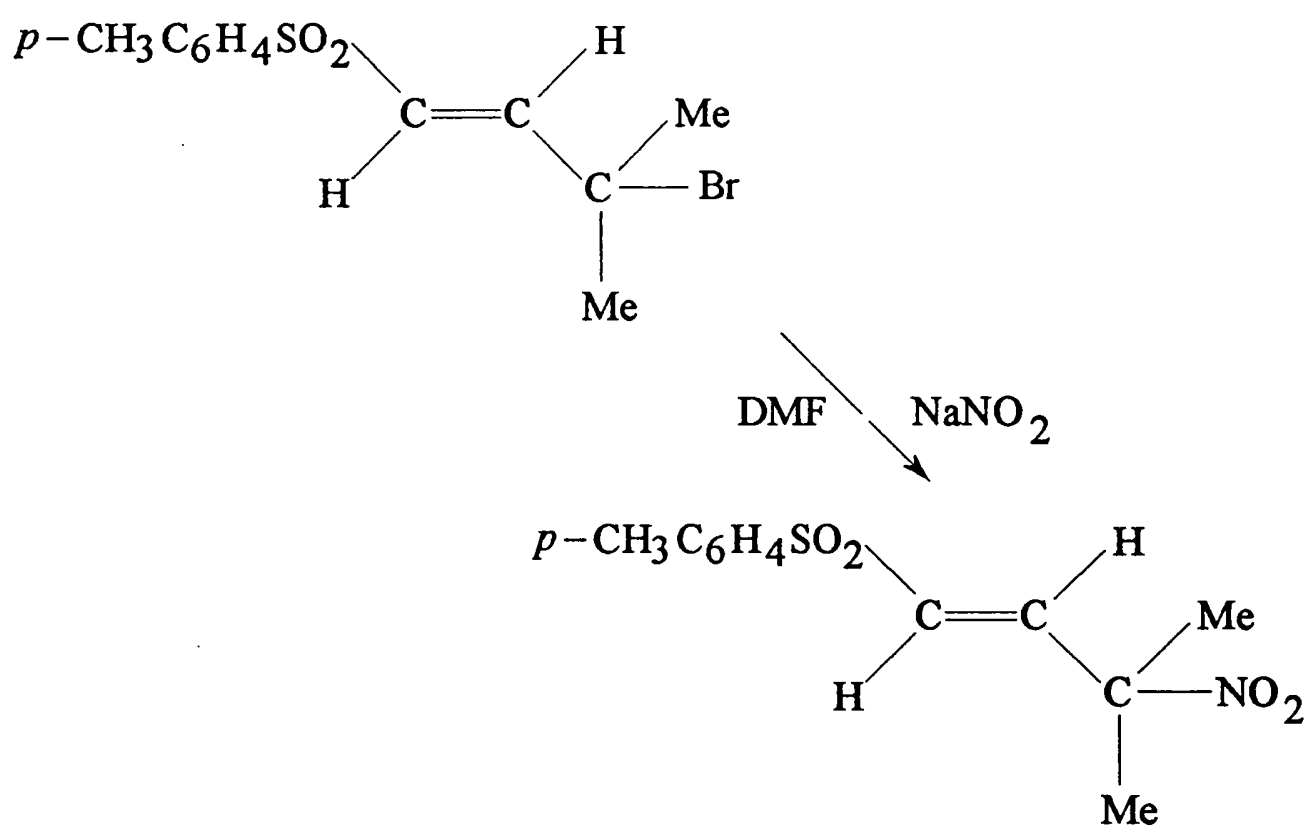

Scheme 5.7 
Bordwell believes this reaction occurs via an $\mathrm{S}_{\mathrm{N}}$ 2-type mechanism that involves ion pair formation by nucleophilic assistance. The fact that Bordwell essentially isolated the nitro product indicates a more covalent transition state, that is, a classical $\mathrm{S}_{\mathrm{N}} 2$ mechanism. The evidence would therefore suggest that $\mathrm{S}_{\mathrm{N}} 2$ mechanisms at tertiary alkyl bromides, with nitrite as the nucleophile, are possible.

\subsection{Heterolytic Termolecular Processes}

The observed termolecular kinetic component in the reaction of sodium nitrite with $p$-nitrocumyl bromide in dimethyl sulphoxide may be due to a variation in the second order rate constants, caused by the addition of sodium perchlorate. However, the possibility of a true heterolytic termolecular process cannot be ruled out. As we have mentioned earlier, true termolecular processes are rare, but examples do exist in nucleophilic substitution 57 and electrophilic addition 58,59 .

\subsubsection{Termolecular Nucleophilic Substitution}

C.Gardner Swain discovered a heterolytic nucleophilic substitution reaction that obeyed, within experimental error, third order kinetics. 57 Swain found that when triphenylmethyl (trityl) chloride or bromide was treated with methanol in dry benzene solution, which contained a tertiary amine, the product obtained was a trityl methyl ether. The tertiary amine was used simply to take up the hydrogen halide formed and render the reaction irreversible. The reaction between trityl halides and tertiary amines was found to be negligibly slow under these conditions, and the rate of reaction with methanol was unaffected by changing the concentration of tertiary amine used. Within experimental error the reaction with methanol was exactly third order (first order in trityl halide, second order in methanol). As the order of this reaction is so precisely third, rather than intermediate between second and third or between third and fourth, Swain pointed out the fact that he was dealing with a pure mechanism. 
Swain also found that tris-( $p$-t-butyl)-trityl chloride reacted with methanol in dry benzene solution thirty times as rapidly as did trityl chloride. According to Hammett's treatment of the reactions of $m$ - and $p$-substituted benzene derivatives, the $p-t$-butyl group has a $\sigma^{+}$value of -0.26 . This gives a reaction constant of -7.5 , or -2.5 per $t$-butyl group, representing a rather high sensitivity of the reaction to substituent. The direction of the change in rate was opposite to what one would expect if stabilisation of the transition state or formation of the covalent bond to oxygen were the most important factors determining the rate (Transition State 5.2):<smiles>CO[C]C(c1ccccc1)(c1ccccc1)C(C)OC</smiles>

Transition State 5.2

However, it was what one would expect if the transition state and product formed by the rate determining step were as follows (Scheme 5.8):<smiles>CO[14CH]=[GeH]C(c1ccccc1)(c1ccccc1)c1ccccc1</smiles><smiles>CO[CH]Cl</smiles>

Scheme 5.8 
The product formed by the rate-determining step is a solvated ion pair. The bonds with three dashes represent ion-dipole solvation bonds. The solvated pair may then react to form products. It is impossible kinetically to distinguish a termolecular reaction from a rapid bimolecular association of two of the reactants to give a low equilibrium concentration of a complex, followed by slow bimolecular reaction of the complex with the third reactant. Thus the rate determining step in Swain's experiments might be a back side attack by methanol on a solvated trityl halide complex, $\left(\mathrm{C}_{6} \mathrm{H}_{5}\right)_{3} \mathrm{CCl}----\mathrm{HOR}$.

The reaction of sodium nitrite with $p$-nitrocumyl bromide in dimethyl sulphoxide has a major difference with Swain's trityl halide/methanol system: The nitrite anion is a negatively charge species and cannot emulate the role of methanol. However, the attack of nitrite on $p$-nitrocumyl bromide to give an intermediate, followed by attack of a second nitrite on the intermediate to give products is quite possible (Scheme 5.9):

$$
\mathrm{RBr}+\mathrm{NO}_{2}^{-} \stackrel{\text { Fast }}{\rightleftharpoons} \text { Intermediate } \stackrel{\mathrm{NO}_{2}^{-}}{\longrightarrow} \text { Products }
$$

Scheme 5.9

\subsubsection{A Possible Termolecular Nucleophilic Substitution Mechanism for the Reaction of Sodium Nitrite with p-Nitrocumyl Bromide in Dimethyl Sulphoxide}

There is evidence in the literature for a mechanism similar to the one postulated in Scheme 5.9. Thibblin et al. 70 found that the iodide ion accelerated the acid-catalysed solvolysis of 1,1-diphenyl-1-methoxyethane (Scheme 5.10). Thibblin postulated that the acceleration of the solvolysis by addition of the iodide anion was caused by nucleophilic attack on the initially formed carbocation-methanol pair (Scheme 5.10). The unstable iodo intermediate is expected to react very fast to yield the alcohol product. Thibblin concluded that the alkene was formed mainly by elimination from the ion pair. This piece of work by Thibblin et al. suggests that nucleophiles can catalyse certain reactions. 
<smiles>COC(C)(c1ccccc1)c1ccccc1</smiles>

$\mathrm{Ph}$<smiles>C[C+]=CC(C)(c1ccccc1)c1ccccc1</smiles>

$$
1
$$<smiles>CC(c1ccccc1)(c1ccccc1)c1ccccc1</smiles>

Unstable Intermediate

Carbocation-Methanol Pair

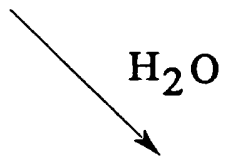<smiles>CC(O)(c1ccccc1)c1ccccc1</smiles>

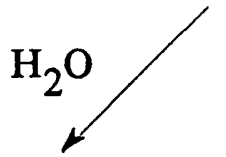<smiles>C=C(c1ccccc1)c1ccccc1</smiles>

Scheme 5.10

A mechanism can now be postulated in order to explain the termolecular kinetic component of the reaction of sodium nitrite with p-nitrocumyl bromide in dimethyl sulphoxide (Scheme 5.11). In Scheme 5.11 -nitrocumyl bromide is in rapid equilibrium with its ion pair (Step 1). The ion pair is then attacked by nitrite on an ortho aromatic carbon to form an ion-molecule pair (Step 2). There is a fast equilibrium between the ion pair and the ion-molecule pair. The ion pair formed in step 1 will have a degree of positive charge on the ortho aromatic carbons. Nitrite will therefore preferentially attack via oxygen to give the unstable ion-molecule pair intermediate. 

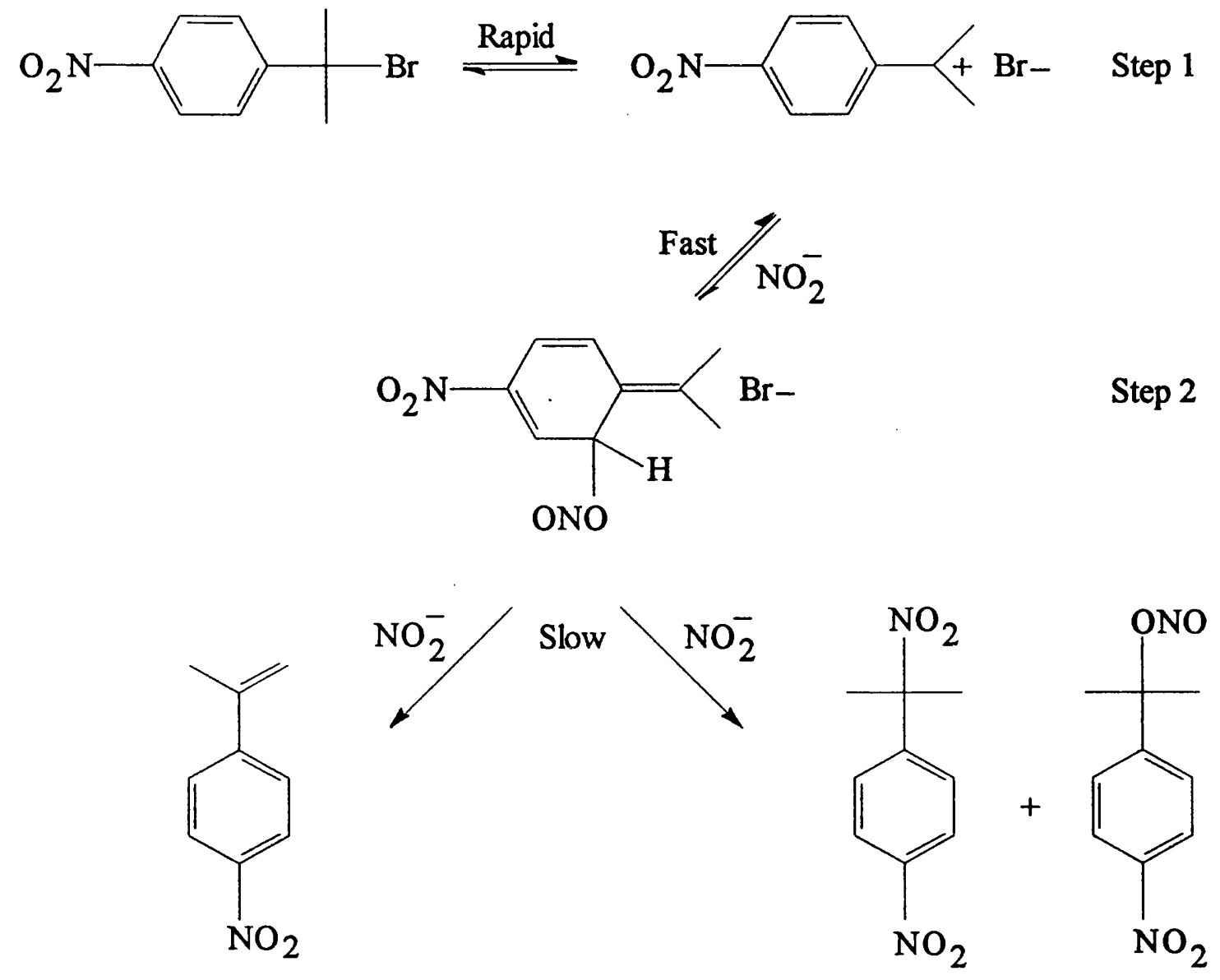

Elimination

Substitution

Scheme 5.11

A second molecule of nitrite, acting as a nucleophile, may then attack this ion-molecule pair via an $\mathrm{S}_{\mathrm{N}} 2^{\prime}$-type mechanism to give substitution products. The second molecule of nitrite will now be attacking a neutral vinylic carbon so substitution will preferentially, but not necessarily exclusively, occur via nitrogen: $\alpha, p$-Dinitrocumene becomes the major product at high concentrations of sodium nitrite. A second molecule of nitrite, acting as a base, may then attack this ion-molecule pair via an E2'-type mechanism to give elimination products. When ${ }^{15} \mathrm{~N}$-labelled sodium nitrite was used, there was no sign of ${ }^{15} \mathrm{~N}$ coupling to the aromatic protons in the proton n.m.r. spectra of the isolated products. Hence, nitrite attack ipso to the $p$-nitro group can be ruled out since there would be a $50 / 50$ chance of the original nitro group departing. 
Termolecular kinetics will only be observed if Steps 1 and 2 are rapid and the substitution and elimination processes are slow: The substrate and two molecules of nitrite would be involved in the rate determining step. However, if Step 2 is slow and the substitution and elimination processes are fast then bimolecular kinetics will be observed.

There is evidence in the literature for complexation at unsubstituted aromatic carbons in dimethyl sulphoxide. ${ }^{69}$ A number of adducts of trinitrobenzene in dimethyl sulphoxide have been characterised by ${ }^{1} \mathrm{H}$ n.m.r. (Scheme 5.12):

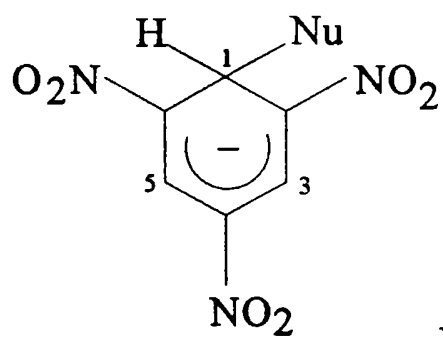

$$
\mathrm{Nu}=\mathrm{OH}, \mathrm{OCH}_{3}, \mathrm{OC}_{6} \mathrm{H}_{5}, \mathrm{NH}_{2}, \mathrm{CH}_{3}, \mathrm{CH}\left(\mathrm{CH}_{3}\right) \mathrm{NO}_{2}
$$

Scheme 5.12

The formation of the sigma complex in Scheme 5.12 is characterised by the disappearance of the singlet from trinitrobenzene $(\delta=9.20 \mathrm{ppm})$ and the concomitant appearance of an $\mathrm{AX}_{2}$ system at higher field. In accord with the change in hybridisation

from $s p^{2}$ to $s p^{3}$, the ring proton at C-1 exhibits a high field resonance but, importantly, this resonance is sensitive to the nature of the atom or group bonded to that carbon.

In light of the above evidence, the ion-molecule pair intermediate in Scheme 5.11 may be possible. The complete mechanism in Scheme 5.11 is probably unlikely, but it is a mechanism that can account for the termolecular kinetic component in the reaction of sodium nitrite with $p$-nitrocumyl bromide in dimethyl sulphoxide.

\subsection{Final Conclusion}

The reaction of sodium nitrite with p-nitrocumyl bromide in dimethyl sulphoxide proceeds via a heterolytic mechanism to give the products $\alpha, p$-dinitrocumene, $p$ - 


\section{Chapter 5}

nitrocumyl alcohol and $p$-nitro- $\alpha$-methylstyrene respectively. The overall disappearance of $p$-nitrocumyl bromide can be expressed as follows:

$$
-\left(d[\mathrm{RBr}]_{\mathrm{t}} / d t\right)=k_{\mathrm{S}}[\mathrm{RBr}]_{\mathrm{t}}+k_{3}^{\prime}[\mathrm{RBr}]_{\mathrm{t}}\left[\mathrm{NO}_{2}{ }^{-}\right]_{\mathrm{t}}{ }^{2}
$$

The unimolecular component of the overall rate of reaction can be attributed to the elimination of $p$-nitrocumyl bromide in dimethyl sulphoxide. The termolecular component of the overall rate of reaction cannot be characterised so easily.

The termolecular component could be due to a decrease in the rate constant for a bimolecular process caused by the addition of sodium perchlorate. There is strong evidence to support this premise as a very large termolecular rate constant is obtained when sodium perchlorate is excluded. This bimolecular process would probably either be an $\mathrm{S}_{\mathrm{N}}$ 2/E2C mechanism or a mechanism involving ipso attack at the isopropyl group followed by neighbouring group participation or a 1,2 . shift.

A true termolecular mechanism can be postulated. This mechanism involves rapid formation of an ion-molecule pair intermediate, which incorporates a nitrite molecule, followed by attack of a second nitrite molecule on this intermediate to give substitution and elimination products. This mechanism is rather elaborate and seems very unlikely, but it does account for the termolecular kinetic component. 
Chapter 5 


\section{CHAPTER 6}

\section{A Kinetic Study of the Reaction of Lithium Azide with p-Nitrocumyl Bromide in \\ Dimethyl Sulphoxide \\ PART 1}

\subsection{Introduction}

Much work has been carried out on the reaction of $p$-nitrocumyl chloride with the azide anion in various dipolar aprotic solvents. 17,63 Kornblum et al. have shown that when $p$-nitrocumyl chloride was treated with sodium azide in hexamethylphosphoramide (HMPA), under an argon atmosphere, the reaction was 65\% complete in 75 seconds, but in the presence of $10 \mathrm{~mol} \%$ of $p$-dinitrobenzene (strong electron acceptor) no reaction occurred $^{17}$ (Equation 6.1):

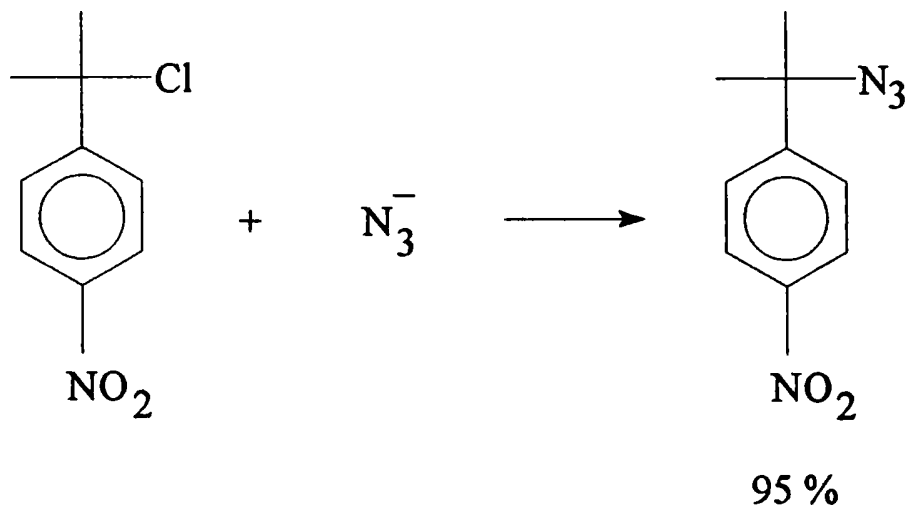

However, when dimethyl sulphoxide was used as the solvent the reaction was much slower. When p-nitrocumyl chloride was treated with lithium azide (two fold excess) in dimethyl sulphoxide, under an argon atmosphere, and irradiated with ultraviolet light, the reaction had a half-life of 7 minutes. In the dark this reaction had a half-life of 50 hours. Kornblum et al. believe that the reaction in Equation 6.1 involves a radical chain process.

At present there is no known literature on the reaction of $p$-nitrocumyl bromide with the azide anion, so a detailed investigation of the reaction was carried out. When $p$ - 
nitrocumyl bromide was treated with lithium azide (two fold excess) in dimethyl sulphoxide and under an argon atmosphere (see 9.4.8), the reaction had a half-life of 10 minutes at $30^{\circ} \mathrm{C}$ (Equation 6.2):

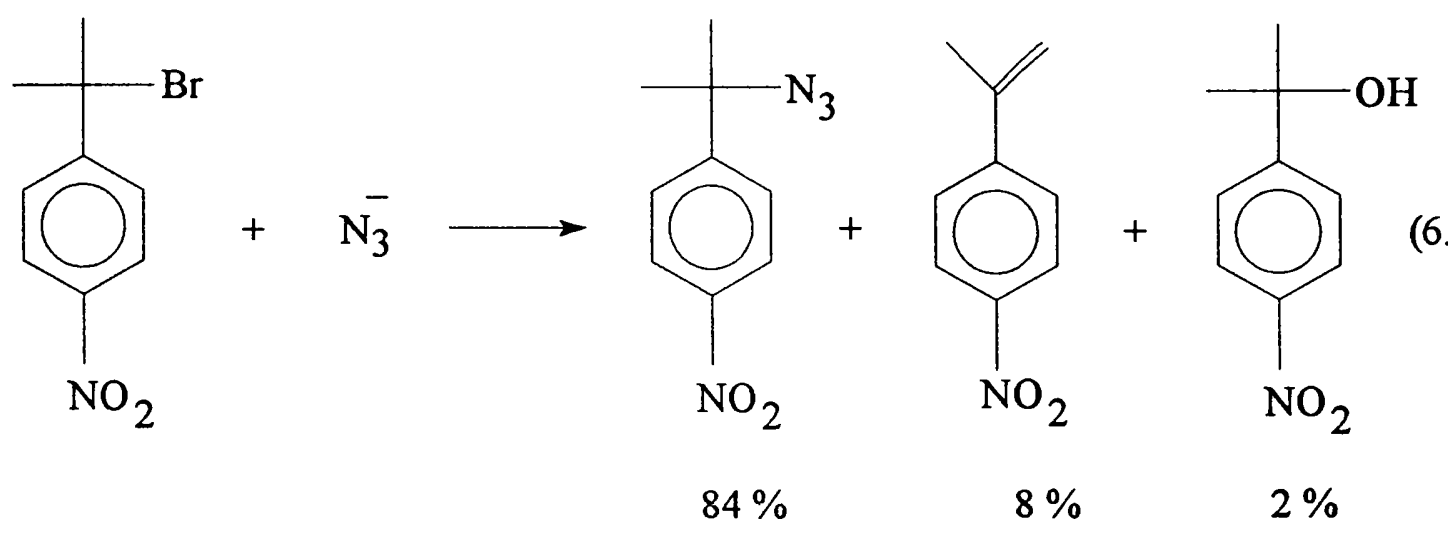

The major product formed is the same tertiary azido compound produced in Equation 6.1. The minor products seem to have resulted from the elimination of $p$-nitrocumyl bromide in dimethyl sulphoxide.

The reaction of lithium azide with $p$-nitrocumyl bromide in dimethyl sulphoxide was initially investigated using $100 \mathrm{MHz}{ }^{1} \mathrm{H}$ n.m.r. spectroscopy. This investigation showed that the rate of reaction was dependent on the concentration of lithium azide. In this chapter, a detailed kinetic analysis will be carried out using $400 \mathrm{MHz}{ }^{1} \mathrm{H}$ n.m.r. spectroscopy. A kinetic model will be postulated that not only fits to the disappearance of p-nitrocumyl bromide, it also fits to the creation of products. This chapter only deals with the kinetic model and the derivation of any rate equations. In chapters 7 and 8 , the possible mechanisms that may give rise to the observed kinetics will be discussed.

\subsection{Calculation of Rate Coefficients}

From spectra taken during the kinetic studies, it was possible to calculate the concentrations of $p$-nitrocumyl bromide and products at given times. The start of each kinetic study was taken as being when the $p$-nitrocumyl bromide solution was added to the salt solution (see 9.5.1). It was, therefore, possible to calculate rate coefficients for the 
disappearance of $p$-nitrocumyl bromide using the method of least squares or if necessary the computer programmes GEAR and GIT. The programme GEAR does a simple numerical integration whose output is the concentration of the species versus time. GIT compares the GEAR output with experimental data and allows optimisation by variation of rate constants. All of the rate coefficients are reported along with their corresponding correlation coefficients, $r$, and standard errors, $\sigma$ (expressed as a percentage of the rate coefficient). A residual plot is often helpful in identifying unusual or highly influential observations and in revealing patterns in the data that may suggest how an improved fit can be achieved. A desirable plot is one that exhibits no particular pattern (such as curvature or much greater spread in one part of the plot than in another part) and has no point that is far removed from others. It will be seen, just as in chapter 3 , that the first point in a kinetic run is usually slightly removed from others. This is probably an error resulting from the mixing of the two solutions and the consequent uncertainty over the time at which the reaction can be considered to start.

\section{3 $400 \mathrm{MHz}-\underline{1}$ N.M.R. Study of the Reaction of Lithium Azide with $p$ -}

\section{Nitrocumyl Bromide in Dimethyl Sulphoxide}

All of the kinetic studies in chapters 6 and 7 were followed using a $400 \mathrm{MHz}$ pulsed Fourier transform n.m.r. spectrometer. The use of a Fourier transform n.m.r. spectrometer for ${ }^{1} \mathrm{H}$ n.m.r. spectroscopy requires the use, as far as possible, of deuterated materials, with the obvious exception of the compound being studied; thus deuterated solvents were used. Reaction solutions were made up as described in Section 9.5.1. The spectra were recorded at specific time intervals automatically. The temperature of the n.m.r. probe was maintained at a constant value during all of the ${ }^{1} \mathrm{H}$ n.m.r. studies using the spectrometer's variable temperature controller. The temperature of the n.m.r. probe was found to be $(30 \pm 1)^{\circ} \mathrm{C}$ for all studies.

The course of the reactions were followed by observing the growth and disappearance of the ${ }^{1} \mathrm{H}$ n.m.r. signals in the aliphatic region (Figure 6.1). In Figure 6.1, 
the ${ }^{1} \mathrm{H}$ n.m.r. signal corresponding to the aliphatic protons of $p$-nitrocumyl alcohol can hardly be seen due to its extremely slow formation. The concentrations of each species, at given times, were calculated from their integrals (I) as follows (Equations 6.3, 6.4, 6.5, and 6.6):

$\mathrm{R}=\mathrm{C}_{9} \mathrm{H}_{10} \mathrm{NO}_{2}$

$[\mathrm{RBr}]_{\mathrm{t}}=\frac{\mathrm{I}(\mathrm{RBr}) \times[\mathrm{RBr}]_{0}}{\mathrm{I}(\mathrm{RBr})+\mathrm{I}\left(\mathrm{RN}_{3}\right)+\mathrm{I}(\mathrm{ROH})+2 \mathrm{I} \text { (Alkene) }}$

$\left[\mathrm{RN}_{3}\right]_{\mathrm{t}}=\frac{\mathrm{I}\left(\mathrm{RN}_{3}\right) \times[\mathrm{RBr}]_{0}}{\mathrm{I}(\mathrm{RBr})+\mathrm{I}\left(\mathrm{RN}_{3}\right)+\mathrm{I}(\mathrm{ROH})+2 \mathrm{I} \text { (Alkene) }}$

$[\mathrm{ROH}]_{t}=\frac{\mathrm{I}(\mathrm{ROH}) \times[\mathrm{RBr}]_{0}}{\mathrm{I}(\mathrm{RBr})+\mathrm{I}\left(\mathrm{RN}_{3}\right)+\mathrm{I}(\mathrm{ROH})+2 \mathrm{I} \text { (Alkene) }}$

$[\text { Alkene }]_{t}=\frac{2 I \text { (Alkene) } \times[R B r]_{0}}{I(R B r)+I\left(\mathrm{RN}_{3}\right)+I(R O H)+2 I \text { (Alkene) }}$

In each kinetic study 10 spectra were accumulated, each consisting of $820 \mu \mathrm{s}$ pulses each followed by a two second acquisition time (see 9.5.2). For the purpose of calculating rate coefficients, the time ascribed to each spectrum was the mid-point of the accumulation. 
Time $=0 \mathrm{~s}$

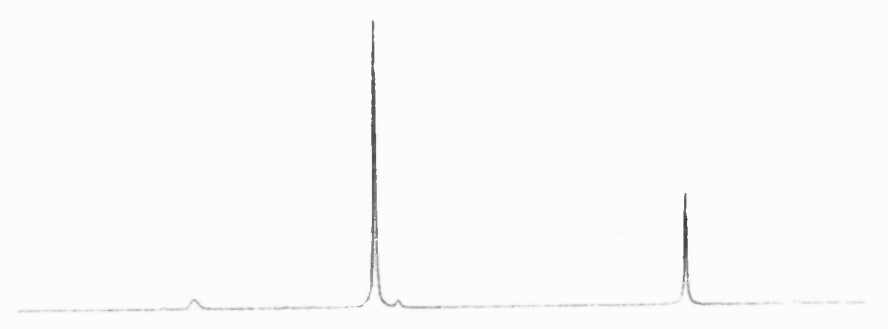

Time $=360 \mathrm{~s}$

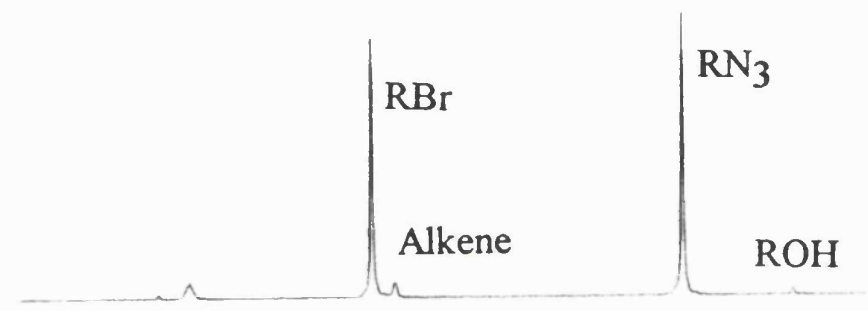

Time $=720 \mathrm{~s}$

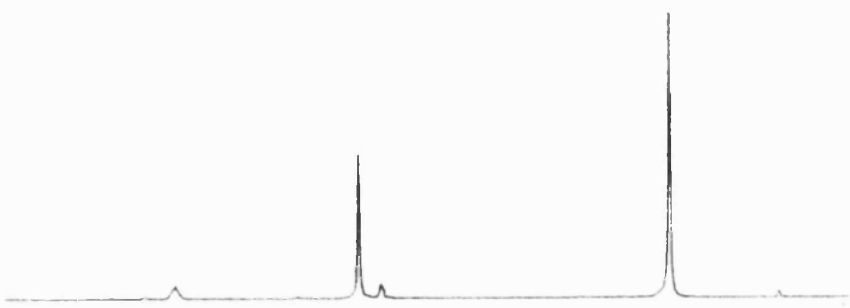

Time $=1080 \mathrm{~s}$

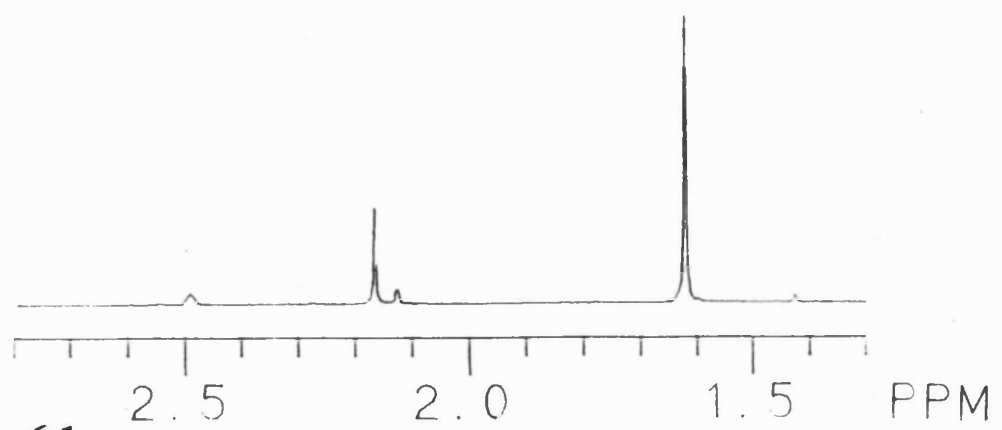

Time $=1440 \mathrm{~s}$

Figure 6.1

The growth and disappearance of the ${ }^{1} \mathrm{H}$ n.m.r. signals in the aliphatic region for the reaction of lithium azide with $p$-nitrocumyl bromide in ${ }^{2} \mathrm{D}_{6}$-labelled dimethyl sulphoxide (Table 6.1). 


\subsection{The Order with Respect to Azide}

Three series of kinetic studies were performed, each at a different initial concentration of lithium azide, but with the initial concentration of $p$-nitrocumyl bromide held constant. The ionic strength of the reaction solution was held essentially constant by the addition of lithium perchlorate. The concentration of $p$-nitrocumyl bromide at given times, derived from these kinetic studies, are presented in Tables 6.1, 6.2, and 6.3; the spectra in Figure 6.1 correspond to the data in Table 6.1. The spectrum for time equal to zero was obtained by taking an ${ }^{1}$ H n.m.r. spectrum of the $p$-nitrocumyl bromide solution on its own. For time equal to zero, the concentration of $p$-nitrocumyl bromide in the reaction mixture was set equal to one half the concentration of the $p$-nitrocumyl bromide solution on its own.

Figure 6.2 shows the disappearance of $p$-nitrocumyl bromide in its reaction with lithium azide for various different initial molarities of lithium azide (Tables 6.1, 6.2 and 6.3). Clearly, the rate of reaction is dependent on the initial concentration of lithium azide.

Rate coefficients were calculated assuming that the reaction was overall first order with respect to $p$-nitrocumyl bromide (Figures $6.3,6.5$ and 6.7) and first order with respect to both $p$-nitrocumyl bromide and lithium azide, that is, second order overall (Figures 6.4, 6.6 and 6.8). It will be seen that the data fit second order kinetics rather better than first order kinetics.

For the initial concentration of lithium azide equal to $0.40 \mathrm{~mol} \mathrm{dm}-3$ the plot for an overall first order reaction is a reasonable fit (Figure 6.3). However, when the residuals are examined it can be seen that the pattern is a curved one with the very first point slightly removed from others. The plot for an overall second order reaction is a very good fit and this is exemplified by the correlation coefficient obtained (Figure 6.4). The residual plot has no real significant pattern and the very first point is slightly removed from others.

For the initial concentration of lithium azide equal to $0.30 \mathrm{~mol} \mathrm{dm}^{-3}$ the plot for an overall first order reaction is a reasonable fit (Figure 6.5). However, when the residuals are examined it can be seen that the pattern is a curved one with no real isolated points. 


\section{Chapter 6}

Table 6.1

Temperature

Solvent

[RBr] 0

$\left[\mathrm{LiN}_{3}\right]_{0}$

$\left[\mathrm{LiClO}_{4}\right]_{0}$

\section{The Order with Respect to Azide Part 1}

$30^{\circ} \mathrm{C}$

$99.9 \% \mathrm{C}_{2} \mathrm{D}_{6} \mathrm{SO}$

$0.20 \mathrm{~mol} \mathrm{dm}^{-3}$

$\left(\mathrm{R}=\mathrm{C}_{9} \mathrm{H}_{10} \mathrm{NO}_{2}\right)$

$0.40 \mathrm{~mol} \mathrm{dm}^{-3}$

$0.00 \mathrm{~mol} \mathrm{dm}^{-3}$

\begin{tabular}{|c|c|c|}
\hline Time Range / s & Mid-point Time $/ \mathrm{s}$ & {$[\mathrm{RBr}]_{\mathrm{t}} / \mathrm{mol} \mathrm{dm}^{-3}$} \\
\hline 0 & 0 & 0.200 \\
\hline $172-188$ & 180 & 0.173 \\
\hline $352-368$ & 360 & 0.133 \\
\hline $532-548$ & 540 & 0.106 \\
\hline $712-728$ & 720 & 0.086 \\
\hline $892-908$ & 900 & 0.071 \\
\hline $1072-1088$ & 1080 & 0.058 \\
\hline $1252-1268$ & 1260 & 0.048 \\
\hline $1432-1448$ & 1440 & 0.041 \\
\hline $1612-1628$ & 1620 & 0.035 \\
\hline
\end{tabular}


$\underline{\text { Table } 6.2}$

Temperature

Solvent

[RBr]0

$\left[\mathrm{LiN}_{3}\right]_{0}$

$\left[\mathrm{LiClO}_{4}\right]_{0}$
The Order with Respect to Azide Part 2

$30^{\circ} \mathrm{C}$

$99.9 \% \mathrm{C}_{2} \mathrm{D}_{6} \mathrm{SO}$

$0.20 \mathrm{~mol} \mathrm{dm}^{-3}$

$\left(\mathrm{R}=\mathrm{C}_{9} \mathrm{H}_{10} \mathrm{NO}_{2}\right)$

$0.30 \mathrm{~mol} \mathrm{dm}^{-3}$

$0.10 \mathrm{~mol} \mathrm{dm}^{-3}$

\begin{tabular}{|c|c|c|}
\hline Time Range / s & Mid-point Time / s & {$[\mathrm{RBr}]_{\mathrm{t}} / \mathrm{mol} \mathrm{dm}^{-3}$} \\
\hline 0 & 0 & 0.200 \\
\hline $262-278$ & 270 & 0.149 \\
\hline $532-548$ & 540 & 0.117 \\
\hline $802-818$ & 810 & 0.094 \\
\hline $1072-1088$ & 1080 & 0.078 \\
\hline $1342-1358$ & 1350 & 0.065 \\
\hline $1612-1628$ & 1620 & 0.056 \\
\hline $1882-1898$ & 1890 & 0.048 \\
\hline $2152-2168$ & 2160 & 0.042 \\
\hline $2422-2438$ & 2430 & 0.036 \\
\hline
\end{tabular}


Table 6.3

Temperature

Solvent

$[\mathrm{RBr}]_{0}$

$\left[\mathrm{LiN}_{3}\right]_{0}$

$\left[\mathrm{LiClO}_{4}\right]_{0}$
The Order with Respect to Azide Part 3

$30^{\circ} \mathrm{C}$

$99.9 \% \mathrm{C}_{2} \mathrm{D}_{6} \mathrm{SO}$

$0.20 \mathrm{~mol} \mathrm{dm}^{-3}$

$\left(\mathrm{R}=\mathrm{C}_{9} \mathrm{H}_{10} \mathrm{NO}_{2}\right)$

$0.20 \mathrm{~mol} \mathrm{dm}^{-3}$

$0.20 \mathrm{~mol} \mathrm{dm}^{-3}$

\begin{tabular}{|c|c|c|}
\hline Time Range $/ \mathrm{s}$ & Mid-point Time $/ \mathrm{s}$ & {$[\mathrm{RBr}]_{\mathrm{t}} / \mathrm{mol} \mathrm{dm}^{-3}$} \\
\hline 0 & 0 & 0.200 \\
\hline $352-368$ & 360 & 0.155 \\
\hline $712-728$ & 720 & 0.129 \\
\hline $1072-1088$ & 1080 & 0.107 \\
\hline $1432-1448$ & 1440 & 0.093 \\
\hline $1792-1808$ & 1800 & 0.082 \\
\hline $2152-2168$ & 2160 & 0.071 \\
\hline $2512-2528$ & 2520 & 0.064 \\
\hline $2872-2888$ & 2880 & 0.059 \\
\hline $3232-3248$ & 3240 & 0.054 \\
\hline
\end{tabular}


The plot for an overall second order reaction is again a very good fit and this is exemplified by the correlation coefficient obtained (Figure 6.6). The residual plot is random and has no isolated points.

For the initial concentration of lithium azide equal to $0.20 \mathrm{~mol} \mathrm{dm}^{-3}$ the plot for an overall first order reaction is a reasonable fit (Figure 6.7). However, when the residuals are examined it can be seen that the pattern is a curved one with the sixth point slightly removed from others. The plot for an overall second order reaction is again a very good fit and this is exemplified by the correlation coefficient obtained (Figure 6.8). The residual plot has no real significant pattern and has the sixth point slightly removed from others.

The first order rate constants $\left(k_{1}\right)$ vary significantly for the different kinetic runs. This indicates that an overall first order model is a poor fit to the data obtained from Tables 6.1, 6.2 and 6.3. However, the second order rate constants $\left(k_{2}\right)$ do not vary significantly for the kinetic runs indicating a good fit to an overall second order model. 


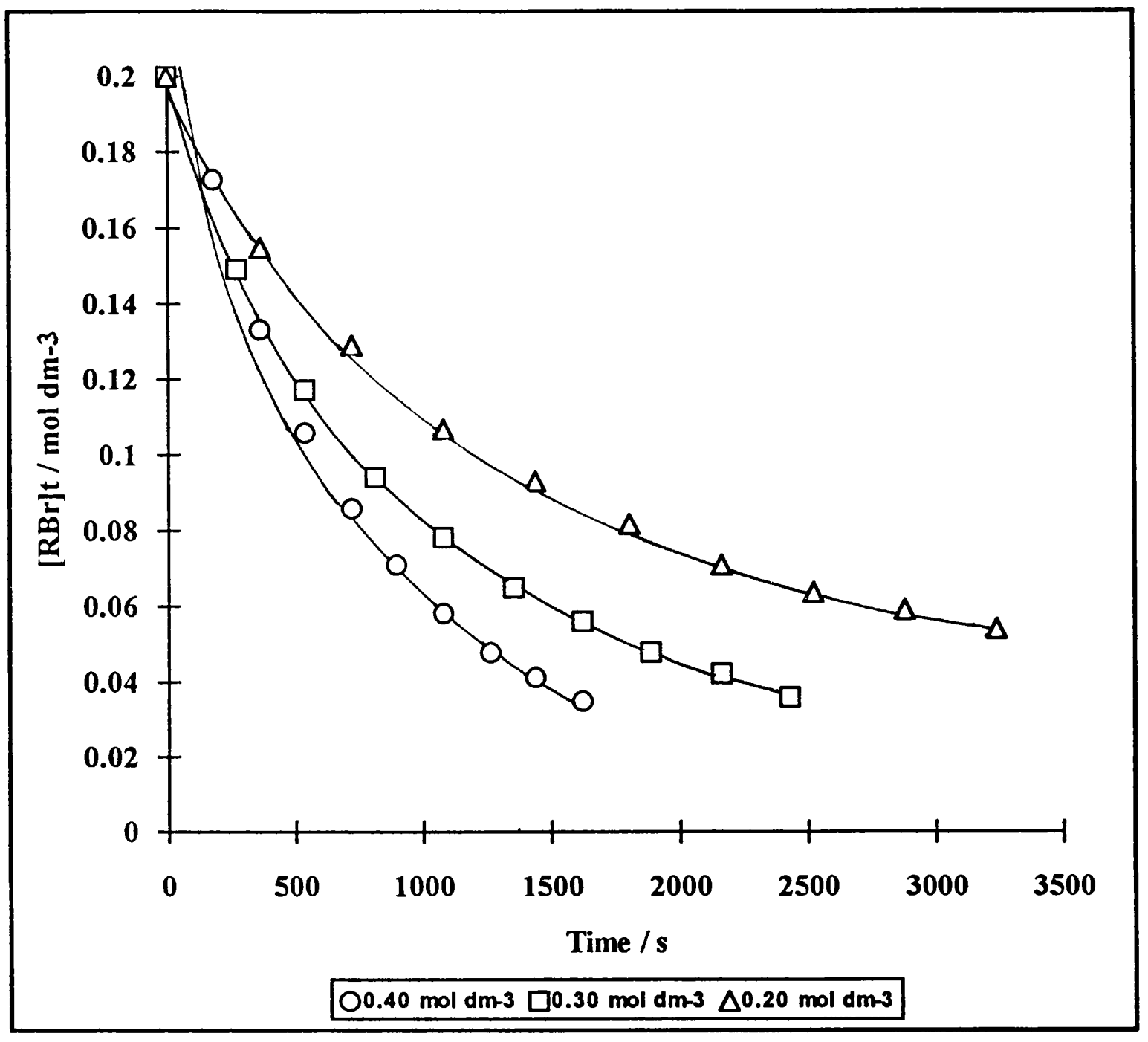

\section{Figure 6.2}

A comparison of the disappearance of $p$-nitrocumyl bromide in its reaction with lithium azide for various different initial molarities of lithium azide (Tables 6.1, 6.2 and 6.3). 


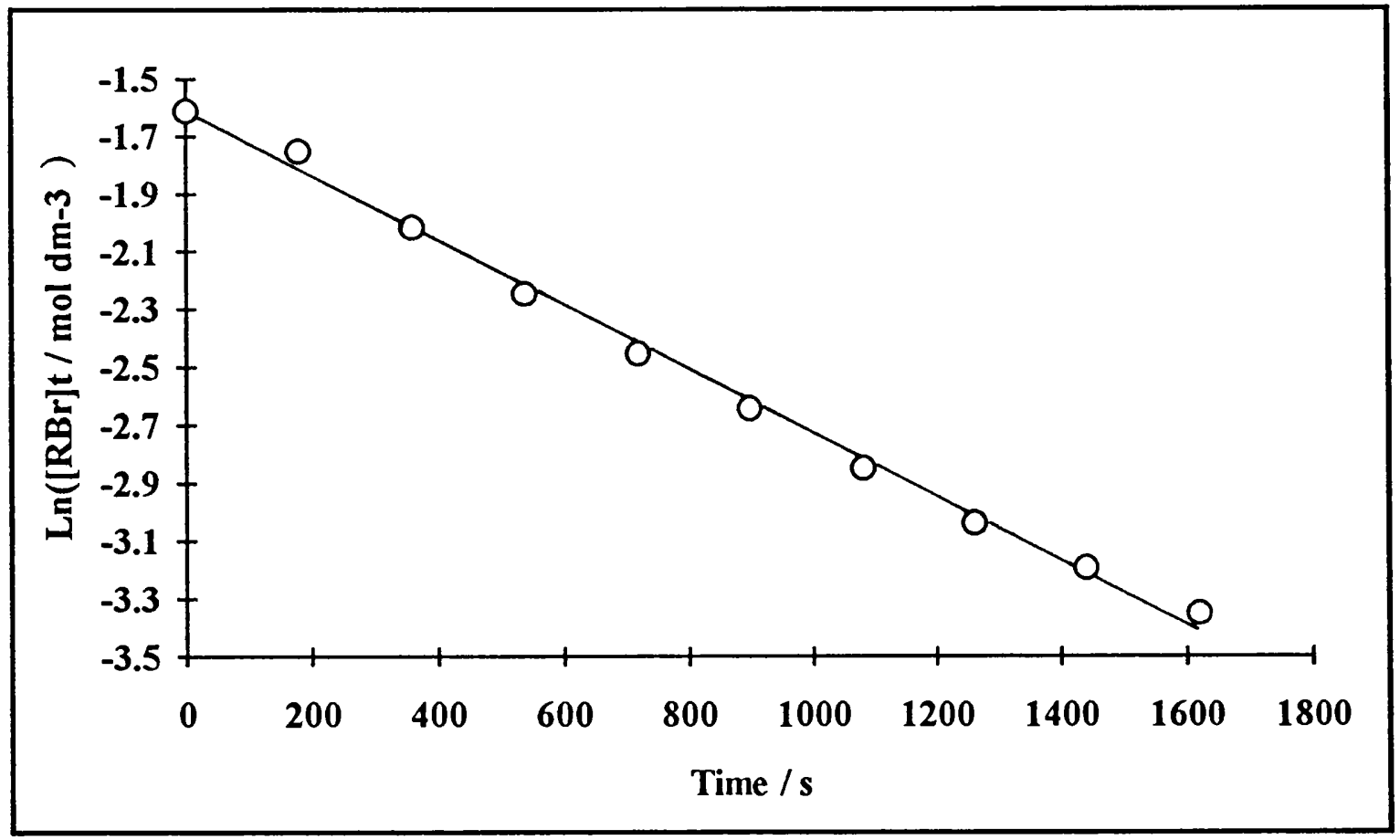

(a)

$$
\begin{aligned}
& k_{1}=1.11 \times 10^{-3} \mathrm{~s}^{-1} \\
& \mathrm{r}=0.9981 \\
& \sigma=2.21 \%
\end{aligned}
$$

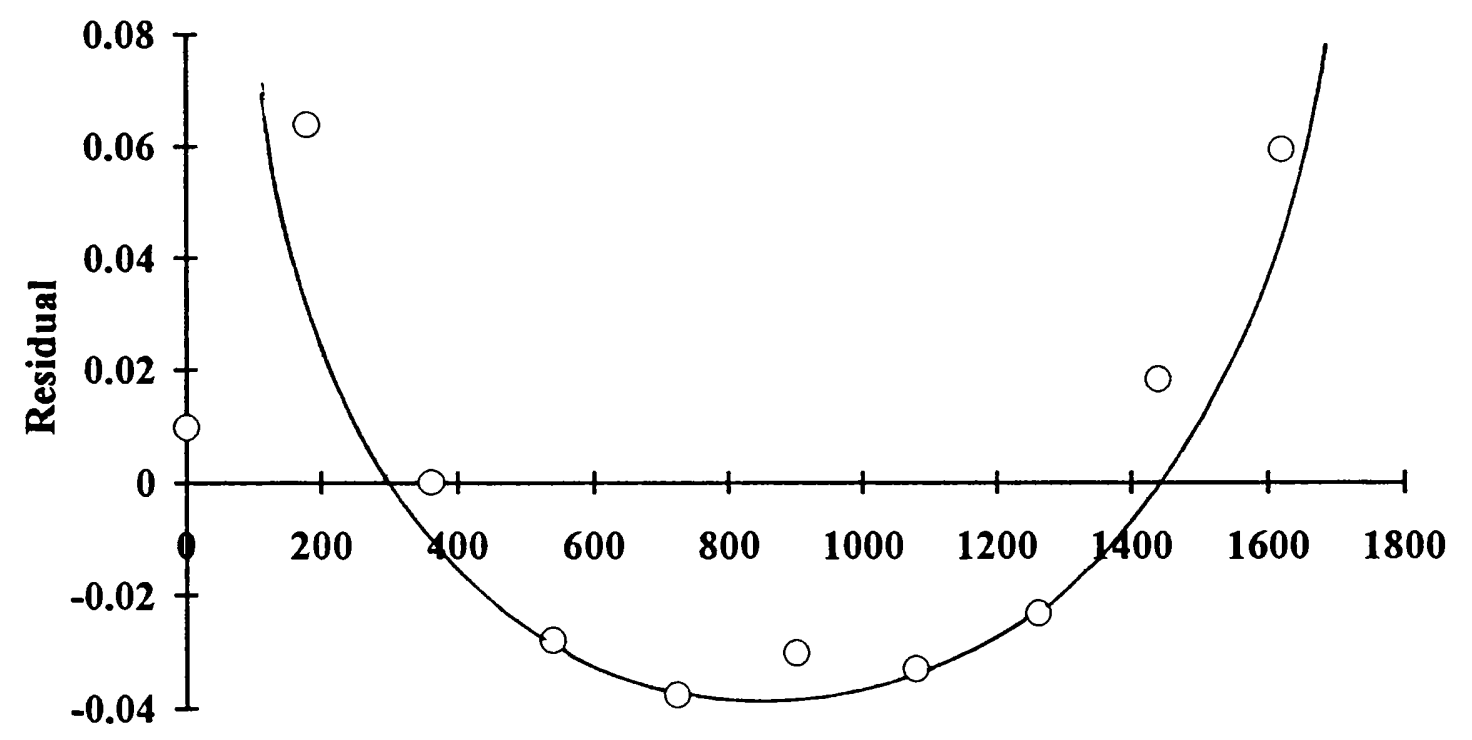

Time / s

(b)

Figure 6.3

Plots of (a) $\mathrm{Ln}\left([\mathrm{RBr}]_{\mathrm{t}} / \mathrm{mol} \mathrm{dm}^{-3}\right)$ and (b) Residuals against time / $\mathrm{s}$ for the reaction of $p$ nitrocumyl bromide with lithium azide (Table 6.1). 


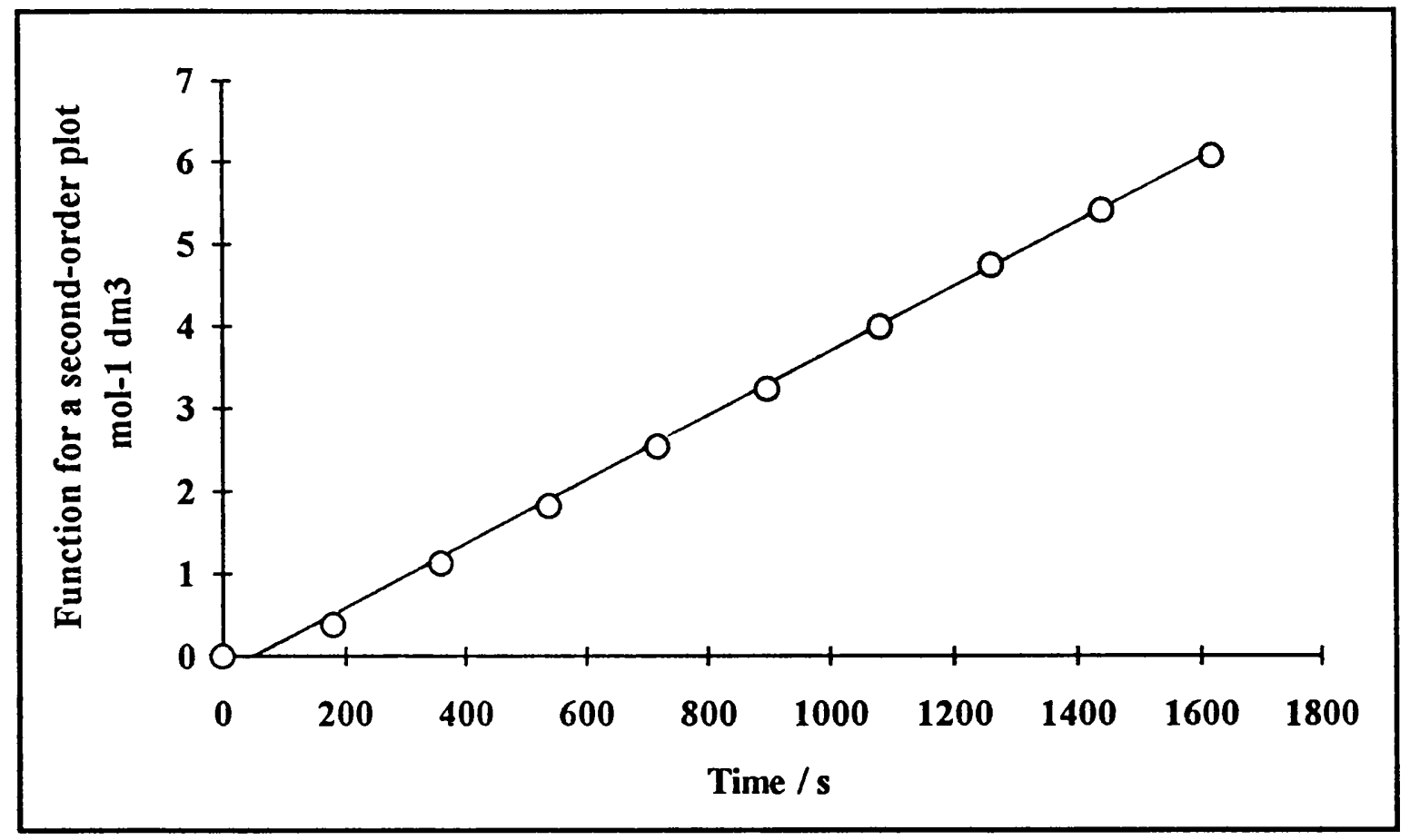

(a)

$$
\begin{aligned}
k_{2}(\mathrm{a} \neq \mathrm{b}) & =3.87 \times 10^{-3} \mathrm{~mol}^{-1} \mathrm{dm}^{3} \mathrm{~s}^{-1} \\
\mathrm{r} & =0.9991 \\
\sigma & =1.50 \%
\end{aligned}
$$

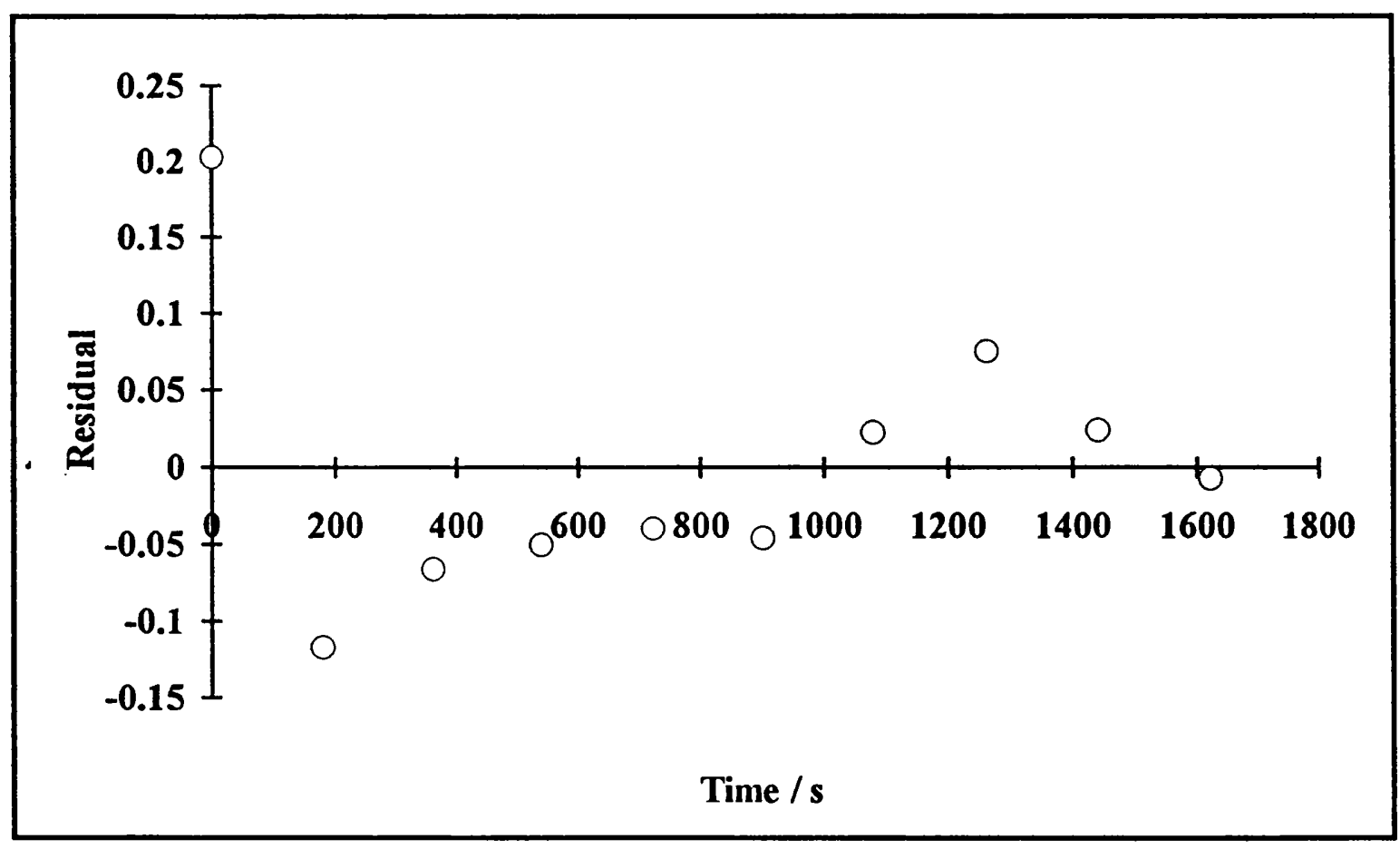

(b)

\section{Figure 6.4}

Plots of (a) Function for a second-order plot / $\mathrm{mol}^{-1} \mathrm{dm}^{3}$ and (b) Residuals against time / $s$ for the reaction of $p$-nitrocumyl bromide with lithium azide (Table 6.1). 


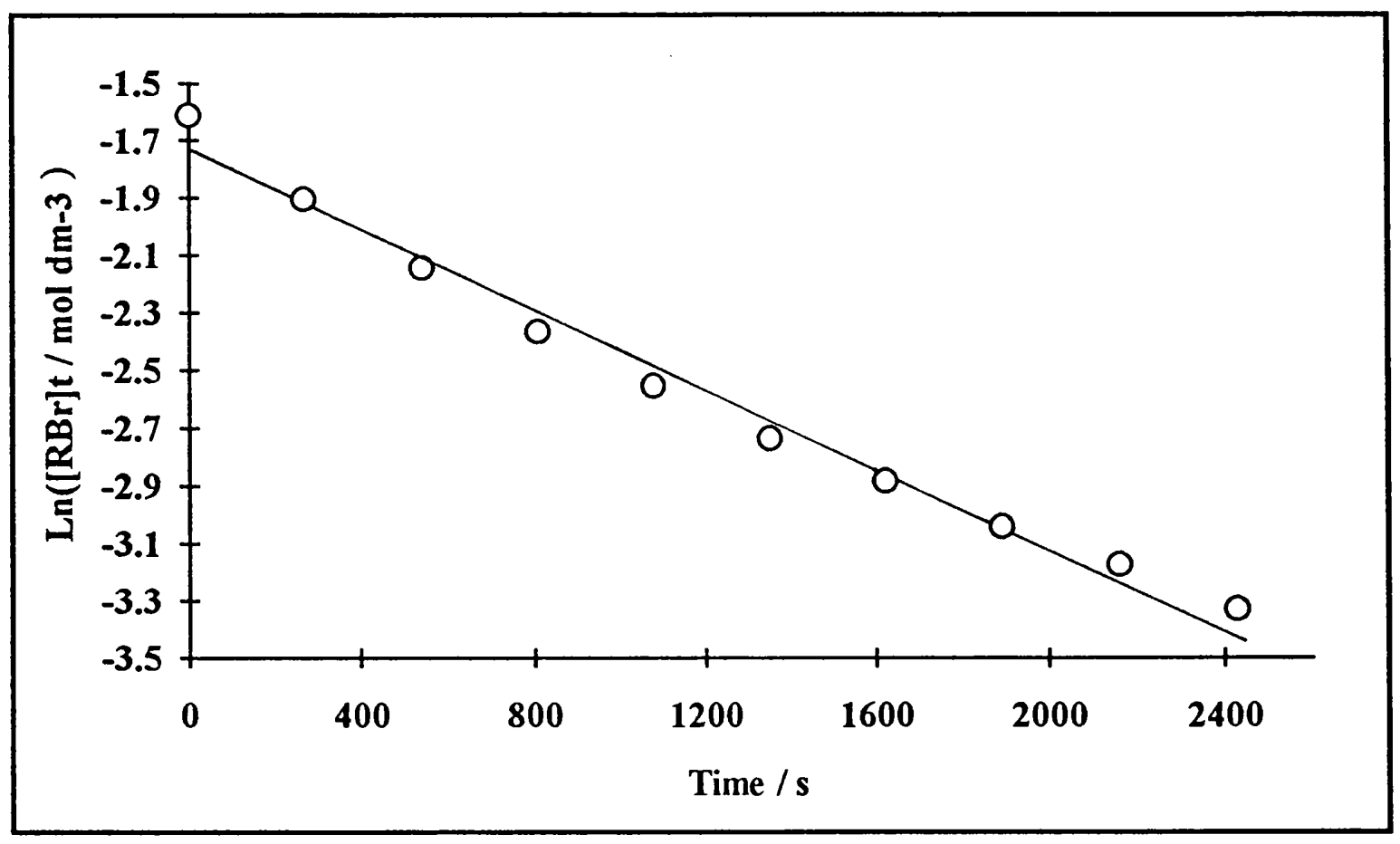

(a)

$$
\begin{aligned}
& k_{1}=6.84 \times 10^{-4} \mathrm{~s}^{-1} \\
& \mathrm{r}=0.9924 \\
& \sigma=4.39 \%
\end{aligned}
$$

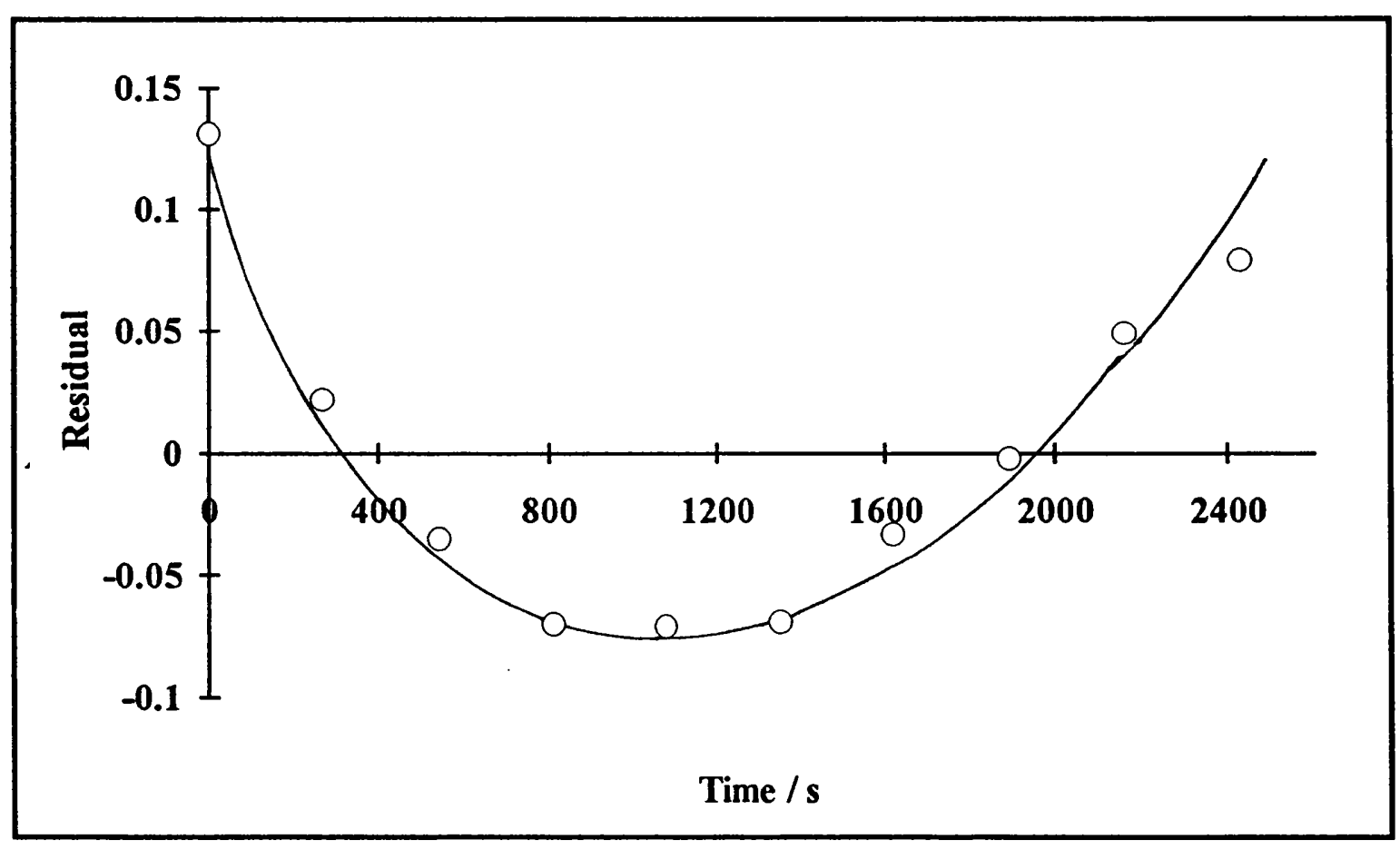

(b)

\section{Figure 6.5}

Plots of (a) $\mathrm{Ln}\left([\mathrm{RBr}]_{\mathrm{t}} / \mathrm{mol} \mathrm{dm}^{-3}\right)$ and (b) Residuals against time / $\mathrm{s}$ for the reaction of $p$ nitrocumyl bromide with lithium azide (Table 6.2). 


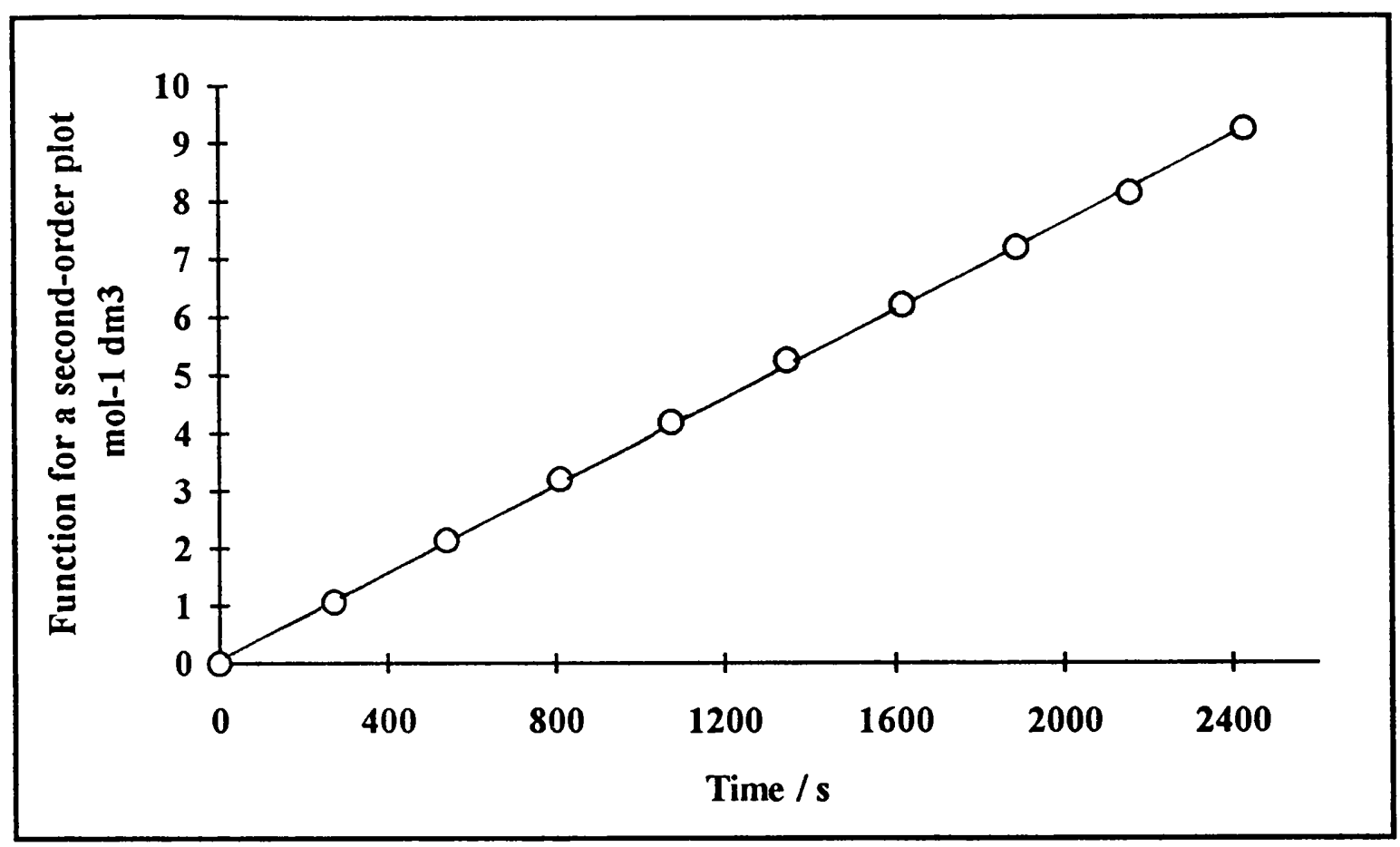

(a)

$$
\begin{aligned}
k_{2}(\mathrm{a} \neq \mathrm{b}) & =3.77 \times 10^{-3} \mathrm{~mol}^{-1} \mathrm{dm}^{3} \mathrm{~s}^{-1} \\
\mathrm{r} & =0.9998 \\
\sigma & =0.66 \%
\end{aligned}
$$

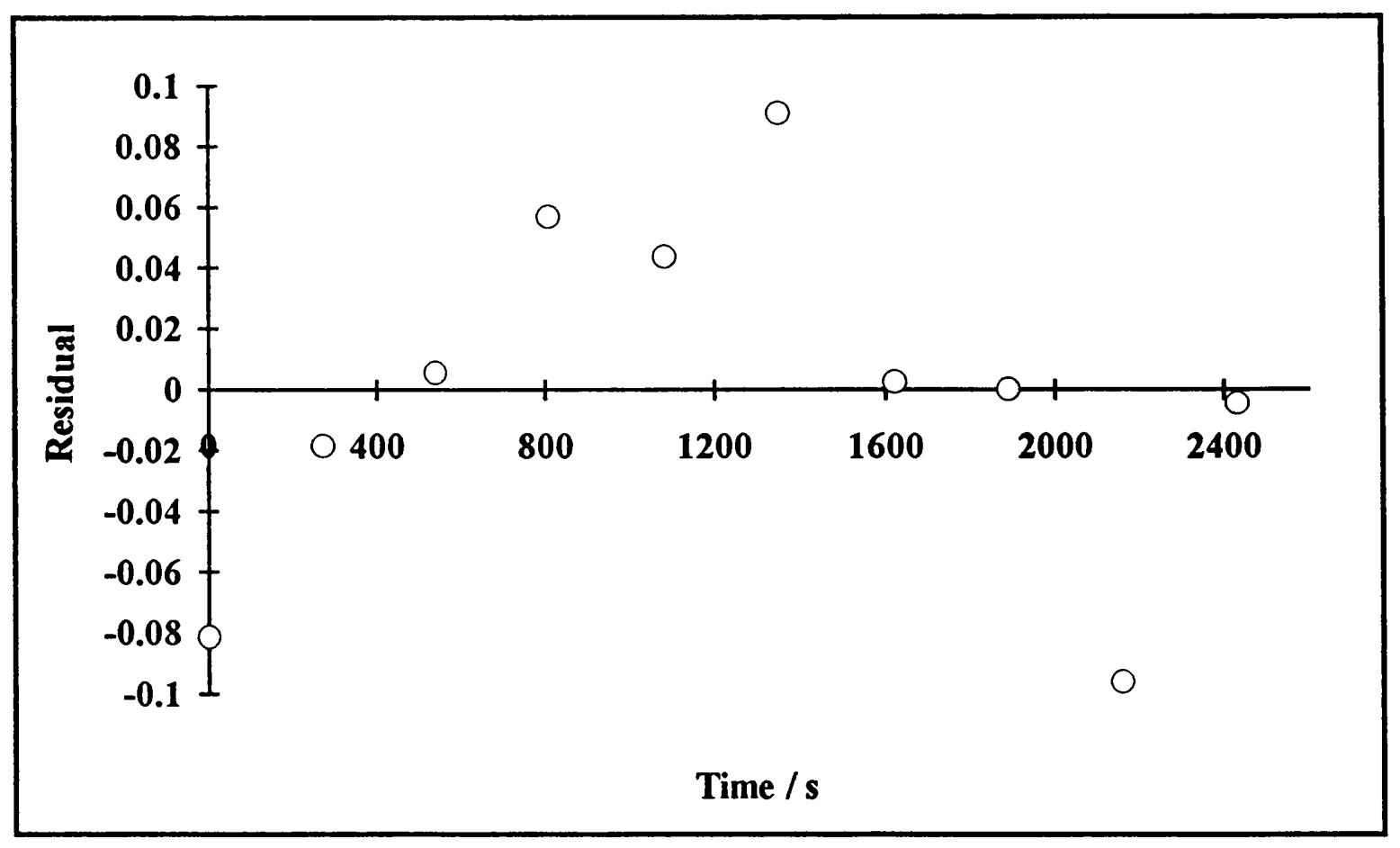

(b)

\section{Figure 6.6}

Plots of (a) Function for a second-order plot $/ \mathrm{mol}^{-1} \mathrm{dm}^{3}$ and (b) Residuals against time / $s$ for the reaction of $p$-nitrocumyl bromide with lithium azide (Table 6.2). 


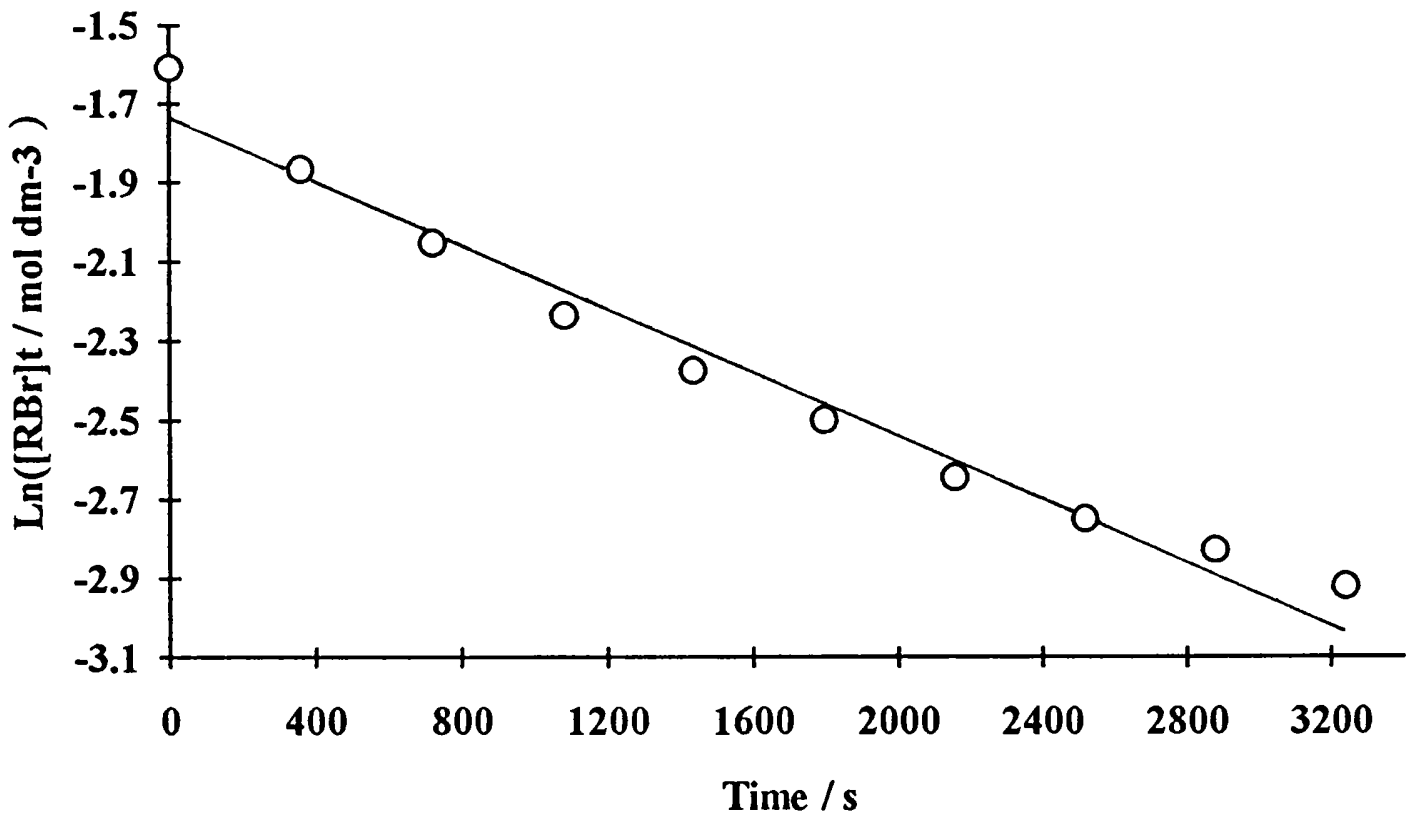

(a)

$$
\begin{aligned}
k_{1} & =3.94 \times 10^{-4} \mathrm{~s}^{-1} \\
r & =0.9868 \\
\sigma & =5.81 \%
\end{aligned}
$$

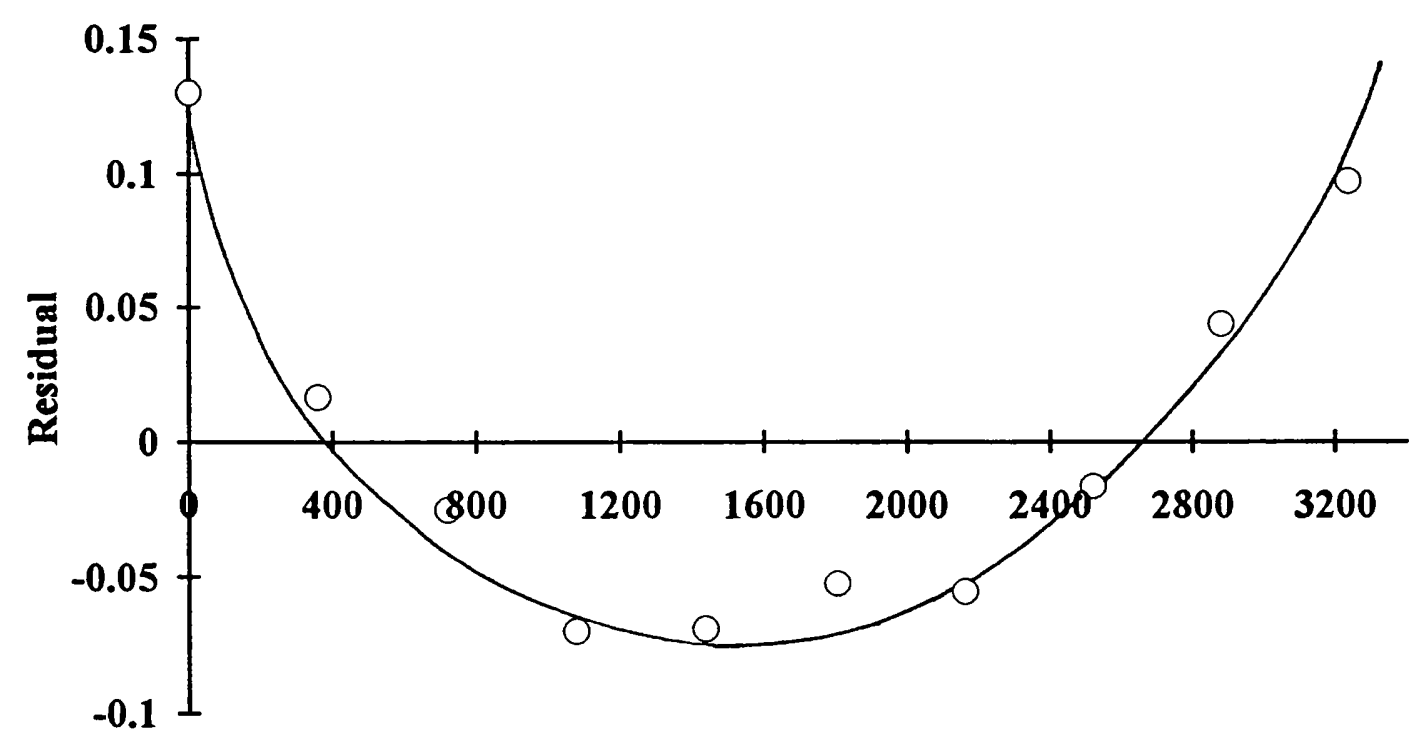

Time / s

(b)

Figure 6.7

Plots of (a) $\mathrm{Ln}\left([\mathrm{RBr}]_{\mathrm{t}} / \mathrm{mol} \mathrm{dm}^{-3}\right)$ and (b) Residuals against time / $\mathrm{s}$ for the reaction of $p$ nitrocumyl bromide with lithium azide (Table 6.3). 


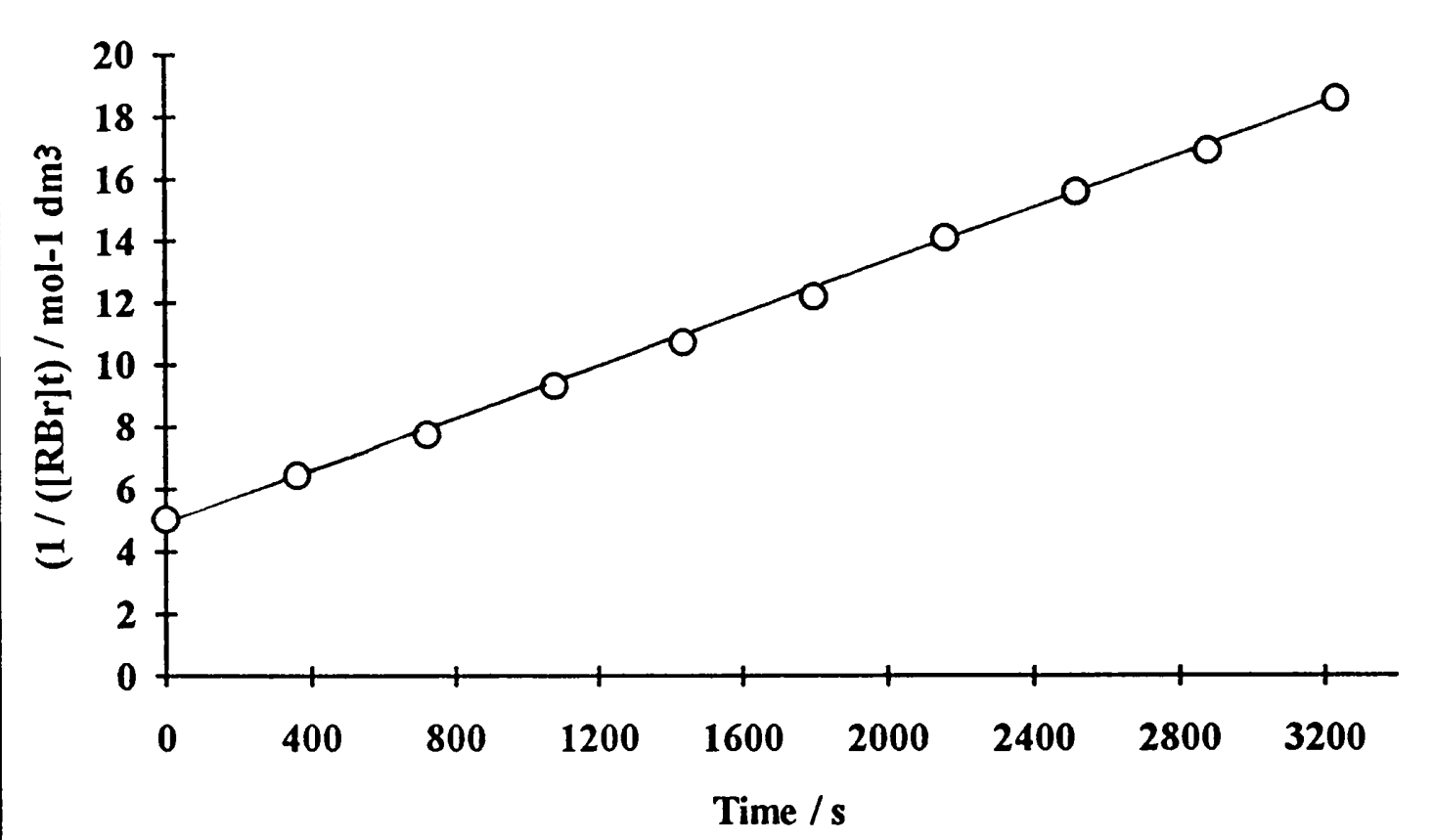

(a)

$$
\begin{aligned}
k_{2}(\mathrm{a}=\mathrm{b}) & =4.21 \times 10^{-3} \mathrm{~mol}^{-1} \mathrm{dm}^{3} \mathrm{~s}^{-1} \\
\mathrm{r} & =0.9995 \\
\sigma & =1.08 \%
\end{aligned}
$$

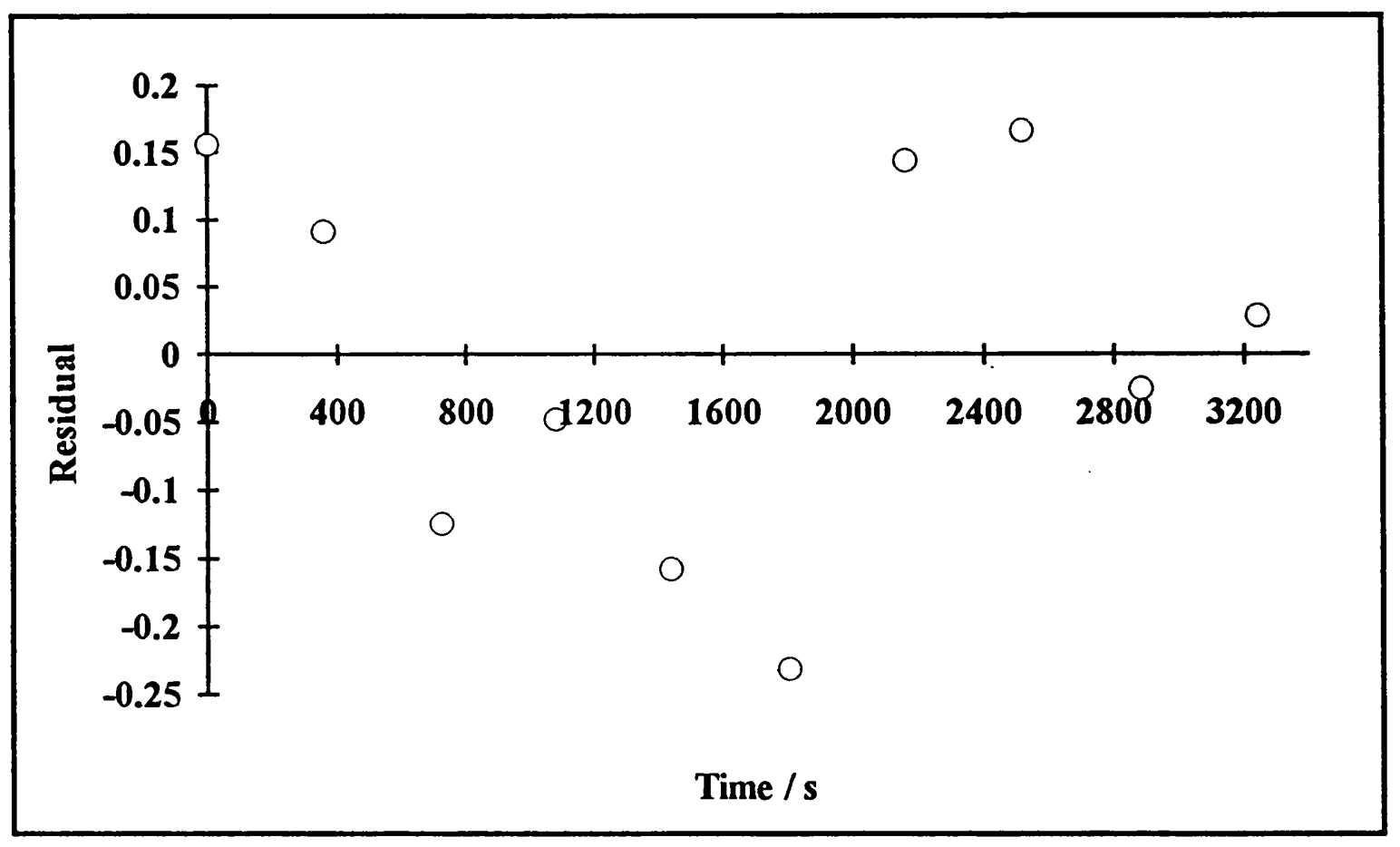

(b)

\section{Figure 6.8}

Plots of (a) $\left(1 /[\mathrm{RBr}]_{\mathrm{t}}\right) / \mathrm{mol}^{-1} \mathrm{dm}^{3}$ and (b) Residuals against time / $\mathrm{s}$ for the reaction of $p$-nitrocumyl bromide with lithium azide (Table 6.3). 


\subsection{The Order with Respect to $p$-Nitrocumyl Bromide}

One kinetic study was performed; the initial concentration of $p$-nitrocumyl bromide was half the initial concentration used in section 6.4. The ionic strength of the reaction solution was again held essentially constant by the addition of lithium perchlorate. The concentrations of $p$-nitrocumyl bromide at given times, derived from this kinetic study, are presented in Table 6.4. Again, the spectrum for time equal to zero was obtained by taking an ${ }^{1} \mathrm{H}$ n.m.r. spectrum of the $p$-nitrocumyl bromide solution on its own. For time equal to zero, the concentration of $p$-nitrocumyl bromide in the reaction mixture was set equal to one half the concentration of the $p$-nitrocumyl bromide solution on its own.

Rate coefficients were calculated assuming that the reaction was overall first order with respect to $p$-nitrocumyl bromide (Figure 6.9) and first order with respect to both $p$ nitrocumyl bromide and lithium azide, that is, second order overall (Figure 6.10). It will be seen that the data fit second order kinetics rather better than first order kinetics.

For the initial concentrations of $p$-nitrocumyl bromide equal to $0.10 \mathrm{~mol} \mathrm{dm}^{-3}$ and lithium azide equal to $0.20 \mathrm{~mol} \mathrm{dm}^{-3}$ (Figures 6.9 and 6.10), the plot for an overall first order reaction is a reasonable fit. However, when the residuals are examined it can be seen that the pattern is a curved one with the very first point slightly removed from others. The plot for an overall second order reaction is a good fit but not as good as the fits obtained in section 6.4. The residual plot has a minor pattern and the very first point is slightly removed from others.

\subsection{Summary}

A summary of first $\left(k_{1}\right)$ and second order rate constants $\left(k_{2}\right)$ are shown in Table 6.5. The second order rate constants obtained from varying the initial concentration of lithium azide have a very good correlation with the second order rate constant obtained from the variation of the initial concentration of $p$-nitrocumyl bromide. 
Table 6.4

Temperature

Solvent

[RBr] 0

$\left[\mathrm{LiN}_{3}\right]_{0}$

$\left[\mathrm{LiClO}_{4}\right]_{0}$
The Order with Respect to $p$-Nitrocumyl Bromide

$30^{\circ} \mathrm{C}$

$99.9 \% \mathrm{C}_{2} \mathrm{D}_{6} \mathrm{SO}$

$0.10 \mathrm{~mol} \mathrm{dm}^{-3}$

$\left(\mathrm{R}=\mathrm{C}_{9} \mathrm{H}_{10} \mathrm{NO}_{2}\right)$

$0.20 \mathrm{~mol} \mathrm{dm}^{-3}$

$0.20 \mathrm{~mol} \mathrm{dm}^{-3}$

\begin{tabular}{|c|c|c|}
\hline Time Range $/ \mathrm{s}$ & Mid-point Time / & {$[\mathrm{RBr}]_{\mathrm{t}} / \mathrm{mol} \mathrm{dm}^{-3}$} \\
\hline 0 & 0 & 0.100 \\
\hline $352-368$ & 360 & 0.065 \\
\hline $712-728$ & 720 & 0.052 \\
\hline $1072-1088$ & 1080 & 0.042 \\
\hline $1432-1448$ & 1440 & 0.034 \\
\hline $1792-1808$ & 1800 & 0.028 \\
\hline $2152-2168$ & 2160 & 0.024 \\
\hline $2512-2528$ & 2520 & 0.019 \\
\hline $2872-2888$ & 2880 & 0.016 \\
\hline $3232-3248$ & 3240 & 0.014 \\
\hline
\end{tabular}




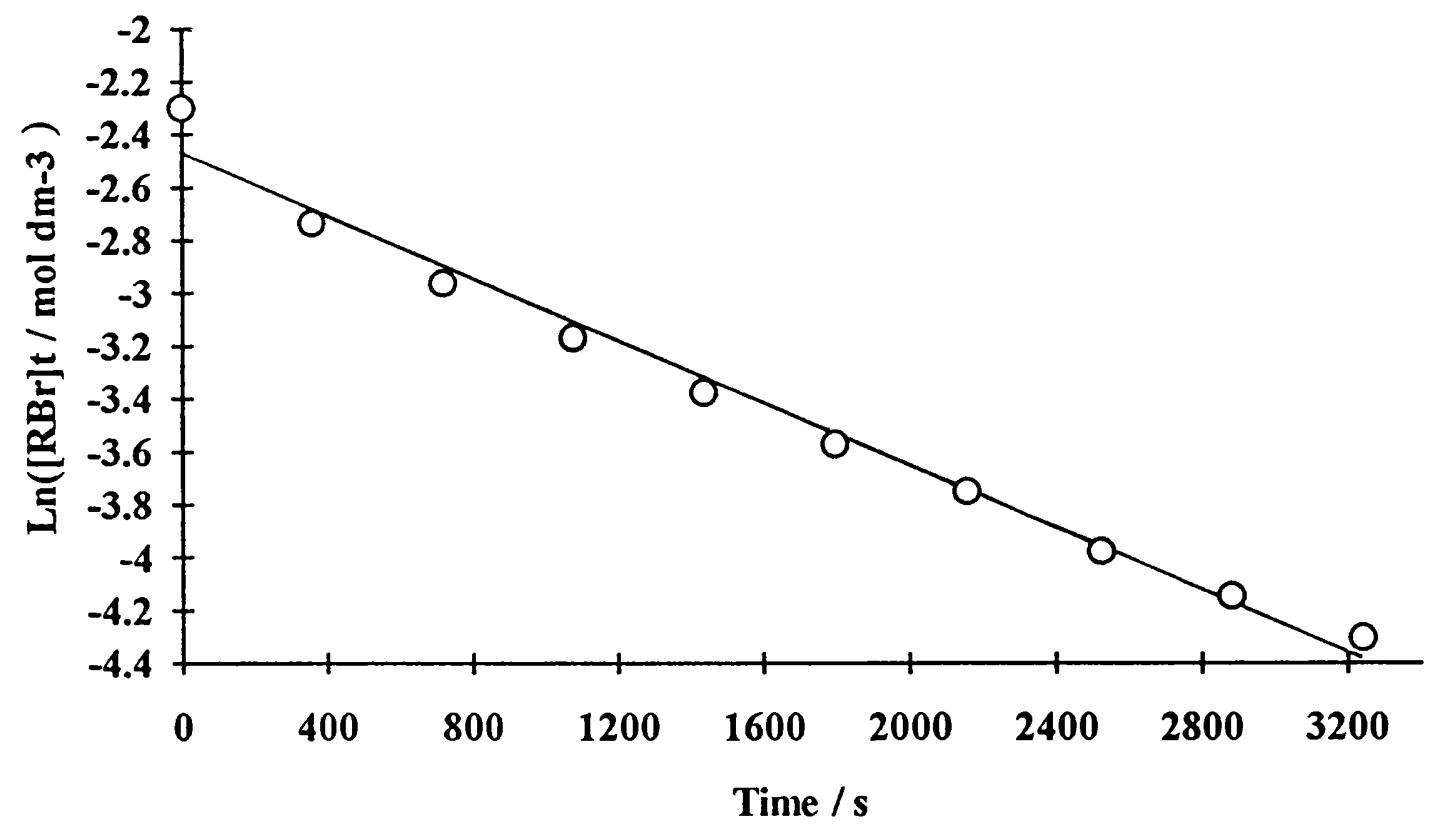

(a)

$$
\begin{aligned}
& k_{1}=5.88 \times 10^{-4} \mathrm{~s}^{-1} \\
& \mathrm{r}=0.9933 \\
& \sigma=4.12 \%
\end{aligned}
$$

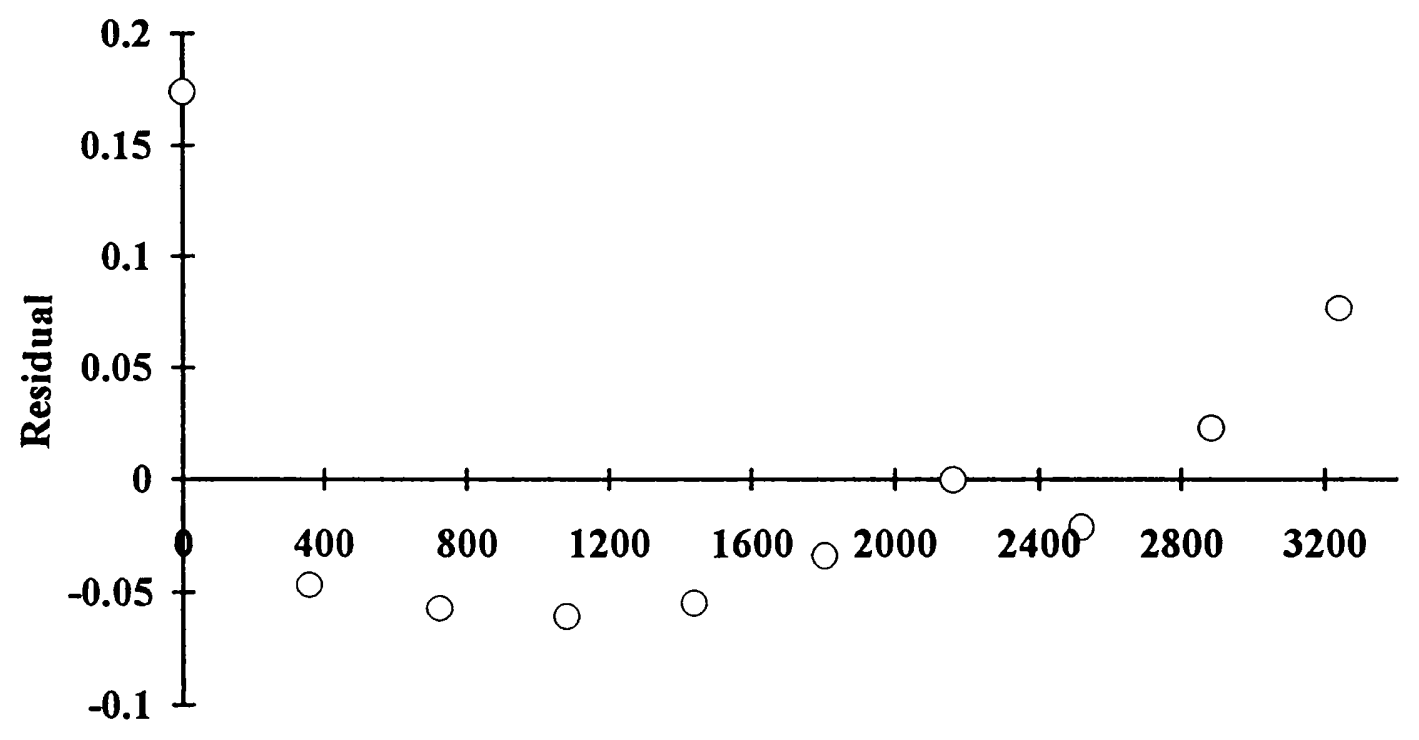

Time / s

(b)

Figure 6.9

Plots of (a) $\operatorname{Ln}\left([\mathrm{RBr}]_{\mathrm{t}} / \mathrm{mol} \mathrm{dm}^{-3}\right)$ and (b) Residuals against time / $\mathrm{s}$ for the reaction of $p$ nitrocumyl bromide with lithium azide (Table 6.4). 


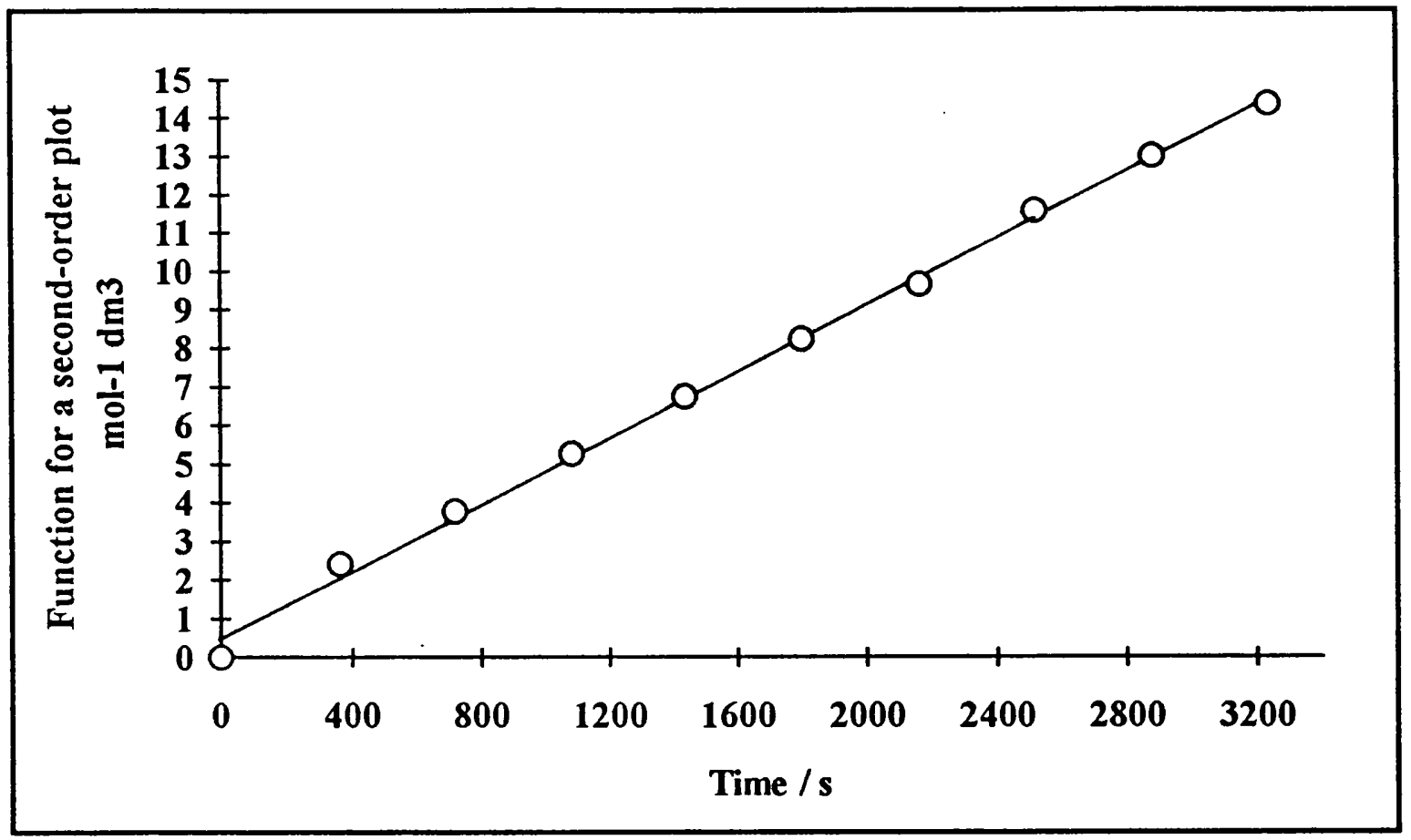

(a)

$$
\begin{aligned}
k_{2}(\mathrm{a} \neq \mathrm{b}) & =4.32 \times 10^{-3} \mathrm{~mol}^{-1} \mathrm{dm}^{3} \mathrm{~s}^{-1} \\
\mathrm{r} & =0.9987 \\
\sigma & =1.78 \%
\end{aligned}
$$

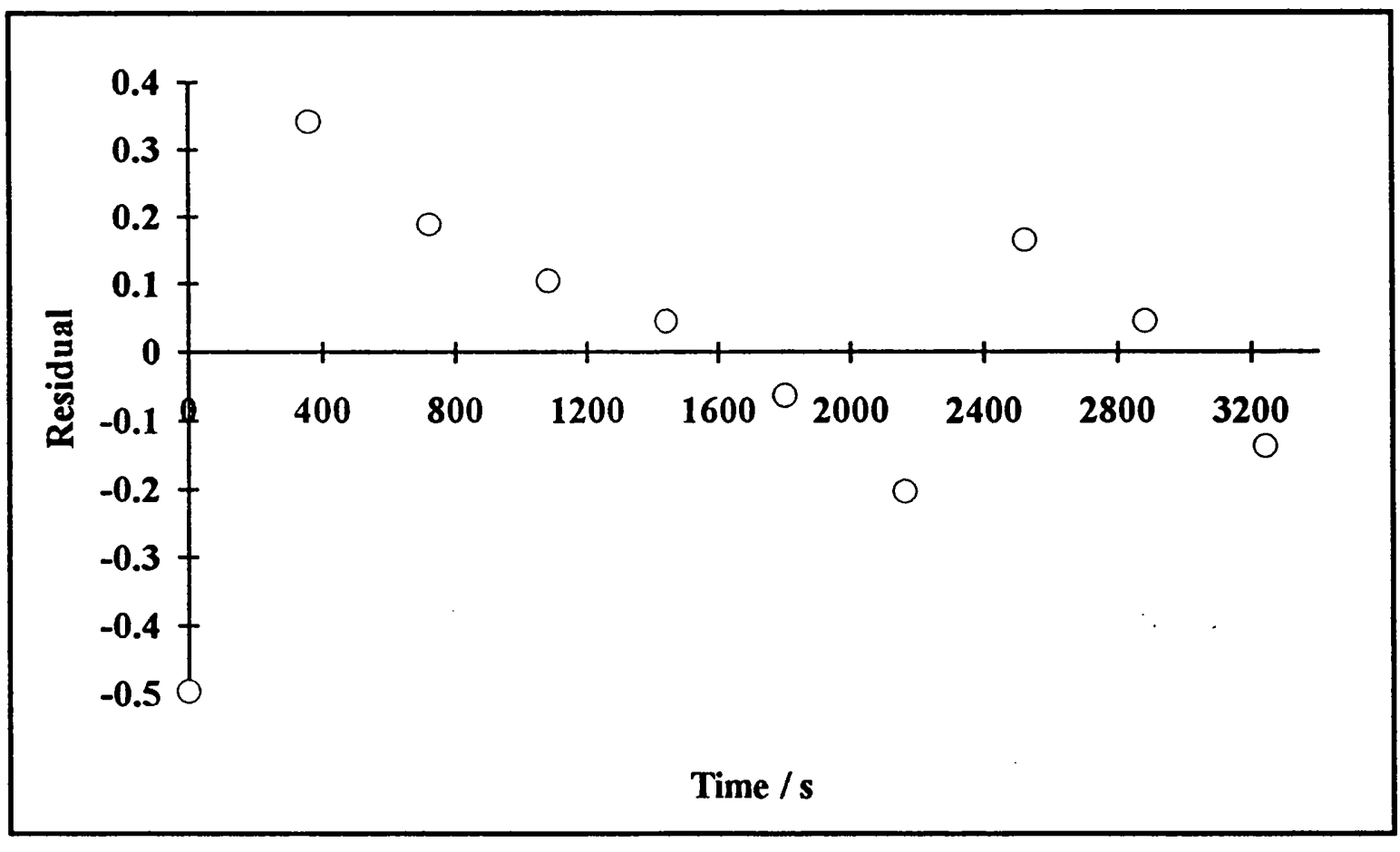

(b)

\section{Figure 6.10}

Plots of (a) Function for second-order plot $/ \mathrm{mol}^{-1} \mathrm{dm}^{3}$ and (b) Residuals against time / $\mathrm{s}$ for the reaction of $p$-nitrocumyl bromide with lithium azide (Table 6.4). 
The rate of the reaction between lithium azide and $p$-nitrocumyl bromide is dependent on both the lithium azide and $p$-nitrocumyl bromide concentrations. This reaction is also first order with respect to both lithium azide and p-nitrocumyl bromide, that is, overall second order.

Any points that were slightly removed from the others were deleted from the data and new rate constants calculated (Table 6.6). The new rate constants are very similar to the old ones, however, their correlation coefficients and corresponding errors are much improved on the old rate constants.

\subsection{The Elimination of p-Nitrocumyl Bromide in Dimethyl Sulphoxide}

We have seen from chapter 3 that $p$-nitrocumyl bromide slowly eliminates to give $p$-nitro- $\alpha$-methylstyrene as the major product. Over a period of 9 hours the only other product formed is $p$-nitrocumyl alcohol (Equation 3.7). If this elimination occurs with $p$ nitrocumyl bromide in the absence of lithium azide then there is no reason why $p$ nitrocumyl bromide should not eliminate in the presence of lithium azide. So it is important to take into account the elimination of $p$-nitrocumyl bromide.

One kinetic study was performed; the initial concentration of $p$-nitrocumyl bromide was equal to the initial concentration used in section 6.4. No lithium azide was added but the ionic strength of the reaction solution was again held essentially constant by the addition of lithium perchlorate. The concentration of $p$-nitrocumyl bromide at given times, derived from this kinetic study, are presented in Table 6.7. As the solvent is in excess a rate coefficient was calculated assuming that the reaction was first order with respect to $p$-nitrocumyl bromide (Figure 6.11).

For the elimination of $p$-nitrocumyl bromide in dimethyl sulphoxide, the plot for an overall first order reaction is a very good fit. When the residuals are examined it can be seen that the pattern is a random one with no single point slightly removed from others. The first order rate constant obtained for this elimination $\left(k_{\mathrm{S}}\right)$ indicates that this process is slow compared to the reaction between lithium azide and $p$-nitrocumyl bromide. 


\section{Table 6.5}

A summary of first and second order rate constants with their corresponding correlation coefficients, $r$, and standard errors, $\sigma$, for the reaction of $p$-nitrocumyl bromide with lithium azide (Tables 6.1, 6.2, 6.3 and 6.4).

\begin{tabular}{|c|c|c|c|c|c|c|}
\hline $\begin{array}{l}{\left[\operatorname{LiN}_{3}\right]_{0}} \\
/ \mathrm{mol} \mathrm{dm}^{-3}\end{array}$ & $\begin{array}{c}{[R B r]_{0}} \\
/ \mathrm{mol} \mathrm{dm}^{-3}\end{array}$ & $\begin{array}{c}{\left[\mathrm{LiClO}_{\mathbf{4}}\right]_{\mathbf{0}}} \\
/ \mathrm{mol} \mathrm{dm}^{-3}\end{array}$ & $\begin{array}{c}10^{4} k_{1} / \\
s^{-1}\end{array}$ & $\begin{array}{c}\mathbf{r} \\
\sigma / \%\end{array}$ & $\begin{array}{c}10^{3} k_{2} / \\
\mathrm{dm}^{3} \mathrm{~mol}^{-1} \mathrm{~s}^{-1}\end{array}$ & $\begin{array}{c}\mathbf{r} \\
\sigma / \%\end{array}$ \\
\hline 0.40 & 0.20 & 0.00 & 11.1 & $\begin{array}{c}0.9981 \\
2.21\end{array}$ & 3.87 & $\begin{array}{c}0.9991 \\
1.50\end{array}$ \\
\hline 0.30 & 0.20 & 0.10 & 6.84 & $\begin{array}{c}0.9924 \\
4.39\end{array}$ & 3.77 & $\begin{array}{c}0.9998 \\
0.66\end{array}$ \\
\hline 0.20 & 0.20 & 0.20 & 3.94 & $\begin{array}{c}0.9868 \\
5.81\end{array}$ & 4.21 & $\begin{array}{c}0.9995 \\
1.08\end{array}$ \\
\hline 0.20 & 0.10 & 0.20 & 5.88 & $\begin{array}{c}0.9933 \\
4.12\end{array}$ & 4.32 & $\begin{array}{c}0.9987 \\
1.78\end{array}$ \\
\hline
\end{tabular}

\section{Table 6.6}

A summary of first and second order rate constants (Isolated points deleted) ${ }^{*}$ with their corresponding correlation coefficients, $\mathrm{r}$, and standard errors, $\sigma$, for the reaction of $p$ nitrocumyl bromide with lithium azide (Tables 6.1, 6.2, 6.3 and 6.4).

\begin{tabular}{|c|c|c|c|c|c|c|}
\hline $\begin{array}{l}{\left[L_{i N}\right]_{0}} \\
/ \mathrm{mol} \mathrm{dm}^{-3} \\
\end{array}$ & $\begin{array}{l}{[R B r]_{0}} \\
/ \mathrm{mol} \mathrm{dm}^{-3}\end{array}$ & $\begin{array}{c}{\left[\mathrm{LiClO}_{4}\right]_{0}} \\
/ \mathrm{mol} \mathrm{dm}^{-3}\end{array}$ & $\begin{array}{c}10^{4} k_{1}{ }^{*} / \\
s^{-1} \\
\end{array}$ & $\begin{array}{c}r^{*} \\
\sigma^{*} / \% \\
\end{array}$ & $\begin{array}{c}10^{3} \mathrm{k}_{2}^{*} / \\
\mathrm{dm}^{3} \mathrm{~mol}^{-1} \mathrm{~s}^{-1} \\
\end{array}$ & $\begin{array}{c}r^{*} \\
\sigma^{*} / \% \\
\end{array}$ \\
\hline 0.40 & 0.20 & 0.00 & 11.0 & $\begin{array}{c}0.9973 \\
2.76\end{array}$ & 3.96 & $\begin{array}{c}0.9999 \\
0.65\end{array}$ \\
\hline 0.30 & 0.20 & 0.10 & 6.84 & $\begin{array}{c}0.9924 \\
4.39\end{array}$ & 3.77 & $\begin{array}{c}0.9998 \\
0.66\end{array}$ \\
\hline 0.20 & 0.20 & 0.20 & 3.93 & $\begin{array}{c}0.9876 \\
6.01\end{array}$ & 4.22 & $\begin{array}{c}0.9997 \\
0.95\end{array}$ \\
\hline 0.20 & 0.10 & 0.20 & 5.48 & $\begin{array}{c}0.9991 \\
1.60\end{array}$ & 4.21 & $\begin{array}{c}0.9995 \\
1.16\end{array}$ \\
\hline
\end{tabular}


Table 6.7

Temperature

Solvent

$[\mathrm{RBr}]_{0}$

$\left[\mathrm{LiN}_{3}\right]_{0}$

$\left[\mathrm{LiClO}_{4}\right]_{0}$
The Elimination of $p$-Nitrocumyl Bromide in Dimethyl

\section{Sulphoxide}

$30^{\circ} \mathrm{C}$

$99.9 \% \mathrm{C}_{2} \mathrm{D}_{6} \mathrm{SO}$

$0.20 \mathrm{~mol} \mathrm{dm}^{-3}$

$\left(\mathrm{R}=\mathrm{C}_{9} \mathrm{H}_{10} \mathrm{NO}_{2}\right)$

$0.00 \mathrm{~mol} \mathrm{dm}^{-3}$

$0.40 \mathrm{~mol} \mathrm{dm}^{-3}$

\begin{tabular}{|c|c|c|}
\hline Time Range $/ \mathrm{s}$ & Mid-point Time $/ \mathrm{s}$ & {$[\mathrm{RBr}]_{\mathrm{t}} / \mathrm{mol} \mathrm{dm}^{-3}$} \\
\hline 0 & 0 & 0.200 \\
\hline $3592-3608$ & 3600 & 0.172 \\
\hline $7192-7208$ & 7200 & 0.148 \\
\hline $10792-10808$ & 10800 & 0.117 \\
\hline $14392-14408$ & 14400 & 0.103 \\
\hline $17992-18008$ & 18000 & 0.086 \\
\hline $21592-21608$ & 21600 & 0.075 \\
\hline $25192-25208$ & 25200 & 0.059 \\
\hline $28792-28808$ & 28800 & 0.051 \\
\hline $32392-32408$ & 32400 & 0.042 \\
\hline
\end{tabular}




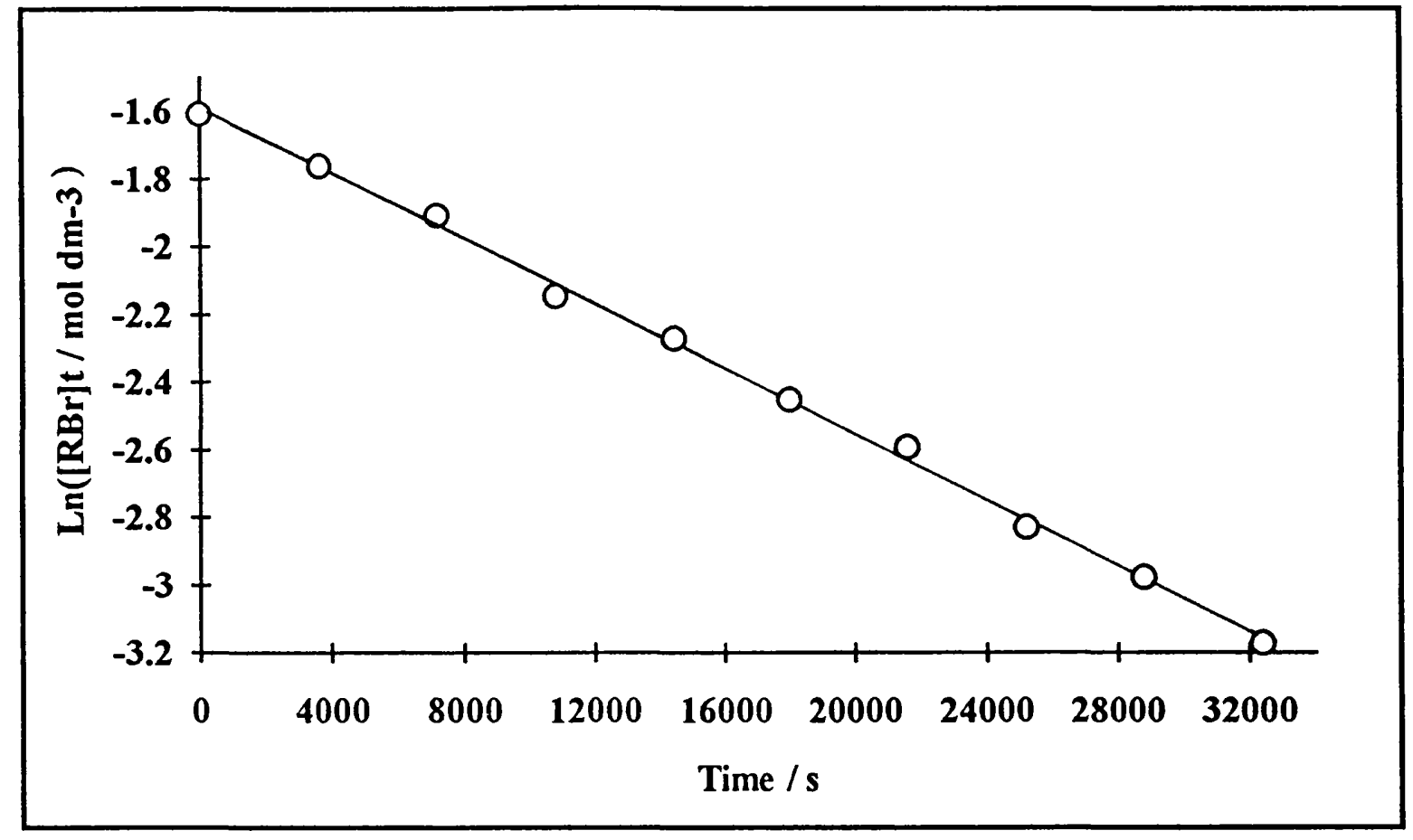

(a)

$$
\begin{aligned}
& k_{1}=4.83 \times 10^{-5} \mathrm{~s}^{-1} \\
& \mathrm{r}=0.9990 \\
& \sigma=1.60 \%
\end{aligned}
$$

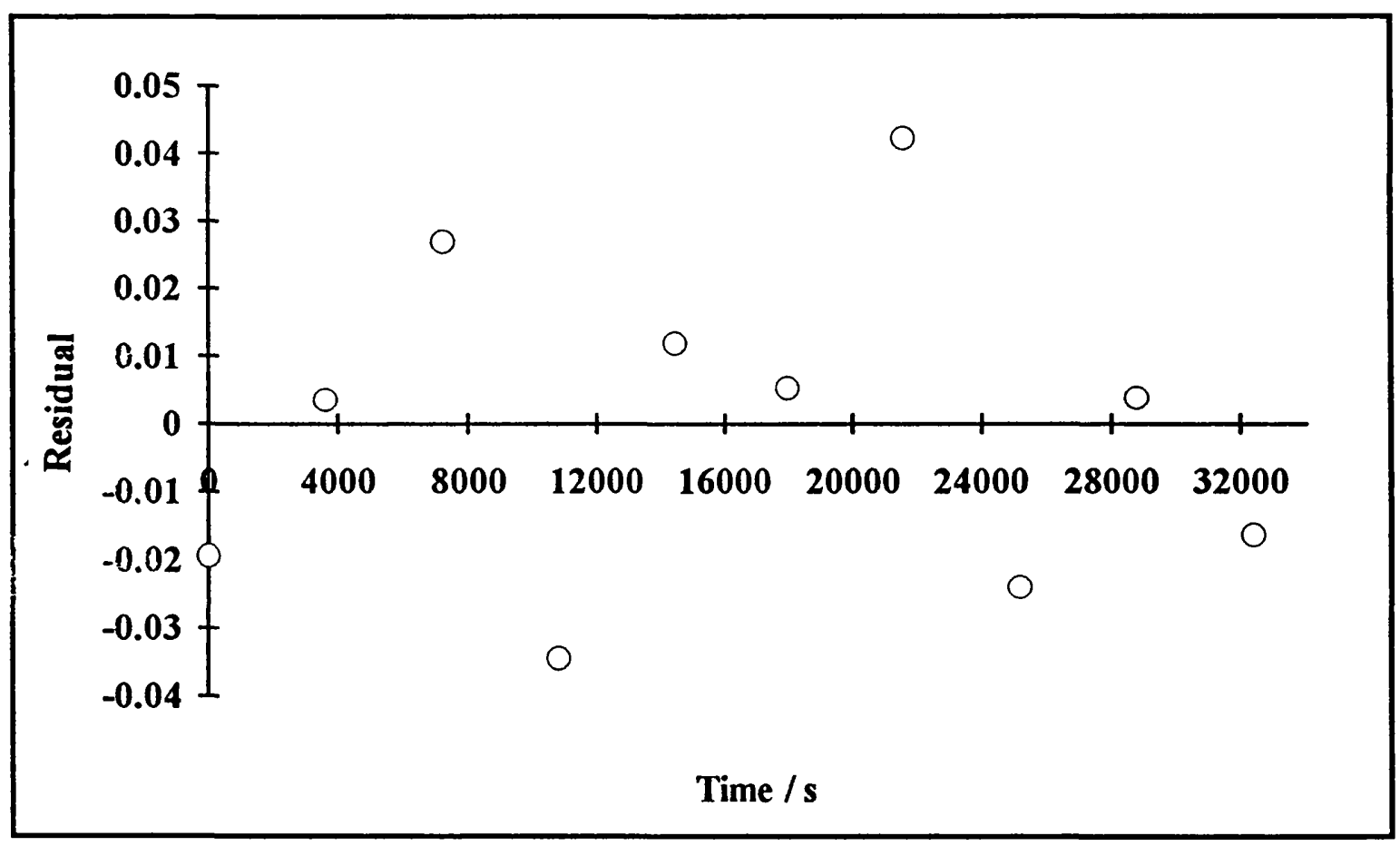

(b)

\section{Figure 6.11}

Plots of (a) $\mathrm{Ln}\left([\mathrm{RBr}]_{\mathrm{t}} / \mathrm{mol} \mathrm{dm}^{-3}\right)$ and (b) Residuals against time / $\mathrm{s}$ for the elimination of $p$-nitrocumyl bromide in dimethyl sulphoxide. 
The $k_{\mathrm{S}}$ obtained for chapter 3 is slightly lower than the $k_{\mathrm{S}}$ obtained here. There is probably a small negative salt effect as the ionic strength is $0.40 \mathrm{~mol} \mathrm{dm}^{-3}$ for the azide runs and $1.00 \mathrm{~mol} \mathrm{dm}^{-3}$ for the nitrite runs.

\subsection{Improved Model}

An overall second order model is a good fit to the data in Tables 6.1, 6.2, 6.3, and 6.4 , but a model incorporating the elimination of p-nitrocumyl bromide in dimethyl sulphoxide can easily be formulated. If a reaction mechanism involves a reactant which can undergo two or more reactions independently and concurrently, the reactions are called parallel or side reactions. As in chapter 3, the method of initial reaction rates is adopted for a preliminary survey of the kinetics.

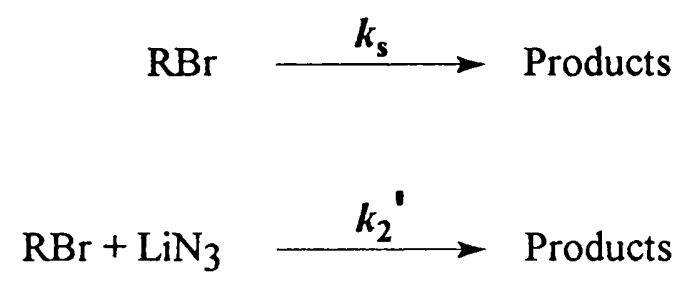

Combining Equations (6.3) and (6.4), the rate can be written quite generally as Equation (6.5):

$$
-\left(d[\mathrm{RBr}]_{\mathrm{t}} / d t\right)=k_{\mathrm{s}}[\mathrm{RBr}]_{\mathrm{t}}+k_{2}^{\prime}[\mathrm{RBr}]_{\mathrm{t}}\left[\mathrm{N}_{3}{ }^{-}\right]_{\mathrm{t}}
$$

At time equal to $0 \mathrm{~s}$ the initial rate will be Equation (6.6):

$$
-\left(d[\mathrm{RBr}]_{0} / d t\right)=k_{\mathrm{S}}[\mathrm{RBr}]_{0}+k_{2}^{\prime}[\mathrm{RBr}]_{0}\left[\mathrm{~N}_{3}{ }^{-}\right]_{0}
$$

Equation 4.6 can be rearranged into Equation 6.7:

$$
-\left(d[\mathrm{RBr}]_{0} / d t\right) /[\mathrm{RBr}]_{0}=k_{\mathrm{S}}+k_{2}^{\prime}\left[\mathrm{N}_{3}^{-}\right]_{0}
$$




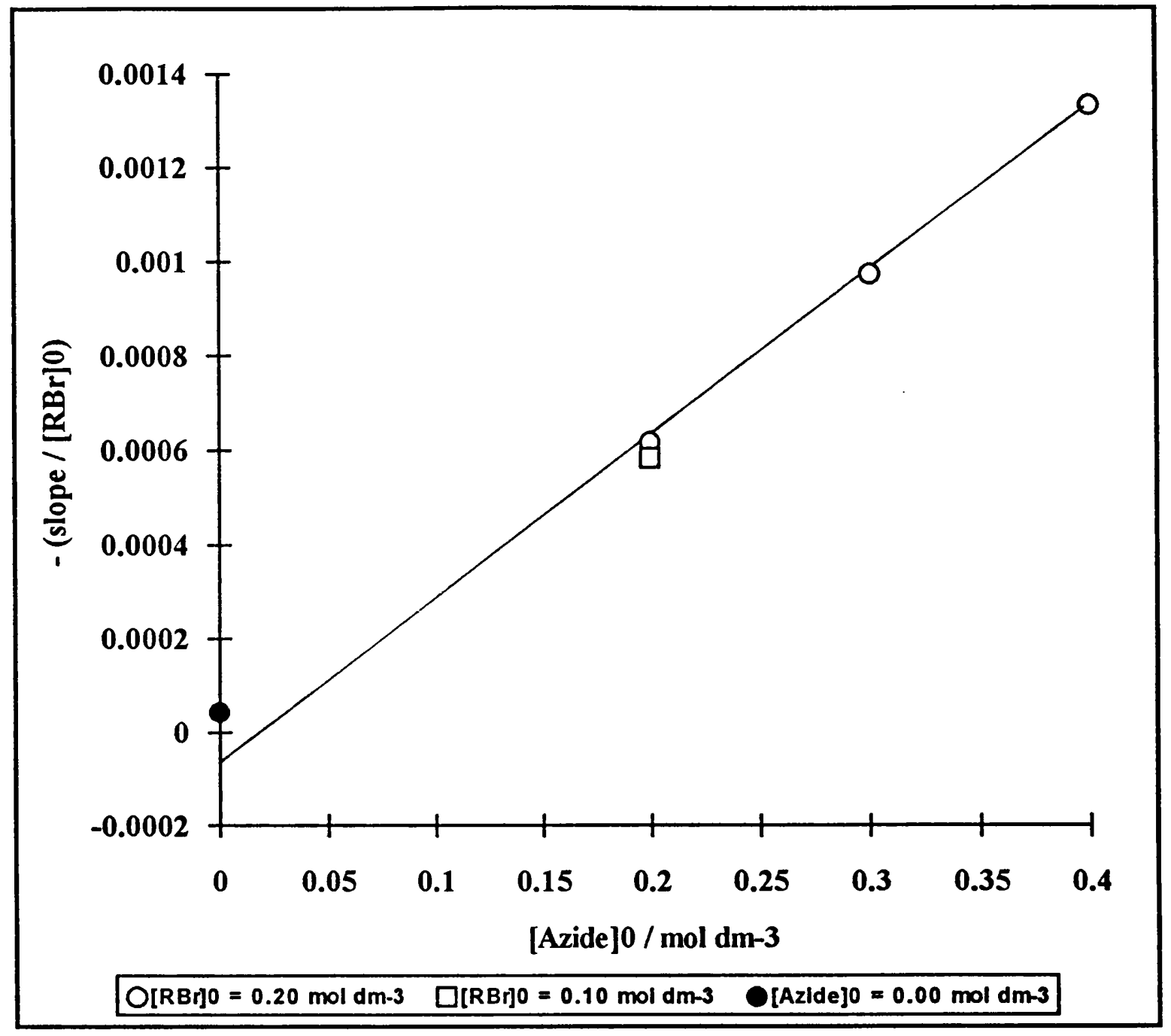

$$
\begin{aligned}
& k_{\mathrm{s}}=-1.28 \times 10^{-4} \mathrm{~s}^{-1} \\
& k_{2}^{\prime}=3.65 \times 10^{-3} \mathrm{~mol}^{-1} \mathrm{dm}^{3} \mathrm{~s}^{-1} \\
& \mathrm{r}=0.9992
\end{aligned}
$$

\section{Figure 6.12}

A plot of $-\left(d[\mathrm{RBr}]_{0} / d t\right) /[\mathrm{RBr}]_{0}$ versus $\left[\mathrm{N}_{3}{ }^{-}\right]_{0}$ for the data contained in Tables 6.1, 6.2, 6.3, 6.4, and 6.7. 
Assuming that the initial concentration of free azide ion is equal to the initial concentration of lithium azide then rate constants can be obtained by plotting $-\left(d[\mathrm{RBr}]_{0} / d t\right) /[\mathrm{RBr}]_{0}$ versus $\left[\mathrm{N}_{3}{ }^{-}\right]_{0}$ (Figure 6.12).

The initial slopes were calculated by firstly fitting third order polynomials to the disappearance of $p$-nitrocumyl bromide. If a kinetic run had its first point obviously removed from others then the point was deleted and a third order polynomial fitted to the remaining points. The initial slopes were then evaluated by substituting time equal to zero into the differentiated functions. A straight line was fitted to the above plot using the method of least squares. The point for the elimination of $p$-nitrocumyl bromide $\left(\left[\mathrm{N}_{3}{ }^{-}\right]_{0}=\right.$

$0.00 \mathrm{~mol} \mathrm{dm}^{-3}$ ) was included in Figure 6.12 , but was not used to determine the least squares fit. Plots of this nature tend to have much larger errors in their intercepts than in their slopes. It is therefore not surprising that the $k_{\mathrm{S}}$ obtained from the plot in Figure 6.12 is small and negative. A negative rate constant has no meaning, however, the slope obtained has a very good correlation coefficient.

A plot of $-\left(d[\mathrm{RBr}]_{0} / d t\right) /[\mathrm{RBr}]_{0}$ versus $\left[\mathrm{N}_{3}{ }^{-}\right]_{0}{ }^{2}$ does not give a straight line, but gives a distinctive curve (Figure 6.13). This indicates that there is no significant termolecular kinetic component in the reaction of lithium azide with $p$-nitrocumyl bromide in dimethyl sulphoxide. As mentioned earlier, the method of initial reaction rate is one technique used for a preliminary survey of the kinetics. The technique only gives approximate rate constants but provides a useful starting point for more advanced methods.

\subsection{Product Analysis}

Observing the formation of products within a reaction provides a fair alternative and complement to following the disappearance of the starting materials in determining the overall order of a reaction. Figures $6.14,6.15,6.16,6.17,6.18$ and 6.19 show the formation of products versus time for the various kinetic runs. 


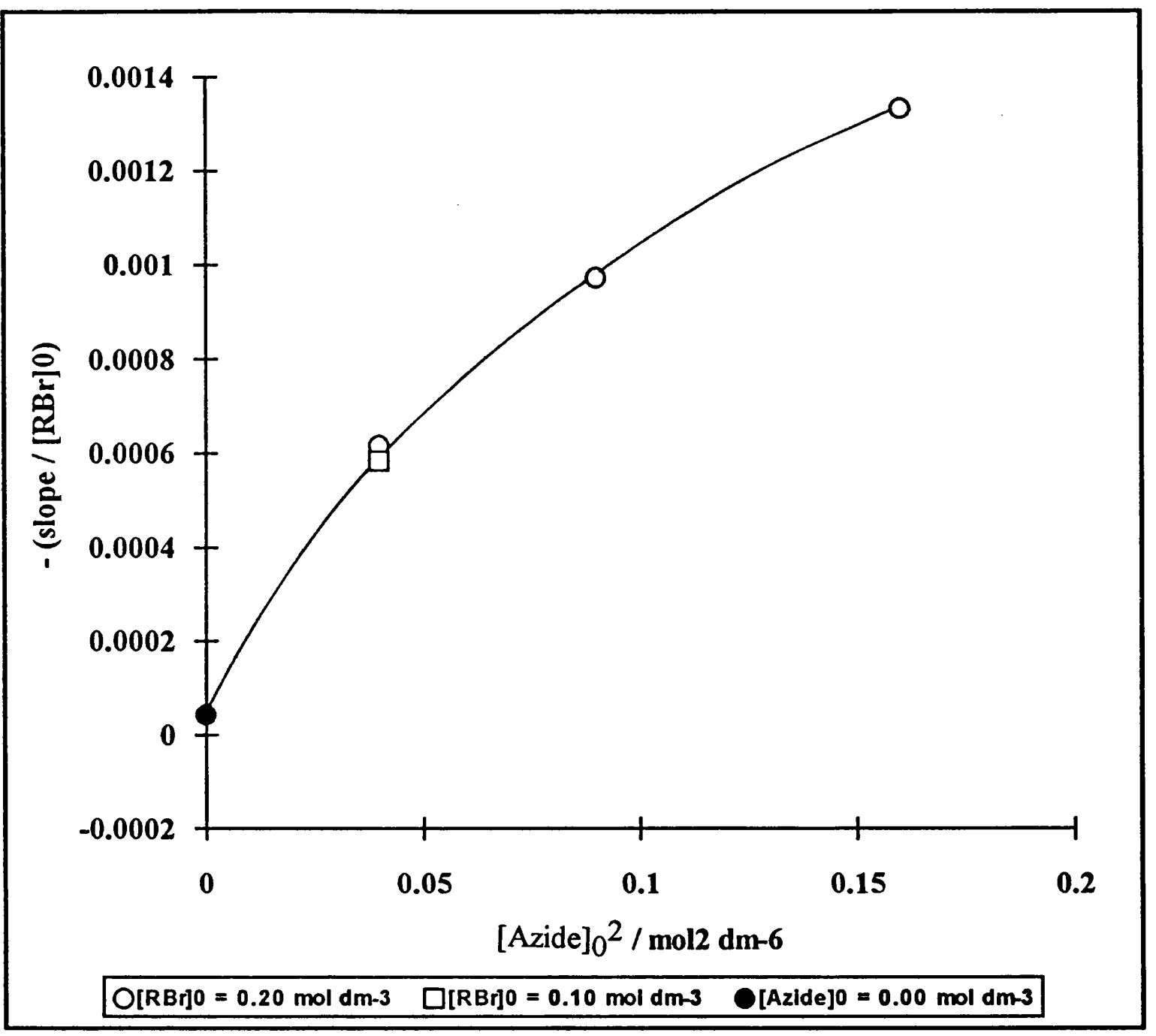

\section{Figure 6.13}

A plot of $-\left(d[\mathrm{RBr}]_{0} / d t\right) /[\mathrm{RBr}]_{0}$ versus $\left[\mathrm{N}_{3}{ }^{-}\right]_{0}{ }^{2}$ for the data contained in Tables 6.1, $6.2,6.3,6.4$, and 6.7. 


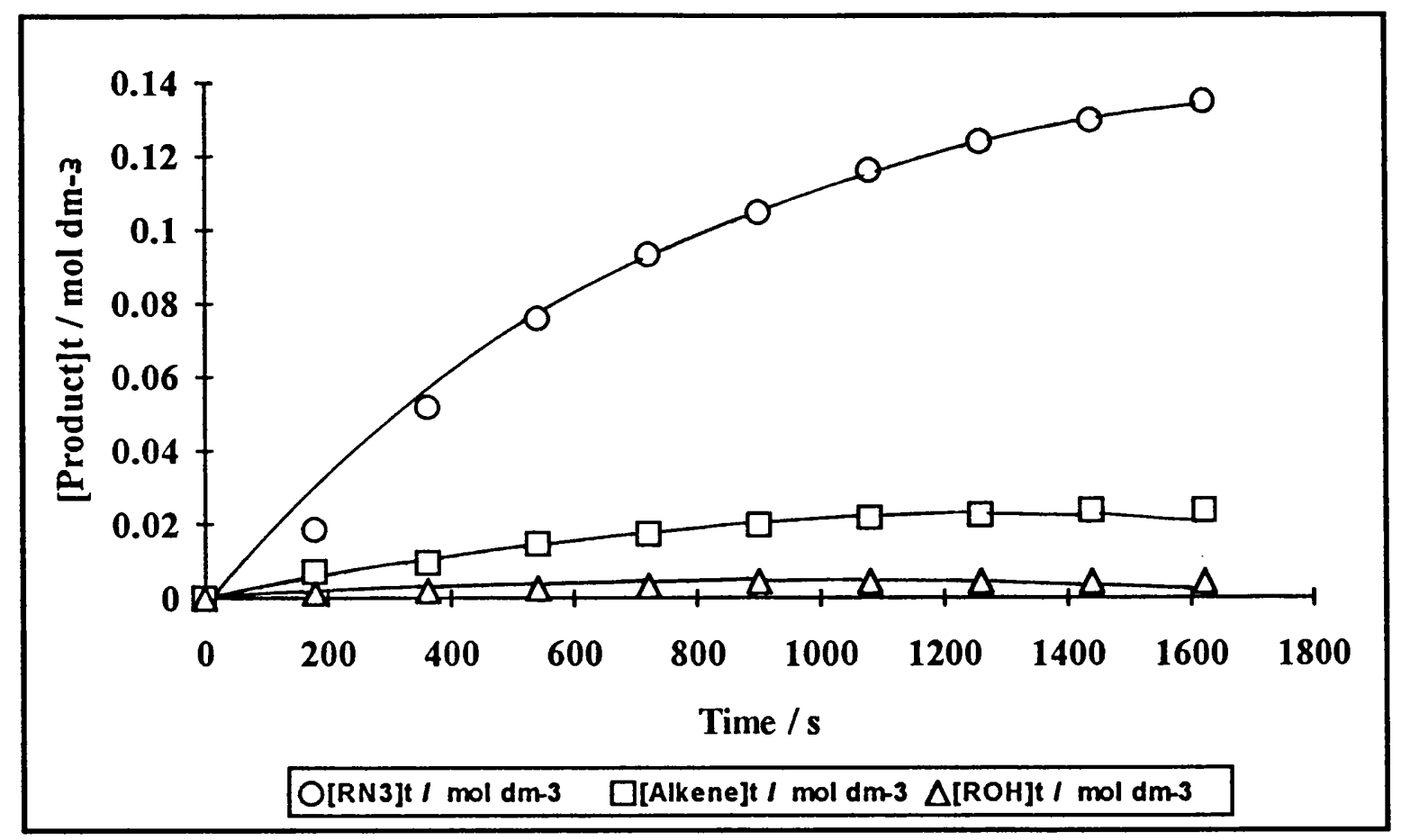

\section{Figure 6.14}

The formation of products for the reaction of lithium azide with p-nitrocumyl bromide in dimethyl sulphoxide. (Table $6.1 ;\left[\mathrm{LiN}_{3}\right]_{0}=0.40 \mathrm{~mol} \mathrm{dm}^{-3},[\mathrm{RBr}]_{0}=0.20 \mathrm{~mol} \mathrm{dm}^{-3}$, $\left.\left[\mathrm{LiClO}_{4}\right]_{0}=0.00 \mathrm{~mol} \mathrm{dm}^{-3}\right)$.

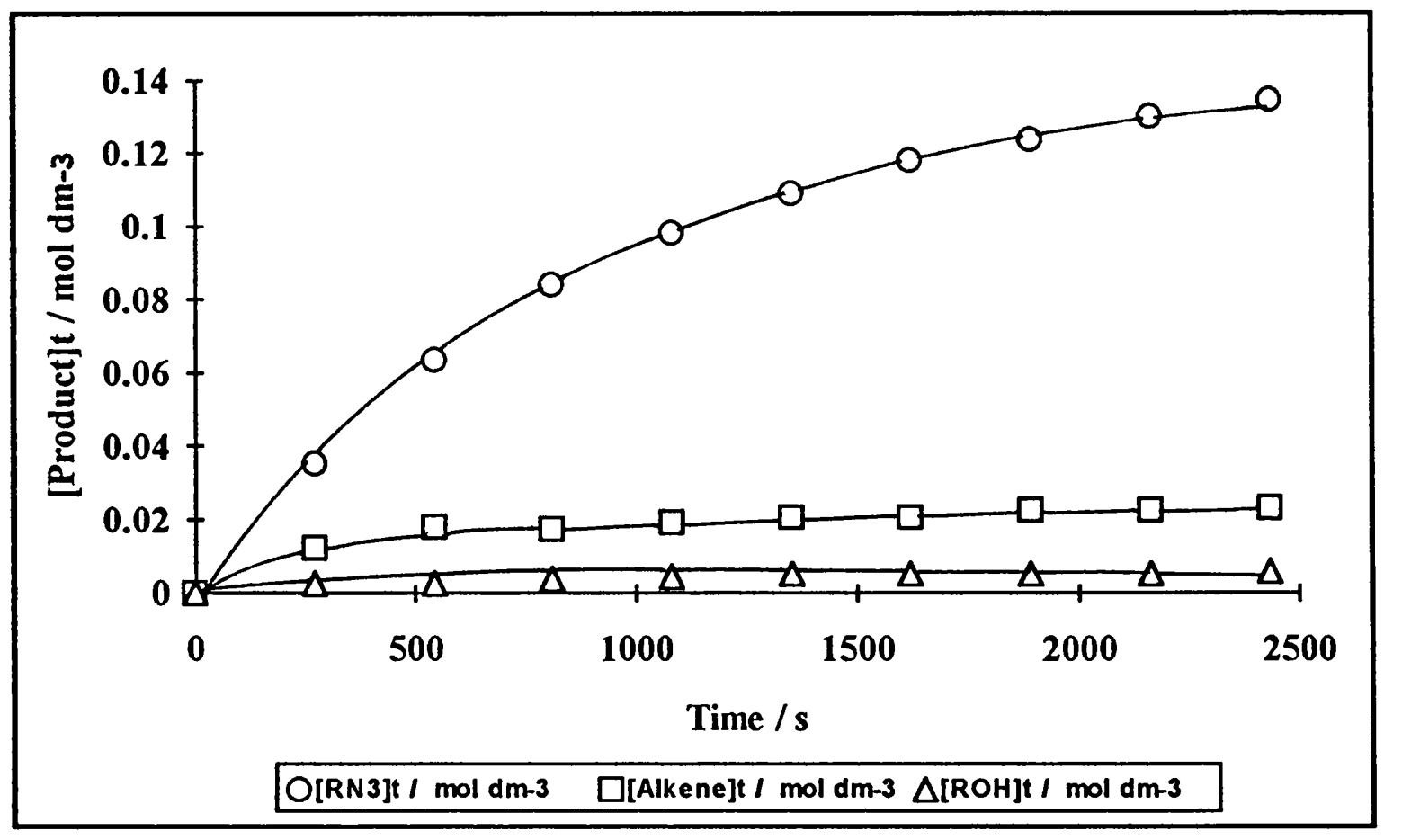

\section{Figure 6.15}

The formation of products for the reaction of lithium azide with $p$-nitrocumyl bromide in dimethyl sulphoxide. (Table 6.2; $\left[\mathrm{LiN}_{3}\right]_{0}=0.30 \mathrm{~mol} \mathrm{dm}^{-3},[\mathrm{RBr}]_{0}=0.20 \mathrm{~mol} \mathrm{dm}^{-3}$, $\left[\mathrm{LiClO}_{4}\right]_{0}=0.10 \mathrm{~mol} \mathrm{dm}^{-3}$ ). 


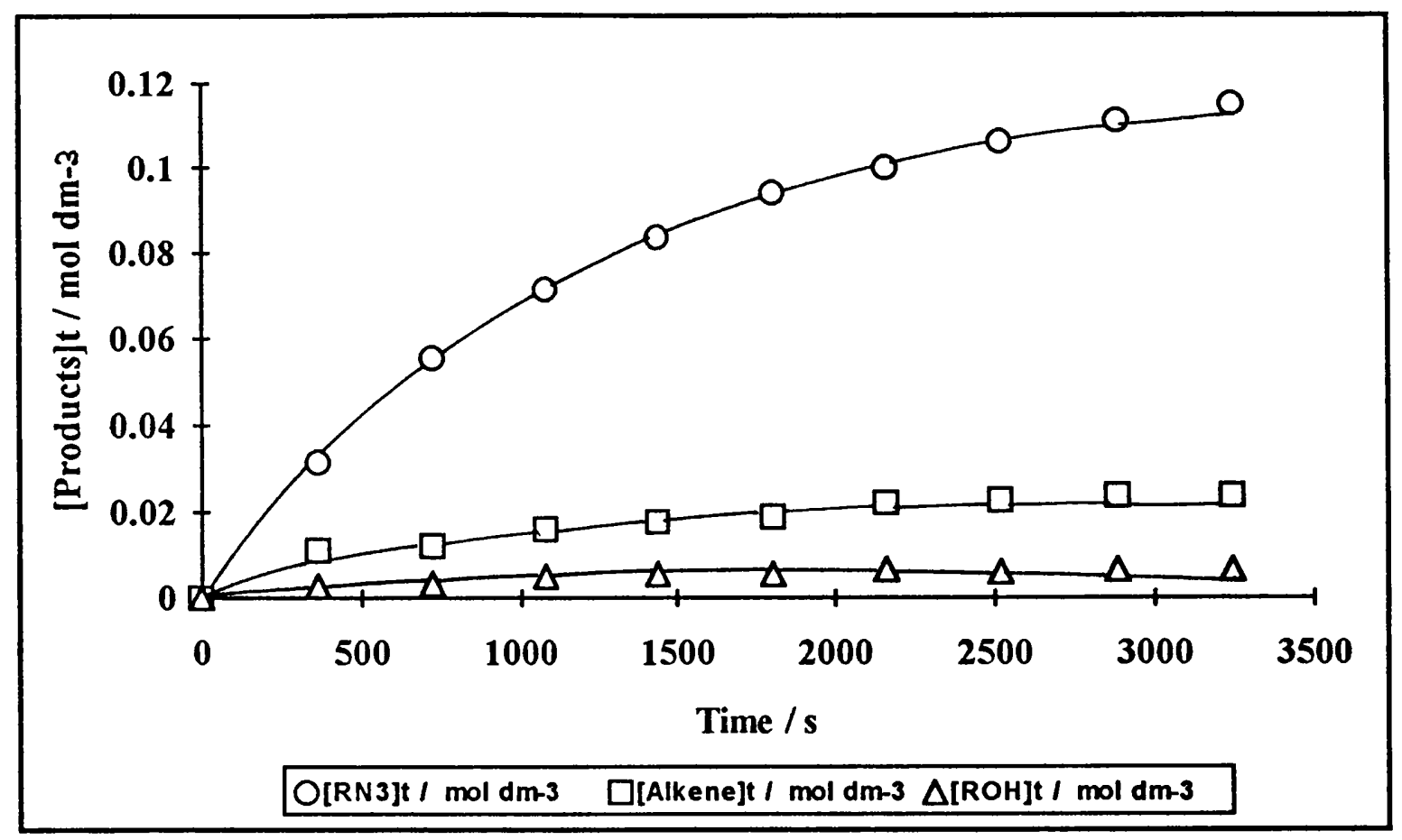

\section{Figure 6.16}

The formation of products for the reaction of lithium azide with $p$-nitrocumyl bromide in dimethyl sulphoxide. (Table 6.3; $\left[\mathrm{LiN}_{3}\right]_{0}=0.20 \mathrm{~mol} \mathrm{dm}^{-3},[\mathrm{RBr}]_{0}=0.20 \mathrm{~mol} \mathrm{dm}^{-3}$, $\left.\left[\mathrm{LiClO}_{4}\right]_{0}=0.20 \mathrm{~mol} \mathrm{dm}^{-3}\right)$.

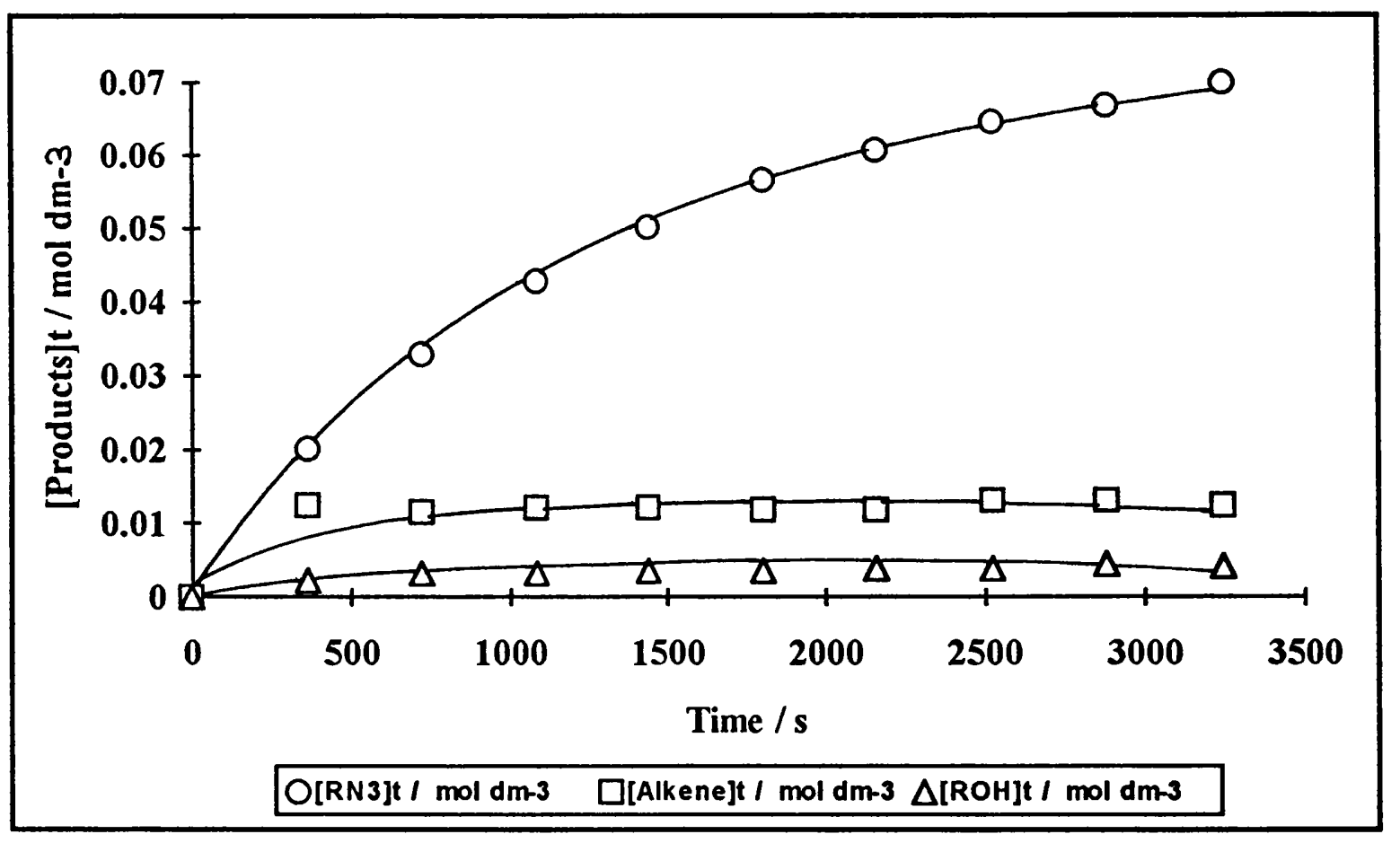

\section{Figure 6.17}

The formation of products for the reaction of lithium azide with $p$-nitrocumyl bromide in dimethyl sulphoxide. (Table $6.4 ;\left[\mathrm{LiN}_{3}\right]_{0}=0.20 \mathrm{~mol} \mathrm{dm}^{-3},[\mathrm{RBr}]_{0}=0.10 \mathrm{~mol} \mathrm{dm}^{-3}$, $\left.\left[\mathrm{LiClO}_{4}\right]_{0}=0.20 \mathrm{~mol} \mathrm{dm}^{-3}\right)$. 
On examining these Figures it is reasonable to say that the rate of formation of $p$ nitrocumyl azide is dependent on the initial concentration of lithium azide. For the various kinetic runs, the rate of formation of $p$-nitrocumyl azide always remains greater than the rate of formation of either $p$-nitro- $\alpha$-methylstyrene or $p$-nitrocumyl alcohol. The rate of formation of $p$-nitrocumyl alcohol is very slow and is almost negligible over the time periods concerned.

Figure 6.18 compares the formation of $p$-nitrocumyl azide for various different initial molarities of lithium azide. Again, it is clear that the rate of formation of $p$ nitrocumyl azide is dependent on the initial concentration of lithium azide.

Figure 6.19 compares the formation of $p$-nitro- $\alpha$-methylstyrene for various different initial molarities of lithium azide. It is unclear from Figure 6.19 whether the rate of formation of $p$-nitro- $\alpha$-methylstyrene is dependent on the initial concentration of sodium nitrite. It can be seen that the rate of formation of the alkene, based on the curve fitted, is initially very large. This is due to a modicum of the $p$-nitro- $\alpha$-methylstyrene being formed prior to mixing, via the elimination of $p$-nitrocumyl bromide in the substrate solution.

Figure 6.20 compares the formation p-nitrocumyl alcohol for various different initial molarities of lithium azide. The ${ }^{1} \mathrm{H}$ n.m.r. integrals for $p$-nitrocumyl alcohol at given times are very small compared to the ${ }^{1} \mathrm{H}$ n.m.r. integrals for the other products at given times. This leads to larger errors in the calculated concentrations of $p$-nitrocumyl alcohol than in the calculated concentrations of the other products. On examining Figure 6.20, the result of these larger errors can quite easily be seen. Again, it is very difficult to tell whether the rate of formation of alcohol is dependent on the initial concentration of lithium azide.

Table 6.7 displays the percentage yields of products for the various kinetic runs. There is a noticeable trend within the table; The percentage yield of $p$-nitrocumyl azide decreases very gradually as the initial concentration of lithium azide decreases. 


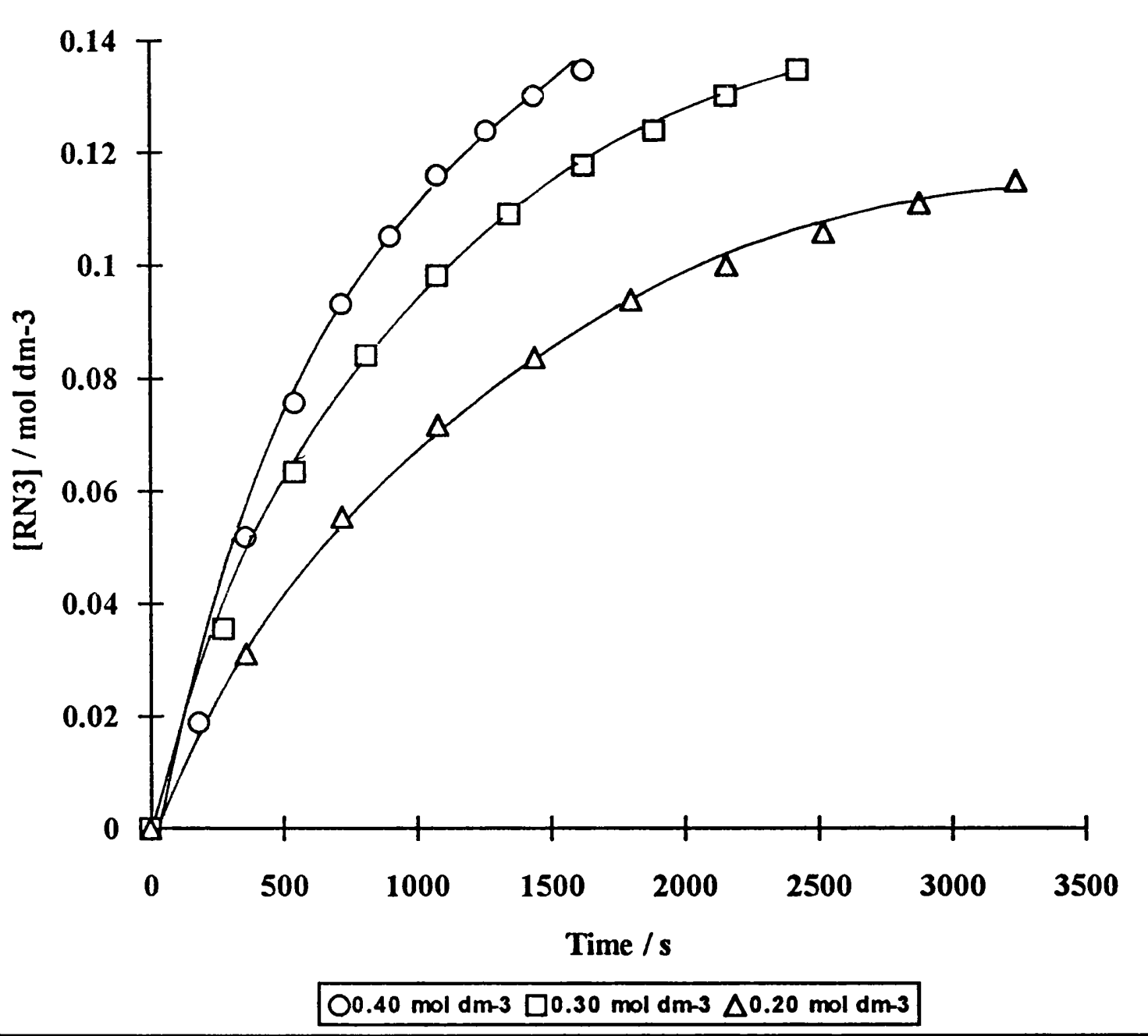

Figure 6.18

A comparison of the formation of $p$-nitrocumyl azide for various different initial molarities of lithium azide (Tables 6.1, 6.2, and 6.3). 


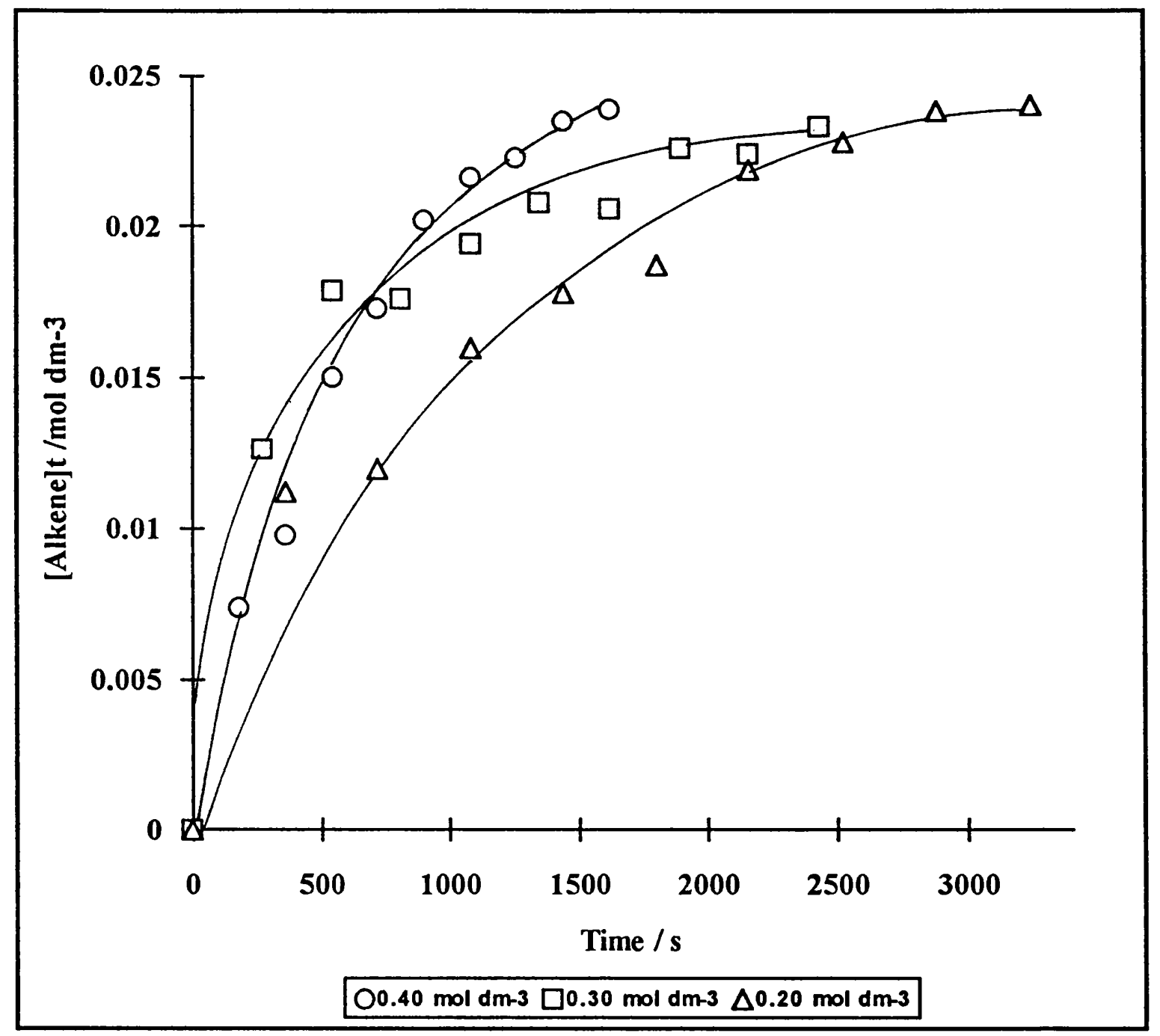

\section{Figure 6.19}

A comparison of the formation of $p$-nitro- $\alpha$-methylstyrene for various different initial molarities of lithium azide (Tables 6.1, 6.2, and 6.3). 


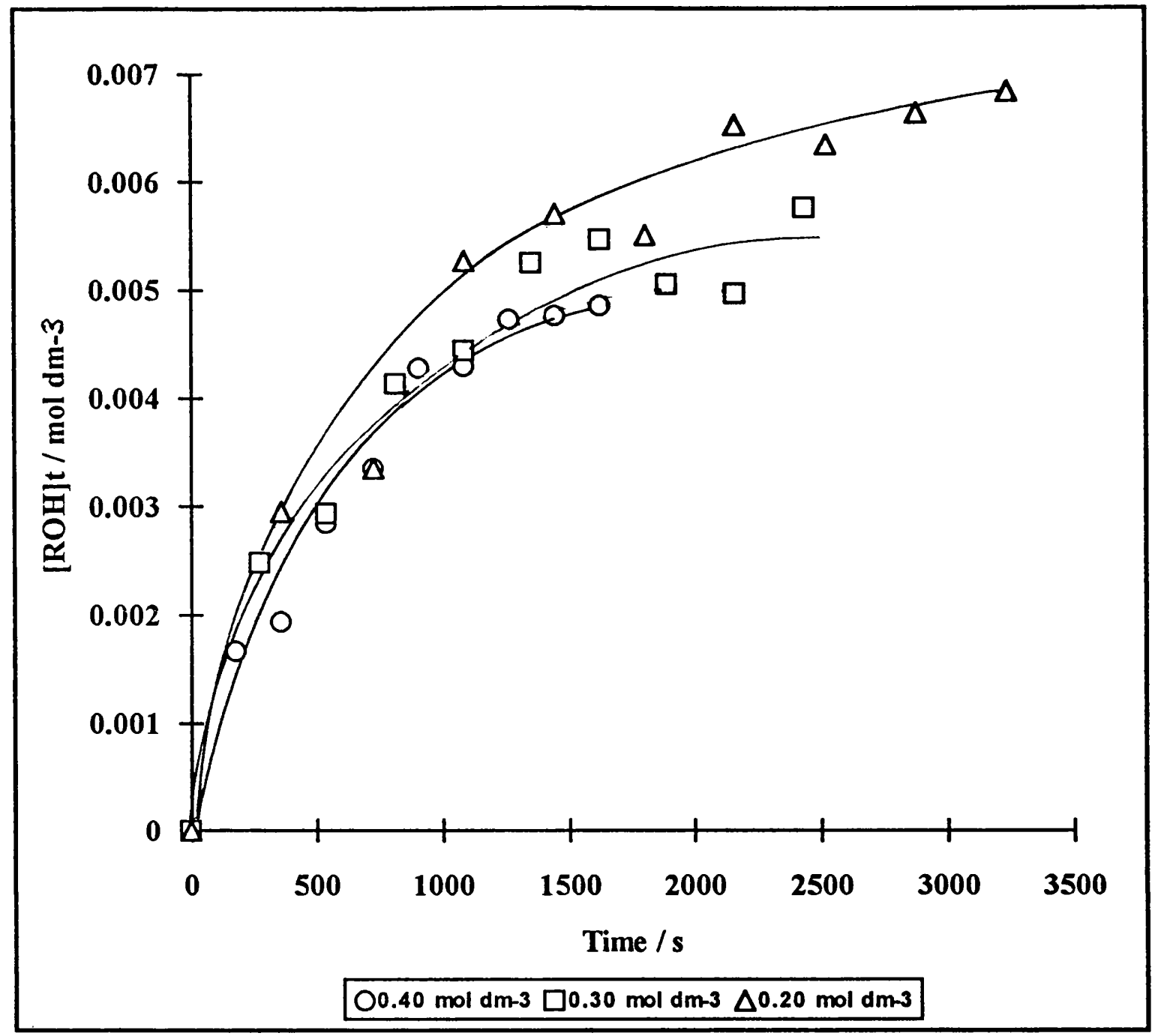

\section{Figure 6.20}

A comparison of the formation of $p$-nitrocumyl alcohol for various different initial molarities of lithium azide (Tables 6.1, 6.2, and 6.3). 
Both the percentage yield of $p$-nitrocumyl alcohol and $p$-nitro- $\alpha$-methylstyrene increase with decreasing initial concentration of lithium azide, however, their final yields always remain far less than that of $p$-nitrocumyl azide.

\section{Table 6.7}

A comparison of product percentage yields ${ }^{*}$ for the reaction of $p$-nitrocumyl bromide with lithium azide in dimethyl sulphoxide.

( ${ }^{*}$ Product percentage yields obtained via ${ }^{1}$ H n.m.r. spectroscopy of the various reaction solutions at infinity).

\begin{tabular}{|c|c|c|c|c|c|}
\hline $\begin{array}{c}{\left[\mathrm{LiN}_{3}\right]_{\mathbf{0}} /} \\
\mathrm{mol} \mathrm{dm}^{-3}\end{array}$ & $\begin{array}{c}{[\mathrm{RBr}]_{\mathbf{0}} /} \\
\mathrm{mol} \mathrm{dm}^{-3}\end{array}$ & $\begin{array}{c}{\left[\mathrm{LiClO}_{\mathbf{4}}\right]_{\mathbf{0}} /} \\
\mathrm{mol} \mathrm{dm}^{-3}\end{array}$ & $\begin{array}{c}\mathrm{RN}_{\mathbf{3}} / \\
\%\end{array}$ & $\begin{array}{c}\text { Alkene } / \\
\%\end{array}$ & $\begin{array}{c}\mathrm{ROH} / \\
\%\end{array}$ \\
\hline 0.40 & 0.20 & 0.00 & 86 & 11 & 3 \\
\hline 0.30 & 0.20 & 0.20 & 82 & 12 & 6 \\
\hline 0.20 & 0.20 & 0.40 & 71 & 21 & 8 \\
\hline 0.20 & 0.10 & 0.60 & 73 & 19 & 8 \\
\hline
\end{tabular}

\subsection{Initial Slopes of Product Formation}

It was mentioned in the previous section that there was some uncertainty concerning the dependency of the rate of formation of both the alcohol and alkene on the initial concentration of lithium azide. The method of initial slopes proved very successful in chapter 4 and will again be used in this case. The initial slopes of product formation can also be used to complement the conclusions derived from the initial slopes of $p$-nitrocumyl bromide disappearance (Section 6.4). If the formation of a product derives from a bimolecular reaction then:

$$
\left(d[\text { Product }]_{0} / d t\right) /[\mathrm{RBr}]_{0}=k(\mathrm{P}) 2\left[\mathrm{~N}_{3}{ }^{-}\right]_{0}
$$


A plot of $\left(d[\text { Product }]_{0} / d t\right) /[\mathrm{RBr}]_{0}$ versus $\left[\mathrm{N}_{3}{ }^{-}\right]_{0}$ should give a straight line through the origin with gradient $k(\mathrm{P}) 2$. However, if the formation of a product derives from a unimolecular reaction then:

$$
\left(d[\text { Product }]_{0} / d t\right) /[\mathrm{RBr}]_{0}=k(\mathrm{P}) 1
$$

A plot of $\left(d[\text { Product }]_{0} / d t\right) /[\mathrm{RBr}]_{0}$ versus $\left[\mathrm{N}_{3}{ }^{-}\right]_{0}$ in the case of (6.9) should give a straight line with no slope. If the formation of a product derives itself from concurrent unimolecular and bimolecular reactions then:

$$
\left(d[\text { Product }]_{0} / d t\right) /[\mathrm{RBr}]_{0}=k(\mathrm{P})_{1}+k(\mathrm{P})_{2}\left[\mathrm{NO}_{2}^{-}\right]_{0}
$$

A plot of $\left(d[\text { Product }]_{0} / d t\right) /[\mathrm{RBr}]_{0}$ versus $\left[\mathrm{N}_{3}^{-}\right]_{0}$ should give a straight line with intercept $k(\mathrm{P}) 1$ and gradient $k(\mathrm{P}) 2$.

The initial slopes were calculated in the usual way and straight lines were fitted to the different plots by the method of least squares. Large errors will be expected in these plots as the kinetic data is rather limited. Also, larger errors will be entailed in the initial slopes derived from the formation of p-nitrocumyl alcohol due to the alcohol's low concentration.

A reasonable straight line with a positive slope and a small intercept is obtained for the plot derived from the formation of $p$-nitrocumyl azide (Figure 6.21). The point for the $[\mathrm{RBr}]_{0}=0.10 \mathrm{~mol} \mathrm{dm}^{-3}$ kinetic run was included in Figure 6.21 , but was not used to determine the least squares fit. Figure 6.21 suggests that $p$-nitrocumyl azide is formed almost exclusively from a bimolecular reaction, as the intercept is small compared to the slope of the line.

A straight line is obtained for the plot derived from the formation of $p$-nitro- $\alpha$ methylstyrene (Figure 6.22), and the line has a moderately large intercept compared to its slope. The points for the elimination of $p$-nitrocumyl bromide $\left(\left[\mathrm{N}_{3}{ }^{-}\right]_{0}=0.00 \mathrm{~mol} \mathrm{dm}^{-3}\right)$ and the $[\mathrm{RBr}]_{0}=0.10 \mathrm{~mol} \mathrm{dm}^{-3}$ kinetic run were included in Figure 6.22 , but were not 
used to determine the least squares fit. The point for the elimination of $p$-nitrocumyl bromide is close to the straight line obtained. Errors in initial slopes for the $[\mathrm{RBr}]_{0}=0.10$ mol dm-3 kinetic runs have been observed in previous chapters, so it is not surprising that it this case the point for $[\mathrm{RBr}]_{0}=0.10 \mathrm{~mol} \mathrm{dm}^{-3}$ is far removed from the line. Figure 6.22 suggests that $p$-nitro- $\alpha$-methylstyrene is formed from concurrent unimolecular and bimolecular reactions. The initial slopes for the formation of the alkene, based on the curve fitted, are larger than expected. This is due to a small amount of $p$-nitro- $\alpha$ methylstyrene being formed prior to mixing, via the elimination of $p$-nitrocumyl bromide in the substrate solution. This implies that the value obtained for $k$ (Alkene)2 is higher that the true rate constant. The unimolecular component seems to have derived itself from the elimination of $p$-nitrocumyl bromide.

A straight line can be fitted to the plot derived from the formation of $p$-nitrocumyl alcohol (Figure 6.23), however, the fit of the line to the points is a very poor one. The points for the elimination of $p$-nitrocumyl bromide $\left(\left[\mathrm{N}_{3}{ }^{-}\right]_{0}=0.00 \mathrm{~mol} \mathrm{dm}^{-3}\right)$ and the $[\mathrm{RBr}]_{0}=0.10 \mathrm{~mol} \mathrm{dm}^{-3}$ kinetic run were included, but were not used to determine the least squares fit. The poor correlation of the points to the line is exemplified by the very low correlation coefficient obtained. The plot in Figure 6.23 suggests that the rate of formation of $p$-nitrocumyl alcohol is independent of the initial concentration of lithium azide.

It must be stressed that the rate constants obtained from the initial slopes method in this case are extremely approximate, in fact, the rate constants obtained have no real quantitative value. The importance of these plots is to get a feel for whether or not the formation of a product depends on the initial concentration of lithium azide. The method of initial slopes serves as a good starting point for more advanced models. 


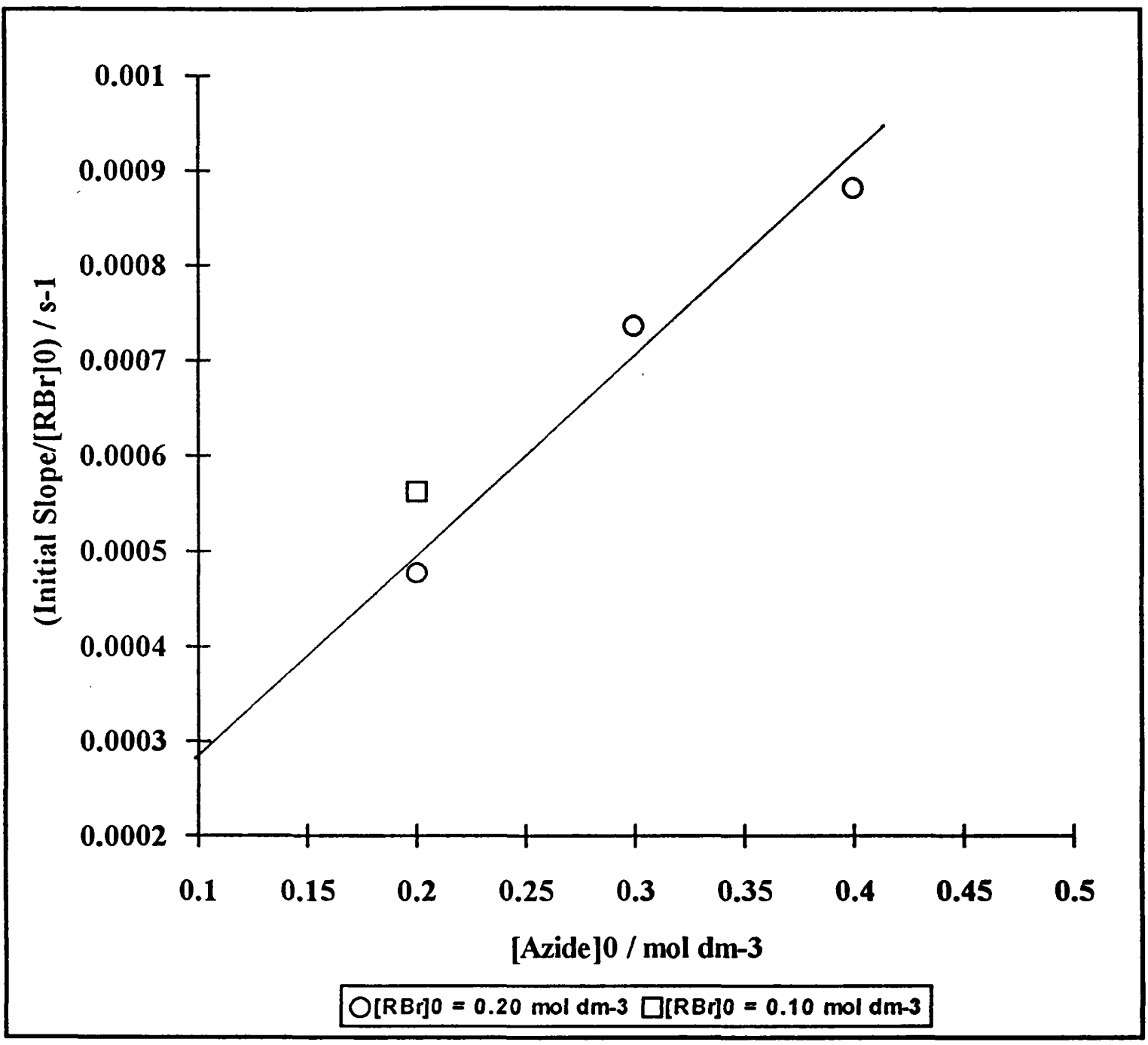

$$
\begin{aligned}
k\left(\mathrm{RN}_{3}\right) 1 & =8.97 \times 10^{-5} \mathrm{~s}^{-1} \\
k\left(\mathrm{RN}_{3}\right)_{2} & =2.03 \times 10^{-3} \mathrm{~mol}^{-1} \mathrm{dm}^{3} \mathrm{~s}^{-1} \\
\mathrm{r} & =0.9876
\end{aligned}
$$

\section{Figure 6.21}

A plot of $\left(d\left[\mathrm{RN}_{3}\right]_{0} / d t\right) /[\mathrm{RBr}]_{0}$ versus $\left[\mathrm{N}_{3}-\right]_{0}$ for the formation of $p$-nitrocumyl azide. 


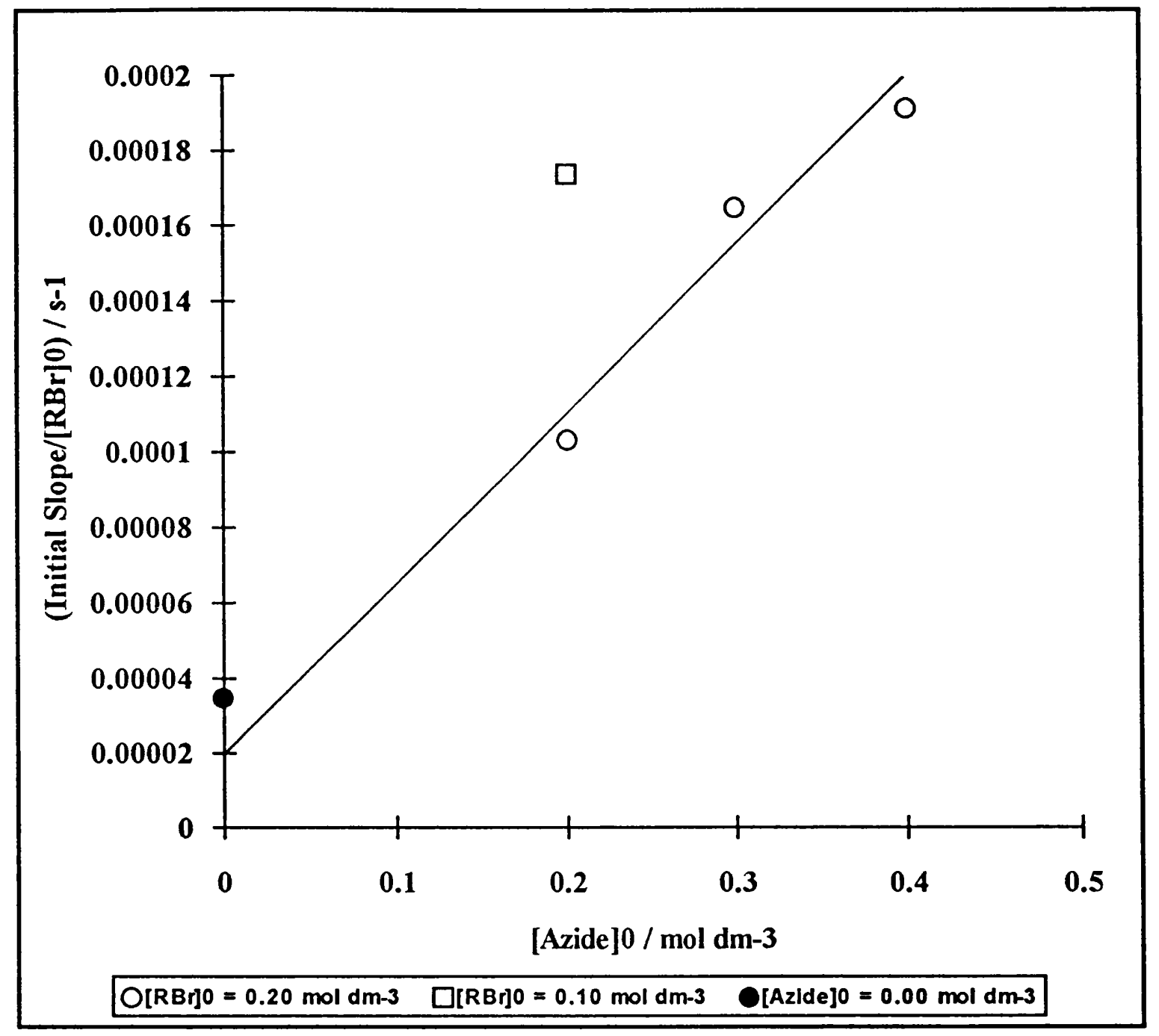

$$
\begin{aligned}
k \text { (Alkene) } 1 & =2.04 \times 10^{-5} \mathrm{~s}^{-1} \\
k \text { (Alkene) } 2 & =4.42 \times 10^{-4} \mathrm{~mol}^{-1} \mathrm{dm}^{3} \mathrm{~s}^{-1} \\
\mathrm{r} & =0.9750
\end{aligned}
$$

\section{Figure 6.22}

A plot of $\left(d[\text { Alkene }]_{0} / d t\right) /[\mathrm{RBr}]_{0}$ versus $\left[\mathrm{N}_{3}{ }^{-}\right]_{0}$ for the formation of $p$-nitro- $\alpha$ methylstyrene. 


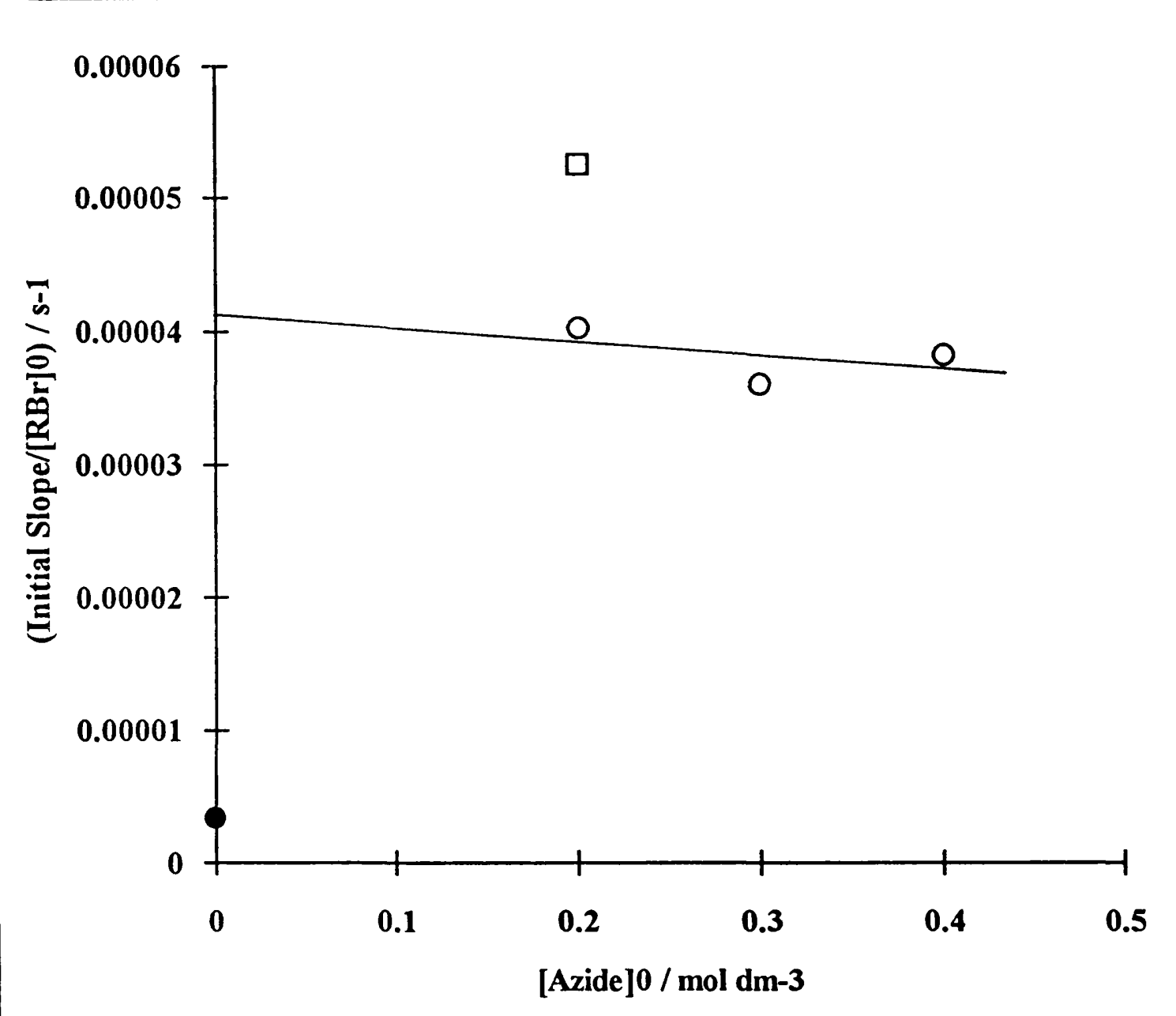

$O[R B r] 0=0.20 \mathrm{~mol} \mathrm{dm}-3 \quad \square[R B r] 0=0.10 \mathrm{~mol} \mathrm{dm}-3 \quad$ OAAzide $] 0=0.00 \mathrm{~mol} \mathrm{dm}-3$

$$
\begin{aligned}
k(\mathrm{ROH}) 1 & =4.12 \times 10^{-5} \mathrm{~s}^{-1} \\
k(\mathrm{ROH}) 2 & =-1.02 \times 10^{-5} \mathrm{~mol}^{-1} \mathrm{dm}^{3} \mathrm{~s}^{-1} \\
\mathrm{r} & =0.4763
\end{aligned}
$$

\section{Figure 6.23}

A plot of $\left(d[\mathrm{ROH}]_{0} / d t\right) /[\mathrm{RBr}]_{0}$ versus $\left[\mathrm{N}_{3}-\right]_{0}$ for the formation of $p$-nitrocumyl alcohol. 


\subsection{Final Kinetic Model}

A detailed kinetic investigation has been carried out on the reaction of lithium azide with $p$-nitrocumyl bromide in dimethyl sulphoxide. After piecing together all the available data a final kinetic model can be postulated. This model can be divided into three reaction types:

\section{Bimolecular Reactions}

$$
\begin{array}{ll}
\mathrm{RBr}+\mathrm{N}_{3}-\stackrel{k\left(\mathrm{RN}_{3}\right)}{\longrightarrow} & \mathrm{RN}_{3}+\mathrm{Br}^{-} \\
\mathrm{RBr}+\mathrm{N}_{3}-\stackrel{k \text { (Alkene) }}{\longrightarrow} & \text { Alkene }+\mathrm{HN}_{3}+\mathrm{Br}^{-}
\end{array}
$$

\section{Unimolecular Reactions}

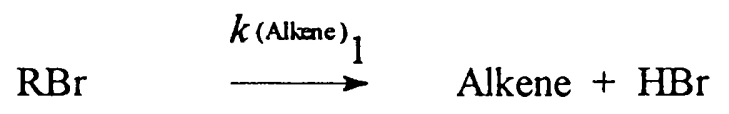

$\mathrm{RBr} \stackrel{k(\mathrm{ROH})}{\longrightarrow} \mathrm{ROH}+\mathrm{Br}^{-}$

\section{Auxiliary Reaction}

$$
\mathrm{HBr}+\mathrm{N}_{3}^{-} \stackrel{k(\mathrm{AUX})}{\longrightarrow} \mathrm{HN}_{3}+\mathrm{Br}^{-}
$$

In dimethyl sulphoxide, the reaction of lithium azide with $p$-nitrocumyl bromide obeys much simpler kinetics than the reaction of sodium nitrite with $p$-nitrocumyl bromide. 
The disappearance of $p$-nitrocumyl bromide can now be expressed as the following:

$-\left(d[\mathrm{RBr}]_{\mathrm{t}} / d t\right)=$
$(k$ (Alkene) $1+k(\mathrm{ROH}) 1)[\mathrm{RBr}]_{\mathrm{t}}+\left(k\left(\mathrm{RN}_{3}\right) 2+k\right.$ (Alkene) 2$)[\mathrm{RBr}]_{\mathrm{t}}\left[\mathrm{N}_{3}-\right]_{\mathrm{t}}$

Equation 6.16 can be simplified to Equation 6.17, which is in fact the same as Equation 6.5:

$$
-\left(d[\mathrm{RBr}]_{\mathrm{t}} / d t\right)=k_{\mathrm{s}}[\mathrm{RBr}]_{\mathrm{t}}+k_{2}^{\prime}[\mathrm{RBr}]_{\mathrm{t}}\left[\mathrm{N}_{3}{ }^{-}\right]_{\mathrm{t}}
$$

Values for $k_{\mathrm{S}}$ and $k_{2}^{\prime}$ have already been estimated by the method of initial slopes, however, more advanced techniques are necessary in order to verify Equation 6.17. The computer programmes GEAR and GIT were used to evaluate $k_{\mathrm{s}}$ and $k_{2}^{\prime}$ using the estimations from the initial slopes method. To simplify matters, the first order component for the formation of $p$-nitrocumyl alcohol (Equation 6.14) was neglected from the model. The first order component for the formation of $p$-nitrocumyl alcohol is almost negligible up to a time period of $5000 \mathrm{~s}$, and minor compared with the first order component for the formation of $p$-nitro- $\alpha$-methylstyrene. This simplification implies that one mole of $\mathrm{HBr}$ is formed from one mole of $p$-nitrocumyl bromide.

Table 6.8 displays a variety of rate constants for the reaction of lithium azide with p-nitrocumyl bromide in dimethyl sulphoxide. We have already seen that the rate constants obtained for an overall first order model have a poor correlation, however, the rate constants obtained for an overall second order model have a good correlation. The concurrent second and first order rate constants, $k_{2}^{\prime}$ and $k_{\mathrm{s}}$ respectively, obtained from the computer programmes GEAR and GIT are shown in table 6.8. The concurrent second order rate constants obtained for the various kinetic runs show excellent correlation. The $k_{2}^{\prime}$ value obtained for the $[\mathrm{RBr}]_{0}=0.10 \mathrm{~mol} \mathrm{dm}^{-3}$ kinetic run is slightly out compared to 
the other concurrent second order rate constants. There will be a smaller signal to noise ratio for the $[\mathrm{RBr}]_{0}=0.10 \mathrm{~mol} \mathrm{dm}{ }^{-3}$ kinetic run compared to the other kinetic runs. This will give larger errors in the ${ }^{1} \mathrm{H}$ n.m.r. integrals, leading to larger errors in the concentrations of the substrate at given times. The concurrent first order rate constants show excellent correlation both for the various kinetic runs and the first order rate constant obtained for the elimination of $p$-nitrocumyl bromide. The rate constants obtained from the computer programmes GEAR and GIT seem to verify that the overall reaction of lithium azide with $p$-nitrocumyl bromide in dimethyl sulphoxide proceeds by concurrent unimolecular and bimolecular reactions as postulated in Equations 6.11 to 6.15. It must be pointed out at this stage that since both GEAR and GIT are based on a single run they may sometimes give anomalous results.

\section{Table 6.8}

A comparison of various rate constants for the kinetic runs in Tables 6.1, 6.2, 6.3, 6.4 and 6.7.

\begin{tabular}{|c|c|c|c|c|c|c|}
\hline $\begin{array}{c}{\left[\mathrm{LiN}_{3}\right]_{0}} \\
/ \mathrm{mol} \mathrm{dm}^{-3}\end{array}$ & $\begin{array}{c}{[R B r]_{0}} \\
/ \mathrm{mol} \mathrm{dm}^{-3}\end{array}$ & $\begin{array}{c}{\left[\text { LIClO }_{4}\right]_{0}} \\
/ \mathrm{mol} \mathrm{dm}^{-3}\end{array}$ & $\begin{array}{c}10^{4} k_{1} / \\
\mathbf{s}^{-1}\end{array}$ & $\begin{array}{c}10^{4} k_{2} / \\
\mathrm{dm}^{3} \mathrm{~mol}^{-1} \mathbf{s}^{-1}\end{array}$ & $\begin{array}{c}10^{4} k_{2}^{\prime} / \\
\mathrm{dm}^{3} \mathrm{~mol}^{-1} \mathbf{s}^{-1}\end{array}$ & $\begin{array}{c}10^{5} k_{\mathbf{s}} / \\
\mathbf{s}^{-1}\end{array}$ \\
\hline 0.40 & 0.20 & 0.00 & 11.1 & 3.87 & 3.48 & 4.86 \\
\hline 0.30 & 0.20 & 0.10 & 6.84 & 3.77 & 3.61 & 4.81 \\
\hline 0.20 & 0.20 & 0.20 & 3.94 & 4.21 & 3.57 & 5.13 \\
\hline 0.20 & 0.10 & 0.20 & 5.88 & 4.32 & 3.96 & 5.21 \\
\hline 0.00 & 0.20 & 0.40 & 0.483 & -- & -- & 4.83 \\
\hline
\end{tabular}

Another approach would be to obtain an integrated function for concurrent unimolecular and bimolecular reactions. This is fairly easy, and can be done by again neglecting the first order component for the formation of $p$-nitrocumyl alcohol (Equation 6.14). Equation 6.17 can be expressed as Equation 6.18: 


$$
-(d \mathrm{~A} / d t)=k_{\mathrm{S}} \mathrm{A}+k_{2}^{\prime} \mathrm{AB}
$$

$\mathrm{A}$ and $\mathrm{B}$ are here used for the concentrations of the corresponding substances, $p$ nitrocumyl bromide and azide respectively. In the simplified model, one mole of $\mathrm{HBr}$ is formed from one mole of $p$-nitrocumyl bromide and it is fairly safe to assume that one mole of $\mathrm{HBr}$ will remove one mole of azide more rapidly than any other reaction.

In this case $\mathrm{A}_{0}-\mathrm{A}=\mathrm{B}_{0}-\mathrm{B}$ and

$$
-(d \mathrm{~A} / d t)=k_{\mathrm{S}} \mathrm{A}+k_{2}^{\prime} \mathrm{A}\left(\mathrm{B}_{0}-\mathrm{A}_{0}+\mathrm{A}\right)
$$

Where $A_{0}$ and $B_{0}$ are the initial concentrations. Equation 6.19 can be expressed as follows:

$$
\frac{-k_{2}^{\prime} d \mathrm{~A}}{k_{\mathrm{s}} \mathrm{A}+k_{2}^{\prime} \mathrm{A}\left(\mathrm{B}_{0}-\mathrm{A}_{0}+\mathrm{A}\right)}=k_{2}^{\prime} d t
$$

Equation 4.18 was integrated on both sides. The function on the left hand side of Equation 4.18 was integrated using the mathematical computer programme DERIVE ${ }^{T M}$. The result of integration, after evaluating the constant of integration, is:

$$
\frac{k_{2}^{\prime}}{\left(k_{\mathrm{S}}+k_{2}^{\prime}\left(\mathrm{B}_{0}-\mathrm{A}_{0}\right)\right.} \operatorname{Ln}\left[\left[\frac{\mathrm{A}_{0}}{k_{\mathrm{s}}+k_{2}^{\prime} \mathrm{B}_{0}}\right]\left[\frac{k_{\mathrm{s}}+k_{2}^{\prime} \mathrm{B}}{\mathrm{A}}\right]\right]=k_{2}^{\prime} t
$$

\section{Equation 6.21}

The rate constants obtained from GEAR and GIT and the data obtained from Tables 6.1, 6.2, 6.3, and 6.4 were substituted into the function on the left hand side of Equation 6.21, and the resulting values plotted against time (Figures 6.24, 6.25, 6.26 and 6.27). The function on the left hand side of Equation 6.21 will be referred, from now on, 
to a function for a concurrent first and second order reaction. These plots are not only a means of testing the fit of the model to the data, but also give new bimolecular rate constants from the slopes of the graphs. If the model is a good one, then the new second order rate constants $\left(k_{2}\right)$ should have a good correlation with the values derived from GEAR and GIT.

It can be seen from Figures $6.24,6.25,6.26$ and 6.27 that a concurrent first and second order model is a very good fit to the data derived from the various kinetic runs. This is exemplified by the excellent correlation coefficients obtained from the plots. The residual plots for the various Figures show very little pattern, in fact, most of the plots have a random pattern.

Table 6.9 compares the concurrent second order rate constants $\left(k_{2}^{\prime}\right)$ obtained from the GEAR and GET programmes with the corresponding concurrent second order rate constants $\left(k_{2}^{\prime \prime}\right)$ obtained from Equation 6.21 . There is a very good correlation between the two sets of rate constants, however as one would expect, they are not identical.

The residual plots in Figures $6.24,6.25,6.26$ and 6.27 show that some points are slightly removed from the others. These points were deleted from the data and new rate constants calculated (Table 6.10). The new rate constants $\left(k_{2}^{\prime \prime}\right)$ are very similar to the old ones $\left(k_{2}\right)$ however, their correlation coefficients and corresponding errors are much improved on the old rate constants. For the initial concentrations of lithium azide equal to $0.20 \mathrm{~mol} \mathrm{dm}^{-3}$ and $p$-nitrocumyl bromide equal to $0.10 \mathrm{~mol} \mathrm{dm}^{-3}$, the rate constant $k_{2}^{\prime \prime}{ }^{*}$ is significantly lower than the $k_{2}^{\prime \prime}$ rate constant. The adjusted rate constant $k_{2}^{\prime \prime}$ is now more in line with the concurrent second order rate constants obtained for the other kinetic runs. 


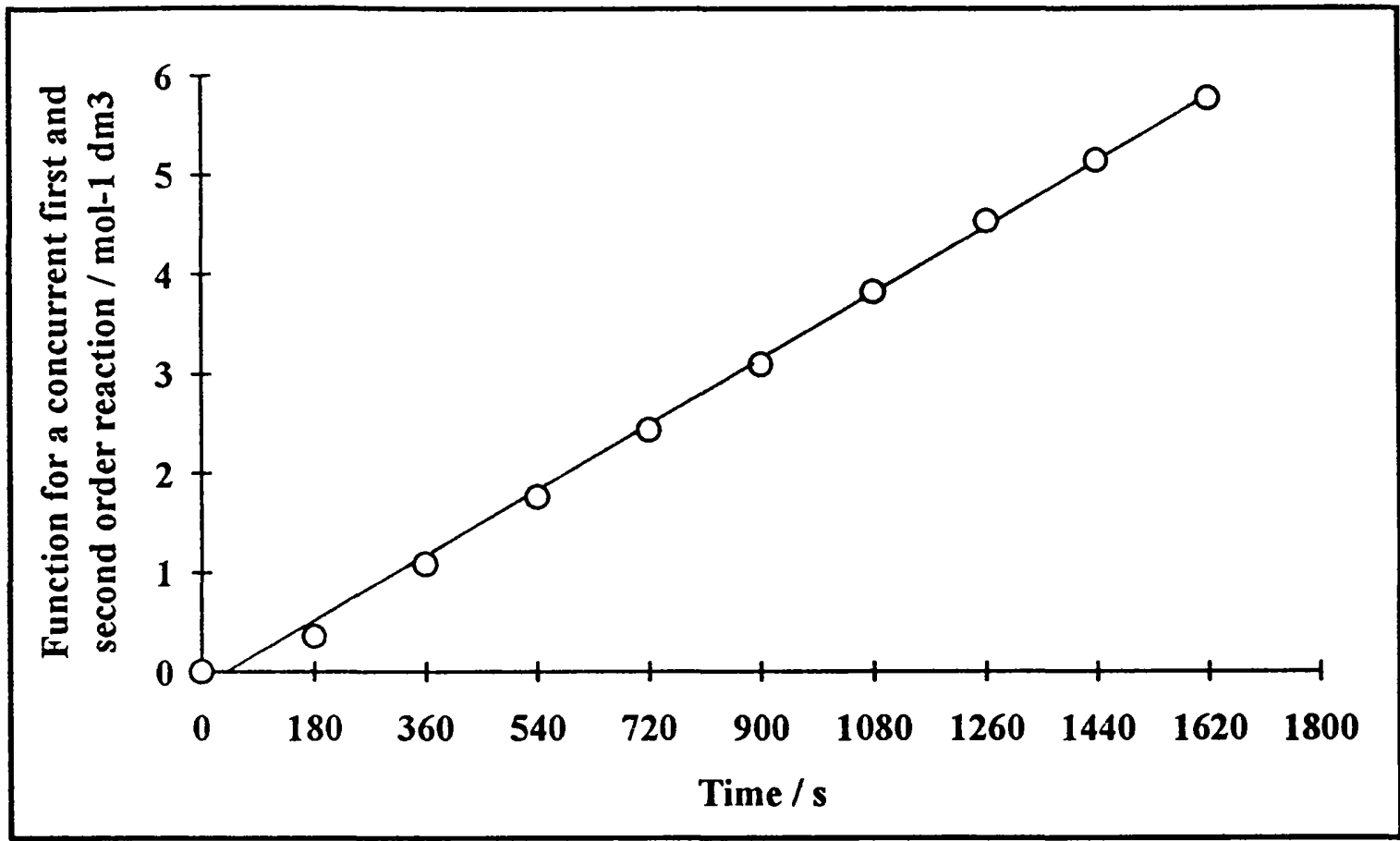

(a)

$$
\begin{aligned}
& k_{2}^{\prime \prime}=3.69 \times 10^{-3} \mathrm{~mol}^{-1} \mathrm{dm}^{3} \mathrm{~s}^{-1} \\
& \mathrm{r}=0.9991 \\
& \sigma=1.46 \%
\end{aligned}
$$

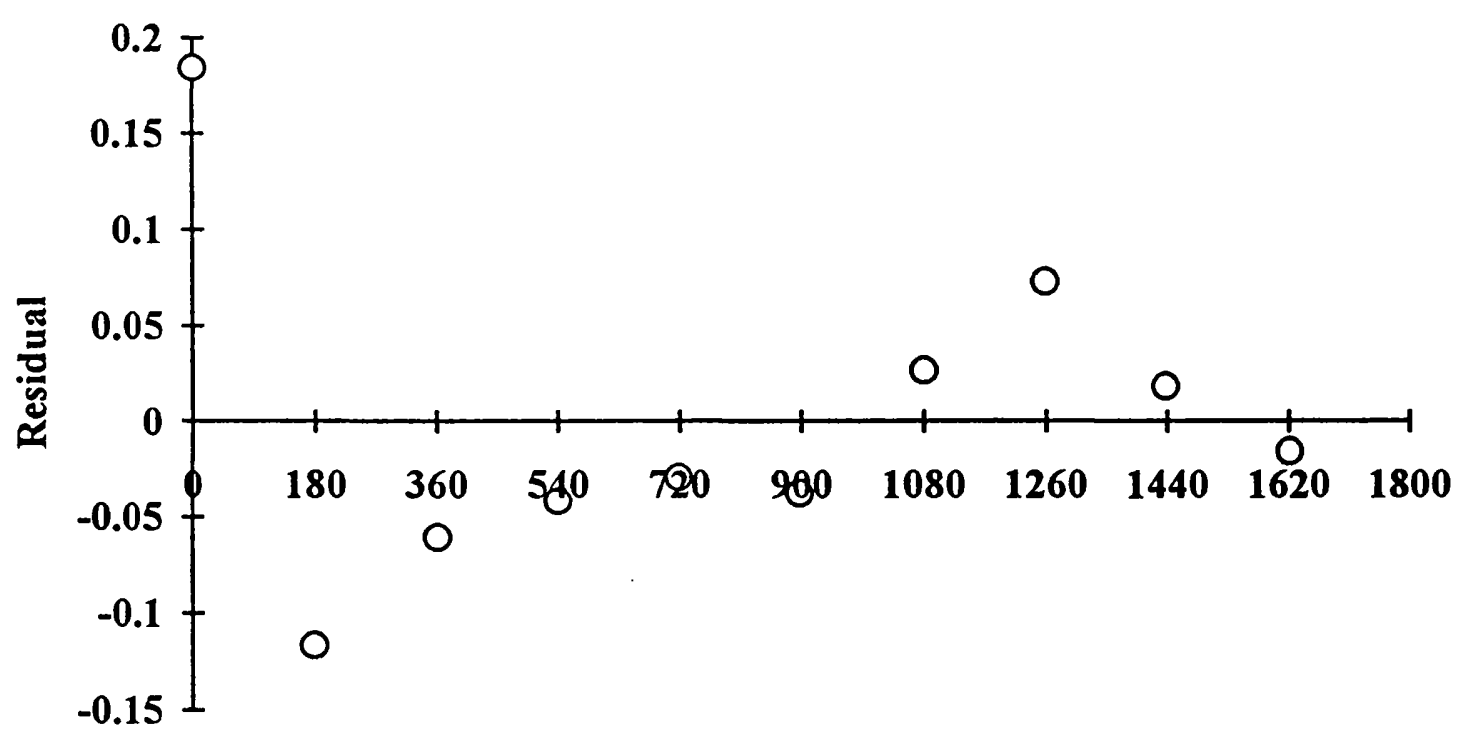

Time / s

(b)

Figure 6.24

Plots of (a) Function for a concurrent first and second order reaction $/ \mathrm{mol}^{-1} \mathrm{dm}^{3}$ and (b) Residuals against time / $\mathrm{s}$. 


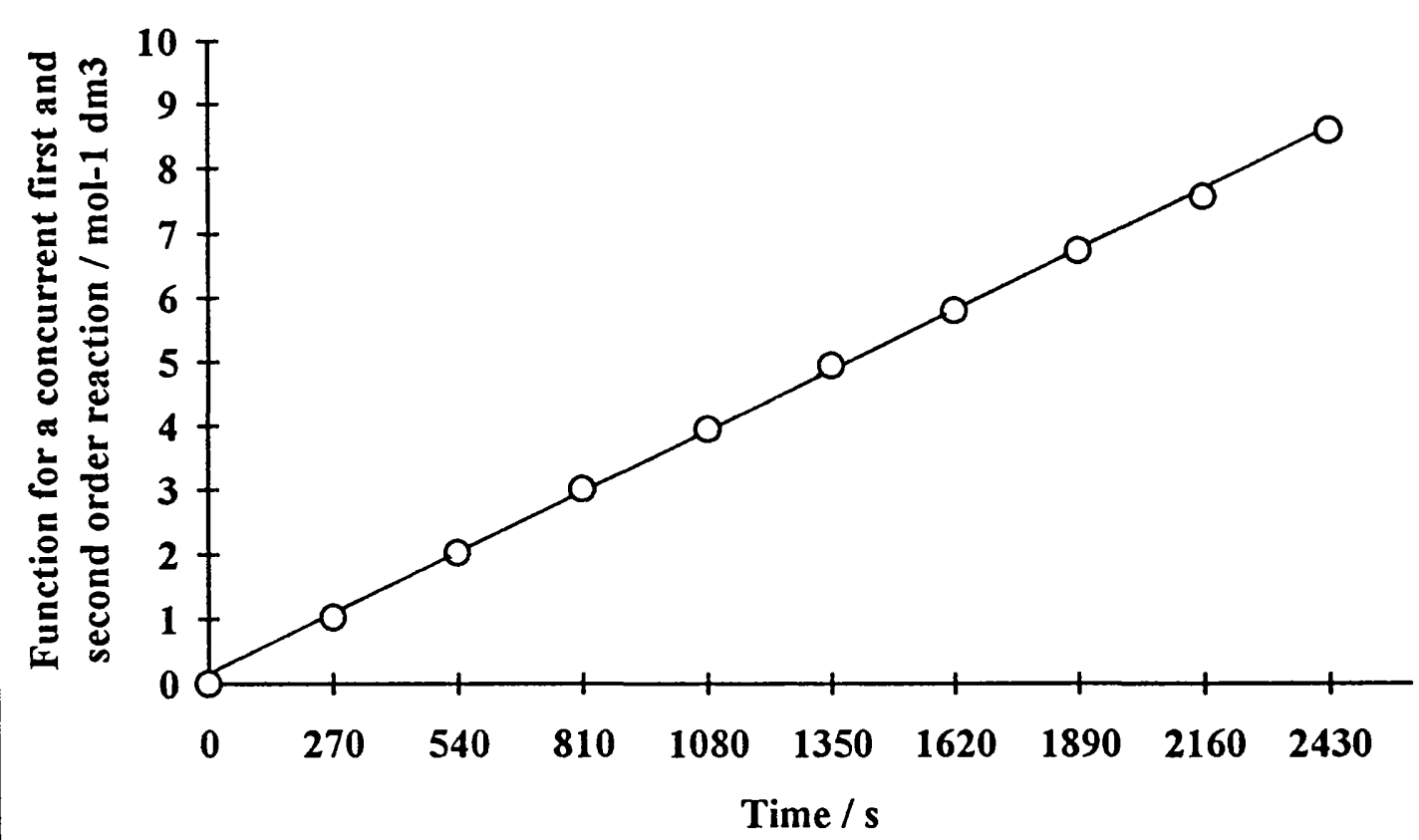

(a)

$$
\begin{aligned}
k_{2}{ }_{2} & =3.50 \times 10^{-3} \mathrm{~mol}^{-1} \mathrm{dm}^{3} \mathrm{~s}^{-1} \\
r & =0.9997 \\
\sigma & =0.86 \%
\end{aligned}
$$

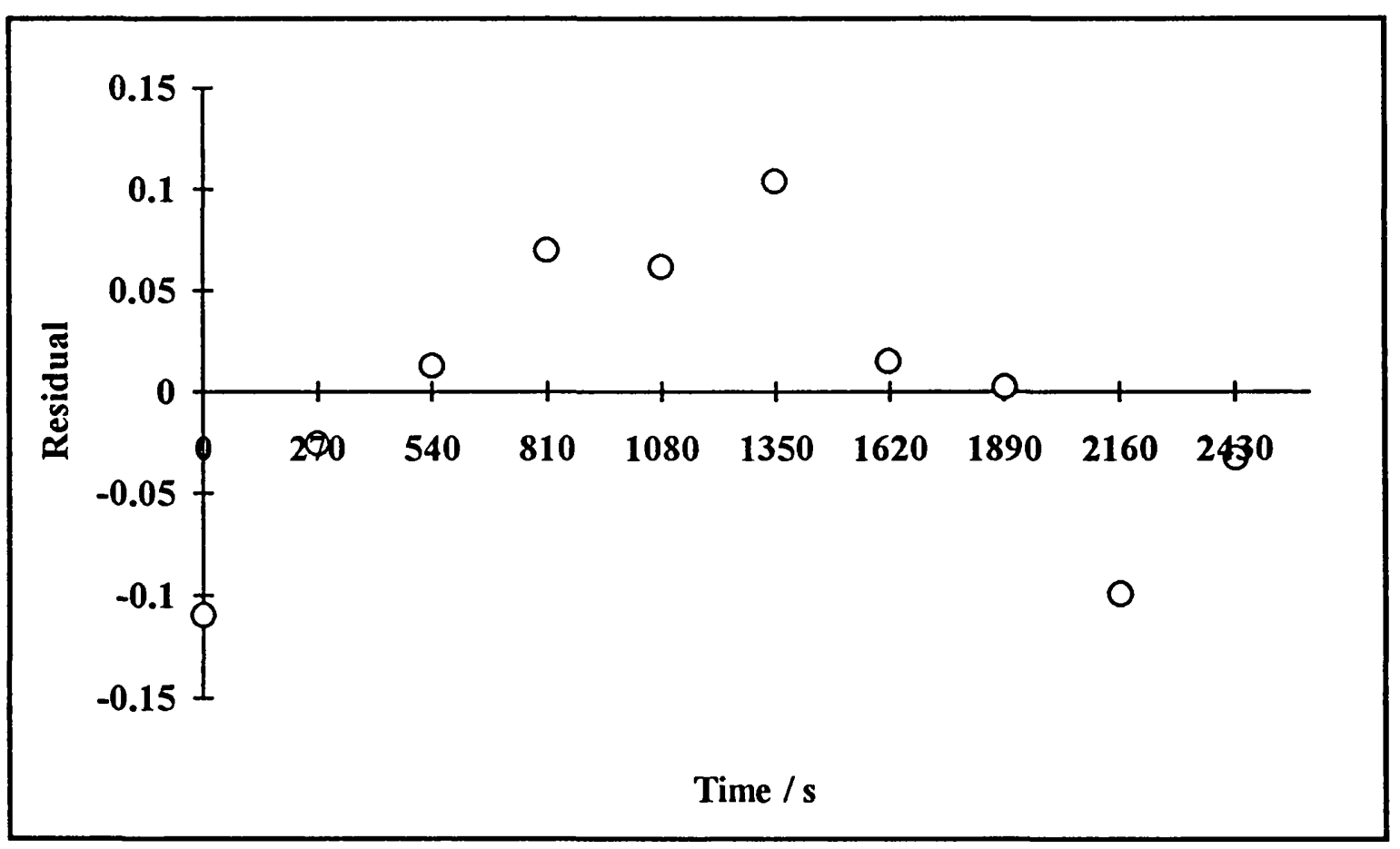

(b)

\section{Figure 6.25}

Plots of (a) Function for a concurrent first and second order reaction $/ \mathrm{mol}^{-1} \mathrm{dm}^{3}$ and (b)

Residuals against time/s. 


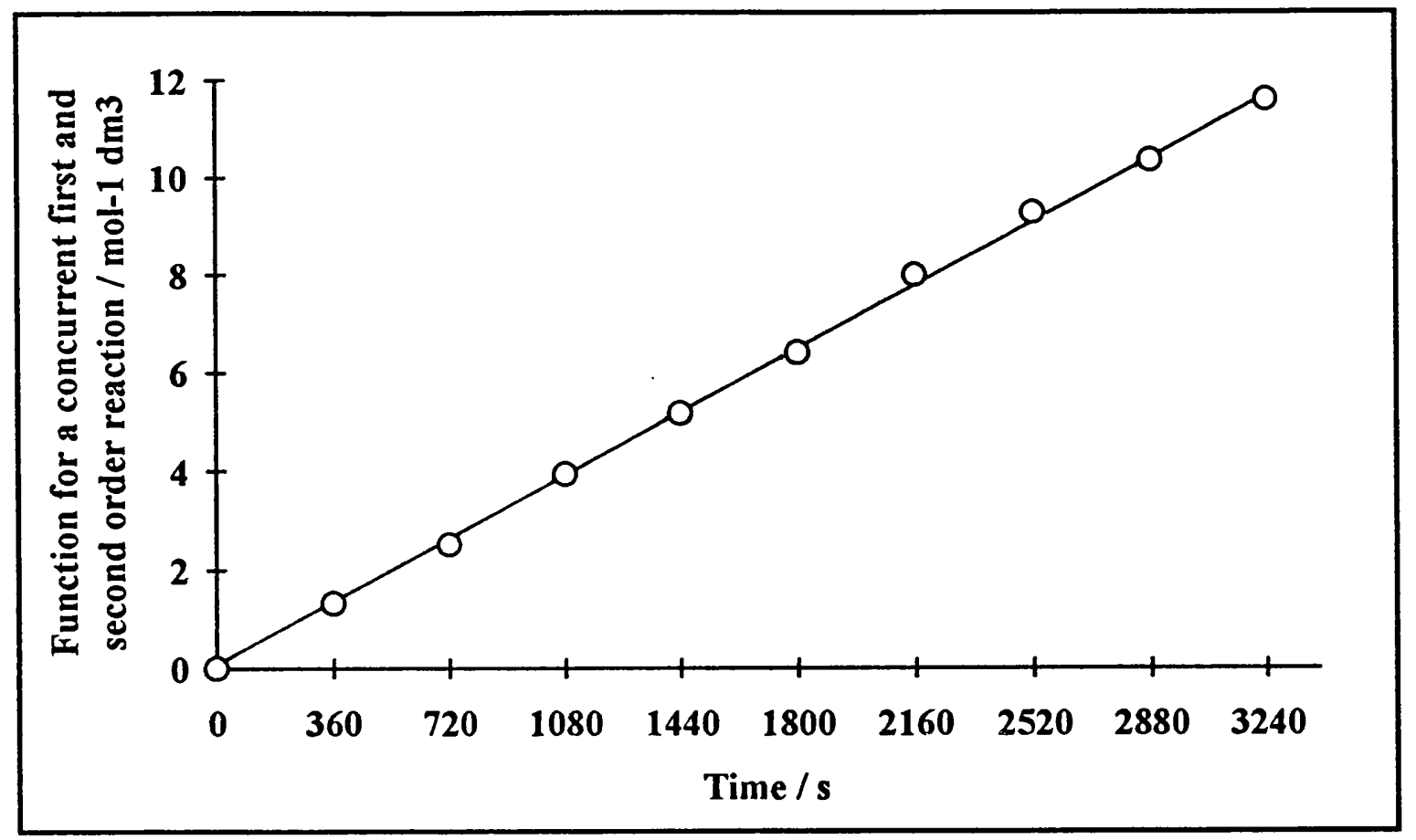

(a)

$$
\begin{aligned}
k_{2} & =3.61 \times 10^{-3} \mathrm{~mol}^{-1} \mathrm{dm}^{3} \mathrm{~s}^{-1} \\
r & =0.9996 \\
\sigma & =0.95 \%
\end{aligned}
$$

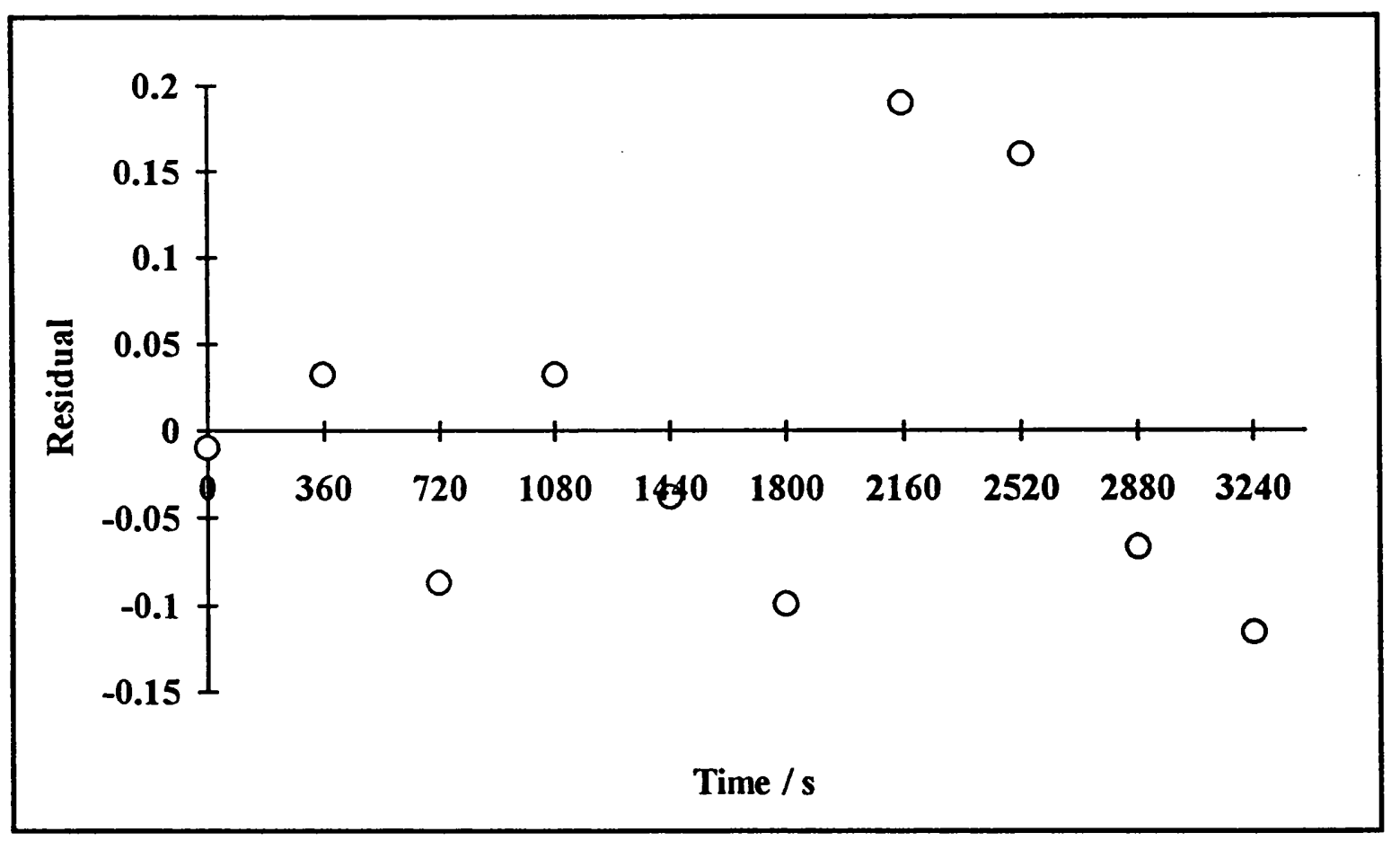

(b)

\section{Figure 6.26}

Plots of (a) Function for a concurrent first and second order reaction $/ \mathrm{mol}^{-1} \mathrm{dm}^{3}$ and (b) Residuals against time / $\mathbf{s}$. 


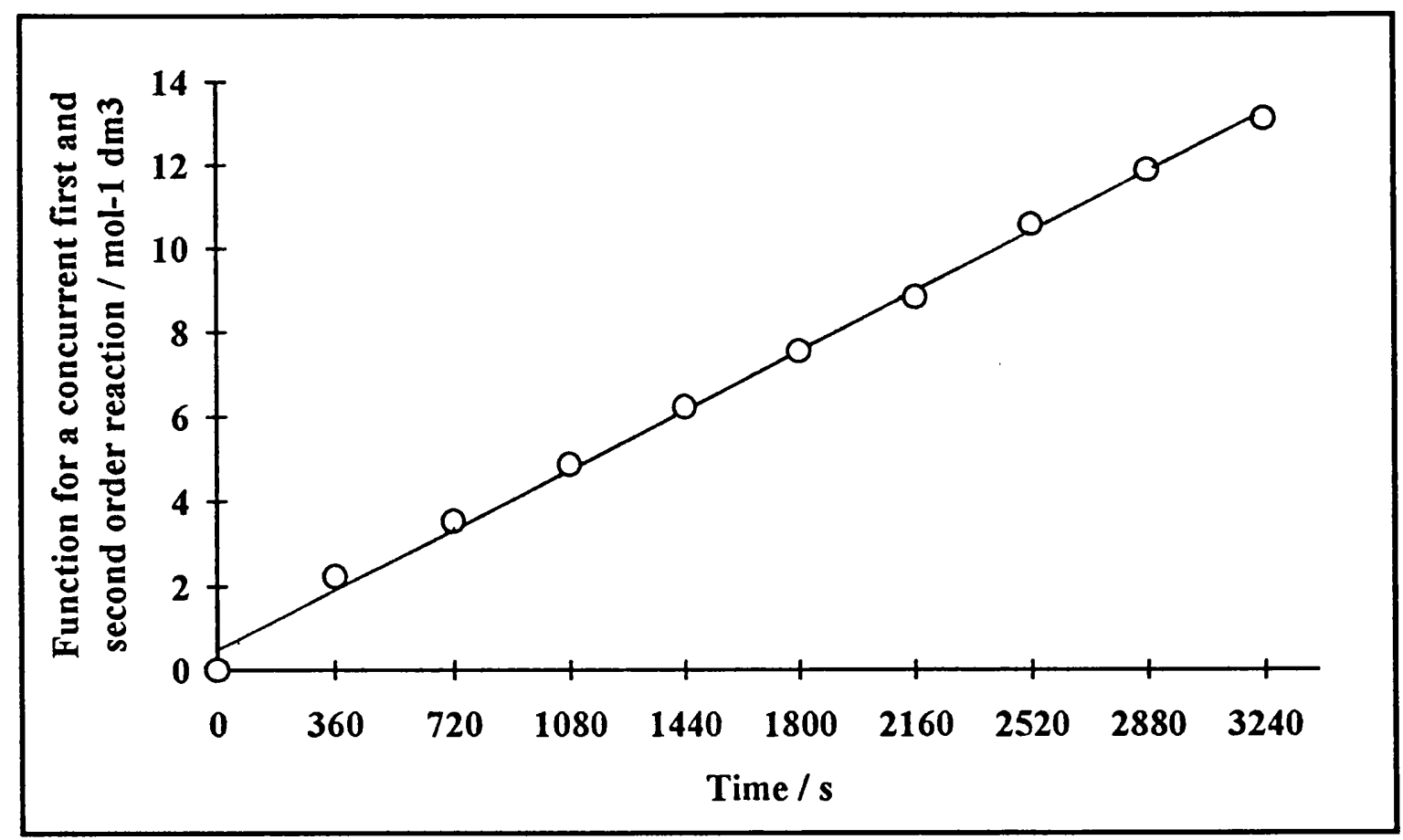

(a)

$$
\begin{aligned}
\mathrm{k}_{2}^{\prime \prime} & =3.94 \times 10^{-3} \mathrm{~mol}^{-1} \mathrm{dm}^{3} \mathrm{~s}^{-1} \\
\mathrm{r} & =0.9985 \\
\sigma & =1.91 \%
\end{aligned}
$$

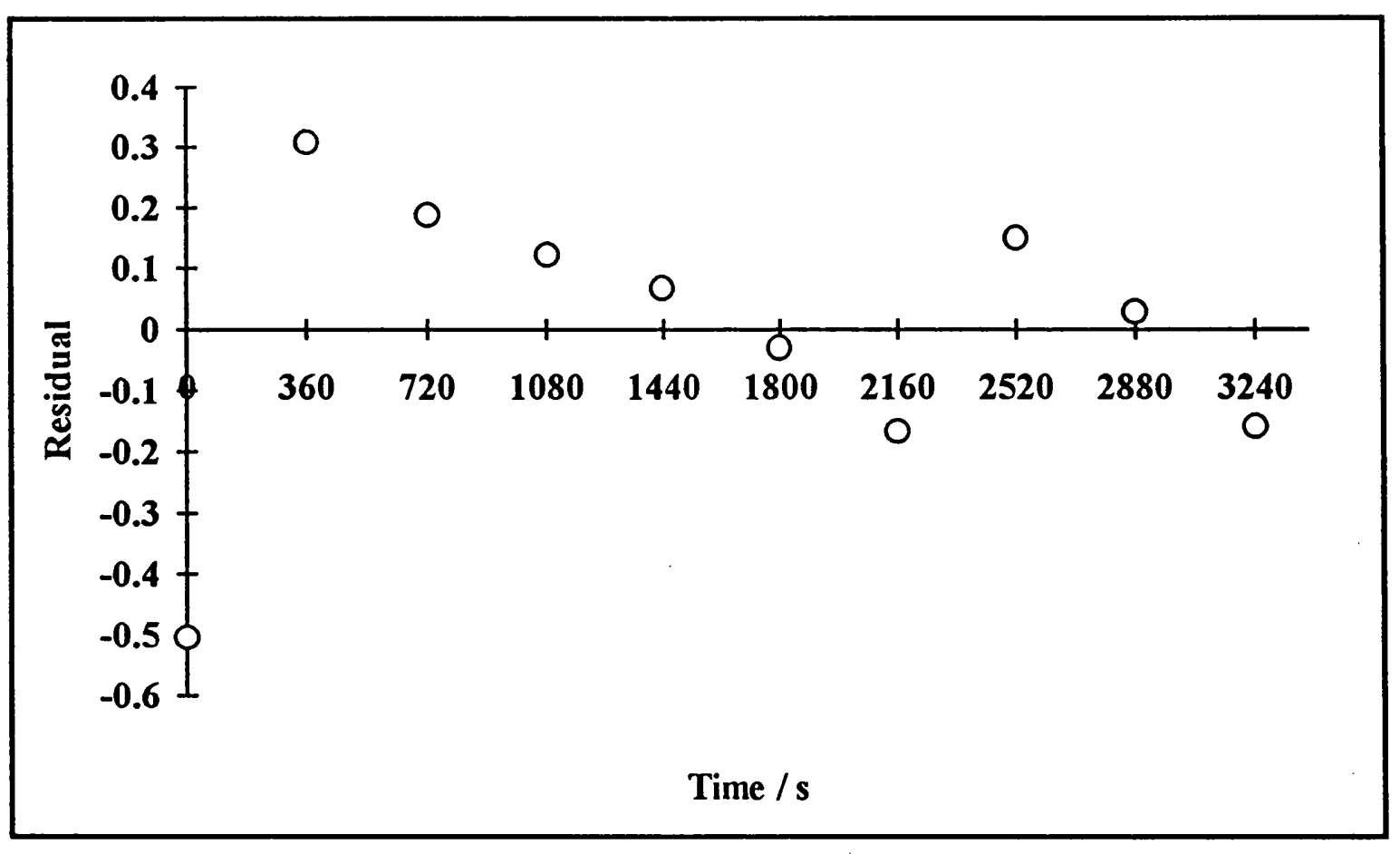

(b)

\section{Figure 6.27}

Plots of (a) Function for a concurrent first and second order reaction $/ \mathrm{mol}^{-1} \mathrm{dm}^{3}$ and (b) Residuals against time / $\mathrm{s}$. 
Table 6.9

A comparison of concurrent second order rate constants derived from GEAR and GIT, $\left(k_{2}^{\prime}\right)$, with the concurrent second order rate constants derived from Equation $6.21,\left(k_{2}^{\prime \prime}\right)$.

\begin{tabular}{|c|c|c|c|c|c|c|}
\hline $\begin{array}{l}{\left[\operatorname{LiN}_{3}\right]_{0}} \\
/ \mathrm{mol} \mathrm{dm}^{-3}\end{array}$ & $\begin{array}{c}{[R B r]_{0}} \\
/ \mathrm{mol} \mathrm{dm}^{-3}\end{array}$ & $\begin{array}{c}{\left[\mathrm{LiClO}_{4}\right]_{0}} \\
/ \mathrm{mol} \mathrm{dm}^{-3}\end{array}$ & $\begin{array}{c}10^{5} k_{s} / \\
s^{-1}\end{array}$ & $\begin{array}{c}10^{3} k_{2}^{\prime} / \\
\mathrm{dm}^{3} \mathrm{~mol}^{-1} \mathrm{~s}^{-1}\end{array}$ & $\begin{array}{c}10^{3} k_{2}^{\prime \prime} / \\
\mathrm{dm}^{3} \mathrm{~mol}^{-1} \mathrm{~s}^{-1}\end{array}$ & $\begin{array}{c}\mathbf{r} \\
\sigma / \%\end{array}$ \\
\hline 0.40 & 0.20 & 0.00 & 4.86 & 3.48 & 3.69 & $\begin{array}{c}0.9991 \\
1.46 \\
\end{array}$ \\
\hline 0.30 & 0.20 & 0.10 & 4.81 & 3.61 & 3.50 & $\begin{array}{c}0.9997 \\
0.86\end{array}$ \\
\hline 0.20 & 0.20 & 0.20 & 5.13 & 3.57 & 3.61 & $\begin{array}{c}0.9996 \\
0.95\end{array}$ \\
\hline 0.20 & 0.10 & 0.20 & 5.21 & 3.96 & 3.94 & $\begin{array}{c}0.9985 \\
1.91\end{array}$ \\
\hline
\end{tabular}

\section{Table 6.10}

A comparison of concurrent second order rate constants derived from GEAR and GIT, $\left(k_{2}^{\prime}\right)$, with the concurrent second order rate constants (Isolated points deleted) ${ }^{*}$ derived from Equation $6.21,\left(k^{\prime \prime}{ }^{*}\right)$.

\begin{tabular}{|c|c|c|c|c|c|c|}
\hline $\begin{array}{l}{\left[\operatorname{LiN}_{3}\right]_{0}} \\
/ \mathrm{mol} \mathrm{dm}^{-3} \\
\end{array}$ & $\begin{array}{l}{[R B r]_{0}} \\
/ \mathrm{mol} \mathrm{dm}^{-3}\end{array}$ & $\begin{array}{c}{\left[\mathrm{LiClO}_{4}\right]_{0}} \\
/ \mathrm{mol} \mathrm{dm}^{-3}\end{array}$ & $\begin{array}{c}10^{5} k_{\mathrm{s}} / \\
\mathrm{s}^{-1} \\
\end{array}$ & $\begin{array}{r}10^{3} k_{2}^{\prime} / \\
\mathrm{dm}^{3} \mathrm{~mol}^{-1} \mathrm{~s}^{-1} \\
\end{array}$ & $\begin{array}{l}10^{3} \mathrm{k}_{2}^{*} / \\
\mathrm{dm}^{3} \mathrm{~mol}^{-1} \mathrm{~s}^{-1} \\
\end{array}$ & $\begin{array}{c}\mathbf{r}^{*} \\
\sigma^{*} / \% \\
\end{array}$ \\
\hline 0.40 & 0.20 & 0.00 & 4.86 & 3.48 & 3.77 & $\begin{array}{c}0.9998 \\
0.71\end{array}$ \\
\hline 0.30 & 0.20 & 0.10 & 4.81 & 3.61 & 3.47 & $\begin{array}{c}0.9998 \\
0.83 \\
\end{array}$ \\
\hline 0.20 & 0.20 & 0.20 & 5.13 & 3.57 & 3.60 & $\begin{array}{c}0.9998 \\
0.79\end{array}$ \\
\hline 0.20 & 0.10 & 0.20 & 5.21 & 3.96 & 3.82 & $\begin{array}{c}0.9996 \\
1.08\end{array}$ \\
\hline
\end{tabular}




\subsection{Conclusion}

The evidence would suggest that the reaction of lithium azide with $p$-nitrocumyl bromide in dimethyl sulphoxide proceeds via a series of concurrent unimolecular and bimolecular reactions as outlined in Equations 4.7 to 4.13. Lithium azide reacts far faster with $p$-nitrocumyl bromide in dimethyl sulphoxide than sodium nitrite, and the kinetics are far simpler. As we have already mentioned, the formation of $p$-nitrocumyl alcohol is neglected in the working kinetic model, however, this simplification creates no significant errors as all of the kinetic runs are investigated over time periods less than $5000 \mathrm{~s}$. Undoubtedly, the unimolecular component comes from the elimination of $p$-nitrocumyl bromide in dimethyl sulphoxide.

One would, but not necessarily, expect some similarity between the reactions of sodium nitrite and lithium azide with $p$-nitrocumyl bromide in dimethyl sulphoxide. There are many mechanisms that can account for the bimolecular kinetic component in the reaction of lithium azide with $p$-nitrocumyl bromide in dimethyl sulphoxide. The fact that the reaction of sodium nitrite with $p$-nitrocumyl bromide proceeds via a non radical process does not necessarily imply that the azide reaction proceeds via a heterolytic mechanism. In the next chapter, the possible mechanisms giving rise to the observed kinetics will be discussed by a process of elimination and deduction. 


\section{CHAPTER 7}

\section{A Kinetic Study of the Reaction of Lithium Azide with p-Nitrocumyl Bromide in \\ Dimethyl Sulphoxide}

\section{PART 2}

\subsection{Introduction}

Chapters 7 and 8 are both concerned with the bimolecular kinetic component in the reaction of lithium azide with $p$-nitrocumyl bromide in dimethyl sulphoxide. The bimolecular component of the kinetics observed in the previous chapter was the result of either a radical or heterolytic process. Firstly the type of process must be deduced, that is, whether the process is radical or not, and secondly, the best mechanism to match the observed kinetics must be found. Other kinetic runs must be carried out in order to distinguish between the many mechanisms possible. In both this chapter and in chapter 8 a process of elimination and deduction will be effected so as to reach a conclusion to the mechanism of the reaction under question.

Kornblum et al. ${ }^{17}$ found that when $p$-nitrocumyl chloride was treated with lithium azide (two fold excess) in dimethyl sulphoxide, under an argon atmosphere, and irradiated with ultraviolet light, the reaction had a half-life of 7 minutes. In the dark this reaction had a half-life of 50 hours. This reaction is believed to proceed via a radical chain process, however, this does not necessarily imply that the reaction of lithium azide with $p$ nitrocumyl bromide also proceeds via a radical process. A good place to start, in finding a mechanism to fit the kinetics, would be to try and rule out the possibility of a radical mechanism.

\subsection{Radical Mechanisms}

In chapter 5 we discussed the effects of various radical/radical anion inhibitors and inducers on the rate of the reaction of sodium nitrite with $p$-nitrocumyl bromide in 
dimethyl sulphoxide. $p$-dinitrobenzene and 4-hydroxy tempo did not retard the reaction, and ultraviolet light did not accelerate the reaction. These radical/radical anion inhibitors and inducers can again be used to determine whether or not the reaction of lithium azide with $p$-nitrocumyl bromide in dimethyl sulphoxide proceeds via a radical mechanism: We now have three kinetic experiments in which we can confirm or rule out a radical mechanism.

Rate coefficients for these kinetic experiments were calculated assuming that the reactions were: (1) overall first order with respect to $p$-nitrocumyl bromide $\left(k_{1}\right),(2)$ first order with respect to both $p$-nitrocumyl bromide and lithium azide, that is, second order overall $\left(k_{2}\right)$, and (3) concurrent first and second order $\left(k_{\mathrm{s}}\right.$ and $\left.k_{2}^{\prime}\right)$. The concurrent first and second order rate constants were calculated using GEAR and GIT. Again, estimates for $k_{\mathrm{S}}$ and $k_{2}^{\prime}$ were obtained from the initial slopes method (See 6.8) and substituted into the computer programmes. The rate constants obtained from GEAR and GIT, with their corresponding data (Tables 7.1, 7.2 and 7.3), were then substituted into the function for a concurrent first and second order reaction. The resulting values were plotted against time and the new rate constants $\left(k_{2}\right)$ were obtained from the slopes of the graphs. The new bimolecular rate constants $\left(k_{2}\right)$ should act as a verification for the bimolecular rate constants obtained from the GEAR and GIT computer programmes.

\subsubsection{The Effect of $p$-Dinitrobenzene on the Rate of Reaction for the Reaction of \\ Lithium Azide with p-Nitrocumyl Bromide in Dimethyl Sulphoxide}

One kinetic study was performed; the initial concentration of $p$-nitrocumyl bromide was set equal to $0.20 \mathrm{~mol} \mathrm{dm}^{-3}$ and the initial concentration of lithium azide was set equal to $0.40 \mathrm{~mol} \mathrm{dm}^{-3}$. p-Dinitrobenzene, a strong electron acceptor, was present in the reaction solution at an initial concentration of $0.10 \mathrm{~mol} \mathrm{dm}^{-3}$. The concentrations of $p$ nitrocumyl bromide at given times, derived from this kinetic study, are presented in Table 7.1. The spectrum for time equal to zero was obtained by taking an ${ }^{1} \mathrm{H}$ n.m.r. spectrum of the $p$-nitrocumyl bromide/ $p$-dinitrobenzene solution. For time equal to zero, the 
concentration of $p$-nitrocumyl bromide in the reaction mixture was set equal to one half the concentration of just the $p$-nitrocumyl bromide/p-dinitrobenzene solution on its own.

Tables 7.4 and 7.5 display all the above mentioned rate constants. It is clear from these Tables that the presence of the strong electron acceptor does not significantly affect the rate of reaction. There was a sufficient amount of $p$-dinitrobenzene present in the reaction mixture to effect a retardation, if the reaction proceeded via radical anion intermediates. The majority of the reaction must proceed via a mechanism that has no radical anion intermediates.

\subsubsection{The Effect of 4-Hydroxy Tempo on the Rate of Reaction for the Reaction of \\ Lithium Azide with p-Nitrocumyl Bromide in Dimethyl Sulphoxide}

One kinetic study was performed; the initial concentration of $p$-nitrocumyl bromide was set equal to $0.20 \mathrm{~mol} \mathrm{dm}^{-3}$ and the initial concentration of lithium azide was set equal to $0.40 \mathrm{~mol} \mathrm{dm}^{-3}$. 4-Hydroxy Tempo, a nitroxyl radical, was present in the reaction solution at an initial concentration of $0.02 \mathrm{~mol} \mathrm{dm}^{-3}$. The concentrations of $p$-nitrocumyl bromide at given times, derived from this kinetic study, are presented in Table 7.2. For time equal to zero, the concentration of $p$-nitrocumyl bromide in the reaction mixture was set equal to one half the concentration of just the p-nitrocumyl bromide/4-hydroxy tempo solution on its own.

Tables 7.4 and 7.5 display all the above mentioned rate constants. It is clear from these Tables that the presence of the radical scavenger does not significantly decrease the rate of reaction, in fact, there seems to be a slight increase in the rate. There was a sufficient amount of 4-hydroxy tempo present in the reaction mixture to effect a retardation, if the reaction proceeded via free-radical intermediates. The majority of the reaction must proceed via a mechanism that has no free-radical intermediates. 


\subsubsection{The Effect of Ultraviolet Light on the Rate of Reaction for the Reaction of Lithium Azide with p-Nitrocumyl Bromide in Dimethyl Sulphoxide}

One kinetic study was performed; both the initial concentrations of $p$-nitrocumyl bromide and lithium azide were set equal to $0.20 \mathrm{~mol} \mathrm{dm}^{-3}$. The reaction mixture in the n.m.r. tube was initially irradiated with ultraviolet light for 5 minutes before being placed into the cavity of the n.m.r. machine. The concentrations of $p$-nitrocumyl bromide at given times, derived from this kinetic study, are presented in Table 7.3. For time equal to zero, the concentration of $p$-nitrocumyl bromide in the reaction mixture was set equal to one half the concentration of just the $p$-nitrocumyl bromide solution on its own. Tables 7.4 and 7.5 display all the above mentioned rate constants. It is clear from these Tables that irradiation of the reaction mixture does not significantly increase the rate of reaction, in fact, there seems to be a slight decrease in the rate. This slight decrease is probably due to the fact that the reaction sample was at room temperature $\left(24^{\circ} \mathrm{C}\right)$, rather than $30^{\circ} \mathrm{C}$, while being irradiated. Irradiation would not have a long term effect and so it is only the first point after $300 \mathrm{~s}$ that we should compare with the other runs.

\subsubsection{Conclusion}

The evidence would suggest that the reaction of lithium azide with $p$-nitrocumyl bromide in dimethyl sulphoxide proceeds via a non-radical process: $p$-dinitrobenzene $\wedge 4$ hydroxy tempo do not retard the reaction and ultraviolet light does not accelerate the reaction. These three kinetic experiments also act as measuresof reproducibility for certain kinetic runs carried out in the previous chapter.

Complex kinetics can quite conveniently be attributed to radical type reactions, however, the evidence would suggest that we have in fact a heterolytic process. The type of heterolytic mechanism responsible for the observed kinetics must now be narrowed down. 
Table 7.1

Temperature

Solvent

[RBr $]_{0}$

$\left[\mathrm{LiN}_{3}\right]_{0}$

$\left[\mathrm{LiClO}_{4}\right]_{0}$

$[p \text {-dinitrobenzene }]_{0}$
The Effect of $p$-Dinitrobenzene on the Reaction of Lithium

Azide with $p$-Nitrocumyl Bromide in Dimethyl Sulphoxide

$30^{\circ} \mathrm{C}$

$99.9 \% \mathrm{C}_{2} \mathrm{D}_{6} \mathrm{SO}$

$0.20 \mathrm{~mol} \mathrm{dm}^{-3}$

$\left(\mathrm{R}=\mathrm{C}_{9} \mathrm{H}_{10} \mathrm{NO}_{2}\right)$

$0.40 \mathrm{~mol} \mathrm{dm}^{-3}$

$0.00 \mathrm{~mol} \mathrm{dm}^{-3}$

$0.10 \mathrm{~mol} \mathrm{dm}^{-3}$

\begin{tabular}{|c|c|c|}
\hline Time Range / & Mid-point Time $/ \mathrm{s}$ & {$[\mathrm{RBr}]_{\mathrm{t}} / \mathrm{mol} \mathrm{dm}^{-3}$} \\
\hline 0 & 0 & 0.200 \\
\hline $172-188$ & 180 & 0.141 \\
\hline $352-368$ & 360 & 0.116 \\
\hline $532-548$ & 540 & 0.094 \\
\hline $712-728$ & 720 & 0.076 \\
\hline $892-908$ & 900 & 0.063 \\
\hline $1072-1088$ & 1080 & 0.056 \\
\hline $1252-1268$ & 1260 & 0.046 \\
\hline $1432-1448$ & 1440 & 0.040 \\
\hline $1612-1628$ & 1620 & 0.034 \\
\hline
\end{tabular}


Table 7.2

Temperature

Solvent

$[\mathrm{RBr}]_{0}$

$\left[\mathrm{LiN}_{3}\right]_{0}$

$\left[\mathrm{LiClO}_{4}\right]_{0}$

[4-hydroxy tempo]0
The Effect of 4-Hydroxy Tempo on the Reaction of Lithium

\section{Azide with $p$-Nitrocumyl Bromide in Dimethyl Sulphoxide}

$30^{\circ} \mathrm{C}$

$99.9 \% \mathrm{C}_{2} \mathrm{D}_{6} \mathrm{SO}$

$0.20 \mathrm{~mol} \mathrm{dm}^{-3}$

$\left(\mathrm{R}=\mathrm{C}_{9} \mathrm{H}_{10} \mathrm{NO}_{2}\right)$

$0.40 \mathrm{~mol} \mathrm{dm}^{-3}$

$0.00 \mathrm{~mol} \mathrm{dm}^{-3}$

$0.02 \mathrm{~mol} \mathrm{dm}^{-3}$

\begin{tabular}{|c|c|c|}
\hline Time Range / s & Mid-point Time $/ \mathrm{s}$ & {$[\mathrm{RBr}]_{\mathrm{t}} / \mathrm{mol} \mathrm{dm}^{-3}$} \\
\hline 0 & 0 & 0.200 \\
\hline $172-188$ & 180 & 0.161 \\
\hline $352-368$ & 360 & 0.125 \\
\hline $532-548$ & 540 & 0.095 \\
\hline $712-728$ & 720 & 0.075 \\
\hline $892-908$ & 900 & 0.060 \\
\hline $1072-1088$ & 1080 & 0.048 \\
\hline $1252-1268$ & 1260 & 0.040 \\
\hline $1432-1448$ & 1440 & 0.032 \\
\hline $1612-1628$ & 1620 & 0.027 \\
\hline
\end{tabular}


Table 7.3

Temperature

Solvent

U.V. irradiation

$[\mathrm{RBr}]_{0}$

$\left[\mathrm{LiN}_{3}\right]_{0}$

$\left[\mathrm{LiClO}_{4}\right]_{0}$
The Effect of Ultraviolet Light on the Reaction of Lithium

Azide with p-Nitrocumyl Bromide in Dimethyl Sulphoxide

$30{ }^{\circ} \mathrm{C}$

$99.9 \% \mathrm{C}_{2} \mathrm{D}_{6} \mathrm{SO}$

5 minutes

$0.20 \mathrm{~mol} \mathrm{dm}^{-3}$

$\left(\mathrm{R}=\mathrm{C}_{9} \mathrm{H}_{10} \mathrm{NO}_{2}\right)$

$0.20 \mathrm{~mol} \mathrm{dm}^{-3}$

$0.20 \mathrm{~mol} \mathrm{dm}^{-3}$

\begin{tabular}{|c|c|c|}
\hline Time Range / s & Mid-point Time $/ \mathrm{s}$ & {$[\mathrm{RBr}]_{\mathrm{t}} / \mathrm{mol} \mathrm{dm}^{-3}$} \\
\hline 0 & 0 & 0.200 \\
\hline $712-728$ & 720 & 0.121 \\
\hline $1072-1088$ & 1080 & 0.101 \\
\hline $1432-1448$ & 1440 & 0.095 \\
\hline $1792-1808$ & 1800 & 0.084 \\
\hline $2152-2168$ & 2160 & 0.076 \\
\hline $2512-2528$ & 2520 & 0.068 \\
\hline $2872-2888$ & 2880 & 0.063 \\
\hline $3232-3248$ & 3240 & 0.058 \\
\hline
\end{tabular}




\section{Table 7.4}

The effect of various radical/radical anion inhibitors and inducers on the reaction rate for the reaction of lithium azide with $p$-nitrocumyl bromide in dimethyl sulphoxide.

\begin{tabular}{|c|c|c|c|c|c|c|}
\hline $\begin{array}{l}{\left[\operatorname{LiN}_{3}\right]_{0}} \\
/ \mathrm{mol} \mathrm{dm}^{-3} \\
\end{array}$ & $\begin{array}{c}{[R B r]_{0}} \\
/ \mathrm{mol} \mathrm{dm}^{-3}\end{array}$ & $\begin{array}{c}{\left[\mathrm{LiClO}_{4}\right]_{0}} \\
/ \mathrm{mol} \mathrm{dm}^{-3}\end{array}$ & $\begin{array}{c}10^{4} k_{1} / \\
s^{-1} \\
\end{array}$ & $\begin{array}{c}10^{3} k_{2} / \\
\mathrm{dm}^{3} \mathrm{~mol}^{-1} \mathrm{~s}^{-1} \\
\end{array}$ & $\begin{array}{c}10^{3} k_{2}^{\prime} / \\
\mathrm{dm}^{3} \mathrm{~mol}^{-1} \mathrm{~s}^{-1} \\
\end{array}$ & $\begin{array}{c}10^{5} k_{s} / \\
s^{-1} \\
\end{array}$ \\
\hline 0.40 & 0.20 & 0.00 & 11.1 & 3.87 & 3.48 & 4.86 \\
\hline \multicolumn{3}{|c|}{$+p$-dinitrobenzene $\left(0.10 \mathrm{~mol} \mathrm{dm}^{-3}\right)$} & 10.5 & 3.73 & 3.88 & 5.11 \\
\hline \multicolumn{3}{|c|}{ + 4-hydroxy tempo $\left(0.02 \mathrm{~mol} \mathrm{dm}^{-3}\right)$} & 12.6 & 4.57 & 4.17 & 5.23 \\
\hline 0.20 & 0.20 & 0.20 & 3.94 & 4.21 & 3.57 & 5.13 \\
\hline \multicolumn{3}{|c|}{+ ultraviolet light ( 5 minutes) } & 3.36 & 3.33 & 3.21 & 4.67 \\
\hline
\end{tabular}

\section{Table 7.5}

A comparison of concurrent bimolecular rate constants derived from GEAR and GIT, $\left(k_{2}^{\prime}\right)$, with the concurrent bimolecular rate constants (Isolated points deleted) ${ }^{*}$ derived from Equation 6.21, $\left(k_{2}{ }^{*}\right)$.

\begin{tabular}{|c|c|c|c|c|c|c|}
\hline $\begin{array}{l}{\left[\operatorname{LiN}_{3}\right]_{0}} \\
/ \mathrm{mol} \mathrm{dm}^{-3} \\
\end{array}$ & $\begin{array}{l}{[R B r]_{0}} \\
/ \mathrm{mol} \mathrm{dm}^{-3} \\
\end{array}$ & $\begin{array}{c}{\left[\mathrm{LiClO}_{4}\right]_{0}} \\
/ \mathrm{mol} \mathrm{dm}^{-3}\end{array}$ & $\begin{array}{c}10^{5} k_{s} / \\
s^{-1} \\
\end{array}$ & $\begin{array}{c}10^{3} k_{2}^{\prime} / \\
\mathrm{dm}^{3} \mathrm{~mol}^{-1} \mathrm{~s}^{-1} \\
\end{array}$ & $\begin{array}{l}10^{3} \mathrm{k}_{2}^{\prime \prime} / \\
\mathrm{dm}^{3} \mathrm{~mol}^{-1} \mathrm{~s}^{-1} \\
\end{array}$ & $\begin{array}{c}\mathbf{r}^{\star} \\
\sigma^{*} / \% \\
\end{array}$ \\
\hline 0.40 & 0.20 & 0.00 & 4.86 & 3.48 & 3.77 & $\begin{array}{c}0.9998 \\
0.71\end{array}$ \\
\hline \multicolumn{3}{|c|}{$+p$-dinitrobenzene $\left(0.10 \mathrm{~mol} \mathrm{dm}^{-3}\right)$} & 5.11 & 3.88 & 3.47 & $\begin{array}{c}0.9993 \\
1.37 \\
\end{array}$ \\
\hline \multicolumn{3}{|c|}{ + 4-hydroxy tempo $\left(0.02 \mathrm{~mol} \mathrm{dm}^{-3}\right)$} & 5.23 & 4.17 & 4.45 & $\begin{array}{c}0.9999 \\
0.53 \\
\end{array}$ \\
\hline 0.20 & 0.20 & 0.20 & 5.13 & 3.57 & 3.60 & $\begin{array}{c}0.9998 \\
0.79 \\
\end{array}$ \\
\hline \multicolumn{3}{|c|}{+ ultraviolet light (15 minutes) } & 4.67 & 3.21 & 2.95 & $\begin{array}{c}0.9986 \\
2.40\end{array}$ \\
\hline
\end{tabular}




\subsection{Heterolytic Mechanisms}

We saw in the previous chapter that the bimolecular kinetic component in the reaction of lithium azide with $p$-nitrocumyl bromide in dimethyl sulphoxide came from two reactions (Equations 6.11 and 6.12):

\section{Bimolecular Reactions}

$$
\begin{array}{ll}
\mathrm{RBr}+\mathrm{N}_{3}-\stackrel{k\left(\mathrm{RN}_{3}\right)}{\longrightarrow} & \mathrm{RN}_{3}+\mathrm{Br}^{-} \\
\mathrm{RBr}+\mathrm{N}_{3}-\stackrel{k \text { (Alkene) } 2}{\longrightarrow} & \text { Alkene }+\mathrm{HN}_{3}+\mathrm{Br}^{-}
\end{array}
$$

As we have seen from chapter 5 , there are many mechanisms that can be formulated in order to explain the bimolecular kinetic component. The bimolecular kinetic component may be explained in terms of a concerted mechanism or perhaps an elimination addition mechanism. There are, however, other explanations for the bimolecular kinetics obtained and these will be discussed in more detail later on.

Two more experiments were carried out in order to shed a little more light on the nature of the mechanism occurring in the reaction of lithium azide with $p$-nitrocumyl bromide in dimethyl sulphoxide. Rate coefficients for these kinetic experiments were calculated assuming that the reactions were: (1) overall first order with respect to $p$ nitrocumyl bromide $\left(k_{1}\right),(2)$ first order with respect to both $p$-nitrocumyl bromide and lithium azide, that is, second order overall $\left(k_{2}\right)$, and (3) concurrent first and second order $\left(k_{\mathrm{S}}\right.$ and $\left.k_{2}^{\prime}\right)$. The concurrent first and second order rate constants were calculated using GEAR and GIT. The rate constants obtained from GEAR and GIT, with their corresponding data (Tables 7.6 and 7.7), were then substituted into the function for a concurrent first and second order reaction. The resulting values were plotted against time and the new rate constants $\left(k_{2}\right)$ were obtained from the slopes of the graphs. The new 
bimolecular rate constants $\left(k_{2}^{\prime \prime}\right)$ should act as a verification for the bimolecular rate constants obtained from the GEAR and GIT computer programmes.

\subsubsection{The Effect of Lithium Bromide on the Rate of Reaction for the Reaction of Lithium Azide with p-Nitrocumyl Bromide in Dimethyl Sulphoxide}

One kinetic study was performed; both the initial concentrations of $p$-nitrocumyl bromide and lithium azide were set equal to $0.20 \mathrm{~mol} \mathrm{dm}^{-3}$. Lithium bromide was present in the reaction solution at an initial concentration of $0.20 \mathrm{~mol} \mathrm{dm}^{-3}$. The concentrations of p-nitrocumyl bromide at given times, derived from this kinetic study, are presented in Table 7.6. For time equal to zero, the concentration of $p$-nitrocumyl bromide in the reaction mixture was set equal to one half the concentration of just the $p$-nitrocumyl bromide solution on its own.

Tables 7.8 and 7.9 display all the above mentioned rate constants. It is clear to see, from these Tables, that addition of lithium bromide to the mixture does not significantly affect the rate of reaction. This indicates that there is no common ion effect.

\subsubsection{The Rate of Reaction for the Reaction of Lithium Azide with p-Nitrocumyl}

\section{Bromide in a $95 \% \mathrm{C}_{2} \underline{\mathrm{D}} 6 \underline{\mathrm{SO}} \underline{\mathrm{SO}} 5 \% \mathrm{H}_{2} \underline{\mathrm{O} \text { Solvent Mixture }}$}

One kinetic study was performed; the initial concentration of $p$-nitrocumyl bromide was set equal to $0.20 \mathrm{~mol} \mathrm{dm}^{-3}$ and the initial concentration of sodium nitrite was set equal to $0.40 \mathrm{~mol} \mathrm{dm}^{-3}$. The solvent used was a $95 \% \mathrm{C}_{2} \mathrm{D}_{6} \mathrm{SO}: 5 \% \mathrm{H}_{2} \mathrm{O}$ mixture. The concentrations of $p$-nitrocumyl bromide at given times, derived from this kinetic study, are presented in Table 7.7. For time equal to zero, the concentration of $p$-nitrocumyl bromide in the reaction mixture was set equal to one half the concentration of just the $p$-nitrocumyl bromide solution on its own.

Tables 7.8 and 7.9 display all the above mentioned rate constants. It is clear from these Tables that the presence of water moderately slows the reaction down. Hydrogen bonding between water and azide will lower the nucleophilicity of azide, also, an increase in the polarity of the solvent could destabilise an $\mathrm{S}_{\mathrm{N}} 2$ transition state. 
Table 7.6

Temperature

Solvent

$[\mathrm{RBr}]_{0}$

$\left[\mathrm{LiN}_{3}\right]_{0}$

$\left[\mathrm{LiClO}_{4}\right]_{0}$

$[\mathrm{LiBr}]_{0}$
The Effect of Lithium Bromide on the Reaction of Lithium

\section{Azide with p-Nitrocumyl Bromide in Dimethyl Sulphoxide}

$30^{\circ} \mathrm{C}$

$99.9 \% \mathrm{C}_{2} \mathrm{D}_{6} \mathrm{SO}$

$0.20 \mathrm{~mol} \mathrm{dm}^{-3}$

$\left(\mathrm{R}=\mathrm{C}_{9} \mathrm{H}_{10} \mathrm{NO}_{2}\right)$

$0.20 \mathrm{~mol} \mathrm{dm}^{-3}$

$0.00 \mathrm{~mol} \mathrm{dm}^{-3}$

$0.20 \mathrm{~mol} \mathrm{dm}^{-3}$

\begin{tabular}{|c|c|c|}
\hline Time Range/s & Mid-point Time/s & {$[\mathrm{RBr}]_{\mathrm{t}} / \mathrm{mol} \mathrm{dm}^{-3}$} \\
\hline 0 & 0 & 0.200 \\
\hline $352-368$ & 360 & 0.155 \\
\hline $712-728$ & 720 & 0.123 \\
\hline $1072-1088$ & 1080 & 0.105 \\
\hline $1432-1448$ & 1440 & 0.092 \\
\hline $1792-1808$ & 1800 & 0.081 \\
\hline $2152-2168$ & 2160 & 0.072 \\
\hline $2512-2528$ & 2520 & 0.065 \\
\hline $2872-2888$ & 2880 & 0.062 \\
\hline $3232-3248$ & 3240 & 0.057 \\
\hline
\end{tabular}


Table 7.7

Temperature

Solvent

$[\mathrm{RBr}]_{0}$

$\left[\mathrm{LiN}_{3}\right]_{0}$

$\left[\mathrm{LiClO}_{4}\right]_{0}$
The Effect of $\mathrm{H}_{2}$ O on the Reaction of Lithium Azide with p-Nitrocumyl Bromide in Dimethyl Sulphoxide

$30^{\circ} \mathrm{C}$

$95 \% \mathrm{C}_{2} \mathrm{D}_{6} \mathrm{SO}: 5 \% \mathrm{H}_{2} \mathrm{O}$

$0.20 \mathrm{~mol} \mathrm{dm}^{-3}$

$\left(\mathrm{R}=\mathrm{C}_{9} \mathrm{H}_{10} \mathrm{NO}_{2}\right)$

$0.40 \mathrm{~mol} \mathrm{dm}^{-3}$

$0.00 \mathrm{~mol} \mathrm{dm}^{-3}$

\begin{tabular}{|c|c|c|}
\hline Time Range / s & Mid-point Time $/ \mathrm{s}$ & {$[\mathrm{RBr}]_{\mathrm{t}} / \mathrm{mol} \mathrm{dm}^{-3}$} \\
\hline 0 & 0 & 0.200 \\
\hline $172-188$ & 180 & 0.161 \\
\hline $352-368$ & 360 & 0.136 \\
\hline $532-548$ & 540 & 0.115 \\
\hline $712-728$ & 720 & 0.099 \\
\hline $892-908$ & 900 & 0.086 \\
\hline $1072-1088$ & 1080 & 0.074 \\
\hline $1252-1268$ & 1260 & 0.065 \\
\hline $1432-1448$ & 1440 & 0.057 \\
\hline $1612-1628$ & 1620 & 0.050 \\
\hline
\end{tabular}




\section{Table 7.8}

The effect of various experiments on the reaction rate of the reaction of lithium azide with p-nitrocumyl bromide in dimethyl sulphoxide.

\begin{tabular}{|c|c|c|c|c|c|c|}
\hline $\begin{array}{c}{\left[\text { LiN }_{3}\right]_{0}} \\
/ \mathrm{mol} \mathrm{dm}^{-3}\end{array}$ & $\begin{array}{c}{[R B r]_{0}} \\
/ \mathrm{mol} \mathrm{dm}^{-3}\end{array}$ & $\begin{array}{c}{\left[\mathrm{LiClO}_{4}\right]_{0}} \\
/ \mathrm{mol} \mathrm{dm}^{-3}\end{array}$ & $\begin{array}{c}10^{4} \boldsymbol{k}_{1} / \\
\mathbf{s}^{-1}\end{array}$ & $\begin{array}{c}10^{3} \boldsymbol{k}_{\mathbf{2}} / \\
\mathrm{dm}^{\mathbf{3}} \mathrm{mol}^{-1} \mathbf{s}^{-1}\end{array}$ & $\begin{array}{c}10^{3} \boldsymbol{k}_{\mathbf{2}}^{\prime} / \\
\mathrm{dm}^{\mathbf{3}} \mathbf{m o l}^{-\mathbf{1}} \mathbf{s}^{-1}\end{array}$ & $\begin{array}{c}10^{5} \boldsymbol{k}_{\mathbf{s}} / \\
\mathbf{s}^{-1}\end{array}$ \\
\hline 0.40 & 0.20 & 0.00 & 11.1 & 3.87 & 3.48 & 4.86 \\
\hline \multicolumn{2}{|c|}{$95 \% \mathrm{C}_{2} \mathrm{D}_{6} \mathrm{SO}: 5 \% \mathrm{H}_{2} \mathrm{O}$} & 8.40 & 2.81 & 2.72 & 4.71 \\
\hline 0.20 & 0.20 & 0.20 & 3.94 & 4.21 & 3.57 & 5.13 \\
\hline $\mathrm{NaBr}\left(0.20 \mathrm{~mol} \mathrm{dm}^{-3}\right)$ & 0.00 & 3.71 & 3.87 & 3.58 & 5.33 \\
\hline
\end{tabular}

\section{Table 7.9}

A comparison of bimolecular rate constants derived from GEAR and GIT, $\left(k_{2}^{\prime}\right)$, with the bimolecular rate constants (Isolated points deleted) ${ }^{*}$ derived from Equation $6.21,\left(k_{2}^{\prime \prime}{ }^{*}\right)$.

\begin{tabular}{|c|c|c|c|c|c|c|}
\hline $\begin{array}{l}{\left[\operatorname{LiN}_{3}\right]_{0}} \\
/ \mathrm{mol} \mathrm{dm}^{-3} \\
\end{array}$ & $\begin{array}{c}{[R B r]_{0}} \\
/ \mathrm{mol} \mathrm{dm}^{-3} \\
\end{array}$ & $\begin{array}{c}{\left[\mathrm{LiClO}_{4}\right]_{0}} \\
/ \mathrm{mol} \mathrm{dm}^{-3}\end{array}$ & $\begin{array}{c}10^{5} k_{s} / \\
s^{-1} \\
\end{array}$ & $\begin{array}{c}10^{3} k_{2}^{\prime} / \\
\mathrm{dm}^{3} \mathrm{~mol}^{-1} \mathrm{~s}^{-1} \\
\end{array}$ & $\begin{array}{c}10^{3} \mathrm{k}_{2}{ }_{2}^{*} / \\
\mathrm{dm}^{3} \mathrm{~mol}^{-1} \mathrm{~s}^{-1}\end{array}$ & $\begin{array}{c}\mathbf{r}^{*} \\
\sigma^{*} / \% \\
\end{array}$ \\
\hline 0.40 & 0.20 & 0.00 & 4.86 & 3.48 & 3.77 & $\begin{array}{c}0.9998 \\
0.71 \\
\end{array}$ \\
\hline \multicolumn{3}{|c|}{$95 \% \mathrm{C}_{2} \mathrm{D}_{6} \mathrm{SO}: 5 \% \mathrm{H}_{2} \mathrm{O}$} & 4.71 & 2.72 & 2.63 & $\begin{array}{c}1.0000 \\
0.33 \\
\end{array}$ \\
\hline 0.20 & 0.20 & 0.20 & 5.13 & 3.57 & 3.60 & $\begin{array}{c}0.9998 \\
0.79 \\
\end{array}$ \\
\hline \multicolumn{2}{|c|}{$\mathrm{NaBr}\left(0.20 \mathrm{~mol} \mathrm{dm}^{-3}\right)$} & 0.00 & 5.33 & 3.58 & 3.48 & $\begin{array}{c}0.9995 \\
1.47\end{array}$ \\
\hline
\end{tabular}




\subsection{Mechanisms Leading to Second Order Kinetics}

The reaction of lithium azide with $p$-nitrocumyl bromide in dimethyl sulphoxide produces far simpler kinetics than in the nitrite reaction. The good agreement amongst the second order rate constants, for the azide reaction, indicates that the degree of association between lithium and azide is constant over the concentration ranges used (0.20-0.40 mol $\mathrm{dm}^{-3}$ ). Several mechanisms leading to second order kinetics will now be discussed.

\subsubsection{Concurrent $\mathrm{S}_{\underline{N}}$ and E2C mechanism}

One mechanism that could be envisaged would be a concurrent $\mathrm{S}_{\mathrm{N}} 2$ and E2C mechanism (Transition State 7.1). The E2C mechanism, 64 as opposed to the E2 Mechanism, is characterised by strong nucleophiles that are weak bases. The reactions are favoured by good leaving groups, the reactivity order is tertiary $>$ secondary $>$ primary, and they are favoured by polar aprotic solvents.

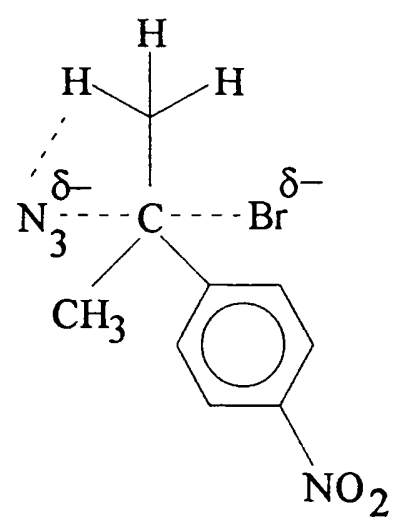

Transition State 7.1

In Transition state 7.1 , azide may interact in the transition state with the $\beta$-hydrogen as well as with the $\alpha$-carbon, however, the azide interacts mainly with the carbon. The linear azide ion, which is a good nucleophile, in dipolar aprotic solvents would provide minimal steric compression. The presence of the $p$-nitrophenyl group will help to stabilise the electron rich transition state and in dimethyl sulphoxide the transition state will be 
stabilised relative to the initial state. Since $\mathrm{S}_{\mathrm{N}} 2$ mechanisms at tertiary carbon atoms are rare, $65-67$ one must be on the alert for other pathways leading to the observed kinetics.

\subsection{2 $\underline{\text { S}} \underline{\text { 2-Type Ion Pair Mechanism }}$}

An alternative to the classical $S_{N^{2}}$ mechanism would be an $S_{N^{2}}$-type ion pair mechanism (Scheme 7.1):
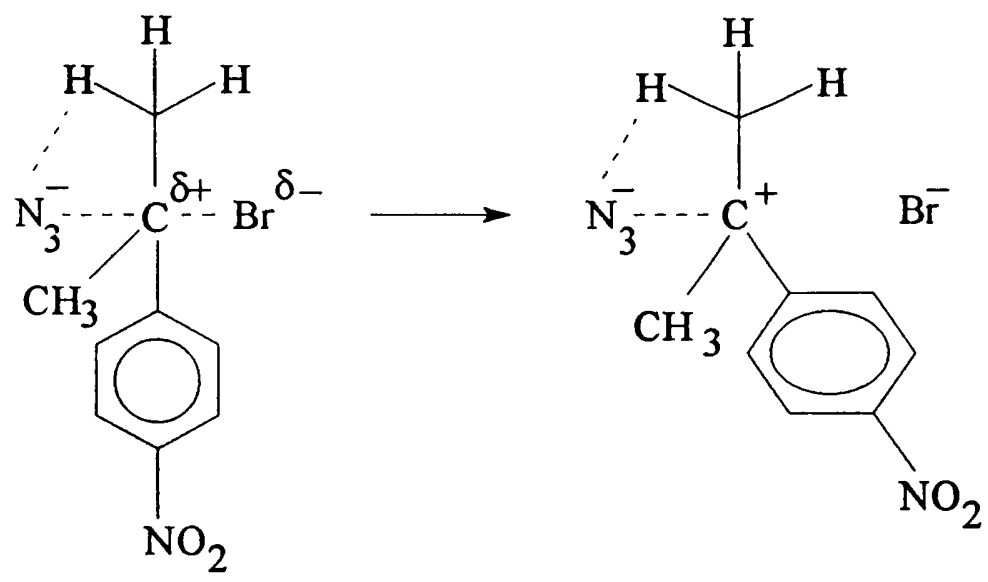

Scheme 7.1

The azide molecule assists in the formation of a tight ion pair (Scheme 7.1). Azide may interact with the $\beta$-hydrogen as well as with the $\alpha$-carbon, however, the azide interacts mainly with the carbon. The $\mathrm{S}_{\mathrm{N}}$ 2-type ion pair mechanism differs from the classical $\mathrm{S}_{\mathrm{N}} 2$ mechanism in that it postulates the formation of an intermediate. The two mechanisms differ with respect to the magnitude of the positive charge on tertiary carbon in the transition state. It should be small in Transition State 7.1 and large in the one leading to the ion pair in Scheme 7.1.

The formation of the tight ion pair may not need the assistance of azide. In this case the $\mathrm{C}-\mathrm{Br}$ bond is broken heterolytically and reversibly in a preliminary step without participation of the azide anion, the principal driving force being solvation of the bromide atom. The reaction is then completed by slow attack of azide on this intimate ion pair. There is very little difference between these two ion pair mechanisms and in either event the nucleophile is involved in the rate limiting step. 


\subsection{3 $\underline{\underline{S}} \underline{2} \underline{C}+$ Mechanism}

One could imagine a mechanism, (Scheme 7.2), in which a carbocation is in fast equilibrium with the $p$-nitrocumyl substrate. Azide may then attack the carbocation at a slow rate to form the substituted products and give second order kinetics. The alkene would be formed from the carbocation via an E1 elimination and its rate of formation would be independent of lithium azide. The addition of lithium bromide would shift the equilibrium to the left and the reaction would be inhibited (common ion effect), however, no common ion effect was observed (see 7.3.1). The experimental evidence suggests that the formation of the alkene is dependent upon the concentration of lithium azide, so Scheme 7.2 is unfavourable.

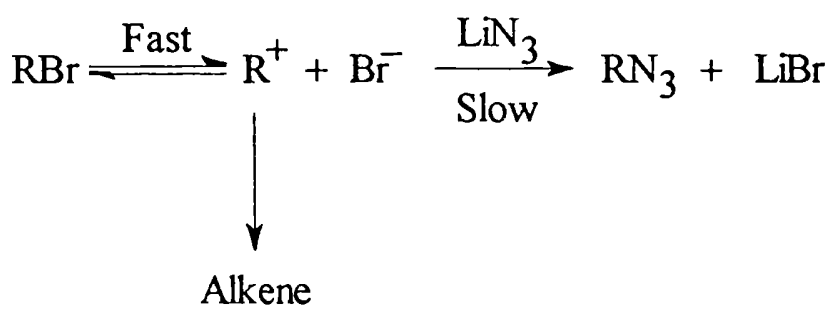

Scheme 7.2

\subsubsection{Carbanion Mechanism}

The electron withdrawing $p$-nitro substituent would help to stabilise a carbanion. The possibility that azide attacks bromine to give a carbanion and this carbanion then gives rise to the observed product by displacing bromide ion from the brominated azide was considered (Scheme 7.3):

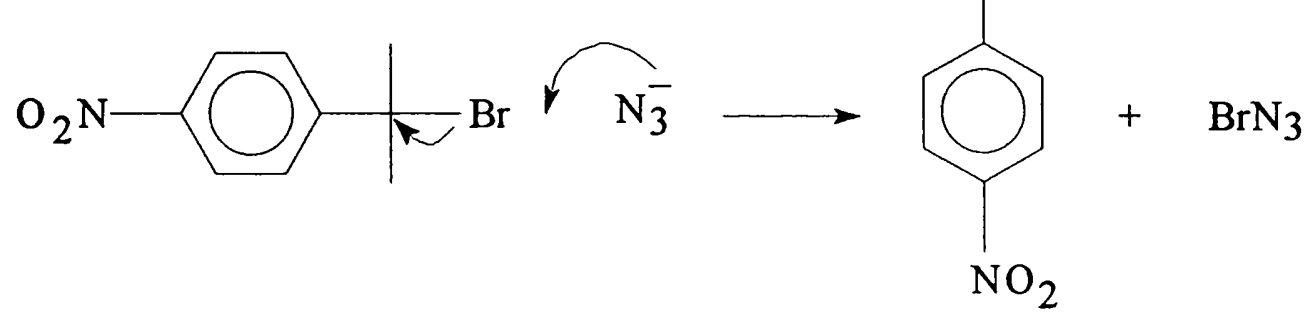



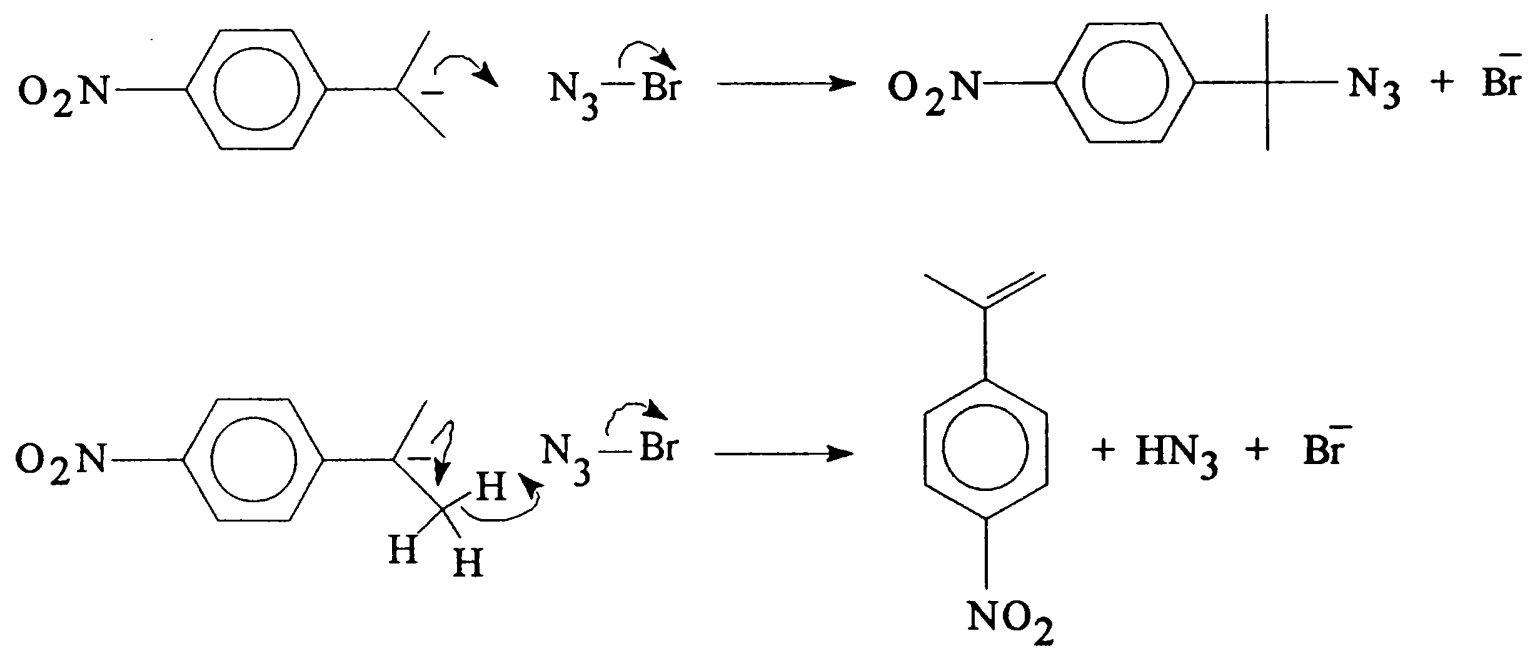

Scheme 7.3

If this were the case, one would expect either hydrazoic acid or traces of water to intercept the carbanion to give $p$-nitrocumene. No $p$-nitrocumene was detected experimentally. The evidence suggests that a carbanion mechanism would be unlikely.

\subsubsection{Elimination-Addition Mechanism}

Rather than having a substitution process, one can envisage an elimination-addition mechanism. This would be an E2 elimination followed by electrophilic addition of hydrazoic acid (Scheme 7.4):

$$
\begin{aligned}
\mathrm{RBr}+\mathrm{N}_{3}^{-} & \longrightarrow \text { Alkene }+\mathrm{HN}_{3}+\mathrm{Br}^{-} \\
\text {Alkene }+\mathrm{HN}_{3} & \longrightarrow \mathrm{RN}_{3}
\end{aligned}
$$

Scheme 7.4

If this mechanism were in progress then we would expect the formation of alkene to level off quite rapidly, but experimentally we do not see this (see section 6.9). It was found experimentally, that hydrazoic acid did not readily add to $p$-nitro- $\alpha$-methylstyrene in 
dimethyl sulphoxide under normal conditions. Again this is another mechanism that is

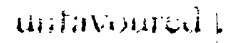

\subsubsection{Association between the Lithium Cation and p-Nitrocumyl Bromide}

There is evidence 71 in the literature for substitution reactions that are assisted by the lithium cation. The Lewis acid-promoted formation of a carbocation by the lithium cation was considered (Scheme 7.5):

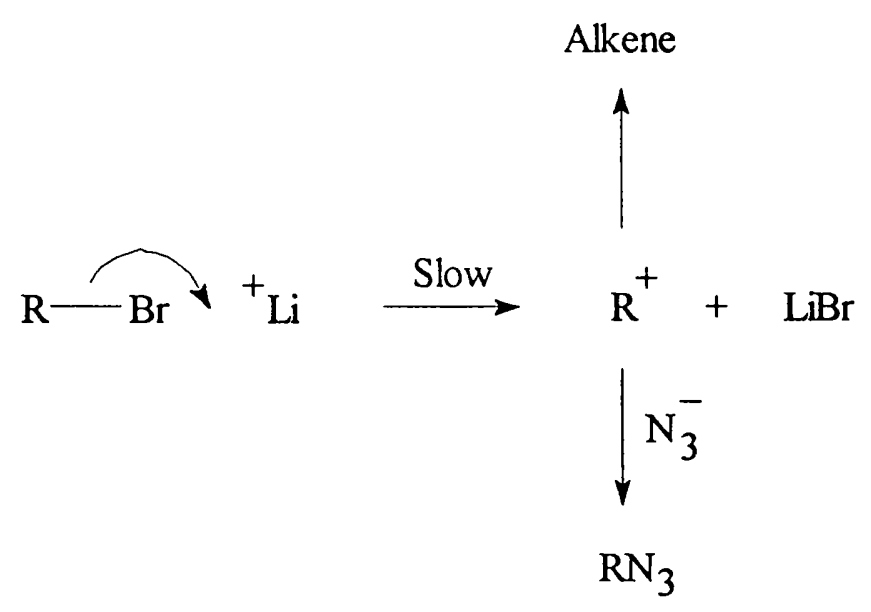

Scheme 7.5

The rate determining step in this mechanism would include both $p$-nitrocumyl bromide and the lithium cation, hence second order kinetics may be obtained (see Section 7.5).

\subsubsection{Ipso Mechanisms}

Several mechanisms involving ipso attack on the aromatic ring can be envisaged. One type of ipso mechanism can be seen in Scheme 7.6.

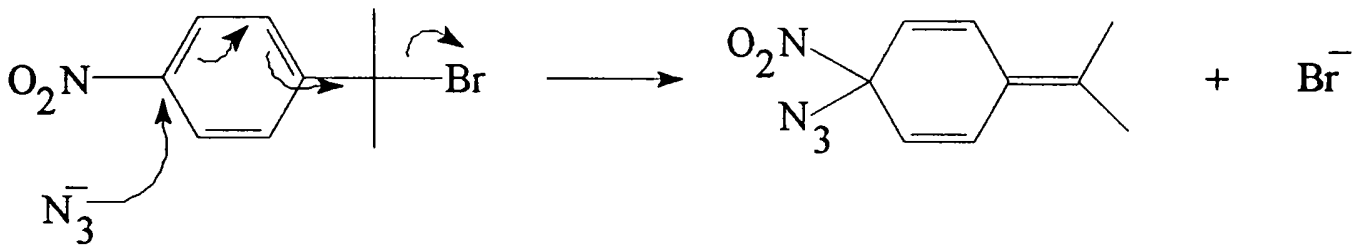



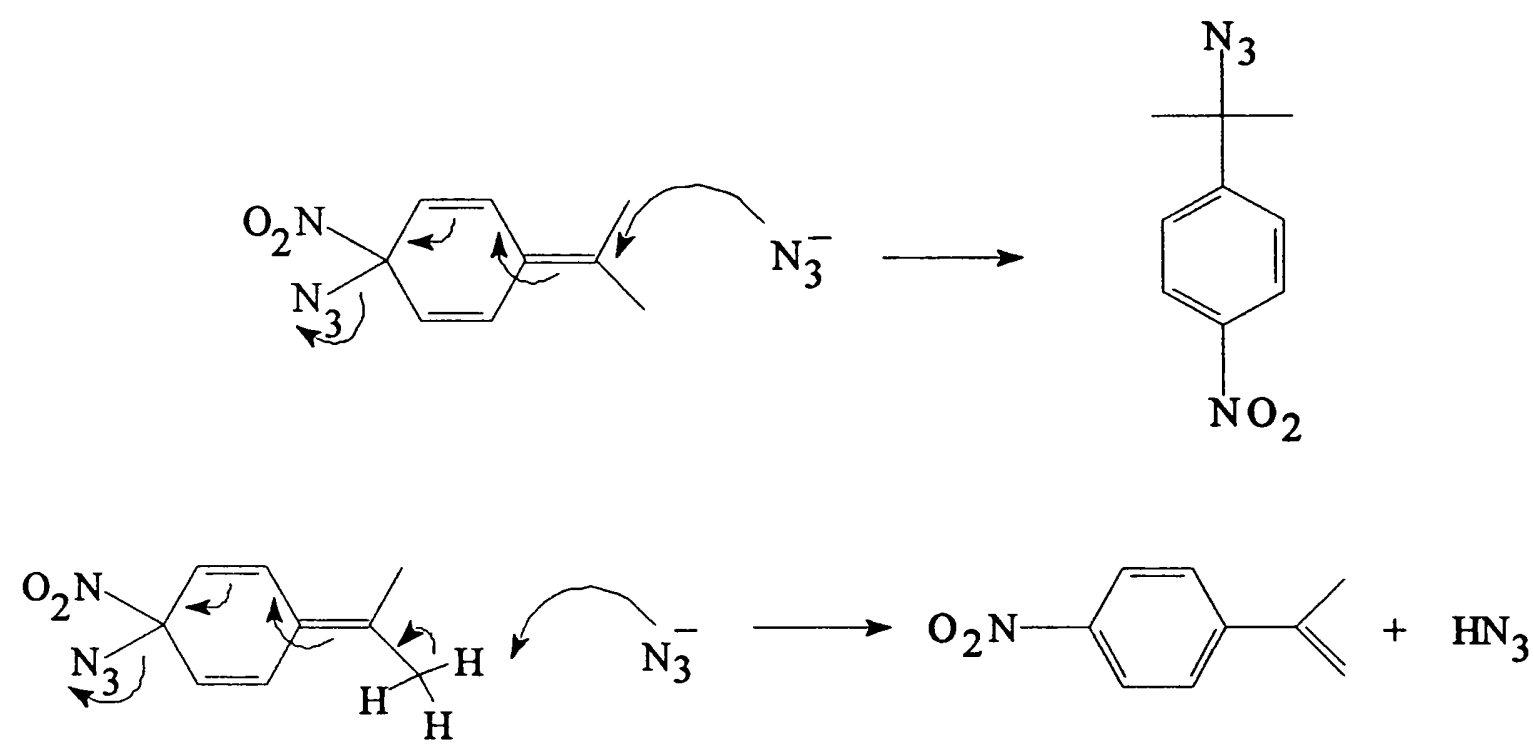

Scheme 7.6

The rate determining step for this mechanism involves azide attack ipso to the nitro group giving second order kinetics. If the mechanism in Scheme 7.6 were occurring then the rate of formation of both $p$-nitrocumyl azide and $p$-nitro- $\alpha$-methylstyrene would depend on the concentrations of both lithium azide and p-nitrocumyl bromide. This would be in agreement with the experimental results. The mechanism in Scheme 7.6 relies on the assumption that only the azido group departs, leaving the nitro substituent intact. However, this is unlikely and one would expect a mixture of $p$-azido and $p$-nitro ring substituents in the isolated products. There was no sign of $p$-azido ring substituents in the products isolated from H.P.L.C. so this mechanism seems unlikely. A more likely mechanism would be one involving azide attack at an ortho position on the aromatic ring. If this attack was rate determining then second order kinetics would be obtained. This mechanism cannot be ruled out.

With a little imagination a mechanism can be postulated that involves azide attack ipso to the isopropyl group. The intermediate could then undergo either neighbouring group participation or a 1,2 shift to give the desired products (Scheme 7.7). We know from chapter 5 that there is evidence 69 for the existence of this type of complex. This mechanism is as appealing as the concurrent $\mathrm{S}_{\mathrm{N}} 2$ and $\mathrm{E} 2 \mathrm{C}$ mechanism or the tight ion pair 
mechanisms. If it were at all possible, isolation of the Meisenheimer complex would be a sure way of proving this ipso mechanism. The presence of the $p$-nitro group will help to stabilise the electron rich complex.
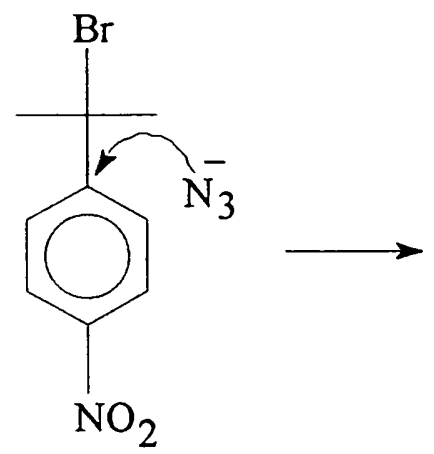

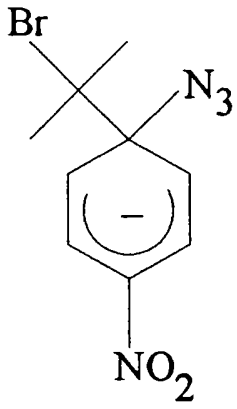

Scheme 7.7

\subsubsection{Discussion}

We now have five valid mechanisms that can account for the bimolecular kinetic component in the reaction of lithium azide with $p$-nitrocumyl bromide in dimethyl sulphoxide. The fact that nitrite has two nucleophilic centres helped us to distinguish between a classical $\mathrm{S}_{\mathrm{N}} 2$ mechanism and an ion pair mechanism. The azide ion is not ambident and this makes it difficult to distinguish between the two mechanisms. Lithium azide was used as a source of azide because of its good solubility in dimethyl sulphoxide, however, the Lewis acid nature of the lithium cation could in itself be responsible for the observed kinetics. Clearly, more experiments must be performed in order to distinguish between the five remaining mechanisms.

\subsection{A Kinetic Study of the Reaction of Tetrabutylammonium Azide with p- Nitrocumyl Bromide in Dimethyl Sulphoxide}

The mechanism in Scheme 7.6 will only give exact second order kinetics under fortuitous circumstances, however, it cannot be discarded. As we have already mentioned, there is evidence 71 in the literature for substitution reactions that are assisted by the 
lithium cation. Pearson et al. 71 have shown that the substitution reactions of allylic acetates and allylic alcohols by a variety of nucleophiles proceed smoothly in the presence of lithium perchlorate in ether. They believe that these reactions proceed by the lithium cation-promoted formation of an allylic carbocation.

Unlike the lithium cation, the tetrabutylammonium ion has no vacant p-orbitals making it a weak Lewis acid. If first order kinetics were to be obtained for the reaction of tetrabutylammonium azide with $p$-nitrocumyl bromide then this would be strong evidence for association between the lithium cation and the p-nitrocumyl bromide substrate. If second order kinetics were to be obtained then this would indicate that an alternative mechanism is in progress.

When $p$-nitrocumyl bromide was treated with tetrabutylammonium azide (two fold excess) in dimethyl sulphoxide and under an argon atmosphere (see 9.4.9), the reaction had a half-life of 6 minutes at $30^{\circ} \mathrm{C}$ (Equation 7.1):

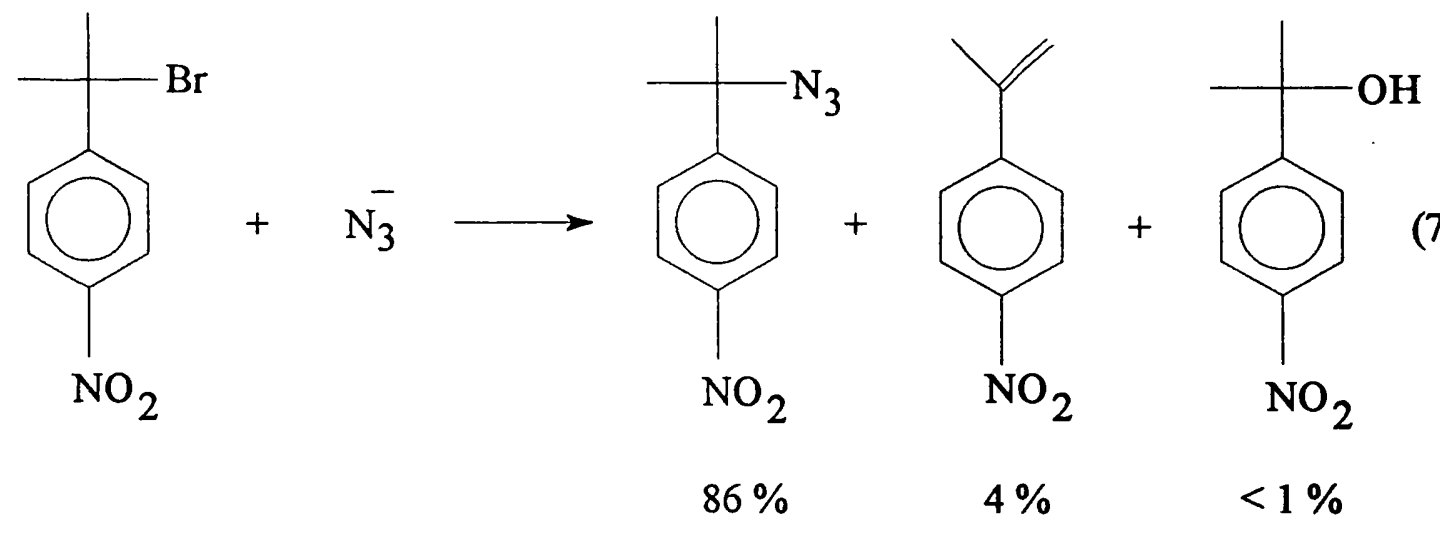

\subsubsection{MHz 1 H Study of the Reaction of Tetrabutylammonium Azide with $p$ - Nitrocumyl Bromide in Dimethyl Sulphoxide}

The ${ }^{1}$ H n.m.r. spectrum of tetrabutylammonium azide can be seen in Figure 7.8. The aliphatic region of the spectrum is crowded with signals and these signals would swamp the signal due to the methyl protons of $p$-nitrocumyl bromide. However, the signals due to the ortho aromatic protons in $p$-nitrocumyl bromide can be used for kinetic study. The course of the reactions were followed by observing the growth and 
disappearance of the ${ }^{1} \mathrm{H}$ n.m.r. signals in the aromatic region (Figure 7.9 ). The concentrations of $p$-nitrocumyl bromide, at given times, were calculated from the integrals (I) of the ortho proton signals as follows (Equation 7.2):

$$
\begin{aligned}
\mathrm{R}=\mathrm{C}_{9} \mathrm{H}_{10} \mathrm{NO}_{2} & \\
{[\mathrm{RBr}]_{\mathrm{t}} } & =\frac{\mathrm{I}(\mathrm{RBr}) \mathrm{X}[\mathrm{RBr}]_{0}}{\mathrm{I}(\mathrm{RBr})+\mathrm{I}\left(\mathrm{RN}_{3}+\mathrm{ROH}+\text { Alkene }\right)}
\end{aligned}
$$

In each kinetic study 10 spectra were accumulated, each consisting of $88 \mu$ s pulses each followed by a two second acquisition time (see 9.5.2). For the purpose of calculating rate coefficients, the time ascribed to each spectrum was the mid-point of the accumulation.

\subsubsection{The Elimination of $p$-Nitrocumyl Bromide in Dimethyl Sulphoxide}

One kinetic study was performed; the initial concentration of $p$-nitrocumyl bromide was set equal to $0.20 \mathrm{~mol} \mathrm{dm}^{-3}$. No tetrabutylammonium azide was added but the ionic strength of the reaction solution was held essentially constant by the addition of tetrabutylammonium perchlorate. The concentrations of $p$-nitrocumyl bromide at given times, derived from this kinetic study, are presented in Table 7.10. As the solvent is in excess a rate coefficient was calculated assuming that the reaction was first order with respect to $p$-nitrocumyl bromide (Figure 7.10).

For the elimination of $p$-nitrocumyl bromide in dimethyl sulphoxide, the plot for an overall first order reaction is a very good fit. When the residuals are examined it can be seen that the pattern is a random one with the very first point slightly removed from others. The elimination rate constant $\left(k_{\mathrm{S}}\right)$ obtained here is slightly lower than the $k_{\mathrm{S}}$ value obtained for the lithium cation, and the reason for this is not entirely obvious. 


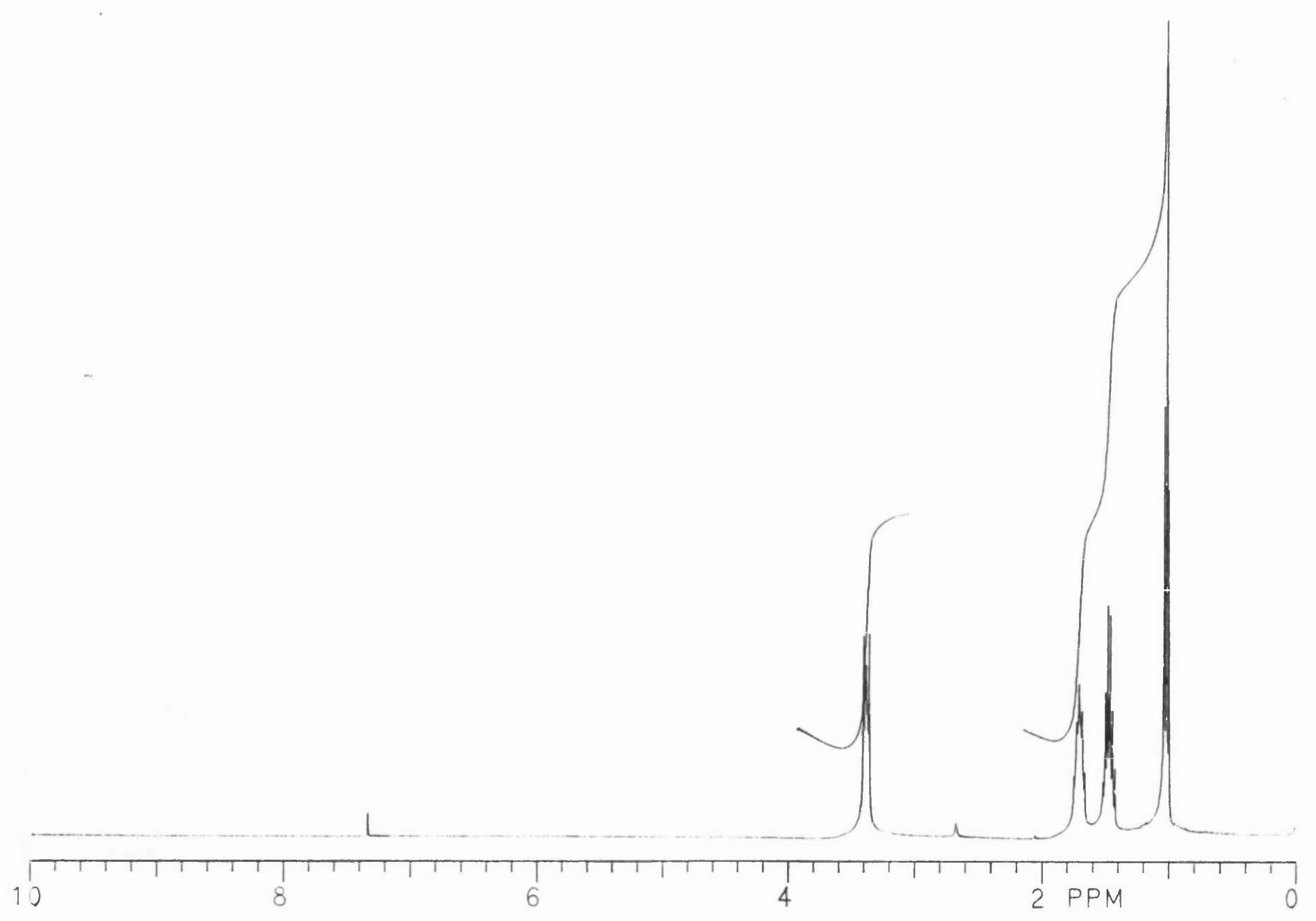

Figure 7.8: The $400 \mathrm{MHz}{ }^{1} \mathrm{H}$ n.m.r. Spectrum of Tetrabutylammonium azide $\left(\mathrm{CDCl}_{3}\right)$ 


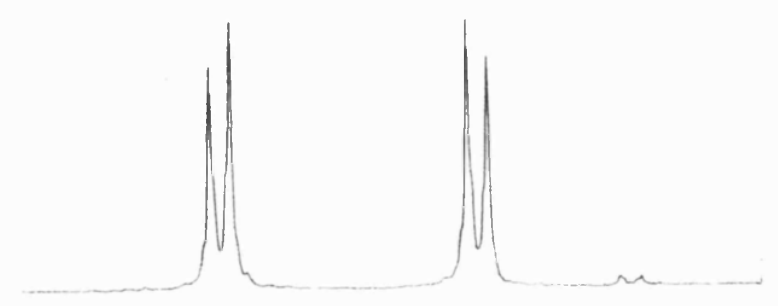

Time $=0 \mathrm{~s}$
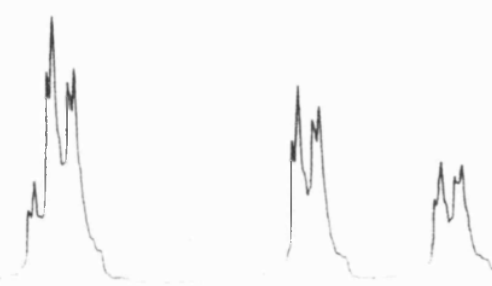

Time $=540 \mathrm{~s}$
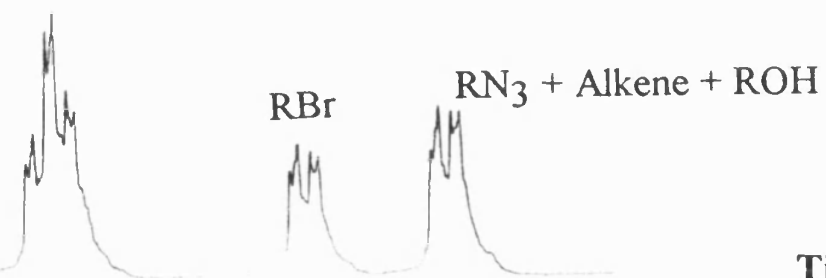

Time $=1080 \mathrm{~s}$
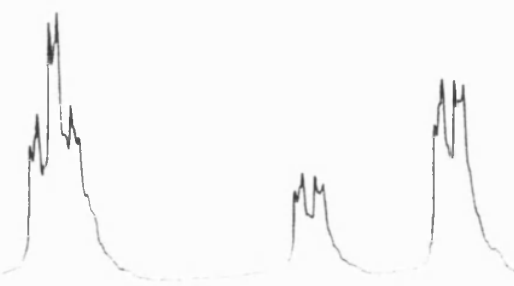

Time $=1620 \mathrm{~s}$

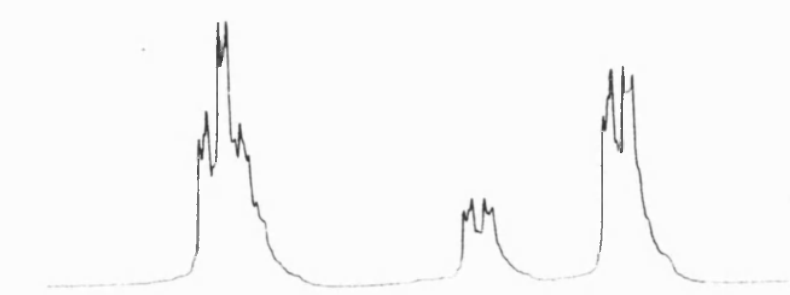

Time $=2160 \mathrm{~s}$

Figure 7.9

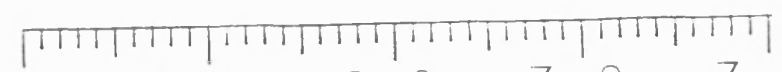

The growth and disappearance of the ${ }^{1} \mathrm{H}$ n.m.r. signals in the aromatic region for the reaction of tetrabutylammonium azide with $p$-nitrocumyl bromide in ${ }^{2} \mathrm{D}_{6}$-labelled dimethyl sulphoxide (Table 7.12). 


\subsubsection{The Order with Respect to Azide}

Two series of kinetic studies were performed, each at a different initial concentration of tetrabutylammonium azide, but with the initial concentration of $p$ nitrocumyl bromide held constant. The ionic strength of the reaction solution was held essentially constant by the addition of tetrabutylammonium perchlorate. The concentrations of $p$-nitrocumyl bromide at given times, derived from these kinetic studies, are presented in Tables 7.11 and 7.12; the spectra in Figure 7.9 correspond to the data in Table 7.12. For time equal to zero, the concentration of $p$-nitrocumyl bromide in the reaction mixture was set equal to one half the concentration of just the p-nitrocumyl bromide solution on its own.

Rate coefficients for these kinetic experiments were calculated assuming that the reactions were: (1) overall first order with respect to $p$-nitrocumyl bromide $\left(k_{1}\right),(2)$ first order with respect to both $p$-nitrocumyl bromide and tetrabutylammonium azide, that is, second order overall $\left(k_{2}\right)$, and (3) concurrent first and second order $\left(k_{\mathrm{s}}\right.$ and $\left.k_{2}^{\prime}\right)$.

The concurrent first and second order rate constants were calculated using GEAR and GIT. Estimates for $k_{\mathrm{S}}$ and $k_{2}^{\prime}$ were obtained from the initial slopes method and substituted into the computer programmes. The rate constants obtained from GEAR and GIT, with their corresponding data (Tables 7.11 and 7.12), were then substituted into the function for a concurrent first and second order reaction. The resulting values were plotted against time and the new rate constants $\left(k_{2}^{\prime \prime}\right)$ were obtained from the slopes of the graphs. The new bimolecular rate constants $\left(k_{2}^{\prime \prime}\right)$ should act as a verification for the bimolecular rate constants obtained from the GEAR and GIT computer programmes.

For the initial concentration of tetrabutylammonium azide equal to $0.40 \mathrm{~mol} \mathrm{dm}^{-3}$ the plot for an overall first order reaction is a poor fit (Figure 7.11). When the residuals are examined it can be seen that the pattern is a curved one with the ninth point slightly removed from others. The plot for an overall second order reaction is a good fit and this is shown by the correlation coefficient obtained (Figure 7.12). The residual plot has no real significant pattern and the ninth point is slightly removed from others. The plot for a concurrent first and second order reaction is also a good fit and again this is shown by the 
correlation coefficient obtained (Figure 7.13). The residual plot has no real significant pattern and the ninth point is slightly removed from others.

For the initial concentration of tetrabutylammonium azide equal to $0.20 \mathrm{~mol} \mathrm{dm}^{-3}$ the plot for an overall first order reaction is again a poor fit (Figure 7.14). When the residuals are examined it can be seen that the pattern is a curved one with the second point slightly removed from others. The plot for an overall second order reaction is a good fit and this is shown by the correlation coefficient obtained (Figure 7.15). However, the residual plot is not random and has a slight curve to it. The plot for a concurrent first and second order reaction is also a good fit (Figure 7.16). The residual plot in Figure 7.16 has a slight curve to it, in fact, it is very similar to the residual plot for an overall second order reaction.

Tables 7.13 and 7.14 display all the above mentioned rate constants. It is clear from Table 7.13 that there is poor agreement between the two rate constants for an overall first order reaction $\left(k_{1}\right)$. However, there is good agreement between the two rate constants for an overall second order reaction $\left(k_{2}\right)$. There is also good agreement between the two second order rate constants $\left(k_{2}^{\prime}\right.$ and $\left.k_{2}^{\prime \prime}\right)$ for a concurrent first and second order reaction. The first order component due to the elimination of $p$-nitrocumyl bromide $\left(k_{\mathrm{S}}\right)$ has less significance in this case. This is due to two factors; firstly $k_{\mathrm{S}}$ is smaller in this instance than in the lithium case, secondly, the second order rate constants ( $k_{2}^{\prime}$ and $\left.k_{2}^{\prime \prime}\right)$ are larger in this instance than in the lithium case. It is therefore not surprising that there is good agreement between $k_{2}, k_{2}^{\prime}$ and $k_{2}^{\prime \prime}$. 
Table 7.10

Temperature

Solvent

$[\mathrm{RBr}]_{0}$

$\left[\left(\mathrm{C}_{4} \mathrm{H}_{9}\right)_{4} \mathrm{~N}_{4}\right]_{0}$

$0.20 \mathrm{~mol} \mathrm{dm}^{-3}$

$0.00 \mathrm{~mol} \mathrm{dm}^{-3}$

$\left[\left(\mathrm{C}_{4} \mathrm{H}_{9}\right)_{4} \mathrm{NClO}_{4}\right]_{0}$

$0.40 \mathrm{~mol} \mathrm{dm}^{-3}$

\section{Sulphoxide}

$30{ }^{\circ} \mathrm{C}$

$99.9 \% \mathrm{C}_{2} \mathrm{D}_{6} \mathrm{SO}$

\begin{tabular}{|c|c|c|}
\hline Time Range / & Mid-point Time $/ \mathrm{s}$ & {$[\mathrm{RBr}]_{\mathbf{t}} / \mathrm{mol} \mathrm{dm}^{-3}$} \\
\hline 0 & 0 & 0.200 \\
\hline $3592-3608$ & 3600 & 0.172 \\
\hline $7192-7208$ & 7200 & 0.148 \\
\hline $10792-10808$ & 10800 & 0.117 \\
\hline $14392-14408$ & 14400 & 0.103 \\
\hline $17992-18008$ & 18000 & 0.086 \\
\hline $21592-21608$ & 21600 & 0.075 \\
\hline $25192-25208$ & 25200 & 0.059 \\
\hline $28792-28808$ & 28800 & 0.051 \\
\hline $32392-32408$ & 32400 & 0.042 \\
\hline
\end{tabular}

The Elimination of $p$-Nitrocumyl Bromide in Dimethyl

$$
\left(\mathrm{R}=\mathrm{C}_{9} \mathrm{H}_{10} \mathrm{NO}_{2}\right)
$$




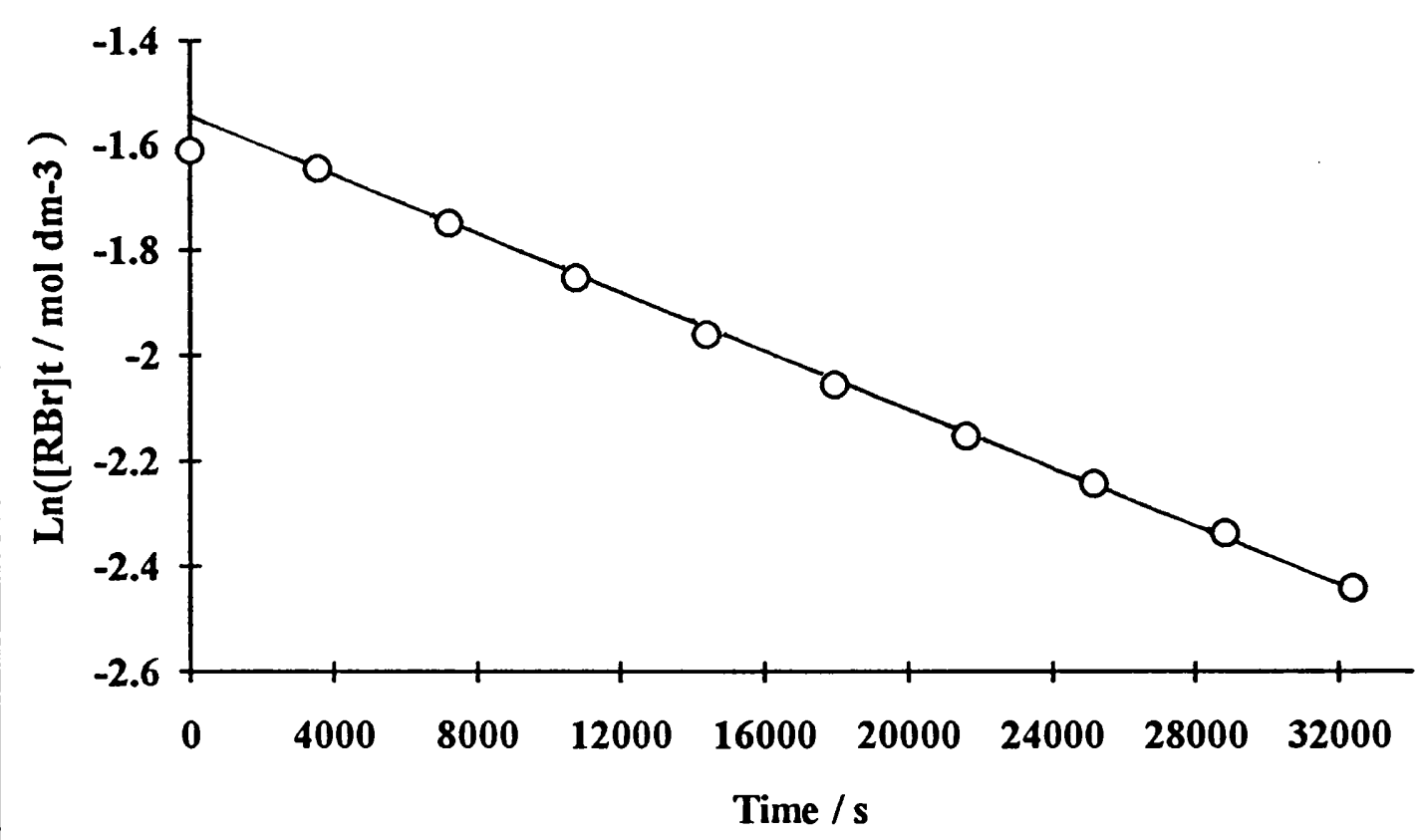

(a)

$$
\begin{aligned}
& k_{1}=2.66 \times 10^{-5} \mathrm{~s}^{-1} \\
& \mathrm{r}=0.9985 \\
& \sigma=1.96 \%
\end{aligned}
$$

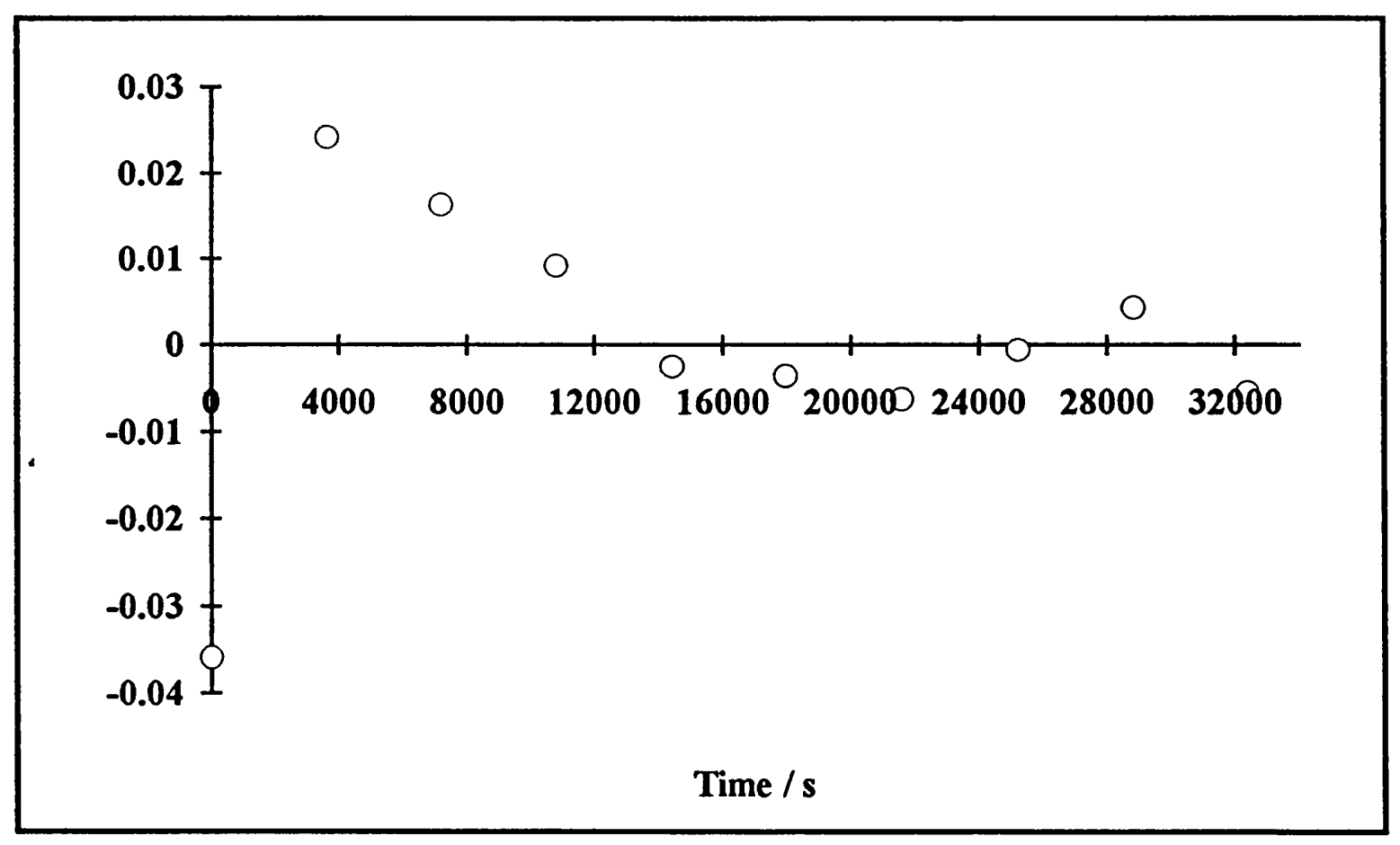

(b)

\section{Figure 7.10}

Plots of (a) $\operatorname{Ln}\left([\mathrm{RBr}]_{\mathrm{t}} / \mathrm{mol} \mathrm{dm}^{-3}\right)$ and (b) Residuals against time / $\mathrm{s}$ for the elimination of $p$-nitrocumyl bromide in dimethyl sulphoxide. 
Table 7.11

Temperature

Solvent

[RBr]0

$\left[\left(\mathrm{C}_{4} \mathrm{H}_{9}\right)_{4} \mathrm{~N}_{4}\right]_{0}$

$\left[\left(\mathrm{C}_{4} \mathrm{H}_{9}\right)_{4} \mathrm{NClO}_{4}\right]_{0}$
The Order with Respect to Azide Part 1

$30^{\circ} \mathrm{C}$

$99.9 \% \mathrm{C}_{2} \mathrm{D}_{6} \mathrm{SO}$

$0.20 \mathrm{~mol} \mathrm{dm}^{-3}$

$\left(\mathrm{R}=\mathrm{C}_{9} \mathrm{H}_{10} \mathrm{NO}_{2}\right)$

$0.40 \mathrm{~mol} \mathrm{dm}^{-3}$

$0.00 \mathrm{~mol} \mathrm{dm}^{-3}$

\begin{tabular}{|c|c|c|}
\hline Time Range / & Mid-point Time $/ \mathrm{s}$ & {$[\mathrm{RBr}]_{\mathrm{t}} / \mathrm{mol} \mathrm{dm}^{-3}$} \\
\hline 0 & 0 & 0.200 \\
\hline $172-188$ & 180 & 0.143 \\
\hline $352-368$ & 360 & 0.100 \\
\hline $532-548$ & 540 & 0.073 \\
\hline $712-728$ & 720 & 0.057 \\
\hline $892-908$ & 900 & 0.042 \\
\hline $1072-1088$ & 1080 & 0.036 \\
\hline $1252-1268$ & 1260 & 0.029 \\
\hline $1432-1448$ & 1440 & 0.027 \\
\hline $1612-1628$ & 1620 & 0.020 \\
\hline
\end{tabular}




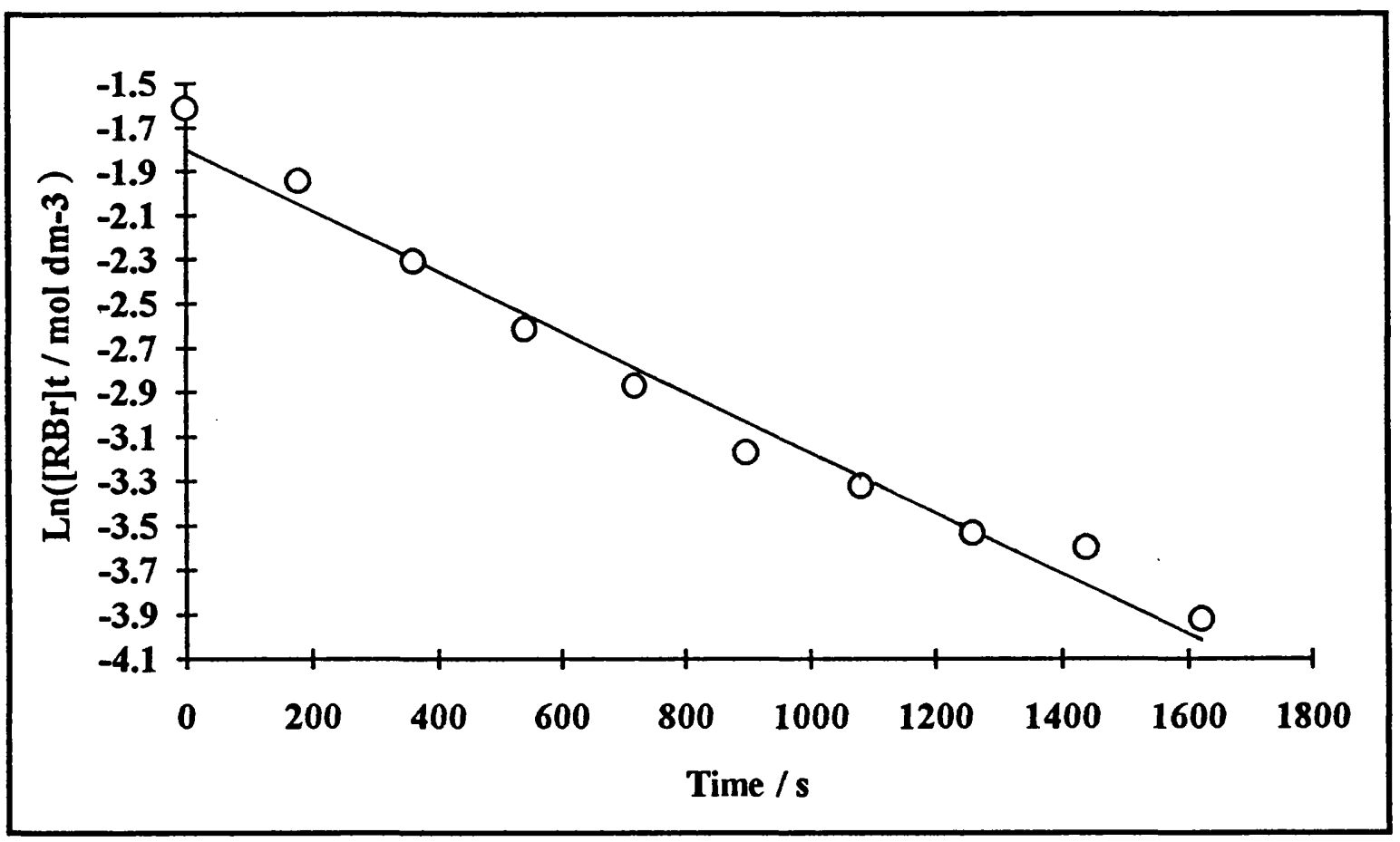

(a)

$$
\begin{aligned}
& k_{1}=1.38 \times 10^{-3} \mathrm{~s}^{-1} \\
& r=0.9890 \\
& \sigma=5.28 \%
\end{aligned}
$$

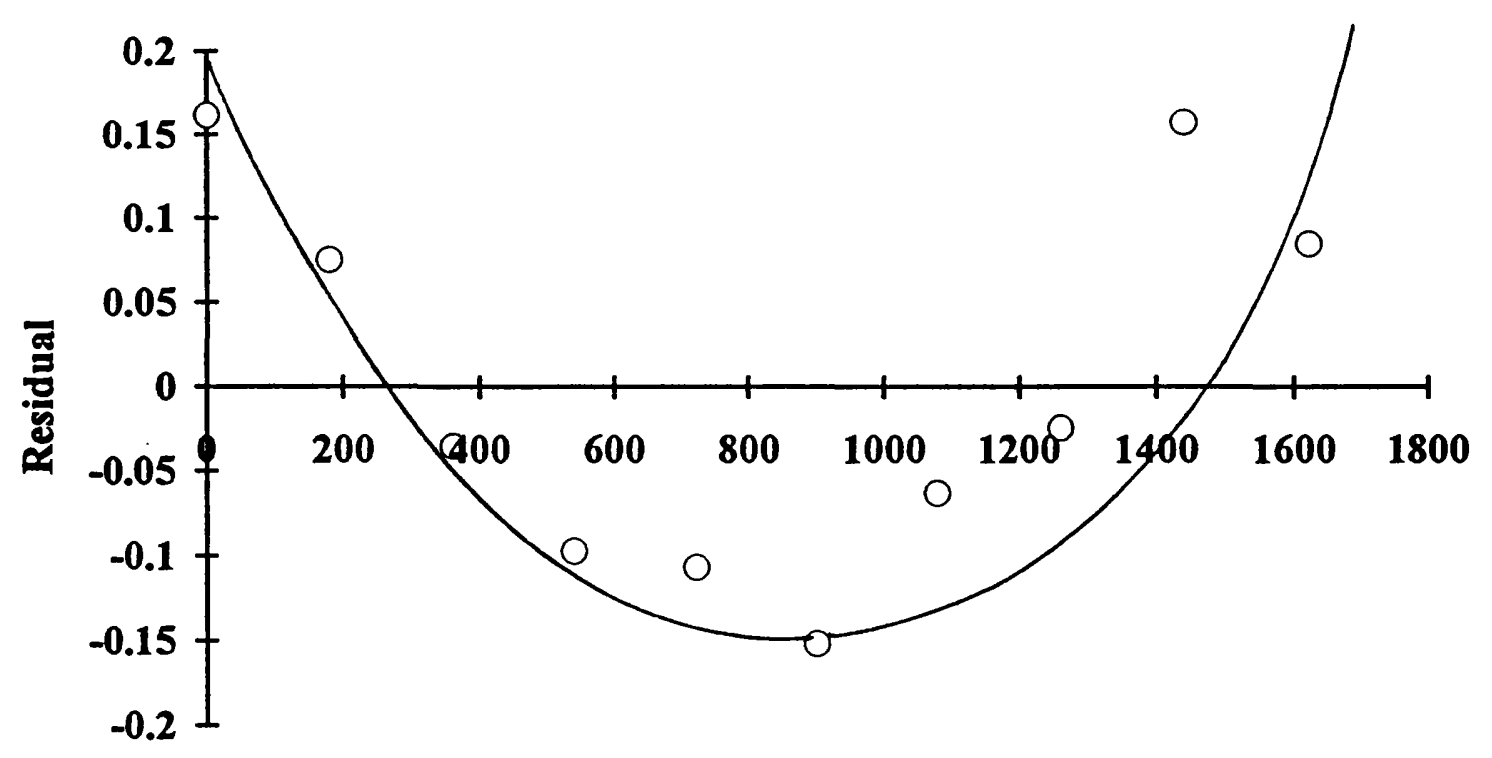

Time / s

(b)

Figure 7.11

Plots of (a) $\mathrm{Ln}\left([\mathrm{RBr}]_{\mathrm{t}} / \mathrm{mol} \mathrm{dm}^{-3}\right)$ and (b) Residuals against time / $\mathrm{s}$ for the reaction of $p$ nitrocumyl bromide with tetrabutylammonium azide (Table 7.11). 


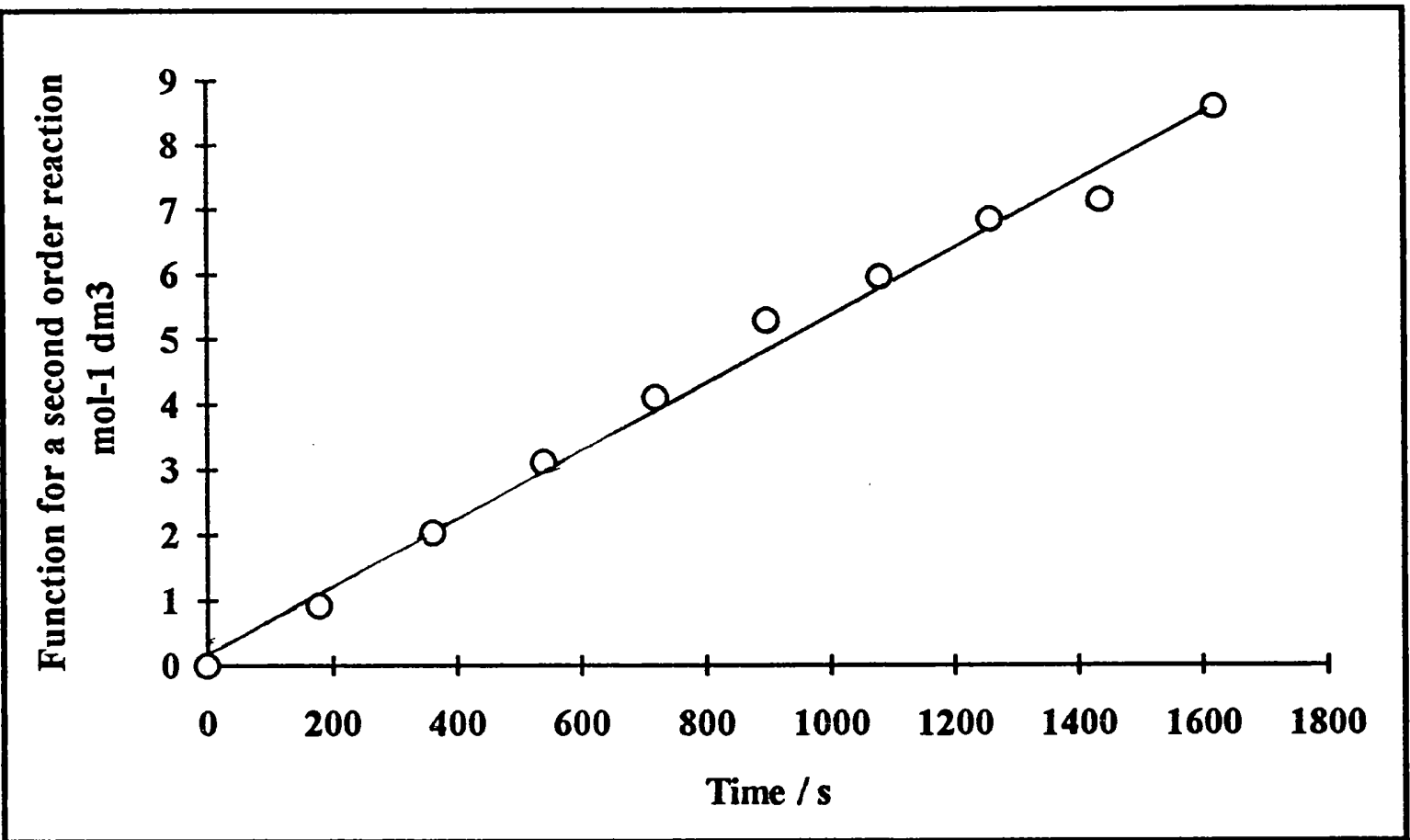

(a)

$$
\begin{aligned}
k_{2}(\mathrm{a} \neq \mathrm{b}) & =5.20 \times 10^{-3} \mathrm{~mol}^{-1} \mathrm{dm}^{3} \mathrm{~s}^{-1} \\
\mathrm{r} & =0.9958 \\
\sigma & =3.25 \%
\end{aligned}
$$

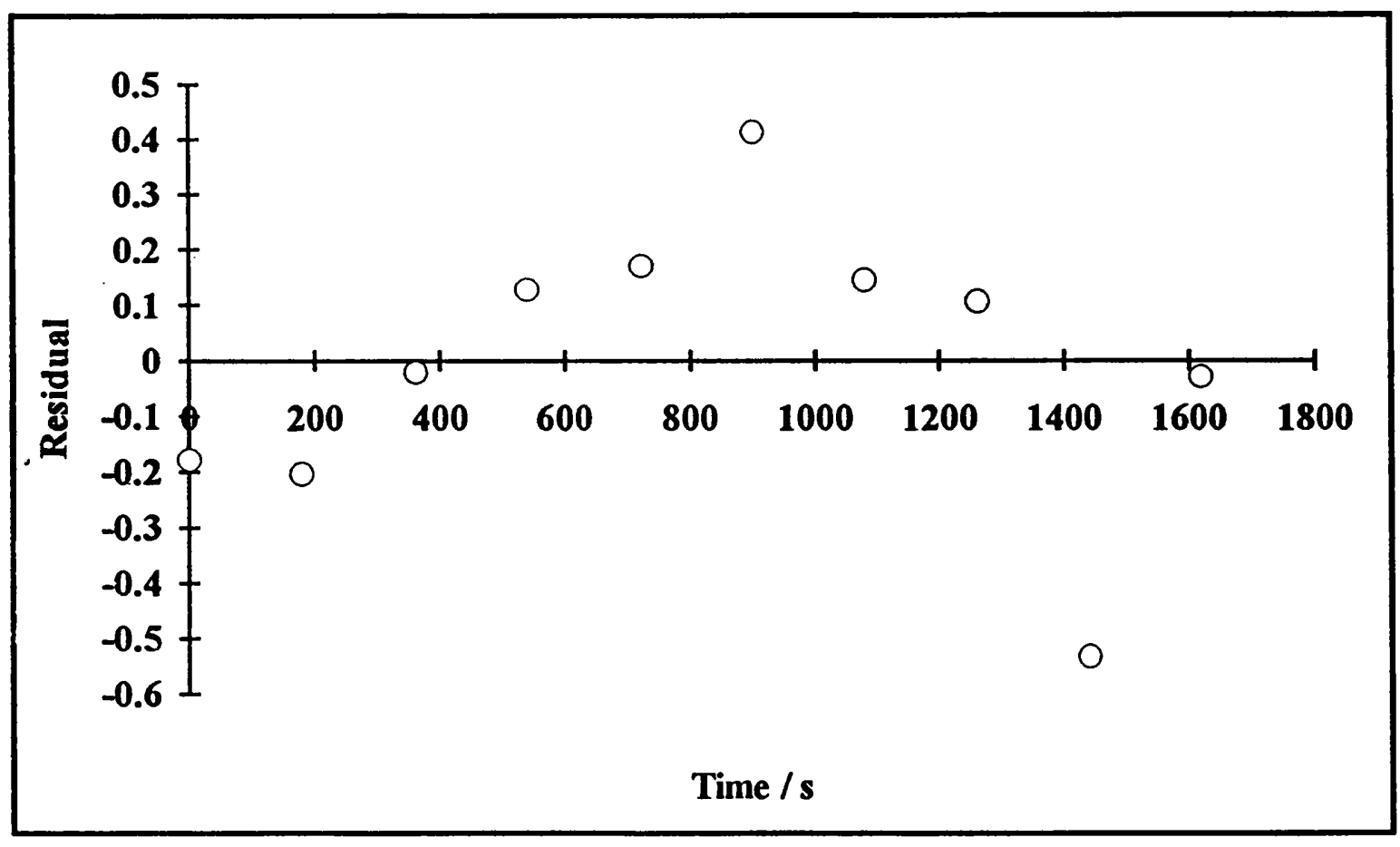

(b)

Figure 7.12

Plots of (a) Function for a second-order reaction $/ \mathrm{mol}^{-1} \mathrm{dm}^{3}$ and (b) Residuals against time / $\mathrm{s}$ for the reaction of $p$-nitrocumyl bromide with tetrabutylammonium azide (Table 7.11). 


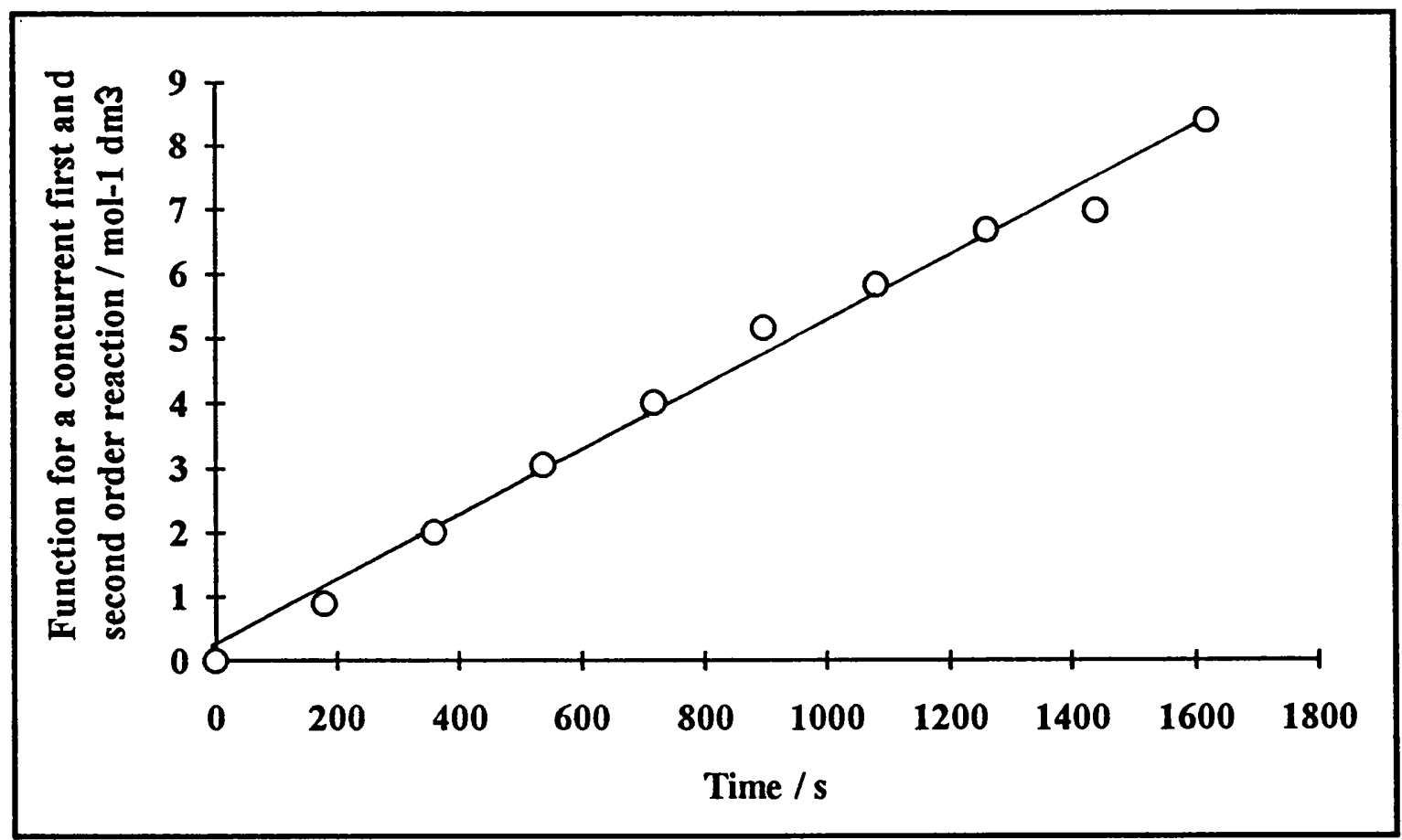

(a)

$$
\begin{aligned}
& k_{2}^{\prime \prime}=5.10 \times 10^{-3} \mathrm{~mol}^{-1} \mathrm{dm}^{3} \mathrm{~s}^{-1} \\
& \mathrm{r}=0.9957 \\
& \sigma=3.27 \%
\end{aligned}
$$

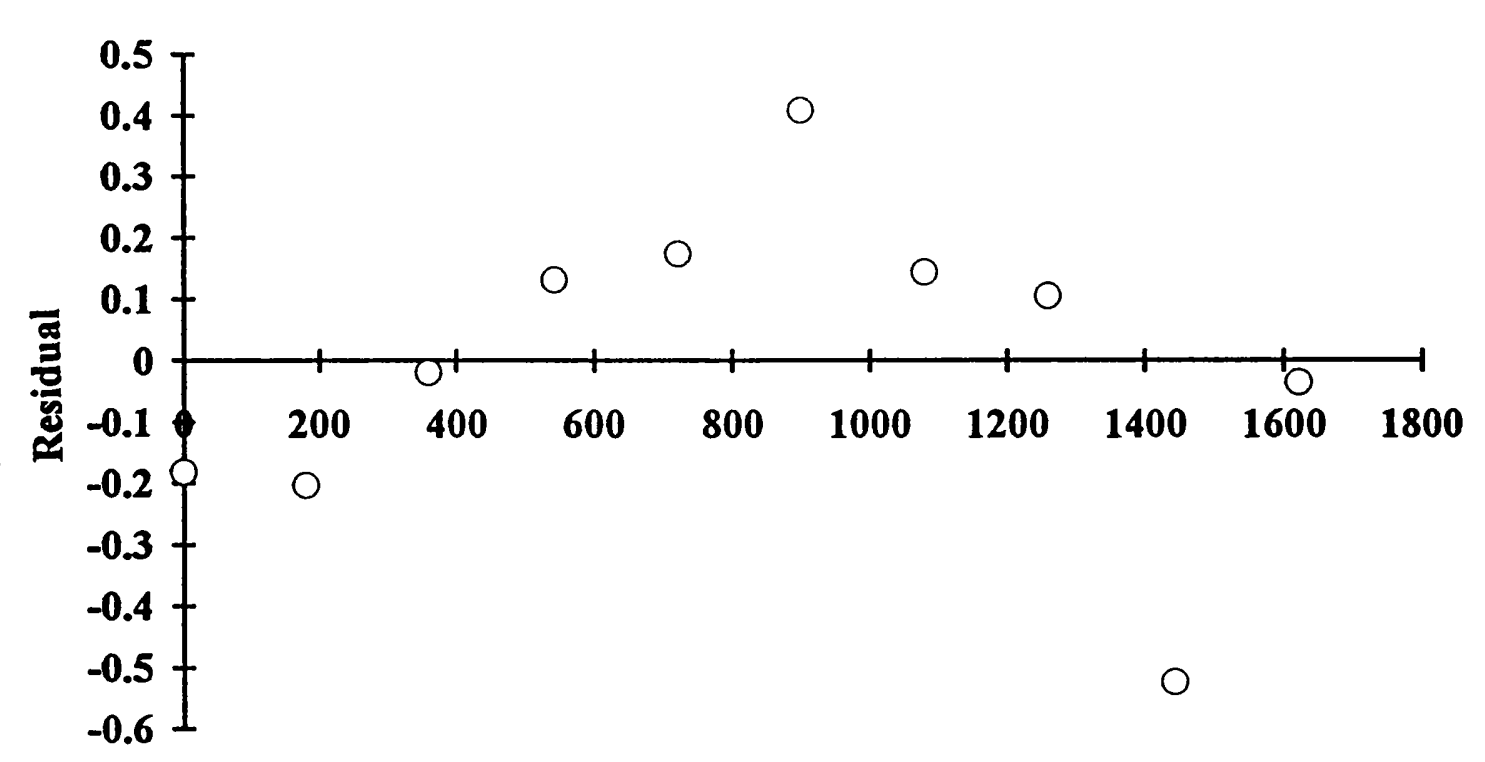

Time / s

(b)

Figure 7.13

Plots of (a) Function for a concurrent first and second order reaction $/ \mathrm{mol}^{-1} \mathrm{dm}^{3}$ and (b) Residuals against time/s for the reaction of $p$-nitrocumyl bromide with tetrabutylammonium azide (Table 7.11). 
Table 7.12

Temperature

Solvent

$[\mathrm{RBr}]_{0}$

$\left[\left(\mathrm{C}_{4} \mathrm{H}_{9}\right)_{4} \mathrm{~N}_{4}\right]_{0}$

$\left[\left(\mathrm{C}_{4} \mathrm{H}_{9}\right)_{4} \mathrm{NClO}_{4}\right]_{0}$

\section{The Order with Respect to Azide Part 2}

$30^{\circ} \mathrm{C}$

$99.9 \% \mathrm{C}_{2} \mathrm{D}_{6} \mathrm{SO}$

$0.20 \mathrm{~mol} \mathrm{dm}^{-3}$

$\left(\mathrm{R}=\mathrm{C}_{9} \mathrm{H}_{10} \mathrm{NO}_{2}\right)$

$0.20 \mathrm{~mol} \mathrm{dm}^{-3}$

$0.20 \mathrm{~mol} \mathrm{dm}^{-3}$

\begin{tabular}{|c|c|c|}
\hline Time Range $/ \mathrm{s}$ & Mid-point Time $/ \mathrm{s}$ & {$[\mathrm{RBr}]_{\mathrm{t}} / \mathrm{mol} \mathrm{dm}^{-3}$} \\
\hline 0 & 0 & 0.200 \\
\hline $262-278$ & 270 & 0.161 \\
\hline $532-548$ & 540 & 0.124 \\
\hline $802-818$ & 810 & 0.102 \\
\hline $1072-1088$ & 1080 & 0.088 \\
\hline $1342-1358$ & 1350 & 0.078 \\
\hline $1612-1628$ & 1620 & 0.069 \\
\hline $1882-1898$ & 1890 & 0.063 \\
\hline $2152-2168$ & 2160 & 0.058 \\
\hline $2422-2438$ & 2430 & 0.054 \\
\hline
\end{tabular}




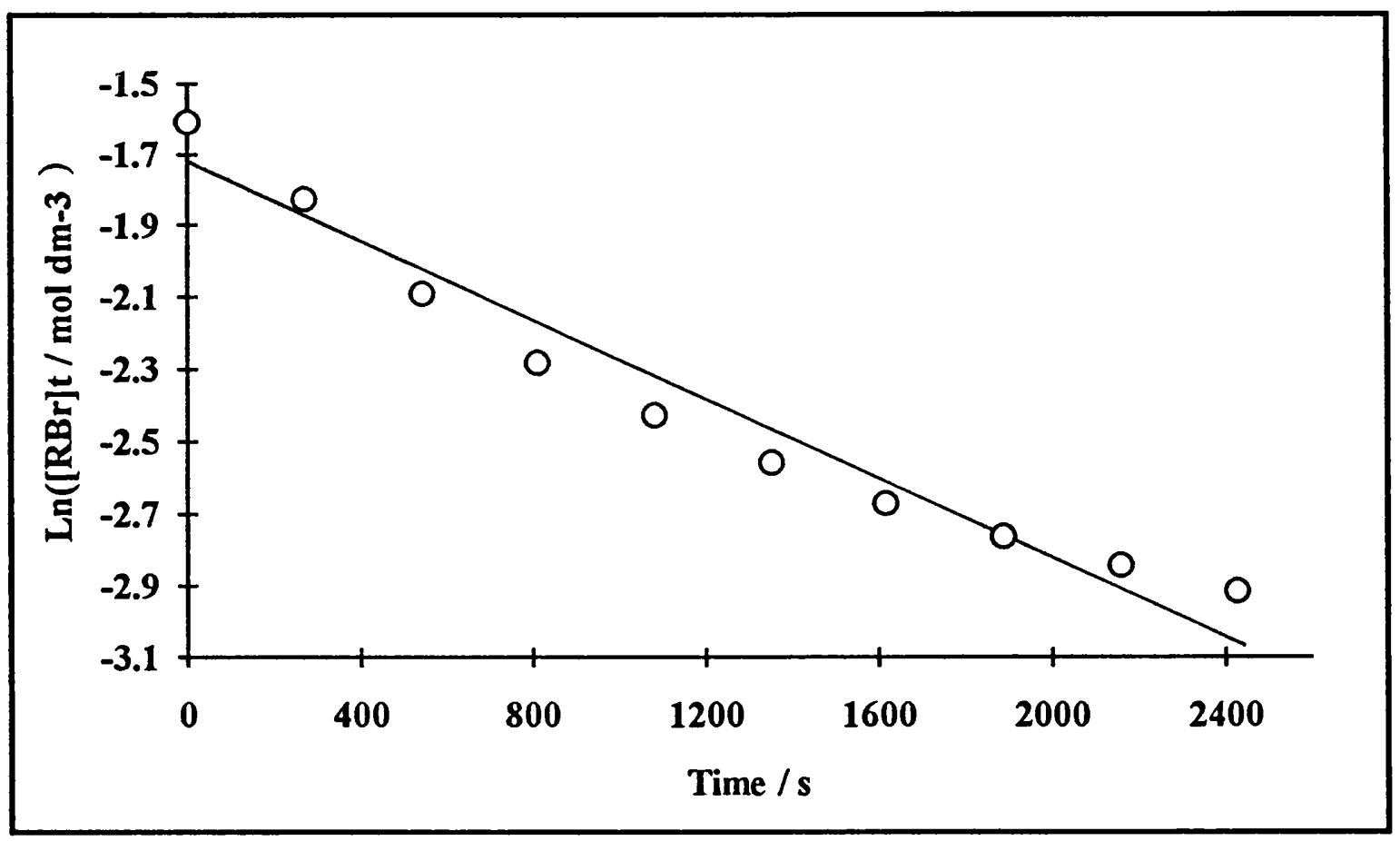

(a)

$$
\begin{aligned}
& k_{1}=5.28 \times 10^{-4} \mathrm{~s}^{-1} \\
& r=0.9776 \\
& \sigma=7.61 \%
\end{aligned}
$$

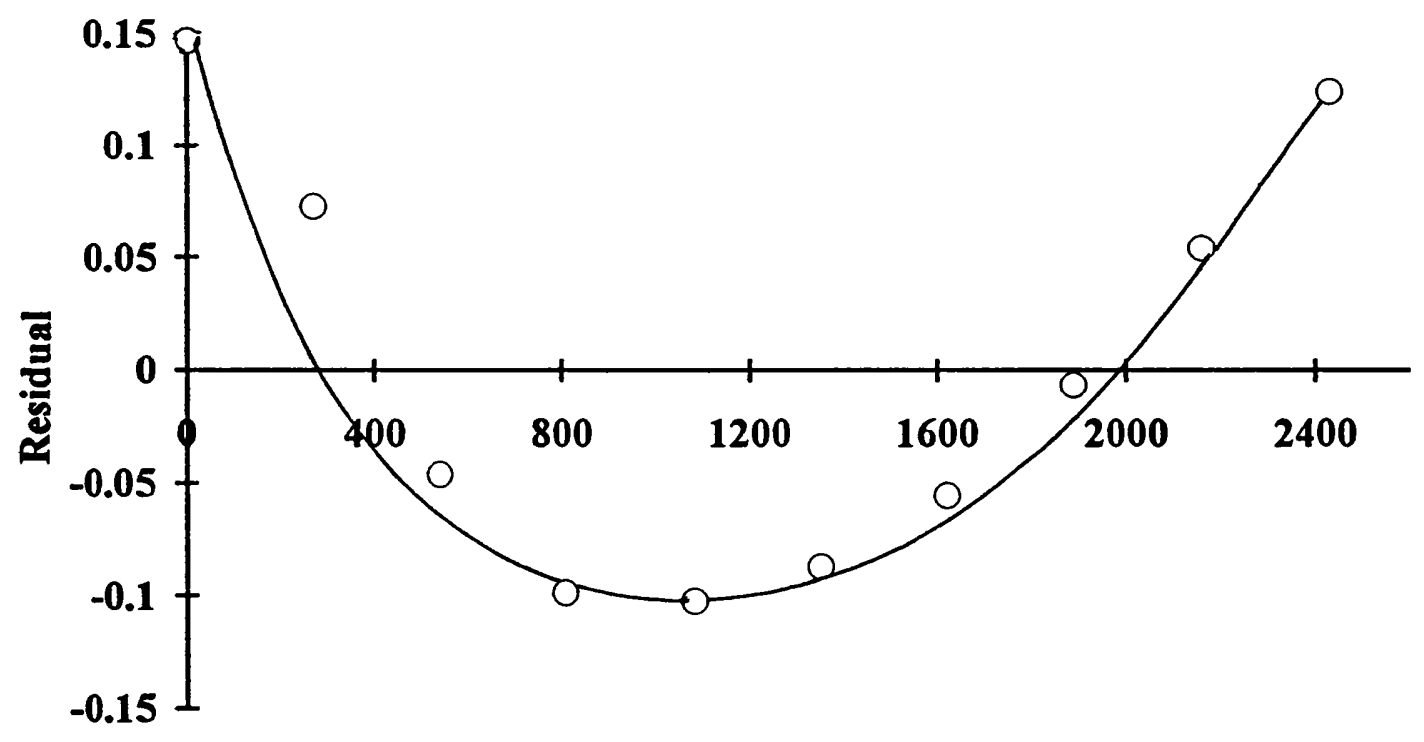

Time / s

(b)

Figure 7.14

Plots of (a) $\mathrm{Ln}\left([\mathrm{RBr}]_{\mathrm{t}} / \mathrm{mol} \mathrm{dm}^{-3}\right)$ and (b) Residuals against time / $\mathrm{s}$ for the reaction of $p$ nitrocumyl bromide with tetrabutylammonium azide (Table 7.12). 


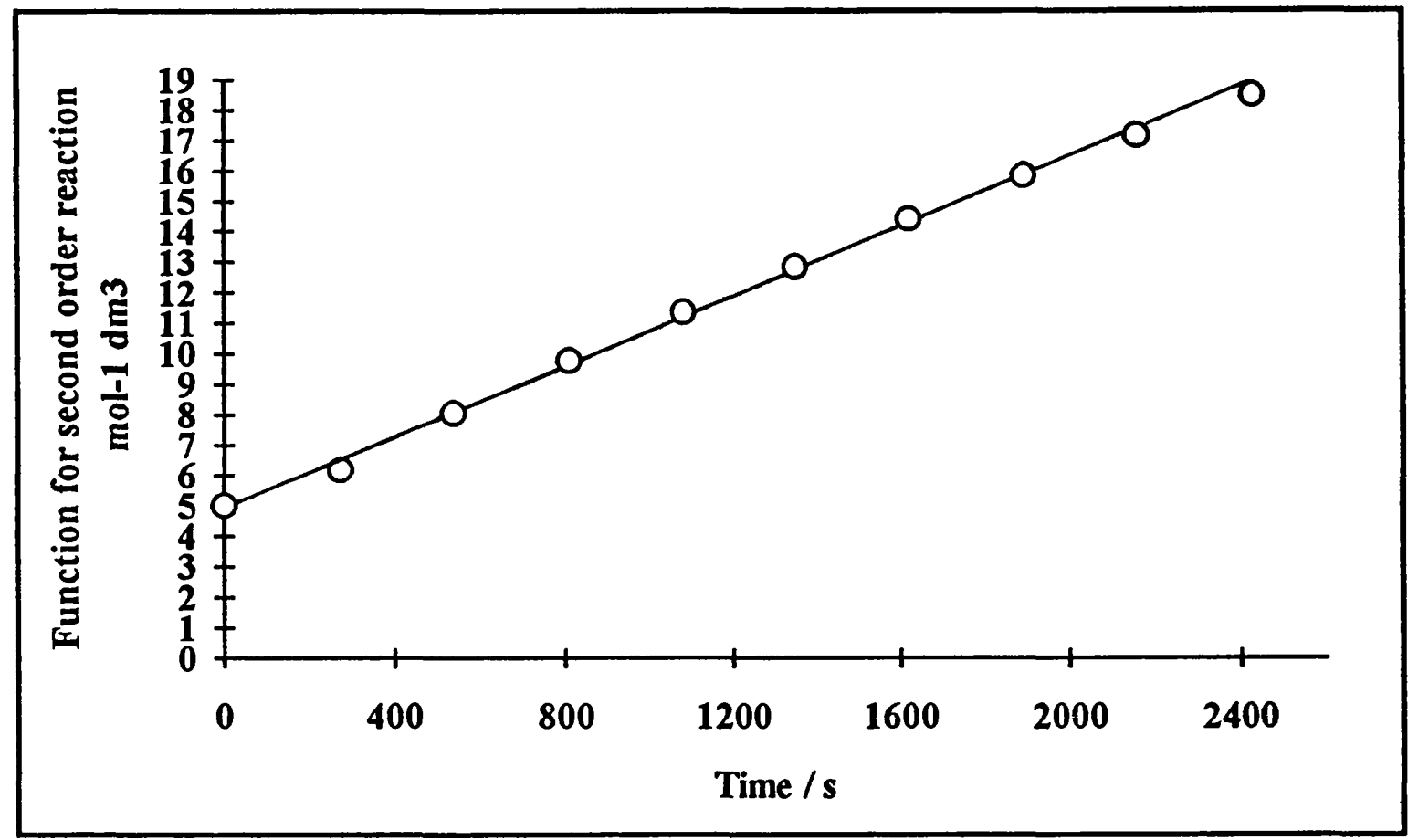

(a)

$$
\begin{aligned}
k_{2}(\mathrm{a}=\mathrm{b}) & =5.66 \times 10^{-3} \mathrm{~mol}^{-1} \mathrm{dm}^{3} \mathrm{~s}^{-1} \\
\mathrm{r} & =0.9990 \\
\sigma & =1.60 \%
\end{aligned}
$$

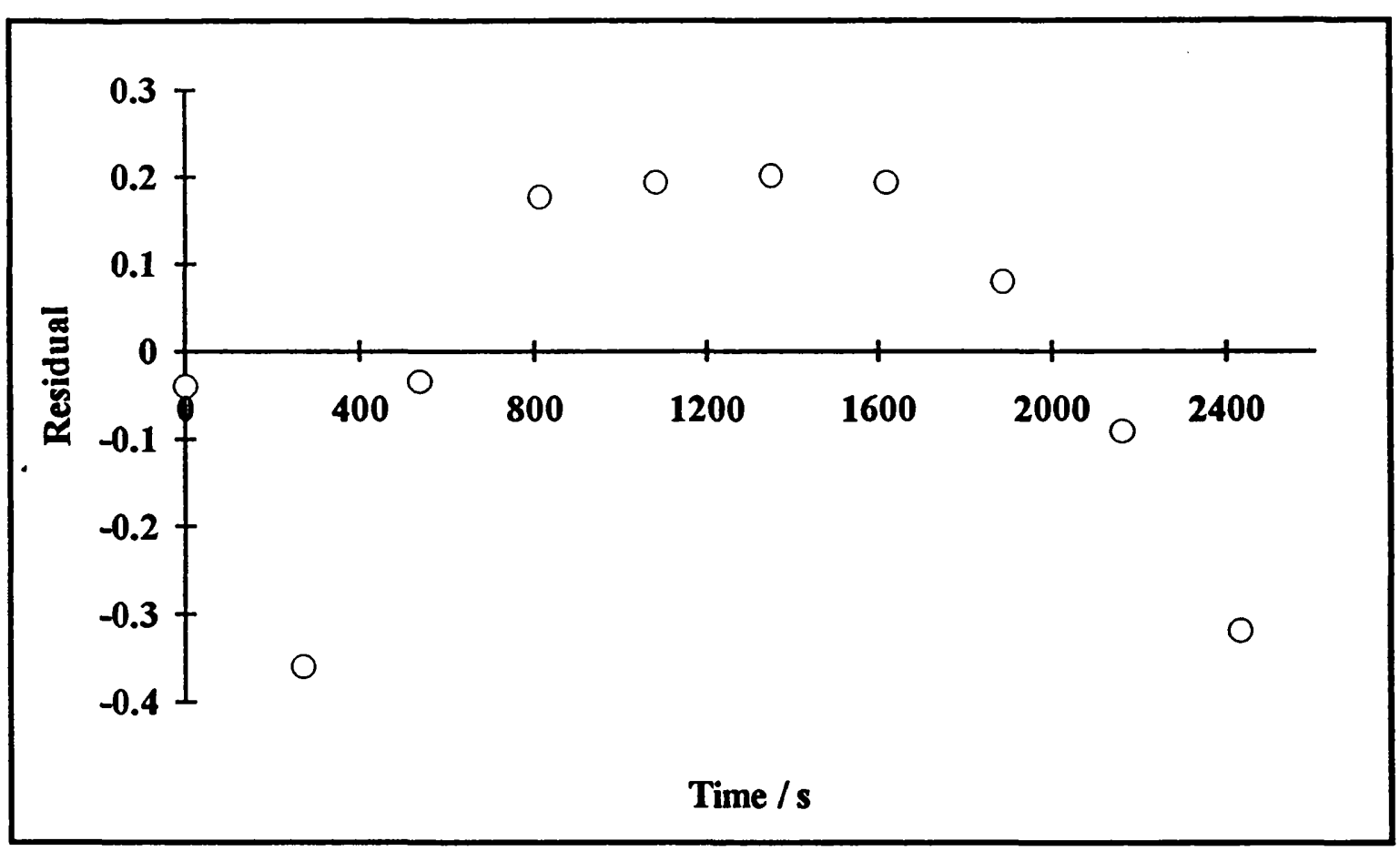

(b)

\section{Figure 7.15}

Plots of (a) Function for a second order reaction $/ \mathrm{mol}^{-1} \mathrm{dm}^{3}$ and (b) Residuals against time / $\mathrm{s}$ for the reaction of $p$-nitrocumyl bromide with tetrabutylammonium azide (Table 7.12). 


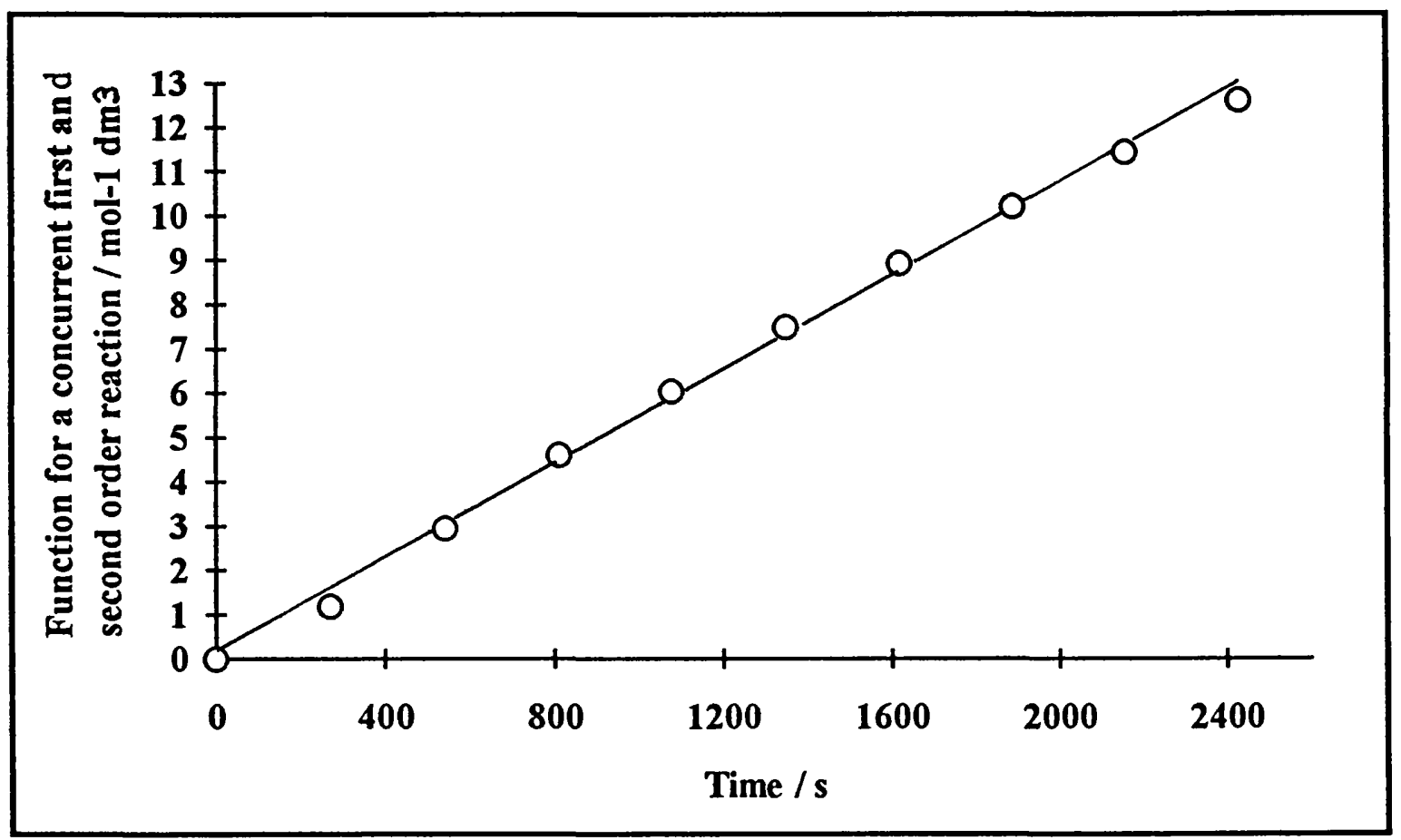

(a)

$$
\begin{aligned}
k_{2}^{\prime \prime} & =5.35 \times 10^{-3} \mathrm{~mol}^{-1} \mathrm{dm}^{3} \mathrm{~s}^{-1} \\
r & =0.9986 \\
\sigma & =1.86 \%
\end{aligned}
$$

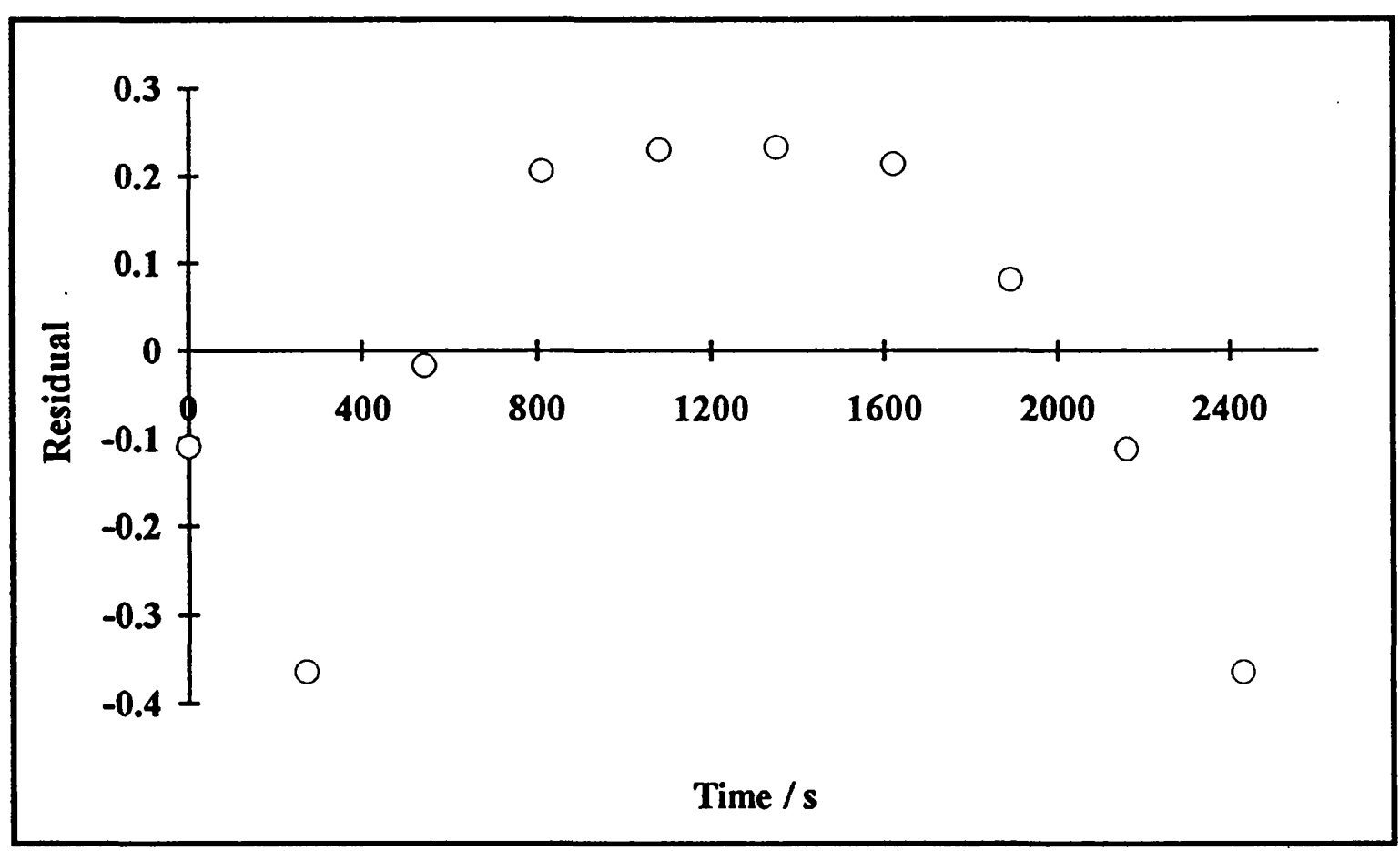

(b)

Figure 7.16

Plots of (a) Function for a concurrent first and second order reaction $/ \mathrm{mol}^{-1} \mathrm{dm}^{3}$ and (b) Residuals against time/s for the reaction of $p$-nitrocumyl bromide with tetrabutylammonium azide (Table 7.12). 


\section{Table 7.13}

A comparison of various rate constants for the reaction of tetrabutylammonium azide with $p$-nitrocumyl bromide in dimethyl sulphoxide.

\begin{tabular}{|c|c|c|c|c|c|c|}
\hline $\begin{array}{c}{[T B A A]_{0} /} \\
\mathrm{mol} \mathrm{dm}^{-3}\end{array}$ & $\begin{array}{c}{[R B r]_{0} /} \\
\mathrm{mol} \mathrm{dm}^{-3}\end{array}$ & $\begin{array}{c}{[T B A P]_{0} /} \\
\mathrm{mol} \mathrm{dm}^{-3}\end{array}$ & $\begin{array}{c}10^{4} k_{1} / \\
\mathbf{s}^{-1}\end{array}$ & $\begin{array}{c}10^{3} k_{2} / \\
\mathrm{dm}^{3} \mathrm{~mol}^{-1} \mathbf{s}^{-1}\end{array}$ & $\begin{array}{c}10^{3} k_{2}^{\prime} / \\
\mathrm{dm}^{3} \mathrm{~mol}^{-1} \mathbf{s}^{-1}\end{array}$ & $\begin{array}{c}10^{5} k_{s} / \\
\mathbf{s}^{-1}\end{array}$ \\
\hline 0.40 & 0.20 & 0.00 & 13.8 & 5.20 & 5.44 & 2.86 \\
\hline 0.20 & 0.20 & 0.20 & 5.28 & 5.66 & 5.50 & 2.71 \\
\hline 0.00 & 0.20 & 0.40 & 0.266 & $-\cdots$ & $-\cdots$ & 2.66 \\
\hline
\end{tabular}

\section{Table 7.14}

A comparison of concurrent bimolecular rate constants derived from GEAR and GIT, $\left(k_{2}^{\prime}\right)$, with the concurrent bimolecular rate constants (Isolated points deleted)* derived from Equation 6.21, $\left(k_{2}^{\prime \prime}{ }^{*}\right)$.

\begin{tabular}{|c|c|c|c|c|c|c|}
\hline $\begin{array}{c}{[T B A A]_{0} /} \\
\mathrm{mol} \mathrm{dm}^{-3}\end{array}$ & $\begin{array}{l}{[R B r]_{0} /} \\
\mathrm{mol} \mathrm{dm}^{-3}\end{array}$ & $\begin{array}{c}{[T B A P]_{0} /} \\
\mathrm{mol} \mathrm{dm}\end{array}$ & $\begin{array}{c}10^{5} k_{s} / \\
s^{-1}\end{array}$ & $\begin{array}{c}10^{3} k_{2}^{\prime} / \\
\mathrm{dm}^{3} \mathrm{~mol}^{-1} \mathrm{~s}^{-1}\end{array}$ & $\begin{array}{l}10^{3} k_{2}{ }_{2}^{*} / \\
\mathrm{dm}^{3} \mathrm{~mol}^{-1} \mathrm{~s}^{-1}\end{array}$ & $\begin{array}{c}\mathbf{r}^{*} \\
\sigma^{*} / \% \\
\end{array}$ \\
\hline 0.40 & 0.20 & 0.00 & 2.86 & 5.45 & 5.23 & $\begin{array}{c}0.9991 \\
0.71\end{array}$ \\
\hline 0.20 & 0.20 & 0.20 & 2.71 & 5.50 & 5.38 & $\begin{array}{c}0.9993 \\
1.53 \\
\end{array}$ \\
\hline 0.00 & 0.20 & 0.40 & 2.66 & --. & -- & - \\
\hline
\end{tabular}

$T B A A=$ Tetrabutylammonium Azide

$T B A P=$ Tetrabutylammonium Perchlorate 


\subsubsection{Conclusion}

The reaction of tetrabutylammonium azide with $p$-nitrocumyl bromide in dimethyl sulphoxide obeys, within experimental error, concurrent first and second order kinetics. If the reaction of the azide anion with $p$-nitrocumyl bromide was catalysed by the lithium cation then one would expect $p$-nitrocumyl bromide to react faster with lithium azide than with tetrabutylammonium azide. Experimentally, $p$-nitrocumyl bromide reacts faster with tetrabutylammonium azide than with lithium azide.

This implies that in dimethyl sulphoxide tetrabutylammonium azide is less associated than lithium azide and that the reaction of the azide anion with $p$-nitrocumyl bromide proceeds via a mechanism that does not involve the Lewis acid-promoted formation of a carbocation. 


\section{CHAPTER 8}

\section{A Kinetic Study of the Reaction of Lithium Azide with $p$-Nitrocumyl Bromide in \\ Dimethyl Sulphoxide}

\section{PART 3}

\subsection{Introduction}

By the method of deduction and elimination, we now have four possible mechanisms left in order to explain the bimolecular kinetic component for the reaction of lithium azide with $p$-nitrocumyl bromide. The four possible mechanisms are an $\mathrm{S}_{\mathrm{N}} 2$ /E2C mechanism, an ion pair mechanism, and two variations of an ipso mechanism. The ion pair mechanism is the only mechanism out of the four that involves carbocation character in its rate determining step. Carbocation character in a rate determining step is usually associated with an isotope effect.

\subsection{Kinetic Isotope Effects}

The replacement of one or more atoms in a reacting system by others of their respective isotopes is one of the most subtle structural perturbations which may be made. Changes in reaction rate which are brought about by isotopic substitution are known as kinetic isotope effects and carry mechanistic information.

\subsubsection{Primary Kinetic Isotope Effects}

A primary kinetic isotope effect results from the breaking of a bond to an isotopic atom in the rate determining step. Replacement of hydrogen by deuterium at a bond which is broken during a reaction may bring around a rate change. The following example 73 illustrates the use of primary kinetic isotope effects in elucidating mechanisms. (Equation 8.1): 
$\mathrm{PhCL}_{2} \mathrm{CH}_{2} \stackrel{+}{\mathrm{N}} \mathrm{Me}_{3} \stackrel{\mathrm{OEt}^{-}}{\longrightarrow} \mathrm{PhCL}=\mathrm{CH}_{2}+\mathrm{NMe}_{3}$

$$
k_{\mathrm{H}} / k_{\mathrm{D}}=4.6
$$

$L=$ a generalised hydrogen isotope (i.e. $\mathrm{H}$ or $\mathrm{D})$

Any mechanism proposed for this reaction must therefore feature fission of the $\beta-C-H$ bond in the activation step consistent with the observation of a primary kinetic isotope effect.

\subsection{2 $\alpha$-Secondary Kinetic Isotope Effects}

Deuterium isotope effects have been found even where it is certain that the C-H bond does not break at all in the reaction. Such effects are called secondary kinetic isotope effects. Secondary isotope effects can be divided into $\alpha$ and $\beta$ effects. An $\alpha$ secondary isotope effect results from a replacement of hydrogen by deuterium at the carbon containing the leaving group. The values of $k_{\mathrm{H}} / k_{\mathrm{D}}$ for $\alpha$ secondary isotope effects range from about 0.90 to $1.30 .73,74$ These effects are also correlated with carbocation character. Nucleophilic substitutions that do not proceed through carbocation intermediates ( $\mathrm{S}_{\mathrm{N}} 2$ reactions) have $\alpha$ isotope effects near unity. ${ }^{75}$ Those that do involve carbocations ( $\mathrm{S}_{\mathrm{N}} 1$ reactions) have higher $\alpha$ isotope effects, which depend on the nature of the leaving group. 76

\subsubsection{B-Secondary Kinetic Isotope Effects}

Kinetic effects are observed not only when the isotopic atom is located at the $\alpha$ carbon, but when it is bonded to more remote centres also. $\beta$-Secondary isotope effects are at least as large as $\alpha$-secondary isotope effects. The interaction between a vacant orbital (e.g. in a carbocation) and a $\beta-\mathrm{C}-\mathrm{H}$ bond is a familiar phenomenon denoted hyperconjugation. Electron density is transferred from the $\beta-\mathrm{C}-\mathrm{H}$ bond to the electron 
deficient centre. This causes weakening of the $\mathrm{C}-\mathrm{H}$ bond and a lowering of its vibrational frequency, C-H being affected more than C-D. Hence, an increase in hyperconjugate interaction with a $\beta$-hydrogen will be accompanied by a small secondary kinetic isotope effect. There is evidence that at least some $\beta$-isotope effects are steric in origin, 77 however, hyperconjugation is the most probable cause in most instances. Whatever the cause, there seems to be a good correlation between $\beta$-secondary isotope effects and the carbocation character in the transition state, and they are thus a useful tool for investigating mechanisms.

\subsubsection{Solvent Isotope Effects}

Kinetic effects carrying mechanistic information may be observed on changing the solvent to one which differs only isotopically, for example from $\mathrm{H}_{2} \mathrm{O}$ to $\mathrm{D}_{2} \mathrm{O}$. There are several possible causes of these rate changes. The solvent may be a reagent and may be covalently bound to the substrate in the rate determining step. Protic solvents may exchange protons with acidic centres in the substrate so that the substrates differ isotopically as do the solvents and this leads to differences in equilibrium constants. The solvation properties of a protic solvent may differ according to isotopic

composition. 78,79 In particular, hydrogen bonding capability changes, and can in turn alter nucleophilicities of reagents, for instance.

\subsection{B-Secondary Deuterium Isotope Effects as Evidence for Carbonium Ion \\ Character}

Both $\alpha$ - and $\beta$-deuterium isotope effects for direct displacements on primary systems are near unity. For ${ }^{131} \mathrm{I}^{-}$exchange on $\mathrm{CH}_{3} \mathrm{I}$ in methanol the $\mathrm{CD}_{3}$ effect is 1.05.80 The $\beta$-secondary deuterium isotope effects 81 for the solvolysis of various substrates are displayed in Table 8.1. The lack of a significant isotope effect for the solvolysis of $\mathrm{EtBr}$ in $\mathrm{H}_{2} \mathrm{O}$ is consistent with direct displacement. The isotope effect 
obtained for $t$ - $\mathrm{BuCl}$ is consistent with a mechanism involving ionisation in the rate controlling process.

Table 8.1

\begin{tabular}{|c|c|c|}
\hline Substrate & Solvent & $\left(\mathrm{k}_{\beta-\mathrm{H}} / \mathrm{k}_{\beta-\mathrm{D}}\right) \operatorname{Per} \mathrm{CD}_{3}$ Group \\
\hline $\mathrm{EtBr}$ & $\mathrm{H}_{2} \mathrm{O}$ & 1.02 \\
\hline$i$-PrOBs & $50 \%$ aqueous EtOH & 1.189 \\
\hline$t-\mathrm{BuCl}$ & $50 \%$ aqueous EtOH & 1.34 \\
\hline
\end{tabular}

Bordwell et al. 82 have shown that $p-\mathrm{C}_{7} \mathrm{H}_{7} \mathrm{SO}_{2} \mathrm{CH}=\mathrm{CHCMe}_{2} \mathrm{Br}$ undergoes second order substitution with lithium azide in dimethyl formamide or methanol. A second order component for the rate was demonstrated also in $60 \%$ aqueous methanol by both kinetic analysis and product analysis. Bordwell believes that this reaction proceeds via an $\mathrm{S}_{\mathrm{N}}$ 2-type ion pair mechanism. 83 Part of Bordwell's evidence for an $\mathrm{S}_{\mathrm{N}}$ 2-type ion pair mechanism comes from an observed $\beta$-secondary deuterium isotope effect of 1.38 per $\mathrm{CD}_{3}$ group for the solvolysis of $p-\mathrm{C}_{7} \mathrm{H}_{7} \mathrm{SO}_{2} \mathrm{CH}=\mathrm{CHCMe}_{2} \mathrm{Br}$ in $60 \%$ aqueous methanol. This effect is markedly higher than that of $i$-PrOBs, in fact, the value is closer to that observed for $t-\mathrm{BuCl}$. Moreover, an effect of 1.22 per $\mathrm{CD}_{3}$ group was observed for the reaction of $p-\mathrm{C}_{7} \mathrm{H}_{7} \mathrm{SO}_{2} \mathrm{CH}=\mathrm{CHCMe}_{2} \mathrm{Br}$ with the azide ion in $60 \%$ aqueous methanol. The effects in methanol and dimethyl formamide were found to be larger than those expected for an $\mathrm{S}_{\mathrm{N}} 2$ mechanism. The effect of 1.22 per $\mathrm{CD}_{3}$ group for this allylic bromide reacting with the azide ion is in the range observed for the hydrolysis of isopropyl substrates. The above evidence suggests that the reaction between $p$ $\mathrm{C}_{7} \mathrm{H}_{7} \mathrm{SO}_{2} \mathrm{CH}=\mathrm{CHCMe}_{2} \mathrm{Br}$ and the azide ion in $60 \%$ aqueous methanol proceeds via a mechanism that involves ionisation as part of the rate controlling step. 


\subsection{A Kinetic Study of the Reaction of Lithium Azide with ${ }_{2}^{2}$-labelled $p$ - Nitrocumyl Bromide in Dimethyl Sulphoxide}

${ }^{2} \mathrm{D}_{6}$-labelled $p$-nitrocumyl bromide was prepared as outlined in section 9.3.12. The $400 \mathrm{MHz}{ }^{1} \mathrm{H}$ n.m.r. spectrum of the prepared ${ }^{2} \mathrm{D}_{6}$-labelled $p$-nitrocumyl bromide $\left(\mathrm{CDCl}_{3}\right)$ can be seen in Figure 8.1. In Figure 8.1, a small signal due to residual protons can be seen at about $2.2 \mathrm{ppm}$. The extent of deuterium labelling can be appreciated when this spectrum is compared to the $400 \mathrm{MHz}{ }^{1} \mathrm{H}$ n.m.r. spectrum of the non-labelled $p$ nitrocumyl bromide $\left(\mathrm{CDCl}_{3}\right.$ ) (Figure 8.2). The $100 \mathrm{MHz}{ }^{13} \mathrm{C}$ n.m.r. spectrum of the prepared ${ }^{2} \mathrm{D}_{6}$-labelled $p$-nitrocumyl bromide $\left(\mathrm{CDCl}_{3}\right)$ can be seen in Figure 8.3. In Figure 8.3 , a multiplet signal due to deuterium coupling can be seen at about $35 \mathrm{ppm}$. A singlet is seen at $35 \mathrm{ppm}$ for the $100 \mathrm{MHz}{ }^{13} \mathrm{C}$ n.m.r. spectrum of the non-labelled p-nitrocumyl bromide $\left(\mathrm{CDCl}_{3}\right)$ (Figure 8.4). The $60 \mathrm{MHz}{ }^{2} \mathrm{H}$ n.m.r. spectrum of ${ }^{2} \mathrm{D}_{6}$-labelled $p$ nitrocumyl bromide $\left(\mathrm{CHCl}_{3}\right)$ can be seen in Figure 8.5. The small peak at $7.24 \mathrm{ppm}$ is a reference signal due to the presence of a modicum of deuterochloroform. It can be seen from Figure 8.5 that there is some deuterium labelling in the ring, however, this will not interfere with our kinetic experiments.

The deuterium labelled substrate will be referred to as ${ }^{2} D_{6}$-labelled $p$-nitrocumyl bromide, however, it is useful to know the ratio of deuterium to hydrogen in the methyl groups. This ratio can be calculated from the integrals of the $400 \mathrm{MHz}{ }^{1} \mathrm{H}$ and $60 \mathrm{MHz}$ ${ }^{2} \mathrm{H}$ n.m.r. spectra of ${ }^{2} \mathrm{D}_{6}$-labelled $p$-nitrocumyl bromide. We can also calculate the ratio of hydrogen to deuterium in the aromatic ring of the labelled $p$-nitrocumyl bromide.

For one molecule of the deuterium labelled $p$-nitrocumyl bromide:

$x=$ average number of deuterium atoms in the methyl groups

$6-x=$ average number of hydrogen atoms in the methyl groups

$y=$ average number of deuterium atoms in the ring

4-y $=$ average number of hydrogen atoms in the ring 


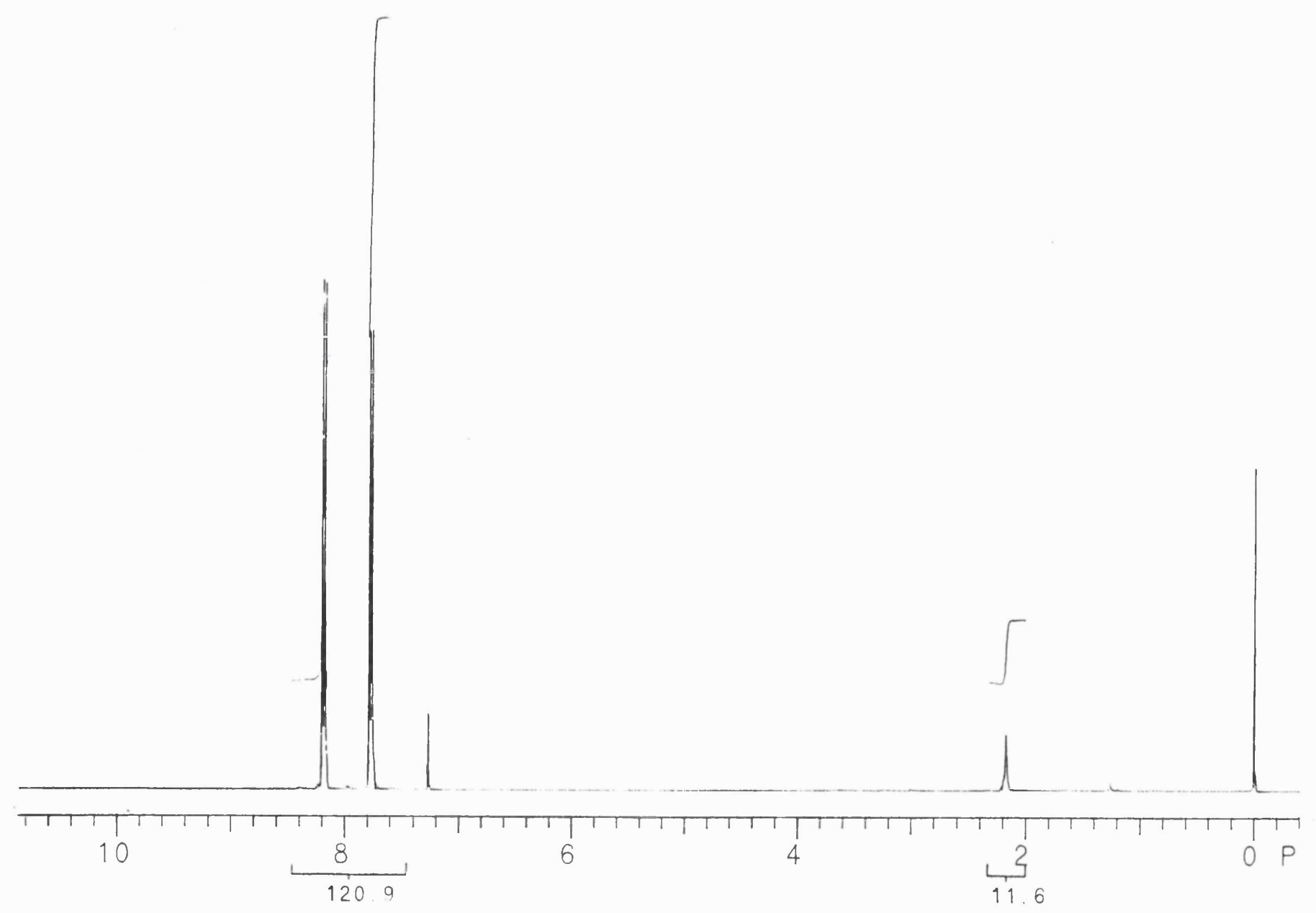

Figure 8.1: The $400 \mathrm{MHz}{ }^{1} \mathrm{H}$ n.m.r. Spectrum of ${ }^{2} \mathrm{D}_{6}$-labelled $p$-nitrocumyl bromide $\left(\mathrm{CDCl}_{3}\right)$ 


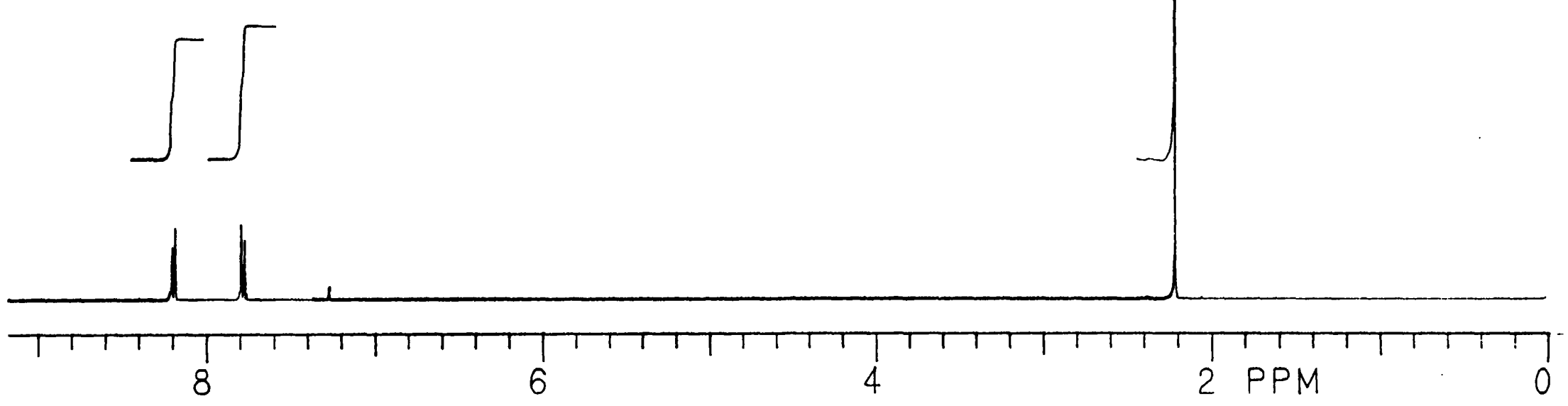

Figure 8.2: The $400 \mathrm{MHz}{ }^{1} \mathrm{H}$ n.m.r. Spectrum of $p$-nitrocumyl bromide $\left(\mathrm{CDCl}_{3}\right)$ 


$$
\Perp
$$




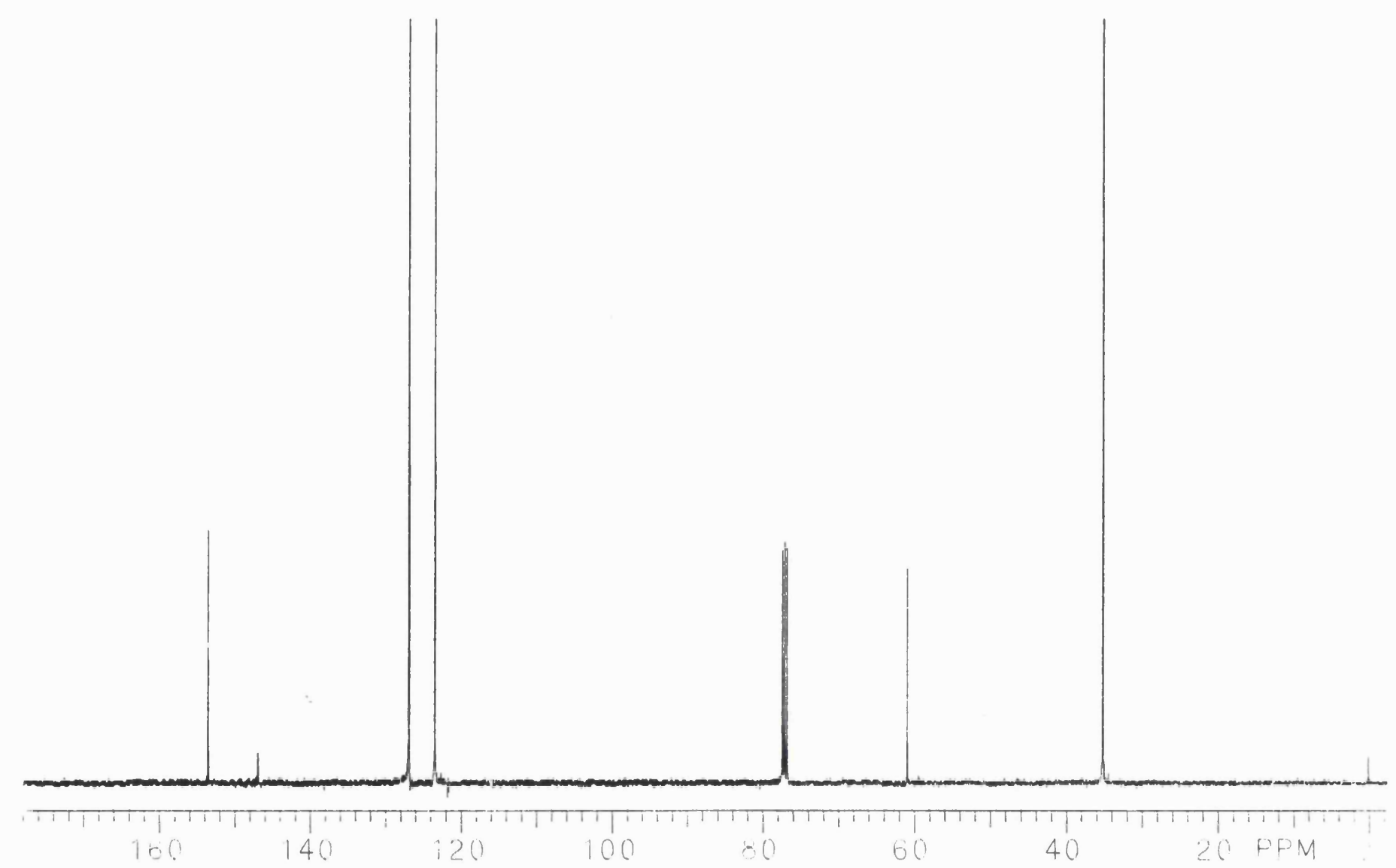

Figure 8.4: The $100 \mathrm{MHz}{ }^{13} \mathrm{C}$ n.m.r. Spectrum of $p$-nitrocumyl bromide $\left(\mathrm{CDCl}_{3}\right)$ 


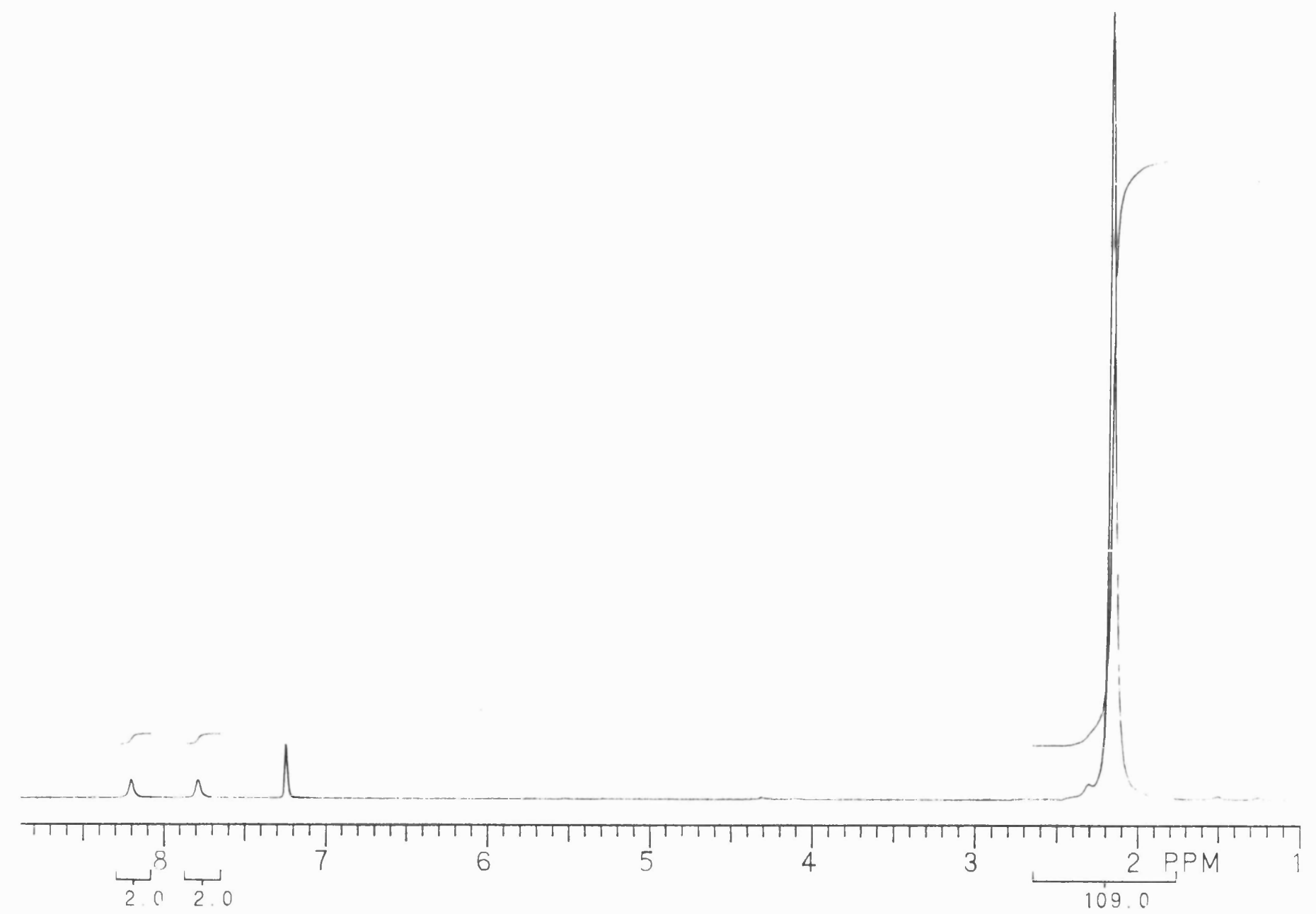

Figure 8.5: The $60 \mathrm{MHz}^{2} \mathrm{H}$ n.m.r. Spectrum of ${ }^{2} \mathrm{D}_{6}$-labelled p-nitrocumyl bromide $\left(\mathrm{CHCl}_{3}\right)$ 
The following ratios can be obtained from the integrals of the $400 \mathrm{MHz}{ }^{1} \mathrm{H}$ and $60 \mathrm{MHz}$ ${ }^{2}$ H n.m.r. spectra of labelled p-nitrocumyl bromide (Equations 8.2 and 8.3):

$$
\begin{array}{r}
\frac{(6-x)}{(4-y)}=\frac{11.6}{120.9} \\
\frac{(x)}{(y)}=\frac{109.0}{4.0}
\end{array}
$$

Solving Equations 8.2 and 8.3 simultaneously, $x=5.636$ and $y=0.208$. The ratio of deuterium to hydrogen in the methyl groups is denoted $\left(\mathrm{D}^{\mathrm{m}}: \mathrm{H}^{\mathrm{m}}\right)$ and the ratio of hydrogen to deuterium in the aromatic ring is denoted $\left(\mathrm{H}^{\mathrm{r}}: \mathrm{D}^{\mathrm{n}}\right)$

$$
\begin{aligned}
& \left(\mathrm{D}^{\mathrm{m}}: \mathrm{H}^{\mathrm{m}}\right)=5.636: 0.364 \text { or } 94 \%: 6 \% \\
& \left(\mathrm{H}^{\mathrm{r}}: \mathrm{D}^{\mathrm{T}}\right)=3.792: 0.208 \text { or } 95 \%: 5 \%
\end{aligned}
$$

The relative molecular mass of the labelled $p$-nitrocumyl bromide can now be calculated (Equation 8.6):

$$
R M M . \text { of } C_{9} H_{(0.364+3.792)} D_{(5.636+0.208)} \mathrm{NO}_{2} \mathrm{Br}=249.95 \mathrm{~g} \mathrm{~mol}^{-1}
$$

In comparison, the relative molecular mass of $\mathrm{C}_{9} \mathrm{H}_{4} \mathrm{D}_{6} \mathrm{NO}_{2} \mathrm{Br}$ is equal to $250.12 \mathrm{~g} \mathrm{~mol}^{-1}$.

When the deuterium labelled $p$-nitrocumyl bromide was treated with lithium azide (two fold excess) in dimethyl sulphoxide and under an argon atmosphere (see 9.4.10), the reaction had a half-life of 10 minutes at $30^{\circ} \mathrm{C}$ (Equation 8.7). The major product formed is the deuterated analogue of the tertiary azido compound produced in Equation 6.1. The minor products seem to have resulted from the elimination of ${ }^{2} \mathrm{D}_{6}$-labelled $p$-nitrocumyl 
bromide in dimethyl sulphoxide. The course of the above reaction was followed by both $60 \mathrm{MHz}^{2} \mathrm{H}$ and $400 \mathrm{MHz}{ }^{1} \mathrm{H}$ n.m.r.<smiles>CC(C)(C)C(C)(Br)c1ccc([N+](=O)[O-])cc1</smiles>

$88 \%$

$4 \%$

$2 \%$

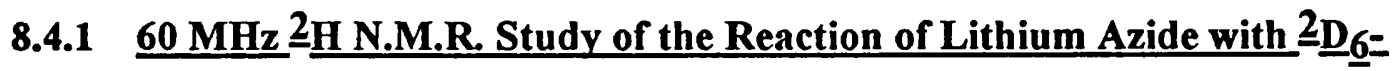 \\ Labelled p-Nitrocumyl Bromide in Dimethyl Sulphoxide}

All of the kinetic studies in this section were followed using a $400 \mathrm{MHz}$ pulsed fourier transform n.m.r. spectrometer. The use of a fourier transform n.m.r. spectrometer for ${ }^{2} \mathrm{H}$ n.m.r. spectroscopy requires the use, as far as possible, of non-deuterated materials, with the obvious exception of the compound being studied; thus non-deuterated solvents were used. Reaction solutions were made up as described in Section 9.5.1. The spectra were recorded at specific time intervals automatically. The temperature of the n.m.r. probe was maintained at a constant value during all of the ${ }^{2} \mathrm{H}$ n.m.r. studies using the spectrometer's variable temperature controller. The temperature of the n.m.r. probe was found to be $(30 \pm 1){ }^{\circ} \mathrm{C}$ for all studies.

The course of the reactions were followed by observing the growth and disappearance of the ${ }^{2} \mathrm{H}$ n.m.r. signals in the aliphatic region (Figure 8.6). The deuterium nucleus possess a quadrupole moment which gives rise to broadening of signals in the ${ }^{2} \mathrm{H}$ n.m.r. spectrum. This broadening effect can be seen in the signals of the spectra in Figure 8.6. The aliphatic signals due to the substrate and alkene are now merged, however, the integrals of the vinylic signals due to the alkene can be used to calculate the integrals for 
its aliphatic signals. Hence, the integrals of the aliphatic signals due to the substrate can be calculated. The concentrations of ${ }^{2} \mathrm{D}_{6}$-labelled $p$-nitrocumyl bromide, at given times, were calculated from the integrals (I) of the deuteron signals as follows (Equation 8.8):

$\mathrm{R}=\mathrm{C}_{9} \mathrm{H}_{4} \mathrm{D}_{6} \mathrm{NO}_{2}$

$[R B r]_{t}=\frac{\left(I\left(R B r+\text { Alkene }^{a}\right)-3 I / 2\left(\text { Alkene }^{\mathrm{V}}\right)\right) \times[R B r]_{0}}{I\left(R B r+\text { Alkene }^{a}\right)+3 I / 2(\text { Alkene })+I\left(\mathrm{RN}_{3}\right)+I(R O H)}$

$\mathrm{a}=$ aliphatic, $\mathrm{v}=$ vinylic

In each kinetic study 10 spectra were accumulated, each consisting of $817.5 \mu \mathrm{s}$ pulses each followed by a two second acquisition time (see 9.5.2). For the purpose of calculating rate coefficients, the time ascribed to each spectrum was the mid-point of the accumulation. 


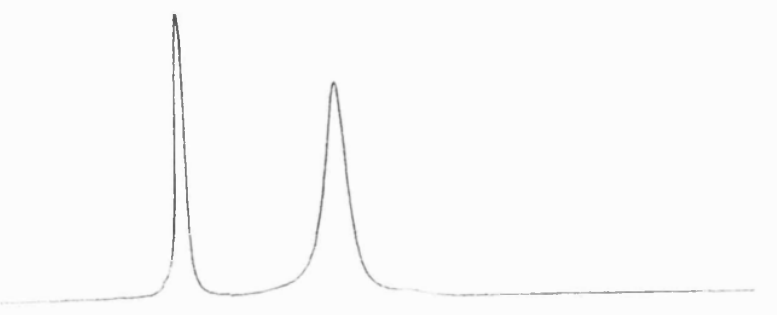

Time $=0 \mathrm{~s}$

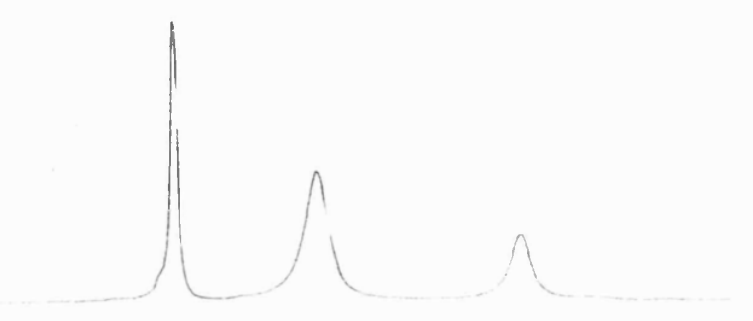

Time $=360 \mathrm{~s}$

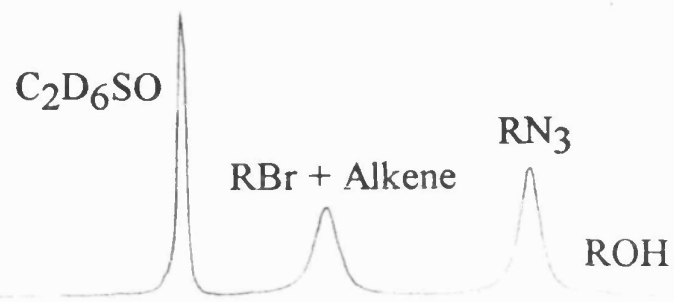

Time $=720 \mathrm{~s}$

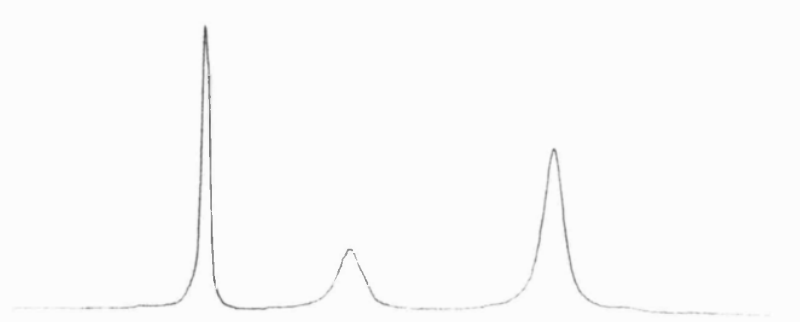

Time $=1080 \mathrm{~s}$

Figure 8.6

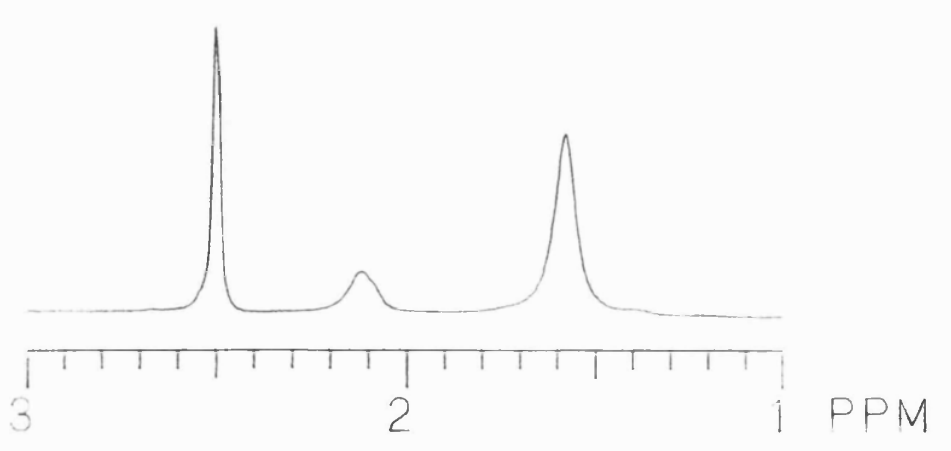

Time $=1440 \mathrm{~s}$

The growth and disappearance of the ${ }^{2} \mathrm{H}$ n.m.r. signals in the aliphatic region for the reaction of lithium azide with ${ }^{2} \mathrm{D}_{6}$-labelled $p$-nitrocumyl bromide in dimethyl sulphoxide (Table 8.3). 


\subsubsection{The Elimination of $\underline{\mathbf{D}}_{\mathbf{6}}$-labelled $p$-Nitrocumyl Bromide in Dimethyl}

\section{Sulphoxide}

One kinetic study was performed; the initial concentration of ${ }^{2} \mathrm{D}_{6}$-labelled $p$ nitrocumyl bromide was set equal to $0.20 \mathrm{~mol} \mathrm{dm}^{-3}$. No lithium azide was added but the ionic strength of the reaction solution was held essentially constant by the addition of lithium perchlorate. The concentrations of ${ }^{2} \mathrm{D}_{6}$-labelled $p$-nitrocumyl bromide at given times, derived from this kinetic study, are presented in Table 8.2. As the solvent is in excess a rate coefficient was calculated assuming that the reaction was first order with respect to ${ }^{2} \mathrm{D}_{6}$-labelled $p$-nitrocumyl bromide.

The elimination rate constant $\left(k_{\mathrm{S}}\right)$ obtained for ${ }^{2} \mathrm{D}_{6}$-labelled $p$-nitrocumyl bromide is much lower than the $k_{\mathrm{S}}$ value obtained for the non-labelled $p$-nitrocumyl bromide (Table 8.3). The measured isotope effect for this elimination is moderate, $k_{\mathrm{S}}(\mathrm{H}) / k_{\mathrm{S}}(\mathrm{D})=2.71$ (corresponding to $k_{\mathrm{S}}(\mathrm{H}) / k_{\mathrm{S}}(\mathrm{D})=1.19$ per deuteron) (Table 8.5). The measured isotope effect suggests that there is a significant amount of internal return (Scheme 8.1):

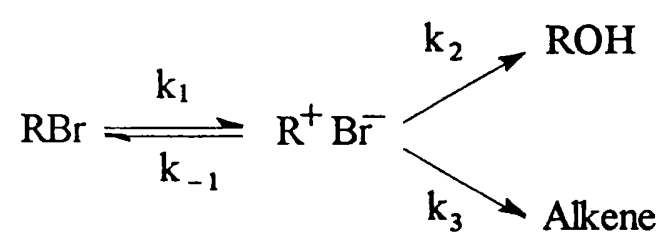

Scheme 8.1

If internal return is negligible, $\left(k_{.1}<<k_{2}, k_{3}\right)$, then ionisation will be rate limiting and the secondary isotope effect for solvolysis is expected to have a small value (1.05 per deuteron $<k_{\mathrm{S}}(\mathrm{H}) / k_{\mathrm{S}}(\mathrm{D})<1.15$ per deuteron). ${ }^{84}$ If on the other hand we have fast internal return, $\left(k_{-1}>k_{2}, k_{3}\right)$, then $k_{2}$ and $k_{3}$ will be rate limiting. The primary isotope effect for the elimination reaction, $k_{3}(H) / k_{3}(D)$, is expected to be large and therefore its contribution to $k_{\mathrm{S}}(\mathrm{H}) / k_{\mathrm{S}}(\mathrm{D})$ will be large. 
Table 8.2

Temperature

Solvent

$[\mathrm{RBr}]_{0}$

$\left[\mathrm{LiN}_{3}\right]_{0}$

$\left[\mathrm{LiClO}_{4}\right]_{0}$
The Elimination of $\underline{2} \underline{\mathbf{D}}_{6}-$-labelled $p$-Nitrocumyl Bromide in

\section{Dimethyl Sulphoxide}

$30^{\circ} \mathrm{C}$

$99.5 \% \mathrm{C}_{2} \mathrm{H}_{6} \mathrm{SO}: 0.5 \% \mathrm{C}_{2} \mathrm{D}_{6} \mathrm{SO}$

$0.20 \mathrm{~mol} \mathrm{dm}^{-3}$

$\left(\mathrm{R}=\mathrm{C}_{9} \mathrm{H}_{4} \mathrm{D}_{6} \mathrm{NO}_{2}\right)$

$0.00 \mathrm{~mol} \mathrm{dm}^{-3}$

$0.40 \mathrm{~mol} \mathrm{dm}^{-3}$

\begin{tabular}{|c|c|c|}
\hline Time Range $/ \mathrm{s}$ & Mid-point Time $/ \mathrm{s}$ & {$[\mathrm{RBr}]_{\mathrm{t}} / \mathrm{mol} \mathrm{dm}^{-3}$} \\
\hline 0 & 0 & 0.200 \\
\hline $3592-3608$ & 3600 & 0.193 \\
\hline $7192-7208$ & 7200 & 0.171 \\
\hline $10792-10808$ & 10800 & 0.168 \\
\hline $14392-14408$ & 14400 & 0.157 \\
\hline $17992-18008$ & 18000 & 0.146 \\
\hline $21592-21608$ & 21600 & 0.136 \\
\hline $25192-25208$ & 25200 & 0.128 \\
\hline $28792-28808$ & 28800 & 0.121 \\
\hline $32392-32408$ & 32400 & 0.113 \\
\hline
\end{tabular}


The experimental value of $k_{\mathrm{S}}(\mathrm{H}) / k_{\mathrm{S}}(\mathrm{D})=1.19$ per deuteron suggests ionisation is not completely free of internal return since the measured isotope effect is larger than the maximum secondary kinetic deuterium isotope effect for a $\mathrm{CD}_{3}$ group, which has been estimated at 1.52 (corresponding to $k(\mathrm{H}) / k(\mathrm{D})=1.15$ per deuteron). 84

This isotope effect is calculated on the premise that there is no solvent isotope effect. This is a fairly safe premise, however, a solvent isotope effect may arise from protonation of dimethyl sulphoxide. As hydrogen bromide is formed there is a possibility that the solvent may be protonated.

\subsubsection{The Order with Respect to Azide}

One kinetic study was performed; the initial concentrations of ${ }^{2} \mathrm{D}_{6}$-labelled $p$ nitrocumyl bromide and lithium azide were set equal to $0.20 \mathrm{~mol} \mathrm{dm}^{-3}$ and $0.40 \mathrm{~mol} \mathrm{dm}^{-3}$ respectively. The concentrations of the labelled p-nitrocumyl bromide at given times, derived from this kinetic study, are presented in Table 8.3; the spectra in Figure 8.6 correspond to the data in Table 8.3. For time equal to zero, the concentration of labelled $p$-nitrocumyl bromide in the reaction mixture was set equal to one half the concentration of just the labelled $p$-nitrocumyl bromide solution on its own.

Rate coefficients for this kinetic experiment were calculated assuming that the reaction was: (1) overall first order with respect to $p$-nitrocumyl bromide $\left(k_{1}\right),(2)$ first order with respect to both $p$-nitrocumyl bromide and lithium azide, that is, second order overall $\left(k_{2}\right)$, and (3) concurrent first and second order $\left(k_{\mathrm{s}}\right.$ and $\left.k_{2}^{\prime}\right)$. The concurrent first and second order rate constants were calculated using GEAR and GIT. The rate constants obtained from GEAR and GIT, with their corresponding data (Table 8.3), were then substituted into the function for a concurrent first and second order reaction. The resulting values were plotted against time and the new rate constants $\left(k_{2}^{\prime \prime}\right)$ were obtained from the slopes of the graphs.

The concurrent second order rate constant $\left(k_{2}^{\prime}\right)$ obtained for ${ }^{2} \mathrm{D}_{6}$-labelled $p$ nitrocumyl bromide is not significantly different to the $k_{2}^{\prime}$ value obtained for the nonlabelled p-nitrocumyl bromide (Table 8.5). 
Table 8.3

Temperature

Solvent

$[\mathrm{RBr}]_{0}$

$\left[\mathrm{LiN}_{3}\right]_{0}$

$\left[\mathrm{LiClO}_{4}\right]_{0}$
The Order with Respect to Azide

$30^{\circ} \mathrm{C}$

$99.5 \% \mathrm{C}_{2} \mathrm{H}_{6} \mathrm{SO}: 0.5 \% \mathrm{C}_{2} \mathrm{D}_{6} \mathrm{SO}$

$0.20 \mathrm{~mol} \mathrm{dm}^{-3}$

$\left(\mathrm{R}=\mathrm{C}_{9} \mathrm{H}_{4} \mathrm{D}_{6} \mathrm{NO}_{2}\right)$

$0.40 \mathrm{~mol} \mathrm{dm}^{-3}$

$0.00 \mathrm{~mol} \mathrm{dm}^{-3}$

\begin{tabular}{|c|c|c|}
\hline Time Range $/ \mathrm{s}$ & Mid-point Time $/ \mathrm{s}$ & {$[\mathrm{RBr}]_{\mathrm{t}} / \mathrm{mol} \mathrm{dm}^{-3}$} \\
\hline 0 & 0 & 0.200 \\
\hline $172-188$ & 180 & 0.169 \\
\hline $352-368$ & 360 & 0.130 \\
\hline $532-548$ & 540 & 0.102 \\
\hline $712-728$ & 720 & 0.082 \\
\hline $892-908$ & 900 & 0.068 \\
\hline $1072-1088$ & 1080 & 0.056 \\
\hline $1252-1268$ & 1260 & 0.048 \\
\hline $1432-1448$ & 1440 & 0.041 \\
\hline $1612-1628$ & 1620 & 0.035 \\
\hline
\end{tabular}




\section{Table 8.4}

A comparison of various rate constants for the reaction of lithium azide with ${ }^{2} \mathrm{D}_{6}$-labelled (D) and non-labelled $(\mathrm{H})$ p-nitrocumyl bromide in dimethyl sulphoxide.

\begin{tabular}{|c|c|c|c|c|c|c|}
\hline $\begin{array}{c}{\left[\mathrm{LiN}_{3}\right]_{0}} \\
/ \mathrm{mol} \mathrm{dm}^{-3}\end{array}$ & $\begin{array}{c}{[R B r]_{0}} \\
/ \mathrm{mol} \mathrm{dm}^{-3}\end{array}$ & $\begin{array}{c}{\left[\mathrm{LiClO}_{4}\right]_{0}} \\
/ \mathrm{mol} \mathrm{dm}^{-3}\end{array}$ & $\begin{array}{c}10^{4} k_{1} / \\
\mathbf{s}^{-1}\end{array}$ & $\begin{array}{c}10^{3} k_{2} / \\
\mathrm{dm}^{3} \mathrm{mor}^{-1} \mathbf{s}^{-1}\end{array}$ & $\begin{array}{c}10^{3} k_{2}^{\prime} / \\
\mathrm{dm}^{\mathbf{3}} \mathrm{mol}^{-1} \mathbf{s}^{-1}\end{array}$ & $\begin{array}{c}10^{5} \boldsymbol{k}_{\mathbf{s}} / \\
\mathbf{s}^{-1}\end{array}$ \\
\hline 0.40 & $0.20^{\mathrm{D}}$ & 0.00 & 10.9 & 3.82 & 3.67 & 1.84 \\
\hline 0.40 & $0.20^{\mathrm{H}}$ & 0.00 & 11.1 & 3.87 & 3.48 & 4.86 \\
\hline 0.00 & $0.20^{\mathrm{D}}$ & 0.40 & 0.178 & $-\cdots$ & $-\cdots$ & 1.78 \\
\hline 0.00 & $0.20^{\mathrm{H}}$ & 0.40 & 0.483 & --- & $-\cdots$ & 4.83 \\
\hline
\end{tabular}

\section{Table 8.5}

A comparison of concurrent bimolecular rate constants derived from GEAR and GIT, $\left(k_{2}^{\prime}\right)$, with the concurrent bimolecular rate constants (Isolated points deleted) ${ }^{*}$ derived from Equation 6.21, $\left(k_{2}^{\prime \prime}{ }^{*}\right)$.

\begin{tabular}{|c|c|c|c|c|c|c|}
\hline $\begin{array}{c}{\left[\text { LiN }_{3}\right]_{0}} \\
/ \mathrm{mol} \mathrm{dm}^{-3}\end{array}$ & $\begin{array}{c}{[\mathrm{RBr}]_{0}} \\
/ \mathrm{mol} \mathrm{dm}^{-3}\end{array}$ & $\begin{array}{c}{\left[\mathrm{LiClO}_{4}\right]_{0}} \\
/ \mathrm{mol} \mathrm{dm}^{-3}\end{array}$ & $\begin{array}{c}10^{5} k_{\mathrm{s}} / \\
\mathrm{s}^{-1}\end{array}$ & $\begin{array}{c}10^{3} k_{2}^{\prime} / \\
\mathrm{dm}^{3} \mathrm{~mol}^{-1} \mathrm{~s}^{-1}\end{array}$ & $\begin{array}{c}10^{3} \mathrm{k}_{2}^{*} / \\
\mathrm{dm}^{3} \mathrm{~mol}^{-1} \mathrm{~s}^{-1}\end{array}$ & $\begin{array}{c}\mathbf{r}^{*} \\
\sigma^{*} / \%\end{array}$ \\
\hline 0.40 & $0.20^{\mathrm{D}}$ & 0.00 & 1.84 & 3.67 & 3.71 & $\begin{array}{c}0.9995 \\
1.18\end{array}$ \\
\hline 0.40 & $0.20^{\mathrm{H}}$ & 0.00 & 4.86 & 3.48 & 3.77 & $\begin{array}{c}0.9998 \\
0.71\end{array}$ \\
\hline
\end{tabular}

\section{Table 8.6}

Isotope effects for: (1) the elimination of $p$-nitrocumyl bromide in dimethyl sulphoxide, $k_{\mathrm{S}}(\mathrm{H}) / k_{\mathrm{S}}(\mathrm{D})$, and (2) the second order component in the reaction of $p$-nitrocumyl bromide with lithium azide in dimethyl sulphoxide, $k_{2}^{\prime}(\mathrm{H}) / k_{2}^{\prime}(\mathrm{D})$.

\begin{tabular}{|c|c|c|c|c|c|}
\hline$k_{s}(\mathrm{H}) / k_{\mathrm{S}}(\mathrm{D})$ & $\begin{array}{c}k_{\mathrm{s}}(\mathrm{H}) / \boldsymbol{k}_{\mathrm{S}}(\mathrm{D}) \\
\text { per deuteron }\end{array}$ & $\begin{array}{c}k_{\mathrm{s}}(\mathrm{H}) / \boldsymbol{k}_{\mathrm{S}}(\mathrm{D}) \\
\text { per } \mathrm{CD}_{3}\end{array}$ & $\boldsymbol{k}_{2}^{\prime}(\mathrm{H}) / \boldsymbol{k}_{2}^{\prime}(\mathrm{D})$ & $\begin{array}{c}\boldsymbol{k}_{2}^{\prime}(\mathrm{H}) / \boldsymbol{k}_{2}^{\prime}(\mathrm{D}) \\
\text { per deuteron }\end{array}$ & $\begin{array}{c}\boldsymbol{k}_{2}^{\prime}(\mathrm{H}) / \boldsymbol{k}_{2}^{\prime}(\mathrm{D}) \\
\text { per } \mathrm{CD}_{3}\end{array}$ \\
\hline 2.71 & 1.19 & 1.70 & 0.95 & 0.99 & 0.97 \\
\hline
\end{tabular}


The measured isotope effect for this component is close to unity, $k_{2}^{\prime}(\mathrm{H}) / k_{2}^{\prime}(\mathrm{D})=0.95$ (corresponding to $k_{2}^{\prime}(\mathrm{H}) / k_{2}^{\prime}(\mathrm{D})=0.99$ per deuteron) (Table 8.6). The lack of an isotope effect is indicative of a mechanism involving direct displacement. This isotope effect is calculated on the premise that there is no solvent isotope effect.

\subsection{4 $\underline{400 \mathrm{MHz}} \underline{\mathbf{1}}$ N.M.R. Study of the Reaction of Lithium Azide with $\underline{2} \underline{\mathbf{D}} \underline{\mathbf{6}}=$ Labelled p-Nitrocumyl Bromide in Dimethyl Sulphoxide}

As a measure of reproducibility, the reaction of lithium azide with ${ }^{2} \mathrm{D}_{6}$-labelled $p$ nitrocumyl bromide in dimethyl sulphoxide was followed by ${ }^{1} \mathrm{H}$ n.m.r. The signals due to the ortho aromatic protons in the labelled $p$-nitrocumyl bromide were used for kinetic study. The course of the reactions were followed by observing the growth and disappearance of the ${ }^{1} \mathrm{H}$ n.m.r. signals in the aromatic region. The concentrations of labelled p-nitrocumyl bromide, at given times, were calculated from the integrals (I) of the ortho proton signals as in Equation 8.9:

$\mathrm{R}=\mathrm{C}_{9} \mathrm{H}_{4} \mathrm{D}_{6} \mathrm{NO}_{2}$

$$
[\mathrm{RBr}]_{\mathrm{t}}=\frac{\mathrm{I}(\mathrm{RBr}) \times[\mathrm{RBr}]_{0}}{\mathrm{I}(\mathrm{RBr})+\mathrm{I}\left(\mathrm{RN}_{3}+\mathrm{ROH}+\text { Alkene }\right)}
$$

In each kinetic study 10 spectra were accumulated, each consisting of $820 \mu \mathrm{s}$ pulses each followed by a two second acquisition time (see 9.5.2). For the purpose of calculating rate coefficients, the time ascribed to each spectrum was the mid-point of the accumulation. 


\subsubsection{The Elimination of $\underline{2} \underline{D}_{6}$-labelled $p$-Nitrocumyl Bromide in Dimethyl}

\section{Sulphoxide}

One kinetic study was performed; the initial concentration of ${ }^{2} \mathrm{D}_{6}$-labelled $p$ nitrocumyl bromide was set equal to $0.20 \mathrm{~mol} \mathrm{dm}^{-3}$. No lithium azide was added but the ionic strength of the reaction solution was held essentially constant by the addition of lithium perchlorate. The concentrations of ${ }^{2} \mathrm{D}_{6}$-labelled $p$-nitrocumyl bromide at given times, derived from this kinetic study, are presented in Table 8.7. As the solvent is in excess a rate coefficient was calculated assuming that the reaction was first order with respect to ${ }^{2} \mathrm{D}_{6}$-labelled $p$-nitrocumyl bromide.

The elimination rate constant $\left(k_{\mathrm{S}}\right)$ obtained from this kinetic run is very similar to the $k_{\mathrm{S}}$ value obtained from the $60 \mathrm{MHz}{ }^{2} \mathrm{H}$ n.m.r. run: this gives us a measure of reproducibility. The elimination rate constant $\left(k_{\mathrm{s}}\right)$ obtained for ${ }^{2} \mathrm{D}_{6}$-labelled $p$-nitrocumyl bromide in this case is much lower than the $k_{\mathrm{S}}$ value obtained for the non-labelled $p$ nitrocumyl bromide (Table 8.9). The measured isotope effect for this elimination is again moderate, $k_{\mathrm{S}}(\mathrm{H}) / k_{\mathrm{S}}(\mathrm{D})=2.93$ (corresponding to $k_{\mathrm{S}}(\mathrm{H}) / k_{\mathrm{S}}(\mathrm{D})=1.21$ per deuteron) (Table 8.11). However, ionisation is not completely free of internal return since the measured isotope effect is larger than the maximum secondary kinetic deuterium isotope effect for a $\mathrm{CD}_{3}$

\subsubsection{The Order with Respect to Azide}

One kinetic study was performed; the initial concentrations of ${ }^{2} \mathrm{D}_{6}$-labelled $p$ nitrocumyl bromide and lithium azide were set equal to $0.20 \mathrm{~mol} \mathrm{dm}^{-3}$ and $0.40 \mathrm{~mol} \mathrm{dm}^{-3}$ respectively. The concentrations of the labelled p-nitrocumyl bromide at given times, derived from this kinetic study, are presented in Table 8.8. For time equal to zero, the concentration of labelled $p$-nitrocumyl bromide in the reaction mixture was set equal to one half the concentration of just the labelled $p$-nitrocumyl bromide solution on its own. Rate coefficients for this kinetic experiment were calculated in the usual way.

The concurrent second order rate constant $\left(k_{2}^{\prime}\right)$ obtained from this kinetic run is very similar to the $k_{2}^{\prime}$ value obtained from the $60 \mathrm{MHz}{ }^{2} \mathrm{H}$ n.m.r. run: this gives us a 
measure of reproducibility. The concurrent second order rate constant $\left(k_{2}^{\prime}\right)$ obtained for ${ }^{2} \mathrm{D}_{6}$-labelled $p$-nitrocumyl bromide, in this case, is slightly smaller than the $k_{2}^{\prime}$ value obtained for the non-labelled $p$-nitrocumyl bromide (Table 8.10). The measured isotope effect for this component is close to unity, $k_{2}^{\prime}(\mathrm{H}) / k_{2}^{\prime}(\mathrm{D})=1.05$ (corresponding to $k_{2}^{\prime}(\mathrm{H}) / k_{2}^{\prime}(\mathrm{D})=1.00$ per deuteron) (Table 8.11 ). The lack of an isotope effect is indicative of a mechanism involving direct displacement.

\subsubsection{Conclusion}

A moderately large isotope effect was obtained for the solvolysis of $p$-nitrocumyl bromide in dimethyl sulphoxide. This suggests that there is considerable internal return and hence, ionisation is not rate limiting. No significant isotope effect was obtained for the second order kinetic component in the reaction of lithium azide with $p$-nitrocumyl bromide. This suggests that there is little carbocation character in the rate limiting step for the second order kinetic component. A mechanism which is consistent with the evidence is described in Scheme 8.2:

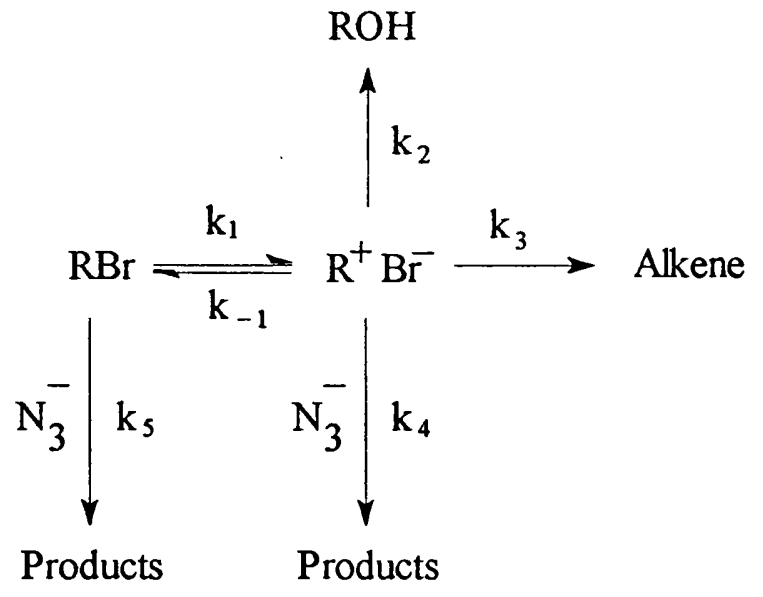

Scheme 8.2 
Table 8.7

Temperature

Solvent

$[\mathrm{RBr}]_{0}$

$\left[\mathrm{LiN}_{3}\right]_{0}$

$\left[\mathrm{LiClO}_{4}\right]_{0}$
The Elimination of $\underline{2}$ - - -labelled $p$-Nitrocumyl Bromide in

\section{Dimethyl Sulphoxide}

$30^{\circ} \mathrm{C}$

$99.9 \% \mathrm{C}_{2} \mathrm{D}_{6} \mathrm{SO}$

$0.20 \mathrm{~mol} \mathrm{dm}^{-3}$

$\left(\mathrm{R}=\mathrm{C}_{9} \mathrm{H}_{4} \mathrm{D}_{6} \mathrm{NO}_{2}\right)$

$0.00 \mathrm{~mol} \mathrm{dm}^{-3}$

$0.40 \mathrm{~mol} \mathrm{dm}^{-3}$

\begin{tabular}{|c|c|c|}
\hline Time Range / s & Mid-point Time / & {$[\mathrm{RBr}]_{\mathrm{t}} / \mathrm{mol}^{\mathrm{dm}} \mathbf{3}^{-3}$} \\
\hline 0 & 0 & 0.200 \\
\hline $3592-3608$ & 3600 & 0.185 \\
\hline $7192-7208$ & 7200 & 0.176 \\
\hline $10792-10808$ & 10800 & 0.167 \\
\hline $14392-14408$ & 14400 & 0.157 \\
\hline $17992-18008$ & 18000 & 0.150 \\
\hline $21592-21608$ & 21600 & 0.142 \\
\hline $25192-25208$ & 25200 & 0.131 \\
\hline $28792-28808$ & 28800 & 0.125 \\
\hline $32392-32408$ & 32400 & 0.116 \\
\hline
\end{tabular}


Table 8.8

Temperature

Solvent

[RBr]0

$\left[\mathrm{LiN}_{3}\right]_{0}$

$\left[\mathrm{LiClO}_{4}\right]_{0}$
The Order with Respect to Azide

$30^{\circ} \mathrm{C}$

$99.9 \% \mathrm{C}_{2} \mathrm{D}_{6} \mathrm{SO}$

$0.20 \mathrm{~mol} \mathrm{dm}^{-3}$

$\left(\mathrm{R}=\mathrm{C}_{9} \mathrm{H}_{4} \mathrm{D}_{6} \mathrm{NO}_{2}\right)$

$0.40 \mathrm{~mol} \mathrm{dm}^{-3}$

$0.00 \mathrm{~mol} \mathrm{dm}^{-3}$

\begin{tabular}{|c|c|c|}
\hline Time Range / & Mid-point Time $/ \mathrm{s}$ & {$[\mathrm{RBr}]_{\mathrm{t}} / \mathrm{mol} \mathrm{dm}^{-3}$} \\
\hline 0 & 0 & 0.200 \\
\hline $172-188$ & 180 & 0.161 \\
\hline $352-368$ & 360 & 0.126 \\
\hline $532-548$ & 540 & 0.105 \\
\hline $712-728$ & 720 & 0.086 \\
\hline $892-908$ & 900 & 0.073 \\
\hline $1072-1088$ & 1080 & 0.062 \\
\hline $1252-1268$ & 1260 & 0.055 \\
\hline $1432-1448$ & 1440 & 0.048 \\
\hline $1612-1628$ & 1620 & 0.042 \\
\hline
\end{tabular}


Table 8.9

A comparison of various rate constants for the reaction of lithium azide with ${ }^{2} \mathrm{D}_{6}$-labelled (D) and non-labelled (H) p-nitrocumyl bromide in dimethyl sulphoxide.

\begin{tabular}{|c|c|c|c|c|c|c|}
\hline $\begin{array}{l}{\left[\operatorname{LiN}_{3}\right]_{0}} \\
/ \mathrm{mol} \mathrm{dm}^{-3} \\
\end{array}$ & $\begin{array}{c}{[R B r]_{0}} \\
/ \mathrm{mol} \mathrm{dm}^{-3}\end{array}$ & $\begin{array}{c}{\left[\mathrm{LiClO}_{4}\right]_{0}} \\
/ \mathrm{mol} \mathrm{dm}^{-3}\end{array}$ & $\begin{array}{c}10^{4} k_{1} / \\
s^{-1}\end{array}$ & $\begin{array}{c}10^{3} k_{2} / \\
\mathrm{dm}^{3} \mathrm{~mol}^{-1} \mathrm{~s}^{-1}\end{array}$ & $\begin{array}{c}10^{3} k_{2}^{\prime} / \\
\mathrm{dm}^{3} \mathrm{~mol}^{-1} \mathrm{~s}^{-1}\end{array}$ & $\begin{array}{c}10^{5} k_{s} / \\
s^{-1}\end{array}$ \\
\hline 0.40 & $0.20^{\mathrm{D}}$ & 0.00 & 9.57 & 3.29 & 3.33 & 1.69 \\
\hline 0.40 & $0.20^{\mathrm{H}}$ & 0.00 & 11.1 & 3.87 & 3.48 & 4.86 \\
\hline 0.00 & $0.20^{\mathrm{D}}$ & 0.40 & 0.165 & ---- & --- & 1.65 \\
\hline 0.00 & $0.20^{\mathrm{H}}$ & 0.40 & 0.483 & --- & .... & 4.83 \\
\hline
\end{tabular}

\section{Table 8.10}

A comparison of concurrent bimolecular rate constants derived from GEAR and GIT, $\left(k_{2}^{\prime}\right)$, with the concurrent bimolecular rate constants (Isolated points deleted) ${ }^{*}$ derived from Equation $6.21,\left(k_{2}^{\prime \prime}\right)$.

\begin{tabular}{|c|c|c|c|c|c|c|}
\hline $\begin{array}{c}{\left[\mathrm{LiN}_{3}\right]_{0}} \\
/ \mathrm{mol} \mathrm{dm}^{-3}\end{array}$ & $\begin{array}{c}{[R B r]_{0}} \\
/ \mathrm{mol} \mathrm{dm}^{-3}\end{array}$ & $\begin{array}{c}{\left[\mathrm{LiClO}_{4}\right]_{0}} \\
/ \mathrm{mol} \mathrm{dm}^{-3}\end{array}$ & $\begin{array}{c}10^{5} \boldsymbol{k}_{\mathrm{s}} / \\
\mathbf{s}^{-1}\end{array}$ & $\begin{array}{c}10^{3} k_{2}^{\prime} / \\
\mathrm{dm}^{3} \mathrm{~mol}^{-1} \mathbf{s}^{-1}\end{array}$ & $\begin{array}{c}10^{3} k_{2}^{\prime \prime} / / \\
\mathrm{dm}^{3} \mathrm{~mol}^{-1} \mathbf{s}^{-1}\end{array}$ & $\begin{array}{c}\mathbf{r}^{*} \\
\sigma^{*} / \%\end{array}$ \\
\hline 0.40 & $0.20^{\mathrm{D}}$ & 0.00 & 1.69 & 3.33 & 3.23 & $\begin{array}{c}0.9991 \\
1.59\end{array}$ \\
\hline 0.40 & $0.20 \mathrm{H}$ & 0.00 & 4.86 & 3.48 & 3.77 & $\begin{array}{c}0.9998 \\
0.71\end{array}$ \\
\hline
\end{tabular}

\section{Table 8.11}

Isotope effects for: (1) the eliminaton of $p$-nitrocumyl bromide in dimethyl sulphoxide, $k_{\mathrm{S}}(\mathrm{H}) / k_{\mathrm{S}}(\mathrm{D})$, and (2) the second order component in the reaction of $p$-nitrocumyl bromide with lithium azide in dimethyl sulphoxide, $k_{2}^{\prime}(\mathrm{H}) / k_{2}^{\prime}(\mathrm{D})$.

\begin{tabular}{|c|c|c|c|c|c|}
\hline$k_{\mathrm{s}}(\mathrm{H}) / k_{\mathrm{S}}(\mathrm{D})$ & $k_{\mathrm{s}}(\mathrm{H}) / k_{\mathrm{S}}(\mathrm{D})$ & $k_{\mathrm{s}}(\mathrm{H}) / k_{\mathrm{S}}(\mathrm{D})$ & $k_{2}^{\prime}(\mathrm{H}) / k_{2}^{\prime}(\mathrm{D})$ & $k_{2}^{\prime}(\mathrm{H}) / k_{2}^{\prime}(\mathrm{D})$ & $k_{2}^{\prime}(\mathrm{H}) / k_{2}^{\prime}(\mathrm{D})$ \\
per deuteron & $\mathrm{CD}_{3}$ & & 1.05 & 1.00 & 1.02 \\
\hline 2.93 & 1.21 & 1.77 & per deuteron $\mathrm{CD}_{3}$ \\
\hline
\end{tabular}


In Scheme 8.2, there is competition between direct displacement $\left(k_{5}\right)$ and ionisation $\left(k_{1}\right)$ with $k_{5}>k_{1}$. There is also significant internal return $\left(k_{-1}>k_{2}, k_{3}\right.$, and $\left.k_{4}\right)$, hence, the ionisation step is not rate limiting. The main contribution to the second order kinetic component of the reaction will come from direct displacement. A small contribution to the second order kinetic component will come from azide attack on the preformed ion pair. Therefore, one would expect an isotope effect close to unity. The direct displacement process will probably have a "loose" $\mathrm{S}_{\mathrm{N}} 2$ transition state. A substantial positive charge will develop at the tertiary carbon atom because both the entering and leaving group are less tightly bound than in the "tight" transition states characteristic of normal $\mathrm{S}_{\mathrm{N}} 2$ reactions.

Scheme 8.2 suggests that substitution by azide can occur by two distinct processes. The first process, in which the breaking of the $\mathrm{C}-\mathrm{Br}$ bond is aided by the azide anion, incorporates a spectrum of transition states. At one end of the spectrum the breaking of the $\mathrm{C}-\mathrm{Br}$ bond is aided by bond formation (classical $\mathrm{S}_{\mathrm{N}}$ ) and at the other end of the spectrum aided by electrostatic interaction (nucleophilic assisted ion pair formation). A "loose" $\mathrm{S}_{\mathrm{N}} 2$ transition state would lie somewhere in between the two extremes.

The second process, in which the breaking of the $\mathrm{C}-\mathrm{Br}$ bond is not aided by the azide anion, involves an equilibrium between the $p$-nitrocumyl substrate and its ion pair. If this reverse reaction is slow then ionisation will be rate limiting $\left(\mathrm{S}_{\mathrm{N}} 1\right)$, however, if this equilibrium is fast then attack by azide on the preformed ion pair will be rate limiting. The evidence from the observed isotope effects indicates that the reverse reaction is fast.

\subsection{Molecular Orbital Calculations}

There was a time when semi-empirical molecular orbital calculations could only be carried out by large mainframe computers. Today, these calculations can be preformed on small personal computers in a matter of hours. Two of the latest semi-empirical methods are AM1 and PM3. In some ways AM1 is better than PM3 and in other ways PM3 is 
better than AM1. For the purpose of the optimisation of a geometry there is little difference between the two methods.

It is difficult to calculate the geometry of an $\mathrm{S}_{\mathrm{N}} 2$ transition state for the reaction of azide anion with p-nitrocumyl bromide because a geometry would have to be calculated that represents the highest energy along the reaction co-ordinate. However, a geometry close to that of the transition state can be calculated quite easily (Scheme 8.3):

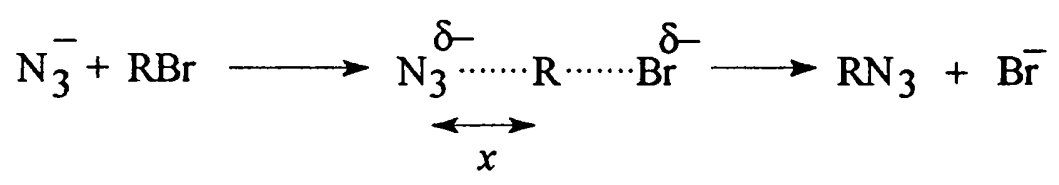

Scheme 8.3

The distance $x$ is set to a value slightly greater than that for a real bond, in our calculations we have set this distance to $2 \AA$. An optimised geometry can then be obtained by varying all of the other parameters.

A three dimensional structure can be represented by a z-matrix. A z-matrix contains data pertaining to bond length, bond angle and twist angle. The twist angle or dihedral angle is the angle between two planes each defined by three atoms. A z-matrix was first constructed for the $p$-nitrocumyl bromide substrate. This was accomplished using the computer programme PC Model. Bond lengths, bond angles and twist angles representing an incoming azide anion were then added to this z-matrix. The distance between the tertiary carbon atom and the nitrogen atom on azide was set at $2 \AA$. The resulting z-matrix, which from now will be called the initial z-matrix, was given a charge of minus 1 .

\subsubsection{The AM1 Method}

The geometry represented by the initial z-matrix was optimised using the AM1 semi-empirical method. All parameters were optimised except for the distance between the tertiary carbon atom and one of the terminal nitrogen atoms on the azide ion which 
was fixed at $2 \AA$. The final optimised z-matrix can be seen in Table 8.12. The most striking value within Table 8.12 is the bond length between one of the methyl protons and the methyl carbon. An association between this methyl proton and the leaving bromine group can be seen in Figure 8.8. This suggests that there is a considerable amount of charge on the bromine. Figure 8.8 suggests that the azide group approaches the tertiary carbon from an angled orientation, moreover, the azide group is slanted towards the ring. The reason for this approach is not entirely obvious, but it may have something to do with steric relief.

\subsubsection{The PM3 Method}

The geometry represented by the initial z-matrix was optimised using the PM3 semi-empirical method. All parameters were optimised except for the distance between the tertiary carbon atom and one of the terminal nitrogen atoms on the azide ion which was fixed at $2 \AA$. The final optimised z-matrix can be seen in Table 8.13. There are no anomalous $\mathrm{C}-\mathrm{H}$ bond lengths within Table 8.13. Moreover, there is no noticeable association between the methyl protons and the leaving bromine group (Figure 8.9). Figure 8.9 suggests that the azide group approaches the tertiary carbon from an angled orientation and again the azide group slants towards the ring.

The major difference between the two geometries (Figures 8.8 and 8.9) is that in the AM1 method bromine associates with a methyl proton, but in the PM3 method it does not. Also, the $\mathrm{C}-\mathrm{Br}$ bond length optimised by the PM3 method is much shorter than the $\mathrm{C}-\mathrm{Br}$ bond length optimised by the AM1 method. Hence, the geometry optimised by PM3 represents a far tighter transition state than the one optimised by the AM1.

No solvent molecules are included in any of the calculations, so the results refer to species in the gas phase. Errors will arise due to the lack of solvation, however, as the reaction solvent is dimethyl sulphoxide these errors should not be excessive. 
Table 8.12 Final Optimised Z-Matrix (AM1 Method)

\begin{tabular}{|c|c|r|r|r|r|r|r|}
\hline $\begin{array}{c}\text { Alom Number } \\
\text { (I) }\end{array}$ & $\begin{array}{c}\text { Chemical } \\
\text { Symbol }\end{array}$ & $\begin{array}{c}\text { Bond Lenglh } \\
\text { (Angstroms) } \\
\text { NA:I }\end{array}$ & $\begin{array}{c}\text { Bond Angle } \\
\text { (Degres) } \\
\text { NB:NA:I }\end{array}$ & $\begin{array}{c}\text { Twist Angle } \\
\text { (Degres) } \\
\text { NC:NB:NA:I }\end{array}$ & NA & NB & NC \\
\hline 1 & $\mathrm{C}$ & & & & & & \\
2 & $\mathrm{C}$ & 1.47909 & & & 1 & & \\
3 & $\mathrm{C}$ & 1.40429 & 119.82762 & & 2 & 1 & \\
4 & $\mathrm{C}$ & 1.38969 & 121.22782 & -180.04406 & 3 & 2 & 1 \\
5 & $\mathrm{C}$ & 1.49832 & 117.53221 & 185.79264 & 1 & 2 & 3 \\
6 & $\mathrm{C}$ & 1.43726 & 118.42050 & -30.33994 & 1 & 2 & 3 \\
7 & $\mathrm{C}$ & 1.40342 & 118.50654 & 179.87103 & 2 & 3 & 1 \\
8 & $\mathrm{C}$ & 1.39105 & 121.21900 & 0.52899 & 7 & 2 & 3 \\
9 & $\mathrm{C}$ & 1.40371 & 119.32435 & -0.77629 & 8 & 7 & 2 \\
10 & $\mathrm{~N}$ & 1.47995 & 119.78661 & -179.50450 & 9 & 8 & 7 \\
11 & $\mathrm{H}$ & 1.10080 & 120.59009 & 179.38104 & 7 & 2 & 3 \\
12 & $\mathrm{H}$ & 1.10198 & 120.30936 & -180.47871 & 8 & 7 & 2 \\
13 & $\mathrm{H}$ & 1.10233 & 120.11472 & -179.81685 & 4 & 3 & 2 \\
14 & $\mathrm{H}$ & 1.10211 & 119.72430 & 0.10381 & 3 & 2 & 1 \\
15 & $\mathrm{Br}$ & 3.76397 & 91.46515 & -76.09069 & 1 & 2 & 3 \\
16 & $\mathrm{H}$ & 1.11806 & 110.02025 & -164.59322 & 5 & 1 & 2 \\
17 & $\mathrm{H}$ & 1.11533 & 113.30604 & -44.06613 & 5 & 1 & 2 \\
18 & $\mathrm{H}$ & 1.12117 & 108.39574 & 77.60322 & 5 & 1 & 2 \\
19 & $\mathrm{H}$ & 1.10943 & 113.68096 & 181.04042 & 6 & 1 & 2 \\
20 & $\mathrm{H}$ & 1.33075 & 106.66482 & -66.17854 & 6 & 1 & 2 \\
21 & $\mathrm{H}$ & 1.10681 & 116.34720 & 50.57065 & 6 & 1 & 2 \\
22 & $\mathrm{O}$ & 1.20493 & 119.37201 & -1.50166 & 10 & 9 & 8 \\
23 & $\mathrm{O}$ & 1.20452 & 119.49786 & 179.16296 & 10 & 9 & 8 \\
24 & $\mathrm{~N}$ & 2.00000 & 97.20052 & 79.06279 & 1 & 2 & 3 \\
25 & $\mathrm{~N}$ & 2.74063 & 85.58495 & 99.32324 & 1 & 2 & 3 \\
26 & $\mathrm{~N}$ & 3.71808 & 80.29800 & 109.10935 & 1 & 2 & 3 \\
\hline & & & & & &
\end{tabular}



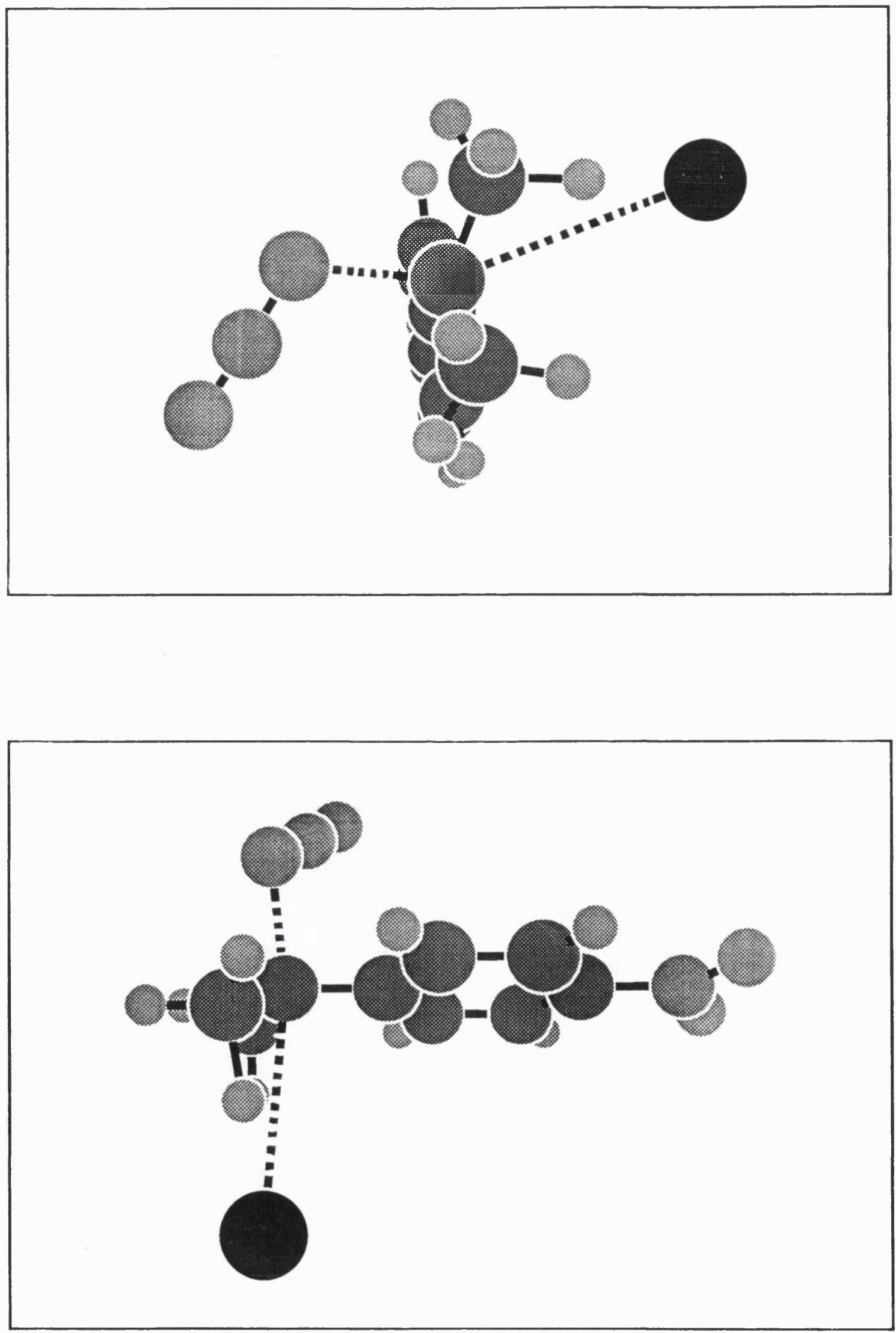

Figure 8.8: Two Different Views of the Structure Optimised by the AM1 Method 
Table 8.13 Final Optimised Z-Matrix (PM3 Method)

\begin{tabular}{|c|c|r|r|r|r|r|r|}
\hline $\begin{array}{c}\text { Atom Number } \\
\text { (I) }\end{array}$ & $\begin{array}{c}\text { Chemical } \\
\text { Symbol }\end{array}$ & $\begin{array}{c}\text { Bond Length } \\
\text { (Angstroms) }\end{array}$ & $\begin{array}{c}\text { Bond Angle } \\
\text { (Degrees) } \\
\text { NB:I }\end{array}$ & $\begin{array}{c}\text { Twist Angle } \\
\text { (Degrees) } \\
\text { NC:NB:NA:I }\end{array}$ & NA & NB & NC \\
\hline 1 & $\mathrm{C}$ & & & & & & \\
2 & $\mathrm{C}$ & 1.48474 & & & 1 & & \\
3 & $\mathrm{C}$ & 1.40462 & 119.33739 & & 2 & 1 & \\
4 & $\mathrm{C}$ & 1.38206 & 120.78799 & -175.73317 & 3 & 2 & 1 \\
5 & $\mathrm{C}$ & 1.48969 & 119.94051 & 171.41271 & 1 & 2 & 3 \\
6 & $\mathrm{C}$ & 1.49251 & 115.81787 & -39.36323 & 1 & 2 & 3 \\
7 & $\mathrm{C}$ & 1.39903 & 118.63405 & 172.93501 & 2 & 3 & 1 \\
8 & $\mathrm{C}$ & 1.38555 & 120.75509 & 5.47327 & 7 & 2 & 3 \\
9 & $\mathrm{C}$ & 1.40328 & 120.41965 & -4.07996 & 8 & 7 & 2 \\
10 & $\mathrm{~N}$ & 1.48037 & 120.64818 & -180.37793 & 9 & 8 & 7 \\
11 & $\mathrm{H}$ & 1.10272 & 118.42873 & 180.46181 & 7 & 2 & 3 \\
12 & $\mathrm{H}$ & 1.09792 & 119.03439 & -184.58641 & 8 & 7 & 2 \\
13 & $\mathrm{H}$ & 1.09802 & 118.67160 & -178.89528 & 4 & 3 & 2 \\
14 & $\mathrm{H}$ & 1.10207 & 118.25475 & 6.80132 & 3 & 2 & 1 \\
15 & $\mathrm{Br}$ & 2.80156 & 69.67031 & -118.52646 & 1 & 2 & 3 \\
16 & $\mathrm{H}$ & 1.09910 & 112.38440 & -143.99513 & 5 & 1 & 2 \\
17 & $\mathrm{H}$ & 1.10148 & 112.26329 & -20.63242 & 5 & 1 & 2 \\
18 & $\mathrm{H}$ & 1.10334 & 108.88829 & 98.29969 & 5 & 1 & 2 \\
19 & $\mathrm{H}$ & 1.09762 & 112.18398 & 165.34762 & 6 & 1 & 2 \\
20 & $\mathrm{H}$ & 1.10301 & 109.52379 & -74.27217 & 6 & 1 & 2 \\
21 & $\mathrm{H}$ & 1.10327 & 111.04809 & 43.30198 & 6 & 1 & 2 \\
22 & $\mathrm{O}$ & 1.21986 & 120.19814 & 9.34630 & 10 & 9 & 8 \\
23 & $\mathrm{O}$ & 1.22003 & 120.59981 & 188.62284 & 10 & 9 & 8 \\
24 & $\mathrm{~N}$ & 2.00000 & 102.73159 & 63.91807 & 1 & 2 & 3 \\
25 & $\mathrm{~N}$ & 3.00743 & 88.44449 & 69.93756 & 1 & 2 & 3 \\
26 & $\mathrm{~N}$ & 4.10569 & 83.63774 & 72.43107 & 1 & 2 & 3 \\
\hline
\end{tabular}



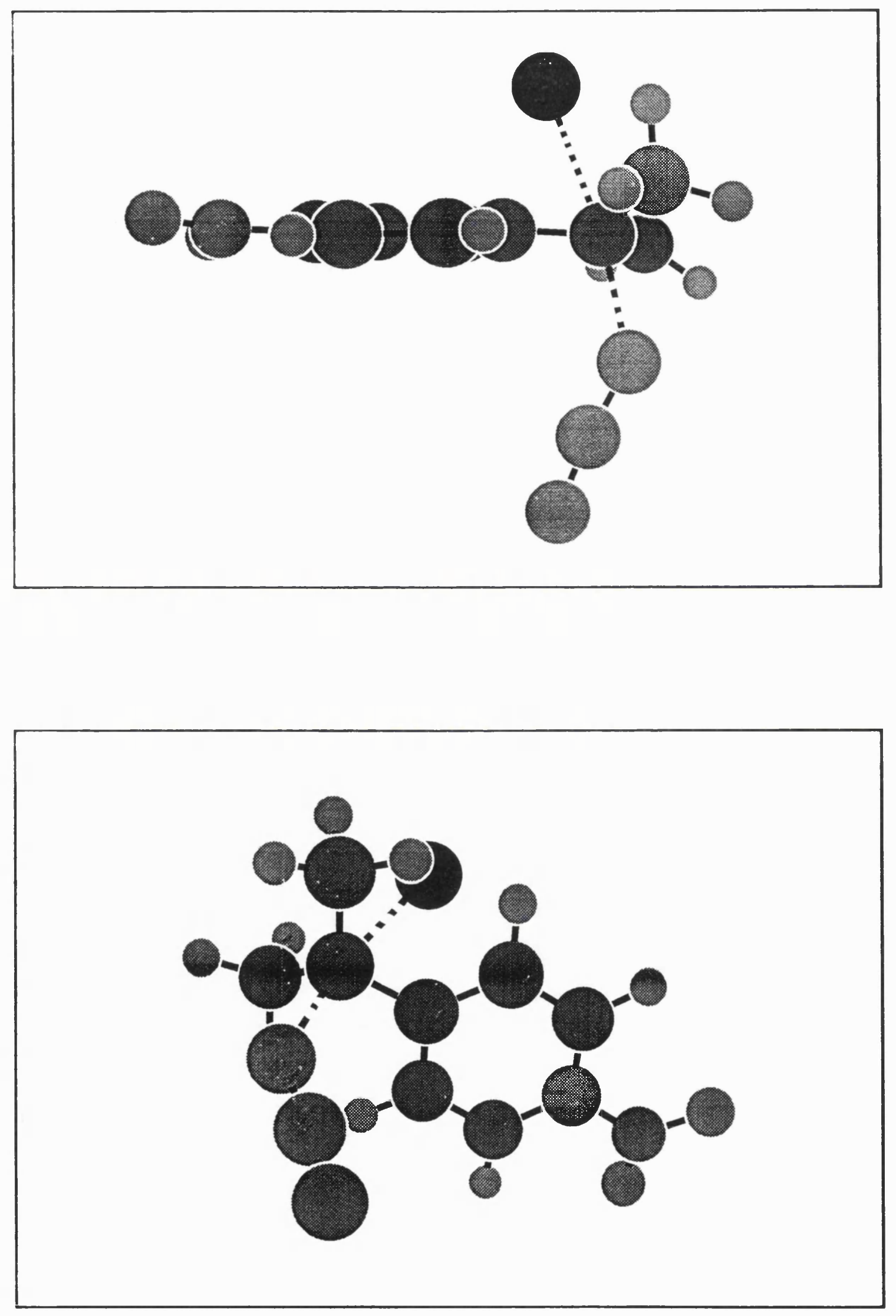

Figure 8.9: Two Different Views of the Structure Optimised by the PM3 Method 


\section{6. $200 \mathrm{MHz}-1$ N.M.R. Study of the Reaction of Lithium Azide with $p$ - Nitrocumyl Chloride in Dimethyl Sulphoxide}

Kornblum et al. 17 found that a quantitative yield of $p$-nitrocumyl azide was obtained when $p$-nitrocumyl chloride was treated with sodium azide in various dipolar aprotic solvents (Equation 6.1). Kornblum et al. believe that the reaction in Equation 6.1 involves a radical chain process. When $p$-nitrocumyl chloride was treated with lithium azide (two fold excess) in dimethyl sulphoxide, under an argon atmosphere, and irradiated with ultraviolet light, the reaction had a half-life of 7 minutes. In the dark this reaction had a half-life of 50 hours. The reaction in the dark may be due to a very slow radical process or it may be due to a residual $\mathrm{S}_{\mathrm{N}} 2$ process. The possibility of the latter was explored.

The kinetic study in this section was followed using a $200 \mathrm{MHz}$ pulsed Fourier transform n.m.r. spectrometer. It was easier to obtain the necessary time on the Varian XI-200 n.m.r. spectrometer, however, the thermocouple on the probe normally used for ${ }^{1} \mathrm{H}$ n.m.r. was broken. Variable temperature ${ }^{1} \mathrm{H}$ n.m.r. studies can only be performed using a broad band probe. The result of this is a spectrum of low resolution, hence, accuracy in the integrals is impaired. Reaction solutions were made up as described in Section 9.5.1. The spectra were recorded at specific time intervals automatically. The temperature of the broad band n.m.r. probe was maintained at a constant value during the ${ }^{1}$ H n.m.r. study using the spectrometer's variable temperature controller. The temperature of the n.m.r. probe was found to be $(30 \pm 2)^{\circ} \mathrm{C}$ for this study.

The course of this reaction was followed by observing the growth and disappearance of the ${ }^{1} \mathrm{H}$ n.m.r. signals in the aliphatic region. The darkness within the cavity of the n.m.r. probe provides the appropriate reaction conditions. The only product observed in the reaction of lithium azide with $p$-nitrocumyl chloride in dimethyl sulphoxide was $p$-nitrocumyl azide. The concentrations of $p$-nitrocumyl chloride, at given times, were calculated from the following integrals (I) (Equation 8.10): 


$$
\mathrm{R}=\mathrm{C}_{9} \mathrm{H}_{10} \mathrm{NO}_{2}
$$

$$
[\mathrm{RCl}]_{\mathrm{t}}=\frac{\mathrm{I}(\mathrm{RCl}) \times[\mathrm{RCl}]_{0}}{\mathrm{I}(\mathrm{RCl})+\mathrm{I}\left(\mathrm{RN}_{3}\right)}
$$

\subsubsection{The Order with Respect to Azide}

One kinetic study was performed; the initial concentrations of $p$-nitrocumyl chloride and lithium azide were set equal to $0.20 \mathrm{~mol} \mathrm{dm}^{-3}$ and $0.40 \mathrm{~mol} \mathrm{dm}^{-3}$ respectively. The concentrations of the $p$-nitrocumyl chloride at given times, derived from this kinetic study, are presented in Table 8.14. For time equal to zero, the concentration of $p$-nitrocumyl chloride in the reaction mixture was set equal to one half the concentration of just the $p$-nitrocumyl chloride solution on its own.

Rate coefficients were calculated assuming that the reaction was overall first order with respect to $p$-nitrocumyl chloride (Figure 8.10) and first order with respect to both $p$ nitrocumyl chloride and lithium azide, that is, second order overall (Figure 8.11).

The plot for an overall first order reaction is a good fit (Figure 8.10). However, when the residuals are examined it can be seen that there is a slight pattern. The plot for an overall second order reaction is a very good fit and this is exemplified by the correlation coefficient obtained (Figure 8.11). The residual plot has no real significant pattern.

The concurrent second order rate constant $\left(k_{2}^{\prime}\right)$ obtained for the reaction of $p$ nitrocumyl bromide with lithium azide is 359 times larger than the second order rate constant $\left(k_{2}\right)$ obtained here. $\mathrm{S}_{\mathrm{N}} 2$ reactions in dipolar aprotic solvents tend to have large $k^{\mathrm{Br} /} k^{\mathrm{Cl}}$ ratios, for instance, $k^{\mathrm{Br} / k^{\mathrm{Cl}}}$ is 178 for $\mathrm{EtX}$ reacting with $\mathrm{LiCl}$ in acetone 85 and 250 for the reaction of azide with $\mathrm{MeX}$ in dimethyl formamide. 86 Bordwell et al. have observed $^{83}$ a $k^{\mathrm{Br} / k^{\mathrm{Cl}}}$ ratio of 570 for the reaction of azide with $p$ $\mathrm{C}_{7} \mathrm{H}_{7} \mathrm{SO}_{2} \mathrm{CH}=\mathrm{CHCH}_{2} \mathrm{X}$ in dimethyl formamide. Hence, a $k^{\mathrm{Br} / k^{\mathrm{Cl}}}$ ratio of 359 is consistent with an $\mathrm{S}_{\mathrm{N}} 2$ mechanism. 
Table 8.14

Temperature

Solvent

$[\mathrm{RCl}]_{0}$

$\left[\mathrm{LiN}_{3}\right]_{0}$

$\left[\mathrm{LiClO}_{4}\right]_{0}$

\section{The Order with Respect to Azide}

$30^{\circ} \mathrm{C}$

$99.9 \% \mathrm{C}_{2} \mathrm{D}_{6} \mathrm{SO}$

$0.20 \mathrm{~mol} \mathrm{dm}^{-3}$

$\left(\mathrm{R}=\mathrm{C}_{9} \mathrm{H}_{4} \mathrm{D}_{6} \mathrm{NO}_{2}\right)$

$0.40 \mathrm{~mol} \mathrm{dm}^{-3}$

$0.00 \mathrm{~mol} \mathrm{dm}^{-3}$

\begin{tabular}{|c|c|c|}
\hline Time Range / & Mid-point Time $/ \mathrm{s}$ & {$[\mathrm{RCl}]_{\mathrm{t}} / \mathrm{mol} \mathrm{dm}^{-3}$} \\
\hline 0 & 0 & 0.200 \\
\hline $17992-18008$ & 18000 & 0.187 \\
\hline $35992-36008$ & 36000 & 0.174 \\
\hline $53992-54008$ & 54000 & 0.165 \\
\hline $71992-72008$ & 72000 & 0.155 \\
\hline $89992-90008$ & 90000 & 0.144 \\
\hline $107992-108008$ & 108000 & 0.138 \\
\hline $125992-126008$ & 126000 & 0.128 \\
\hline $143992-144008$ & 144000 & 0.122 \\
\hline $161992-162008$ & 162000 & 0.115 \\
\hline
\end{tabular}




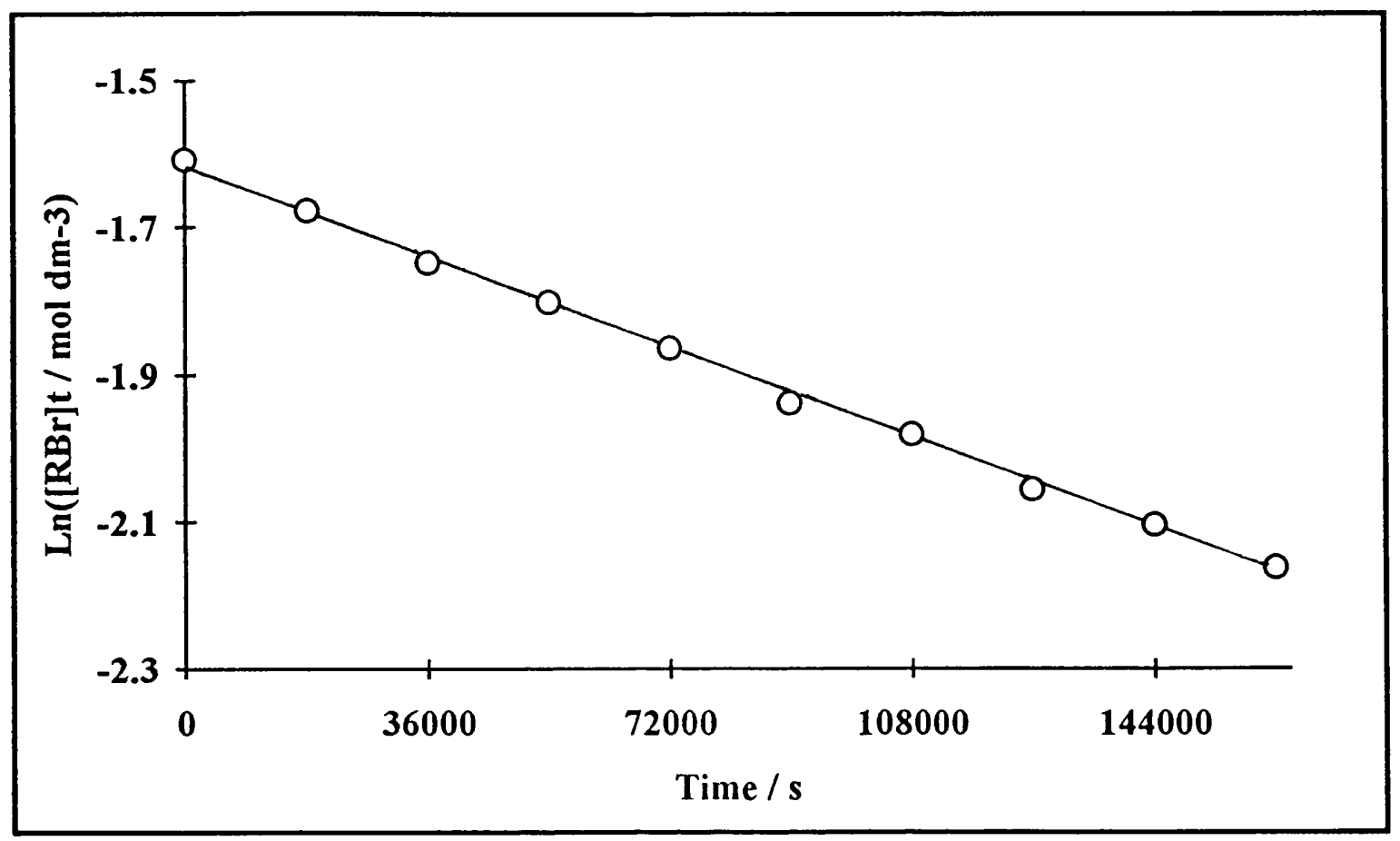

(a)

$$
\begin{aligned}
& k_{1}=3.41 \times 10^{-6} \mathrm{~s}^{-1} \\
& r=0.9992 \\
& \sigma=1.42 \%
\end{aligned}
$$

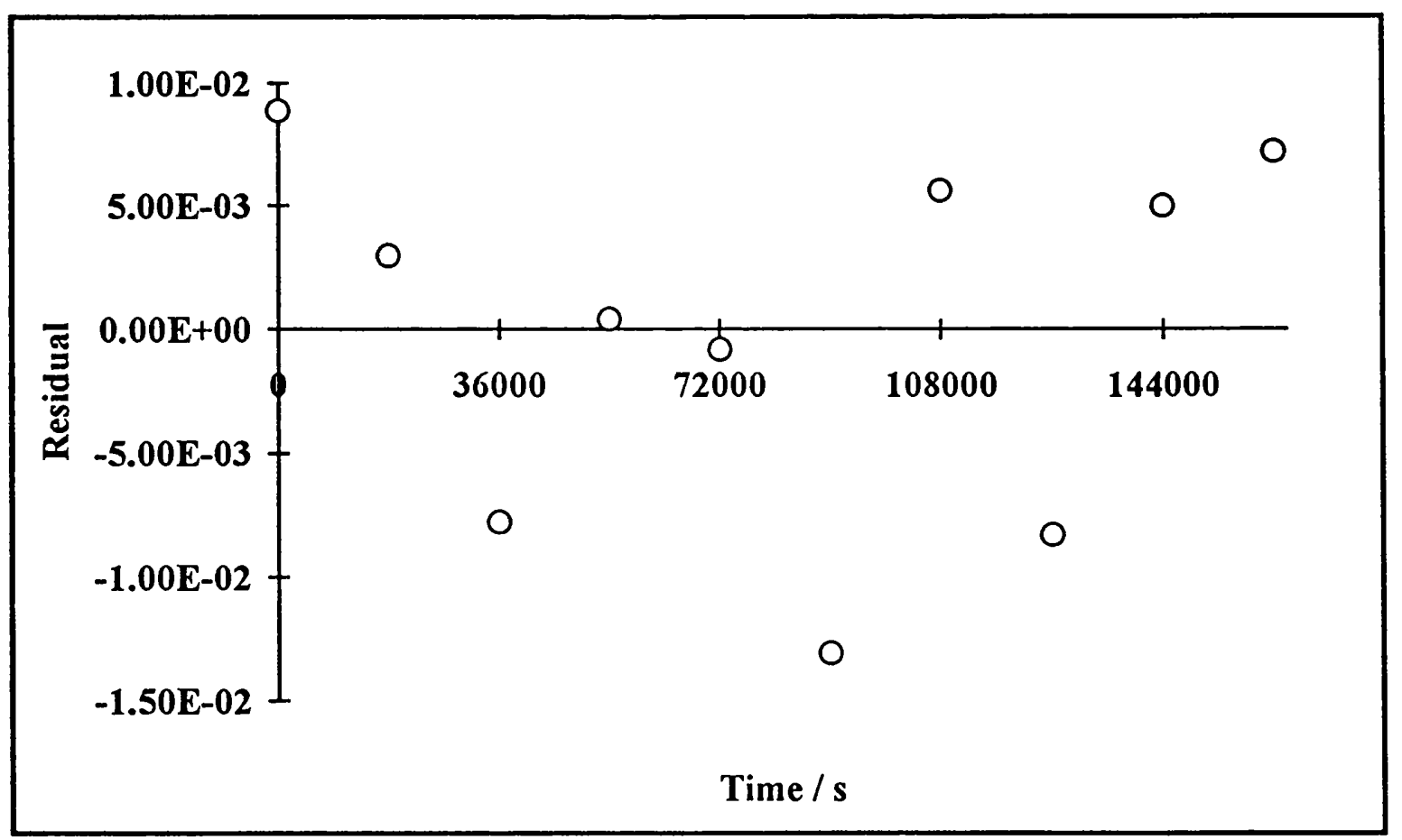

(b)

\section{Figure 8.10}

Plots of (a) $\mathrm{Ln}\left([\mathrm{RBr}]_{\mathrm{t}} / \mathrm{mol} \mathrm{dm}^{-3}\right)$ and (b) Residuals against time / $\mathrm{s}$ for the reaction of $p$ nitrocumyl chloride with lithium azide (Table 8.14). 


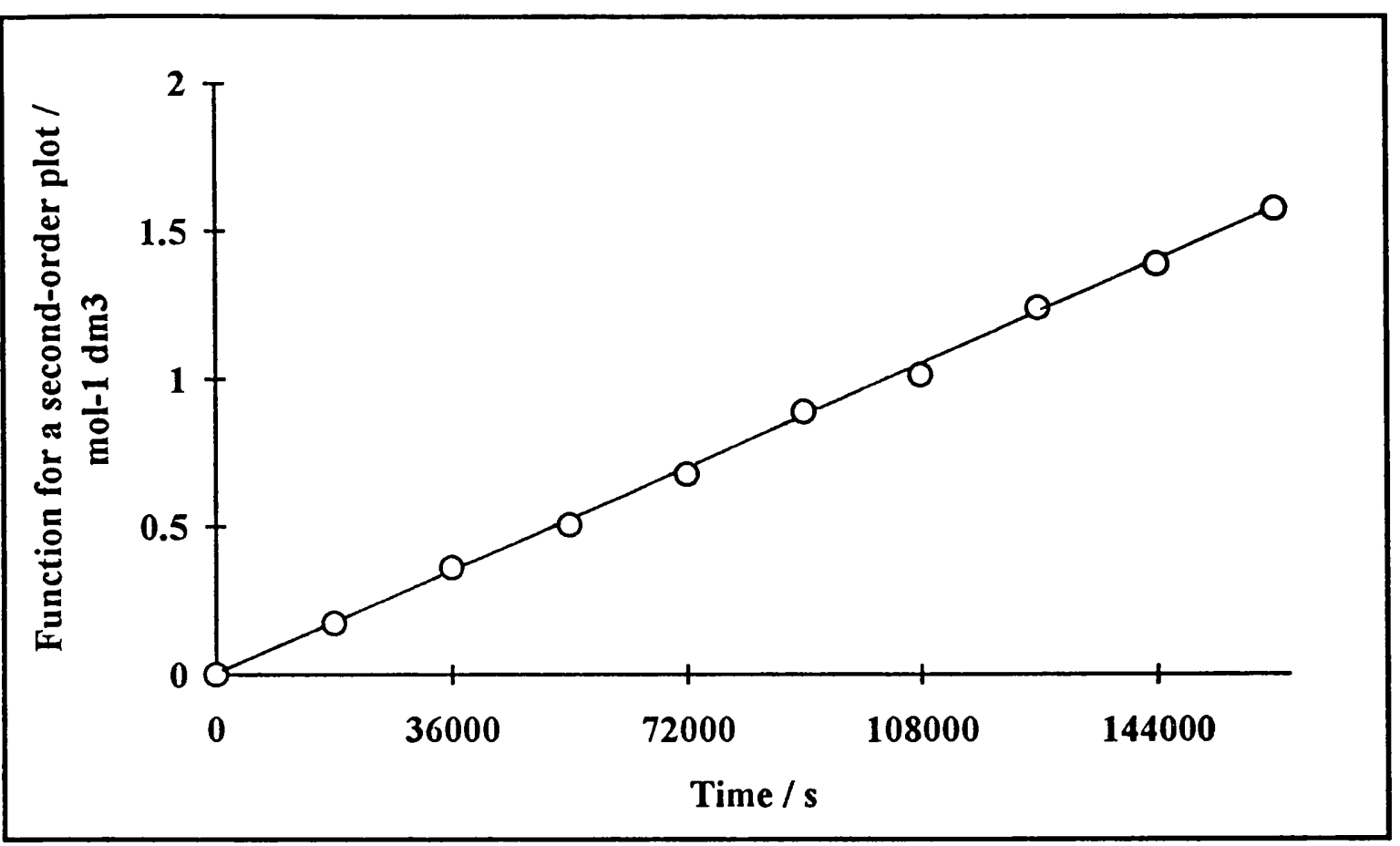

(a)

$$
\begin{aligned}
k_{2}(\mathrm{a} \neq \mathrm{b}) & =9.70 \times 10^{-6} \mathrm{~mol}^{-1} \mathrm{dm}^{3} \mathrm{~s}^{-1} \\
r & =0.9995 \\
\sigma & =1.13 \%
\end{aligned}
$$

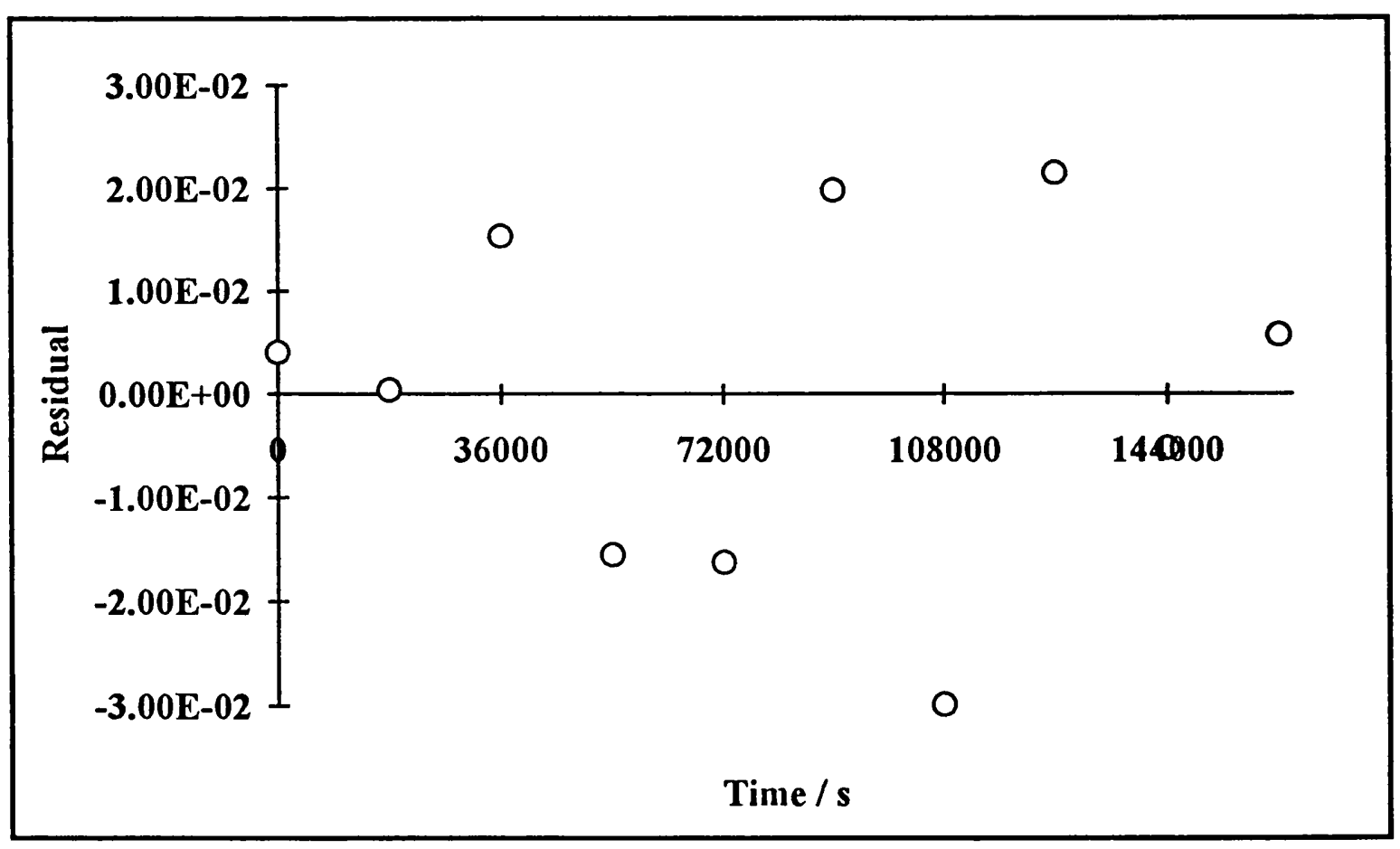

(b)

Figure 8.11

Plots of (a) Function for second-order plot / mol-1 $\mathrm{dm}^{3}$ and (b) Residuals against time / s for the reaction of $p$-nitrocumyl chloride with lithium azide (Table 8.14). 


\subsection{Summary}

The reaction of lithium azide with $p$-nitrocumyl bromide in dimethyl sulphoxide proceeds via a heterolytic mechanism to give the products $p$-nitrocumyl azide, $p$ nitrocumyl alcohol and $p$-nitro- $\alpha$-methylstyrene respectively. The overall disappearance of p-nitrocumyl bromide can be expressed as follows:

$$
-\left(d[\mathrm{RBr}]_{\mathrm{t}} / d t\right)=k_{\mathrm{s}}[\mathrm{RBr}]_{\mathrm{t}}+k_{2}^{\prime}[\mathrm{RBr}]_{\mathrm{t}}\left[\mathrm{N}_{3}{ }^{-}\right]_{\mathrm{t}}
$$

Moreover, the reaction of tetrabutylammonium azide with $p$-nitrocumyl bromide in dimethyl sulphoxide also obeys, within experimental error, concurrent first and second order kinetics. The unimolecular component of the overall rate of reaction can be attributed to the elimination of $p$-nitrocumyl bromide in dimethyl sulphoxide.

The bimolecular kinetic component is best explained by a "loose" $S_{N} 2 / E 2 C$ mechanism. The lack of an isotope effect for the bimolecular component indicates that there is very little carbocation character in the rate-determining step. The large $k^{\mathrm{Br} / k^{\mathrm{Cl}}}$ ratio obtained for this reaction is indicative of $\mathrm{S}_{\mathrm{N}} 2$ reactions in a dipolar aprotic solvents.

Two variations of an ipso type mechanism cannot be ruled out. It would be extremely difficult to distinguish between a "loose" $\mathrm{S}_{\mathrm{N}} 2 / \mathrm{E} 2 \mathrm{C}$ mechanism and an ipso type mechanism. However, an ipso type mechanism postulates the formation of a complex where a "loose" $S_{N} 2 / E 2 C$ mechanism does not. The detection of a complex would be strong evidence for an ipso type mechanism.

\subsection{Further Studies}

A superficial survey of reactions, closely related to the reactions of lithium azide and sodium nitrite with $p$-nitrocumyl bromide in dimethyl sulphoxide respectively, was carried out. The experiments involved in this survey provide further scope for study. 


\subsubsection{The Reaction of Lithium Azide with 2-Bromo-2-(p-Nitrophenyl)Butane in Dimethyl Sulphoxide}

2-Bromo-2-(p-nitrophenyl)butane has a similar structure to $p$-nitrocumyl bromide, however, the former possesses a chiral centre. The $400 \mathrm{MHz}{ }^{1} \mathrm{H}$ n.m.r. spectrum of 2bromo-2-( $p$-nitrophenyl)butane can be seen in Figure 8.12. 2-Bromo-2-(pnitrophenyl)butane has two diastereotopic protons as well as a chiral centre.

Kinetic evidence is a necessary but not a sufficient condition for a reaction proceeding via an $\mathrm{S}_{\mathrm{N}} 2$ mechanism. Much more convincing evidence is obtained from the fact that the mechanism predicts inversion of configuration when substitution occurs at a chiral carbon. If optically active 2-bromo-2-(p-nitrophenyl)butane were to undergo a nucleophilic substitution reaction that proceeded by an $S_{N^{2}}$ mechanism, then an inversion of configuration would be expected. The 2-bromo-2-(p-nitrophenyl)butane prepared was a mixture of enantiomers.

When 2-bromo-2-(p-nitrophenyl)butane was treated with lithium azide (two fold excess) in dimethyl sulphoxide and under an argon atmosphere (see 9.4.11), the reaction had a half-life of 20 minutes at $30^{\circ} \mathrm{C}$ (Equation 8.11). The yield of tertiary azido product obtained here is far lower than the yield obtained for the reaction of lithium azide with $p$ nitrocumyl bromide, however, the yield of alkene in this case is far greater.

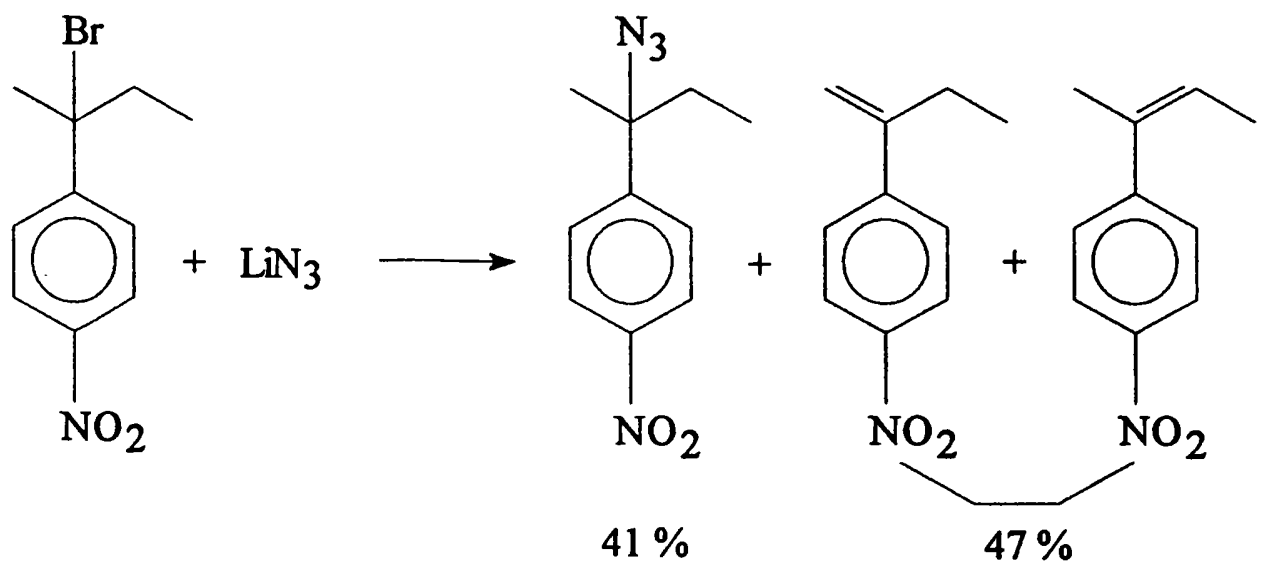


$\ddot{8}$

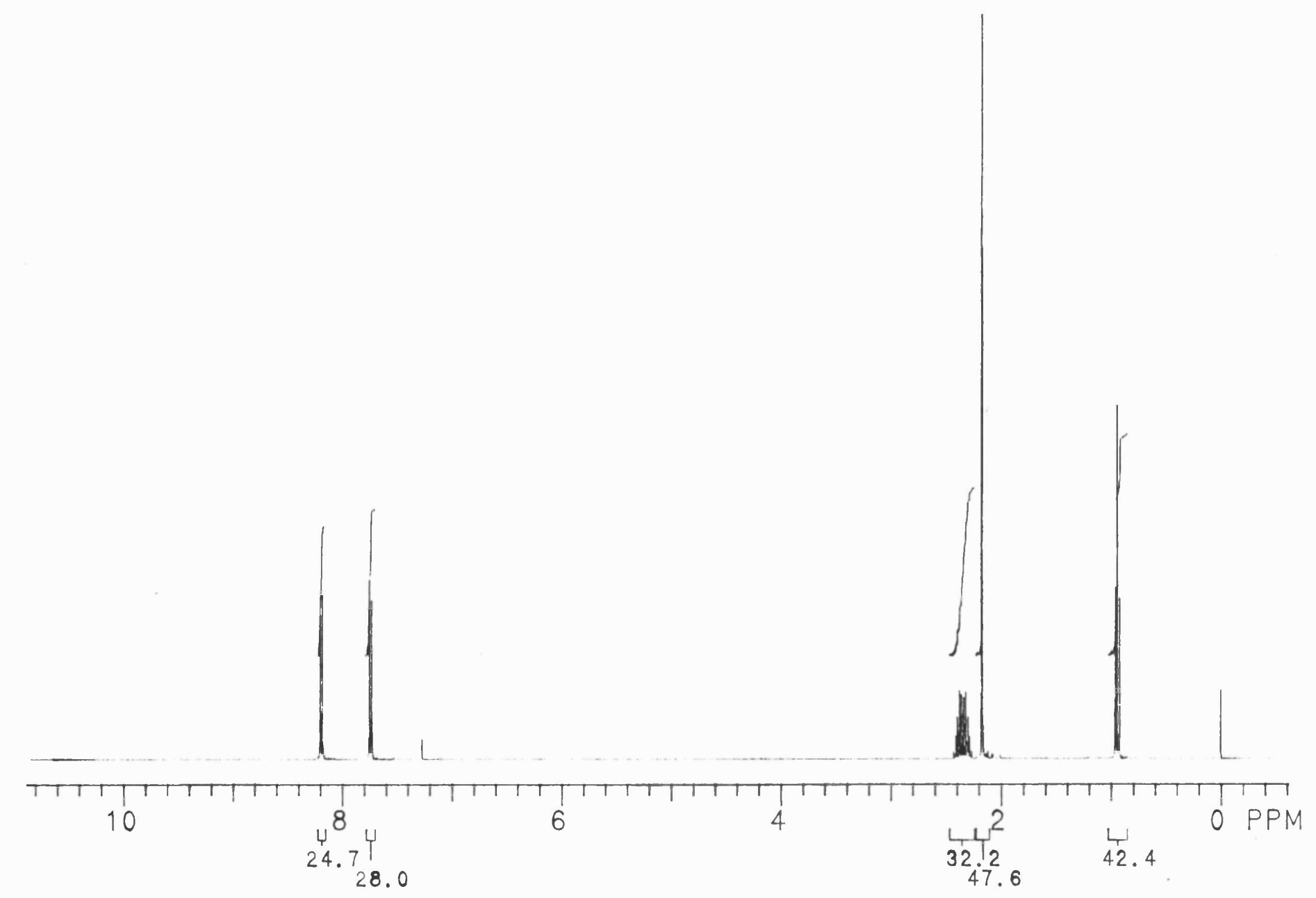

Figure 8.12: The $400 \mathrm{MHz}{ }^{1} \mathrm{H}$ n.m.r. spectrum of 2-bromo-2-(p-nitrophenyl)butane $\left(\mathrm{CDCl}_{3}\right)$ 
This reaction provides further scope for study. The synthesis of 2-bromo-2-(pnitrophenyl)butane rich in one enantiomer would be a fair challenge to any synthetic chemist. The difficulty in any synthesis arises from the ease in which the molecule eliminates. Chiral high performance liquid chromatography is often used as an alternative to asymmetric synthesis. However, there is no guarantee that a chiral column will separate a pair of enantiomers. If the isolation of one enantiomer were possible then experiments could be carried out in order to test for inversion of configuration.

\subsubsection{The Reaction of $p$-Nitrocumyl Bromide with Other Nucleophiles in \\ Dimethyl Sulphoxide}

So far we have investigated the reactions of both nitrite and azide with $p$ nitrocumyl bromide in dimethyl sulphoxide. Detailed investigation has shown that these reactions are heterolytic processes. The following two investigations were carried out in order to give a superficial picture of the reaction of $p$-nitrocumyl bromide with large nucleophiles that are also good electron donors.

\subsubsection{The Reaction of Sodium Thiophenoxide with p-Nitrocumyl Bromide in}

\section{Dimethyl Sulphoxide}

When $p$-nitrocumyl bromide was treated with sodium thiophenoxide (two fold excess) in dimethyl sulphoxide and under an argon atmosphere (see 9.5.12), the reaction was complete within a minute at room temperature (Equation 8.12):

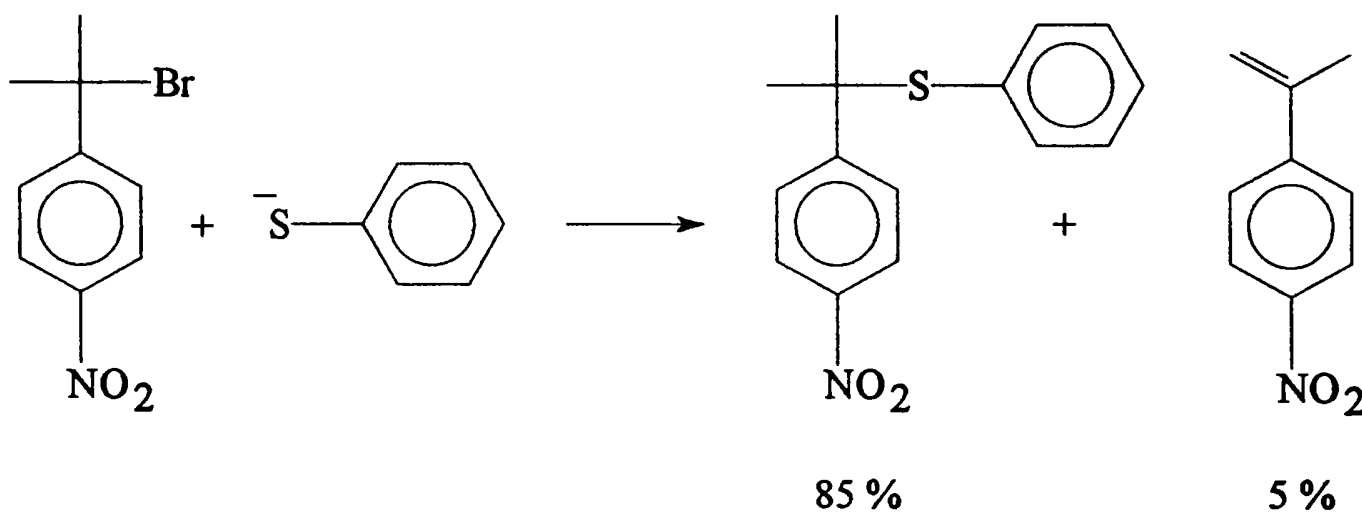


The major product isolated was $p$-nitrocumyl phenyl sulphide. In the presence of 4hydroxy tempo the reaction in Equation 8.12 did not occur and the only product formed was the alkene. Undoubtedly, the formation of the alkene resulted from the solvolysis of $p$-nitrocumyl bromide in dimethyl sulphoxide. The evidence suggests that the reaction in equation 8.12 almost exclusively proceeds via a radical chain process.

\subsubsection{The Reaction of the Lithium Salt of 2-Nitropropane with p-Nitrocumyl}

\section{Bromide in Dimethyl Sulphoxide}

When $p$-nitrocumyl bromide was treated with the lithium salt of 2-nitropropane (two fold excess) in dimethyl sulphoxide and under an argon atmosphere (see 9.4.13), the reaction was complete within 10 minutes at room temperature (Equation 8.13):

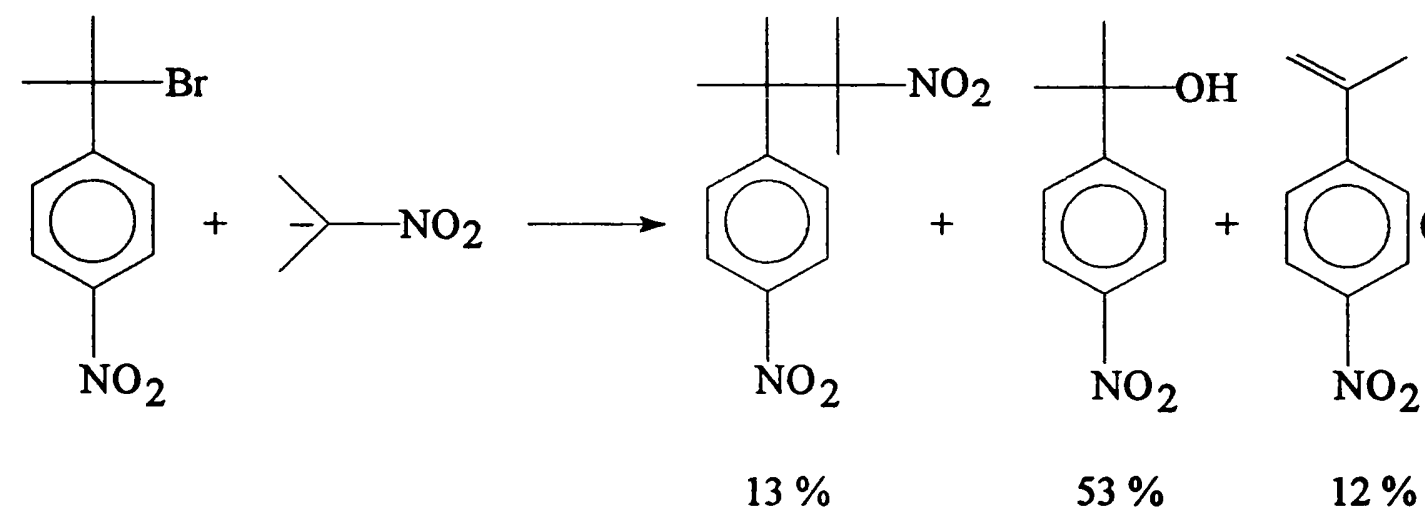

The major product isolated was $p$-nitrocumyl alcohol. The minor products were 2,3dimethyl-2-nitro-3-(p-nitrophenyl)butane and $p$-nitro- $\alpha$-methylstyrene. When $p$ nitrocumyl bromide was treated with the lithium salt of 2-nitropropane (two fold excess) in dimethyl sulphoxide and under an oxygen atmosphere, the only products observed were the alcohol and alkene. No thexyl product was observed.

Kornblum et al. 87 found that when $p$-nitrobenzyl chloride was treated with the lithium salt of 2-nitropropane in dimethyl formamide the carbon alkylated product was obtained in a $95 \%$ yield, but the oxygen alkylated product was obtained in only a $1 \%$ yield. However, when $p$-nitrobenzyl bromide was treated with the lithium salt of 2- 
nitropropane in dimethyl formamide the carbon alkylated product was obtained in only a $17 \%$ yield, but the oxygen alkylated product was obtained in a $65 \%$ yield. On the basis of these findings Kornblum proposed that oxygen alkylation, the usual mode of reaction of a nitroparaffin anion, derives simply from nucleophilic displacement by the oxygen of the anion on the benzylic carbon. When the leaving group is one which is witiculity displaced, a second mode of attack by the 2-nitropropane anion has a chance to compete and it is this second process which is productive of carbon alkylation. This second mode of attack has been shown to be a radical chain process.

The ratio of oxygen alkylated products to carbon alkylated products for the reaction in Equation 8.13 is very similar to the ratio obtained for the reaction of the 2nitropropane anion with $p$-nitrobenzyl bromide in dimethyl formamide. This would suggest that both reactions proceed by two competing mechanisms; the heterolytic substitution being more dominant then the radical chain process.

\subsubsection{Conclusion}

The $p$-nitrocumyl bromide system is a very interesting system indeed. Unlike most tertiary alkyl bromides, $p$-nitrocumyl bromide reacts smoothly with small nucleophiles, such as azide and nitrite, in dimethyl sulphoxide to give substitution products. The rate laws for these reactions depend upon the concentration of nucleophile. These reactions mainly proceed via heterolytic mechanisms involving a high degree of covalency in their respective transition states.

p-Nitrocumyl bromide also reacts smoothly with large nucleophiles, that are good electron donors, in dimethyl sulphoxide. Both the thiophenoxide anion and the 2nitropropane anion react with $p$-nitrocumyl bromide to give highly ramified products. These reactions proceed via competing heterolytic and radical chain mechanisms. 
Chapter 8 


\section{CHAPTER 9}

\section{EXPERIMENTAL}

\subsection{Equipment}

The $100 \mathrm{MHz}{ }^{1} \mathrm{H}$ n.m.r. spectra were obtained using a JEOL JNM-PS-100 n.m.r. spectrometer; the $200 \mathrm{MHz}{ }^{1} \mathrm{H}$ n.m.r. spectra were obtained using a Varian XL-200 n.m.r. spectrometer; the $400 \mathrm{MHz}{ }^{1} \mathrm{H}, 100 \mathrm{MHz}{ }^{13} \mathrm{C}, 40 \mathrm{MHz}{ }^{15} \mathrm{~N}$ and $60 \mathrm{MHz}^{2} \mathrm{D}$ n.m.r. spectra were obtained using a Varian VXR-400 n.m.r. spectrometer. The ${ }^{\mathbf{l}_{\mathbf{H}}}$ (nonkinetic) and ${ }^{13} \mathrm{C}$ n.m.r. spectra were reported in $\delta$ values relative to tetramethylsilane as the internal standard. The spectra were recorded in ${ }^{2} \mathrm{D}$-labelled chloroform $(C),{ }^{2} \mathrm{D}_{6}-$ labelled dimethyl sulphoxide (D) or ${ }^{2} \mathrm{D}_{4}$-labelled methanol (M). The following abbreviations are used in signal assignments; s (singlet), $d$ (doublet), $t$ (triplet), $q$ (quartet), qn (quintet), sp (septet), m (multiplet). An AB quartet will be expressed as two doublets for convenience. Microanalyses were carried out on non-hygroscopic compounds by the microanalytical section of the Chemistry Department, University College London. Melting points were determined on a Reicher melting point apparatus and are uncorrected. Mass spectra were recorded on a VG7070H mass spectrometer with Finnigan Incos II data system at University College, or on a VG ZAB-2F (E.I.) or VG 12250 (C.I.) mass spectrometer at the London School of Pharmacy. Only molecular ions $\left(\mathrm{M}^{+}\right)$, if present, base peaks and two other peaks due to abundant ions are reported. High performance liquid chromatography was performed on a Waters Associates differential refractometer machine and high pressure liquid chromatography was performed on a Waters Associates System 500 machine. All kinetic rate constants and semi-empirical molecular orbital calculations were performed using a $386 \mathrm{SX} 25 \mathrm{MHz}$ (25 MHz maths co-processor) I.B.M. compatible personnel computer. An Oertling R20 balance was used to weigh samples for the n.m.r. studies; a precisa $1600 \mathrm{c}$ balance was used to weigh all 
other samples. Irradiation experiments were carried out using a mercury arc lamp as the light source.

\subsection{Materials}

\subsubsection{Organic Compounds}

All organic compounds were supplied by the Aldrich Chemical Company except for cumene and p-nitrocumene which were supplied by B.D.H. and Lancaster Synthesis respectively. Authentic samples of $15_{\mathrm{N}}$-labelled nitrobenzene and $15_{\mathrm{N}}$-labelled nitromesitylene were supplied by R.G. Coombes and J.F. Johnson respectively.

\subsubsection{Inorganic Compounds}

All salts were supplied by the Aldrich Chemical Company except for lithium azide and sodium thiophenoxide which were supplied by the Eastman Kodak and Fluka Companies respectively. The highest purity grades were used and each salt, except tetrabutylammonium hydroxide, was dried by pumping at $35^{\circ} \mathrm{C}$ and $0.10 \mathrm{~mm} \mathrm{Hg}$ for 6 hours. Nitric, sulphuric, and acetic acids were supplied as Fison laboratory grade reagents and were used without further purification. ${ }^{15} \mathrm{~N}$-Labelled nitric acid was supplied as a 40 $45 \%$ (by weight) aqueous solution by M.S.D. Isotopes. Hydrogen peroxide (85\%) was supplied by Laporte Industries and should be used as described in the safety instuctions provided by the suppliers.

\subsubsection{Solvents}

All solvents supplied were B.D.H. AnalaR grade and were used without further purification except for the following: dimethyl sulphoxide was distilled from calcium hydride onto activated $4 \AA$ molecular sieves and from then on was handled under dry argon. Methanol $(99.9+\%)$ was stored over activated $3 \AA$ molecular sieves and again handled under dry argon. Super purity solvents used for high pressure and high 
performance liquid chromatography were supplied by Romil Chemicals. All labelled solvents were supplied by the Aldrich Chemical Company. ${ }^{2} \mathrm{D}_{6}$-labelled dimethyl sulphoxide (99.9 atom \%) and ${ }^{2} \mathrm{D}_{4}$-labelled methanol (99.8 atom \%) were stored over activated 4 and $3 \AA$ molecular sieves respectively, and from then on were handled under dry argon. $2 \mathrm{D}$-labelled chloroform (99.9 atom \%) and ${ }^{2} \mathrm{D}_{8}$-labelled propan-2-ol (99+ atom \%) were stored over $4 \AA$ molecular sieves and under dry argon.

\subsubsection{Gases}

All gases were supplied by B.O.C. except for the following: hydrogen chloride and hydrogen bromide/bromine were produced from the action of sulphuric acid on sodium chloride and sodium bromide respectively. All gases were dried by standard methods.

\subsection{Preparation of Starting Materials}

\subsubsection{Preparation of the Lithium Salt of 2-Nitropropane ${ }^{87}$}

Into a flask, equipped with a magnetic stirrer and a balloon filled with dry argon, were placed absolute methanol $\left(100 \mathrm{~cm}^{3}\right)$ and lithium methoxide $(5.23 \mathrm{~g}, 0.138 \mathrm{~mol})$. After this solution had been stirred for 10 minutes, 2-nitropropane (17.02 g, $0.19 \mathrm{~mol})$ was added to the flask and the mixture was stirred for a further 10 minutes. Evaporation of the solvent gave a viscous solution and addition of dry ethyl ether caused precipitation of the salt. The resulting slurry was filtered in a dry argon filled glove bag, the precipitate was washed with ether, and the resulting solid dried by pumping at $35^{\circ} \mathrm{C}$ and $0.10 \mathrm{~mm}$ $\mathrm{Hg}$ for 5 hours to give the lithium salt of 2-nitropropane $(12.42 \mathrm{~g}, 0.130 \mathrm{~mol})$ with a yield of $94 \%$. 
For the lithium salt of 2-nitropropane:

$1_{\text {H n.m.r. (D), } \delta: ~} 1.80(\mathrm{~s}, 6 \mathrm{H})$.

\subsubsection{Preparation of 15 N-Labelled 2-Nitropropane}

Into a flask, equipped with a magnetic stirrer and a balloon filled with dry argon, were placed dimethyl sulphoxide $\left(20 \mathrm{~cm}^{3}\right)$ and ${ }^{15} \mathrm{~N}$-labelled sodium nitrite $(1.03 \mathrm{~g}$, $0.0147 \mathrm{~mol})$. After this solution had been stirred for 10 minutes, 2-bromopropane $(2.00 \mathrm{~g}$, $0.0163 \mathrm{~mol}$ ) was added to the flask and the mixture was stirred for a further 6 hours. The reaction mixture was poured on to ice $(50 \mathrm{~g})$ and the aqueous solution was extracted with hexane $\left(5 \times 10 \mathrm{~cm}^{3}\right)$. The hexane solution was washed with water $\left(4 \times 5 \mathrm{~cm}^{3}\right)$ and dried over anhydrous magnesium sulphate. The drying agent was removed by filtration and the hexane solution was distilled through a small column at atmospheric pressure. The fraction boiling between $119-122^{\circ} \mathrm{C}$ gave ${ }^{15} \mathrm{~N}$-labelled 2-nitropropane $\left(0.65 \mathrm{~g}, 7.3 \times 10^{-}\right.$ 3 mol) with a yield of $50 \%$.

For ${ }^{15} \mathrm{~N}$-labelled 2-nitropropane:

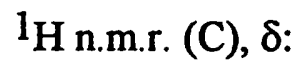

$$
\begin{aligned}
& 4.67\left(\mathrm{dsp}, \mathrm{J}_{1_{\mathrm{H}^{-}}{ }^{15} \mathrm{~N}}=1.62 \mathrm{~Hz}, 1 \mathrm{H}\right), \\
& 1.56\left(\mathrm{dd}, \mathrm{J}_{1 \cdot{ }^{15} \mathrm{~N}}=3.4 \mathrm{~Hz}, 6 \mathrm{H}\right) .
\end{aligned}
$$

${ }^{13}$ C n.m.r. (C), $\delta$ :

$78.5\left(\mathrm{~d}, \mathrm{~J}^{13} \mathrm{C}_{-}{ }^{15} \mathrm{~N}=15.2 \mathrm{~Hz}\right), 20.7$.

\subsubsection{Preparation of the 15 N-Labelled Lithium Salt of 2-Nitropropane}

Into a flask, equipped with a magnetic stirrer and a balloon filled with dry argon, were placed absolute methanol $\left(20 \mathrm{~cm}^{3}\right)$ and lithium methoxide $\left(0.23 \mathrm{~g}, 6.1 \times 10^{-3} \mathrm{~mol}\right)$. After this solution had been stirred for 10 minutes, ${ }^{15} \mathrm{~N}$-labelled 2-nitropropane $(0.60 \mathrm{~g}$, $6.7 \times 10^{-3} \mathrm{~mol}$ ) was added to the flask and the mixture was stirred for a further 10 minutes. Evaporation of the solvent gave a viscous solution and addition of dry ethyl 
ether caused precipitation of the salt. The resulting slurry was filtered in a dry argon filled glove bag, the precipitate was washed with ether, and the resulting solid dried by pumping at $35{ }^{\circ} \mathrm{C}$ and $0.10 \mathrm{~mm} \mathrm{Hg}$ for 5 hours to give the ${ }^{15} \mathrm{~N}$-labelled lithium salt of 2 nitropropane $\left(0.54 \mathrm{~g}, 5.6 \times 10^{-3} \mathrm{~mol}\right)$ with a yield of $92 \%$.

For the ${ }^{15} \mathrm{~N}$-labelled lithium salt of 2 -nitropropane:

lH n.m.r. (D), $\delta$ :

$1.78\left(\mathrm{~d}, 6 \mathrm{H}, \mathrm{J}_{\mathrm{H}_{\mathrm{H}-}-1 \mathrm{~N}_{\mathrm{N}}}=3.5 \mathrm{~Hz}\right)$

\subsubsection{Preparation of $p$-Nitrocumyl Alcohol ${ }^{88}$}

Into a flask equipped with a thermometer, a gas inlet tube, a pressure-equalizing addition funnel, and an efficient magnetic stirrer was placed p-nitrocumene $(5.00 \mathrm{~g}$, $0.0303 \mathrm{~mol})$ and dimethyl sulphoxide $\left(40 \mathrm{~cm}^{3}\right)$. Oxygen was bubbled into this solution for 15 minutes with stirring. At this point, potassium tertiary butoxide $\left(0.71 \mathrm{~g}, 6.3 \times 10^{-3}\right.$ mol) dissolved in tertiary butyl alcohol $\left(15 \mathrm{~cm}^{3}\right)$ was added, dropwise, with vigorous stirring and continued bubbling of oxygen. Several times during the addition of the tertiary butoxide solution the temperature of the reaction solution gradually rose to $35{ }^{\circ} \mathrm{C}$ whereupon the reaction vessel was immediately immersed in an ice bath, cooled to $20^{\circ} \mathrm{C}$, then removed from the ice bath. Addition of the tertiary butoxide solution required about 15 minutes. Vigorous stirring and the passing in of oxygen were continued for an additional 2 hours.

The resulting deep purple solution was poured on to ice (500 g) and then sodium chloride (15 g) was added. The aqueous solution was extracted with diethyl ether (5 X $\left.50 \mathrm{~cm}^{3}\right)$, the ether solution was washed with water $\left(4 \times 50 \mathrm{~cm}^{3}\right)$ and dried over anhydrous potassium carbonate. Removal of the solvent gave a red-brown liquid (5.16 g) and this was purified by high pressure liquid chromatography, eluting with $60 \%$ hexane$40 \%$ ethyl acetate to give $p$-nitrocumyl alcohol $(3.89 \mathrm{~g}, 0.0215 \mathrm{~mol})$ as a colourless liquid with a yield of $71 \%$. 
For $p$-nitrocumyl alcohol:

${ }^{1} \mathrm{H}$ n.m.r. (C), $\delta: \quad 8.18(\mathrm{~d}, 2 \mathrm{H}), 7.66(\mathrm{~d}, 2 \mathrm{H}), 2.11(\mathrm{~s}, 1 \mathrm{H}), 1.62(\mathrm{~s}, 6 \mathrm{H})$.

${ }^{13}$ C n.m.r. (C), $\delta$ :

$156.4,146.6,125.4,123.4,72.5,31.7$

Analysis: $\mathrm{C}_{9} \mathrm{H}_{11} \mathrm{NO}_{3}$

Calculated:

C, 59.66; H, 6.12; N, 7.73.

Found:

C, 59.38; H, 6.11; N, 7.65.

M.S. $m / e$ :

$181\left(\mathrm{M}^{+}\right), 164\left(\mathrm{M}^{+}-17\right), 136\left(\mathrm{M}^{+}-45\right), 45\left(\mathrm{M}^{+}-136\right)$.

\subsubsection{Preparation of $p$-Nitrocumyl Chloride ${ }^{88}$}

Into a flask fitted with a magnetic stirrer, a gas dispersion tube, an addition funnel, and a gas outlet tube were placed anhydrous zinc chloride $(5 \mathrm{~g})$ and dichloromethane (50 $\mathrm{cm}^{3}$ ). The flask was immersed in an ice bath and, while stirring, a stream of anhydrous hydrogen chloride was passed into the mixture for 20 minutes. Then $p$-nitrocumyl alcohol $(3.02 \mathrm{~g}, 0.0167 \mathrm{~mol})$ dissolved in dichloromethane $\left(15 \mathrm{~cm}^{3}\right)$ was added while the temperature of the mixture was maintained at $0{ }^{\circ} \mathrm{C}$. The reaction was allowed to proceed an additional 20 minutes while the flow of hydrogen chloride was maintained and the mixture was then filtered. Silicic acid $(3 \mathrm{~g})$ was added to the dichloromethane solution, and the mixture was swirled for a minute or two, filtered, and concentrated under reduced pressure. This gave a yellow liquid $(3.07 \mathrm{~g})$ and this was purified by high pressure liquid chromatography, eluting with $80 \%$ hexane- $20 \%$ ethyl acetate to give p-nitrocumyl chloride $(2.91 \mathrm{~g}, 0.0146 \mathrm{~mol})$ as a pale yellow liquid with a yield of $87 \%$.

For $p$-nitrocumyl chloride:

${ }^{1}$ H n.m.r. (C), $\delta$ :

$8.21(\mathrm{~d}, 2 \mathrm{H}), 7.76(\mathrm{~d}, 2 \mathrm{H}), 2.01(\mathrm{~s}, 6 \mathrm{H})$. 
${ }^{13}$ C n.m.r. (C), $\delta$ :

$153.2,147.1,126.7,123.5,68.0,34.1$.

Analysis: $\mathrm{C}_{9} \mathrm{H}_{10} \mathrm{NO}_{2} \mathrm{Cl} \quad$ Calculated: $\quad$ C, $54.15 ; \mathrm{H}, 5.05 ; \mathrm{N}, 7.02 ; \mathrm{Cl}, 17.76$.

Found: $\quad$ C, $53.80 ; \mathrm{H}, 5.08 ; \mathrm{N}, 6.83 ; \mathrm{Cl}, 18.16$.

M.S. m/e:

$199\left(M^{+}\right), 164\left(M^{+}-35\right), 115\left(M^{+}-84\right), 91\left(M^{+}-108\right)$.

\subsubsection{Preparation of 15 N-Labelled $p$-Nitrocumyl Alcohol}

Cumene $(1.90 \mathrm{~g}, 0.0158 \mathrm{~mol})$ was dissolved in acetic anhydride $\left(25 \mathrm{~cm}^{3}\right)$ and cooled in an ice/water bath. ${ }^{15} \mathrm{~N}$-labelled nitric acid $(1.00 \mathrm{~g}$ in $2.2-2.5 \mathrm{~g}$ of aqueous solution, $0.0153 \mathrm{~mol}$ ) was dissolved in acetic acid $\left(5 \mathrm{~cm}^{3}\right)$ and added to the cumene solution. Sulphuric acid $\left(98 \%, 1 \mathrm{~cm}^{3}\right)$ was added to the mixture which was then stirred, in an ice/water bath, for three hours. The mixture was then poured into ice/water (600 $\mathrm{cm}^{3}$ ) and allowed to warm to room temperature. The resulting solution was extracted with dichloromethane $\left(1 \times 100 \mathrm{~cm}^{3}, 1 \times 20 \mathrm{~cm}^{3}, 8 \times 10 \mathrm{~cm}^{3}\right)$. The organic phase was washed with $5 \%$ aqueous sodium carbonate $\left(3 \times 10 \mathrm{~cm}^{3}\right)$ and water $\left(3 \times 40 \mathrm{~cm}^{3}\right)$ and dried with magnesium sulphate. Evaporation of the solvent gave a red-brown liquid (2.32 g). The ${ }^{1} \mathrm{H}$ n.m.r. spectrum showed the liquid to be a mixture of $2 \%$ cumene and 24,4 , and $70 \%$, respectively, of ${ }^{15} \mathrm{~N}$-labelled $o-, m$-, and $p$-nitrocumenes. This corresponds to a $64 \%$ yield of ${ }^{15} \mathrm{~N}$-labelled $p$-nitrocumene.

Into a flask equipped with a thermometer, a gas inlet tube, a pressure-equalizing addition funnel, and an efficient magnetic stirrer was placed the above $15 \mathrm{~N}$-labelled nitrocumene mixture $\left(2.29 \mathrm{~g},{ }^{15} \mathrm{~N}\right.$-labelled $p$-nitrocumene $\left.\left(9.66 \times 10^{-3} \mathrm{~mol}\right)\right)$ and dimethyl sulphoxide $\left(30 \mathrm{~cm}^{3}\right)$. Oxygen was bubbled into this solution for 15 minutes with stirring. At this point, potassium tertiary butoxide $\left(0.22 \mathrm{~g}, 2.0 \times 10^{-3} \mathrm{~mol}\right)$ dissolved in tertiary butyl alcohol $\left(10 \mathrm{~cm}^{3}\right)$ was added, dropwise, with vigorous stirring and continued bubbling of oxygen. Several times during the addition of the tertiary butoxide solution the temperature of the reaction solution gradually rose to $35^{\circ} \mathrm{C}$ whereupon the reaction vessel was immediately immersed in an ice bath, cooled to $20^{\circ} \mathrm{C}$, then removed from the 
ice bath. Addition of the tertiary butoxide solution required about 10 minutes. Vigorous stirring and the passing in of oxygen were continued for an additional 2 hours.

The resulting deep purple solution was poured into ice $(300 \mathrm{~g})$ and then sodium chloride (10 g) was added. The aqueous solution was extracted with diethyl ether ( $5 \mathrm{X}$ $\left.50 \mathrm{~cm}^{3}\right)$, the ether solution was washed with water $\left(4 \times 30 \mathrm{~cm}^{3}\right)$ and dried over anhydrous potassium carbonate. Removal of the solvent gave a red-brown liquid $(2.20 \mathrm{~g})$. The ${ }^{1} \mathrm{H}$ n.m.r. spectrum showed this liquid to be a mixture of $65 \%{ }^{15} \mathrm{~N}$-labelled $p$ nitrocumyl alcohol and 26,4 , and $5 \%$, respectively, of $15 \mathrm{~N}$-labelled $o-, m$-nitrocumenes and an unknown. There was no trace of $15 \mathrm{~N}$-labelled $p$-nitrocumene. The above mixture was purified by high pressure liquid chromatography, eluting with $50 \%$ hexane- $50 \%$ ethyl acetate to give ${ }^{15} \mathrm{~N}$-labelled $p$-nitrocumyl alcohol $\left(1.28 \mathrm{~g}, 7.03 \times 10^{-3} \mathrm{~mol}\right)$ as a colourless liquid with a yield of $73 \%$.

For ${ }^{15} \mathrm{~N}$-labelled $p$-nitrocumyl alcohol:

$1_{\text {H n.m.r. (C), } \delta \text { : }}$

$8.14\left(\mathrm{dd}, 2 \mathrm{H}, \mathrm{J}_{\mathrm{H}^{-}-{ }_{\mathrm{N}}}=1.76 \mathrm{~Hz}\right), 7.66(\mathrm{~d}, 2 \mathrm{H})$,

$2.83(\mathrm{~s}, 1 \mathrm{H}) 2.01(\mathrm{~s}, 6 \mathrm{H})$.

${ }^{13}$ C n.m.r. (C), $\delta$ :

$156.5,146.3\left(\mathrm{~d}, \mathrm{~J}^{13} \mathrm{C}_{-15} \mathrm{~N}=14.9 \mathrm{~Hz}\right), 125.4,123.2,72.4$, 31.5.

Analysis: $\mathrm{C}_{9} \mathrm{H}_{11}{ }^{15} \mathrm{NO}_{3} \quad$ Calculated: $\quad$ C, 59.33; $\mathrm{H}, 6.09 ; \mathrm{N}, 7.69$.

Found: $\quad$ C, $58.94 ; \mathrm{H}, 6.12 ; \mathrm{N}, 7.52$.

M.S. $m / e: \quad 182\left(\mathrm{M}^{+}\right), 165\left(\mathrm{M}^{+}-17\right), 150\left(\mathrm{M}^{+}-32\right), 134\left(\mathrm{M}^{+}-48\right)$.

\subsubsection{Preparation of 15 -Labelled $p$-Nitrocumyl Chloride}

Into a flask fitted with a magnetic stirrer, a gas dispersion tube, an addition funnel, and a gas outlet tube were placed anhydrous zinc chloride $(2 \mathrm{~g})$ and dichloromethane 
$\left(30 \mathrm{~cm}^{3}\right)$. The flask was immersed in an ice bath and, while stirring, a stream of anhydrous hydrogen chloride was passed into the mixture for 20 minutes. Then ${ }^{15} \mathrm{~N}$-labelled $p$ nitrocumyl alcohol $\left(1.21 \mathrm{~g}, 6.65 \times 10^{-3} \mathrm{~mol}\right)$ dissolved in dichloromethane $\left(10 \mathrm{~cm}^{3}\right)$ was added while the temperature of the mixture was maintained at $0{ }^{\circ} \mathrm{C}$. The reaction was allowed to proceed an additional 20 minutes while the flow of hydrogen chloride was maintained and the mixture was then filtered. Silicic acid $(2 \mathrm{~g})$ was added to the dichloromethane solution, and the mixture was swirled for a minute or two, filtered, and concentrated under reduced pressure. This gave a yellow liquid (1.22 $\mathrm{g})$ and this was purified by high pressure liquid chromatography, eluting with $80 \%$ hexane- $20 \%$ ethyl acetate to give ${ }^{15} \mathrm{~N}$-labelled $p$-nitrocumyl chloride $\left(1.19 \mathrm{~g}, 5.94 \times 10^{-3} \mathrm{~mol}\right)$ as a pale yellow liquid with a yield of $89 \%$.

For ${ }^{15} \mathrm{~N}$-labelled $p$-nitrocumyl chloride:

${ }^{1}$ H n.m.r. (C), $\delta$ :

$8.21\left(\mathrm{dd}, 2 \mathrm{H}, \mathrm{J}_{\mathrm{H}^{-}-1 \mathrm{~N}_{\mathrm{N}}}=1.88 \mathrm{~Hz}\right), 7.76(\mathrm{~d}, 2 \mathrm{H})$, $2.01(\mathrm{~s}, 6 \mathrm{H})$.

${ }^{13}$ C n.m.r. (C), $\delta$ : $153.1,147.0\left(\mathrm{~d}, \mathrm{~J}^{13} \mathrm{C}_{-}{ }^{15} \mathrm{~N}=15.2 \mathrm{~Hz}\right), 126.6,123.5,67.9$, 34.1.

Analysis: $\mathrm{C}_{9} \mathrm{H}_{10}{ }^{15} \mathrm{NO}_{2} \mathrm{Cl} \quad$ Calculated: $\quad \mathrm{C}, 53.88 ; \mathrm{H}, 5.02 ; \mathrm{N}, 6.98 ; \mathrm{Cl}, 17.67$. Found: $\quad$ C, $54.16 ; \mathrm{H}, 5.28 ; \mathrm{N}, 6.73 ; \mathrm{Cl}, 17.57$.

M.S. $m / e$ : $200\left(M^{+}\right), 165\left(M^{+}-35\right), 115\left(M^{+}-84\right), 91\left(M^{+}-108\right)$.

\subsubsection{Preparation of $p$-Nitrocumyl Bromide ${ }^{89}$}

Into a round-bottomed flask were placed $p$-nitrocumene $(20.08 \mathrm{~g}, 0.122 \mathrm{~mol}), \mathrm{N}$ bromosuccinimide $(21.85 \mathrm{~g}, 0.123 \mathrm{~mol})$, benzoyl peroxide $(0.2 \mathrm{~g})$ and carbon tetrachloride $\left(150 \mathrm{~cm}^{3}\right)$. This mixture was heated under reflux until all the yellow $\mathrm{N}$ - 
bromosuccinimide resting on the bottom of the flask had reacted, giving rise to white succinimide floating on top of the mixture (about 1 hour). The mixture was cooled and the solid removed by filtration under suction. Evaporation of the solvent gave a redbrown liquid (27.21 g), which crystallised on standing for several hours. The solid obtained was recrystallised from hexane (after cooling to $5^{\circ} \mathrm{C}$ ) to give p-nitrocumyl bromide $(25.92 \mathrm{~g}, 0.106 \mathrm{~mol})$ as pale lemon needle-like crystals with a yield of $87 \%$.

For $p$-nitrocumyl bromide:

M.pt:

${ }^{1}$ H n.m.r. (C), $\delta$ :

${ }^{13}$ C n.m.r. (C), 8 :

Analysis: $\mathrm{C}_{9} \mathrm{H}_{10} \mathrm{NO}_{2} \mathrm{Br}$

M.S. $m / e$ :
$33-34{ }^{\circ} \mathrm{C}$.

$8.19(\mathrm{~d}, 2 \mathrm{H}), 7.78(\mathrm{~d}, 2 \mathrm{H}), 2.21(\mathrm{~s}, 6 \mathrm{H})$.

$153.5,146.9,126.9,123.5,60.9,35.1$.

\subsubsection{Preparation of Tetrabutylammonium Azide ${ }^{90}$}

Into a flask was placed tetrabutylammonium hydroxide $40 \mathrm{wt} \%$ solution $(15.10 \mathrm{~g}$, tetrabutylammonium hydroxide $(0.0233 \mathrm{~mol}))$. A solution of sodium azide $(3.32 \mathrm{~g}, 0.0511$ mol) in water $\left(100 \mathrm{~cm}^{3}\right)$ was added and the mixture was stirred for 10 minutes. The resulting solution was extracted with dichloromethane $\left(2 \times 100 \mathrm{~cm}^{3}\right)$. Evaporation of the solvent gave crude tetrabutylammonium azide $(6.87 \mathrm{~g})$ as a colourless liquid. Residual water was removed by azeotropic distillation with toluene, and the resulting solid was recrystallised from ethyl acetate. The crystals formed were dried by pumping at $35^{\circ} \mathrm{C}$ and 
$0.10 \mathrm{~mm} \mathrm{Hg}$ for 6 hours to give tetrabutylammonium azide $(5.77 \mathrm{~g}, 0.0203 \mathrm{~mol})$ with a yield of $87 \%$. It is very hygroscopic and was handled under dry argon at all times.

For tetrabutylammonium azide:

M.pt:

$78-81^{\circ} \mathrm{C}$.

${ }^{1}$ H n.m.r. (C), $\delta$ :

$3.38(\mathrm{t}, 2 \mathrm{H}), 1.72-1.68(\mathrm{~m}, 2 \mathrm{H}), 1.50-1.44(\mathrm{~m}, 2 \mathrm{H})$,

$1.02(t, 3 \mathrm{H})$.

${ }^{13}$ C n.m.r. (C), $\delta$ :

$58.5,23.8,19.6,13.5$.

M.S. $m / e$ :

$243\left(\mathrm{M}^{+}-41\right), 185\left(\mathrm{M}^{+}-99\right), 142\left(\mathrm{M}^{+}-142\right)$.

\subsubsection{Preparation of Tetrabutylammonium Perchlorate}

Into a flask was placed tetrabutylammonium hydroxide $40 \mathrm{wt} \%$ solution (15.02 g, tetrabutylammonium hydroxide $(0.0232 \mathrm{~mol}))$. A solution of sodium perchlorate $(6.20 \mathrm{~g}$, $0.0506 \mathrm{~mol})$ in water $\left(100 \mathrm{~cm}^{3}\right)$ was added and the mixture was stirred for 10 minutes. The white precipitate that formed was removed by filtration and washed with cold water $\left(20 \mathrm{~cm}^{3}\right)$. Any residual water was removed by azeotropic distillation with toluene, and the resulting solid was recrystallised from ethyl acetate. The crystals formed were dried by pumping at $35^{\circ} \mathrm{C}$ and $0.10 \mathrm{~mm} \mathrm{Hg}$ for 6 hours to give tetrabutylammonium perchlorate $(7.14 \mathrm{~g}, 0.0209 \mathrm{~mol})$ with a yield of $90 \%$.

For tetrabutylammonium perchlorate:

M.pt:

$218-220^{\circ} \mathrm{C}$ 
${ }^{1}$ H n.m.r. (C), $\delta$ :

${ }^{13}$ C n.m.r. (C), $\delta$ :

Analysis: $\mathrm{C}_{16} \mathrm{H}_{36} \mathrm{NO}_{4} \mathrm{Cl} \quad$ Calculated:

Found: $3.23(\mathrm{t}, 2 \mathrm{H}), 1.66-1.60(\mathrm{~m}, 2 \mathrm{H}), 1.46-1.40(\mathrm{~m}, 2 \mathrm{H})$, $1.00(t, 3 \mathrm{H})$.

$58.5,23.8,19.6,13.5$

M.S. $m / e$ :

$242\left(\mathrm{M}^{+}-99\right), 184\left(\mathrm{M}^{+}-157\right), 142\left(\mathrm{M}^{+}-199\right)$.

\subsubsection{Preparation of $\underline{\mathbf{2}} \underline{\mathbf{D}} \underline{\mathbf{6}} \underline{\text {-Labelled } p \text {-Nitrocumyl Alcohol }}$}

Into a two-necked flask fitted with a reflux condenser, a magnetic stirrer and a dropping funnel protected by a calcium chloride guard-tube were placed dry benzene $(19.4 \mathrm{~g}, 0.249 \mathrm{~mol})$ and anhydrous aluminium chloride $(10.2 \mathrm{~g}, 0.0764 \mathrm{~mol})$. The mixtured was stirred and ${ }^{2} \mathrm{D}_{8}$-labelled propan-2-ol $(4.94 \mathrm{~g}, 0.0735 \mathrm{~mol})$ was added from the dropping funnel. The mixture was gently heated and hydrogen chloride was evolved. Finally, the mixture was heated to reflux for 30 minutes, cooled, and poured on to ice $(100 \mathrm{~g})$. After warming to room temperature, the mixture was poured into a separatory funnel and the lower layer was discarded. The organic phase was washed with $5 \%$ aqueous sodium carbonate $\left(2 \times 10 \mathrm{~cm}^{3}\right)$ and water $\left(2 \times 10 \mathrm{~cm}^{3}\right)$ and dried with magnesium sulphate. The excess benzene was removed by flash distillation from a boilling water bath. ${ }^{1} \mathrm{H}$ n.m.r. showed the mixture $(5.06 \mathrm{~g})$ to be crude ${ }^{2} \mathrm{D}_{7}$-labelled cumene with about $5 \%{ }^{1} \mathrm{H}$ exchange.

The above ${ }^{2} \mathrm{D}_{7}$-labelled cumene $(4.12 \mathrm{~g}, 0.0324 \mathrm{~mol})$ was dissolved in acetic anhydride $\left(25 \mathrm{~cm}^{3}\right)$ and cooled in an ice/water bath. Nitric acid $(3.04 \mathrm{~g}, 69-70 \%, 0.0332$ mol) was dissolved in acetic acid $\left(10 \mathrm{~cm}^{3}\right)$ and added to the cumene solution. Sulphuric acid $\left(98 \%, 1 \mathrm{~cm}^{3}\right)$ was added to the mixture which was then stirred, in an ice/water bath, for three hours. The mixture was then poured into ice/water $\left(600 \mathrm{~cm}^{3}\right)$ and allowed to warm to room temperature. The resulting solution was extracted with dichloromethane (1 
$X 100 \mathrm{~cm}^{3}, 1 \times 20 \mathrm{~cm}^{3}, 8 \times 10 \mathrm{~cm}^{3}$ ). The organic phase was washed with $5 \%$ aqueous sodium carbonate $\left(3 \times 20 \mathrm{~cm}^{3}\right)$ and water $\left(3 \times 40 \mathrm{~cm}^{3}\right)$ and dried with magnesium sulphate. Evaporation of the solvent gave a red-brown liquid (4.98 g).

Into a flask equipped with a thermometer, a gas inlet tube, a pressure-equalizing addition funnel, and an efficient magnetic stirrer was placed the above ${ }^{2} \mathrm{D}_{7}$-labelled nitrocumene mixture $\left(4.83 \mathrm{~g},{ }^{2} \mathrm{D}_{7}\right.$-labelled p-nitrocumene $\left.(0.0197 \mathrm{~mol})\right)$ and dimethyl sulphoxide $\left(50 \mathrm{~cm}^{3}\right)$. Oxygen was bubbled into this solution for 15 minutes with stirring. At this point, potassium tertiary butoxide $\left(0.51 \mathrm{~g}, 4.6 \times 10^{-3} \mathrm{~mol}\right)$ dissolved in tertiary butyl alcohol $\left(20 \mathrm{~cm}^{3}\right)$ was added, dropwise, with vigorous stirring and continued bubbling of oxygen. Several times during the addition of the tertiary butoxide solution the temperature of the reaction solution gradually rose to $35^{\circ} \mathrm{C}$ whereupon the reaction vessel was immediately immersed in an ice bath, cooled to $20^{\circ} \mathrm{C}$, then removed from the ice bath. Addition of the tertiary butoxide solution required about 10 minutes. Vigorous stirring and the passing in of oxygen were continued for an additional 2 hours.

The resulting deep purple solution was poured into ice (300 g) and then sodium chloride (10 g) was added. The aqueous solution was extracted with diethyl ether ( $5 \mathrm{X}$ $\left.80 \mathrm{~cm}^{3}\right)$, the ether solution was washed with water $\left(4 \times 40 \mathrm{~cm}^{3}\right)$ and dried over anhydrous potassium carbonate. Removal of the solvent gave a red-brown liquid (4.15 g). The above mixture was purified by high pressure liquid chromatography, eluting with $50 \%$ hexane-50\% ethyl acetate to give ${ }^{2} \mathrm{D}_{6}$-labelled $p$-nitrocumyl alcohol $(2.76 \mathrm{~g}, 0.0148$ mol) as a colourless liquid with a yield of $75 \%$.

For ${ }^{2} \mathrm{D}_{6}$-labelled $p$-nitrocumyl alcohol:

${ }^{1}$ H n.m.r. (C), $\delta$ : $8.20(\mathrm{~d}, 2 \mathrm{H}), 7.66(\mathrm{~d}, 2 \mathrm{H}), 1.86(\mathrm{~s}, 1 \mathrm{H})$, $1.62-1.58(\mathrm{~m}, 0.37 \mathrm{H})$.

${ }^{13}$ C n.m.r. (C), $\delta$ : $156.3,146.7,125.5,123.5,72.3,31.8-30.5(\mathrm{~m})$. 
$\begin{array}{lll}\text { Analysis: } \mathrm{C}_{9} \mathrm{D}_{6} \mathrm{H}_{5} \mathrm{NO}_{3} & \text { Calculated: } & \text { C, } 57.74 ; \mathrm{H}, 5.92 ; \mathrm{N}, 7.48 . \\ & \text { Found: } & \text { C, } 56.61 ; \mathrm{H}, 5.88 ; \mathrm{N}, 7.18 .\end{array}$

M.S. $m / e$ :

$187\left(\mathrm{M}^{+}\right), 170\left(\mathrm{M}^{+}-17\right), 169\left(\mathrm{M}^{+}-18\right), 46\left(\mathrm{M}^{+}-141\right)$

\subsubsection{Preparation of $\underline{2}_{\underline{6}}$-Labelled p-Nitrocumyl Bromide}

Into a flask fitted with a magnetic stirrer, a gas dispersion tube, an addition funnel, and a gas outlet tube were placed anhydrous zinc bromide $(2 \mathrm{~g})$ and dichloromethane $\left(50 \mathrm{~cm}^{3}\right)$. The flask was immersed in an ice bath and, while stirring, a stream of anhydrous hydrogen bromide/bromine was passed into the mixture for 20 minutes. Then ${ }^{2} \mathrm{D}_{6}$ labelled $p$-nitrocumyl alcohol $(2.53 \mathrm{~g}, 0.0135 \mathrm{~mol})$ dissolved in dichloromethane $\left(20 \mathrm{~cm}^{3}\right)$ was added while the temperature of the mixture was maintained at $0{ }^{\circ} \mathrm{C}$. The reaction was allowed to proceed an additional 20 minutes while the flow of hydrogen bromide/bromine was maintained and the mixture was then filtered. Silicic acid $(2 \mathrm{~g})$ was added to the dichloromethane solution, and the mixture was swirled for a minute or two, filtered, and concentrated under reduced pressure. This gave a red-brown liquid (3.22 g), which crystallised on standing for several hours. The solid obtained was recrystallised from hexane upon cooling to $5^{\circ} \mathrm{C}$ to give ${ }^{2} \mathrm{D}_{6}$-labelled $p$-nitrocumyl bromide $(2.98 \mathrm{~g}, 0.0119$ mol) as pale lemon needle-like crystals with a yield of $88 \%$.

For ${ }^{2} \mathrm{D}_{6}$-labelled $p$-nitrocumyl bromide:

M.pt. $34-35^{\circ} \mathrm{C}$.

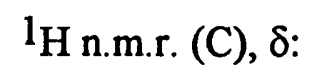
$8.19(\mathrm{~d}, 2 \mathrm{H}), 7.77(\mathrm{~d}, 2 \mathrm{H}), 2.16-2.17(\mathrm{~m}, 0.38 \mathrm{H})$.

${ }^{13}$ C n.m.r. (C), $\delta$ : $153.5,146.9,126.8,123.4,60.5,35.1-34.2(\mathrm{~m})$. 
Analysis: $\mathrm{C}_{9} \mathrm{D}_{6} \mathrm{H}_{4} \mathrm{NO}_{2} \mathrm{Br} \quad$ Calculated: $\quad \mathrm{C}, 43.22 ; \mathrm{H}, 4.02 ; \mathrm{N}, 5.60 ; \mathrm{Br}, 31.95$.

Found: $\quad \mathrm{C}, 43.02 ; \mathrm{H}, 3.95 ; \mathrm{N}, 5.24 ; \mathrm{Br}, 32.18$.

M.S. $m / e$ :

$247\left(M^{+}-2\right), 170\left(M^{+}-79\right), 124\left(M^{+}-125\right)$.

\subsubsection{Preparation of 4-sec-Butylnitrobenzene}

Into a flask was placed a solution of hydrogen peroxide $\left(2.0 \mathrm{~cm}^{3}, 85 \%\right)$ in chloroform $\left(9.0 \mathrm{~cm}^{3}\right)$ containing 2 drops of sulphuric acid (98\%) as catalyst. Acetic anhydride $(9.0 \mathrm{~g})$ was added dropwise to the solution which was then diluted with more chloroform $\left(6.0 \mathrm{~cm}^{3}\right)$ and brought to the boiling point. A solution of 4-sec-butylaniline $(2.12 \mathrm{~g}, 0.0142 \mathrm{~mol})$ in chloroform $\left(3.9 \mathrm{~cm}^{3}\right)$ was then added over a period of 20 minutes and the resulting mixture heated under reflux for 3 hours. This solution was then poured into water $\left(100 \mathrm{~cm}^{3}\right)$ and the organic layer separated, washed with aqueous sodium hydroxide $\left(2 \times 30 \mathrm{~cm}^{3}, 20 \%\right)$ and aqueous hydrochloric acid $\left(30 \mathrm{~cm}^{3}, 10 \%\right)$ and then dried over anhydrous magnesium sulphate. Removal of the solvent gave a red-brown liquid $(1.96 \mathrm{~g})$ and this was purified by high pressure liquid chromatography, eluting with $90 \%$ hexane- $10 \%$ ethyl acetate to give 4-sec-butylnitrobenzene $(1.81 \mathrm{~g}, 0.0101 \mathrm{~mol})$ as a yellow liquid with a yield of $71 \%$.

${ }^{1}$ H n.m.r. (C), $\delta$ :

$8.16(\mathrm{~d}, 2 \mathrm{H}), 7.33(\mathrm{~d}, 2 \mathrm{H}), 2.76-2.70(\mathrm{~m}, 1 \mathrm{H})$,

$1.68-1.59(\mathrm{~m}, 2 \mathrm{H}), 1.27(\mathrm{~d}, 3 \mathrm{H}), 0.83(\mathrm{t}, 3 \mathrm{H})$.

${ }^{13}$ C n.m.r. (C), $\delta$ :

$155.5,146.3,127.8,123.6,41.7,30.9,21.5,12.1$.

Analysis: $\mathrm{C}_{10} \mathrm{H}_{13} \mathrm{NO}_{2} \quad$ Calculated: $\quad$ C, 67.02; H, 7.31; N, 7.82.

Found: $\quad$ C, 66.45; H, 7.52; N, 7.76.

M.S. $m / e$ :

$180\left(\mathrm{MH}^{+}\right), 146\left(\mathrm{M}^{+}-33\right), 133\left(\mathrm{M}^{+}-46\right), 91\left(\mathrm{M}^{+}-88\right)$. 


\subsubsection{Preparation of 2-Bromo-2-(p-nitrophenyl) butane}

Into a round-bottomed flask were placed 4-sec-butyl-nitrobenzene $(1.62 \mathrm{~g}, 9.05 \mathrm{X}$ $\left.10^{-3} \mathrm{~mol}\right), \mathrm{N}$-bromosuccinimide $(1.91 \mathrm{~g}, 0.0107 \mathrm{~mol})$, benzoyl peroxide $(0.1 \mathrm{~g})$ and carbon tetrachloride $\left(50 \mathrm{~cm}^{3}\right)$. This mixture was heated under reflux until all the yellow $\mathrm{N}$-bromosuccinimide resting on the bottom of the flask had reacted, giving rise to white succinimide floating on top of the mixture (about 1 hour). The mixture was cooled and the solid removed by filtration under suction. Evaporation of the solvent gave a redbrown liquid (2.06 g), which crystallised on standing for several hours. The solid obtained was recrystallised from hexane upon cooling to $5{ }^{\circ} \mathrm{C}$ to give 2-bromo-2-( $p$ nitrophenyl)butane $\left(1.96 \mathrm{~g}, 7.60 \times 10^{-3} \mathrm{~mol}\right)$ as yellow needle-like crystals with a yield of $84 \%$.

For 2-bromo-2-(p-nitrophenyl)butane:

M.pt.

${ }^{1}$ H n.m.r. (C), $\delta$ :

${ }^{13}$ C n.m.r. (C), $\delta$ :

Analysis: $\mathrm{C}_{10} \mathrm{H}_{12} \mathrm{NO}_{2} \mathrm{Br}$

M.S. $m / e$ : $43-45^{\circ} \mathrm{C}$.

$8.19(\mathrm{~d}, 2 \mathrm{H}), 7.74(\mathrm{~d}, 2 \mathrm{H}), 2.41-2.88(\mathrm{~m}, 2 \mathrm{H})$,

$2.17(\mathrm{~s}, 3 \mathrm{H}), 0.94(\mathrm{t}, 3 \mathrm{H})$.

$152.4,146.8,127.6,123.4,67.8,40.2,31.2,10.6$.

Found: $\quad$ C, $46.28 ; \mathrm{H}, 4.84 ; \mathrm{N}, 5.17 ; \mathrm{Br}, 30.75$.

$257\left(\mathrm{M}^{+}\right), 178\left(\mathrm{M}^{+}-79\right), 136\left(\mathrm{M}^{+}-121\right), 116\left(\mathrm{M}^{+}-141\right)$ 


\subsection{Identification of Products}

\subsubsection{The Reaction of the Lithium Salt of 2-Nitropropane with p-Dinitrobenzene}

Into a flask equipped with a magnetic stirrer and a balloon filled with dry argon, was placed a solution of the lithium salt of 2-nitropropane $\left(0.51 \mathrm{~g}, 5.4 \times 10^{-3} \mathrm{~mol}\right)$ in dimethyl sulphoxide $\left(20 \mathrm{~cm}^{3}\right)$. To this flask was added a solution of $p$-dinitrobenzene $\left(0.82 \mathrm{~g}, 4.9 \times 10^{-3} \mathrm{~mol}\right)$ in dimethyl sulphoxide $\left(20 \mathrm{~cm}^{3}\right)$. After this solution had been stirred for 30 minutes, the resulting purple solution was poured on to ice (150 g) and then sodium chloride $(2 \mathrm{~g})$ was added. The aqueous solution was extracted with diethyl ether $\left(5 \times 20 \mathrm{~cm}^{3}\right)$, the ether solution was washed with water $\left(4 \times 5 \mathrm{~cm}^{3}\right)$ and dried over anhydrous magnesium sulphate. Removal of the solvent gave a yellow solid $(0.98 \mathrm{~g})$, which, on recrystallisation from ethanol, gave $\alpha, p$-dinitrocumene $\left(0.90 \mathrm{~g}, 4.3 \times 10^{-3} \mathrm{~mol}\right)$ as white crystals with a yield of $87 \%$.

For $\alpha, p$-dinitrocumene :

M.pt. $68-70^{\circ} \mathrm{C}$.

1H n.m.r. (C), $\delta$ :

$8.26(\mathrm{~d}, 2 \mathrm{H}), 7.60(\mathrm{~d}, 2 \mathrm{H}), 2.04(\mathrm{~s}, 6 \mathrm{H})$.

${ }^{13}$ C n.m.r. (C), $\delta$ :

$146.6,142.3,126.5,124.0,89.3,27.3$.

$\begin{array}{lll}\text { Analysis: } \mathrm{C}_{9} \mathrm{H}_{10} \mathrm{~N}_{2} \mathrm{O}_{4} & \text { Calculated: } & \text { C, } 51.43 ; \mathrm{H}, 4.80 ; \mathrm{N}, 13.33 . \\ & \text { Found: } & \text { C, } 51.53 ; \mathrm{H}, 4.67 ; \mathrm{N}, 12.92 .\end{array}$

M.S. $m / e$ :

$211\left(\mathrm{MH}^{+}\right), 164\left(\mathrm{M}^{+}-46\right), 115\left(\mathrm{M}^{+}-95\right), 91\left(\mathrm{M}^{+}-119\right)$

(Matrix subtracted) 


\subsubsection{The Reaction of the 15 N-Labelled Lithium Salt of 2-Nitropropane with $p$ - \\ Dinitrobenzene}

Into a flask equipped with a magnetic stirrer and a balloon filled with dry argon, was placed a solution of the ${ }^{15} \mathrm{~N}$-labelled lithium salt of 2-nitropropane $\left(0.21 \mathrm{~g}, 2.2 \times 10^{-}\right.$ $3 \mathrm{~mol})$ in dimethyl sulphoxide $\left(10 \mathrm{~cm}^{3}\right)$. To this flask was added a solution of $p$ dinitrobenzene $\left(0.32 \mathrm{~g}, 1.9 \times 10^{-3} \mathrm{~mol}\right)$ in dimethyl sulphoxide $\left(10 \mathrm{~cm}^{3}\right)$. After this solution had been stirred for 30 minutes, the resulting light purple solution was poured into ice $(100 \mathrm{~g})$ and then sodium chloride $(2 \mathrm{~g})$ was added. The aqueous solution was extracted with diethyl ether $\left(5 \times 10 \mathrm{~cm}^{3}\right)$, the ether solution was washed with water $(4 \mathrm{X}$ $5 \mathrm{~cm}^{3}$ ) and dried over anhydrous magnesium sulphate. Removal of the solvent gave a yellow solid $(0.41 \mathrm{~g})$, which, on recrystallisation from ethanol, gave ${ }^{15} \mathrm{~N}$-labelled $\alpha, p$ dinitrocumene $\left(0.30 \mathrm{~g}, 1.4 \times 10^{-3} \mathrm{~mol}\right)$ as white crystals with a yield of $74 \%$.

For ${ }^{15} \mathrm{~N}$-labelled $\alpha, p$-dinitrocumene:

M.pt.

${ }^{1}$ H n.m.r. (C), $\delta$ :

${ }^{13}$ C n.m.r. (C), $\delta$ :
$69-72{ }^{\circ} \mathrm{C}$.

$8.26(\mathrm{~d}, 2 \mathrm{H}), 7.60(\mathrm{~d}, 2 \mathrm{H}), 2.04\left(\mathrm{~d}, 6 \mathrm{H}, \mathrm{J}_{\mathrm{H}_{\mathrm{H}} \cdot 1 \mathrm{~N}_{\mathrm{N}}}=3.0 \mathrm{~Hz}\right)$.

$146.6,142.3,126.5,124.0,89.2\left(\mathrm{~d}, \mathrm{~J}_{13} \mathrm{C}_{-}{ }^{15} \mathrm{~N}=15.0 \mathrm{~Hz}\right)$,

27.3.

Analysis: $\mathrm{C}_{9} \mathrm{H}_{10}{ }^{15} \mathrm{NNO}_{4} \quad$ Calculated: $\quad$ C, $51.19 ; \mathrm{H}, 4.77 ; \mathrm{N}, 13.27$.

Found: $\quad$ C, $51.47 ; \mathrm{H}, 5.16 ; \mathrm{N}, 12.85$.

M.S. $m / e$ :

$212\left(\mathrm{MH}^{+}\right), 164\left(\mathrm{M}^{+}-47\right), 115\left(\mathrm{M}^{+}-96\right), 91\left(\mathrm{M}^{+}-120\right)$.

(Matrix subtracted) 


\subsubsection{The Reaction of Sodium Thiophenoxide with p-Nitrocumyl Chloride}

Into a flask equipped with a magnetic stirrer and a balloon filled with dry argon, was placed a solution of sodium thiophenoxide $\left(0.51 \mathrm{~g}, 3.9 \times 10^{-3} \mathrm{~mol}\right)$ in dimethyl sulphoxide $\left(20 \mathrm{~cm}^{3}\right)$. To this flask was added a solution of $p$-nitrocumyl chloride $(0.40 \mathrm{~g}$, $\left.2.0 \times 10^{-3} \mathrm{~mol}\right)$ in dimethyl sulphoxide $\left(20 \mathrm{~cm}^{3}\right)$. After this solution had been stirred for 15 minutes, the resulting light purple solution was poured into ice $(100 \mathrm{~g})$ and then sodium chloride $(2 \mathrm{~g})$ was added. The aqueous solution was extracted with diethyl ether ( $5 \times 20 \mathrm{~cm}^{3}$ ), the ether solution was washed with water $\left(4 \times 5 \mathrm{~cm}^{3}\right)$ and dried over anhydrous magnesium sulphate. Removal of the solvent gave a yellow liquid (0.56 g), which crystallised on standing for several hours. The solid obtained was recrystallised from hexane to give $p$-nitrocumyl phenyl sulphide $\left(0.50 \mathrm{~g}, 1.8 \times 10^{-3} \mathrm{~mol}\right)$ with a yield of $90 \%$.

For $p$-nitrocumyl phenyl sulphide:

M.pt.

${ }^{1}$ H n.m.r. (C), $\delta$ :

${ }^{13}$ C n.m.r. (C), $\delta$ :

$154.1,146.2,136.5,131.6,129.1,128.6,127.5,123.1$,

Analysis: $\mathrm{C}_{15} \mathrm{H}_{15} \mathrm{NO}_{2} \mathrm{~S} \quad$ Calculated: $\quad \mathrm{C}, 65.94 ; \mathrm{H}, 5.54 ; \mathrm{N}, 5.14 ; \mathrm{S}, 11.75$.

Found: $\quad \mathrm{C}, 65.67 ; \mathrm{H}, 5.64 ; \mathrm{N}, 4.84 ; \mathrm{S}, 11.63$.

M.S. $m / e$ :

$273\left(\mathrm{M}^{+}\right), 164\left(\mathrm{M}^{+}-46\right), 115\left(\mathrm{M}^{+}-95\right), 91\left(\mathrm{M}^{+}-119\right)$ 


\subsubsection{The Reaction of Sodium Thiophenoxide with 15 N-Labelled $p$-Nitrocumyl \\ Chloride}

Into a flask equipped with a magnetic stirrer and a balloon filled with dry argon, was placed a solution of sodium thiophenoxide $\left(0.24 \mathrm{~g}, 1.8 \times 10^{-3} \mathrm{~mol}\right)$ in dimethyl sulphoxide $\left(10 \mathrm{~cm}^{3}\right)$. To this flask was added a solution of $15 \mathrm{~N}$-labelled $p$-nitrocumyl chloride $\left(0.20 \mathrm{~g}, 1.0 \times 10^{-3} \mathrm{~mol}\right)$ in dimethyl sulphoxide $\left(10 \mathrm{~cm}^{3}\right)$. After this solution had been stirred for 15 minutes, the resulting light purple solution was poured on to ice $(50 \mathrm{~g})$ and then sodium chloride $(1 \mathrm{~g})$ was added. The aqueous solution was extracted with diethyl ether $\left(5 \times 10 \mathrm{~cm}^{3}\right)$, the ether solution was washed with water $\left(4 \times 5 \mathrm{~cm}^{3}\right)$ and dried over anhydrous magnesium sulphate. Removal of the solvent gave a yellow liquid (0.26 g), which crystallised on standing for several hours. The solid obtained was recrystallised from hexane to give ${ }^{15} \mathrm{~N}$-labelled $p$-nitrocumyl phenyl sulphide $(0.24 \mathrm{~g}, 8.8$ $X 10^{-4} \mathrm{~mol}$ ) with a yield of $88 \%$.

For ${ }^{15} \mathrm{~N}$-labelled $p$-nitrocumyl phenyl sulphide:

M.pt.

$54-56{ }^{\circ} \mathrm{C}$

lH n.m.r. (C), $\delta$ :

$8.11\left(\mathrm{dd}, 2 \mathrm{H}, \mathrm{J}_{\mathrm{H}_{-}-\mathrm{S}_{\mathrm{N}}}=1.72 \mathrm{~Hz}\right), 7.50(\mathrm{~d}, 2 \mathrm{H}), 7.29-7.06$ $(\mathrm{m}, 5 \mathrm{H}), 1.70(\mathrm{~s}, 6 \mathrm{H})$.

${ }^{13}$ C n.m.r. (C), $\delta$ :

$154.0,146.3\left(\mathrm{~d}, \mathrm{~J}_{13} \mathrm{C}^{15} \mathrm{~N}=14.8 \mathrm{~Hz}\right), 136.5,131.6,129.2$, $128.6,127.6,123.0,50.5,29.4$.

Analysis: $\mathrm{C}_{15} \mathrm{H}_{15}{ }^{15} \mathrm{NO}_{2} \mathrm{~S} \quad$ Calculated: $\quad \mathrm{C}, 65.67 ; \mathrm{H}, 5.51 ; \mathrm{N}, 5.10 ; \mathrm{S}, 11.69$.

Found: $\quad$ C, $65.94 ; \mathrm{H}, 5.54 ; \mathrm{N}, 5.14 ; \mathrm{S}, 11.75$.

M.S. $m / e$ :

$274\left(\mathrm{MH}^{+}\right), 165\left(\mathrm{M}^{+}-46\right), 115\left(\mathrm{M}^{+}-95\right), 91\left(\mathrm{M}^{+}-119\right)$. 


\subsubsection{The Reaction of Sodium Nitrite with $p$-Nitrocumyl Bromide}

Into a flask equipped with a magnetic stirrer and a balloon filled with dry argon, was placed a solution of sodium nitrite $(0.714 \mathrm{~g}, 0.0104 \mathrm{~mol})$ in dimethyl sulphoxide (20 $\left.\mathrm{cm}^{3}\right)$. To this flask was added a solution of $p$-nitrocumyl bromide $\left(0.501 \mathrm{~g}, 2.05 \times 10^{-3}\right.$ mol) in dimethyl sulphoxide $\left(20 \mathrm{~cm}^{3}\right)$. After this solution had been stirred for 5 hours, the resulting red-brown solution was poured on to ice $(100 \mathrm{~g})$ and then sodium chloride $(2 \mathrm{~g})$ was added. The aqueous solution was extracted with ethyl acetate $\left(5 \times 20 \mathrm{~cm}^{3}\right)$, the organic phase was washed with water $\left(4 \times 10 \mathrm{~cm}^{3}\right)$ and dried over anhydrous magnesium sulphate. Removal of the solvent gave a red brown liquid $(0.456 \mathrm{~g})$ and this was purified by high pressure liquid chromatography, eluting with $60 \%$ hexane- $40 \%$ ethyl acetate to give $\alpha, p$-dinitrocumene $\left(0.221 \mathrm{~g}, 1.05 \times 10^{-3} \mathrm{~mol}, 51 \%\right), p$-nitrocumyl alcohol $(0.072 \mathrm{~g}$, $\left.3.98 \times 10^{-4} \mathrm{~mol}, 19 \%\right)$ and $p$-nitro- $\alpha$-methylstyrene $\left(0.058 \mathrm{~g}, 3.56 \times 10^{-4} \mathrm{~mol}, 17 \%\right)$.

For $\alpha, p$-dinitrocumene: $\quad$ Data in agreement with 9.4.1.

For $p$-nitrocumyl alcohol: $\quad$ Data in agreement with 9.3.4.

For $p$-nitro- $\alpha$-methylstyrene:

M.pt:

$51-53{ }^{\circ} \mathrm{C}$.

${ }^{1}$ H n.m.r. (C), $\delta$ : $8.19(\mathrm{~d}, 2 \mathrm{H}), 7.60(\mathrm{~d}, 2 \mathrm{H}), 5.53(\mathrm{dd}, 1 \mathrm{H}), 5.30(\mathrm{dd}, 1 \mathrm{H})$, $2.19(\mathrm{~s}, 3 \mathrm{H})$.

${ }^{13}$ C n.m.r. (C), $\delta$ : $147.6,146.9,141.5,126.2,123.6,116.4,21.6$.

Analysis: $\mathrm{C}_{9} \mathrm{H}_{9} \mathrm{NO}_{2}$

Calculated: C, 66.24; H, 5.56; N, 8.58.

Found: C, 66.04; H, 5.64; N, 8.45. 


\subsubsection{The Reaction of 15 -Labelled Sodium Nitrite with $p$-Nitrocumyl Bromide}

Into a flask equipped with a magnetic stirrer and a balloon filled with dry argon, was placed a solution of ${ }^{15} \mathrm{~N}$-labelled sodium nitrite $\left(0.282 \mathrm{~g}, 4.03 \times 10^{-3} \mathrm{~mol}\right)$ in dimethyl sulphoxide $\left(10 \mathrm{~cm}^{3}\right)$. To this flask was added a solution of $p$-nitrocumyl bromide $\left(0.195 \mathrm{~g}, 7.99 \times 10^{-4} \mathrm{~mol}\right)$ in dimethyl sulphoxide $\left(10 \mathrm{~cm}^{3}\right)$. After this solution had been stirred for 5 hours, the resulting red-brown solution was poured on to ice $(50 \mathrm{~g})$ and then sodium chloride $(1 \mathrm{~g})$ was added. The aqueous solution was extracted with ethyl acetate $\left(5 \times 10 \mathrm{~cm}^{3}\right)$, the organic phase was washed with water $\left(4 \times 5 \mathrm{~cm}^{3}\right)$ and dried over anhydrous magnesium sulphate. Removal of the solvent gave a red-brown liquid $(0.180 \mathrm{~g})$ and this was purified by high pressure liquid chromatography, eluting with $60 \%$ hexane$40 \%$ ethyl acetate to give ${ }^{15} \mathrm{~N}$-labelled $\alpha, p$-dinitrocumene $\left(0.084 \mathrm{~g}, 3.98 \times 10^{-4} \mathrm{~mol}\right.$, $50 \%), p$-nitrocumyl alcohol $\left(0.027 \mathrm{~g}, 1.49 \times 10^{-4} \mathrm{~mol}, 19 \%\right)$ and $p$-nitro- $\alpha$ methylstyrene $\left(0.023 \mathrm{~g}, 1.41 \times 10^{-4} \mathrm{~mol}, 18 \%\right)$.

For ${ }^{15} \mathrm{~N}$-labelled $\alpha, p$-dinitrocumene: Data in agreement with 9.4.2.

For $p$-nitrocumyl alcohol: $\quad$ Data in agreement with 9.3.4.

For $p$-nitro- $\alpha$-methylstyrene: $\quad$ Data in agreement with 9.4.5.

\subsubsection{The Elimination of $p$-Nitrocumyl Bromide}

Into a flask equipped with a magnetic stirrer and a baloon filled with dry argon, was placed a solution of $p$-nitrocumyl bromide $\left(0.309 \mathrm{~g}, 1.27 \times 10^{-3} \mathrm{~mol}\right)$ in dimethyl sulphoxide $\left(20 \mathrm{~cm}^{3}\right)$. After this solution had been stirred for 9 hours, the resulting solution was poured on to ice $(100 \mathrm{~g})$ and then sodium chloride $(1 \mathrm{~g})$ was added. The aqueous solution was extracted with diethyl ether $\left(5 \times 20 \mathrm{~cm}^{3}\right)$, the ether solution was washed with water $\left(4 \times 10 \mathrm{~cm}^{3}\right)$ and dried over anhydrous magnesium sulphate. Removal of the solvent gave a yellow liquid $(0.223 \mathrm{~g})$ and this was purified by high pressure liquid chromatography, eluting with $70 \%$ hexane- $30 \%$ ethyl acetate to give $p$-nitro- $\alpha$ - 
methylstyrene $\left(0.114 \mathrm{~g}, 6.99 \times 10^{-4} \mathrm{~mol}, 55 \%\right)$, p-nitrocumyl bromide $(0.065 \mathrm{~g}, 2.66 \mathrm{X}$ $\left.10^{-4} \mathrm{~mol}, 21 \%\right)$ and $p$-nitrocumyl alcohol $\left(0.022 \mathrm{~g}, 1.29 \times 10^{-4} \mathrm{~mol}, 10 \%\right)$.

For $p$-nitro- $\alpha$-methylstyrene: $\quad$ Data in agreement with 9.4.5.

For $p$-nitrocumyl bromide: $\quad$ Data in agreement with 9.3.8.

For $p$-nitrocumyl alcohol: $\quad$ Data in agreement with 9.3.4.

\subsubsection{The Reaction of Lithium Azide with $p$-Nitrocumyl Bromide}

Into a flask equipped with a magnetic stirrer and a balloon filled with dry argon, was placed a solution of lithium azide $\left(0.205 \mathrm{~g}, 4.18 \times 10^{-3} \mathrm{~mol}\right)$ in dimethyl sulphoxide $\left(20 \mathrm{~cm}^{3}\right)$. To this flask was added a solution of $p$-nitrocumyl bromide $(0.516 \mathrm{~g}, 2.11 \mathrm{X}$ $\left.10^{-3} \mathrm{~mol}\right)$ in dimethyl sulphoxide $\left(20 \mathrm{~cm}^{3}\right)$. After this solution had been stirred for 3 hours, the resulting yellow solution was poured on to ice $(100 \mathrm{~g})$ and then sodium chloride $(2 \mathrm{~g})$ was added. The aqueous solution was extracted with diethyl ether $(5$ X 20 $\left.\mathrm{cm}^{3}\right)$, the ether solution was washed with water $\left(4 \mathrm{X} 10 \mathrm{~cm}^{3}\right)$ and dried over anhydrous magnesium sulphate. Removal of the solvent gave a yellow liquid $(0.445 \mathrm{~g})$. and $0.122 \mathrm{~g}$ of this was purified by high performance liquid chromatography: firstly, eluting with $95 \%$ hexane-5\% ethyl acetate to give $p$-nitrocumyl azide $\left(0.100 \mathrm{~g}, 4.85 \times 10^{-4} \mathrm{~mol}, 84 \%\right)$ and $p$-nitro- $\alpha$-methylstyrene $\left(0.008 \mathrm{~g}, 4.9 \times 10^{-5} \mathrm{~mol}, 8 \%\right)$, and secondly, eluting with $50 \%$ hexane- $50 \%$ ethyl acetate to give $p$-nitrocumyl alcohol $\left(0.002 \mathrm{~g}, 1.2 \times 10^{-5} \mathrm{~mol}, 2 \%\right)$.

For $p$-nitrocumyl azide,

${ }^{1}$ H n.m.r. (C), $\delta$ :

$8.23(\mathrm{~d}, 2 \mathrm{H}), 7.62(\mathrm{~d}, 2 \mathrm{H}), 1.68(\mathrm{~s}, 6 \mathrm{H})$.

${ }^{13}$ C n.m.r. (C), $\delta$ :

$152.0,147.1,126.2,123.8,63.3,28.3$. 
Analysis: $\mathrm{C}_{9} \mathrm{H}_{10} \mathrm{~N}_{4} \mathrm{O}_{2} \quad$ Calculated: $\quad$ C, 52.42; $\mathrm{H}, 4.89 ; \mathrm{N}, 27.17$.

Found: $\quad$ C, $52.25 ; \mathrm{H}, 5.06 ; \mathrm{N}, 26.88$.

M.S. $m / e$ :

$207\left(\mathrm{MH}^{+}\right), 164\left(\mathrm{M}^{+}-46\right), 117\left(\mathrm{M}^{+}-95\right), 76\left(\mathrm{M}^{+}-119\right)$.

(Matrix subtracted)

For $p$-nitro- $\alpha$-methylstyrene: Data in agreement with 9.4.5.

For $p$-nitrocumyl alcohol: $\quad$ Data in agreement with 9.3.4.

\subsubsection{The Reaction of Tetrabutylammonium Azide with $p$-nitrocumyl bromide}

Into a flask equipped with a magnetic stirrer and a balloon filled with dry argon, was placed a solution of tetrabutylammonium azide $\left(1.154 \mathrm{~g}, 4.06 \times 10^{-3} \mathrm{~mol}\right)$ in dimethyl sulphoxide $\left(20 \mathrm{~cm}^{3}\right)$. To this flask was added a solution of $p$-nitrocumyl bromide $\left(0.490 \mathrm{~g}, 2.01 \times 10^{-3} \mathrm{~mol}\right)$ in dimethyl sulphoxide $\left(20 \mathrm{~cm}^{3}\right)$. After this solution had been stirred for 3 hours, the resulting yellow solution was poured on to ice $(100 \mathrm{~g})$ and then sodium chloride $(2 \mathrm{~g}$ ) was added. The aqueous solution was extracted with diethyl ether $\left(5 \times 20 \mathrm{~cm}^{3}\right)$, the ether solution was washed with water $\left(4 \times 20 \mathrm{~cm}^{3}\right)$ and dried over anhydrous magnesium sulphate. Removal of the solvent gave a yellow liquid $(0.483 \mathrm{~g})$ and $0.164 \mathrm{~g}$ of this was purified by high performance liquid chromatography: firstly, eluting with $95 \%$ hexane- $5 \%$ ethyl acetate to give $p$-nitrocumyl azide $(0.121 \mathrm{~g}, 5.87 \mathrm{X}$ $\left.10^{-4} \mathrm{~mol}, 86 \%\right)$ and $p$-nitro- $\alpha$-methylstyrene $\left(0.004 \mathrm{~g}, 2.7 \times 10^{-5} \mathrm{~mol}, 4 \%\right)$, and secondly, eluting with $50 \%$ hexane- $50 \%$ ethyl acetate to give $p$-nitrocumyl alcohol $(0.001$ g, $\left.5.8 \times 10^{-6} \mathrm{~mol},<1 \%\right)$.

For $p$-nitrocumyl azide:

Data in agreement with 9.4.8.

For $p$-nitro- $\alpha$-methylstyrene: $\quad$ Data in agreement with 9.4.5. 
For $p$-nitrocumyl alcohol: $\quad$ Data in agreement with 9.3.4.

\subsubsection{The Reaction of Lithium Azide with ${ }_{2}^{2}$-Labelled p-Nitrocumyl Bromide}

Into a flask equipped with a magnetic stirrer and a balloon filled with dry argon, was placed a solution of lithium azide $\left(0.201 \mathrm{~g}, 4.10 \times 10^{-3} \mathrm{~mol}\right)$ in dimethyl sulphoxide $\left(20 \mathrm{~cm}^{3}\right)$. To this flask was added a solution of ${ }^{2} \mathrm{D}_{6}$-labelled $p$-nitrocumyl bromide $(0.498$ $\left.\mathrm{g}, 1.99 \times 10^{-3} \mathrm{~mol}\right)$ in dimethyl sulphoxide $\left(20 \mathrm{~cm}^{3}\right)$. After this solution had been stirred for 4 hours, the resulting yellow solution was poured on to ice $(100 \mathrm{~g})$ and then sodium chloride $(2 \mathrm{~g})$ was added. The aqueous solution was extracted with diethyl ether (5 X 20 $\left.\mathrm{cm}^{3}\right)$, the ether solution was washed with water $\left(4 \times 10 \mathrm{~cm}^{3}\right)$ and dried over anhydrous magnesium sulphate. Removal of the solvent gave a yellow liquid $(0.441 \mathrm{~g})$ and $0.212 \mathrm{~g}$ of this was purified by high performance liquid chromatography: firstly, eluting with $95 \%$ hexane-5\% ethyl acetate to give ${ }^{2} \mathrm{D}_{6}$-labelled $p$-nitrocumyl azide $\left(0.178 \mathrm{~g}, 8.40 \times 10^{-4}\right.$ mol, $88 \%$ ) and ${ }^{2} \mathrm{D}_{5}$-labelled $p$-nitro- $\alpha$-methylstyrene (0.006 g, $\left.3.57 \times 10^{-4} \mathrm{~mol}, 4 \%\right)$, and secondly, eluting with $50 \%$ hexane-50\% ethyl acetate to give ${ }^{2} \mathrm{D}_{6}$-labelled $p$ nitrocumyl alcohol $\left(0.003 \mathrm{~g}, 1.7 \times 10^{-5} \mathrm{~mol}, 2 \%\right)$.

For ${ }^{2} \mathrm{D}_{6}$-labelled $p$-nitrocumyl azide:

${ }^{1}$ H n.m.r. (C), $\delta$ :

$8.23(\mathrm{~d}, 2 \mathrm{H}), 7.62(\mathrm{~d}, 2 \mathrm{H}), 1.64-1.66(\mathrm{~m}, 0.40 \mathrm{H})$.

${ }^{13}$ C n.m.r. (C), $\delta$ :

$152.0,147.1,126.2,123.8,63.0,27.8-27.3(\mathrm{~m})$.

Analysis: $\mathrm{C}_{9} \mathrm{H}_{10} \mathrm{~N}_{4} \mathrm{O}_{2} \quad$ Calculated: $\quad$ C, $50.93 ; \mathrm{H}, 4.75 ; \mathrm{N}, 26.40$.

Found: $\quad$ C, $50.90 ; \mathrm{H}, 4.83 ; \mathrm{N}, 26.29$.

M.S. $m / e$ :

$213\left(\mathrm{MH}^{+}\right), 170\left(\mathrm{M}^{+}-42\right), 55\left(\mathrm{M}^{+}-157\right), 41\left(\mathrm{M}^{+}-171\right)$.

(Matrix subtracted) 
For ${ }^{2} \mathrm{D}_{5}$-labelled $p$-nitro- $\alpha$-methylstyrene:

M.pt:

$49-52^{\circ} \mathrm{C}$.

1H n.m.r. (C), $\delta$ :

$8.20(\mathrm{~d}, 2 \mathrm{H}), 7.60(\mathrm{~d}, 2 \mathrm{H}), 2.17-2.20(\mathrm{~m}, 0.18 \mathrm{H})$.

Analysis: $\mathrm{C}_{9} \mathrm{D}_{5} \mathrm{H}_{4} \mathrm{NO}_{2} \quad$ Calculated: $\quad \mathrm{C}, 64.27 ; \mathrm{H}, 5.39 ; \mathrm{N}, 8.33$.

Found: $\quad$ C, $64.50 ; \mathrm{H}, 5.14 ; \mathrm{N}, 7.81$.

For ${ }^{2} \mathrm{D}_{6}$-labelled $p$-nitrocumyl alcohol: $\quad$ Data in agreement with 9.3.11.

\subsubsection{The Reaction of Lithium Azide with 2-Bromo-2-(p-Nitrophenyl)Butane}

Into a flask equipped with a magnetic stirrer and a balloon filled with dry argon, was placed a solution of lithium azide $\left(0.211 \mathrm{~g}, 4.31 \times 10^{-3} \mathrm{~mol}\right)$ in dimethyl sulphoxide $\left(20 \mathrm{~cm}^{3}\right)$. To this flask was added a solution of 2-bromo-2-( $p$-nitrophenyl) butane $(0.552$ $\left.\mathrm{g}, 2.14 \times 10^{-3} \mathrm{~mol}\right)$ in dimethyl sulphoxide $\left(20 \mathrm{~cm}^{3}\right)$. After this solution had been stirred for 6 hours, the resulting yellow solution was poured on to ice (100 g) and then sodium chloride $(2 \mathrm{~g})$ was added. The aqueous solution was extracted with diethyl ether ( 5 X 20 $\left.\mathrm{cm}^{3}\right)$, the ether solution was washed with water $\left(4 \times 10 \mathrm{~cm}^{3}\right)$ and dried over anhydrous magnesium sulphate. Removal of the solvent gave a yellow liquid $(0.485 \mathrm{~g})$ and $0.254 \mathrm{~g}$ of this was purified by high performance liquid chromatography, eluting with $95 \%$ hexane-5\% ethyl acetate to give 2-azido-2-( $p$-nitrophenyl)butane $\left(0.101 \mathrm{~g}, 4.60 \times 10^{-4}\right.$ mol, $41 \%)$ and a mixture of 2-(p-nitrophenyl)but-1-ene and 2-(p-nitrophenyl)but-2-ene $\left(0.093 \mathrm{~g}, 5.2 \times 10^{-4} \mathrm{~mol}, 47 \%\right)$.

For 2-azido-2-(p-nitrophenyl)butane:

${ }^{1}$ H n.m.r. (C), $\delta$ :

8.22(d, 2H), 7.57 (d, 2H), 1.96-1.89 (m, 2H),

$1.71(\mathrm{~s}, 3 \mathrm{H}), 0.80(\mathrm{t}, 3 \mathrm{H})$. 
${ }^{13} \mathrm{C}$ n.m.r. (C), $\delta$ :

$150.7,147.1,126.7,123.7,66.9,34.9,25.5,8.5$.

Analysis: $\mathrm{C}_{10} \mathrm{H}_{12} \mathrm{~N}_{4} \mathrm{O}_{2} \quad$ Calculated: $\quad \mathrm{C}, 54.54 ; \mathrm{H}, 5.49 ; \mathrm{N}, 25.44$.

Found: $\quad$ C, 54.23; H, 5.64; N, 24.96 .

M.S. $m / e$ :

$221\left(\mathrm{MH}^{+}\right), 178\left(\mathrm{M}^{+}-42\right), 136\left(\mathrm{M}^{+}-84\right), 55\left(\mathrm{M}^{+}-165\right)$.

(Matrix subtracted)

For 2-(p-nitrophenyl)butene mixture (but-1-ene : but-2-ene $=1: 6$ ):

${ }^{1}$ H n.m.r. (C),

But-1-ene, $\delta$ :

$8.19(\mathrm{~d}, 2 \mathrm{H}), 7.55(\mathrm{~d}, 2 \mathrm{H}), 5.42(\mathrm{dd}, 1 \mathrm{H}), 5.25(\mathrm{dd}, 1 \mathrm{H})$,

2.55-2.53 (m, 2H), $1.12(\mathrm{t}, 3 \mathrm{H})$.

But-2-ene, $\delta$ :

$8.16(\mathrm{~d}, 2 \mathrm{H}), 7.49(\mathrm{~d}, 2 \mathrm{H}), 6.06(\mathrm{q}, 1 \mathrm{H}), 2.06(\mathrm{~s}, 3 \mathrm{H})$,

$1.86(\mathrm{~d}, 3 \mathrm{H})$.

Analysis: $\mathrm{C}_{10} \mathrm{H}_{11} \mathrm{NO}_{2} \quad$ Calculated: $\quad \mathrm{C}, 67.78 ; \mathrm{H}, 6.26 ; \mathrm{N}, 7.90$.

Found: $\quad$ C, $67.90 ; \mathrm{H}, 5.94 ; \mathrm{N}, 7.41$.

\subsubsection{The Reaction of Sodium Thiophenoxide with p-Nitrocumyl Bromide}

Into a flask equipped with a magnetic stirrer and a balloon filled with dry argon, was placed a solution of sodium thiophenoxide $\left(0.537 \mathrm{~g}, 4.07 \times 10^{-3} \mathrm{~mol}\right)$ in dimethyl sulphoxide $\left(20 \mathrm{~cm}^{3}\right)$. To this flask was added a solution of $p$-nitrocumyl bromide $(0.515$ $\left.\mathrm{g}, 2.11 \times 10^{-3} \mathrm{~mol}\right)$ in dimethyl sulphoxide $\left(20 \mathrm{~cm}^{3}\right)$. After this solution had been stirred for 15 minutes, the resulting light purple solution was poured on to ice $(100 \mathrm{~g})$ and then sodium chloride $(2 \mathrm{~g})$ was added. The aqueous solution was extracted with diethyl ether $\left(5 \times 20 \mathrm{~cm}^{3}\right)$, the ether solution was washed with water $\left(4 \times 10 \mathrm{~cm}^{3}\right)$ and dried over 
anhydrous magnesium sulphate. Removal of the solvent gave gave a yellow liquid $(0.60$ g), which crystallised on standing for several hours. The solid was purified by high pressure liquid chromatography, eluting with $80 \%$ hexane- $20 \%$ ethyl acetate to give $p$ nitrocumyl phenyl sulphide $\left(0.492 \mathrm{~g}, 1.80 \times 10^{-3} \mathrm{~mol}, 85 \%\right)$ and $p$-nitro- $\alpha$-methylstyrene $\left(0.017 \mathrm{~g}, 1.0 \times 10^{-4} \mathrm{~mol}, 5 \%\right)$.

For $p$-nitrocumyl phenyl sulphide: Data in agreement with 9.4.3.

For $p$-nitro- $\alpha$-methylstyrene: $\quad$ Data in agreement with 9.4.5.

\subsubsection{The Reaction of the Lithium Salt of 2-Nitropropane with $p$-Nitrocumyl}

\section{Bromide}

Into a flask equipped with a magnetic stirrer and a balloon filled with dry argon, was placed a solution of the lithium salt of 2-nitropropane $\left(0.506 \mathrm{~g}, 5.33 \times 10^{-3} \mathrm{~mol}\right)$ in dimethyl sulphoxide $\left(20 \mathrm{~cm}^{3}\right)$. To this flask was added a solution of $p$-nitrocumyl bromide $\left(0.648 \mathrm{~g}, 2.66 \times 10^{-3} \mathrm{~mol}\right)$ in dimethyl sulphoxide $\left(20 \mathrm{~cm}^{3}\right)$. After this solution had been stirred for 15 minutes, the resulting light purple solution was poured on to ice (100 g) and then sodium chloride $(2 \mathrm{~g})$ was added. The aqueous solution was extracted with diethyl ether $\left(5 \times 20 \mathrm{~cm}^{3}\right)$, the ether solution was washed with water $\left(4 \times 10 \mathrm{~cm}^{3}\right)$ and dried over anhydrous manesium sulphate. Removal of the solvent gave a yellow liquid $(0.492$ g), and this was purified by high pressure liquid chromatography, eluting with $60 \%$ hexane- $40 \%$ ethyl acetate to give $p$-nitrocumyl alcohol $\left(0.254 \mathrm{~g}, 1.40 \times 10^{-3} \mathrm{~mol}, 53 \%\right)$, p-nitro- $\alpha$-methylstyrene $\left(0.052 \mathrm{~g}, 3.20 \times 10^{-4} \mathrm{~mol}, 12 \%\right)$ and 2,3-dimethyl-2-nitro-3-(pnitrophenyl)butane $\left(0.085 \mathrm{~g}, 3.37 \times 10^{-3} \mathrm{~mol}, 13 \%\right)$.

For $p$-nitrocumyl alcohol: $\quad$ Data in agreement with 9.3.4.

For $p$-nitro- $\alpha$-methylstyrene: Data in agreement with 9.4.5. 
For 2,3-dimethyl-2-nitro-3-( $p$-nitrophenyl)butane:

${ }^{1}$ H n.m.r. (C), $\delta$ :

${ }^{13}$ C n.m.r. (C), $\delta$ :

Analysis: $\mathrm{C}_{12} \mathrm{H}_{16} \mathrm{~N}_{2} \mathrm{O}_{4} \quad$ Calculated:

Found:

$151.0,143.4,128.7,122.6,93.8,44.6,24.8,23.1$.

M.S. $m / e$ :

$253\left(\mathrm{MH}^{+}\right), 206\left(\mathrm{M}^{+}-46\right), 164\left(\mathrm{M}^{+}-88\right), 55\left(\mathrm{M}^{+}-165\right)$.

(Matrix subtracted)

\subsection{General Kinetic Methods}

\subsubsection{Solutions}

Salt solutions of known concentration were made up by adding a mass of salt, and any additives, into a $2.0 \mathrm{~cm}^{3}$ grade A volumetric flask within a dry argon filled glove bag. The flask would be stoppered with a B10 subaseal ${ }^{T M}$, weighed, and this procedure carried out repeatedly until the desired mass was obtained. The volumetric flask would again be placed into a dry argon filled glove bag, made up to the $2.0 \mathrm{~cm}^{3}$ mark with the appropriate solvent system and stoppered. Substrate solutions of known concentration were made up in an identical manner to salt solutions and used immediately. Under an argon atmosphere equivalent volumes of salt and substrate solution were injected into a 5 mm O.D. n.m.r. tube using two $500 \mu$ Hamilton gas tight syringes. The tube was stoppered, agitated, and a stop-watch started. The tube was immediately placed into the cavity of the n.m.r. machine and spectra recorded at specific time intervals. 


\subsubsection{N.M.R. Studies}

The JEOL JNM-PS-100 continuous wave n.m.r. spectrometer requires spectra to be recorded manually, however, the Varian XL-200 and Varian VXR-400 pulsed fourier transform n.m.r. spectrometers allow spectra to be recorded at specific time intervals automatically. The temperature within the probe of the n.m.r. spectrometer was calibrated using ethylene glycol (100\%). The majority of kinetic studies were performed using 400 $\mathrm{MHz}{ }^{1} \mathrm{H}$ n.m.r. spectroscopy with dimethyl sulphoxide as the internal (I) standard (Table 9.1).

It is not possible to lock onto and observe the sample at the same time for 60 $\mathrm{MHz}^{2} \mathrm{D}$ n.m.r. measurements. The sample must first be locked, the lock turned off, and then the sample observed (Table 9.2).

An external reference tube was placed inside a $5 \mathrm{~mm}$ O.D. n.m.r. tube for $40 \mathrm{MHz}$ ${ }^{15} \mathrm{~N}$ n.m.r. spectra. The ${ }^{15} \mathrm{~N}$ nucleus was observed proton coupled in order to remove the possibility of a nuclear overhauser effect. The long relaxation time of the ${ }^{15} \mathrm{~N}$ nucleus required a delay of $10 \mathrm{~s}$ between pulsing and acquiring (Table 9.3).

Table 9.1

\begin{tabular}{|ll|}
\hline \multicolumn{2}{|c|}{$400 \mathrm{MHz} \mathbf{1}^{\mathbf{H}}$ n.m.r. parameters } \\
Temperature & $30^{\circ} \mathrm{C}$ \\
Volume of solution & $600 \mu \mathrm{l}(300 \mu \mathrm{l}+300 \mu \mathrm{l})$ \\
Pulse width & $5-20 \mu \mathrm{s}$ \\
Acquisition time & $1.998 \mathrm{~s}$ \\
Acquisitions & 8 \\
Decoupler mode & No \\
Reference & Dimethyl sulphoxide (I) \\
\hline
\end{tabular}


Table 9.2

\begin{tabular}{|ll|}
\hline \multicolumn{2}{|c|}{$60 \mathrm{MHz}^{2} \mathrm{D}$ n.m.r. parameters } \\
Temperature & $30^{\circ} \mathrm{C}$ \\
Volume of solution & $600 \mu \mathrm{l}(300 \mu \mathrm{l}+300 \mu \mathrm{l})$ \\
Pulse width & $17.5 \mu \mathrm{s}$ \\
Acquisition time & $1.998 \mathrm{~s}$ \\
Acquisitions & 8 \\
Decoupler mode & $\mathrm{Yes}^{2}$ \\
Reference & $2 \mathrm{D}_{6}$-dimethyl sulphoxide (I) \\
\end{tabular}

\section{Table 9.3}

$40 \mathrm{MHz}{ }^{15} \mathrm{~N}$ n.m.r. parameters

$\begin{array}{ll}\text { Temperature } & 30^{\circ} \mathrm{C} \\ \text { Volume of solution } & 500 \mu \mathrm{l}(250 \mu \mathrm{l}+250 \mu \mathrm{l}) \\ \text { Pulse width } & 8 \mu \mathrm{s} \\ \text { Delay } & 10 \mathrm{~s} \\ \text { Acquisition time } & 1.066 \mathrm{~s} \\ \text { Acquisitions } & 12 \\ \text { Decoupler mode } & \text { No } \\ \text { Reference } & 15_{\mathrm{N} \text {-nitrobenzene }} \text { (E) or } \\ & 15_{\mathrm{N} \text {-nitromesitylene }} \text { (E) }\end{array}$


Chapter 9 


\section{References}

\section{REFERENCES}

1. C.K. Ingold, "Structure and Mechanism in Organic Chemistry", Bell, Lond., 1953, Chapters 5 and 7.

2.

W.A. Cowdrev, E. D. Hughes, C.K. Ingold, S. Masteman, and A.D. Scott. $1937,1252$.

3

S. Winstein, E. Clippinger, A.H. Fainberg. R. Heck, and G.C. Robinson, J. Am. Chem. Soc., 1956, 78, 328.

4. V. Shiner. and R.D. Fisher, F. Am?. Chem. Soc. 1971, 93, 2553

5. S. Winstein, L.G. Savedoff, S. Smith, I.D.R. Stevens and J.S. Gall, Tetrahedron Letters, 1960, 9, 24.

6. C.A. Bunton and B. Nayak, J. Chem. Soc, 1959, 3854.

7. H. Weiner and R.A. Sneen, J. Am. Chem. Soc, 1965, 87, 292.

8. R.A. Sneen and I.W. Larsen. Am Chem. Soc. 1969.91, 362.6031.

9. T.W. Bentley and P.v.R. Schleyer, J. Am. Chem. Soc. 1976. 98. 7658.

10. L. Lewis and C.E. Boozer, Jh. Chem. Soc., 1952, 74, 308.

11. TD Roherts, D.A. Semenow, H.E. Simmons, and L.A. Cartsmith. 1. Ant. Chem. Soc. $7956,78,601$.

12. J.K. Kim and J.F. Bunnett, J. Am. Chem. Soc., 1970, 92, 7463, 7464.

13. R.C. Kerber, G.W. Urry, and N. Kornblum, J. Am. Chem. Soc., 1964, 86, 3904.

14. R.C. Kerber, G.W. Urry, and N. Kornblum, J. Am. Chem. Soc., 1965, 87, 4520.

15. N. Kornblum, R.E. Michel, and R.C. Kerber, J. Am. Chem. Soc., 1966, 88, 5660, 5662.

16. N. Kornblum, T.M. Davies, G.W. Earl, N.L. Holy, R.C. Kerber, M.T. Musser, and D.H. Snow, J. Am. Chem. Soc., 1967, 89, 725. 
17. N. Kornblum, L. Cheng, T.M. Davies, G.W. Earl, N.L. Holy, and R.C. Kerber, J. Org. Chem., 1986, 52, 196.

18. M.C.R. Symons and W.R. Bowman, J. Chem. Soc. Perkin Trans. II, 1988, 583.

19. D.B. Denney and D.Z. Denney, Tetrahedron, 1991, 47, 6577.

20. J.Q. Chambers and R.N. Adams, J. Electroanal. Chem., 1965, 9, 400.

21. S.M. Shein, L.V. Bryukhovetskaya, F.V. Pischugin, V.N. Stavichhenko, and V.V. Voevodskii, J. Streutoral Chem., 1970, 11, 228.

22. S.M. Shein, L.V. Bryukhovetskaya, and T.M. Ivanova, Izv. Akad. Nauk. SSR, Ser. Khim, 1976, 1594.

23. L.A Blyumenfel'd, L.V. Bryukhovetskaya, G.V. Fomin, and S.M. Shein, Russ. J. Phys. Chem., 1970, 44, 518.

24. T. Abe and Y. Ikegamo, Bull. Chem. Soc. Japan, 1976, 49, 3227.

25. T. Abe and Y. Ikegamo, Bull. Chem. Soc. Japan, 1978, 51, 196.

26. P.G. Sammes, D. Thitford, and M.Voyle, J. Chem. Soc. Perkin Trans. I, 1988, 3229.

27. M. Chanon and M. Tobe, Agnew. Chem., Int. Ed. Engl., 1982, 21, 1.

28. D.M Kukovitskii, V.V Zorin, I.T. Kivillov, V.V. Plakhtinskii, and D.L. Rakhmakulov, Zhurnal Obshchei Khimii, 1987, 57, 2758.

29. G.A. Russell, B. Mudryk, F. Ros, and M. Jawdosuik, Tetrahedron, 1982, 38, 1059.

30. T. Teherani and A.J. Bard, Acta. Chemica. Scand., 1983, B37, 413.

31. J.M. Saveant and A.J. Thiebault, J. Electroanal. Chem., 1978, 89, 335.

32. F.G. Bordwell and J.A. Harrelson, J. Org. Chem., 1989, 54, 4893. 
33. F.G. Bordwell and J.A. Harrelson, J. Am. Chem. Soc., 1987, 109, 8112.

34. X. Zhang, D. Yang, and Y. Liu, J. Org. Chem., 1993, 58, 224.

35. R. Bacaloglu, C.A. Bunton, and F. Ortega, J. Am. Chem. Soc., 1988, 110, 3495.

36. M.R. Crampton, Adv. Phys. Org. Chem., 1969, 7, 211.

37. M.J. Strauss, Chem. Rev., 1970, 70, 667.

38. M.R. Crampton, A.B. Davis, C. Greenhalgh, and J.A. Stevens, J. Chem. Soc. Perkin Trans. II, 1989, 675.

39. "Tables of Physical and Chemical Constants", (Original Compilers, G.W.C. Kaye, and T.H. Laby), Longman 1973, p 200.

40. J. Bargon, H. Fischer, and U. Johnsen, Z. Naturforsch., 1967, 22a, 1951.

41. H.R. Ward, J. Am. Chem. Soc., 1967, 89, 5517.

42. H.R. Ward and R.G. Lawler, J. Am. Chem. Soc., 1967, 89, 5518.

43. G.L. Closs, J. Am. Chem. Soc., 1969, 91, 4552.

44. R.Kaptein and L.J. Oosterhoff, Chem. Phys. Lett., 1969, 4, 195.

45. M.C.R. Symons, J. Wyatt, T. Kam, and T. Lim, J. Chem. Soc. Perkin Trans. II, 1993, 151.

46. J.R. Morton, K.F. Preston, and S.J. Strach, J. Phys. Chem., 1979, 83, 533.

47. R. Kaptein, J. Chem. Soc. Chem. Comm., 1971, 732.

48. N.A. Porter, G.R. Dubay, and J. G. Green, J. Am. Chem. Soc., 1978, 100, 920.

49. K.M. Salikhov, Y.N. Molin, R.Z. Sagdeev, and A.L. Buchachenko, "Spin Polarisation and Magnetic Effects in Radical Reactions (Y.N. Molin Ed.), (Studies in Physical and Theoretical Chemistry Volume 22)", Elsevier 1984. 
50. N. Kornblum, L. Cheng, R.C. Kerber, M.M. Kestner, B.N. Newton, H.W. Pinnick, R.G. Smith, and P.A. Wade, J. Org. Chem., 1976, 41, 1560.

51. F.G. Bordwell and G.A. Pagani, J. Am. Chem. Soc., 1975, 97, 118.

52. For reviews, see Larsen, in Feuer, "The Chemistry of the Nitro and Nitroso Groups", Pt. 1, p 325-339, Interscience, New York, 1969.

53. N. Kornblum, Org. React., 1962, 12, 101.

54. S.G. Smith and S. Winstein, Tetrahedron, 1958, 3, 317.

55

56

57. C.G. Swain, J. Am. Chem. Soc., 1948, 70, 1119.

58.

59.

I.E. Wordiander, I.E. Haky, and J.P. Landino, J. Am, Chem, Soc, 1980, 102.

60. G.A. Russell and W.C. Danen, J. Am. Chem. Soc., 1966, 88, 5663.

61. N. Kornblum, T.M. Davies, G.W. Earl, N.L. Holy, R.C. Kerber, M.T. Musser, and D.H. Snow, J. Am. Chem. Soc., 1967, 89, 725.

62. N. Kornblum and F.W. Stuchal, J. Am. Chem. Soc., 1970, 92, 1804.

63. P.A. Wade, H.A. Morrison, and N. Kornblum, J. Org. Chem., 1987, 52, 3102.

64

65. O.E. Edwards and C. Grieco, Can. J. Chem., 1974, 52, 3561.

66. C.A. Grob, K. Seckinger, S.W. Tam, and R. Traber, Tetrahedron Lett., 1973, 32, 3051 . 
67. U. Miotti and A. Fava, J. Am. Chem. Soc., 1966, 88, 4274.

68. "Hchunced Inorgunic Chemistry", F.A. Cotton and G. Wilkinson, $4^{\text {th }}$ Edition,

69. "Nucleophilic Aromatic Displacement", François Terrier, VCH, "Organic Nitro Chemistry Series".

70. A. Thibblin, J. Chem. Soc. Perkin Trans. II, 1992, 1195.

71. W.H. Pearson and J.M. Schkeryantz, J. Org. Chem., 1992, 57, 2986.

72. W.H. Saunders and A.F. Cockerill, "Elimination Reactions", Wiley, New York, 1973.

73.

Shiner. W.E. Buddenbaum. B. L. Murr, and G. Lamaty, J. Am. Chem. Soc.. 1968, 90, 418.

74. I.M. Hanis, R.E. Hall, and P.v.R. Schleyer, J. Am. Chem. Soo, 1971, 93, 2551.

75. For reported exceptions, see N. Tanaka, A. Kaji, and I. Hayami, Chem. Leth. $1972,1223$.

76.

4. Streitwieser, R.H. Jago, R.C. Fahey, and S. Suzuki, J.Am. Chem. Soc., 1958. 80, 2326

77. I.S. Bartell, J. Am. Chom. Soc. 1961, 83, 3567.

78. R.E. Robertson, Prog. Phys. Org. Chem., 1967, 4, 213.

79. C.G. Swain and E.R. Thornton, J. Am. Chem. Soc., 1962, 84, 822.

80. S. Seltzer and A.A. Zavitas, Can. J. Chem., 1967, 45, 2023.

81. F.G. Bordwell, P.F. Wiley, and T.G. Mecca, J. Am. Chem. Soc., 1975, 97, 132.

82. F.G. Bordwell and T.G. Mecca, J. Am. Chem. Soc., 1975, 97, 123.

83. F.G. Bordwell and T.G. Mecca, J. Am. Chem. Soc., 1975, 97, 127. 
84. Values of $1.10 \pm 0.05 / \beta-\mathrm{H}$ have been reported: K.C. Westaway, "Isotopes in Organic Chemistry", E. Buncel, and C.C. Lee, Eds., Elsevier, Amsterdam 1987, Chapter 5.

85. A. Streitwieser, Jr., "Solvolytic Displacement Reactions", Mc Graw-Hill, New York, N.Y., 1962.

86. R. Alexander, E.C.F. Ko, A.J. Parker, and T. J. Buxton, J. Am. Chem. Soc., 1968, 90, 5049.

87. R.C. Kerber, G.W. Urry, and N. Kornblum, J. Am. Chem. Soc., 1965, 87, 4520.

88. N. Kornblum, P. Ackermann, and R.T. Swiger, J. Org. Chem., 1980, 45, 5294.

89. Y. Okamoto and H.C. Brown, J. Am. Chem. Soc., 1956, 79, 1909.

90. A. Brändström, B. Lamm, and I. Palmertz, ACTA Chem. Scand., Ser. B, 1974, 28, 699. 